\title{
Fifty Plus in Ireland 2011 \\ First results from the Irish Longitudinal Study on Ageing (TILDA)
}

\section{Edited by:}

Alan Barrett, George Savva, Virpi Timonen and Rose Anne Kenny

\section{Contributors:}

Alan Barrett ${ }^{1}$, Helen Burke², Hilary Cronin'1, Anne Hickey², Yumiko Kamiya', Rose Anne Kenny', Richard Layte ${ }^{3}$, Siobhán Maty ${ }^{5}$, Hannah McGee², Karen Morgan², Irene Mosca', Charles Normand4', Claire O'Regan', Vincent O' Sullivan', George Savva', Nick Sofroniou', Virpi Timonen', and Brendan Whelan' 
Copyright (c) The Irish Longitudinal Study on Ageing 2011

The Irish Longitudinal Study on Ageing

Chemistry Extension Building

Trinity College Dublin

Dublin 2

Republic of Ireland

Tel: +35318964120

Email: tilda@tcd.ie

Website: www.tilda.ie

ISBN: 978-1-907894-01-5 


\section{Acknowledgements}

TILDA would not have been possible without the contributions and support of many groups and individuals.

First we would like to acknowledge the vision and commitment of our funders, Irish Life, the Atlantic Philanthropies and the Department of Health and Children, which is providing funding on behalf of the State. We would also like to state that any views expressed in this report are not necessarily those of the Department of Health and Children or of the Minister for Health.

TILDA, headed by its lead principle investigator Prof Rose Anne Kenny, involves collaborators from many higher educational establishments in Ireland and thanks must go to these, and in particular to the lead institution Trinity College Dublin and Provost Dr John Hegarty.

Thanks also to the original instigators of TILDA - Rose Anne Kenny, Patrick Prendergast, Amanda Piesse, Virpi Timonen, Charles Normand, and Nicholas Sparrow of the Trinity Ageing Consortium, for which TILDA was the flagship project.

The members of the International Scientific Advisory Board provide invaluable advice on the design and implementation of TILDA. Past and current members of this board include: Aartjan Beekman (Vrije University, The Netherlands), Lisa Berkman (Harvard Center for Population and Development Studies, USA), Axel Boersch-Supan (Mannheim Research Institute for the Economics of Aging, University of Mannheim, Germany), Carol Brayne (Institute of Public Health, Cambridge, UK), Robert Clarke (Clinical Trial Service Unit, Oxford, UK), John C Henretta (Dept. of Sociology and Criminology \& Law, University of Florida, USA), Stacy Tessler Lindau (The University of Chicago, USA), Michael Marmot (International Institute for Society and Health, University College London, UK), Anne Newman (Center for Aging and Population Health, University of Pittsburgh, USA), Carol Ryff (Institute on Aging, University of Wisconsin, USA), James Smith (RAND Center for the Study of Aging, California, USA) and David Weir (Institute for Social Research, University of Michigan, USA),

The TILDA Oversight Board has enabled TILDA to deliver its objectives. Past and current members of this group include: Siobhán Carey (Central Statistics Office), Patricia Conboy (Older and Bolder), Tom Costello, Jean Manahan and Mary Sutton (The Atlantic Philanthropies), Mary Cunningham (people's representative), Patrick Geoghegan, Robert Gilligan, David Lloyd and Dermot Kelleher (Trinity College Dublin), David Harney (Irish Life), Eileen Kehoe (Department of the Taoiseach), 
Marie Kennedy and Ronan Toomey (Dept. of Health and Children, Office for Older People), Hannah McGee (Royal College of Surgeons in Ireland), Orlaigh Quinn (Dept. of Social Protection), Alan Barrett, Rose Anne Kenny and Brendan Whelan (TILDA). We particularly acknowledge the chairman Brendan Tuohy.

The TILDA Steering Committee provides ongoing guidance on all aspects of the study. Past and current members include: Alan Barrett, Stephen Beatty, Rodd Bond, Anne Connolly, Tom Fahey, Brendan Gannon, Michael Gill, Colm Harmon, Patricia Kearney, Frank Kee, Rose Anne Kenny, Richard Layte, Gerry Loughrey, Mary McCarron, Hannah McGee, Caoimhe Ni Lochlainn, Charles Normand, Zhanna O'Clery, Eamon O'Shea, Ivan Perry, Sinead Quill, Tom Scharf, Virpi Timonen, Maryann Valiulis and Brendan Whelan.

TILDA fieldwork was conducted by Ipsos MORI who have co-ordinated a large team of dedicated interviewers. The research nurses and health-centre managers have ensured a constantly high quality of data collection in the Dublin and Cork health centres and at home assessments. The health assessment nurses include: Patricia Costello, Sandra McGrath, Tracey Quinn, Kay Poland, Laura Dunne, Tara Frayne, Sally Cooper, Annemarie Kenny, Lorna Green, Hazel Bergin, Anne Hughes, Roisin Nevin, Debbie Hurley, Carol-Anne O'Shea, Sinead Kelly, Nollaig Baker and Coleen Sweeney.

Many past and current members of the TILDA team have contributed time and effort to creating this report, those not listed among the authors of this report include Ciarán Finucane, Conor Moody, Ian Clifford, Jacinta O'Grady, Jennifer Erangey, Kathryn Richardson, Amilcar Moreira, Orla McBride, Mark Hanly, Niamh Dunphy, Orna Donoghue and Pauline Walsh.

Finally we must thank our participants among the over 50s of Ireland, who have exceeded our expectations in their enthusiasm and participation in all components of the study, and the vast majority of whom have agreed to be recontacted for later waves of the project. Without their time and effort neither this report nor the resource for future research offered by TILDA would have been possible. 


\section{Contents}

Executive Summary.

1. Introduction

Rose Anne Kenny and Alan Barrett

2. Socio-Demographic Characteristics Of Older People In Ireland.

Yumiko Kamiya and Nick Sofroniou

3. Older People As Members Of Their Families And Communities

Yumiko Kamiya and Virpi Timonen

4. Social Engagement Of Older People

Virpi Timonen, Yumiko Kamiya and Siobhan Maty

5. Physical And Behavioural Health Of Older Irish Adults.

Hilary Cronin, Claire O'Regan and Rose Anne Kenny

6. Mental Health And Cognitive Function

Claire O'Regan, Hilary Cronin and Rose Anne Kenny

7. Health And Social Care Utilisation

Charles Normand, Yumiko Kamiya, Virpi Timonen and Brendan Whelan

8. Retirement And Labour Market Participation.

Irene Mosca and Alan Barrett

9. Income and Asset Levels of Older People.

Vincent $O$ ' Sullivan and Richard Layte

10. Quality Of Life And Beliefs About Ageing.

Hannah McGee, Karen Morgan, Anne Hickey, Helen Burke and George Savva

11. Methodology.

George Savva 


\section{List of Tables}

\section{Introduction}

Table 1:

Projected population ratios

\section{Older people as members of their families and communities}

\section{Table 3.1:}

Percentage of the older population with living parents by age and sex

Table 3.2:

Percentage of the older population with living parents by age and education

\section{Social engagement of older people}

\section{Table 4.1:}

Proportion (\%) of older persons within each volunteering frequency category by age and education level

Table 4.2:

Mean quality of life measured by CASP-19 score among older people by age and frequency of volunteer activity

Table 4.3:

Mean quality of life score on the CASP-19 by Berkman-Syme Social Network Index level of social connection and age

Table 4.4:

Mean loneliness score (measured by UCLA loneliness scale) by age and education

Table 4.5:

Mean loneliness score (measured by UCLA loneliness scale) by age

and self-rated physical health

Table 4.6:

Voting participation of older people, by age and education level

\section{Physical and behavioural health of older Irish adults}

Appendix 5A: Tables on physical and behavioural health older people

Table 5.A1:

Self-rated health by age and gender

Table 5.A2:

Self-rated health by age and education

Table 5.A3: 
Table 5.A4:

Cardiovascular risk factors by age and sex

Table 5.A5:

Cardiovascular risk factors by age and education

Table 5.A6:

Cardiovascular risk factors by age and wealth

Table 5.A7:

Prevalence of cardiovascular disease by age and sex

Table 5.A8:

Prevalence of cardiovascular disease by age and sex

Table 5.A9:

Prevalence of cardiovascular disease by age and wealth

Table 5.A10:

Non-cardiovascular chronic conditions by age and sex

Table 5.A11:

Prevalence of non-cardiovascular chronic conditions by age and education

Table 5.A12:

Prevalence of non-cardiovascular chronic conditions by age and wealth

Table 5.A13:

Prevalence of sensory impairment and eye disease by age and sex

Table 5.A14:

Prevalence of sensory impairment and eye disease by age and education

Table 5.A15:

Prevalence of sensory impairment and eye disease by age and wealth quartile

Table 5.A16:

Difficulty following a conversation with 1 person by age and sex

Table 5.A17:

Number of falls in the last year by age and sex

Table 5.A18:

Number of falls in the last year by age and education

Table 5.A19:

Number of falls in the past year by age and wealth

Table 5.A20:

Smoking history by age and sex

Table 5.A21:

Smoking history by age and education

Table 5.A22:

Smoking history by age and wealth

Table 5.A23:

Problematic alcohol use and diagnosed substance abuse by age and sex

Table 5.A24:

Problematic alcohol use and diagnosed substance abuse by age and education

Table 5.A25:

Problematic alcohol use and diagnosed substance abuse by age and wealth

Table 5.A26:

Physical activity by age and sex 
Table 5.A27:

Physical activity by age and education

Table 5.A28:

Physical activity by age and wealth

Table 5.A29:

Flu vaccination and medical screening by age and sex

Table 5.A30:

Flu vaccination and medical screening by age and education

Table 5.A31:

Flu vaccination and medical screening by age and wealth

Table 5.A32:

Breast cancer screening behaviour by age and area of residence

Table 5.A33:

Prevalence and severity of pain by age and sex

Table 5.A34:

Prevalence and severity of pain by age and education

Table 5.A35:

Prevalence and severity of pain by age and wealth

Table 5.A36:

Prevalence of urinary incontinence by age and sex

Table 5.A37:

Prevalence of urinary incontinence by age and education

Table 5.A38:

Prevalence of urinary incontinence by age and wealth

Table 5.A39:

Prevalence of fear of falling by age and sex

Table 5.A40:

Prevalence of fear of falling by age and education

Table 5.A41:

Prevalence of fear of falling by age and wealth

Table 5.A42:

Activity limitation due to incontinence, pain and fear of falling by age and sex

Table 5.A43:

Activity limitation due to incontinence, pain and fear of falling by age and education

Table 5.A44:

Activity limitation due to incontinence, pain and fear of falling by age and wealth

Table 5.A45:

Number of regular medications used by age and sex

Table 5.A46:

Number of regular medications used by age and education

Table 5.A47:

Number of regular medications used by age and wealth

Table 5.A48:

Number of regular medications used by age and medical insurance cover

Table 5.A49:

Number of falls in the last year by medication use and age 
Table 5.A50:

Number of falls in the last year by medication use and education

Table 5.A51:

Distribution of $B M I$ by age and sex

Table 5.A52:

Distribution of BMI by age and education

Table 5.A53:

Distribution of BMI by age and wealth

Table 5.A54a:

Prevalence of objectively measured hypertension by age and sex

Table 5.A54b:

Prevalence of objectively measured hypertension by education and sex

Table 5.A54c:

Prevalence of objectively measured hypertension by wealth and sex

Table 5.A55:

Proportion of the population with a diagnosis of hypertension

by objective measure of blood pressure in men and women aged 50 and over

Table 5.A56a:

Prevalence of objectively measured osteoporosis by age and sex

Table 5.A56b:

Prevalence of objectively measured osteoporosis by education and sex

Table 5.A56c:

Prevalence of objectively measured osteoporosis by wealth quartile and sex

Table 5.A57:

Proportion of the population with a diagnosis of osteoporosis by

objective measure of bone density in men and women aged 50 and over

\section{Mental health and cognitive function}

\section{Table 6.1:}

Prevalence of sleep disruption by age

Table 6.2:

Mean number of words recalled by age and sex

Table 6.3:

Percentage who failed prospective memory task by age and sex

Table 6.4

Verbal fluency (mean number of animals named) by age and sex

Table 6.5:

Global cognitive function by age and sex

Table 6.5:

Cognitive impairment by disability level

Appendix 6A: Tables on mental health and cognitive function

\section{Table 6.A1:}


Table 6.A2:

Prevalence of depression by age and sex

Table 6.A3:

Prevalence of depression by age and wealth

Table 6.A4:

Prevalence of disability by depression and sex

Table 6.A5 :

Physical activity by depression and age

Table 6.A6 :

Prevalence of sleep disruption by depression and age

Table 6.A7:

Employment by age and depression

Table 6.A8 :

Healthcare utilisation by depression and age

Table 6.A9:

Anxiety by age and sex

Table 6.A10:

Anxiety by age and education

Table 6.A11:

Anxiety by age and wealth

Table 6.A12 (a):

Prevalence of comorbid anxiety by level of depression

Table 6.A12 (b):

Prevalence of comorbid depression by level of anxiety

Table 6.A13:

Suicidal ideation and disability by anxiety, depression and age

Table 6.A14:

Self-reported memory by age and sex

Table 6.A15:

Self-reported memory by age and education

Table 6.A16 :

Self-reported memory by age and wealth

Table 6.A17:

Prospective memory by age and education

Table 6.A18:

Cognitive impairment (MMSE<25) by age and education

Table 6.A19:

Global Cognitive function by age and sex

Table 6.A20:

Cognitive impairment by age and employment

Table 6.A21:

Cognitive impairment by age and wealth

Table 6.A22:

Cognitive impairment by age and wealth 


\section{Health and social care utilisation}

\section{Table 7.1:}

Health care entitlement status by age

Table 7.2:

Characteristics of the population aged 50 and over by entitlement status

Table 7.3:

Self-rated health status by age

Table 7.4:

Percentage of persons who utilised different types of healthcare, classified by entitlement status and self-rated health

Table 7.5:

Percentage of persons who utilised different types of healthcare,

classified by age group and self-rated health

Table 7.6:

Number of nights in hospital for those hospitalised in the past year, classified by age

Table 7.7:

Percentage of the population availing of different social services in the past year,

classified by age, and percentage satisfied with the service

Table 7.8:

Prevalence of disability by age and sex

\section{Retirement and labour market participation}

\section{Table 8.1:}

Labour market status by sex and age group

Table 8.2:

Weekly average number of hours spent at work by sex and age group, employees only

\section{Appendix A8. Tables on labour market status of older people}

\section{Table 8.A1:}

Labour market status by sex and age group

Table 8.A2:

Expected retirement age by educational attainment and sex, employees aged 50-64

Table 8.A3:

Pension coverage by socioeconomic group, employees aged 50-64

\section{Income and Asset Levels of Older People}

\section{Table 9.1:}

Mean disposable income of adults aged 65 and over (Euro per week). 


\section{Quality of Life and Beliefs about Ageing}

Table 10.1:

Mean CASP-19 scores in TILDA with ELSA scores for comparison

Table 10.2:

Mean CASP-19 scores by age

Table 10.3:

Mean CASP-19 scores by age in ELSA

Table 10.4:

Mean scores on CASP-19 domains by gender, with ELSA scores for comparison

Table 10.5:

Mean CASP-19 scores by education

Table 10.6:

Mean CASP-19 scores by self-rated health status

272

Table 10.7:

Mean CASP-19 scores by wealth category

Table 10.8:

Mean CASP-19 scores by living arrangements

Table 10.9:

Mean CASP-19 scores by residential location

Table 10.10:

Mean scores on APQ sub-dimensions

Table 10.11:

Mean scores on $A P Q$ sub-dimensions by age

Table 10.11:

Mean scores on APQ sub-dimensions by age

Table 10.12:

Mean scores on APQ sub-dimensions by sex

278

Table 10.13:

Mean scores on APQ sub-dimensions by education

Table 10.14:

Mean scores on $A P Q$ sub-dimensions by self-rated health status

Table 10.15:

Mean scores on APQ sub-dimensions by wealth

Table 10.16:

Mean scores on APQ sub-dimensions by living arrangements

Table 10.17:

Mean scores on APQ sub-dimensions by residential location

Appendix 10A: Tables on Quality of Life and Beliefs about Ageing

Table 10.A1:

Responses to CASP-19 statements

Table 10.A2:

Responses to CASP-19 statements by sex 
Table 10.A3:

Responses to CASP-19 statements by age

Table 10.A4:

Responses to $A P Q$ statements

Table 10.A5:

Responses to APQ statements by sex

Table 10.A6:

Responses to APQ statements by age group

11. Methodology

\section{Table 11.1:}

Number of respondents, self-completion questionnaires and health assessments included in this report

Table 11.2:

The distribution of age, sex and educational attainment in the population compared to the TILDA sample

Table 11.3:

Classification of respondents by socio-economic and health status and their participation in different components of TILDA 


\section{List of Figures}

\section{Socio-demographic characteristics of older people in Ireland}

Figure 2.1:

Age and sex composition of the TILDA sample

Figure 2.2:

Distribution of marital status by age and sex

Figure 2.3:

Distribution of marital status by education and sex

Figure 2.4:

Distribution of the living arrangements by age and sex

Figure 2.5:

Number of living children by marital status

Figure 2.6:

Percentage of older people in Ireland who have lived abroad for more than six months

Figure 2.7:

Irish older people who have lived abroad for more than six months, by education

Figure 2.8:

Educational attainment by age and sex

Figure 2.9:

Father's education and respondent's education outcome

Figure 2.10:

Distribution of current or former (in the case of those retired) occupation by age and sex. Those currently unemployed, out of work through long-term illness or who are occupied by looking after a home or family are classified as 'Not applicable'.

\section{Older people as members of their families and communities}

Figure 3.1:

Co-residence and proximity to children by age group

Figure 3.2:

Frequency of face to face contact with mother, by mother's health

Figure 3.3:

Percentage of older people giving or receiving transfers to or from their children by age

Figure 3.4:

The median, interquartile range and range of values of financial transfers from older people to their children by age

Figure 3.5:

Percentage of older people providing care to grandchildren and the provision of and receipt of other help to or from children by age 
Figure 3.6:

Percentage of older people providing help to or receiving

help from friends and neighbours by age

\section{Social engagement of older people}

\section{Figure 4.1:}

Distribution (\%) of older people who participate in different social activities (intimate social relationships, formal organisational involvement outside of work, active and relatively social leisure, and passive and relatively solitary leisure), by age and sex

\section{Figure 4.2:}

Distribution (\%) of older people who participate in different social activities (intimate social relationships, formal organisational involvement outside of work, active and relatively social leisure, and passive and relatively solitary leisure), by sex and education

\section{Figure 4.3:}

Distribution (\%) of older people in each volunteering

frequency category by age and sex

Figure 4.4.

Proportion (\%) of older people within each Berkman-Syme Social

Network Index level of social connection, by sex

\section{Figure 4.5:}

Older people who reported 'poor health' within each Berkman-Syme Social Network Index level of social connection, by age

\section{Figure 4.6:}

Proportion (\%) of older people within each Berkman-Syme Social Network Index level of social connection, by age and education

Figure 4.7:

Distribution of people who feel isolated (often, some of the time, or never) by Berkman-Syme Social Network Index level of social connection

Figure 4.8:

Frequency of older persons' attendance in religious services, by age and sex

\section{Figure 4.9:}

Degree of importance of religion in older persons' lives, by age and sex

Figure 4.10:

Proportion (\%) of older people who get comfort and strength from religion, by age and sex

Figure 4.11:

Percentage of older people who voted in the last general election, by age and sex

Figure 4.12.

Percentage of older people who regularly drive themselves, regularly are driven

by friends and family and regularly use public buses by age

Figure 4.13

Percentage of older people who rate their local public transport system as 'poor' by age and location of residence 


\section{Physical and behavioural health of older Irish adults}

Figure 5.1:

Self-rated health by age, sex and education

Figure 5.2:

Self-rated health by age, sex and wealth $\quad 76$

Figure 5.3

Prevalence of cardiovascular risk factors by age and sex

Figure 5.4:

Prevalence of cardiovascular disease by age and sex

Figure 5.5:

Lung disease by age, education and smoking status

Figure 5.6:

Prevalence of arthritis and osteoporosis by age and sex

Figure 5.7:

Prevalence of eye disease by age and sex

Figure 5.8:

Prevalence of pain by site, age and sex

Figure 5.9:

Number of medications taken by age and sex

\section{Mental health and cognitive function}

Figure 6.1:

Self-rated emotional health by age, sex and education

Figure 6.2:

Prevalence of depression by sex, age and education

Figure 6.3:

Depression by sensory function

Figure 6.4

Physical activity by depression, age and sex

Figure 6.5a:

Polypharmacy (regularly taking five or more medications) by depression, age and sex

Figure 6.5b:

Percentage of the population who fell in the last year by depression, polypharmacy and age

Figure 6.6:

Percentage of the population currently at work by depression, age and sex

Figure 6.7:

GP visits by depression age and sex

Figure 6.8:

Anxiety by age, sex and education

Figure 6.9:

Disability and suicidal ideation by anxiety, depression and age

Figure 6.10:

Self-reported memory by age and sex

Figure 6.11:

Immediate recall (mean) by age and education

Figure 6.12:

Prospective memory task (\% failed) by age, sex and education

Figure 6.13:

Verbal fluency (mean) by age, sex and education

Figure 6.14:

Cognitive impairment (MMSE<25) by age and education

Figure 6.15

Cognitive impairment (MMSE<25) by age and employment 
Figure 6.16:

Cognitive impairment by age and wealth

\section{Health and social care utilisation}

\section{Figure 7.1:}

Percentage of the population receiving home help service, meals on wheels and personal care attendant services by level of disability

\section{Retirement and labour market participation}

Figure 8.1:

Proportion of the population aged 50-64 at work by selfrated health status and sex

Figure 8.2:

Employment rate by educational attainment and sex in those aged 50-64

Figure 8.3:

Employment rate by wealth quartile and sex in those aged 50-64

Figure 8.4:

Employment rate by life satisfaction and sex in those aged 50-64

Figure 8.5:

Employment rate by educational attainment and sex in those aged 65-74

Figure 8.6:

Employment rate by wealth quartile and sex in those aged 65-74

Figure 8.7

Proportion of employees working part time by age and sex

Figure 8.8:

Expected retirement age by sex, employees aged 50-64

Figure 8.9:

Expected retirement age by educational attainment and sex, employees aged 50-64

Figure 8.10:

Pension coverage and sex, employees aged 50-64

Figure 8.11:

Pension coverage by socio-economic group, employees aged 50-64

\section{Income and Asset Levels of Older People}

\section{Figure 9.1:}

The distribution of disposable household income (Euro per week)

\section{Figure 9.2:}

Median household income and equivalised income by age (Euro per week)

Figure 9.3:

Median household income and equivalised income by age (Euro per week)

Figure 9.4:

Median equivalised disposable household income by household type (Euro per week) 
Figure 9.5:

Median equivalised disposable income of retirees only by years

of service (Euro per week)

Figure 9.6:

Median equivalised disposable income of retirees only by years since

retirement (Euro per week)

Figure 9.7:

Median equivalised disposable income of retirees only by socioeconomic

group of their former occupation (Euro per week)

Figure 9.8:

The distribution of sources of gross household income by age and education

Figure 9.9

Proportion (\%) by age and education of those whose sole source of income comes from state transfers

Figure 9.10:

Housing tenure by age group and highest educational attainment

Figure 9.11:

Median of current valuations of private residence by highest educational attainment

Figure 9.12:

Proportion with property other than current residence, debt or savings

by highest educational attainment

Figure 9.13:

Median value of property (other than current residence) by highest

educational attainment (Euro)

Figure 9.14:

Median level of savings or other financial assets by highest educational

attainment (Euros)

Figure 9.15:

Median level of debt by highest educational attainment (Euro)

Figure 9.16:

Median net assets by level of weekly household disposable income (Euro) 


\section{Executive Summary}

\section{Introduction}

The Irish Longitudinal Study on Ageing (TILDA) is a large-scale, nationally representative study of people aged 50 and over in Ireland. It is the most ambitious study of ageing ever carried out in Ireland and represents a step-change in terms of data, knowledge and understanding of ageing with which to inform policy and novel research.

TILDA is designed to maximise comparability with other well-established international longitudinal studies.

More than 8,000 people aged 50 and over accepted the invitation to participate in the first wave of TILDA, and the majority of these also agreed to undertake a comprehensive health assessment.

\section{Socio-demographic characteristics of the older population}

The socio-demographic picture that has emerged of Ireland's older people reflects the social and economic circumstances that were present during their lives and consequent heterogeneity of different age cohorts. Major social changes such as the introduction of free secondary schooling and the liberalisation of the contraceptive laws are evident in educational attainment and fertility differences by age. Social processes such as the intergenerational transmission of educational attainment are also seen. Low levels of economic growth which resulted in large-scale out-migration is evident in the remarkably high proportion of former emigrants in the older population.

Among the key findings are the following:

- In the population aged 50 and over, $48 \%$ are men and $52 \%$ are women.

- Most of the people aged 50 and over (58\%) are in the 50-64 age group.

- Almost $10 \%$ of older people have never been married. Men are more likely to have never married than women ( $13 \%$ men, $7 \%$ women).

- Most (73\%) older adults live with their spouse or with a spouse and children. This proportion decreases by age and the proportion of individuals living alone increases by age. 
- Older people have an average of three living children. There are differences in the mean number of living children by age cohort, education and religion.

- Most older adults (62\%) in Ireland have achieved at least secondary education.

- Nearly one-quarter (22\%) of older people had lived abroad for more than six months. Those with only primary education and those with a tertiary degree are more likely to have emigrated for a period of time than those with a secondary level education.

\section{Older people as members of their families and communities}

The role of the family is often emphasised in Ireland, but to date there is little evidence on what families provide to older adults, and what older adults give to their families. TILDA enables a detailed analysis of the relationship of older adults to their families and communities in terms of the contact that older people have with family members, the exchanges that take place within families and the broader networks of help and support among friends and neighbours. The findings presented here support an optimistic view that the majority of older people live relatively near to their children and surviving parents, have frequent contact with them, and intergenerational transfers are common.

Among the key findings are the following:

- Three-quarters of all adults aged 50 and over live in close proximity to at least one of their children.

- Over $70 \%$ of the age group most likely to need care and support (75 and over) live with their children or have at least one child living in the same county.

- Three-quarters of older adults whose parents are still alive see their parents frequently (daily, weekly, or several times per month).

- Half of 50-64 year olds with surviving parents provide help with household tasks to their parents, on average for 10 hours per week; over one quarter provide their parents with personal care, on average for 18 hours per week.

- Family financial transfers flow mainly from ageing parents to their adult children. Nearly one-quarter (24\%) of older households have given large financial or material gifts (worth $€ 5,000$ or more) to their children in the last ten years. In contrast, only $9 \%$ of older adults have received financial transfers from their children.

- Non-financial transfers from ageing parents to their children are also very common in Ireland. Over one third of older adults provide practical household help including shopping and household chores to their adult children and nearly half provide care to grandchildren.

- Nearly one-quarter of older people in Ireland provide some form of help to their neighbours and friends, on average for 8 hours per month. Almost one-fifth of older people receive some form of help from their neighbours and friends. 


\section{Social engagement of older people}

Social engagement comprises participation in leisure activities and volunteering, and connectedness to family and friendship networks. Social scientists have a long-standing interest in the effects of leisure participation among older persons. Participation in leisure activities is associated with a lower risk for negative mental and physical health outcomes and mortality. Many studies have shown that engaging in voluntary work in later life predicts better self-rated health, functioning, physical activity, and life satisfaction, and also decreases depression, hypertension, and mortality among older people. Conversely, loneliness has been shown to predict a wide variety of negative mental and physical health outcomes, such as depression, nursing home admission, and mortality. People also engage with their communities through religion, and participation in religious activities has been associated with better quality of life and health outcomes in older persons.

Among the key findings are the following:

- Approximately $90 \%$ of older people visit with family and friends once a week or more. Frequency of visits increases with age, and women visit with family and friends more frequently than men.

- One in five older people aged 65-74 do voluntary work at least once a week or more.

- Participation in formal organised activities, including volunteering, is greatest among older adults with high levels of education.

- Similar proportions of older men and women (around 10\%) are engaged in highintensity voluntary work.

- Quality of life increases with greater social integration.

- In Ireland 6\% of older women and 7\% of older men are socially isolated.

- Older persons with poorer self-rated health are most likely to be socially isolated.

- Among the $95 \%$ of the older Irish population who report having a religion, $60 \%$ attend religious services at least once a week. Nearly $80 \%$ of people aged 75 and over attend a religious service once a week or more.

- Over $80 \%$ of older adults voted in the 2007 general election.

- Three-quarters of the older population rely on cars as their main mode of transport.

\section{Behavioural and physical health of older people}

The promotion of active and healthy ageing is a global challenge. The European Union has set a target to increase the average healthy life span in the EU by two years by 2020 . This can only be realised by prevention and health promotion, integrated care and independent living. Ongoing measurement of the prevalence and incidence of disease in a nationally representative sample of older adults is needed to predict future health care needs and to inform policy development and strategies to decrease ill-health and disability among older adults in Ireland. The 
focus of TILDA's health research is on conditions that have public health significance, that is, diseases that are most prevalent among older people or that are most likely to result in morbidity, work disability and social isolation as well as health behaviours such as smoking, drinking alcohol and taking exercise. Three-quarters of older Irish adults rate their health as excellent, very good or good but this rate declines with age. TILDA is unique among longitudinal studies in the depth and quality of objective measures collected and technologies used for collection. Marked discrepancies between self-report and objective measures of health are evident in TILDA respondents.

Among the key findings are the following:

- Both cardiovascular and non-cardiovascular diseases are common in older adults with the prevalence of most chronic conditions increasing with age.

- Hypertension, angina, and stroke are more common in men; osteoporosis, arthritis and high cholesterol are more common in women.

- One in five older Irish adults is a current smoker, the highest rates of smoking are seen in the poorest and those with lowest education levels.

- Half of those aged 75 years and older report low levels of physical activity.

- Wealthier and better educated adults have the highest physical activity levels.

- Screening for cancer varies significantly by age, education and wealth. Older, poorer, less educated adults are less likely to screen for prostate or breast cancer.

- One in five older adults takes five or more medications (polypharmacy). This proportion rises to almost one in two for those aged 75 years and older. Polypharmacy is more than twice as likely in medical card holders compared with adults without cover or with medical insurance.

- Three-quarters of older Irish adults are objectively overweight or obese. Poorer individuals and those with lower levels of education have the highest levels of obesity.

- There is a significant discrepancy between self-reported disease and objective measure of disease; for example, $58 \%$ of men and $49 \%$ of women with objective evidence of hypertension are undiagnosed.

\section{Mental health and cognitive function of older people:}

The potential public health burden of late-life mental health disorders will increase as the population ages. Good mental health is associated with greater economic success, better social relationships and reduced risk of physical illness. Mental illness is not a normal consequence of ageing and can be prevented, treated and managed. The impact of mental illness on overall health and productivity is profoundly underrecognised in older adults worldwide. In addition to good mental health, cognitive function is a key marker of population health and independence at all ages. Adequate cognitive functioning is required to perform simple activities of daily living such as dressing and bathing as well as more complex tasks such as managing money, paying bills and taking medications. Cognitive impairment limits ability to carry out these activities. 
Despite its importance, the implications of declining cognitive functioning on older persons' daily lives are complex and poorly understood. One reason is the lack of adequate data sources from which to derive population-based estimates of the prevalence and consequences of cognitive impairment. TILDA addresses this information gap by providing comprehensive nationally representative data on cognitive function in older adults using both self-reported and objective measures.

Among the key findings are the following:

- Depression is common among older adults in Ireland, with $10 \%$ of the population reporting clinically significant depressive symptoms with a further $18 \%$ reporting 'sub-threshold' levels of depression.

- Anxiety is more common than depression among older adults. Among older adults $13 \%$ report clinically significant anxiety symptoms while $29 \%$ report subthreshold levels of anxiety.

- There is evidence of under-diagnosis and hence under-treatment of depression and anxiety. Of older adults with objective evidence of depression, $78 \%$ do not report a doctor's diagnosis of depression. Similarly, $85 \%$ of older adults with objective evidence of anxiety do not report a doctor's diagnosis of anxiety.

- Depression is associated with disability. Nearly two-thirds of older adults with depression have a longstanding illness or disability compared to one-third of people who are depression free.

- Depression is associated with increased medication use. Of people aged 75 and over with depression, $56 \%$ are taking five or more medications compared to $36 \%$ of adults without depression.

- Older adults with depression have extremely low rates of labour force participation. Of adults aged 50-64 without depression, $60 \%$ are in employment compared to $30 \%$ of older adults with depression.

- Health service is increased utilisation in people with depression. Depressed adults aged 75 and over have an average of 7 visits to their GP in the past year compared to an average of 4 visits among the non-depressed older population.

- Cognitive impairment rises sharply with age. Of adults aged 80 and over, 35\% have cognitive impairment compared to $4 \%$ of adults aged between 50 and 64 .

- There was a high level of memory impairment in the sample, particularly in the older groups. Of adults aged 80 and over, $42 \%$ forgot to carry out an action they had earlier been instructed to perform raising concerns about activities such as remembering to take medication, pay bills or take safety precautions.

\section{Health and social care utilisation}

It is important to understand how the ageing of the population will affect the demands for health and social care services. While funding from taxation currently pays around $80 \%$ of the costs of health care, nearly half of the population has supplementary private insurance, and most people face full cost fees for using primary care services. This complex pattern of entitlements to free or subsidised 
services has been shown in other studies to influence the patterns of service use. Patterns of use of services are presented, taking into account individual's entitlements, health and level of disability.

Among the key findings are the following:

- Nearly all (97\%) of those aged 80 or over have medical cards that exempt them from paying fees for primary care and hospital care. This compares with $91 \%$ for people in their 70 s and $30 \%$ of those in their 50 s.

- Nearly $60 \%$ of people between 50 and 69 have private medical insurance, dropping to $46 \%$ for those in their 70 s and $32 \%$ of those over 80 .

- The likelihood of being a user of GP care rises slightly with age, but is similar for all those over 70 .

- The likelihood of having a hospital admission is similar for different ages over 60, but the length of stay increases slightly with age, and people over 80 are lower users of outpatient services than those in their 60 s and 70 s.

- The prevalence of disabilities rises with age from less than $10 \%$ of those between 50 and 64 to nearly $30 \%$ of those over 75 .

- People with impairments in activities of daily living (ADL) and instrumental activities of daily living (IADL) receive on average 118 hours of help per month.

- The most common primary helper for this group is the recipients' spouse, this represents a large contribution by older adults into the care of older adults.

- Only 3.5\% of people over 50 receive state provided home help services.

- Of those with both ADL and IADL impairments, $12 \%$ do not receive formal or informal help and these people constitute a potentially very vulnerable group.

\section{Retirement and labour market participation of older people}

The labour market participation of older people is important from a broad range of perspectives. For the individual, participation in the labour market can be associated with increased resource and enhanced levels of life satisfaction, if work is a source of positive social contact and engagement. At the level of the wider macro-economy, higher levels of participation among older people translate into a bigger labour force and hence increased output. If higher participation is combined with later payment of pensions, reductions in pensions can be achieved. Increased participation is increasingly viewed as a prerequisite for tackling the long-run costs associated with population ageing and this policy objective is reflected in the National Pensions Framework. Given this context, it is important to understand more fully the patterns and determinants of labour market participation among the over 50s. 
Among the key findings are the following:

- Among those aged 50 to $64,62 \%$ of men and $46 \%$ of women are at work compared to $16 \%$ of men and $8 \%$ of women aged 65 to 74 .

- Of men aged 65 to $74,82 \%$ describe themselves as retired, compared to $52 \%$ of women. However, $36 \%$ of women aged 65 to 74 report that they are 'looking after home or family'.

- For those below the State Pension Age:

- Labour supply of older adults aged 50 to 64 in Ireland is concentrated amongst the healthiest, most educated, wealthiest and most satisfied with life.

- For example, $53 \%$ of men and $28 \%$ of women with no or primary education are employed, compared to $70 \%$ of men and $62 \%$ of women with tertiary or higher education.

- In the poorest quartile of this population, $34 \%$ of women and $38 \%$ of men are at work compared to $59 \%$ of women and $71 \%$ of men in the richest quartile.

- The average number of hours worked decreases as workers move closer to age 65, suggesting some form of 'wind-down' in advance of retirement.

- Around $25 \%$ of male and female employees expect to retire before state pension age (65). Retirement expectations are different for different education groups, with the more highly educated expecting to retire earlier.

- Of female employees, $41 \%$ are not covered by an occupational, PRSA (Personal Retirement Savings Account) or private pension scheme compared to $20 \%$ of male employees.

- Pension coverage varies by group. Among higher professionals, $78 \%$ are covered by an occupational pension, compared to $32 \%$ of unskilled workers.

- Of those at currently work, $96 \%$ women and $98 \%$ of men report that they are not affected by any kind of workplace discrimination.

\section{Income and asset levels of older people}

Income levels and asset holding of older people are an important measure of material living standards. As their working lives and careers draw towards a close, older people may experience a decline in income and may have greater dependence on state transfers.

There is considerable heterogeneity in the financial position of older people. The levels and sources of income of older people vary by age group and education levels. In particular, the income levels of retirees vary by the length of working life, former occupation and level of education.

Asset holdings are also of interest as they represent a lifetime accumulation of wealth. These wealth holdings can be drawn down to replace labour income. Assets can be held as an insurance against negative shocks, such as unexpected medical costs relating to a serious illness or a positive unexpected event such as living longer 
than expected. Assets may also act as a resource to help family members or to provide a bequest to them after death.

Among the key findings are the following:

- The average weekly household disposable income is $€ 767$ but around half live on under $€ 400$ per week.

- About one in eight older people have weekly disposable incomes of $€ 1,000$ or more.

- Older people who had professional or managerial jobs have significantly higher incomes in retirement than the general population largely due to occupational pension schemes and higher levels of financial assets.

- State pensions are the most important source of income among older people in Ireland and make up around two-thirds of gross income for those aged 65 and over.

- Around $26 \%$ depend on state transfers as their sole source of income.

- A majority (about 70\%) own their home and have finished paying off their mortgage. The median self-valuation of current residence is $€ 300,000$ for those with tertiary education. This is just under twice the median self-reported house value amongst those with only primary education.

- Savings and financial assets (other than property) vary with level of education from an average of $€ 14,000$ for those with primary education to $€ 60,000$ for those with tertiary education.

\section{Older people's quality of life and beliefs about ageing}

With greater longevity, better health and higher expectations for old age among the older generation, the well-being of this population has become a focus for social scientists and policy-makers. Well-being is viewed as an indicator of successful ageing, a pointer to the individual's adaptability to the losses of ageing. Much interest centres on the personal, material and social factors that account for wellbeing in later life, with the aim of optimising the subjective experience of ageing. Accumulating research, including that conducted by TILDA, indicates that, despite negative stereotyping, people derive considerable satisfaction and enjoyment from life in their later years. Clear social divisions are evident, however, in the experience of old age, where some groups age more successfully than others.

Among the key findings are the following:

- The older population as a whole experiences a high quality of life. The mean score for older people on the CASP-19 quality of life scale is 42.7, representing $75 \%$ of the total possible score of 57 .

- The best quality of life is experienced by older people with the highest asset wealth.

- The group of older people who have the lowest quality of life, by a considerable margin, are those who rate their health as fair or poor (scoring 36.3 on CASP-19). 
- Older people on the whole perceive the ageing process positively, believing they have considerable control over the positive experiences of ageing, but less over the negative aspects.

- The most educated have the strongest sense of control over the positive and negative aspects of ageing.

- Older people in the highest wealth category are least aware of the negative aspects of ageing and least aware of the ageing process.

\section{Methodology}

- TILDA recruited a stratified clustered sample of 8178 individuals representative of the community living Irish population aged 50 years and over. Younger spouses and partners were also invited to participate, primarily to provide information regarding family and financial circumstances.

- Each participant underwent an extensive face-to-face interview, was left a questionnaire to complete and return and was invited to a health assessment either at a dedicated centre or in the home.

- The overall response rate to the study was $62.0 \%$. The subsequent participation in the health assessment and the proportion returning the self-completion questionnaire is high, and collection of both is ongoing. 


\section{Introduction}

Rose Anne Kenny and Alan Barrett

\section{Contents}

1.1 Background.

1.2 Objectives and Design ................................................ 17

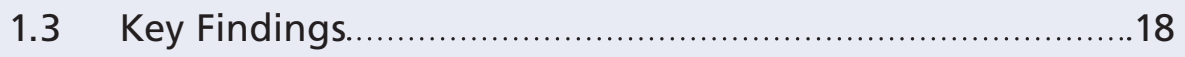




\section{Introduction}

TILDA is the most comprehensive longitudinal study of adults and ageing ever conducted in Ireland. The study is led by Trinity College Dublin (TCD) in collaboration with a majority of the other principal academic institutions in Ireland. A wide range of experts from many disciplines have been involved from the outset in the development and execution of this complex strategic research study.

The purpose of TILDA is to bring about a step change in the quality, quantity and prominence of information and research about ageing in Ireland. This will add substantially to the scientific knowledge about the ageing process in general and highlight the effects of Irish public policy on all domains of older peoples' lives. By providing robust, in-depth research based on a large, representative sample ${ }^{1}$ the project will empower policy-makers, researchers, NGOs and citizens with the information needed to help to make Ireland a better place to grow old. The detailed characterisation of the population provides a rich and unique research resource for Ireland. TILDA data contains high quality health and socio-economic data that will facilitate highly innovative multi-disciplinary research, in addition, to single discipline research in areas such as early detection of disease, development of medical and social interventions and the identification of novel bio-markers. In this way, TILDA will contribute to the broad national policy objective of enhancing Ireland's research and development capacities and reputation. The research generated will provide critical inputs into policy design in areas such as healthcare delivery, the labour market and income support.

TILDA is designed to maximise comparability with other well-established international longitudinal studies, in particular the Health and Retirement Survey (HRS) in the US, the Survey of Health, Ageing and Retirement in Europe (SHARE), and the English Longitudinal Study on Ageing (ELSA), and thereby to facilitate cross-country comparisons. Because it is a 'new' longitudinal study, TILDA has been designed to address questions raised by these other studies and will, therefore, help to fill the gaps in international knowledge.

The promotion of active healthy ageing is a global societal challenge. In recognition of this, the European Union has recently set a target for researchers and policymakers to increase average healthy life span by two years before 2020. TILDA is designed to meet this challenge by incorporating novel and comprehensive

1 As the sample is large and representative, results can be generalised to the population. 
assessments of health and well-being together with social and economic measures. These will allow a better understanding of the multidimensional causality of age-related diseases and disabilities. Detailed characterisation of the older Irish population will thus inform new prevention strategies, new interventions, new models of health and social care delivery and ultimately contribute to societal changes for better quality of life for all.

As will be seen in the chapters that follow, a large amount and wide variety of data on the lives of Ireland's older people has been analysed for this report. The data is collected in the context of Ireland's fast changing demographics - a projected $44 \%$ increase in the number of people over 65 in the next ten years, a doubling over the next 30 years, with the greatest increase occurring in the over $80 \mathrm{~s}$. This is coupled with projected dramatic falls in the ratio of 'working age' relative to retired persons from 5.7 in 2011 to 2.6 in 2041, all culminating in enormous challenges in ensuring extended healthy life span, pension provision, labour market participation and the macro-environment. TILDA affords Ireland an opportunity to prepare efficiently for change in order to shape our new society.

Results from TILDA emphasise that the over 50s are not a homogenous group - there are marked divergences in most domains between young old and older old, although there are very few differences between rural and urban dwellers. Men and women have different experiences of ageing, in particular with respect to health status and pension cover. Ireland's older adults generally experience a high quality of life and make significant contributions both within their families and their communities. A persistent finding is the importance of childhood education on lifelong health, wealth and happiness. This is coupled with important lifelong influences of childhood events and of socio-economic gradients across many outcomes. There are major differences between self report and objective health measures, which may have methodological implications for other countries' longitudinal studies.

In the next section we set out the broad context providing the rationale for undertaking TILDA. In particular, we discuss population projections for Ireland which show how the population structure is likely to change in the coming years with the proportion over the age of 65 rising from its current level of $11.4 \%$ to $22.4 \%$ in 2041. We also discuss the associated policy issues that are likely to arise across economic, health and other domains. One such issue is the forecast increase in public spending on pensions, with a possible doubling in spending as a proportion of GDP by 2060 envisaged. Section 1.3 provides a very broad overview of some of the key findings from this first analysis of the data. Included here are positive findings such as the generally high quality of life experienced by Ireland's older adults but also the variation across education and wealth groups in areas such as health status and social participation. 


\subsection{The background}

Population ageing is now generally understood to be one of the major challenges which is confronting, or will confront, many countries in the world. Ireland is no exception to this and will face the full set of ageing-related issues in the coming years. To understand the magnitude of the challenge which will unfold in Ireland, it is helpful to outline some key features of the most up-to-date population projections from the Central Statistics Office. ${ }^{2}$

The projected number of people aged 65 and over in 2011 is 535,716, or 11.4 per cent of the total population. This number is projected to increase to 796,484 in 2021, or 14.1 per cent of the total population; an increase of 44 per cent in the number of people in this age bracket. The number of those aged 80 and over is expected to rise by 45 per cent over the next ten years from 130,598 (2.8 per cent of the population) in 2011 to 189,051 (3.5 per cent of the population) in 2021(see table 1).

This trend in population ageing is expected to continue well beyond 2021. The number of people aged 65 and over is projected to double between 2011 and 2031. The projected increase from 2011 to 2041 is 160 per cent (that is an increase in absolute numbers from 535,716 in 2011 to 1,396,585 in 2041). As a proportion of the population, this represents an increase from 11.4 per cent in 2011 to 22.4 per cent in 2041. While the projected changes in the population aged 65 and over are striking, changes for the group aged 80 and over are even more dramatic. Over the same 30 year period, the number of people aged 80 and over is projected to rise from 130,598 to 457,962 - an increase of 250 per cent.

Table 1: Projected population ratios

\begin{tabular}{lrrrr|} 
& 2011 & 2021 & 2031 & 2041 \\
\hline $\begin{array}{l}\text { Over 65 } \\
\text { \% of population }\end{array}$ & 535,716 & 769484 & 1060496 & 1396585 \\
& 11.4 & 14.1 & 18.0 & 22.4 \\
\hline $\begin{array}{l}\text { Over 80 } \\
\text { \% of population }\end{array}$ & 130598 & 189051 & 311312 & 457962 \\
\hline $\begin{array}{l}\text { Dependency ratio } \\
\text { (popn 65+/popn 18-64) }\end{array}$ & 2.8 & 3.5 & 5.3 & 7.3 \\
\hline $\begin{array}{l}\text { Inverse of the dependency } \\
\text { ratio }\end{array}$ & 0.18 & 0.23 & 0.30 & 0.38 \\
\hline
\end{tabular}

2 Given the economic downturn and the resulting population outflows, actual population figures are likely to differ from projections in the short run. However, on the assumption that economic recovery eventually takes hold, these outflows may be reversed and so the broad trends projected in Table 1 are still highly relevant. 
Data on population structure are often presented in terms of dependency ratios as these provide an insight into the impact of population ageing. The projected ratio of those aged 65 and over to those in the 'working age' bracket of 18 to $64^{3}$ rises from 0.18 in 2011 to 0.38 in 2041 . The inverse of the dependency ratio can give a more intuitive sense of what these figures mean as it can be interpreted as the number of people of working age who "support" those aged 65 and over. This figure is expected to fall from 5.7 in 2011 to 2.6 in 2041.

A change in the structure of a population along the lines suggested by Table 1 will have many implications. Among the topics most often discussed in the context of ageing societies are the likely increased demands on pension, healthcare and longterm care systems.

The typical model of state pension provision within Europe (including Ireland) is a pay-as-you-go system, through which the pensions of today's pensioners are paid out of revenue which is paid by today's workers ${ }^{4}$. As long as the ratio of workers to pensioners remains somewhat stable, and with all else remaining equal, this system is sustainable. However, when the ratio of pensioners to workers increases, existing levels of payments and retirement ages can only be maintained if current workers make higher contributions.

According to the European Commission/Economic Policy Committee (2), state spending on pensions in Ireland could rise from 5.2 per cent of GDP in 2007 to 8 per cent by 2035 and to 11.3 per cent in 2060 . Of course, such projections are subject to many assumptions and these particular projections were produced before the publication of the National Pensions Framework (3) and without factoring in the proposals that are contained in that document. Even so, the scale of the public pensions challenge is clear.

The issues surrounding healthcare are numerous and complex but, as with pensions, can be addressed in terms of needs and systems of delivery. In general, healthcare needs increase with advancing age and so systems of healthcare delivery will have to evolve to cater for the changing age structure of the population. Information on the prevalence of diseases and disabilities, a better understanding of both patterns of healthcare need and of utilisation among older people are essential for policy planning. It is important to understand how our system of healthcare delivery is currently performing in the specific context of older people and to gather evidence on the likely cost implications and effects on health and well-being of possible extensions, modifications and improvements.

3 We place inverted commas around the term working age in recognition that many people retire before 65 while many other work beyond 65 (see Chapter 7).

4 Payments out of the National Pension Reserve Fund will not commence until 2025 at which time it is expected that the fund will make a contribution towards paying social welfare pensions and public sector pensions. 
It is only through detailed information on health and healthcare use that we can accurately project how healthcare spending might evolve as the population ages. Spending on pensions can be projected based on somewhat mechanical exercises, partly because we can say with a degree of certainty how many people will start collecting state pensions at the state pension age. However, in the case of healthcare there is a much greater degree of uncertainty. Although it is often asserted that healthcare spending will rise in an ageing population, the processes linking population ageing and healthcare spending are complex. To take one example, lower mortality rates are one factor giving rise to population ageing. As lower mortality rates imply that fewer people of a given age are in the last year of life, it is possible that this will result in lower healthcare costs because healthcare spending tends to be concentrated in the last year of life (4).

According to the European Commission/Economic Policy Committee (2), healthcare spending in Ireland was projected to raise from 5.8 per cent of GDP in 2007 to 7.6 per cent in 2060 as a result of population ageing. This increase is relatively modest and reflects in part the uncertainties discussed in the preceding paragraph. However, in proportionate terms, the European Commission/Economic Policy Committee (2) projects a bigger rise in spending on long-term care. Starting from a base of 0.8 per cent of GDP in 2007, the 2060 figure is projected to be 1.3 per cent. Institution based long-term care is not dealt with in this report as people in nursing homes were not included in the Wave 1 survey for reasons of sampling technicalities ${ }^{5}$. However, a critical objective of Wave 2 and subsequent waves will be to interview people (or close relatives) who have moved into nursing homes, thereby generating information on the process of entry and the nature of care. This information coupled with objective measures of disability will inform new paradigms for health and social care delivery.

Issues such as pensions and healthcare spending are often presented as problems of an ageing society. To the extent that population ageing results from lower mortality rates and an associated improvement in the health status of older people, extending working lives offers one route through which the costs discussed above can be made more sustainable. By postponing retirement, people draw on public pensions for shorter durations thereby lowering costs. In addition, by remaining in the labour force people increase the productive potential of the economy, thereby helping to reduce spending as a proportion of GDP.

Extending working lives is a potentially appealing solution to the cost element of population ageing. It may also be of benefit at the individual level if it is the case that extended employment has positive benefits in terms, for example, of social participation and mental health. However, rates of labour force participation vary across groups of older adults and this is likely to reflect factors such as the fact that

5 As discussed in the methods chapter, the sampling framework is based on a register of private houses and so extending to institutional care would make it difficult to draw inferences from the data collected. 
for some occupations longer working lives are more feasible. Much research in this area has also highlighted the importance of the incentives provided by pension systems and will feature in future research on this area (5).

While much of the discussion above has focussed on the 'needs' of older people, it is also important that the contribution that older people clearly make to society is understood and appreciated. Ireland's older adults generally experience a high quality of life and make significant contributions both within their families and their communities. As will be seen from our results, older people are frequent providers of care within their families and across all generations. They not only often care for grandchildren but also for spouses, siblings, neighbours and friends. In addition to transfers of time, they also transfer financial resources within families. Many continue to work for pay but also in a volunteer capacity. As society ages, a failure to fully capture the societal contribution which older people can make based on their skills, knowledge and experience will amount to a huge loss to current and future generations. Furthermore, an ageing society will afford new opportunities for restructuring of society as a whole and for new employment opportunities and for development of novel models of service delivery. A better society in which to grow old is a better society for all.

Ireland, like many other countries in the world, is in the midst of a process of population ageing. This process is the result of both declining fertility and longer life expectancy. Focussing on the latter element, the process of population ageing will have profound implications for the individuals who will live longer than earlier generations. In addition, there will be profound implications for Irish society in terms, for example, of how we organise the delivery and financing of many public services, particularly pensions, healthcare and long-term care. We may also have to rethink our concepts of working age and retirement and, more broadly, to re-imagine our understanding of older peoples' lives and of ageing.

\subsection{Objectives and design}

TILDA was designed to provide the evidence base for tackling the current and emerging policy issues described above. The specific aims of TILDA were to:

- Provide comprehensive internationally comparable baseline data on older people in Ireland, leading to improvements in policy and planning;

- Provide new insights into the causal pathways underlying the ageing process;

- Add to the prominence of ageing as an issue of public interest and allow the voice of older people to be heard more clearly, by effectively disseminating results to various audiences;

- Lead to further extensive analysis by academic researchers both in Ireland and abroad, helping to create an enhanced infrastructure for ageing research in Ireland and to attract international scholars and funding, by making its anonymised dataset openly available. 
The specific objectives and rationale for the design and methodology of TILDA are described in the TILDA design report (6). The selection of the cohort, the fieldwork process and the analytical methodology used in the creation of this report are described in Chapter 11. In brief, a nationally representative sample of 8178 individuals aged 50 or over underwent a detailed interview including questions on many aspects of their lives including but not limited to their physical and mental health, family and financial circumstances, social activity, working life, and use of healthcare services. Each was then invited to undertake a comprehensive health assessment, and to complete and return a questionnaire including questions deemed too sensitive for face-to-face interview. Findings from each of these data sources are presented in this report.

\subsection{Key findings}

As will be seen in the chapters which follow, a large amount of data on the lives of Ireland's older people has been used in preparing this report and the variety of the data, in terms of topics covered, is wide. As a result, any overview will be highly selective. With that caveat in mind, we would draw attention to the following findings. For a more detailed summary of key findings we refer you to the Executive Summary.

Ireland's older adults are a heterogeneous group and so statements about them in aggregate should be treated with caution. With that qualification in mind, the data suggest that Ireland's older adults generally experience a high quality of life (see Chapter 10). Older people derive considerable enjoyment from life - 85 per cent report that they often enjoy the things they do, while 81 per cent often look forward to each day. Over 80 per cent feel that life is full of opportunities.

We also find that Ireland's older adults make significant contributions both within their families (Chapter 3 ) and their communities (Chapters 3 and 4). Over one- third provide practical household help including shopping and household chores to their non-coresident children and nearly half provide care to grandchildren. Twenty-seven per cent of those aged 50-64 have at least one living parent and child (including minor and adult children) and so are part of the 'sandwich generation' with potential care demands from both children and parents. Over one quarter of older households report giving a financial or material gift worth $€ 5,000$ or more to one (or more) of their children within the last ten years. Of those households that gave money to children, the mean value is $€ 60,512$ while the median value was $€ 20,000$. In contrast, only 9 per cent of the older population received financial transfers from their children. Hence, while public policy related transfers may flow disproportionately from middle-aged to older households, this appears to be partially offset by withinfamily transfers.

For those with limitations in daily activities, the principal source of help is the family. The most common primary helper is the care recipient's spouse, representing a large 
contribution by older adults to the care of older adults. However, $12 \%$ of people with significant disability receive no formal or informal care and are potentially at risk.

With respect to communities, nearly one-quarter of older people in Ireland provide some form of help to their neighbours and friends, on average for 8 hours per month. Over a quarter of older adults do voluntary work at least once or twice a month. Two-thirds of this group do voluntary work once a week.

One unusual feature of Ireland's population of older people is that almost a quarter are returned migrants who have lived outside of the country for a period of six months or more. This feature of the older population is due to Ireland's historic experience of emigration and subsequent return, and is not evident in many other countries (Chapter 2).

While these findings provide a positive picture of the lives of community-living older people, it needs to be stressed that there is a high degree of variation within the group across the variables discussed and across many aspects of life. Unsurprisingly, the experience of being over 50 varies considerably with age within that group. Based on a broad measure, quality of life is higher for those aged between 65-74 years relative to those aged between 50 and 64 and is lowest for those aged 75 years and older (Chapter 10). Self-reported health declines across age groups, with the oldest adults less likely to report their health as excellent, very good or good when compared to their younger counterparts (79 per cent of those aged between 50 and 64 versus 66 per cent in those aged 75 and older). Again as expected, this pattern of variation by age is also found in the burden of chronic disease. For example, the prevalence of high blood pressure increases from 29.7 per cent in those aged 5064 years to 53.7 per cent in those aged 75 and over. Similarly, the prevalence of an abnormal heart rhythm increases with age, effectively doubling with each decade (Chapter 5). We find relatively few differences between urban and rural dwellers in most areas of life, although lower levels of satisfaction are expressed by rural dwellers regarding the quality of public transport (Chapter 4).

Other notable factors which give rise to variations in the patterns observed are education and wealth. Echoing findings from studies based on, for example, the English Longitudinal Study on Ageing (ELSA), the findings from TILDA show that those with higher levels of education and wealth are likely to enjoy better outcomes later in life based on indicators such as health, social participation and labour force participation. As an example, within the health domain, we find that individuals with a primary education or less report substantially higher levels of chronic lung disease (5.5 per cent) compared to individuals with second or third level education (3.6 per cent and 2.7 per cent respectively). Also for chronic lung disease, there is a clear wealth gradient with adults in the lowest wealth quartile reporting almost three times the rate of chronic lung disease than adults in the highest wealth quartile (6.5 per cent versus 2.5 per cent). 
Looking at the labour market issues, we find that more educated older adults are more likely to be in employment, and that the strength of the association appears to be particularly strong for women. For men, the proportion aged 50-64 who are employed rises from $53 \%$ among those with primary education to $65 \%$ for secondary and to $70 \%$ for those with third level education. For women, this employmenteducation gradient starts at $28 \%$, increases to $47 \%$ for those with second level education and then increases to $62 \%$ for those with third level education (Chapter 8 ).

Among the more troubling findings from this first analysis of the data are those concerning mental health. Overall, $10 \%$ reported clinically significant depressive symptoms while a further $18 \%$ reported 'sub-threshold' depression (Chapter 6). However, only $5 \%$ reported a doctor's diagnosis of depression. These figures suggest a significant under-diagnosis of depression in older Irish adults and hence an unmet need for mental health services (Chapter 6). The comparison of self-reported hypertension and osteoporosis with actual measurements provides similarly worrying evidence that under-diagnosis of these conditions is also highly prevalent (Chapter 5).

Many, and possibly all, of these findings have policy implications. Further policy implications arise from a range of other findings and we list some of them here. We find that state transfers are the only source of income for a high proportion of less educated older people. In that group, around 35 per cent of people aged 50-64 have no other source of income and this rises to 53 per cent for those aged 75 and over (Chapter 9). This illustrates the vulnerability of this group to reductions in the levels of state transfers.

TILDA shows that female employees aged 50 to 64 are less likely to be covered by occupational and private pension schemes than their male counterparts. Amongst women at work, 41 per cent are not covered by an occupational, PRSA or private pension scheme compared to 20 per cent of men. Pension coverage also varies significantly by socioeconomic group. For example, 74 per cent of managers and 78 per cent of higher professionals are covered by an occupational pension, compared to 48 per cent of semi-skilled and 32 per cent of unskilled workers (Chapter 8).

We find that among older people in poor health, attendance at either GP clinics or emergency rooms is lower for those without medical cards or private cover (Chapter 7). This raises questions over access to care for those who may be too well off to qualify for medical cards but not well off enough to purchase private cover.

According to the data, people with disabilities, defined in terms of having difficulties with activities of daily living ( $A D L$ ) or instrumental activities of daily living (IADL), receive on average of 118 hours of help per month. As the most common primary helper for this group is the care recipient's spouse, this translates into extensive inputs by older adults into the care of other older adults (Chapter 7). 
In conclusion, much has been learned from this first analysis of the data that has emerged from Wave 1 of the TILDA study. However, substantially more will be learned in the coming years as TILDA becomes a truly longitudinal study and the second and later series of interviews are conducted with the TILDA respondents. By following the same people over time, we will be able to develop a much clearer picture of the process of ageing and to disentangle many of the causal relationships which underpin the observations which we have made from Wave 1.

\section{References}

1. Central Statistics Office. Population and labour force projections. Dublin: Stationery Office; 2008.

2. European Commission/Economic Policy Committee. The 2009 ageing report: economic and budgetary projections for the EU-27 member states (2008-2060). 2009. Available from: http://europa.eu/epc/pdf/2009_ageing_report.pdf

3. Department of Social and Family Affairs. National pensions framework. Dublin: Stationery Office; 2010.

4. Lee R, Miller T. An approach to forecasting health expenditures, with applications to the US medicare system. Health Serv Res. 2002;37(5):1365-1386.

5. Gruber J, Wise DA, editors. Social security and retirement around the world. Chicago: University of Chicago Press; 1999.

6. The Irish Longitudinal Study on Ageing. The design of the Irish Longitudinal Study on Ageing (TILDA); 2010. Available from: http://www.tcd.ie/tilda/assets/pdf/ DesignReport2010.pdf 


\section{Socio-Demographic Characteristics of Older People in Ireland}

Yumiko Kamiya and Nick Sofroniou

\section{Contents}

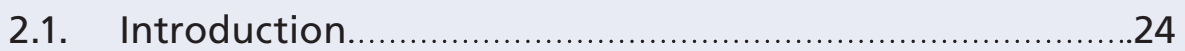

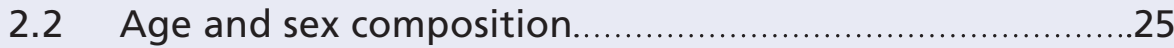

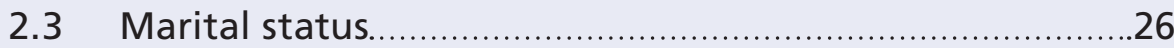

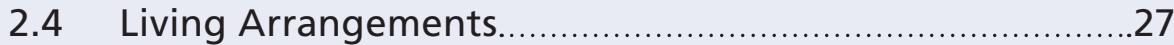

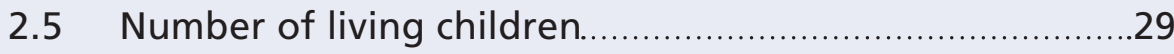

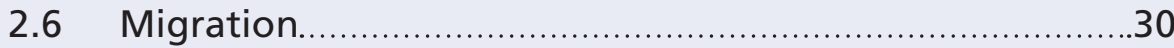

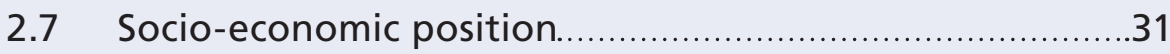

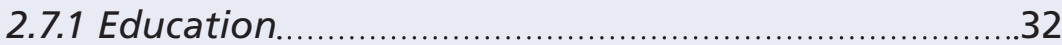

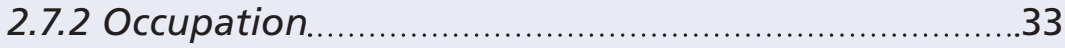

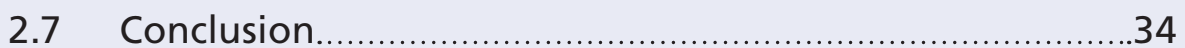




\section{Socio-Demographic Characteristics of Older People in Ireland}

\section{Key findings}

- In the population aged 50 and over, $48 \%$ are men and $52 \%$ are women.

- Most of the people aged 50 and over (58\%) are in the 50-64 age group.

- Almost $10 \%$ of older people have never been married. Men are more likely to have never married than women (13\% men, $7 \%$ women).

- Most (73\%) older adults live with their spouse or with a spouse and children. This proportion decreases by age and the proportion of individuals living alone increases by age.

- Older people have an average of three living children. There are differences in the mean number of living children by age cohort, education and religion.

- Most older adults (62\%) in Ireland have achieved at least secondary education.

- Nearly one-quarter (22\%) of older people had lived abroad for more than six months. Those with only primary education and those with a tertiary degree are more likely to have emigrated for a period of time than those with a secondary level education.

\subsection{Introduction}

This chapter provides a profile of older people in Ireland, in terms of age, sex, marital status, living arrangements, migration, education, and occupation. The findings that are presented are of interest partly because they reflect many of the economic and social conditions and changes that have been features of Ireland's development over the latter part of the last century. The results are presented at the individual level and attention is drawn to cohort and sex differences with regard to marital status, living arrangements, education and employment status.

The socio-demographic profile of older people in Ireland is the result of trends in marriage, mortality and emigration. Demographic trends in Ireland differed from those of the rest of Europe as Ireland did not experience the demographic transition ${ }^{1}$ typical of most Western European countries (1). Historically, Ireland had a remarkable combination of high emigration, high marital fertility, low nuptiality and low non-marital fertility. For many decades, high marital fertility compensated for low marriage rates and Ireland had the highest crude birth rate (i.e., childbirths per 1,000 people per year) in Europe (2). However, the adoption at the end of the 1950s of new economic policies based on the encouragement of foreign direct investment

1 The demographic transition is a model used to represent the transition from high birth and death rates to low birth and death rates. 
from the multinational corporate sector led to economic growth during the 1960s, with increased job creation, a drop in outward migration and a consequent rise in the marriage rate. However, the improved economic conditions of the 1960s did not last. In the 1980s, high unemployment caused massive net emigration of over 20,000 persons (or approximately $5 \%$ of the population) (3). In the 1990s, Ireland emerged as the Celtic Tiger with real GDP growth rates of over $8 \%$ and this generated a high level of net inward migration In the mid-1990s, the great majority of immigrants were returning Irish migrants but from 2004, there was a large inflow from the EU's accession states. (3). Additional inward migration from non-EEA countries has occurred (4).

\subsection{Age and sex composition}

Based on the TILDA sample and applying weights (as discussed in Chapter 11), 47.9 per cent of Ireland's population aged 50 years and over are men and $52.1 \%$ are women (See Figure 2.1). The largest proportion of the population is in the younger $50-64$ age group representing $58.3 \%$ of the total population $(60.9 \%$ of men and $56 \%$ of women).

Figure 2.1. Age and sex composition of the TILDA sample

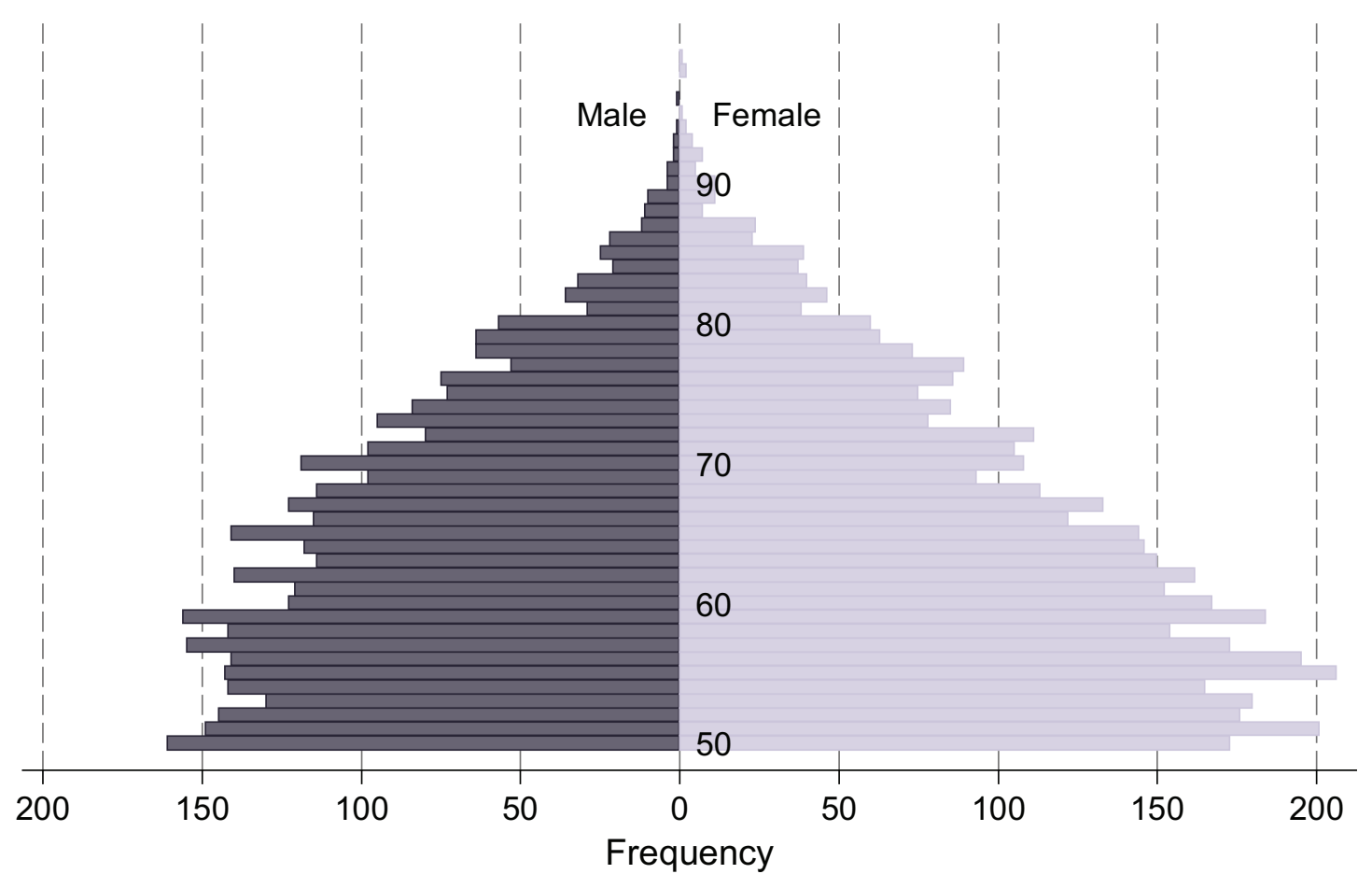

The median age is defined as that age which divides the population into two equal parts i.e., half with ages below the median age and the other half with ages above the median. The median age of the over-50s is 63.2 for men and 64.6 for women. There are approximately equal numbers of men and women between the ages of 50 
and 74, but owing to the higher mortality rate in men the majority of the oldest old are women. In the oldest age group, women outnumber men by a factor of 1.5, i.e., there are 100 men per 150 women among those aged 75 and over.

Figure 2.2: Distribution of marital status by age and sex

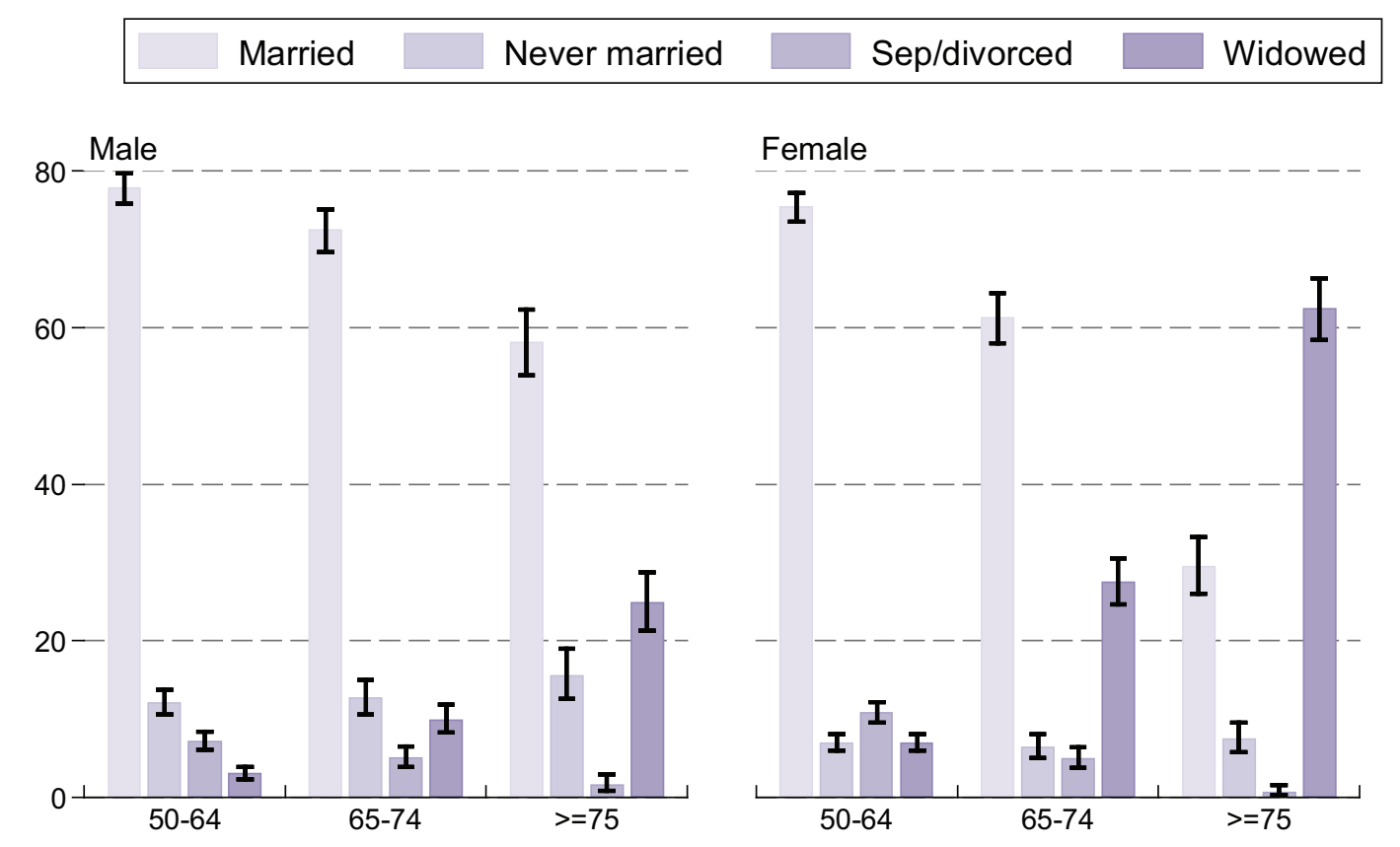

Note. $\mathrm{N}=8178$; Missing obs $=0$; Error bars correspond to $95 \%$ confidence intervals

\subsection{Marital status}

Owing to historical inheritance patterns, Ireland has had a unique pattern of marital status, having the highest proportion of individuals in Western Europe who never married, or married very late in life. By custom, only the heir was allowed to marry and to remain in the home; other siblings were required to remain single $(5,6)$ or to emigrate (6). This trend changed in the 1960s and 1970s when Ireland experienced a marriage boom. Those who married at that time are now entering old age, increasing the proportion of married people in the older population (7).

The distribution of marital status presented in Figure 2.2 reflects this historical shift in the marriage pattern. Men are more likely to have never married than women $(13 \%$ men, $7 \%$ women). Among men, $15 \%$ of those now aged 75 and older never married compared to $13 \%$ of those aged $65-74$ and $12 \%$ of those aged $50-64$. In the oldest age group, most men are married (58\%), while the majority of women are widowed $(63 \%)$ as a result of men tending to marry a younger woman and the higher life expectancy of women. Figure 2.3 shows that for both sexes, but in particular for men, 
higher levels of education are associated with greater likelihoods of having married and lower likelihoods of being widowed. The proportion of men who did not marry decreases with increasing educational attainment but more highly educated women are less likely to have married, relative to those with second level schooling. Of men, $17 \%$ with primary education did not marry compared to $7 \%$ of men with tertiary education while $4 \%$ of women with primary education did not marry compared to $12 \%$ of those with tertiary degree. Divorce rates are low in this cohort but increase with educational attainment especially for women, as $2 \%$ of women with primary education are divorced in contrast with $5 \%$ of those with a tertiary degree.

Figure 2.3: Distribution of marital status by education and sex

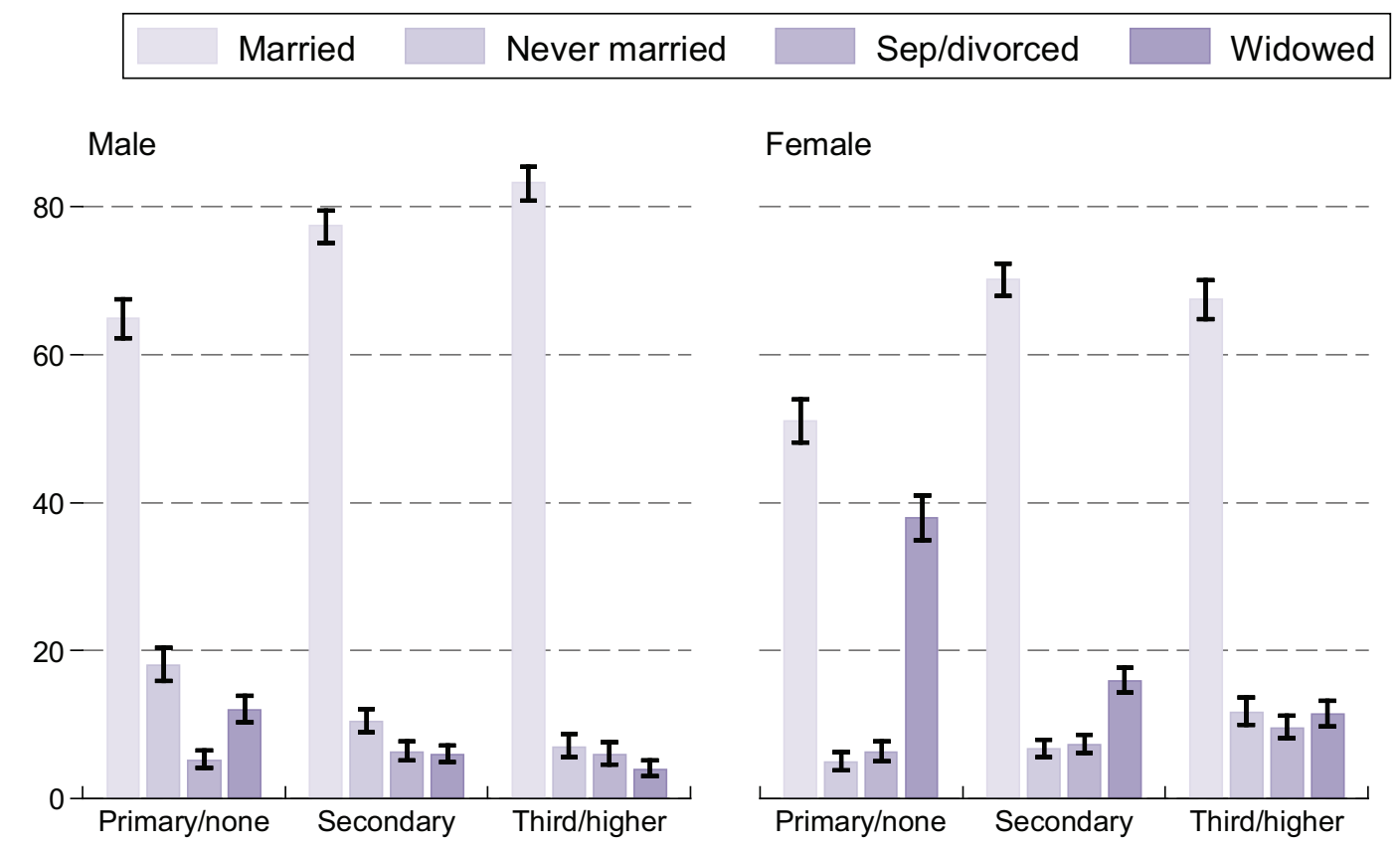

Note. $\mathrm{N}=8174$; Missing obs $=4$; Error bars correspond to $95 \%$ confidence intervals

\subsection{Living arrangements}

One of the main policy issues arising from population ageing is how countries will allocate resources across competing claims as age-related spending on pensions, long-term care and healthcare rise. Many governments are promoting more selfreliance in respect of pension income and greater family responsibility for providing care (8). Consequently, patterns of caregiving and living arrangements become key components of the well-being of older people.

Figure 2.4 shows the living arrangements of older adults by age and sex. The proportion of individuals living alone increases with age as the proportion living 
with their children decreases. The proportion of older people living with their spouse only has an inverted U-shape, as the 50-64 years-old cohort often have co-resident children, while the 65-74 years-old cohort experience nest-leaving and the 75 and over cohort are more likely to experience widowhood.

The proportion of those living with related and non-related co-residents other than their spouses or children is small $(0.6 \%)$ and remains almost constant with age. Overall, living alone or as a couple is the dominant living arrangement among older people in Ireland.

Those living alone are thought more likely to need outside assistance in the case of illness or disability, and are at greater risk of social isolation (see Chapter 4). Older women are more likely than older men to be living alone, partly because of the age differentials in mortality and marriage between men and women. The consequences of widowhood and living alone will be the subject of future TILDA analyses.

Figure 2.4: Distribution of the living arrangements by age and sex

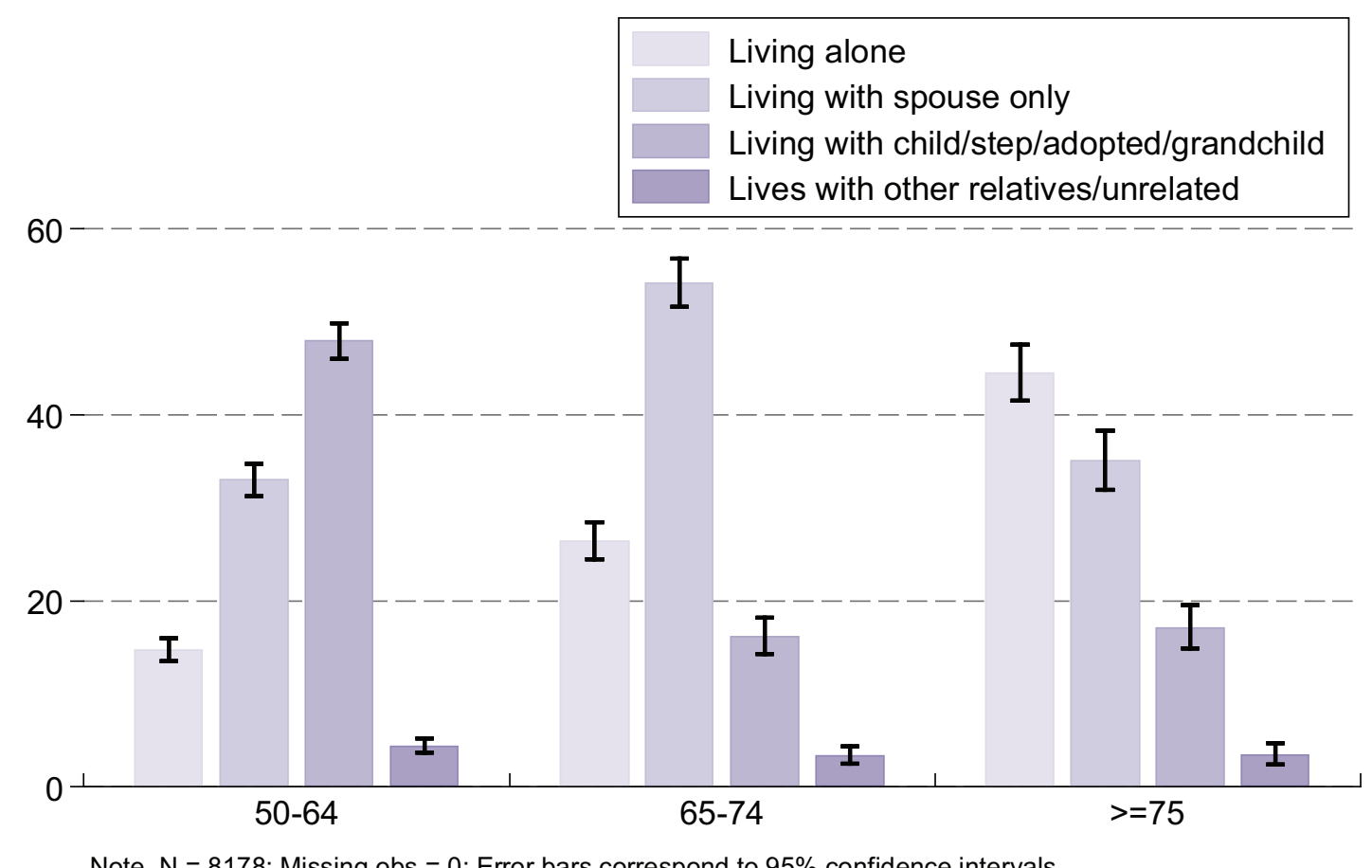

Note. $\mathrm{N}=8178$; Missing obs $=0$; Error bars correspond to $95 \%$ confidence intervals 


\subsection{Number of living children}

As discussed above, since the late nineteenth century a combination of a low marriage rate but with large families has led to a unique childbearing pattern in Ireland $(9,10)$. In the 1960s, one-third of births in Ireland were in families with five births or more but by the 1980 s this number had declined to $15 \%$. By the late 1990 s birth rates had converged towards international norms (11). The overall decline in the total fertility rate, from 4.03 in 1965 to 1.84 in 1995, resulted from a fall in the fertility rate across all age groups. This decline reflected both cultural changes and the change in regulatory framework governing the availability of contraceptives. Until 1973 the use of artificial contraceptive methods was illegal in Ireland (12). The continuing liberalisation of contraceptive laws in the 1980s and 1990s has allowed fertility to be further controlled.

Figure 2.5 shows the number of living children by marital status. Among those who married, those in older age groups are more likely to have living children. This reflects the high fertility rate of older generations. The mean number of living children for the youngest cohort is 2.84 , while for the oldest cohort it is 3.3. Religion and education also affected the fertility of those now aged 50 and over. Older women who are Catholic have more living children (mean 3.1) than those who are Protestant (mean 2.3). The mean number of living children for women with primary education is 3.27, for secondary education is 2.9 and for tertiary education is 2.6

Figure 2.5: Number of living children by marital status

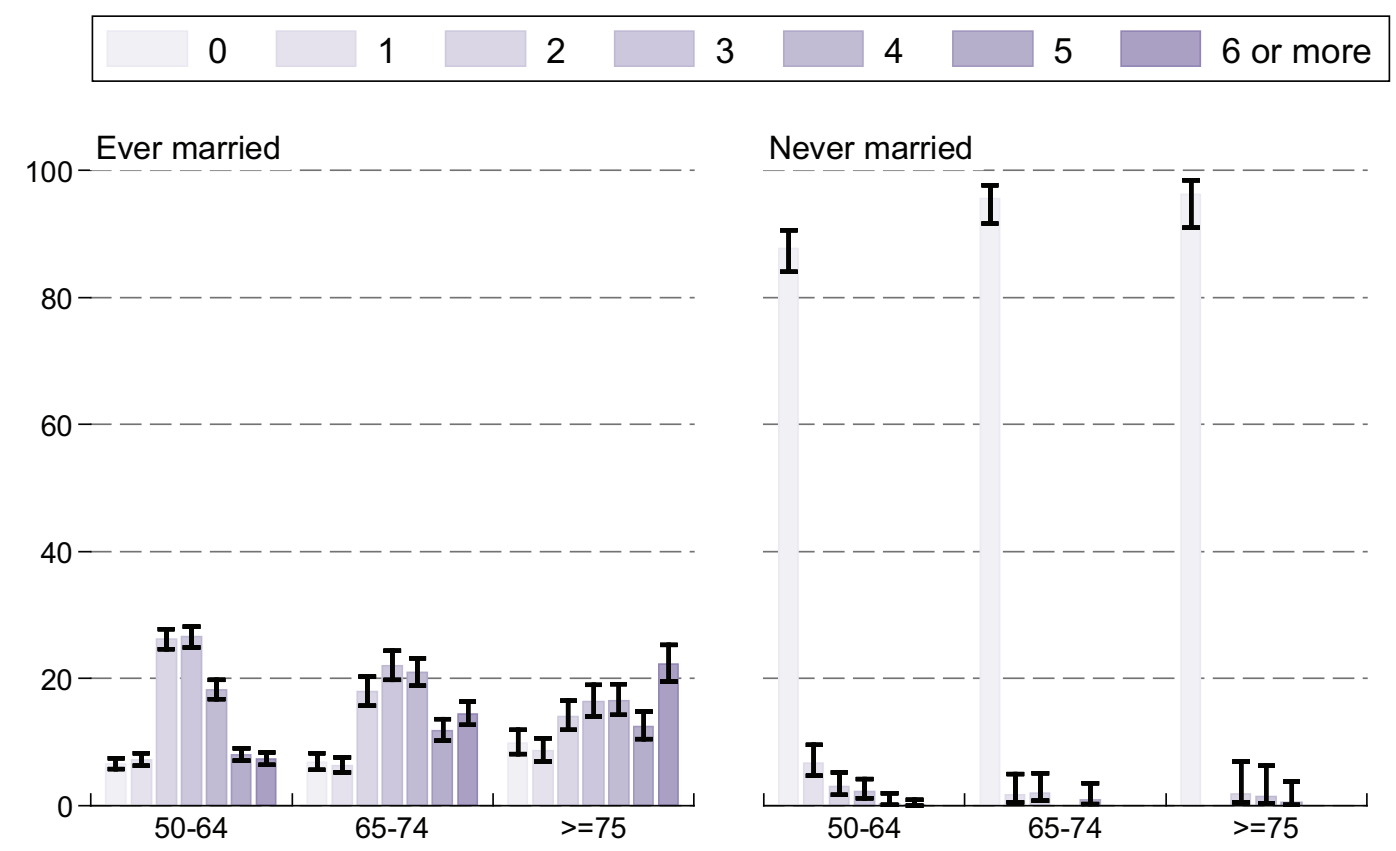

Note. $\mathrm{N}=8178$; Missing obs = 0; Error bars correspond to $95 \%$ confidence intervals 


\subsection{Migration}

Between 1871 and 1961, the average annual net emigration from Ireland consistently exceeded the natural increase in the Irish population, which shrank from about 4.4 to 2.8 million during that time. Today, an estimated 3 million Irish citizens live abroad, of whom 1.2 million were born in Ireland. The majority of these live in the US and the UK (13).

For much of the last century Ireland's economic growth was weak, with the exception of periods such as the late 1970s and the mid to late 1990s. This led to a significant emigration of younger people, particularly males, between 1960 and 1995 (12). However, the booming economy of the late 1990s led to an increase in net immigration, largely because of the return of Irish workers and their families as well as new immigrants.

Figure 2.6 shows that $23 \%$ of older men and $19 \%$ of older women currently living in Ireland have lived abroad for more than six months at some point in the past, with those aged between 65 and 74 most likely to be returning migrants. Examining by educational attainment (see Figure 2.7), the returnees are more likely to have either primary education or tertiary education.

Figure 2.6: Percentage of older people in Ireland who have lived abroad for more than six months

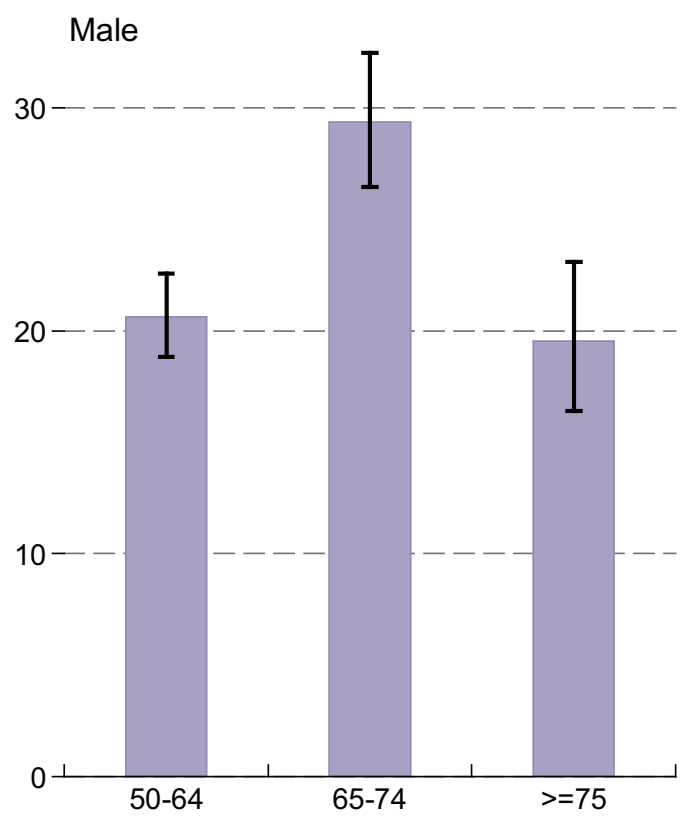

Female

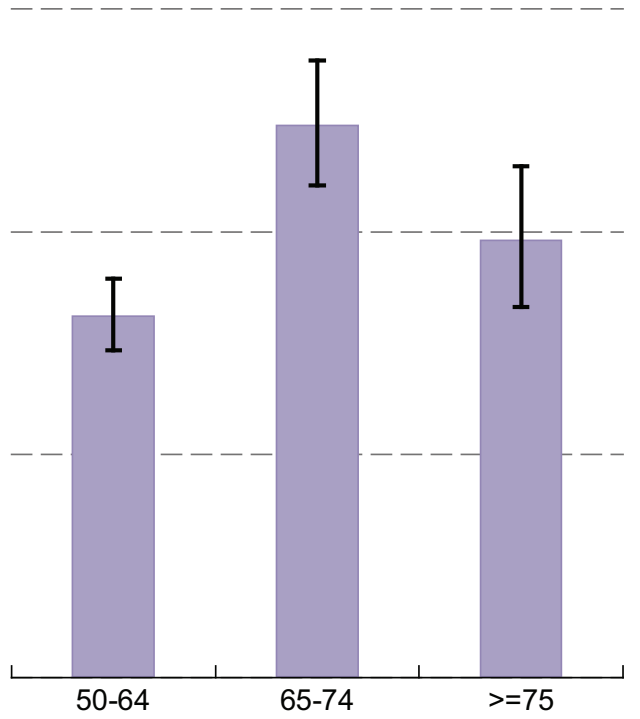

Note. $\mathrm{N}=8178$; Missing obs $=0$; Error bars correspond to $95 \%$ confidence intervals 


\subsection{Socio-economic position}

Socio-economic status (SES) or position is a powerful predictor of health inequalities and death in older people. In general, indicators of SES are meant to provide information about an individual's access to social and economic resources (14). The common socio-economic status indices employed in the literature are based on education, occupation, household income, and wealth (15). This section describes two of the main socio-economic variables used in the literature, namely, education and occupation. Income and wealth will be explored in Chapter 9 and the association with socio-economic status and health outcomes will be explored in Chapters 5 and 6.

As education is usually acquired early in life and then remains fixed, there is generally less problem when making causal inferences between education and outcome variables (15). Education has been associated with cognitive reserve, better health behaviours and access to preventive health services. A person's occupation represents exposure to psychosocial and physical strains in the work environment and has been found to predict a wide range of health outcomes.

Figure 2.7: Irish older people who have lived abroad for more than six months, by education

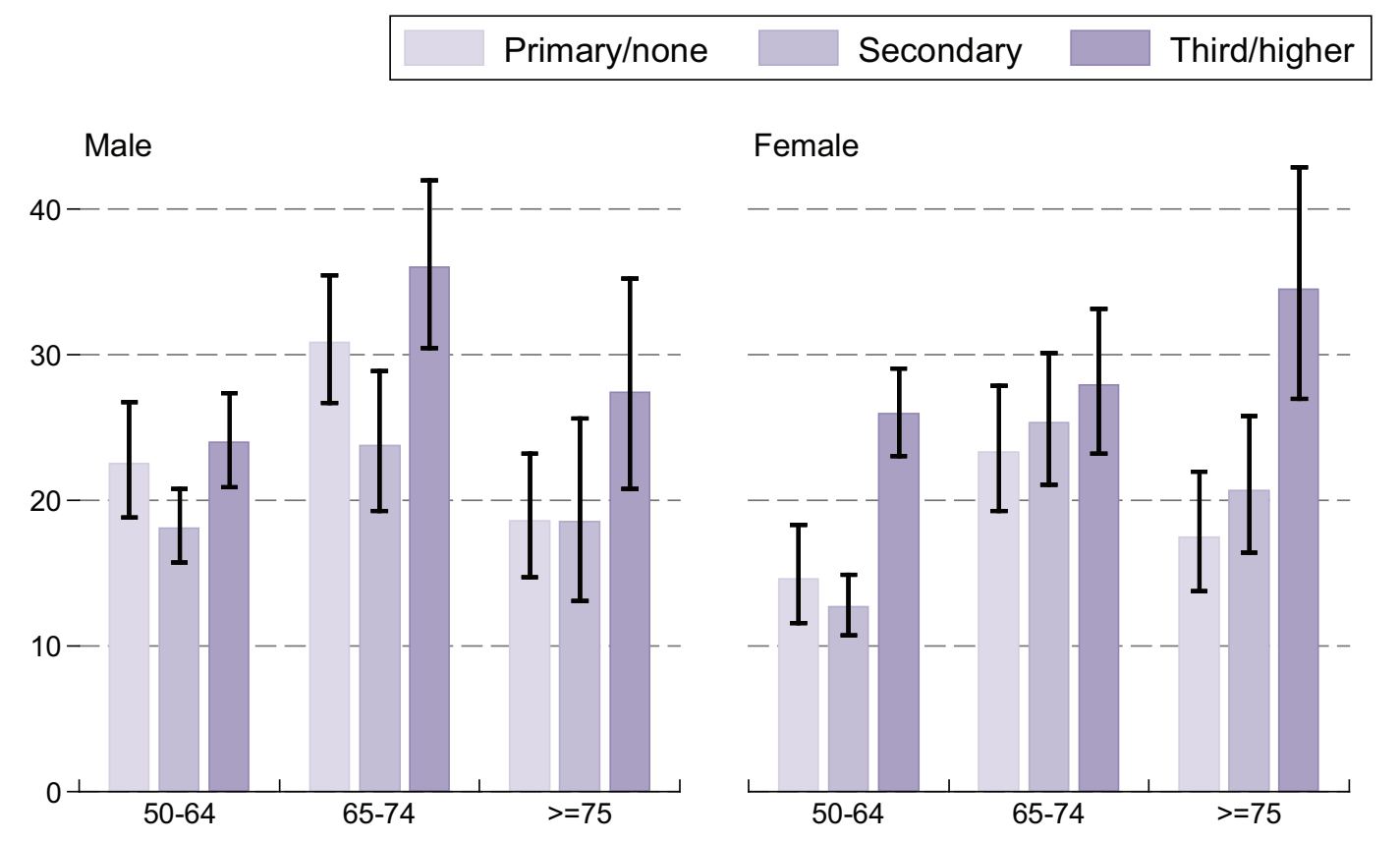

Note. $\mathrm{N}=8174$; Missing obs $=4$; Error bars correspond to $95 \%$ confidence intervals 


\subsubsection{Education}

Most older people in Ireland have achieved at least secondary education (62\%). Examining education across age group for both sexes reveals that the younger cohort have higher educational attainment (Figure 2.8). For example, $23 \%$ of men aged between $50-64$ have a tertiary degree compared to $15 \%$ of men aged between $65-74$ and $11 \%$ of men aged 75 or over. Similarly, the proportion of those with only primary education increases with age. This is due to a major expansion in education attendance which occurred in the late 1960s with the introduction of free secondary schooling in 1968. The effect of this policy is observed for the 50-64 age group with higher attendance in secondary school than in older groups. Some sex differences can be seen, as more women than men achieved at least secondary education in the 50-64 and 65-74 age group. The gradient of increasing proportions of primary/none education with increasing age is steeper for women than men. This trend will be explored in the further studies.

Figure 2.8: Educational attainment by age and sex

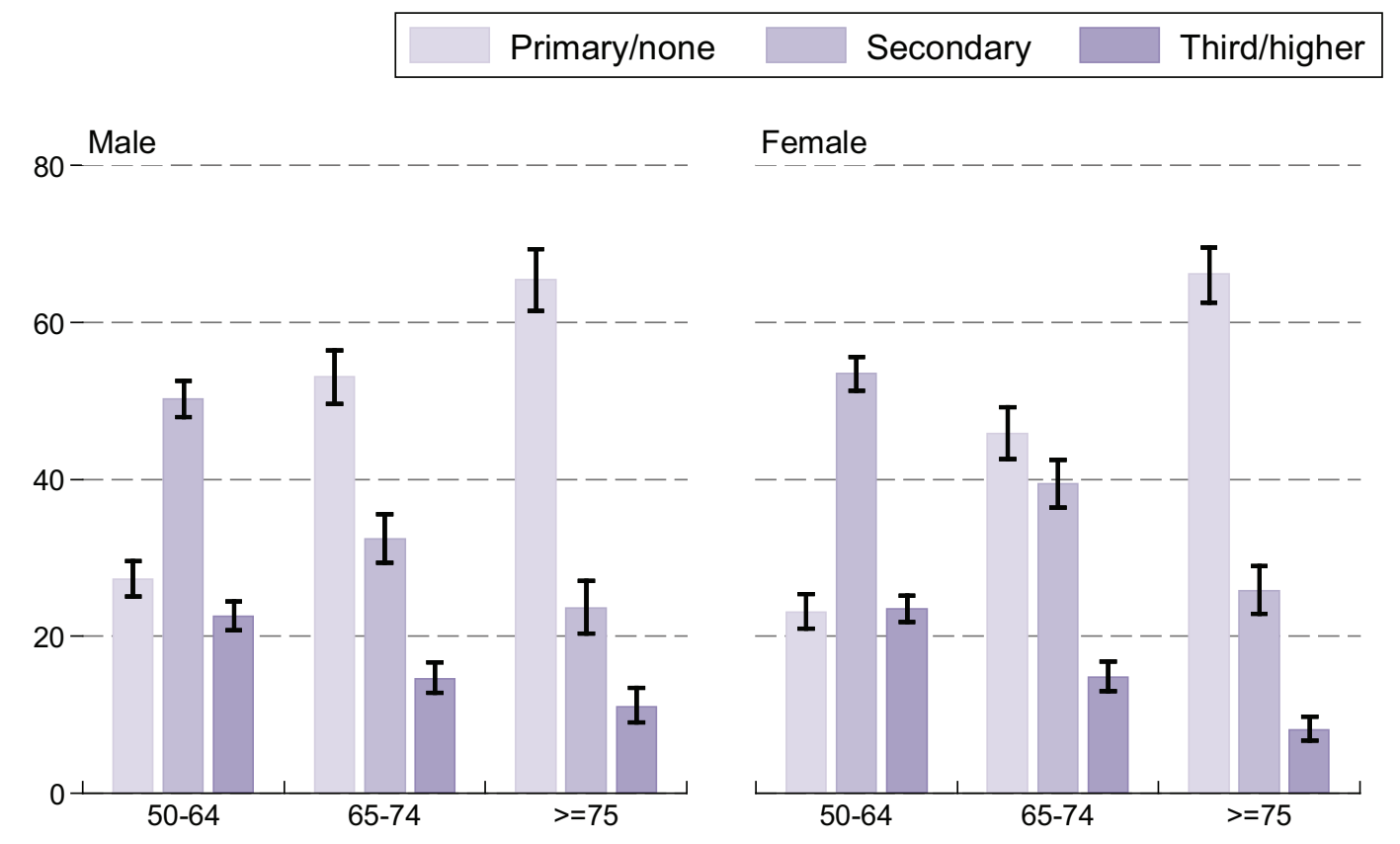

Note. $\mathrm{N}=8174$; Missing obs $=4$; Error bars correspond to $95 \%$ confidence intervals

Patterns of intergenerational transmission of socio-economic position mean that education levels are likely to be passed from one generation of families to the next. Figure 2.9 shows there is a strong relationship between father's education and respondent's education, that is, $45 \%$ of those whose father was educated to primary level were educated to primary level themselves, while $58 \%$ of those whose father completed third level education also completed third level education. Across the age 
cohorts, parental education also decreases markedly, as $78.7 \%$ of the parents of agegroup 50-64 years-old had completed only primary education, compared with $82.0 \%$ and $87.0 \%$ of the age group $65-74$ and 75 and over, respectively. This pattern could reflect in part differential mortality rates by parental education level, along with the intergenerational transmission of education.

Figure 2.9: Father's education and respondent's education outcome

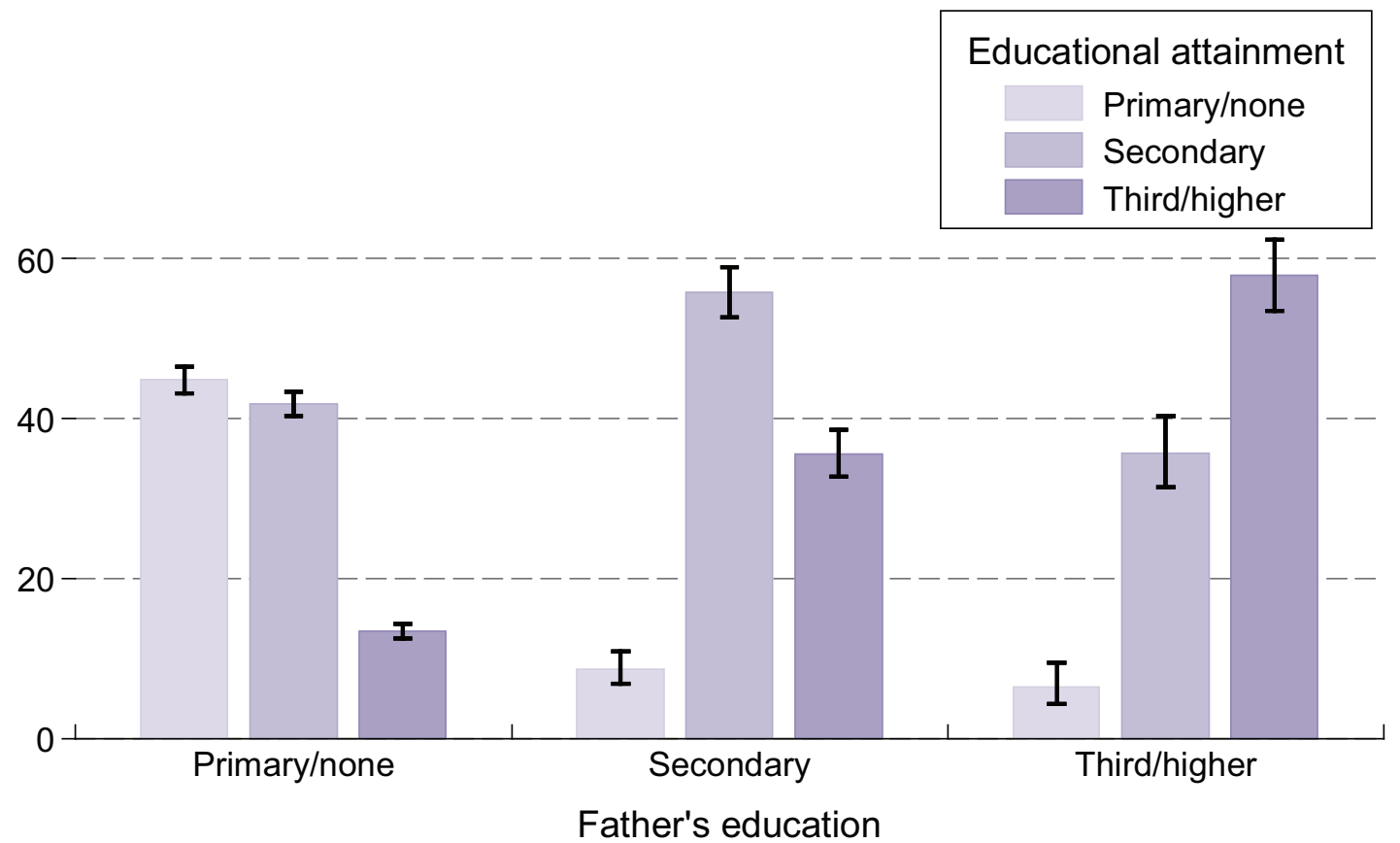

Note. $\mathrm{N}=7459$; Missing obs $=719$; Error bars correspond to $95 \%$ confidence intervals

\subsubsection{Occupation}

In this sub-section, occupations for those who are currently employed or retired are reported. TILDA did not record previous occupations for individuals who are unemployed, permanently sick or disabled, or who are looking after family/home. Chapter 8 presents a detailed discussion of the of the labour force participation of the older population.

Figure 2.10 illustrates age and sex differences by occupation. Those currently unemployed, out of work through long-term illness or who are occupied by looking after a home or family are classified as 'not applicable'. In the 50-64 age group, 17\% of men and $14 \%$ of women are in managerial and higher and lower professional positions, $5 \%$ of men and $20 \%$ of women are in other non-manual occupations, $17 \%$ of men and $11 \%$ of women are in manual occupations, and $16 \%$ of men and $4 \%$ of women are self-employed. The largest sex differences are found in the oldest 
age groups reflecting changes that have occurred in employment, with women in younger cohorts entering more into professions which used to be almost exclusively male.

Figure 2.10: Distribution of current or former (in the case of those retired) occupation by age and sex. Those currently unemployed, out of work through long-term illness or who are occupied by looking after a home or family are classified as 'Not applicable'.

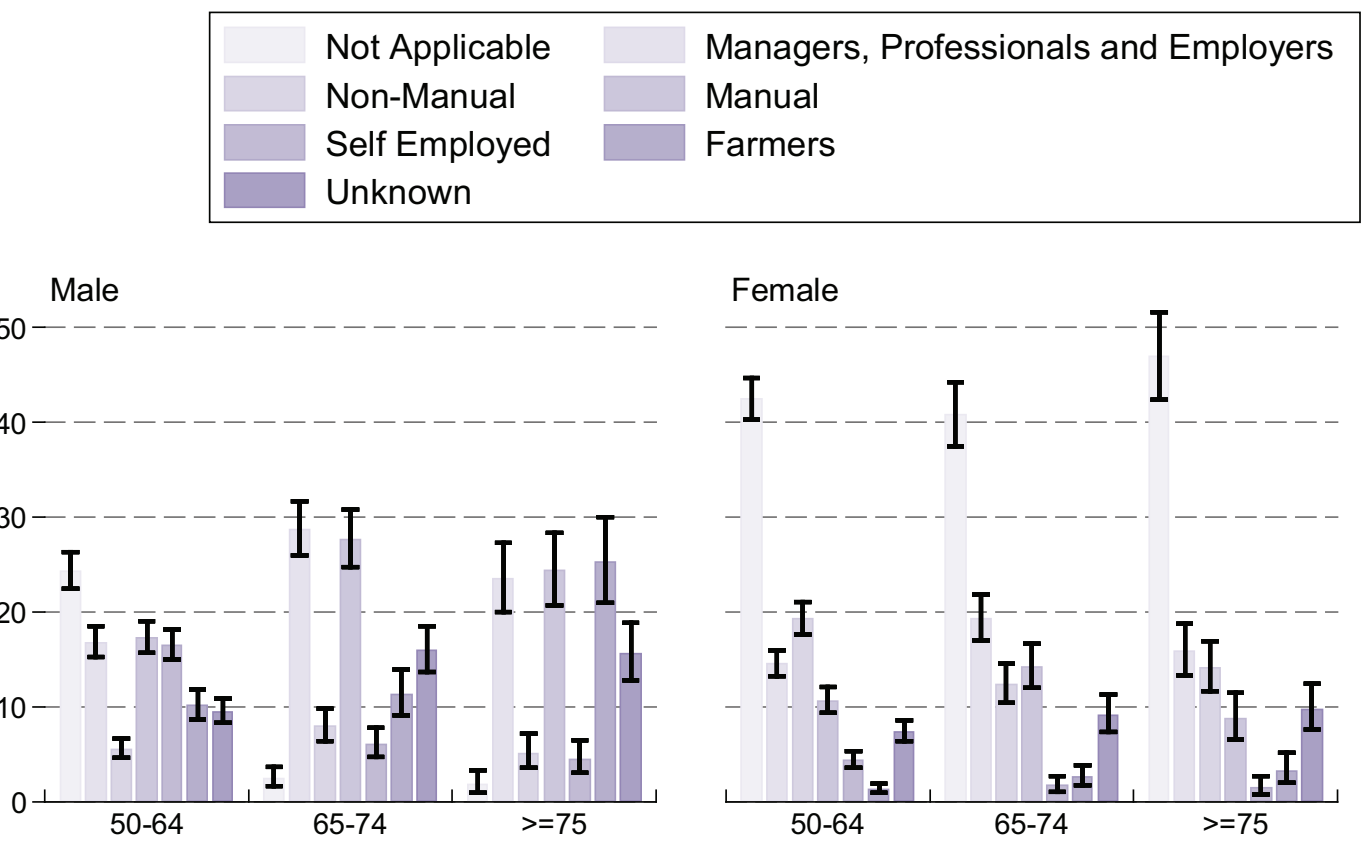

Note. $\mathrm{N}=8178$; Missing obs = 0; Error bars correspond to $95 \%$ confidence intervals

\subsection{Conclusions}

This chapter provides demographic data and information on the context of the lives of older people, namely, marital status, living arrangements, number of living children, migration, education and occupation.

The proportion of people who are married is high, although this proportion decreases with increasing age as widowhood becomes more prevalent. More highly educated people were more likely to be currently married and less likely to be widowed, although more educated women are less likely to have ever married.

Living arrangements differ among age groups and between sexes. Those aged 50-64 are most likely to live with a spouse and children. This proportion declines with age, with older adults especially women living alone. Living arrangements also differed 
by educational attainment. People with higher educational attainment are less likely to live alone or with children even at the oldest ages and are more likely to live with a partner. Older people in Ireland have on average three living children. The mean number of living children differs by both age group and education, with the oldest cohort having more children than the youngest and more educated women having had fewer children.

Twenty two per cent of people aged 50 and over have lived abroad. Those who only completed primary education and those with a tertiary degree are more likely to have emigrated than those with secondary schooling. Many differences between sex and age groups in education and current and former occupation are evident.

In conclusion, the socio-demographic picture that has emerged of Ireland's older people reflects many of the social and economic circumstances that were present at various stages of their lives. Major social changes such as the introduction of free secondary schooling and the liberalisation of the contraceptives laws are evident in educational attainment and fertility differences by age. Social processes such as the intergenerational transmission of educational attainment are also evident. Low levels of economic growth which resulted in large-scale out-migration are reflected in the remarkably high proportion of former emigrants in the data. To the extent that socio-environmental circumstances at various stages of life affect the process of ageing at an individual level, these social circumstances and processes will provide an important context for much of the work that will emerge from TILDA.

\section{References:}

1. Murphy-Lawless J, McCarthy J. Social Policy and Fertility Change in Ireland : The Push to Legislate in Favour of Women's Agency. European Journal of Women's Studies. 1999;6:69-96.

2. O'Grada C, Walsh B. Fertility and Population in Ireland, North and South. Population Studies. 1995;49:259-79.

3. Barret A. Irish Migration: Characteristics, Causes, and Consequences. In: Zimmermann K, editor. European Migration: What Do we Know? New York: Oxford University Press; 2005.

4. Barrett A, Duffy D. Are Ireland's Immigrants Integrating into Its Labor Market? International Migration Review. 2008;42(3):597-619.

5. Arensberg CM, Kimball ST. Family and Community in Ireland. Cambridge: Harvard University Press; 1940.

6. Fitzpatrick D. Marriage in post-famine Ireland. In Marriage in Ireland. In: Cosgrove A, editor. Dublin: College Press; 1985.

7. Fahey T, Maitre B, Nolan B, Whelan CT. A Social Portrait of Older People in Ireland. Dublin: The Economic and Social Research Institute 2007.

8. Nations U. Ageing and Living Arrangements of Older Persons: Critical Issues and Policy Responses. In: Affairs DoEaS, editor. New York 2001. 
9. Nations U, Affairs DoEaS, Division P. World Population Prospects: The 2004 Revision. New York: United Nation; 2005.

10. Strassmann BI, Clarke AL. Ecological Constraints on Marriage in Rural Ireland. Evolution and Human Behavior. 1998;19(1):33-55.

11. Fahey T. Trends in Irish Fertility Rates in Comparative Perspective. The Economic and Social Review. 20001;32(2):153-80.

12. O'Donoghue $C$, Meredith D, O'Shea E. Postponing maternity in Ireland. Cambridge Journal of Economics. 2010:1-26.

13. O'Rourke K. Emigration and living standards in Ireland since the Famine. Journal of Population Economics 1994;8(4):407-21.

14. Duncan GJ, Daly MC, McDonough P, Williams DR. Optimal Indicators of Socioeconomic Status for Health Research. American Journal of Public Health. 2002;92(7).

15. Grundy E, Holt G. The socioeconomic status of older adults: How should we measure it in studies of health inequalities? The Journal of Epidemiology and Community Health 2001;55:895-904 


\section{Older People As Members Of Their Families And Communities \\ Yumiko Kamiya and Virpi Timonen}

\section{Contents}

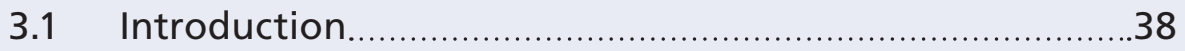

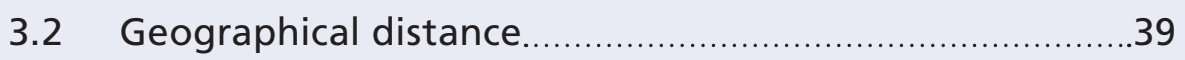

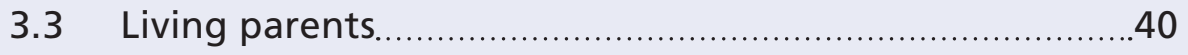

3.3.1 Frequency of contact with parents .......................43

3.3.2 Provision of care and other
non-financial help to parents.................................

3.4 Prevalence and characteristics

of the "sandwich generation".......................................44

3.5 Financial and non-financial transfers ...........................45

3.5.1 Financial transfers to and from children ................45

3.5.2 Non-financial transfers to and from children and grandchildren..........................46

3.6 Transfers to non-family members .................................47

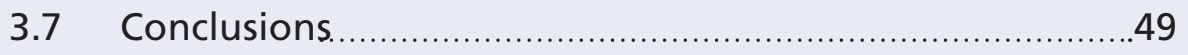




\section{Older People As Members Of Their Families And Communities}

\section{Key Findings}

- Three-quarters of all adults aged 50 and over live in close proximity to at least one of their children.

- Over $70 \%$ of the age group most likely to need care and support (75 and over), live with their children or have at least one child living in the same county.

- Three-quarters of older adults whose parents are still alive see their parents frequently (daily, weekly, or several times per month).

- Half of 50-64 year olds with surviving parents provide help with household tasks to their parents, on average for 10 hours per week; over one-quarter provide their parents with personal care, on average for 18 hours per week.

- Family financial transfers flow mainly from ageing parents to their adult children. Nearly one-quarter (24\%) of older households have given large financial or material gifts (worth $€ 5,000$ or more) to their children in the last ten years. In contrast, only $9 \%$ of older adults have received financial transfers from their children.

- Non-financial transfers from ageing parents to their children are also very common in Ireland. Over one-third of older adults provide practical household help including shopping and household chores to their adult children and nearly half provide care to grandchildren.

- Nearly one-quarter of older people in Ireland provide some form of help to their neighbours and friends, on average for 8 hours per month. Almost one-fifth of older people receive some form of help from their neighbours and friends.

\subsection{Introduction}

The role of the family is often emphasised in Ireland, but to date we have lacked comprehensive information on what families provide to older adults, and what older adults give to their families. With the help of TILDA data, we can now for the first time analyse the relationship of older adults to their families and communities in great depth. This chapter describes the contact that older people have with family members and the transfers that they make to and receive from their families. We define intergenerational transfers as "the redistribution of resources within an extended family structure, incorporating both intra-household and inter-household exchanges" (1). The chapter also incorporates some data on supports given to and received from non-family members (neighbours and friends). 
Families remain central organising units for economic, emotional and care support of individuals. In many countries, family support acts as a social protection mechanism which provides informal insurance for social risks such as inability to earn an income and greater support needs due to unemployment or old age. Families continue to be the most significant source of care for dependent older people in almost every country in the world. These informal family supports may become increasingly important as policy-makers in most OECD countries express reservations about being able to meet the increased demand for formal (State) supports. A key policy relevant question is, therefore, to what extent family support is available in times of need.

However, older family members are not only recipients of family support, but are also an increasingly important source of support for their families due to major social and economic shifts including increased incidence of marital breakdown, women's labour market participation and lone parenthood. Grandparental care of young grandchildren, especially in countries with weak provision of public child care services, enables parents in dual-earning families and lone parents to participate in the labour market.

The geographical distance between parents and children, and the demands of labour market participation both affect opportunities for intergenerational contact and transfers. This chapter begins by examining the geographical distance between older Irish adults and their children. Proximity enables intergenerational contact and transfers while greater distance tends to suppress frequency of contact and tends to make support provision more difficult. The proportion of Irish older adults with surviving parents will then be discussed. This is important because in some cases having a surviving parent translates into being called upon to meet their care needs. Where these care demands occur in tandem with having to meet the care needs of younger family members, the 'sandwich generation' phenomenon occurs.

The focus on family in this chapter does not diminish the importance of informal support received from and provided to friends and neighbours, and these are reported at the end of the chapter. Measuring both informal and formal (paid or State-organised) support - as TILDA does - is important because the provision of formal health and social care services interacts with and affects the type and intensity of the support given by the family to older persons. Utilisation of formal care and supports is discussed in Chapter 7.

\subsection{Geographical distance}

Figure 3.1 shows the proximity to children according to age (and also the proportion of older people who have no children - for more detail on this see Chapter 2. Of people aged 50 and over in Ireland, 36\% have co-resident children, and an additional 
$38 \%$ have at least one child living in the same county ${ }^{1}$. Overall, therefore, $74 \%$ of the older adult population of Ireland live in very close or fairly close proximity to at least one of their children. However, there is considerable variation in the proximity to children by age group. Figure 3.1 shows that there is a notable decline in the proportion with co-resident children from the 50-64 age group (50\%) to the $65-74$ age group (17\%), reflecting the nest-leaving process. Among those aged 75 and over, i.e. the age group most likely to need care and support, $71 \%$ either live with their children or have at least one child living in the same county. However, members the oldest age-group are also more likely to have all of their children living abroad than younger age groups, reflecting historical patterns of emigration.

Figure 3.1. Co-residence and proximity to children by age group

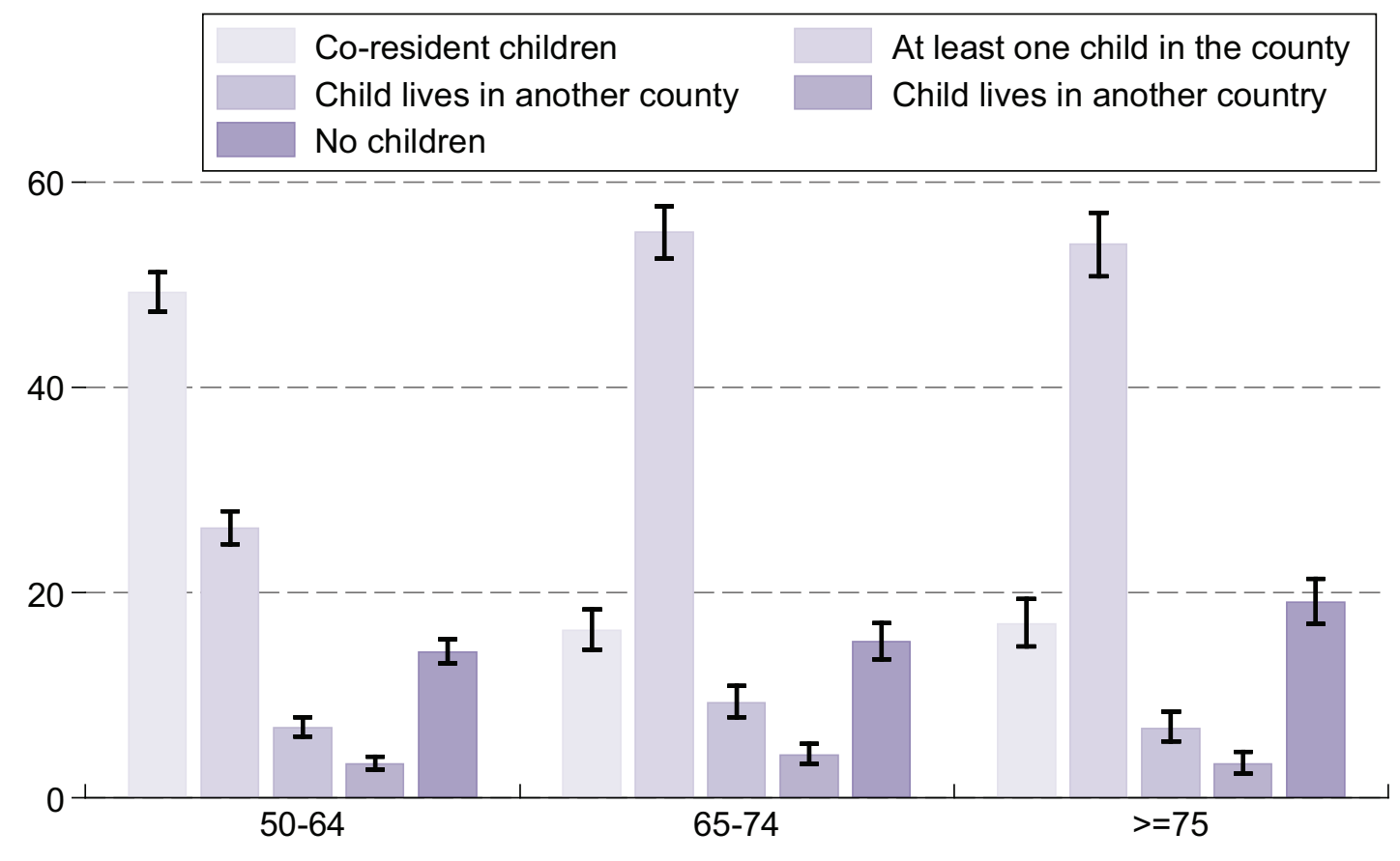

Note. $\mathrm{N}=8178$; Missing obs = 0; Error bars correspond to $95 \%$ confidence intervals

\subsection{Living parents}

The number, age and health status of living parents and children can lead to competing demands on the 'middle generation' (i.e. the adult children of ageing parents who are simultaneously parents of young children). Added to this, for some, are the demands of paid work. Although having a living parent does not always

1 The measurement of distance by the same or different county of residence only yields an approximate estimate of geographical distance as some people who live in the same county as their parent live at a greater distance from each other than some of those who live in different counties (e.g. the latter could live just across the county border from each other). TILDA adopted this way of measuring distance to children and parents as the most user-friendly and pragmatic as well as arguably the most accurate approach because pilots showed most respondents to be highly uncertain about distances by miles / kilometres. 
translate into a demand for care, the availability of kin either in ascending (older) or descending (younger) generations indicates a potentially rich set of intergenerational transfers that may change direction as individuals age (2).

Table 3.1 shows that $27 \%$ of men and $27 \%$ of women aged $50-64$ have a surviving mother. This proportion decreases to 3\% for both sexes in the 65-74 age group. At age 75 and over, the percentage with a surviving parent is negligible. Only $5 \%$ of women and $6 \%$ of men in the 50-64 age group have both parents alive. The average age of living parents of all 50-64 year olds is 82.9 years for mothers and 83.0 years for fathers.

Table 3.1: Percentage of the older population with living parents by age and sex

\begin{tabular}{|c|c|c|c|c|c|c|c|c|c|c|}
\hline & \multicolumn{2}{|c|}{ Neither alive } & \multicolumn{2}{|c|}{$\begin{array}{l}\text { Only mother } \\
\text { alive }\end{array}$} & \multicolumn{2}{|c|}{$\begin{array}{l}\text { Only } \\
\text { father } \\
\text { alive }\end{array}$} & \multicolumn{2}{|c|}{$\begin{array}{l}\text { Both } \\
\text { parents } \\
\text { alive }\end{array}$} & \multirow[t]{2}{*}{ Total } & \multirow{2}{*}{$\begin{array}{c}\text { Number } \\
\text { in } \\
\text { sample }\end{array}$} \\
\hline & $\%$ & $95 \% \mathrm{Cl}$ & $\%$ & $95 \% \mathrm{Cl}$ & $\%$ & $95 \% \mathrm{Cl}$ & $\%$ & $95 \% \mathrm{Cl}$ & & \\
\hline \multicolumn{11}{|l|}{ Male } \\
\hline $50-64$ & 69 & $(67-71)$ & 21 & $(19-23)$ & 4 & $(3-5)$ & 6 & $(5-7)$ & 100 & 2073 \\
\hline $65-74$ & 96 & $(95-97)$ & 3 & $(2-5)$ & 0 & $(0-1)$ & 0 & $(0-1)$ & 100 & 1063 \\
\hline$>=75$ & 100 & $(99-100)$ & 0 & $(0-1)$ & 0 & $(0-1)$ & 0 & - & 100 & 596 \\
\hline Total & 80 & $(78-81)$ & 14 & $(12-15)$ & 3 & $(2-3)$ & 4 & (3-4) & 100 & 3732 \\
\hline \multicolumn{11}{|c|}{ Female } \\
\hline $50-64$ & 69 & $(67-71)$ & 22 & $(21-24)$ & 4 & $(3-4)$ & 5 & $(4-6)$ & 100 & 2566 \\
\hline $65-74$ & 97 & (95-98) & 3 & $(2-4)$ & 0 & $(0-0)$ & 0 & $(0-0)$ & 100 & 1085 \\
\hline$>=75$ & 100 & $(100-100)$ & 0 & $(0-0)$ & 0 & - & 0 & - & 100 & 749 \\
\hline Total & 82 & $(81-83)$ & 13 & $(12-14)$ & 2 & $(2-3)$ & 3 & $(2-3)$ & 100 & 4400 \\
\hline \multicolumn{11}{|l|}{ Total } \\
\hline $50-64$ & 69 & $(67-70)$ & 22 & $(21-23)$ & 4 & $(3-5)$ & 6 & $(5-6)$ & 100 & 4639 \\
\hline $65-74$ & 96 & $(95-97)$ & 3 & (3-4) & 0 & $(0-0)$ & 0 & $(0-1)$ & 100 & 2148 \\
\hline$>=75$ & 100 & $(100-100)$ & 0 & $(0-0)$ & 0 & $(0-0)$ & 0 & $(.-)$. & 100 & 1345 \\
\hline Total & 81 & $(80-82)$ & 13 & $(13-14)$ & 2 & $(2-3)$ & 3 & $(3-4)$ & 100 & 8132 \\
\hline
\end{tabular}

Note. $\mathrm{Cl}=$ confidence interval; Missing observations $=0.56 \%$ 
Social class is associated with the likelihood of having surviving parents. Table 3.2 shows that $25 \%$ of $50-64$ year olds with tertiary (degree level) education have a surviving mother while for those with primary education this percentage is only $15 \%$. Of 50-64 year olds with tertiary education, $9 \%$ have two living parents compared to only $2 \%$ of those with primary education. This is likely to be due to the transmission of the social gradient across generations and its effect on life expectancy.

Table 3.2: Percentage of the older population with living parents by age and education

\begin{tabular}{|c|c|c|c|c|c|c|c|c|c|c|}
\hline & \multicolumn{2}{|c|}{ Neither alive } & \multicolumn{2}{|c|}{$\begin{array}{l}\text { Only mother } \\
\text { alive }\end{array}$} & \multicolumn{2}{|c|}{$\begin{array}{l}\text { Only } \\
\text { father } \\
\text { alive }\end{array}$} & \multicolumn{2}{|c|}{$\begin{array}{l}\text { Both } \\
\text { parents } \\
\text { alive }\end{array}$} & \multirow[t]{2}{*}{ Total } & \multirow{2}{*}{$\begin{array}{c}\text { Number } \\
\text { in } \\
\text { sample }\end{array}$} \\
\hline & $\%$ & $95 \% \mathrm{Cl}$ & $\%$ & $95 \% \mathrm{Cl}$ & $\%$ & $95 \% \mathrm{Cl}$ & $\%$ & $95 \% \mathrm{Cl}$ & & \\
\hline \multicolumn{11}{|c|}{ Primary/none } \\
\hline $50-64$ & 79 & $(76-81)$ & 15 & $(13-18)$ & 4 & $(3-5)$ & 2 & $(2-4)$ & 100 & 943 \\
\hline $65-74$ & 96 & $(95-98)$ & 3 & $(2-5)$ & 0 & - & 0 & $(0-1)$ & 100 & 851 \\
\hline$>=75$ & 100 & - & 0 & - & 0 & - & 0 & - & 100 & 683 \\
\hline Total & 91 & $(90-92)$ & 7 & $(6-8)$ & 1 & $(1-2)$ & 1 & $(1-1)$ & 100 & 2477 \\
\hline \multicolumn{11}{|c|}{ Secondary } \\
\hline $50-64$ & 67 & $(65-69)$ & 24 & $(22-25)$ & 4 & $(3-5)$ & 5 & $(4-7)$ & 100 & 2109 \\
\hline $65-74$ & 96 & $(95-97)$ & 3 & $(2-5)$ & 0 & $(0-1)$ & 0 & $(0-1)$ & 100 & 727 \\
\hline$>=75$ & 100 & $(98-100)$ & 0 & - & 0 & $(0-2)$ & 0 & - & 100 & 416 \\
\hline Total & 76 & (74-78) & 17 & $(16-19)$ & 3 & $(2-4)$ & 4 & $(3-5)$ & 100 & 3252 \\
\hline \multicolumn{11}{|c|}{ Third/higher } \\
\hline $50-64$ & 62 & $(59-64)$ & 25 & $(22-27)$ & 4 & $(3-6)$ & 9 & $(8-11)$ & 100 & 1587 \\
\hline $65-74$ & 96 & $(94-97)$ & 3 & $(2-5)$ & 0 & $(0-1)$ & 0 & $(0-1)$ & 100 & 569 \\
\hline$>=75$ & 99 & $(97-100)$ & 1 & $(0-3)$ & 0 & - & 0 & - & 100 & 243 \\
\hline Total & 72 & $(69-74)$ & 18 & $(17-20)$ & 3 & $(2-4)$ & 7 & $(6-8)$ & 100 & 2399 \\
\hline \multicolumn{11}{|l|}{ Total } \\
\hline $50-64$ & 69 & $(67-70)$ & 22 & $(21-23)$ & 4 & $(3-5)$ & 6 & $(5-6)$ & 100 & 4639 \\
\hline $65-74$ & 96 & $(95-97)$ & 3 & $(3-4)$ & 0 & $(0-0)$ & 0 & $(0-1)$ & 100 & 2148 \\
\hline$>=75$ & 100 & $(100-100)$ & 0 & $(0-0)$ & 0 & $(0-0)$ & 0 & $(0-1)$ & 100 & 1345 \\
\hline Total & 81 & $(80-82)$ & 13 & $(13-14)$ & 2 & $(2-3)$ & 3 & $(3-4)$ & 100 & 8132 \\
\hline
\end{tabular}

Note: $\mathrm{Cl}=$ confidence interval; Missing observations $=0.56 \%$ 


\subsubsection{Frequency of contact with parents}

The majority of older adults with surviving parents have frequent contact with them. Although only 3\% of 50-64 year olds live in the same household with their mothers, $4 \%$ with their fathers and $2 \%$ with both parents, the frequency of faceto-face contact is high. Of those with living parents, $53 \%$ have face-to-face contact with them daily or several times a week, $24 \%$ have face-to-face contact several times per month, $19 \%$ have contact several times per year while only $2 \%$ have almost no contact with their parent(s). In other words, three-quarters of older adults whose parents are still alive see their parents frequently (daily, weekly, or several times per month).

Figure 3.2 explores the relationship between the mother's health and the frequency of face-to-face contact. Interestingly, there is no association between the mother's health and frequency of face-to-face contact, suggesting that contact is motivated both by the wish to spend time together and by help provision (when care needs arise). Father's health and face-to-face contact is not explored in this section because of the small number of respondents with living fathers in the TILDA sample.

Figure 3.2: Frequency of face to face contact with mother, by mother's health

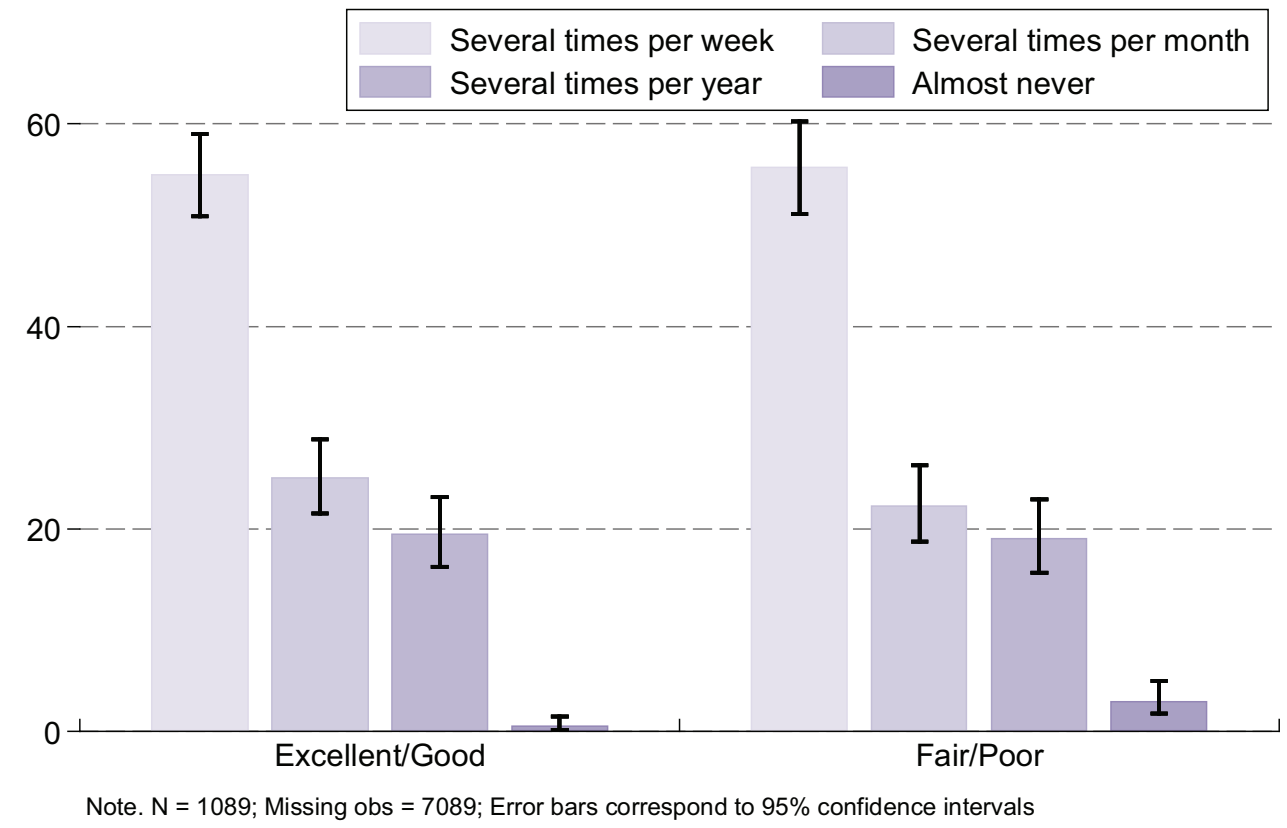




\subsubsection{Provision of care and other non-financial help to parents}

Older adults make remarkably high contributions towards the care of their surviving parents. TILDA includes two separate questions on the amount of help provided to parents with personal care and amount of help provided with other things such as household chores, errands, shopping and transportation.

Of 50-64 year olds, $28 \%$ with surviving parent(s) provide personal care to their parents, on average for 14 hours per week. Of these $50-64$ year olds $50 \%$ help their surviving parents with non-personal care duties such as household chores, errands and transportation, on average for 10 hours per week. As the questions in TILDA about provision of care and other types of help are asked separately, it is not possible to give the total numbers of hours of help provided to parents. However, $26 \%$ report providing both types of help. Most non-financial help is provided to mothers, as 50 64 years olds have more surviving mothers than fathers. Social class has little effect on whether older people provide help to surviving parents. Of those aged 50-64 with primary education, $31 \%$ provide personal care to their parents; and of those with secondary or tertiary education, $27 \%$ provide personal care to their parents.

\subsection{Prevalence and characteristics of the 'sandwich generation'}

This section describes the prevalence and characteristics of the sandwich generation i.e., people with potentially competing demands from both older and younger family members. Of those aged $50-64,27 \%$ have at least one living parent and child (including minor and adult children), $59 \%$ have only children, $4 \%$ have only parent(s) alive and $10 \%$ have neither surviving parents nor children.

Examining by age group, $28 \%$ of people aged 50-64 have both parents and children alive; this proportion declines to $4 \%$ in the $65-74$ age-group and to $0.1 \%$ among those aged 75 and over. Among the 50-64 year olds in the 'sandwich generation', $21 \%$ have parents who have care needs.

Respondents with higher levels of education are more likely to be in the 'sandwich generation'. For example, $19 \%$ of middle generation members with primary education had both surviving parent(s) and children, compared to $33 \%$ of those with tertiary education. Individuals with higher levels of education are, therefore, more likely to have the challenges of providing support to both younger and older family members; however, they may also be better equipped to do so than individuals with lower levels of education who typically have smaller financial resources. Moreover, better health status among the more highly educated may also attenuate the extent to which more highly educated older people have to respond to care needs arising from their parents' poor health; further research will be conducted to examine this. 


\subsection{Financial and non-financial transfers}

One of the most important policy-relevant questions that TILDA can answer concerns the types of help that family members provide to each other. TILDA collects information on transfers of money and time to and from children. Respondents quantify the specific amounts (in Euros) of financial help transferred as well as the number of hours per month that help was provided with specific types of tasks.

Figure 3.3 shows the distribution of transfers of money or time to and from the older population and their children. The rate of giving transfers decreases significantly with increasing age, while the rate of receiving transfers increases with age. Between the ages of 50 and 64, individuals are more likely to make transfers than to receive them. The next section will examine the types of transfers that older adults provide and receive.

Figure 3.3: Percentage of older people giving or receiving transfers to or from their children by age

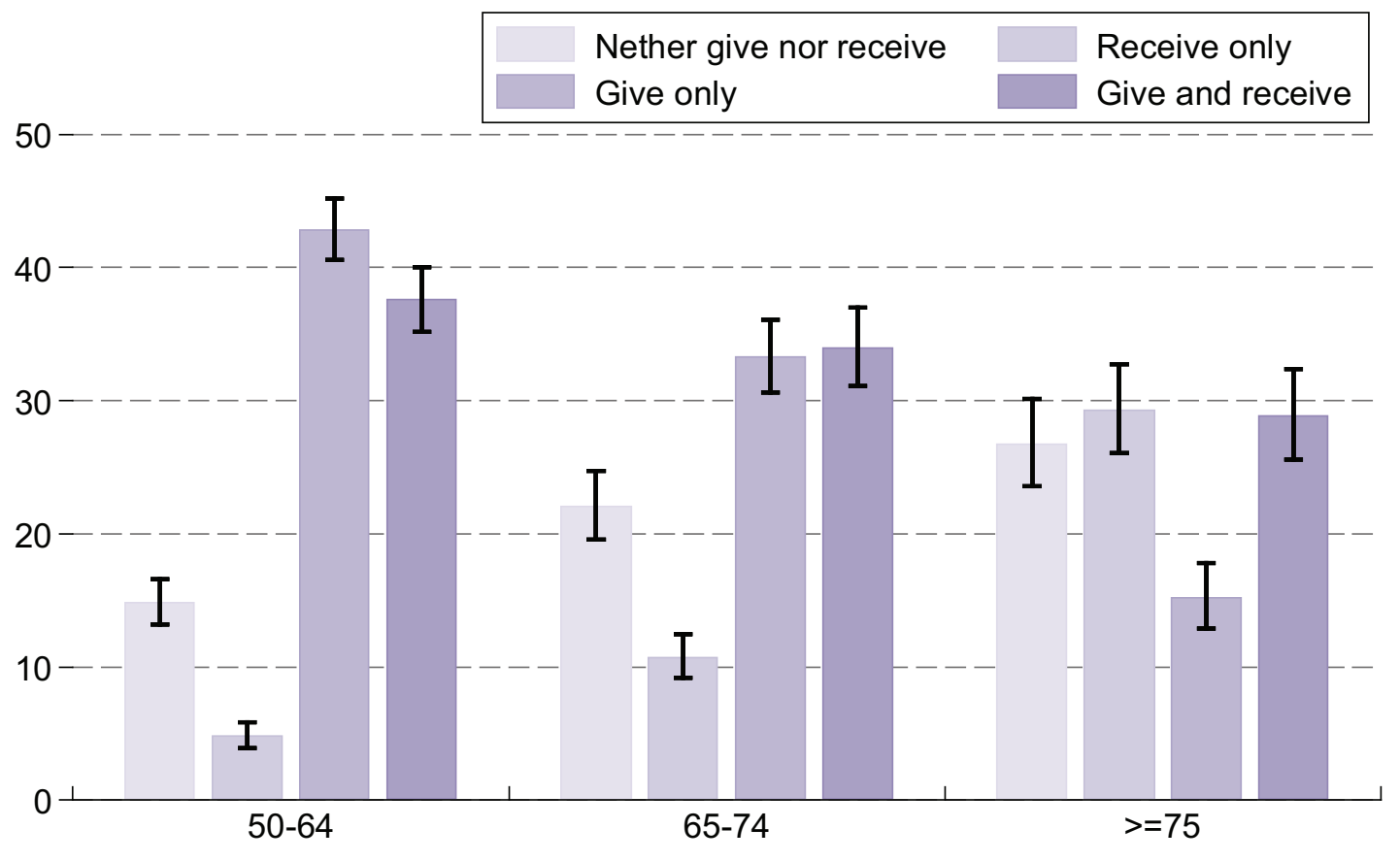

Note. $\mathrm{N}=6073$; Missing obs $=2105$; Error bars correspond to $95 \%$ confidence intervals

\subsubsection{Financial transfers to and from children}

Nearly one-quarter $(24 \%)$ of older households report giving a financial or material gift worth $€ 5,000$ or more to one or more of their children within the last ten years, with this number lowest (16\%) in the over 75 age group. The distribution of financial transfers is highly skewed by a small number of respondents who transferred very large material gifts to their children. Of those households that gave gifts worth more 
than $€ 5,000$ to children, the mean value of the gift was $€ 60,512$ while the median value was $€ 20,000$. Figure 3.4 shows that the median value of financial transfers given to children increases as the age of the gift-giving parent(s) increases. The median financial transfer to children is $€ 20,000$ for those aged $50-64, € 24,000$ for those aged 65-74 and $€ 30,000$ for those aged 75 and over. Therefore, while fewer older adults give financial gifts, the amounts of money that they give are on average larger.

Only $9 \%$ of the older population received financial transfers from their children. This increased from 7\% among people aged 50-64 to $12 \%$ among those aged 75 and older. The mean value of these transfers is $€ 2,347$ with a median value of $€ 1,000$. Family financial transfers in Ireland, therefore, flow mainly from parents to children, a finding in common with research conducted in other several other developed world contexts (3).

Figure 3.4: The median, interquartile range and range of values of financial transfers from older people to their children by age. A logarithmic scale is used to incorporate large values

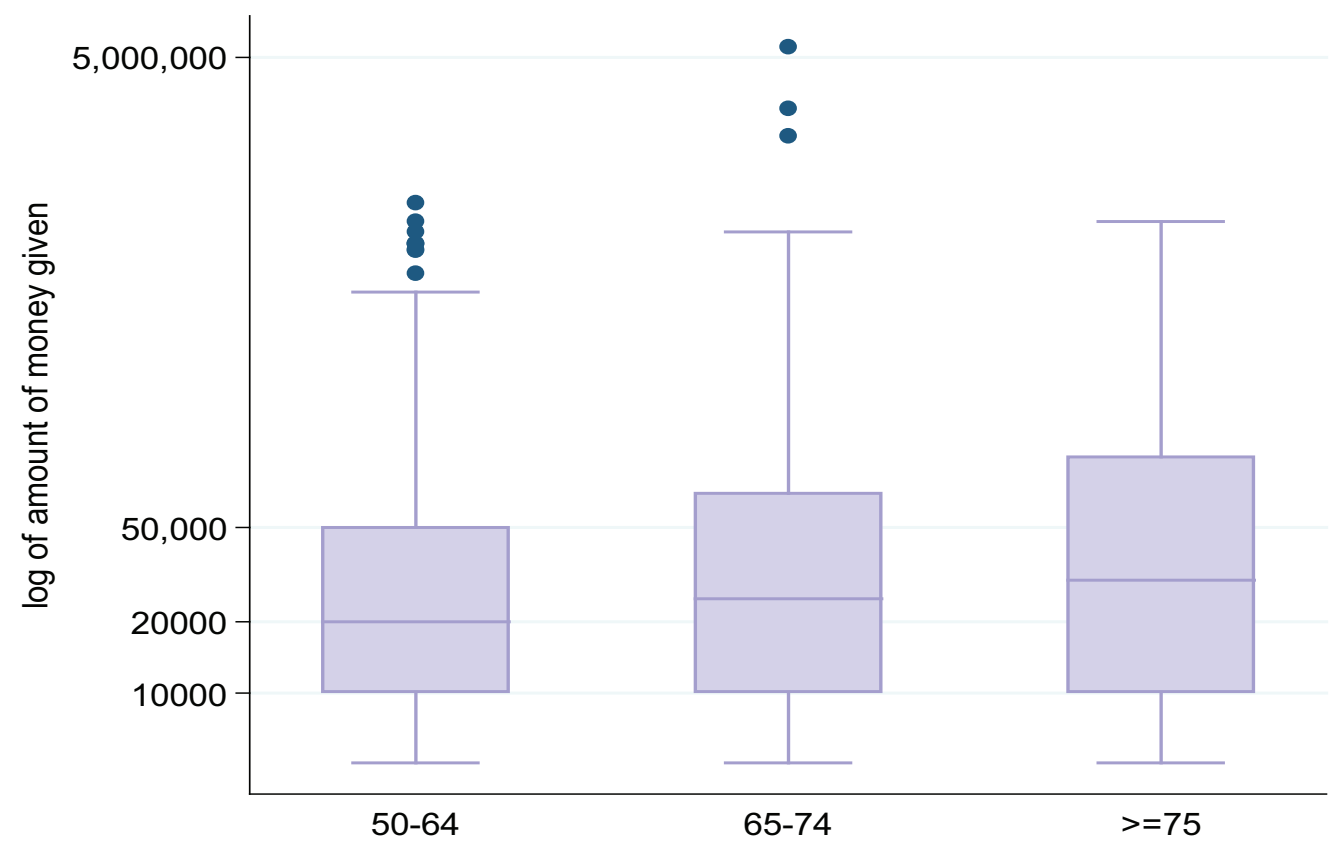

\subsubsection{Non-financial transfers to and from children and grandchildren}

Non-financial transfers from older parents to their children are also very common (see Figure 3.5). Over one-third (36\%) of older adults provide practical household help including shopping and household chores to their non-coresident children and 
nearly half $(47 \%)$ provide care to grandchildren. Practical household help provided to children decreases with age of the parent, from $43 \%$ among people aged 50-64 to $20 \%$ in the $75+$ age group.

Figure 3.5: Percentage of older people providing care to grandchildren and the provision of and receipt of other help to or from children by age

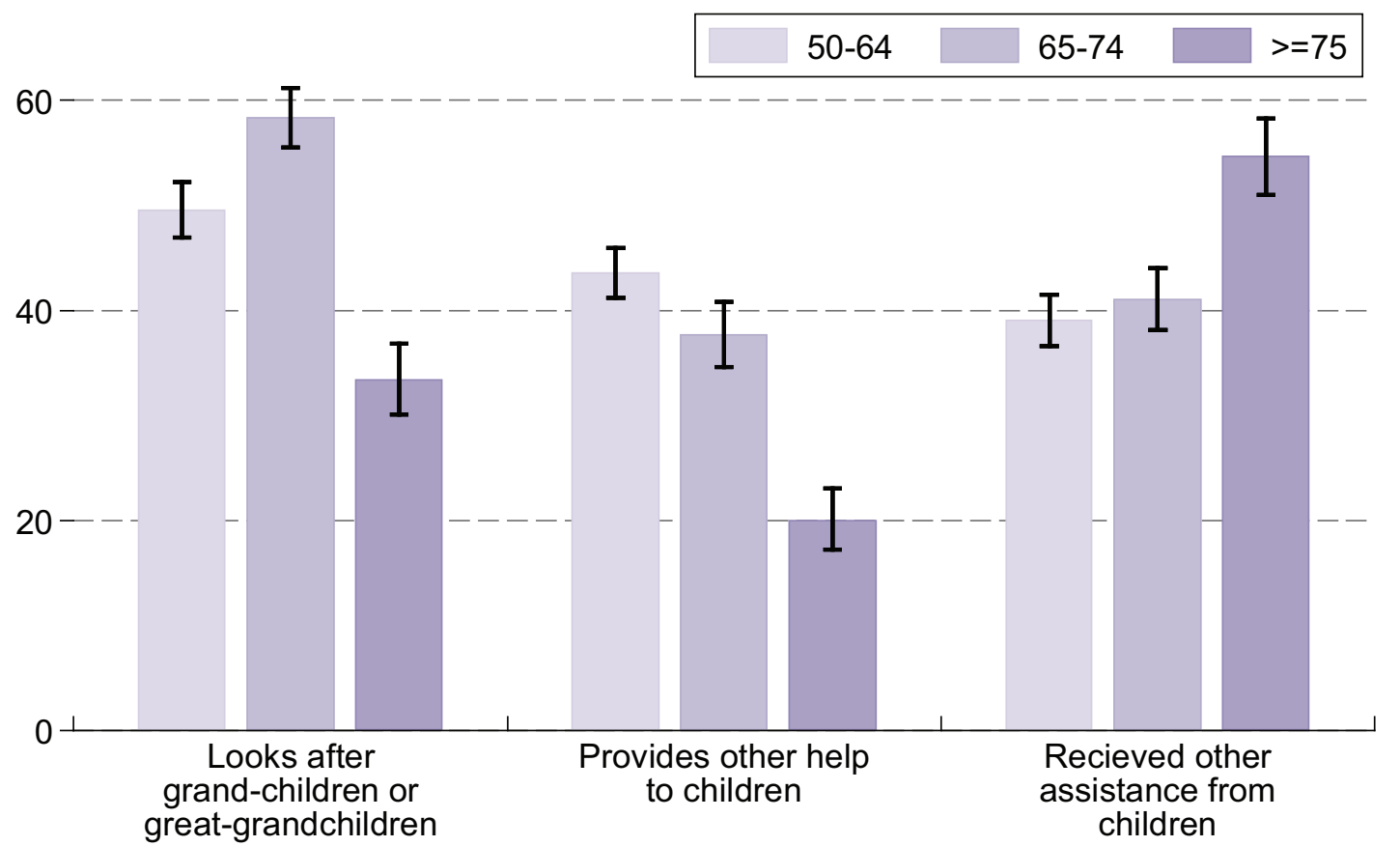

Note. $\mathrm{N}=5185$; Missing obs = 2993; Error bars correspond to $95 \%$ confidence intervals

Figure 3.5 also shows an inverse U-shape relationship between the proportion of older adults looking after grandchildren and the respondents' age, with the highest provision of care to grandchildren seen in the 65-74 age group. Gender, education, and employment status are some of the other determinants of providing childcare to grandchildren.

Of older people, $41 \%$ receive assistance with general help such as household help, home repairs, gardening, transportation and help with paper work. Figure 3.5 also shows that rates of receiving general forms of help from children increase significantly with increasing age; from 39\% among people aged $50-64$ years to $55 \%$ among those aged 75 and older.

\subsection{Transfers to non-family members}

The previous section showed how TILDA data indicates a net downward flow of resources (financial and non-financial) from the older generations to their adult offspring and grandchildren. This section examines the contribution of older people 
beyond the family sphere, i.e. to neighbours and friends. Acts of sharing and kindness among neighbours and friends such as watering plants or caring for pets during absences, dealing with mail and packages, occasionally picking up groceries or providing transport become an important strategy for offsetting the effects of poverty and lack of familial resources for some older people (4).

Nearly a quarter (23\%) of older people in Ireland provide some form of help (household help, transportation, personal care or help with paperwork) to neighbours and friends, an average of 8 hours per month. Figure 3.6 shows that $27 \%$ of older people aged 50-64 give help while at age 75 and over this decreases to $13 \%$. Provision of help to friends and neighbours is more common among older adults with higher educational attainment. Among people aged 50-64 years, 25\% with primary education provide help and $32 \%$ with tertiary education do so; the corresponding percentage are $22 \%$ and $30 \%$ among those $65-74$ years-old; and $11 \%$ and $16 \%$ among those aged 75 and over.

Figure 3.6: Percentage of older people providing help to or receiving help from friends and neighbours by age

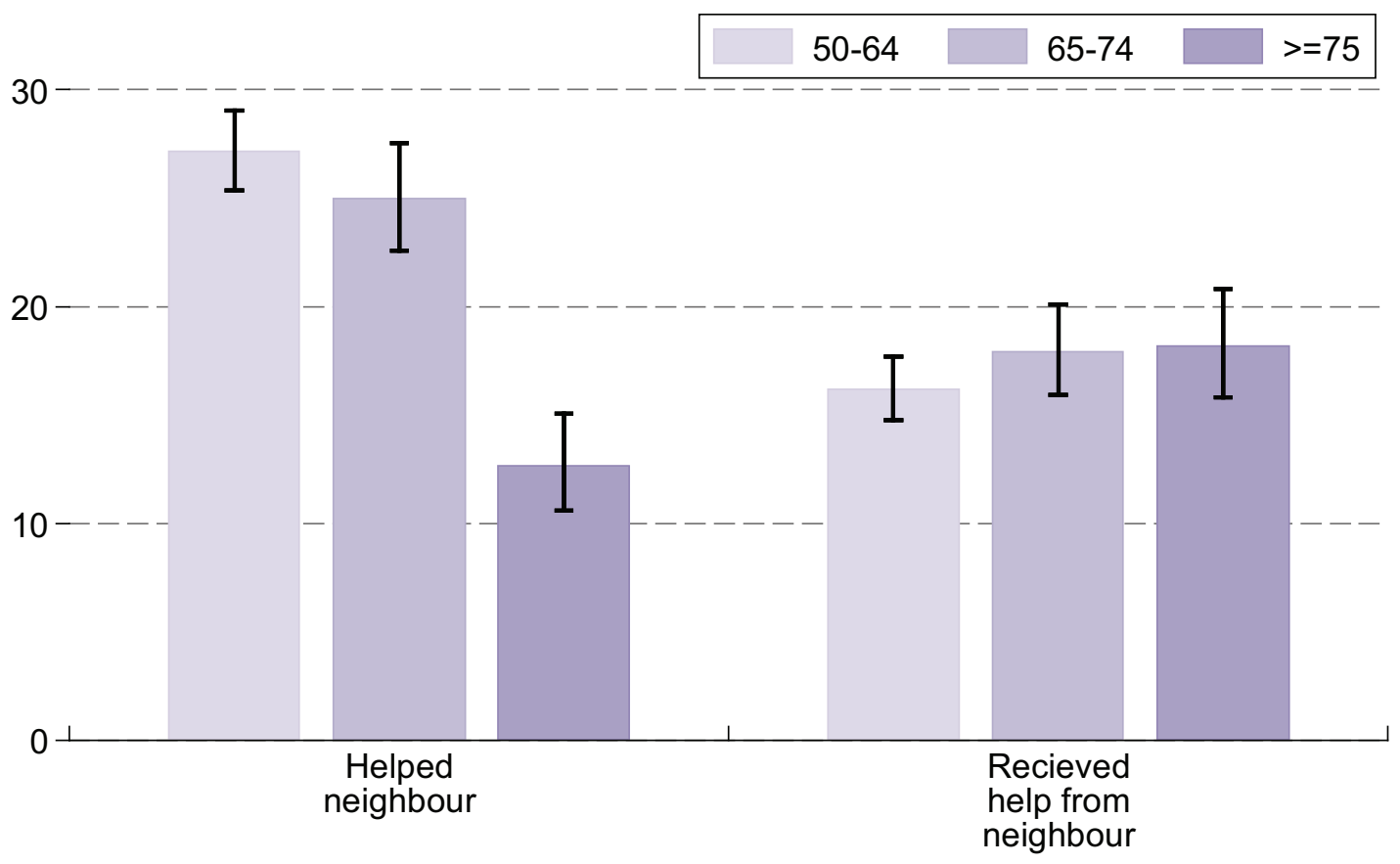

Note. $\mathrm{N}=8094$; Missing obs $=84$; Error bars correspond to $95 \%$ confidence intervals

Figure 3.6 also shows that $17 \%$ of older people receive some form of help from neighbours and friends and that the likelihood of receiving help increases only slightly with age. Sixteen per cent of women aged 50-64 years receive help, compared to $18 \%$ of those aged $65-74$, and $18 \%$ of those aged 75 years and over. A possible reason for the absence of an age gradient may be that the help provided by friends and neighbours tends to be household oriented rather than personal care 
oriented, and that while the specific nature of this help may change with age, the overall level required does not.

\subsection{Conclusions}

This chapter has described the informal intergenerational contacts and exchanges that take place within families and the broader networks of help and support among friends and neighbours. The findings presented here support an optimistic view that the majority of older people live relatively near to their children and surviving parents, have frequent contact with them, and intergenerational transfers are common.

Being in close proximity to at least one child is a good indicator of potentially available practical and emotional support, and well over two-thirds (74\%) of older adults in Ireland are in this position. Of those aged 75 years and older, $71 \%$ live with their children or have at least one child residing in the same county. This age group is most likely to have care and support needs.

Three-quarters of older adults whose own parents are still alive see their parents frequently, that is, daily, weekly, or several times per month. Half of the 50-64 year olds with surviving parents provide help with household tasks to their parents, on average for 10 hours per week, and over one quarter (28\%) assist their parents with personal care, on average for 14 hours a week. This indicates very high prevalence and intensity of involvement in the care of old adults, by older adults., This is a particularly noteworthy finding as older adults are often portrayed as recipients of help, care and support, and very rarely as givers of care and support.

Nearly one-quarter (24\%) of older households have given large financial or material gifts $(€ 5,000$ or more) to their children over the last decade. In contrast, less than one-tenth $(9 \%)$ of older people had received financial transfers from their children. At a family level, Ireland therefore adheres to the pattern established in several other developed countries where flows of transfers from older generations to younger generations exceed the transfers from younger to older generation (3).

Excluding personal care, most non-financial transfers also occur downward from parents to children. Over one-third (35\%) of older households provide practical household help including shopping and household chores to their non-coresident children and nearly half (47\%) provide care to grandchildren.

Transfers of practical help are not restricted to family members and there is considerable evidence of high levels of assistance provided within friendship and neighbourhood networks. Nearly one-quarter (23\%) of older people in Ireland provide some form of help to their neighbours and friends, on average for 8 hours per month. Almost one-fifth (17\%) of older people receive some form of help from their neighbours and friends, indicating that these members of extra-familial 
networks are important sources of support to older people in Ireland.

Another important finding in this chapter pertains to the socio-economic differentials in fertility and mortality which results in differences in the availability of kin. Higher education is associated with a greater likelihood of having both living parents and children, whereas lower education is associated with the probability of having more children but lower probability of having parents alive. The implications of this pattern are yet to be fully established.

The key question for policy-makers is how the family distributes its resources among its members and contributes to their well-being. Policy-makers have long been interested in the interaction between public and private (family) transfers, specifically whether public transfers 'crowd out' private support within families. Some researchers have pointed that "some of the public transfers to the elderly are channelled back to younger generations through family transfers" (5), and for the less well-off, transfers to family descendants depend on the availability of public pensions $(5,6)$. It is beyond the scope of this report to examine the intricate relationship between public and private transfers. However, disentangling this complex question will be possible with further analysis of the TILDA dataset.

\section{References}

1. Soldo B, Hill MS. Intergenerational transfers: Economic, demographic, and social perspectives. In: Lawton GLMMP, editor. Annual review of gerontology and geriatrics:Focus on kinship, aging, and social change. New York: Springer; 1993.

2. Henretta J, Grudy E, Harri S. Socioeconomic Differences in Having Living Parents and Children A: U.S.-British Comparison of Middle-Aged Women. Journal of Marriage and Family. 2001;63(3):852-67.

3. Lee R. Population Age Structure, Intergenerational Transfer, and Wealth: A New Approach, with Applications to the United States. The journal of Human Resources. 1994;29(4):1027-63

4. Barker J. Neighbors, Friends, and Other Nonkin Caregivers of CommunityLiving Dependent Elders. Journal of Gerontology B Psychol Sci Soc Sci. 2002;57(3):S158-S67

5. Kohli M. Private and Public Transfers Between Generations: Linking the Family and the State. European Societies. 1999;1(1):81-104.

6. Kohli M, Kunemund $\mathrm{H}$, Vogel $\mathrm{C}$. Shrinking families? Marital status, Childlessness and Intergenerationla Relationships. In: Siegrist J, editor. Health, Ageing and Retirement in Europe (2004-2007). Mannheim: Mannheim Research Institute for the Economics of Aging; 2008. 


\section{Social Engagement Of Older People}

Virpi Timonen, Yumiko Kamiya and Siobhan Maty

\section{Contents}

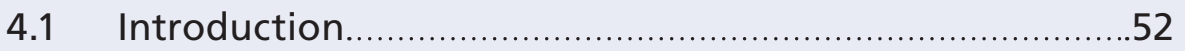

4.2 Participation in leisure activities...................................53

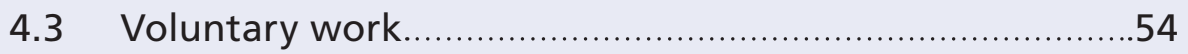

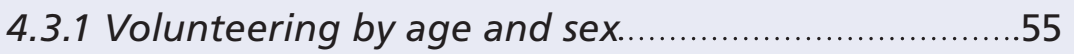

4.3.2 Volunteering by age and education........................55

4.3.3 Volunteering and quality of life .............................56

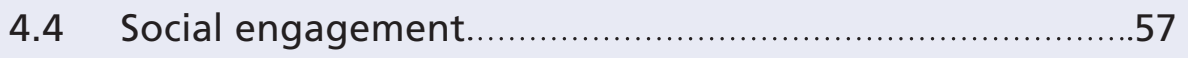

4.4.1 Social engagement and health...............................58

4.4.2 Social engagement, education and wealth.............60

4.4.3 Social engagement and quality of life .....................60

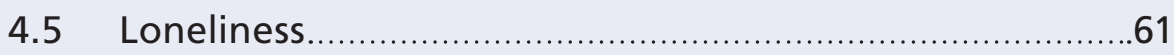

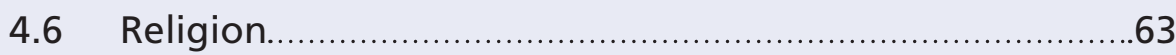

$4.7 \quad$ Voting

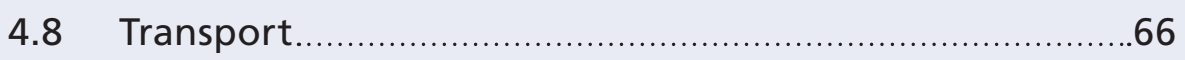

4.9 Conclusions 


\section{Social Engagement of Older People}

\section{Key findings}

- Approximately $90 \%$ of older adults visit with family and friends once a week or more. Frequency of visits increases with age, and women visit with family and friends more frequently than men.

- One in five older people aged 65-74 do voluntary work at least once a week or more.

- Participation in formal organised activities, including volunteering, is greatest among older adults with high levels of education.

- Similar proportions of older men and women (around 10\%) are engaged in high-intensity voluntary work.

- Quality of life increases with greater social integration.

- Six per cent of older women and 7\% of older men in Ireland are socially isolated.

- Older persons with poorer self-rated health are most likely to be socially isolated.

- Among the $95 \%$ of the older Irish population who report having a religion, $60 \%$ attend religious services at least once a week. Nearly $80 \%$ of people aged 75 and over attend a religious service once a week or more.

- Over $80 \%$ of older adults voted in the 2007 general election.

- Three-quarters of the older population rely on cars as their main mode of transport.

\subsection{Introduction}

There are many ways of describing older adults' engagement in social activities and the type and number of social connections they maintain. Chapter 3 analysed older adults in the context of their families and as members of friendship and neighbourhood networks. This chapter focuses on older adults' social engagement as demonstrated by participation in specific leisure activities and volunteer work. To measure social connectedness, TILDA uses the Berkman-Syme Social Network Index (1). This index incorporates marital status, contacts with children, close relatives and close friends and membership of church groups or community organisations (1). The distribution of loneliness, attendance at religious services, and voting behaviours are also presented. The chapter concludes with a discussion of transport and the extent to which transport may limit social participation of some older adults. 
This chapter also investigates differences in social engagement by age, sex, education, and health status. For example, are healthier and more educated older people more or less socially engaged than their peers?

In common with the rest of the this report, although our results demonstrate associations between different domains, no conclusions regarding causality can be drawn due to the cross-sectional nature of the TILDA baseline data. Causal associations will be explored using data from subsequent waves.

\subsection{Participation in leisure activities}

Social scientists have a long-standing interest in the effects of leisure participation among older persons. Participation in leisure activities is associated with a lower risk for negative mental and physical health outcomes and mortality (2-6).

In TILDA, social participation is measured using the classification proposed by House et al. (6). Participation in different social activities is categorised into four groups: 1) intimate social relationships (visits to or from family and friends); 2) formal organisational involvements outside of work (going to religious services or meetings at voluntary associations); 3) active and relatively social leisure (going to classes or lectures, movies, plays and concerts, playing cards or bingo, eating outside the house, taking part in sports); and 4) passive and relatively solitary leisure activities, such as watching television, listening to the radio, or reading. The frequency of participation in each activity group is assessed as 1 ) never or less than once a year; 2) about once or twice a year or every few months; 3 ) at least once a month; or 4) weekly, daily or more (6).

Solitary activities such as watching television and listening to the radio are the most common leisure pursuits among older adults in Ireland. Among the most popular activities (once a week or more) are watching television (98\%), listening to the radio $(94 \%)$, visiting with family or friends $(86 \%)$, and reading books and magazines $(73 \%)$. The least commonly reported activity is attending films, plays, or concerts, with only $5 \%$ of the $50+$ population attending these events weekly.

Figure 4.1 shows the distribution of older persons who participate in the four main types of activities by age and sex. Daily participation in intimate social relationships, such as visiting with family and friends, is greater for women than men, and is more common among older age groups. Involvement in formal organisational activities outside of work does not differ significantly by sex or age, although women aged 75 years and older report these activities less than any other age-sex grouping. Participation in active and relatively social leisure activities is greater for men than women, and is lowest in the oldest age group (75 years or more). No difference in passive or solitary activities was observed by age or sex. 
Figure 4.1: Distribution (\%) of older people who participate in different social activities (intimate social relationships, formal organisational involvement outside of work, active and relatively social leisure, and passive and relatively solitary leisure), by age and sex

\begin{tabular}{|l|l|l|}
\hline $50-64$ & $65-74$ & $\square=75$ \\
\hline
\end{tabular}
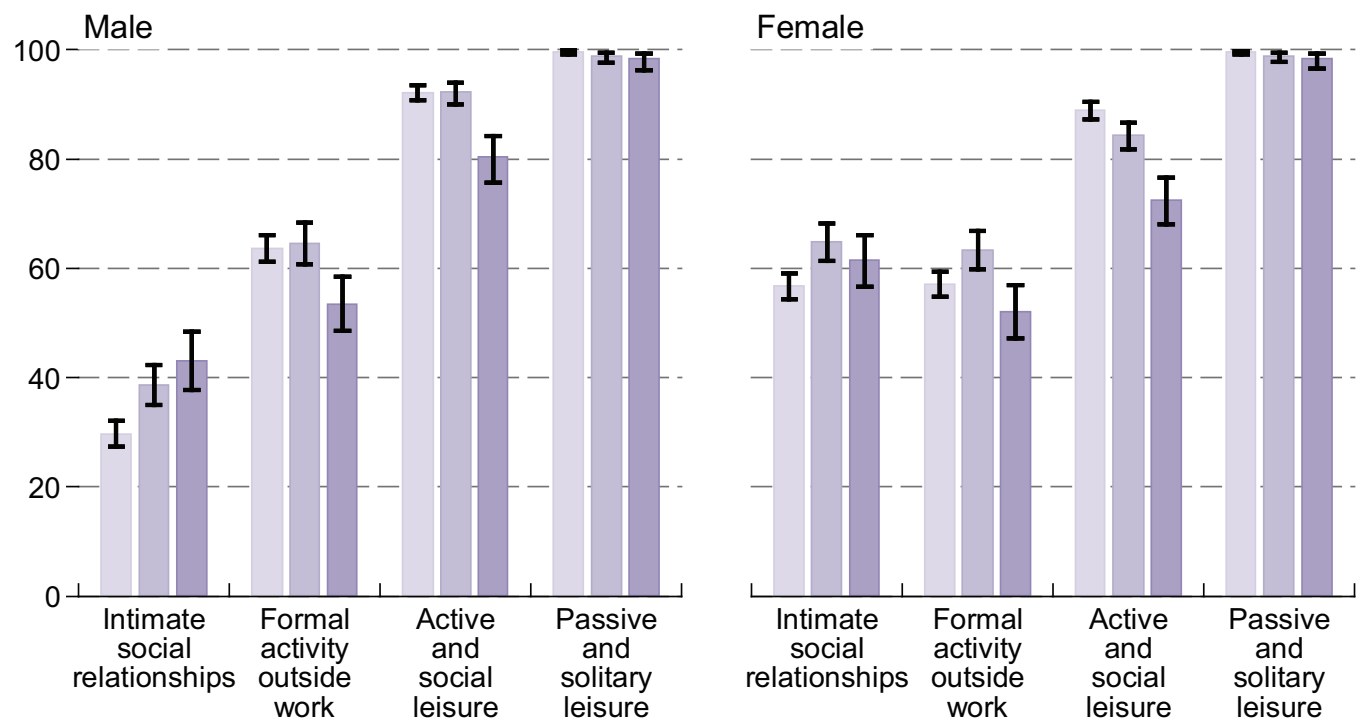

Note. $\mathrm{N}=6170$; Missing obs = 92; Error bars correspond to 95\% confidence intervals

When stratified by sex and educational attainment (primary, secondary, or tertiary completion), an education gradient was observed for both formal organisational, and active and social leisure activities (see Figure 4.2 below). Those with the highest education (tertiary) were more likely to participate in these activities compared to the lowest (primary) education group, regardless of sex. However, persons with more education were less likely to engage in intimate social relationships.

The frequency of participation in each activity is not shown but some trends are reported here. Within the population over 50, older people are more likely to go to the pub than younger people. Women are more likely than men to read books and magazines, visit friends or do voluntary work. Those who attained a higher level of education are more likely to attend films, plays, concerts and lectures. Those who report being in better health are more likely to participate in sporting activities, attend classes and to spend time on hobbies and creative activities.

\subsection{Voluntary work}

Many studies have shown that engaging in voluntary work in later life predicts better self-rated health, functioning, physical activity, and life satisfaction, and also 
Figure 4.2: Distribution (\%) of older people who participate in different social activities (intimate social relationships, formal organisational involvement outside of work, active and relatively social leisure, and passive and relatively solitary leisure), by sex and education

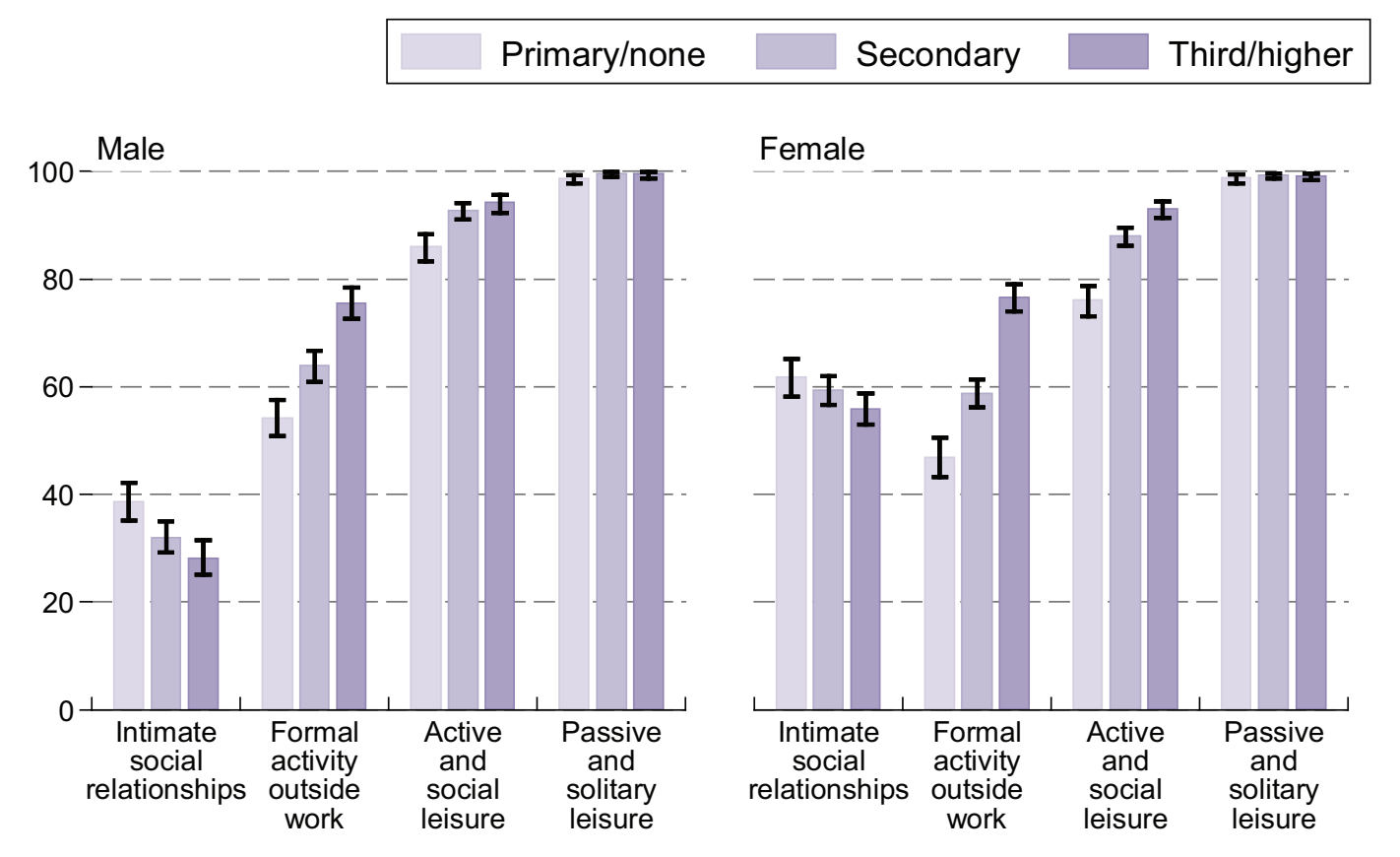

Note. $\mathrm{N}=6168$; Missing obs $=94 ;$ Error bars correspond to $95 \%$ confidence intervals

decreases depression, hypertension, and mortality among older people (7-13). In TILDA, volunteering is measured by response to the question, "how often, if at all, do you do voluntary work?". Fifteen per cent of older adults volunteer at least once per week, $11 \%$ at least once per month, $16 \%$ at least once per year and $58 \%$ never engage in voluntary work (see Table 4.1).

\subsubsection{Volunteering by age and sex}

The frequency of volunteering varies by age, but there is little difference in volunteering between men and women (see Figure 4.3). People aged 65-74 years are more likely to volunteer frequently compared to people in other age groups (50-64 years and 75 years and older), regardless of sex. The proportion of men and women who report never volunteering grows with increasing age. 
Figure 4.3: Distribution (\%) of older people in each volunteering frequency category by age and sex

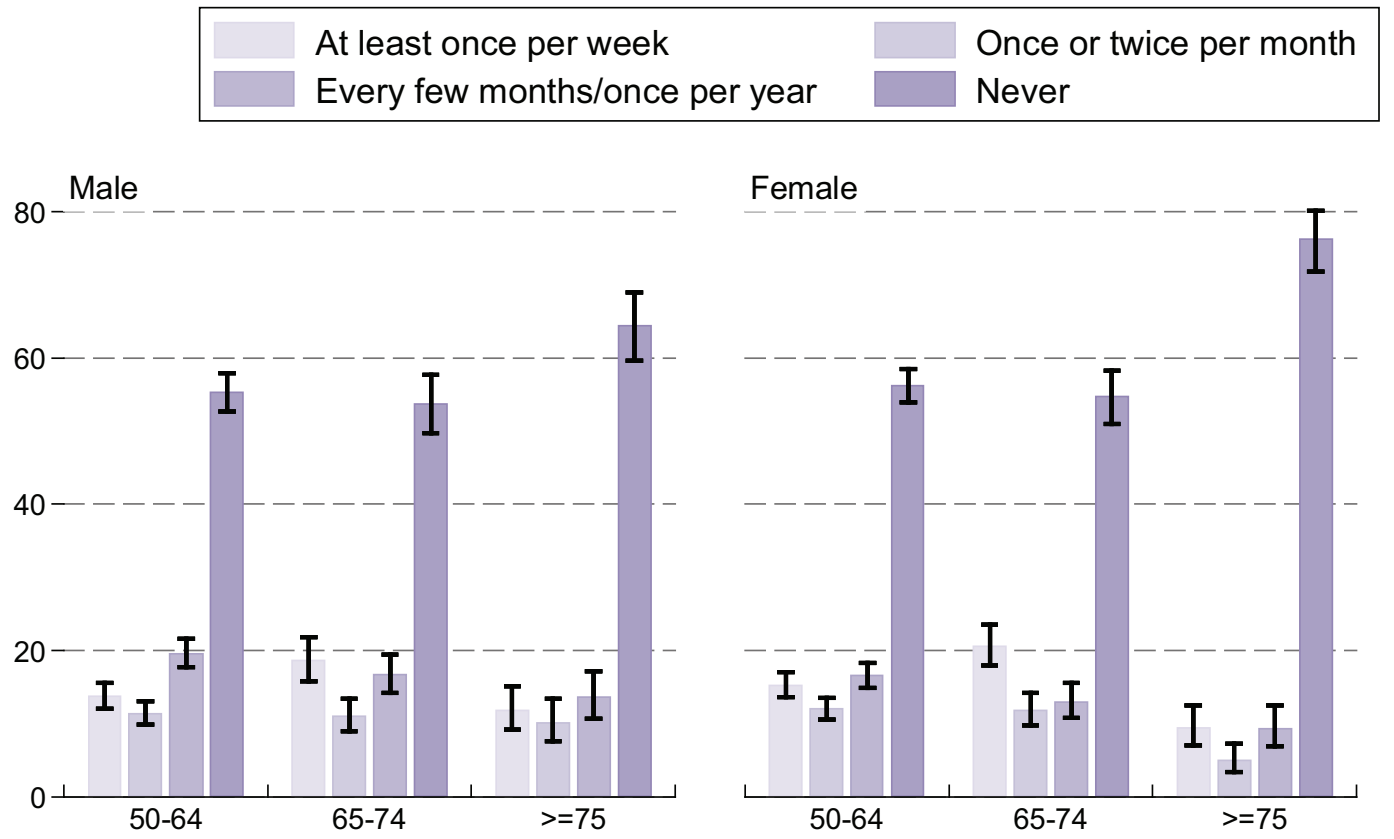

Note. $\mathrm{N}=5995$; Missing obs $=267$; Error bars correspond to $95 \%$ confidence intervals

\subsubsection{Volunteering by age and education}

Research literature suggests that individuals with higher education and income and married persons are more likely to participate in voluntary organisations and to do voluntary work than those who are unmarried or of lower educational or economic means $(8,10,14)$. TILDA data confirms that the frequency of volunteer activity increases with increasing education (see Table 4.1).

\subsubsection{Volunteering and quality of life}

The positive association between voluntary work and well-being $(10,12,14,15)$ is widely documented. In TILDA, quality of life is measured using the CASP-19 scale, which is the sum of nineteen items that assess four life domains: control, autonomy, self-actualisation and pleasure (see Chapter 10 for a full breakdown of the CASP scale). Scores on the CASP-19 range from 0-57, with higher scores indicating better quality of life (16). The scale has been used in other longitudinal studies and has good psychometric properties (17). Table 4.2 presents the mean CASP-19 scores for each age group by frequency of voluntary work. The lowest mean quality of life scores are found within the population that never volunteers, regardless of age group with smaller increases in quality of life associated with increasing volunteering frequency. 
Table 4.1: Proportion (\%) of older persons within each volunteering frequency category by age and education level

\begin{tabular}{|c|c|c|c|c|c|c|c|c|c|c|}
\hline & \multicolumn{2}{|c|}{$\begin{array}{l}\text { Volunteers at } \\
\text { least once per } \\
\text { week }\end{array}$} & \multicolumn{2}{|c|}{$\begin{array}{l}\text { Volunteers } \\
\text { once or twice } \\
\text { per month }\end{array}$} & \multicolumn{2}{|c|}{$\begin{array}{l}\text { Volunteers } \\
\text { every few } \\
\text { months or } \\
\text { once per year }\end{array}$} & \multicolumn{2}{|c|}{$\begin{array}{c}\text { Never } \\
\text { volunteers }\end{array}$} & \multirow[t]{2}{*}{ Total } & \multirow[t]{2}{*}{$\begin{array}{l}\text { Number } \\
\text { in } \\
\text { sample }\end{array}$} \\
\hline & $\%$ & $95 \% \mathrm{Cl}$ & $\%$ & $95 \% \mathrm{Cl}$ & $\%$ & $95 \% \mathrm{Cl}$ & $\%$ & $95 \% \mathrm{Cl}$ & & \\
\hline \multicolumn{11}{|c|}{ Primary/none } \\
\hline $50-64$ & 13 & $(10-16)$ & 7 & $(5-10)$ & 14 & $(11-17)$ & 66 & $(63-70)$ & 100 & 614 \\
\hline $65-74$ & 17 & $(14-20)$ & 8 & $(6-10)$ & 12 & $(10-15)$ & 63 & $(59-67)$ & 100 & 585 \\
\hline$>=75$ & 7 & $(5-10)$ & 5 & $(4-8)$ & 9 & $(7-12)$ & 78 & $(74-82)$ & 100 & 400 \\
\hline Total & 12 & $(11-14)$ & 7 & $(6-8)$ & 12 & $(10-14)$ & 69 & $(67-71)$ & 100 & 1599 \\
\hline \multicolumn{11}{|c|}{ Secondary } \\
\hline $50-64$ & 18 & $(16-20)$ & 18 & $(16-10)$ & 23 & $(21-26)$ & 41 & $(38-44)$ & 100 & 1261 \\
\hline $65-74$ & 26 & $(22-30)$ & 18 & $(15-22)$ & 19 & $(16-23)$ & 36 & $(32-41)$ & 100 & 469 \\
\hline$>=75$ & 21 & $(16-28)$ & 13 & $(9-19)$ & 19 & $(14-26)$ & 46 & $(39-53)$ & 100 & 189 \\
\hline Total & 20 & $(18-22)$ & 17 & $(16-19)$ & 22 & $(20-24)$ & 40 & $(38-43)$ & 100 & 1919 \\
\hline \multicolumn{11}{|c|}{ Third/higher } \\
\hline $50-64$ & 18 & $(16-20)$ & 18 & $(16-20)$ & 23 & $(21-26)$ & 41 & $(38-44)$ & 100 & 1261 \\
\hline $65-74$ & 26 & $(22-30)$ & 18 & $(15-22)$ & 19 & $(16-23)$ & 36 & $(32-41)$ & 100 & 46 \\
\hline$>=75$ & 21 & $(16-28)$ & 13 & (9-19) & 19 & $(14-26)$ & 46 & $(39-53)$ & 100 & 189 \\
\hline Total & 20 & $(18-22)$ & 17 & $(16-19)$ & 22 & $(20-24)$ & 40 & $(38-43)$ & 100 & 191 \\
\hline \multicolumn{11}{|l|}{ Total } \\
\hline $50-64$ & 14 & $(13-16)$ & 12 & $(11-13)$ & 18 & $(17-19)$ & 56 & $(54-57)$ & 100 & 3496 \\
\hline $65-74$ & 20 & $(18-22)$ & 11 & $(10-13)$ & 15 & $(13-17)$ & 54 & $(52-57)$ & 100 & 1619 \\
\hline$>=75$ & 10 & $(9-13)$ & 7 & $(6-9)$ & 11 & $(9-13)$ & 71 & $(68-74)$ & 100 & 880 \\
\hline Total & 15 & $(14-16)$ & 11 & $(10-12)$ & 16 & $(15-17)$ & 58 & (57-59) & 100 & 5995 \\
\hline
\end{tabular}

Table 4.2: Mean quality of life measured by CASP-19 score among older people by age and frequency of volunteer activity

\begin{tabular}{|c|c|c|c|c|c|c|c|c|}
\hline \multirow{2}{*}{$\begin{array}{l}\text { Frequency of } \\
\text { voluntary work }\end{array}$} & \multicolumn{2}{|r|}{$50-64$} & \multicolumn{2}{|c|}{$65-74$} & \multicolumn{2}{|r|}{$>=75$} & \multicolumn{2}{|r|}{ Total } \\
\hline & Mean & $95 \% \mathrm{Cl}$ & Mean & $95 \% \mathrm{Cl}$ & Mean & $95 \% \mathrm{Cl}$ & Mean & $95 \% \mathrm{C}$ \\
\hline $\begin{array}{l}\text { At least once } \\
\text { per week }\end{array}$ & 44.1 & $(43.4-44.8)$ & 45.2 & $(44.4-46.0)$ & 45.0 & $(43.7-46.3)$ & 44.5 & $(44.0-45.0)$ \\
\hline $\begin{array}{l}\text { Once or twice } \\
\text { per month }\end{array}$ & 44.1 & $(43.4-44.7)$ & 44.8 & $(43.9-45.8)$ & 43.8 & $(42.3-45.3)$ & 44.2 & $(43.7-44.7)$ \\
\hline $\begin{array}{l}\text { Every few } \\
\text { months or once } \\
\text { per year }\end{array}$ & 43.1 & $(42.6-43.7)$ & 44.2 & $(43.4-45.0)$ & 42.9 & $(41.8-44.0)$ & 43.3 & $(42.9-43.8)$ \\
\hline $\begin{array}{l}\text { Never } \\
\text { volunteers }\end{array}$ & 41.5 & $(41.1-42.0)$ & 41.9 & $(41.2-42.5)$ & 40.1 & (39.4-40.8) & 41.3 & $(41.0-41.6)$ \\
\hline Total & 42.5 & $(42.2-42.8)$ & 43.3 & $(42.8-43.7)$ & 41.3 & (40.7-41.9) & 42.5 & $(42.2-42.7)$ \\
\hline
\end{tabular}




\subsection{Social engagement}

In TILDA, the extent of each respondent's social engagement is measured using the Berkman-Syme Social Network Index (SNI) (1). This index is a composite measure of four types of social connections: marital status (married vs. not married); sociability (frequency of contacts $(0=$ few to $1=$ many) with close children, relatives and friends, church group membership (yes (1) or no (0)), and membership in other voluntary organisations (yes (1) or no (0)). Scores from each social connection type are combined to create four levels (0-4) of social connection or engagement: most isolated (0-1), moderately isolated (2), moderately integrated (3) and most integrated (4) (1).

Using the Social Network Index, the patterns of social connection in the older adult population of Ireland are similar for both men and women, and across all age groups. Figure 4.4 shows that $6 \%$ of women and $7 \%$ of men are classified as being most isolated, while $26 \%$ of men and $23 \%$ of women fall into the most integrated level of social engagement. Most respondents are classified as moderately integrated, regardless of age or sex. Interestingly, in the oldest age group (75+), men are more socially integrated than women.

Figure 4.4. Proportion (\%) of older people within each Berkman-Syme Social Network Index level of social connection, by sex

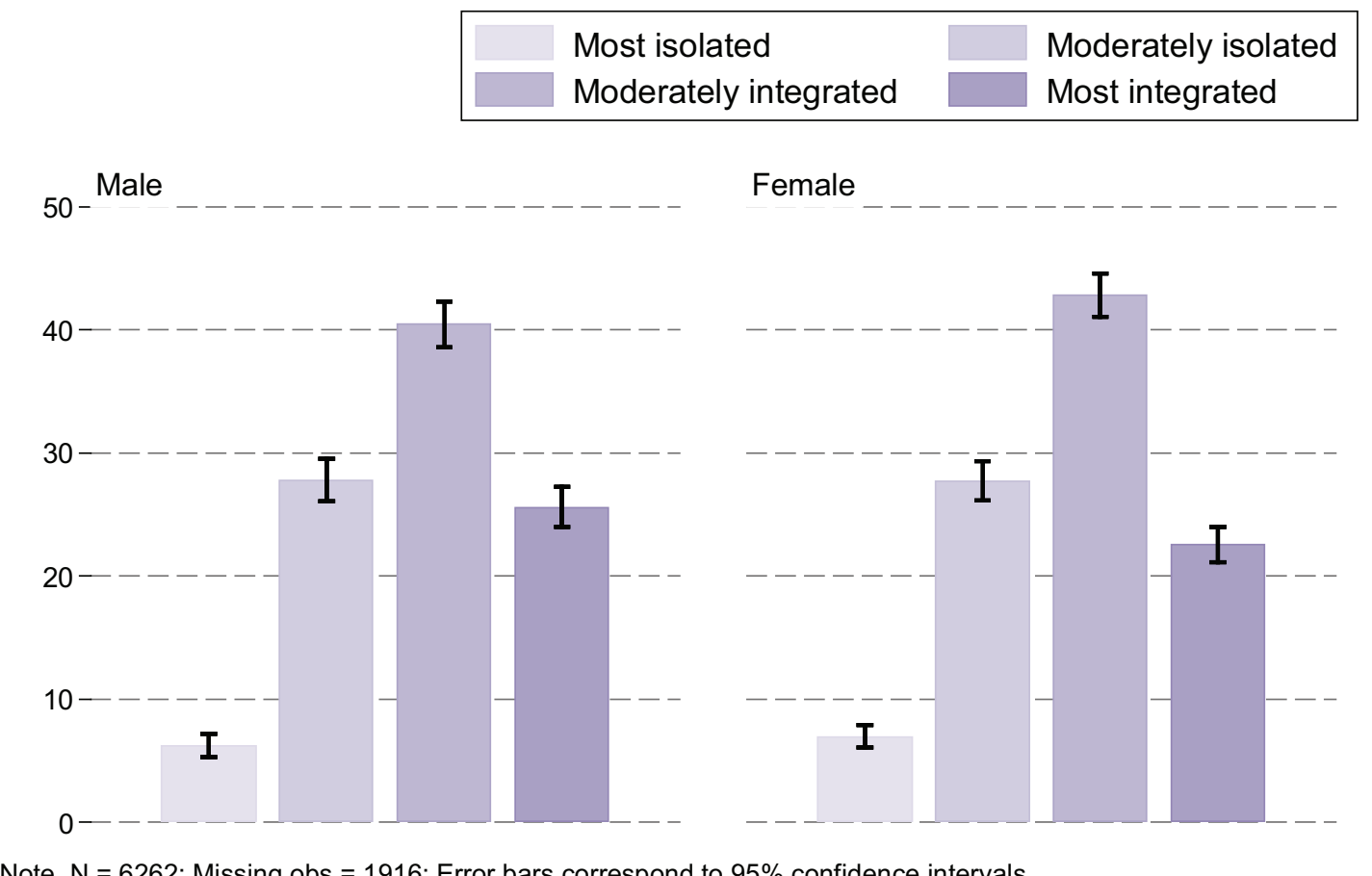

Note. $\mathrm{N}=6262$; Missing obs = 1916; Error bars correspond to $95 \%$ confidence intervals 


\subsubsection{Social engagement and health}

Several international studies have shown a strong positive association between social engagement and physical and mental health outcomes (4, 7, 18-24). In TILDA, selfrated general health status is measured by asking individuals to rate their health on a five-point scale (excellent, very good, good, fair, or poor).

Two categories of self-reported health were created for use in analyses: (a) those reporting excellent, very good or good health (good); and (b) those reporting fair or poor health (poor). A clear gradient in the proportion of older people who reported fair or poor health was observed by level of integration (Figure 4.5). The most isolated persons were most likely to report fair or poor health.

Figure 4.5: Older people who reported 'poor health' within each Berkman-Syme Social Network Index level of social connection, by age

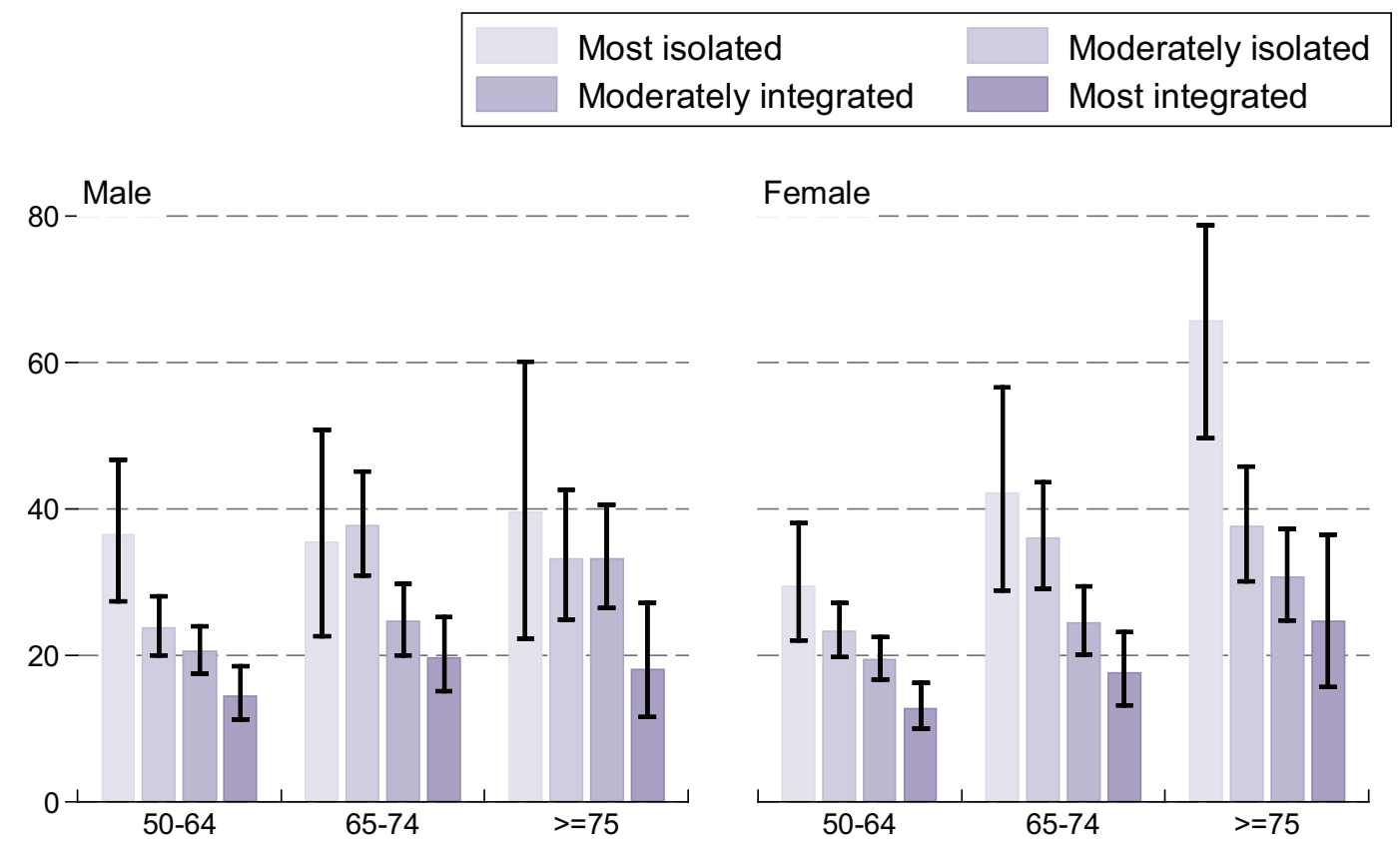

Note. $\mathrm{N}=6261$; Missing obs = 1; Error bars correspond to $95 \%$ confidence intervals 


\subsubsection{Social engagement, education and wealth}

TILDA data (Figure 4.6) support findings from previous studies of older people which have demonstrated the association between increasing education and greater social engagement $(18,25,26)$. This is not unexpected as higher education is associated with greater income and wealth, and with better opportunities to engage in different social and leisure activities. In the older Irish population, the education gradient is greatest within the most isolated and most integrated groups, where the most integrated group is the most educated and the most isolated group is the least educated. The same patterns were observed when stratified by wealth quartiles (data not shown).

Figure 4.6: Proportion (\%) of older people within each Berkman-Syme Social Network Index level of social connection, by age and education

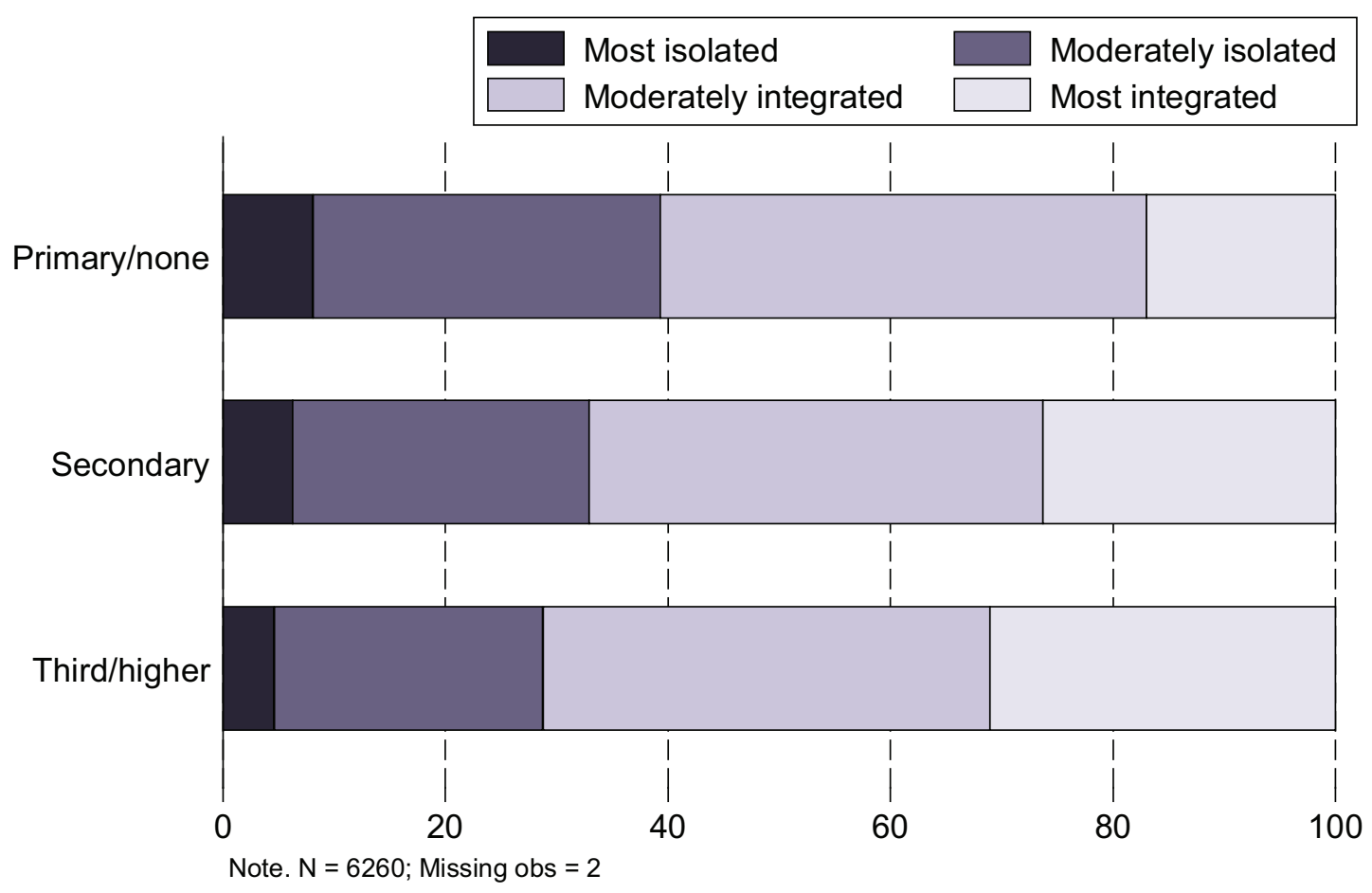

\subsubsection{Social engagement and quality of life}

Table 4.3 shows the mean CASP-19 quality of life score for each of the four BerkmanSyme Social Network Index levels of social connection (most/moderate isolation, moderate/most integration), stratified by age group. A clear gradient exists for the mean quality of life scores across levels of social connection. The mean scores increase with greater social integration. Although this gradient persists across all three age groups, the range of mean quality of life scores differs by age (see Table 4.3). As 
with education, TILDA findings confirm findings of other studies, such as the Survey of Health, Ageing and Retirement in Europe (SHARE), that observed a significant association between social engagement and quality of life $(27,28)$.

Table 4.3: Mean quality of life score on the CASP-19 by Berkman-Syme Social Network Index level of social connection and age

\begin{tabular}{|c|c|c|c|c|c|c|c|c|}
\hline \multirow[t]{2}{*}{$\begin{array}{l}\text { Social } \\
\text { Connection }\end{array}$} & \multicolumn{2}{|c|}{$50-64$} & \multicolumn{2}{|c|}{$65-74$} & \multicolumn{2}{|c|}{$>=75$} & \multicolumn{2}{|c|}{ Total } \\
\hline & Mean & $95 \% \mathrm{Cl}$ & Mean & $95 \% \mathrm{Cl}$ & Mean & $95 \% \mathrm{Cl}$ & Mean & $95 \% \mathrm{Cl}$ \\
\hline Most isolated & 39.7 & (38.4-40.9) & 39.7 & $(37.5-42.0)$ & 36.3 & $(34.0-38.7)$ & 39.1 & $(38.1-40.1)$ \\
\hline $\begin{array}{l}\text { Moderately } \\
\text { isolated }\end{array}$ & 41.5 & $(40.9-42.0)$ & 41.8 & $(40.8-42.8)$ & 40.3 & (39.1-41.4) & 41.3 & $(40.9-41.8)$ \\
\hline $\begin{array}{l}\text { Moderately } \\
\text { integrated }\end{array}$ & 42.8 & $(42.4-43.3)$ & 43.6 & $(43.0-44.1)$ & 42.3 & $(41.6-43.1)$ & 42.9 & $(42.6-43.2)$ \\
\hline $\begin{array}{l}\text { Most } \\
\text { integrated }\end{array}$ & 44 & $(43.6-44.5)$ & 44.8 & (44.1-45.4) & 43.2 & $(42.2-44.1)$ & 44.1 & $(43.8-44.5)$ \\
\hline Total & 42.5 & $(42.2-42.8)$ & 43.3 & $(42.8-43.7)$ & 41.3 & $(40.7-41.9)$ & 42.5 & $(42.2-42.7)$ \\
\hline
\end{tabular}

\subsection{Loneliness}

Although social isolation is sometimes equated with loneliness, loneliness and social isolation are separate concepts and do not necessarily co-occur. Social isolation refers to the absence of relationships, and is related to objective characteristics. Loneliness is the feeling of missing intimate relationships or missing a wider network, which is conceptualised as an individual's subjective evaluation of their degree of social participation or isolation (29).

Loneliness has been shown to predict a wide variety of mental and physical health outcomes, such as depression, nursing home admission, and mortality (20,30-32). In TILDA, loneliness is assessed using a modified version of the University of CaliforniaLos Angeles Loneliness Scale (33). We selected four negatively-worded questions (e.g., How often do you feel left out?) and one positively-worded question (How often do you feel in tune with the people around you?), each with a three-point response scale of hardly ever or never; some of the time; or often. The responses to the five items are summed, with higher scores signifying greater loneliness. The average score for older adults is 2, on a scale from 0 (not lonely) to 10 (extremely lonely). Figure 4.7 examines one of the components of loneliness - "feeling isolated from others". Not all persons who are less socially engaged in fact experience loneliness; $60 \%$ of people who are 'objectively' socially isolated state that they never feel isolated from others. 
Figure 4.7: Distribution of people who feel isolated (often, some of the time, or never) by Berkman-Syme Social Network Index level of social connection

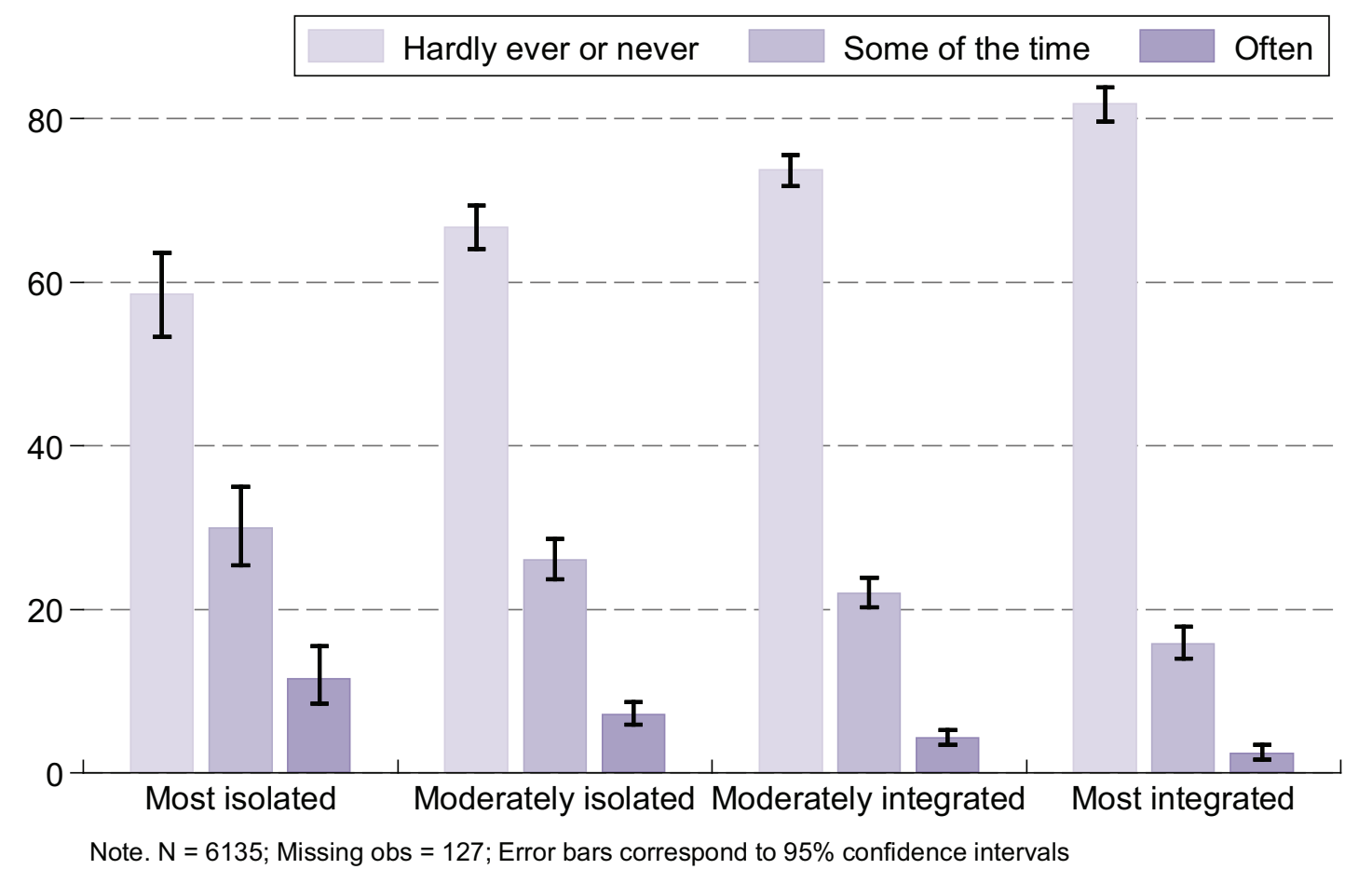

Exploration of the association between sex, education, health and loneliness across age groups shows that, in general, women are more likely to feel lonely than men across the age spectrum (see Table 4.4). It seems that there is a socio-economic gradient, as more educated individuals are less likely to feel lonely. Individuals who report excellent, very good and good self-rated health are also less likely to feel lonely (Table 4.5.). These complex relationships will be explored in further research emanating from TILDA.

Table 4.4: Mean loneliness score (measured by UCLA loneliness scale) by age and education

\begin{tabular}{|l|r|r|r|r|r|r|r|r|}
\hline \multirow{2}{*}{ Education } & \multicolumn{2}{|c|}{$\mathbf{5 0 - 6 4}$} & \multicolumn{2}{c|}{$\mathbf{6 5 - 7 4}$} & \multicolumn{2}{c|}{$>=75$} & \multicolumn{2}{c|}{ Total } \\
\hline Pean & $95 \% \mathrm{Cl}$ & Mean & $95 \% \mathrm{Cl}$ & Mean & $95 \% \mathrm{Cl}$ & Mean & $95 \% \mathrm{Cl}$ \\
\hline Primary/none & 2.3 & $(2.1-2.5)$ & 2.2 & $(2.0-2.4)$ & 2.3 & $(2.0-2.5)$ & 2.3 & $(2.1-2.4)$ \\
\hline Secondary & 2 & $(1.8-2.1)$ & 1.8 & $(1.6-1.9)$ & 2 & $(1.8-2.2)$ & 1.9 & $(1.8-2.0)$ \\
\hline Third/higher & 1.8 & $(1.7-1.9)$ & 1.8 & $(1.6-2.0)$ & 1.7 & $(1.4-1.9)$ & 1.8 & $(1.7-1.9)$ \\
\hline Total & 2 & $(1.9-2.1)$ & 2 & $(1.9-2.1)$ & 2.2 & $(2.0-2.3)$ & 2 & $(2.0-2.1)$ \\
\hline
\end{tabular}


Table 4.5: Mean loneliness score (measured by UCLA loneliness scale) by age and selfrated physical health

\begin{tabular}{|c|c|c|c|c|c|c|c|c|}
\hline \multirow{2}{*}{$\begin{array}{l}\text { Self-rated physical } \\
\text { health }\end{array}$} & \multicolumn{2}{|c|}{$50-64$} & \multicolumn{2}{|c|}{$65-74$} & \multicolumn{2}{|c|}{$>=75$} & \multicolumn{2}{|c|}{ Total } \\
\hline & Mean & $95 \% \mathrm{Cl}$ & Mean & $95 \% \mathrm{Cl}$ & Mean & $95 \% \mathrm{Cl}$ & Mean & $95 \% \mathrm{Cl}$ \\
\hline Excellent & 1.3 & $(1.2-1.4)$ & 1.3 & $(1.1-1.5)$ & 1.5 & $(1.0-1.9)$ & 1.3 & $(1.2-1.4)$ \\
\hline Very good & 1.6 & $(1.5-1.7)$ & 1.4 & $(1.2-1.5)$ & 1.9 & $(1.6-2.1)$ & 1.6 & $(1.5-1.7)$ \\
\hline Good & 2.1 & $(2.0-2.3)$ & 2 & $(1.8-2.2)$ & 2 & $(1.7-2.2)$ & 2.1 & $(1.9-2.2)$ \\
\hline Fair & 2.9 & $(2.7-3.1)$ & 2.5 & $(2.3-2.8)$ & 2.6 & $(2.2-2.9)$ & 2.7 & $(2.6-2.9)$ \\
\hline Poor & 3.5 & $(3.0-3.9)$ & 3.8 & $(3.2-4.4)$ & 3.7 & $(2.8-4.6)$ & 3.6 & $(3.2-3.9)$ \\
\hline Total & 2 & $(1.9-2.1)$ & 2 & $(1.9-2.1)$ & 2.2 & $(2.0-2.3)$ & 2 & $(2.0-2.1)$ \\
\hline
\end{tabular}

\subsection{Religion}

Religion is another way in which people engage with their communities. This can occur through active participation in religious services, prayer, or volunteering with religious-based organisations. Participation in religious activities has been associated with better quality of life and health outcomes in older persons $(28,34,35)$, although the patterns are not consistent across study population or measures of religious activity.

In TILDA, respondents were asked about their membership of formal religious groups, the frequency with which they participate in religious activities, and whether or not they draw strength from their religious faith. Ninety per cent report that they are Catholic, 3\% Anglican, 2\% other Christians, and 5\% report having no religion. Among the $95 \%$ who reported having a religion, $60 \%$ attend religious services at least once a week.

Figure 4.8 indicates that most older men and women in all age groups attend a religious service at least once per week. However, weekly attendance is less common among the 50-64 (48\%) and 65-74 (67\%) age groups than among people aged 75 years and over (76\%). Men aged $50-64$ years (approximately $18 \%$ ) are most likely to never/almost never attend religious services compared to women in the same age group (16\%) or men and women in the older age groups.

Religion is more important to the oldest old than to those aged 50-64, and is more important to women (Figure 4.9) than to men. Women and oldest adults also derive more comfort and strength from religion than men or younger adults in this population (Figure 4.10). 
Figure 4.8: Frequency of older persons' attendance in religious services, by age and sex

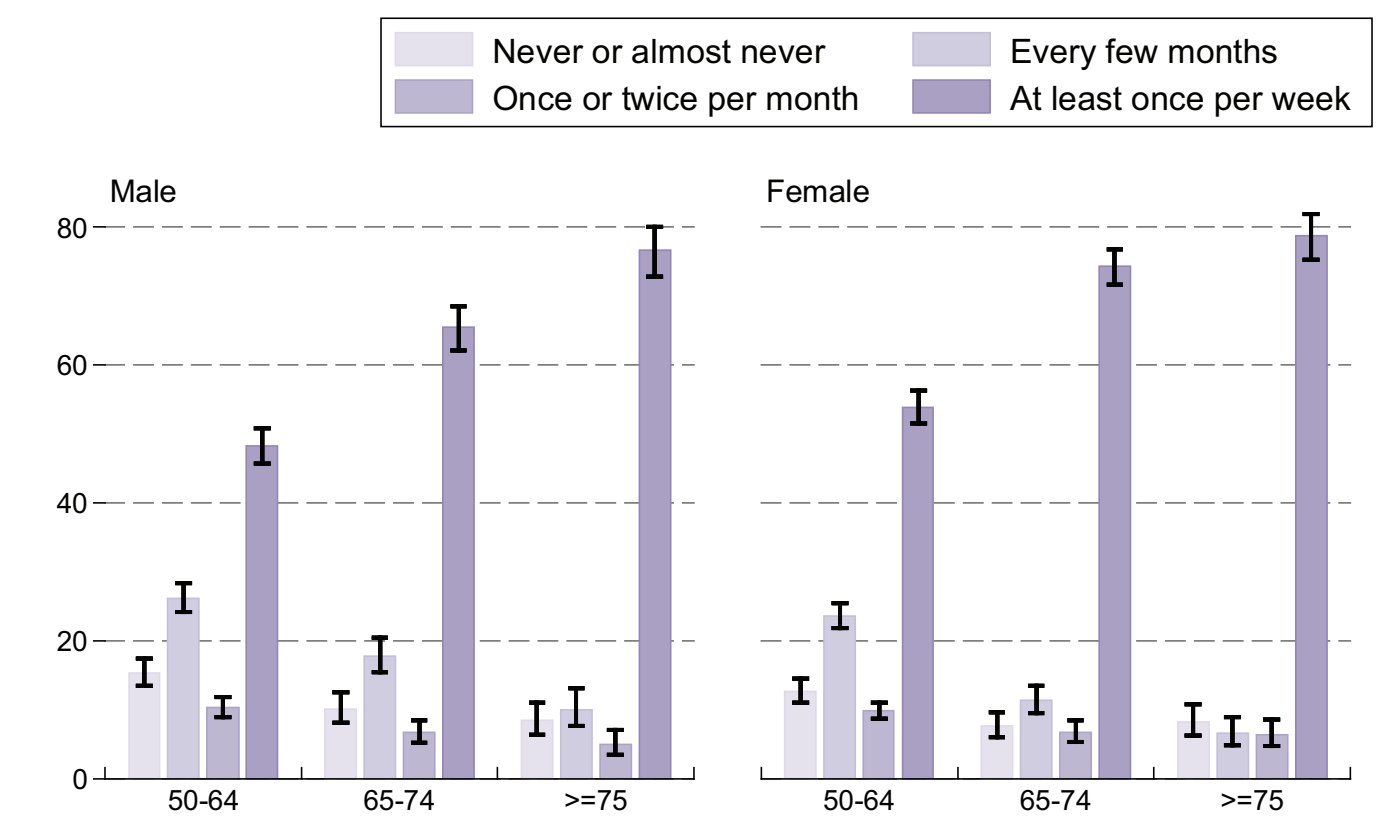

Note. $\mathrm{N}=7749$; Missing obs $=429$; Error bars correspond to $95 \%$ confidence intervals

Figure 4.9: Degree of importance of religion in older persons' lives, by age and sex

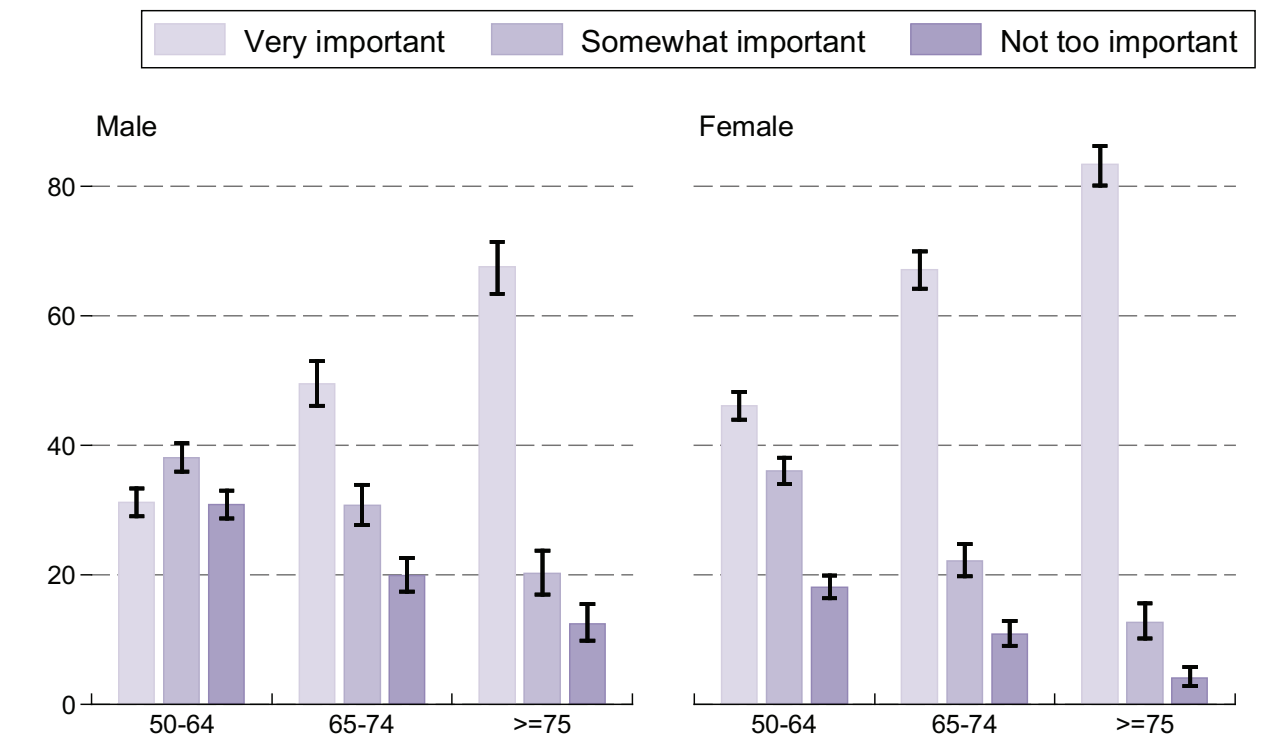

Note. $N=7745$; Missing obs $=433$; Error bars correspond to $95 \%$ confidence intervals 
Figure 4.10: Proportion (\%) of older people who get comfort and strength from religion, by age and sex

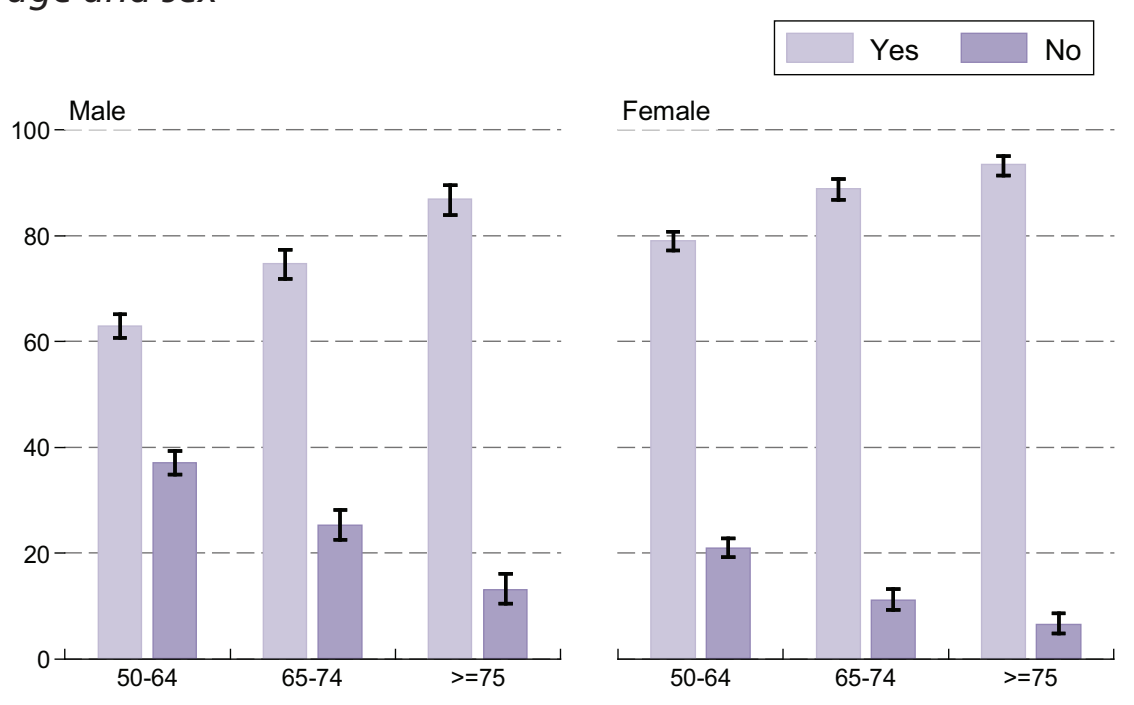

Note. $\mathrm{N}=7627$; Missing obs $=551$; Error bars correspond to $95 \%$ confidence intervals

\subsection{Voting}

Voting is a civic form of social engagement. Attending religious services, marital status, and recent contact with political lobbyists have been previously shown to be determinants of voting behaviour (36), as are self-reported health status and education (37-39). In TILDA, respondents were asked if they had voted in the 2007 general election. Over $80 \%$ of the older population had voted in the last election. This proportion differs slightly by age among women, but not men, with the oldest women being the least likely to have voted (Figure 4.11).

Figure 4.11: Percentage of older people who voted in the last general election, by age and sex

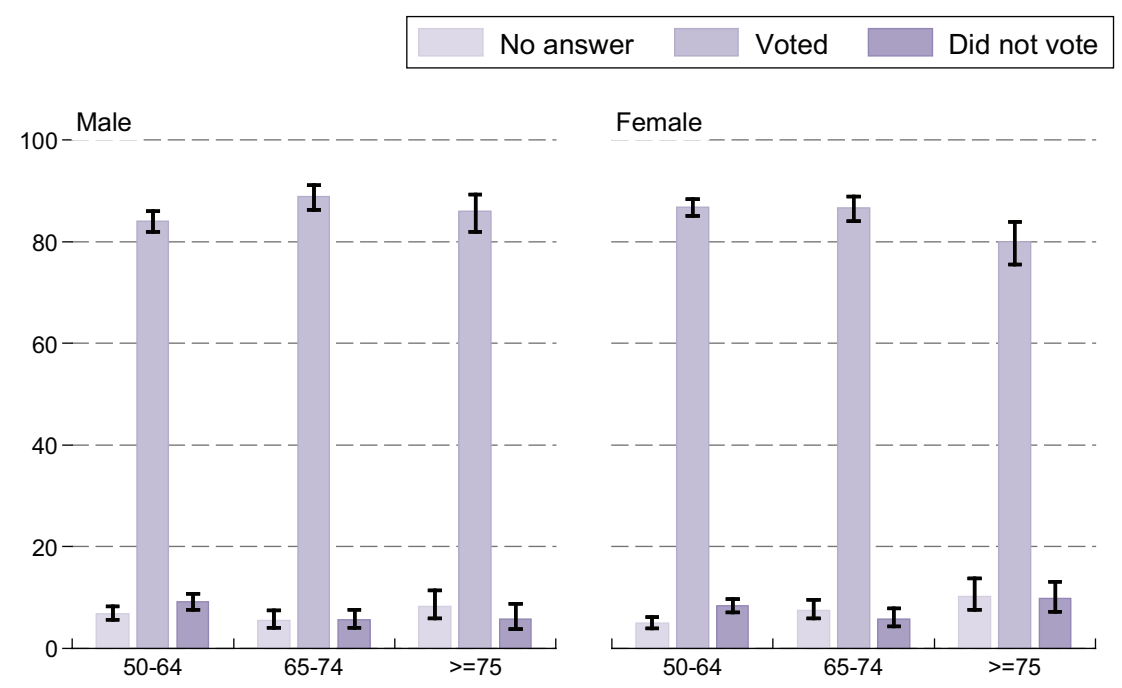

Note. $\mathrm{N}=6235 ;$ Missing obs $=27$; Error bars correspond to $95 \%$ confidence intervals 
Consistent with current international knowledge of the determinants of voting behaviour, less educated older Irish people are less likely to vote. Regardless of education level, people in the youngest and oldest age groups are less likely to vote than those aged 65-74 years (see Table 4.6).

Table 4.6: Voting participation of older people, by age and education level

\begin{tabular}{|c|c|c|c|c|c|c|c|c|}
\hline & \multicolumn{2}{|c|}{ No Response } & \multicolumn{2}{|c|}{ Voted } & \multicolumn{2}{|c|}{ Did not vote } & \multirow{2}{*}{ Total } & \multirow{2}{*}{$\begin{array}{c}\text { Number in } \\
\text { sample }\end{array}$} \\
\hline & $\%$ & $95 \% \mathrm{Cl}$ & $\%$ & $95 \% \mathrm{Cl}$ & $\%$ & $95 \% \mathrm{Cl}$ & & \\
\hline \multicolumn{9}{|c|}{ Primary/none } \\
\hline $50-64$ & 9 & $(7-12)$ & 79 & $(76-82)$ & 11 & $(9-14)$ & 100 & 642 \\
\hline $65-74$ & 8 & $(6-10)$ & 85 & $(82-88)$ & 7 & $(5-9)$ & 100 & 621 \\
\hline$>=75$ & 11 & $(8-14)$ & 80 & $(76-84)$ & 9 & $(7-12)$ & 100 & 450 \\
\hline Total & 9 & $(8-11)$ & 82 & $(80-83)$ & 9 & $(8-11)$ & 100 & 1713 \\
\hline \multicolumn{9}{|c|}{ Secondary } \\
\hline $50-64$ & 4 & $(3-5)$ & 88 & $(86-89)$ & 8 & $(7-10)$ & 100 & 1652 \\
\hline $65-74$ & 6 & $(4-8)$ & 90 & $(87-92)$ & 4 & $(3-6)$ & 100 & 584 \\
\hline$>=75$ & 7 & $(5-11)$ & 87 & $(83-90)$ & 5 & $(3-9)$ & 100 & 324 \\
\hline Total & 5 & $(4-6)$ & 88 & $(87-89)$ & 7 & $(6-8)$ & 100 & 2560 \\
\hline \multicolumn{9}{|c|}{ Third/higher } \\
\hline $50-64$ & 5 & $(4-6)$ & 89 & $(87-90)$ & 6 & $(5-8)$ & 100 & 1285 \\
\hline $65-74$ & 3 & $(2-5)$ & 93 & $(90-95)$ & 5 & $(3-7)$ & 100 & 480 \\
\hline$>=75$ & 5 & $(3-10)$ & 90 & $(84-93)$ & 5 & $(3-9)$ & 243 & 195 \\
\hline Total & 5 & $(4-6)$ & 90 & $(88-91)$ & 6 & $(5-7)$ & 100 & 1960 \\
\hline
\end{tabular}

\subsection{Transport}

Mobility is a key determinant of an individual's ability to access services, whether social or practical, and to engage in community activities. Mobility decreases with age, which increases the need for assistance from public transportation and from family and community resources $(40,41)$. Therefore, the accessibility and affordability of different modes of transportation are essential factors to ensuring that older people can remain actively engaged in their communities.

TILDA respondents were asked to specify their primary mode of transport. The majority stated that they drive themselves ( $76 \%$ ), followed by $14 \%$ who are primarily driven by a family member. Public bus is the third most reported method of transport $(5 \%)$. For fewer than $2 \%$, riding a bicycle or motorbike, or being driven by friends, is 
the main mode of transport. The majority of the Irish population aged 50 years and over, therefore, rely heavily on cars as the main mode of transport (Figure 4.12).

Figure 4.12. Percentage of older people who regularly drive themselves, regularly are driven by friends and family and regularly use public buses by age

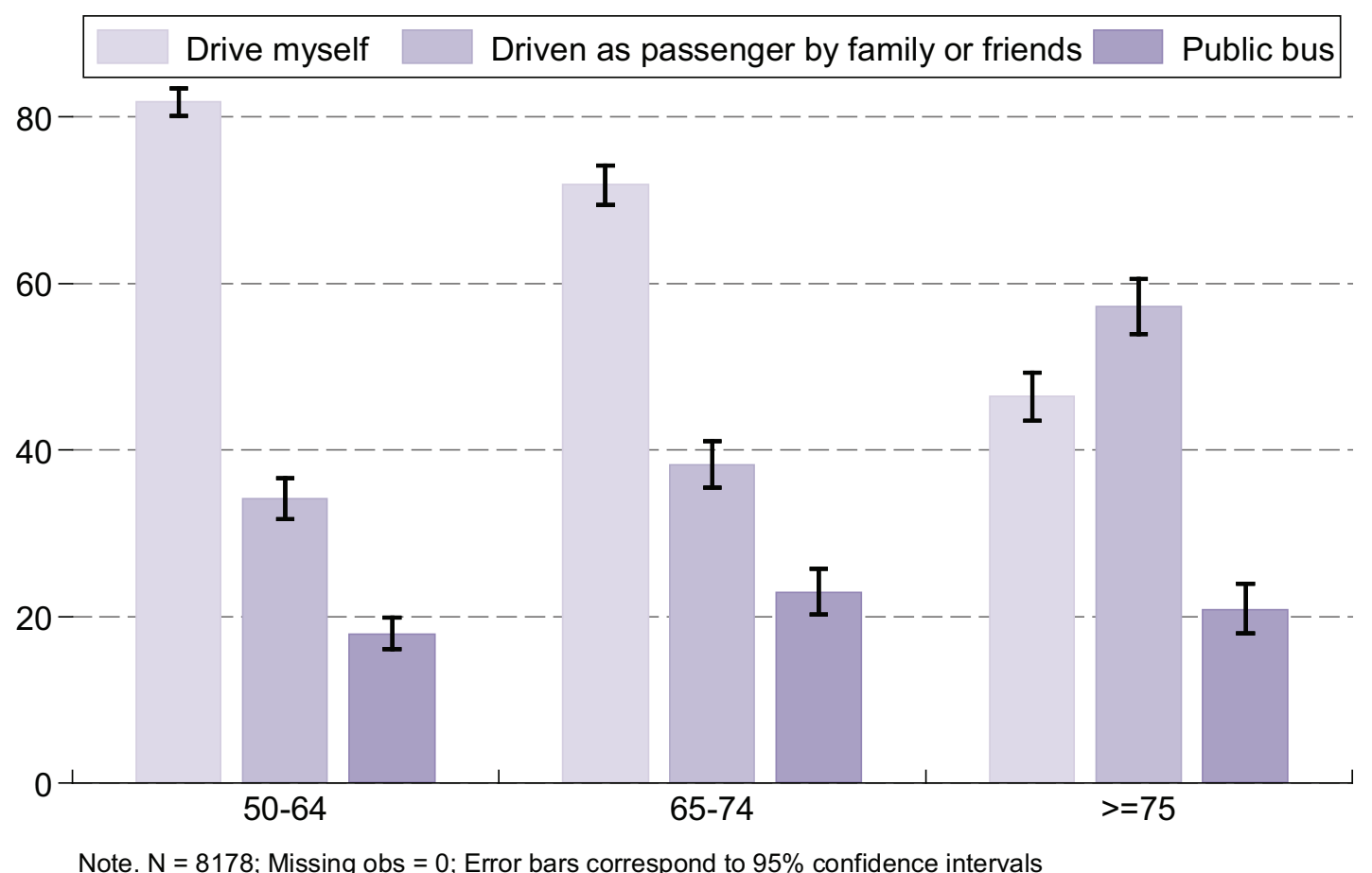

The heavy reliance on cars for mobility may be a consequence of the accessibility and affordability of public transportation services. Figure 4.13 shows how the proportion of older people who report their local public transport system as poor varies by geographic location. The negative perception of public transport systems increased as an individual's geographic location became more rural, with over $70 \%$ of the rural population reporting the local public transport system as poor regardless of age, compared to fewer than $20 \%$ in Dublin.

A reduced dependence upon automobiles for transport among persons aged 50 years and older occurs for many reasons. TILDA respondents who had given up driving were asked to state the main reason. More than $7 \%$ of older people who used to drive in the past are no longer driving. For these individuals, the main reason for this change is related to health, physical incapacity, or mental problems (17\%). Less willingness to drive is the second most important reason to stop driving (9\%). However, of those who no longer drive, only a small percentage $(1.5 \%)$ reported that the inability to drive affects how they socialise with others (e.g., visiting family and friends). 
Figure 4.13 Percentage of older people who rate their local public transport system as 'poor' by age and location of residence

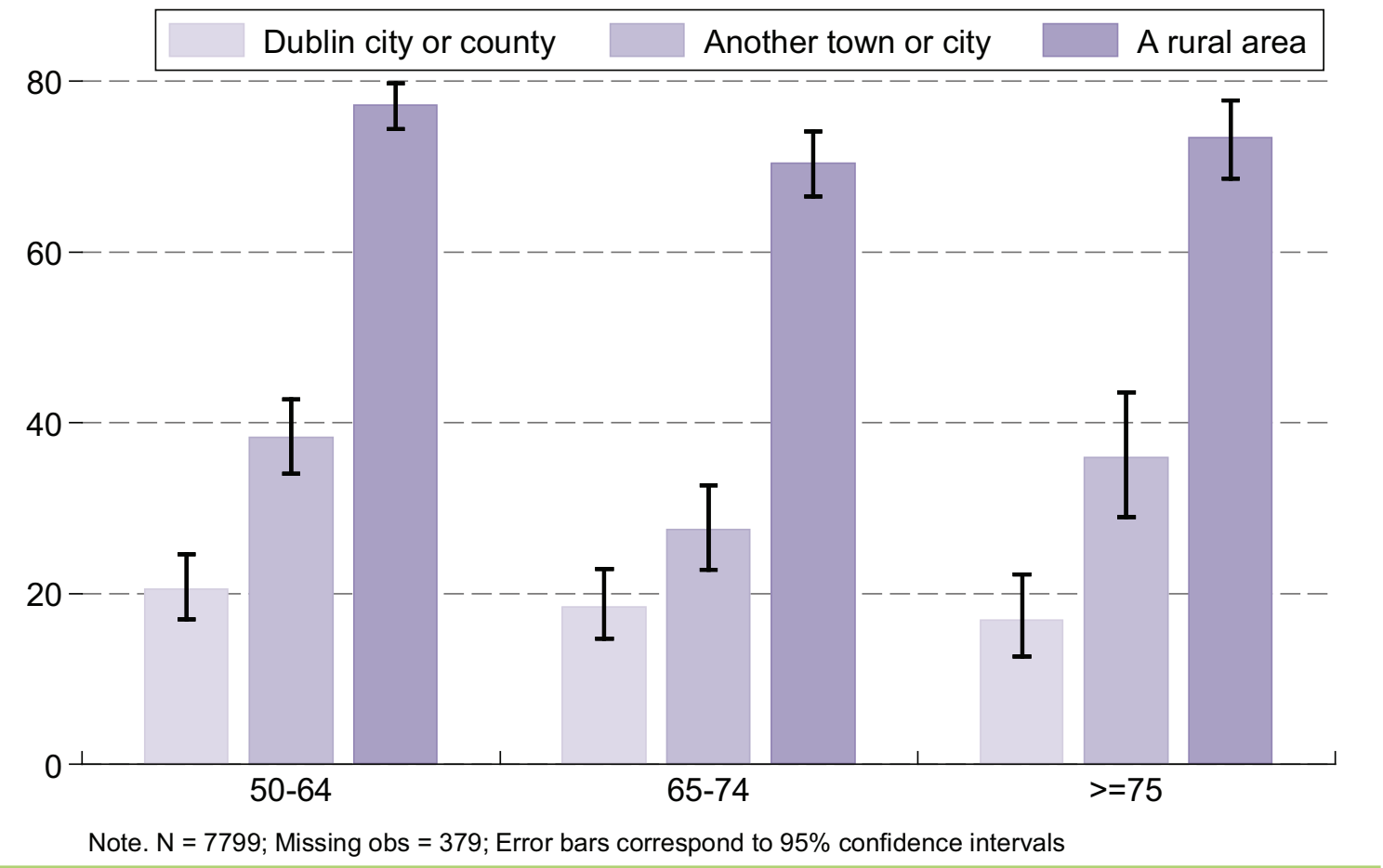

\subsection{Conclusions}

TILDA reveals high levels of engagement with family and friends for the older population as a whole, with nine out of ten older adults visiting with relatives and friends daily or weekly. The frequency of visiting family and friends increases with age; but without longitudinal data it is not possible to say whether this is an age or cohort effect. Within the broader societal context older adults are active respondents in civic and religious activities, with more than 80 per cent of this population group having voted in the last general election and majority attending religious services daily or weekly. Strikingly, one in five older adults aged 65-74 do voluntary work daily or weekly; this represents a very high level of voluntary engagement in activities that support communities and individuals across Ireland.

However, large differences were identified in some aspects of social engagement by levels of education. Participation in formal, organised activities, such as volunteering, is highest among those with higher levels of education. We can surmise that the benefits of higher levels of social engagement also accrue mostly to older adults with higher levels of education, as being more engaged with your community is good for your health and well-being. 
The majority of the older adult population of Ireland is socially integrated as measured by the Social Network Index, but approximately $6 \%$ of women and $7 \%$ of men are socially isolated. Older persons in poorer (self-rated) health are more likely to report being isolated than their healthier counterparts. Not all socially isolated older adults experience loneliness; better interventions must be developed for those who are isolated and lonely.

Many aspects of social engagement vary by sex and age. For instance, women visit with friends and relatives more frequently than men, and religion is more important for older women than for men. Men are more engaged than women in active and relatively social activities such as taking classes, eating out, going to plays and concerts, and taking part in sports. The reasons for these variations and their consequences for health and well-being will be the subject of further research using this and subsequent waves of TILDA.

\section{References}

1. Berkman LF, Syme SL. Social networks, host resistance, and mortality: a nine-year follow-up study of Alameda County residents. Am J Epidemiol 1979;109:186-204.

2. Kåreholt I, Lennartsson C, Gatz M, Parker MG. Baseline leisure time activity and cognition more than two decades later. Int J Geriatr Psychiatry 2011;26(1):65-74.

3. Chen SY, Fu YC. Leisure participation and enjoyment among the elderly: Individual characteristics and sociability. Educ Gerontol 2008;34(10):871-89.

4. Glass TA, De Leon DF, Bassuk SS, Berkman LF. Social engagement and depressive symptoms in late life: longitudinal findings. J Aging Health 2006;18(4):604-28.

5. Verghese J, Lipton RB, Katz MJ, Hall CB, Derby CA, Kuslansky G, et al. Leisure activities and the risk of dementia in the elderly. NEJM 2003;348(19):2508-16.

6. House J, Robbins $\mathrm{C}$, Metzner $\mathrm{H}$. The association of social relationships and activities with mortality: Prospective evidence from the Tecumseh Community Health Study. Am J Epidemiol 1982;116:123-40.

7. Jung Y, Gruenewald TL, Seeman TE, Sarkisian CA. Productive activities and development of frailty in older adults. J Gerontol B Psychol Sci Soc Sci 2010;65B(2):256-61.

8. Morrow-Howell N. Volunteering in later life: research frontiers. J Gerontol B Psychol Sci Soc Sci. 2010;65(4):461-9.

9. Tang F. Late-life volunteering and trajectories of physical health. J Applied Gerontology 2009;28:524-33.

10. Haski-Leventhal D. Elderly volunteering and well-being: A cross-European comparison based on SHARE data. Voluntas: International Journal of Voluntary and Nonprofit Organizations. 2009;20(4):388-404.

11. Burr JA, Tavares J, Mutchler JE. Volunteering and hypertension risk in later life. J Aging Health 2011;23:24-51.

12. Lum TY, Lightfoot $E$. The effects of volunteering on the physical and mental health of older people. Research on Aging 2005;27(1):31-55. 
13. Harris AHS. Volunteering is associated with delayed mortality in older people: Analysis of the Longitudinal Study of Aging. J Health Psychol 2005;10(6):739-52.

14. Thoits PA, Hewitt LN. Volunteer work and well-being. J Health Soc Behav 2001;42(2):115-31.

15. Morrow-Howell N, Hinterlong J, Rozario PA, Tang F. Effects of volunteering on the well-being of older adults. J Gerontol B Psychol Sci Soc Sci 2003;58(3): S137-45.

16. Hyde $M$, Wiggins RD, Blane D, Higgs P. A measure of quality of life in early old age: The theory, development and properties of a needs satisfaction model. Aging Ment Health 2003;7: 86-94.

17. Wiggins RD, Netuveli G, Hyde M, Higgs P, Blane D. The evaluation of a selfenumerated scale of quality of life (CASP-19) in the context of research on ageing: A combination of exploratory and confirmatory approaches. Soc Indic Res 2008;89:61-77.

18. Rodriguez CJ, Elkind MS, Clemow L, Jin Z, Di Tullio M, Sacco RL, et al. Association between social isolation and left ventricular mass. Am J Med 2011;124(2):164-70.

19. Barth J, Schneider S, Von Kanel R. Lack of social support in the etiology and the prognosis of coronary heart disease: A systematic review and meta-analysis. Psychosom Med 2010;72:229-38.

20. Conroy RM, Golden J, Jeffares I, O’Neill D, McGee H. Boredom-proneness, loneliness, social engagement and depression and their association with cognitive function in older people: a population study. Psychol Health Med 2010;15(4): 463-73.

21. Seeman T, Miller-Martinez D, Stein-Merkin S, Lachman M, Tun P, Karlamangla A. Histories of social engagement and adult cognition in middle and late life: the Midlife in the U,S. study. J Gerontol B Psychol Sci Soc Sci 2010 [Epub ahead of print]

22. Ertel KA, Glymour MM, Berkman LF. Effects of social integration on preserving memory function in a nationally representative US elderly population. Am J Public Health 2008;98:1215-20.

23. Lee HY, Jang SN, Lee S, Cho SI, Park EO. The relationship between social participation and self-rated health by sex and age: A cross-sectional survey. I J Nurs Stud 2008;45:1042-54.

24. Sirven N, Debrand T. Social participation and healthy ageing: An international comparison using SHARE data. Soc Sci Med 2008;67:2017-26.

25. Scharf T, Phillipson C, Smith A E. Social exclusion of older people in deprived urban communities of England. Eur J Ageing 2005;2(2):76-87.

26. Agahi N, Parker MG. Are today's older people more active than their predecessors? Participation in leisure-time activities in Sweden in 1992 and 2002. Ageing \& Society 2005;25:925-41.

27. Litwin H. Social networks and well-being: A comparison of older people in Mediterranean and non-Mediterranean countries. J Gerontol B Psychol Sci Soc Sci 2010;65B(5):599-608.

28. Netuveli G, Blane D. Quality of life in older ages. Br Med Bull 2008;85(1):113-26. 
29. Wenger $C$, Davies R, Shahtahmasebi S, Scott A. Social isolation and loneliness in old age: review and model refinement. Ageing Soc 1996;16:333-58.

30. Hawkley LC, Thisted RA, Masi CM, Cacioppo JT. Loneliness predicts increased blood pressure: 5-year cross-lagged analyses in middle-aged and older adults. Psychol Aging 2010;25(1):132-41.

31. Grenade L, Boldy D. Social isolation and loneliness among older people: issues and future challenges in community and residential settings. Aust Health Rev 2008;32(3):468-78.

32. O' Luanaigh C , Lawlor BA. Loneliness and the health of older people.Int J Geriatr Psychiatry 2008;23:1213-21.

33. Russell D. The UCLA Loneliness Scale (Version 3): Reliability, validity, and factor structure. J Pers Assess 1996;66:20-40.

34. Krause N. Church-based volunteering, providing informal support at church, and self-rated health in late life. J Aging Health 2009;21(1):63-84.

35. Keyes CLM, Reitzes DC. The role of religious identity in the mental health of older working and retired adults. Aging \& Mental Health 2007;11(4):434-43.

36. Turner MJ, Shields TG, Sharp D. Changes and continuities in the determinants of older adults' voter turnout 1952-1996. Gerontologist 2001;41(6):805-18.

37. Denny KJ, Doyle OM. ". . .Take up thy bed, and vote" Measuring the relationship between voting behaviour and indicators of health. Eur J Public Health 2007;17(4):400-1.

38. Goerres A. Why are older people more likely to vote? The impact of ageing on electoral turnout in Europe. British Journal of Politics \& International Relations 2007;9(1):90-121.

39. Bazargan M, Kang TS, Bazargan S. A multivariate comparison of elderly African Americans and Caucasians voting behavior: how do social, health, psychological, and political variables effect their voting? Int J Aging Hum Dev 1991;32(3):181-98.

40. Clarke P, Ailshire JA, Lantz P. Urban built environments and trajectories of mobility disability: Findings from a national sample of community-dwelling American adults (1986-2001). Soc Sci Med 2009;69(6): 964-70.

41. Broome K, McKenna K, Fleming J, Worrall L. Bus use and older people: A literature review applying the Person-Environment-Occupation model in macro practice. Scand J Occup Ther 2009;16:3-12. 


\section{Physical And Behavioural Health Of Older Irish Adults}

\section{Hilary Cronin, Claire O'Regan and Rose Anne Kenny}

\section{Contents}

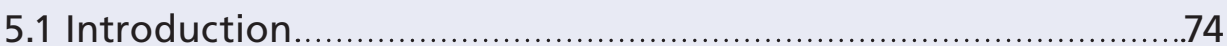

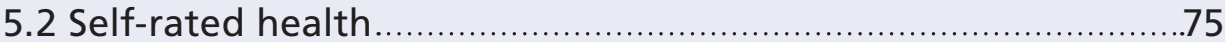

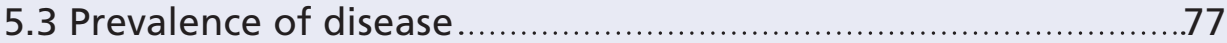

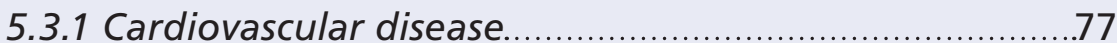

5.3.2 Non-cardiovascular chronic conditions..........................80

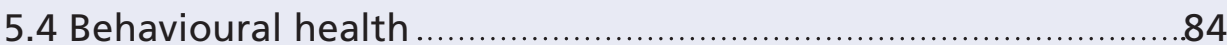

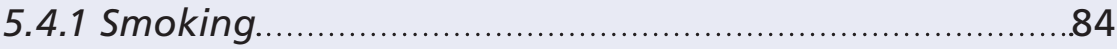

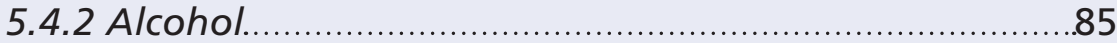

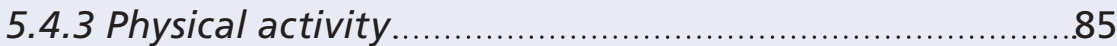

5.4.4 Primary prevention and screening ...............................86

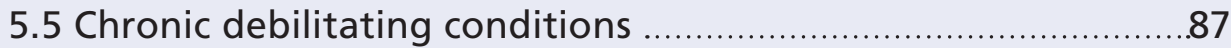

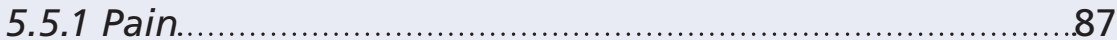

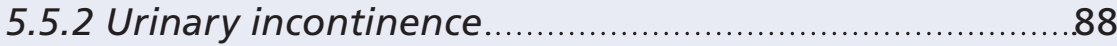

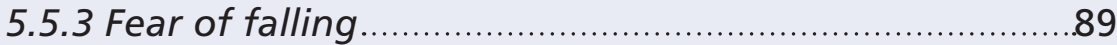

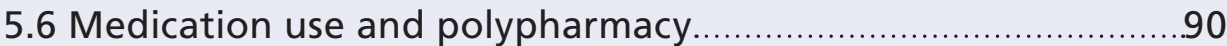

5.7 Objective measures of physical health ...................................90

5.7.1 Anthropometric measures and body mass index .........91

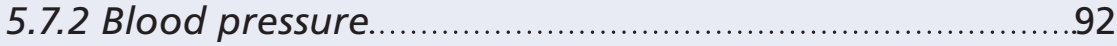

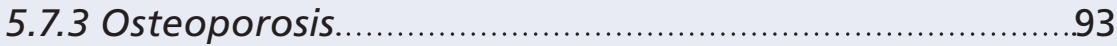

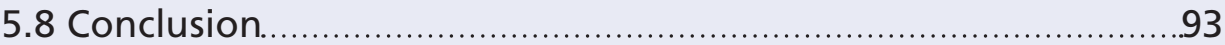




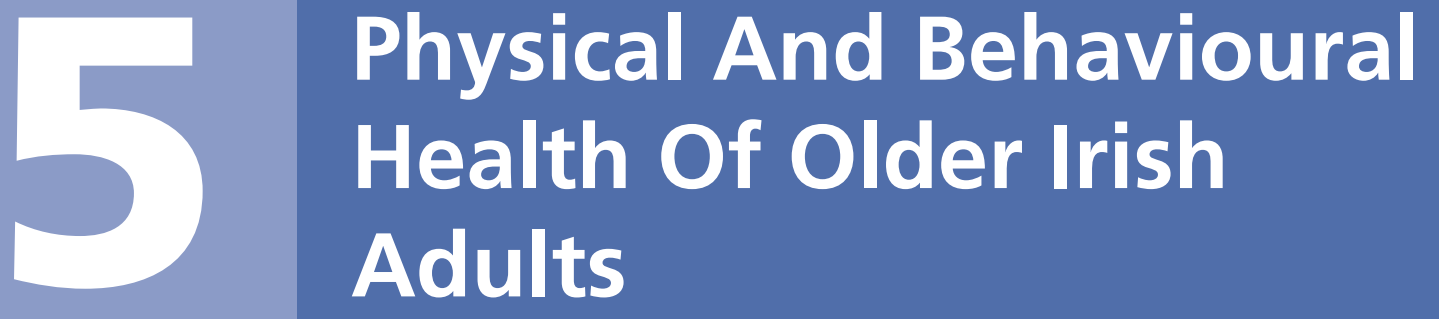

Key findings:

- Both cardiovascular and non-cardiovascular diseases are common in older adults with the prevalence of most chronic conditions increasing with age.

- Hypertension, angina and stroke are more common in men; osteoporosis, arthritis and high cholesterol are more common in women.

- One in five older Irish adults is a current smoker, the highest rates of smoking are seen in the poorest and those with lowest education levels.

- Half of those aged 75 years and older report low levels of physical activity. Wealthier and better educated adults have the highest physical activity levels.

- Screening for cancer varies significantly by age, education and wealth. Older, poorer, less educated adults are less likely to screen for prostate or breast cancer.

- One in five older adults takes five or more medications (polypharmacy). This proportion rises to almost one in two for those aged 75 years and older. Polypharmacy is more than twice as likely in medical card holders compared with adults without cover or with medical insurance.

- Three-quarters of older Irish adults are objectively overweight or obese. Poorer individuals and those with lower levels of education have the highest levels of obesity.

- There is a significant discrepancy between self-reported disease and objective measure of disease; for example, $58 \%$ of men and $49 \%$ of women with objective evidence of hypertension are undiagnosed.

\subsection{Introduction}

Health, wellbeing and independent living are integrally linked to social and economic circumstances $(1,2)$, although the underlying causal mechanisms remain poorly understood. To date, mortality rates and hospital based records (HIPE) have been used to monitor the health of the population in Ireland. These systems do not represent a comprehensive overview of population health, in particular HIPE data is limited, since it does not represent the non-hospitalised population. TILDA health assessment addresses this shortfall.

The focus of TILDA's health research is on common conditions that have public health significance; that is on diseases that are most prevalent among older people and most likely to result in mortality, poor quality of life, disability and social isolation. 
The primary areas of investigation are neuro-cardiovascular stability (cognition, mood, cardiac and autonomic function), locomotion (gait and balance) and sensory function (vision and hearing).

Longitudinal studies typically use subjective information to determine health and well being. Given the reported differences between self-reported and objective health (3), TILDA has collected objective measurements, in some cases using new technologies, which complement the subjective, self-rated information on health and well being from the CAPI and the self-completion questionnaire (SCQ).

TILDA also has information on health behaviours, such as smoking, drinking alcohol and taking exercise, all important determinants of health status in older persons (4). Smoking continues to be a major risk factor for death from cancer, coronary heart disease and stroke in older age, and smoking cessation confers benefits well into older age $(5,6)$. Consumption of alcohol increases the risk of falls $(7)$ and has been linked to cognitive problems and dementia (8). Exercise has a major beneficial influence not just on locomotion and cardiovascular health, but also on mental health and cognitive well being.

This chapter presents the prevalence of chronic diseases in older Irish adults and variations in prevalence associated with age, education and wealth. The pattern of behavioural health and medication use in older adults is described and the relationships between objective and subjective measures of health are examined. Some of the important features of the methodologies employed in the assessments are highlighted in the chapter. For more detailed descriptions, the reader is referred to the design report at www.tilda.ie

\subsection{Self-rated health}

A person's own appraisal of his/her general health is a powerful independent predictor of future morbidity and mortality (9). TILDA respondents were asked to rate their own health directly using a global rating of health as excellent, very good, good, fair, or poor. For some analyses, these five options have been collapsed into two groups (1) good health (excellent, very good and good) and (2) poor health (fair or poor).

Figure 5.1 presents self-rated health by age, sex and education. Overall, $75 \%$ of older adults rate their health as excellent $(14 \%)$, very good $(28 \%)$ or good $(33 \%)$ and $25 \%$ rate their health as fair (19\%) or poor $(6 \%)$. Self-rated health declines with age in both men and women; older adults are less likely to report health as excellent, very good or good (66\% in those aged 75 and over versus $79 \%$ of those aged between 50-64; Table 5.A1). In all age groups, higher education is associated with better selfrated health. $83 \%$ of adults aged 75 years and over, with third level education rate their health as excellent, very good or good compared to $61 \%$ of those with primary or no education (Table 5.A2). For all ages, greater wealth is associated with better 
self-rated health: $37 \%$ of older adults in the lowest wealth quartile report fair or poor self-rated health compared to $12 \%$ in the highest wealth quartile (Table 5.A3; Figure 5.2).

Figure 5.1: Self-rated health by age, sex and education

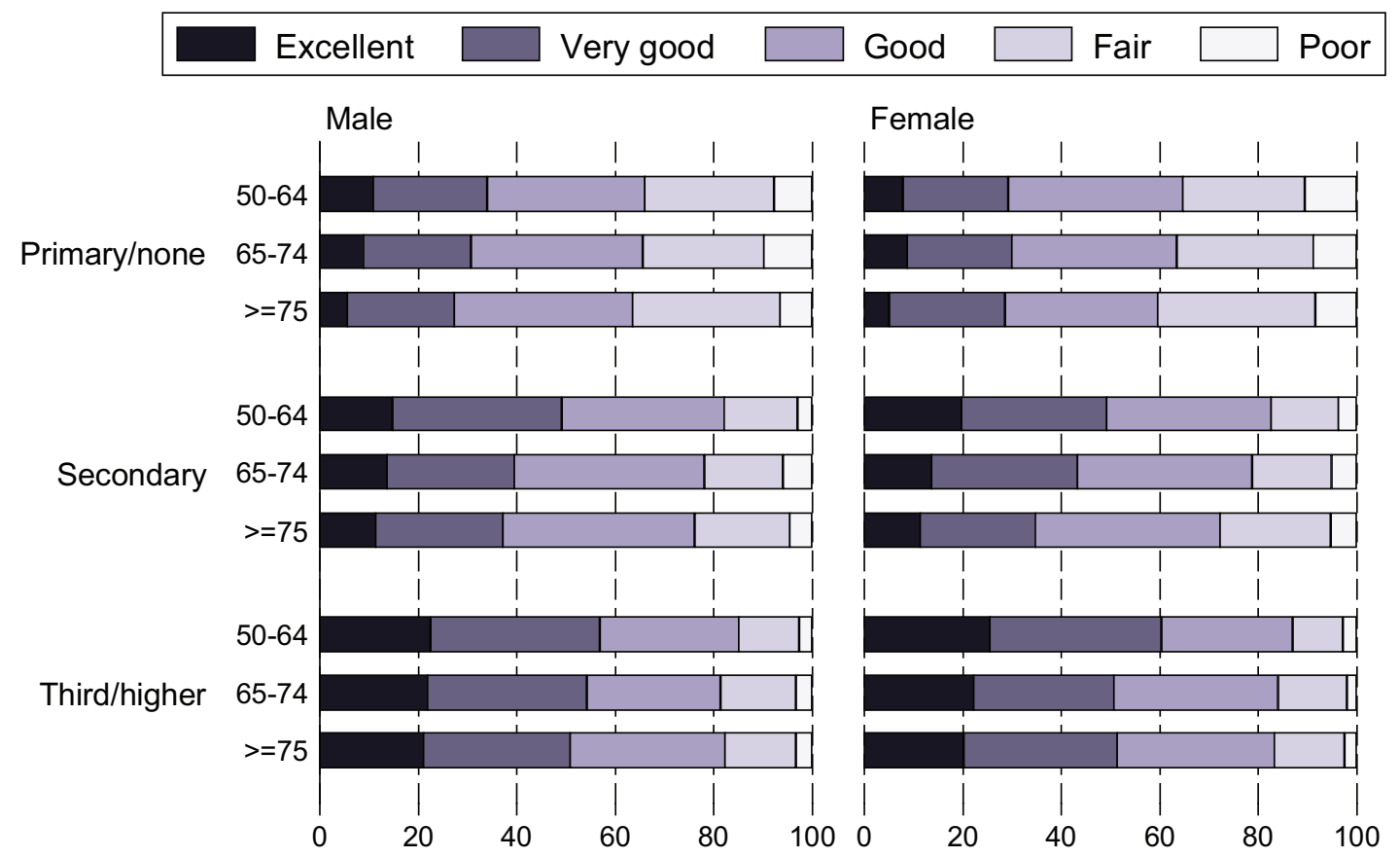

Note. $\mathrm{N}=8173$; Missing obs $=5$

Figure 5.2: Self-rated health by age, sex and wealth

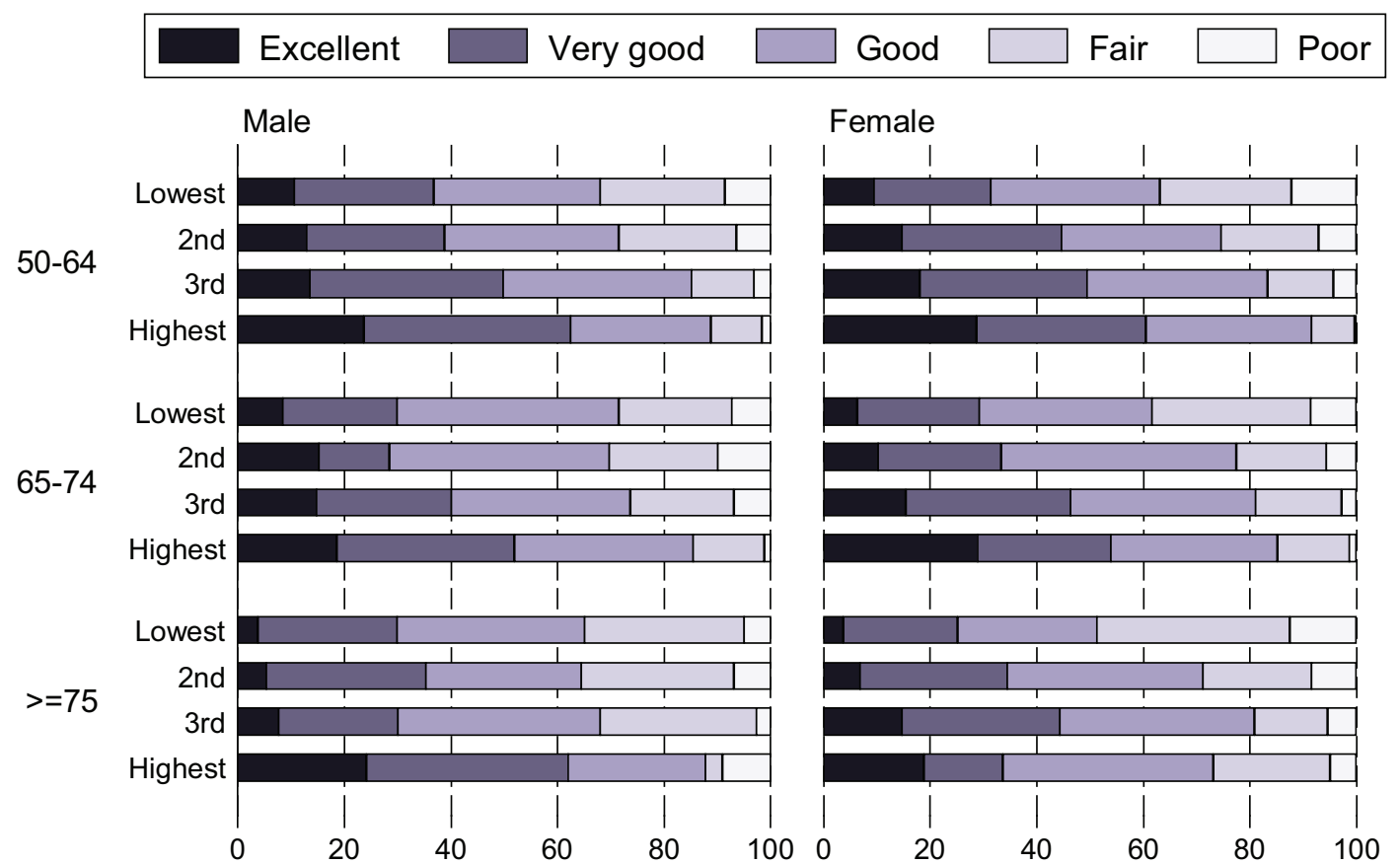

Note. $\mathrm{N}=3950 ;$ Missing obs $=4228$ 


\subsection{Prevalence of disease}

\subsubsection{Cardiovascular disease}

Cardiovascular disease remains the main cause of death in Ireland, accounting for $35 \%$ of all deaths (2.29 deaths per 1,000 of population per year)(10) and is a key focus of the TILDA physical health module. UK research suggests that, despite the success of public health campaigns in reduction of mortality in younger people, morbidity associated with cardiovascular disease in older age groups has not fallen (11). Elevated systolic (SBP) and diastolic (DBP) blood pressures are important risk factors for cardiovascular diseases such as angina, heart attack (myocardial infarction) and stroke (12). High blood pressure (hypertension) is recognised by the World Health Organisation (WHO) as one of the most important preventable causes of premature morbidity and mortality in developed and developing countries (13). Abnormal heart rhythm, in particular atrial fibrillation, is a modifiable cause of stroke and heart failure.

TILDA respondents were asked whether a doctor had ever told them that they suffered from any of the following conditions: high blood pressure, angina, a heart attack, congestive heart failure, an abnormal heart rhythm, diabetes or high blood sugar, a stroke, a mini-stroke or TIA (Transient Ischaemic Attack), high cholesterol or any other heart trouble.

\subsubsection{High blood pressure, high cholesterol and abnormal heart rhythm}

Figure 5.3 presents the prevalence of cardiovascular risk factors by age and sex. One in three older adults report a doctor diagnosis of high blood pressure with a similar proportion reporting high cholesterol. Fewer than one in ten older adults report an abnormal heart rhythm. The prevalence of high blood pressure increases stepwise with age from $29.7 \%$ in those aged $50-64$ years to $53.7 \%$ in those aged 75 and over. Similarly, the prevalence of an abnormal heart rhythm increases with age, from $4.9 \%$ in those aged $50-64$ to $12.4 \%$ in those aged 75 years and older. In contrast, the prevalence of high cholesterol peaks in Irish adults aged 65-74 years and subsequently declines with increasing age (Table 5.A4). Women report higher levels of high blood pressure and high cholesterol than men, with the opposite pattern seen for abnormal heart rhythm. Irish adults with primary education report higher rates of high blood pressure but lower rates of high cholesterol when compared to those with second or third level education (Table 5.A5). A similar association is seen with wealth, older adults in the lowest wealth quartile report higher rates of high blood pressure and lower rates of high cholesterol than those in the highest wealth quartile (Table 5.A6). The prevalence of abnormal heart rhythm does not vary by education or wealth. 
Figure 5.3 Prevalence of cardiovascular risk factors by age and sex

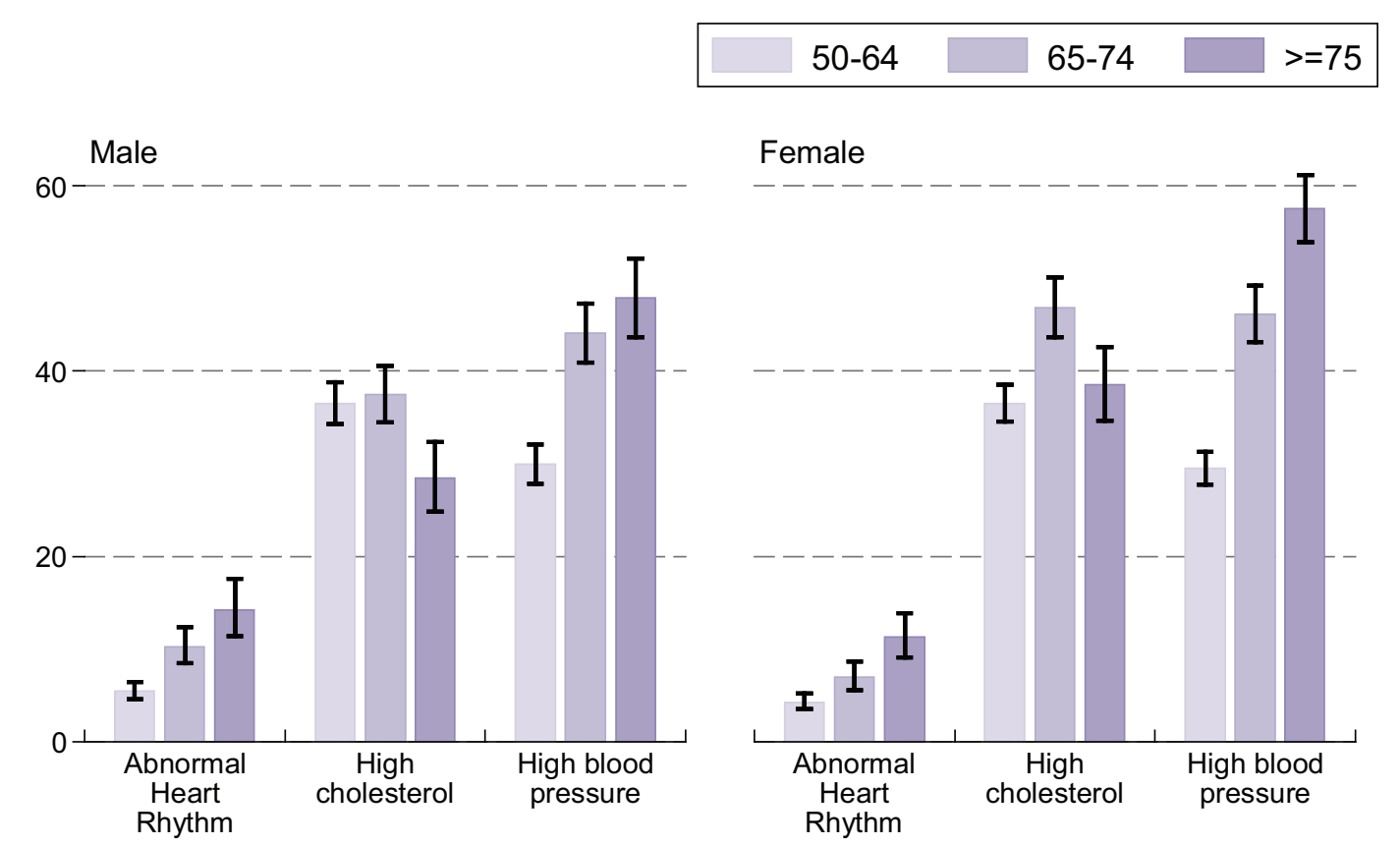

Note. $\mathrm{N}=8178$; Missing obs $=0$; Error bars correspond to $95 \%$ confidence intervals

\subsubsection{Angina, heart attack, heart failure}

Figure 5.4 shows the prevalence of cardiovascular disease by age and sex. One in twenty older Irish adults report angina or a prior heart attack, 1.1\% report heart failure. The prevalence of all three conditions increases with advancing age, for example $2.6 \%$ of adults aged $50-64$ report angina; this rises to $8.5 \%$ in adults aged between 65 and 74 years and $12.2 \%$ in adults aged 75 and over. Likewise the prevalence of heart attack increases from $2.6 \%$ in those aged $50-64$ years to almost $10 \%$ in those aged 75 and over. The prevalence of cardiovascular disease is higher in men than women; $15.3 \%$ of men aged 75 years and over have suffered a heart attack compared to $5.3 \%$ of women of the same age (Table 5.A7). The prevalence of angina, heart attack and heart failure is highest in those with low education; for example $8.6 \%$ of older adults with primary/no education report angina compared to $3.4 \%$ of those with third level education (Table 5.A8). A clear wealth gradient is observed with individuals in the lowest wealth quartile reporting twice as much angina, heart attacks and heart failure than those in the highest quartile (Table 5.A9). 
Figure 5.4: Prevalence of cardiovascular disease by age and sex

$50-64 \square$ 65-74 $\square=75$

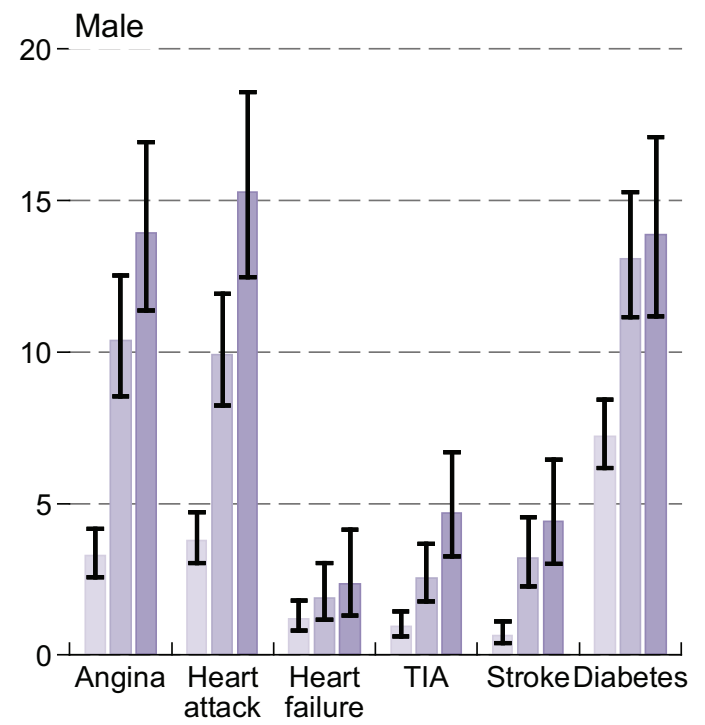

Female

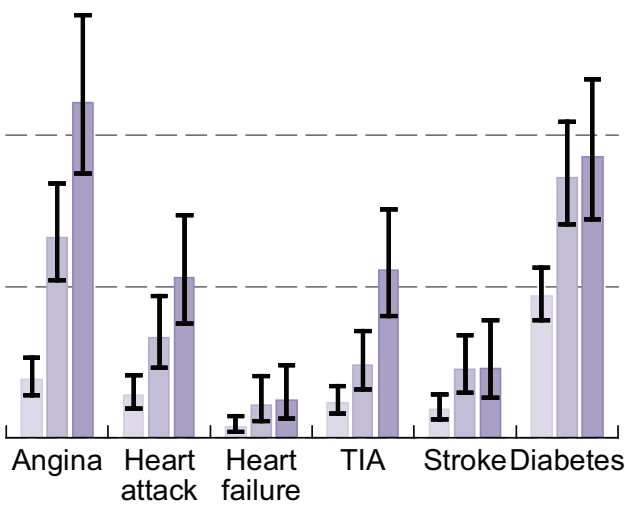

Note. $\mathrm{N}=8178$; Missing obs $=0$; Error bars correspond to $95 \%$ confidence intervals

\subsubsection{Stroke, transient ischaemic attacks (TIA) and diabetes}

Table 5.A7 also presents the prevalence of stroke, TIA and diabetes in older Irish adults. The overall prevalence of stroke is $1.7 \%$ and TIA is $2.1 \%$. There is a strong age gradient with older adults three times more likely to report a stroke and five times more likely to report a TIA than younger adults. TIA and stroke are equally prevalent in men and women. Irish adults with a primary or no education report higher rates of stroke and TIA than those with a second or third level education (Table 5.A8). In addition older adults in the lowest two wealth quartiles report higher rates of stroke and TIA than those in the higher wealth quartiles (Table 5.A9).

One in twelve Irish adults report a doctor's diagnosis of diabetes. The prevalence of diabetes increases with age from $6 \%$ in adults aged $50-64$ years to $11.1 \%$ in adults aged 75 years and older. Regardless of age, diabetes is more common in men than women. Older adults with primary/no education are twice as likely to report a diagnosis of diabetes as those with third level education (10.5\% versus $5.7 \%$, table 5.A8). A similar pattern is observed with wealth; $9.3 \%$ of older adults in the lowest wealth quartile have diabetes compared with just $4.6 \%$ in the highest wealth quartile (Table 5.A9). 


\subsubsection{Non-cardiovascular chronic conditions}

\subsubsection{Respiratory disease}

Chronic respiratory disease is an important cause of morbidity and mortality in old age (10). In Ireland, diseases of the respiratory system account for $12 \%$ of all deaths, affecting in particular the older age-groups (10).

TILDA respondents were asked whether a doctor had ever told them that they suffered from a chronic lung disease such as chronic bronchitis or emphysema.

The prevalence of chronic lung disease in older adults is $4.2 \%$ (Table 5.A10). In men, the prevalence of chronic lung disease increases with age from $3.0 \%$ in those aged 50-64 years, to $5.1 \%$ in those aged $65-74$ years and $5.6 \%$ in those aged 75 years and older, however this consistent increase with age is not seen in women. Smoking is a strong risk factor for lung disease. Figure 5.5 shows the prevalence of lung disease by age, smoking history and education. Older adults who currently smoke are more than twice as likely to report chronic lung disease compared with adults who never smoked but this effect appears to be moderated to some extent by higher levels of education. Table 5.A11 presents the prevalence of chronic respiratory disease by age and education. Individuals with primary or no education report substantially higher levels of chronic lung disease $(5.5 \%)$ compared to individuals with second or third level education ( $3.6 \%$ and $2.7 \%$ respectively). There is also strong evidence of a wealth gradient with adults in the lowest wealth quartile twice as likely to report chronic lung disease than those in the wealthiest quartile $(6.5 \%$ vs $2.7 \%$; see table 5.A12).

\subsubsection{Arthritis, osteoporosis \& fractures}

Arthritis is the most common joint disease, and osteoarthritis (OA) is the commonest form of arthritis (14). The incidence of arthritis rises with age; as a result, the prevalence and burden of this disorder is increasing rapidly (15). Arthritis is a common cause of disability. In Britain, more than $90 \%$ of patients with arthritis report functional limitations in activities of daily living (16).

The prevalence of osteoporosis is also known to increase with age (17) and it is estimated that $40 \%-50 \%$ of women and $25 \%$ of men aged 50 years or older will suffer an osteoporosis-related fracture during their lifetime (18). Osteoporotic fractures, the clinical endpoint of osteoporosis, are associated with increased morbidity and mortality and high socioeconomic cost. In particular, hip fractures are associated with significant morbidity, loss of independence, diminished quality of life and high mortality rates. 
Figure 5.5: Lung disease by age, education and smoking status

\begin{tabular}{|c|c|}
\hline & $65-74$ \\
\hline
\end{tabular}
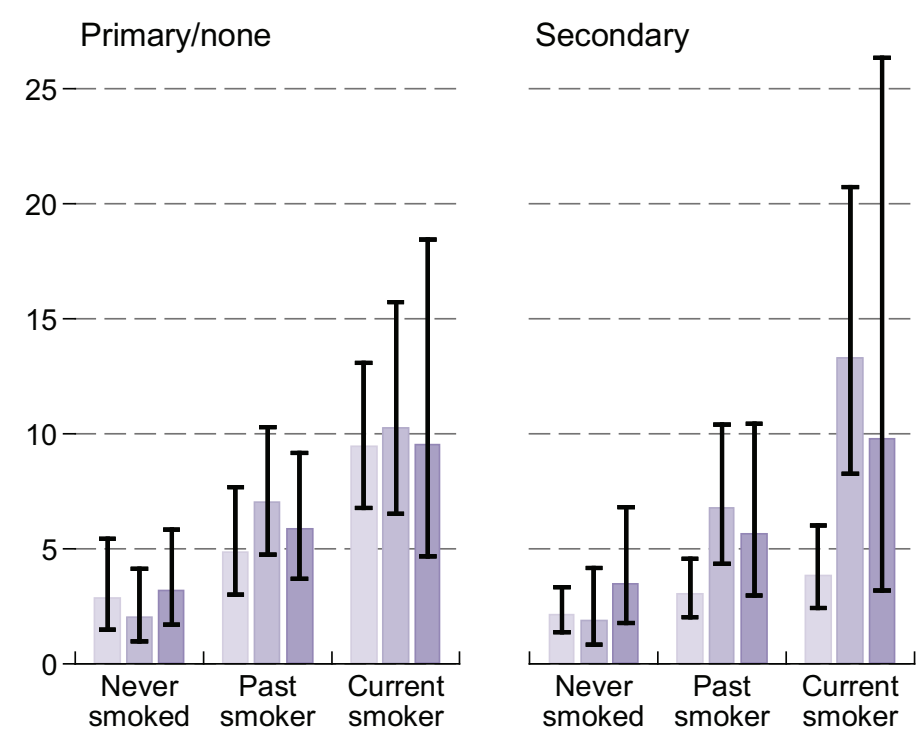

Third/higher

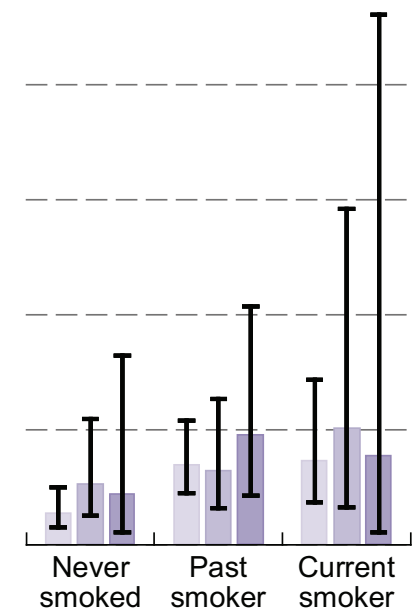

Note. $\mathrm{N}=8173$; Missing obs $=5$; Error bars correspond to $95 \%$ confidence intervals

TILDA respondents were asked whether a doctor had ever told them that they suffered from any of the following conditions: arthritis, osteoporosis (or brittle bones), hip or wrist fracture. In addition, an objective measurement of bone density was taken in those who underwent a health centre assessment.

More than one in four (27.6\%) adults aged 50 or over in Ireland has arthritis, with one in ten reporting a doctor's diagnosis of osteoporosis. A clear age gradient is observed. In women the prevalence of osteoporosis increases from $12.5 \%$ in those aged $50-64$ years to $22.4 \%$ in those aged 75 years or older. Both conditions are more often diagnosed in women than men; for example $16.1 \%$ of women report osteoporosis compared to just $1.9 \%$ of men (Figure 5.6, Table 5.A10).

Overall $3.6 \%$ of older adults report a hip fracture and $11.7 \%$ report a wrist fracture. The prevalence of hip fractures increases with age from $2.8 \%$ in adults aged $50-64$ years to $6.7 \%$ in adults aged 75 years and older. Men report higher levels of both hip and wrist fractures than women, however this pattern does not hold for all age groups. Younger men (those aged 50-64) are more likely to report a hip or wrist fracture than younger women, but this pattern reverses in older age groups (Table 5.A10).

Individuals with primary or no education have higher levels of arthritis, osteoporosis, hip and wrist fractures compared to individuals with third level education. This association is most marked for hip fracture with individuals with primary education 
reporting a threefold higher rate of hip fracture than individuals with third level education (5.1\% versus 1.7\%; see Table 5.A11). Similarly, the highest prevalence of arthritis, osteoporosis, hip and wrist fractures is seen in the lowest wealth quartile (Table 5.A12).

Figure 5.6: Prevalence of arthritis and osteoporosis by age and sex

$50-64 \quad 65-74 \square>=75$

$60^{-}$Male

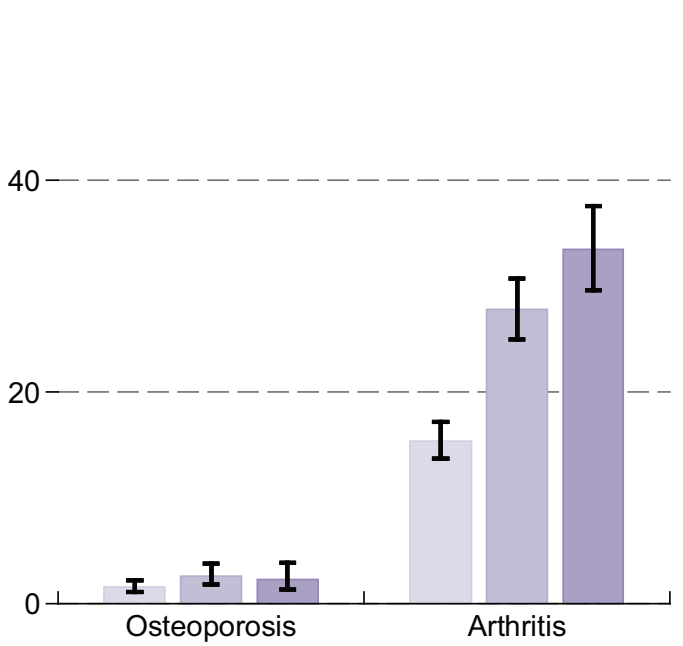

Female

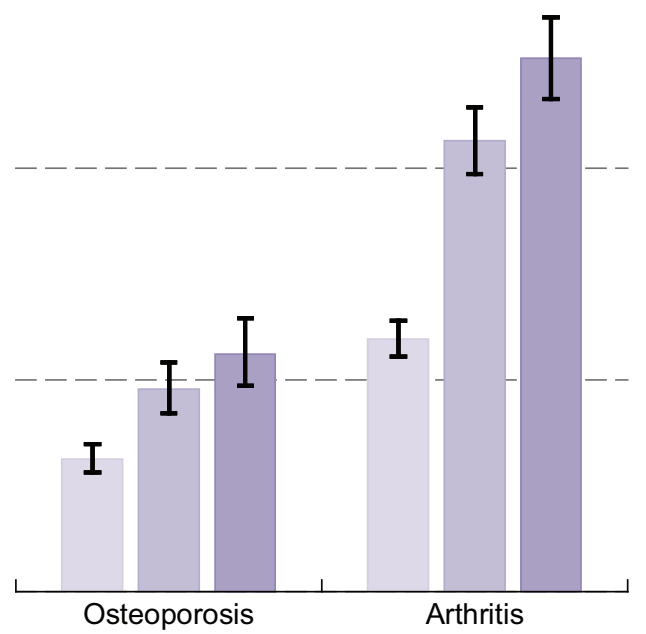

Note. $\mathrm{N}=8178$; Missing obs = 0; Error bars correspond to $95 \%$ confidence intervals

\subsubsection{Eye disease and sensory impairment}

Sensory decline is a common problem in older persons. It is associated with a variety of negative outcomes including reduced physical functioning, falls, increased dependency, withdrawal from social activities and diminished quality of life $(19,20)$.

TILDA respondents were asked to appraise vision and hearing using the following five response options "excellent, very good, good, fair, or poor". Respondents were also asked to report any doctor diagnosis of age-related macular degeneration (ARMD), cataracts and glaucoma. In addition, respondents were asked if they have any difficulty following conversations with one or more people.

Irish adults aged 75 years and older are twice as likely to rate their eyesight as poor when compared to those aged between 50 and 74 (Table 5.A13). The prevalence of cataracts and age-related macular degeneration increase with age and are higher in women than men (Figure 5.7). The prevalence of glaucoma also increases with age and is similar for men and women. 
The association with age can also be seen for self-rated hearing, older adults are more than twice as likely to rate their hearing as poor when compared to younger adults (Table 5.A13). In addition, older persons report more difficulty following a conversation with one person - with or without a hearing aid (14\% of those aged 75 years and over compared to $5 \%$ of those aged $50-64$ years) (Table 5.A16).

Older adults with primary or no education are twice as likely to report poor vision and hearing, as well as a doctor's diagnosis of cataracts, glaucoma, and ARMD than adults with third level education (Table 5.A14). Similarly, there is evidence of a strong wealth gradient for all conditions except glaucoma (Table 5.A15).

Figure 5.7: Prevalence of eye disease by age and sex

\begin{tabular}{|l|l|l|}
\hline $50-64$ & 65-74 & \\
\hline
\end{tabular}
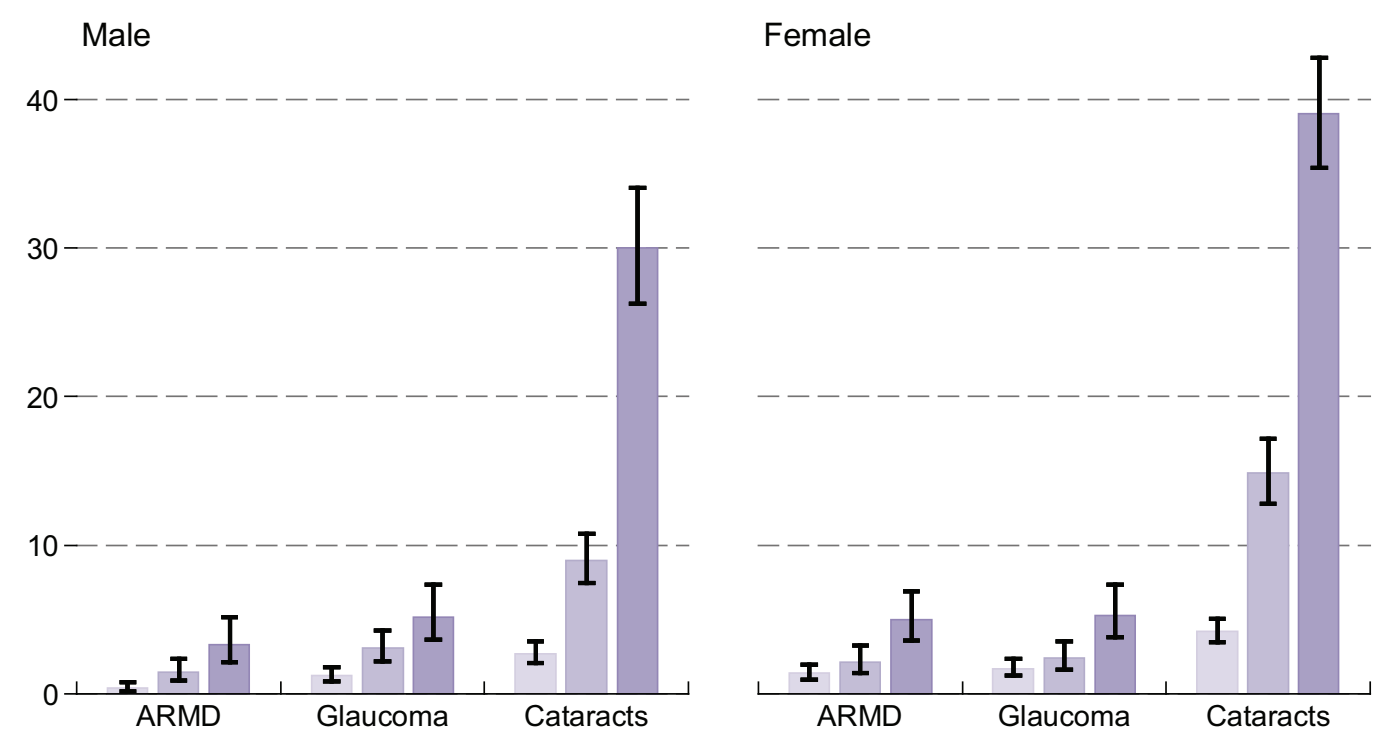

Note. $\mathrm{N}=8161 ;$ Missing obs $=17$; Error bars correspond to $95 \%$ confidence intervals

\subsubsection{Cancer}

Cancer remains the second leading cause of death in older Irish adults (after cardiovascular disease), accounting for $28 \%$ of deaths annually (10). Data from the National Cancer Registry report that the commonest cancers (excluding nonmelanoma skin cancers) in women are breast (30\% of all cancers), bowel (12\%) and lung $(10 \%)$; in men, prostate $(29 \%)$, bowel $(15 \%)$ and lung $(13 \%)$ are most common (21).

TILDA respondents were asked whether a doctor had ever told them that they have cancer or a malignant tumour and if so, what organ or part of the body was affected. 
Overall $6.1 \%$ report a diagnosis of cancer (Table 5.A10). The highest prevalence of cancer is observed in adults aged between 65-74 years (8.8\%) and cancer is more common in women than men (6.8\% versus 5.3\%; Table 5.A10). There is no evidence of an education or wealth gradient on the overall prevalence of cancer, although the effect on site specific cancer rates is yet to be examined (Table 5.A11-5.A12).

\subsubsection{Falls}

Falls are a common and often devastating problem for older people, leading to significant morbidity, mortality and increased use of health care services, in particular premature nursing home admissions (22). As the population ages, it is anticipated that the incidence of falls and consequent injuries will increase. Therefore, investigation of identifiable risk factors for falls and locomotion is a major research interest in TILDA.

Respondents were asked if they had fallen in the past year and if so, how many falls they had sustained.

Table 5.A17 presents the prevalence of falls by age and sex. Overall $19 \%$ of adults report falling in the previous year, with $7 \%$ reporting two or more falls (recurrent falls). The prevalence of falls increases with age in both men and women; $18 \%$ of adults aged between 50 and 64 years fell in the past year compared to $24 \%$ of adults aged 75 and older. There is some evidence of a socio-economic gradient in falls risk, although the effect of education and wealth on falls risk is not strong (table 5.A18-5. A19).

\subsection{Behavioural health}

Individual behaviours influence the prevalence of disease and ill health, or promote good health. The health behaviours recorded by TILDA and discussed here include smoking, alcohol consumption, physical activity, and participation in preventive health screenings.

\subsubsection{Smoking}

Cigarette smoking is one of the most important contributors to preventable morbidity and premature mortality worldwide. It is estimated that approximately 100 million deaths were caused by tobacco use in the 20th century. TILDA's measures on smoking allow a precise lifelong smoking history to be established. Data on smoking was collected using questions on smoking status (current, past, never), age at which the respondent started and stopped smoking and the average number of cigarettes, cigars or cigarillos or pipes smoked per day. In the current analyses individuals are classified as current smokers, previous smokers or having never smoked. 
One in five older Irish adults currently smokes (Table 5.A20). Overall the prevalence of smoking is the same in both men and women (19\%) but higher rates of smoking are reported in the younger old (50-64 years) and in adults with primary/no education (Table 5.A21). Women are more likely to have never smoked, whereas men are more likely to be ex-smokers. A clear association with wealth is observed, older adults in the lowest wealth quartile are almost three times as likely to report being current smokers as those in the highest wealth quartile (32\% vs $12 \%$; Table $5 . A 22$ ).

\subsubsection{Alcohol}

Ireland has one of the highest levels of alcohol consumption in the European Union (23). While there are some reported benefits with light alcohol consumption, alcohol contributes to an array of personal and social difficulties, both acute and long-term. While regular consumption of even moderate amounts of alcohol may create a health risk, the pattern of binge drinking (substantial intake during a single episode of drinking interspersed with periods of low or no intake) carries with it a particularly high risk of behavioural and health difficulties.

TILDA respondents were asked about the frequency of their alcohol consumption as well as the quantity of alcohol consumed within the preceding six months. Respondents were also asked if a doctor had ever told them that they suffered from alcohol or substance abuse. In addition, respondents completed the CAGE (cutannoyed-guilty-eye) questionnaire, which consists of 4 questions evaluating alcohol patterns and behaviour and is a valid screening assessment for alcoholism $(24,25)$.

Overall $1.8 \%$ of older Irish adults report a diagnosed history of alcohol or substance abuse (Table 5.A23). The rate is highest in men aged 65-74 years (3.9\%). No association with education is observed (Table 5.A24). Individuals in the lowest wealth quartile are more likely to report a diagnosis of alcohol and substance abuse compared to those in the highest wealth quartile (Table 5.A25). When alcohol problems are assessed using the CAGE questionnaire, a different pattern emerges. The overall prevalence of "problem drinking" (defined as a CAGE score of 3 or more) is higher at $4.8 \%$ and no association with wealth or education is observed (Table 5.A24-5.A25).

\subsubsection{Physical activity}

Engaging in regular physical activity reduces the risk of cardiovascular disease, preserves functional ability and benefits psychological health in older people (26), yet people who have physical, psychological or mental health disorders are the group most likely to report inactivity (27).

Physical activity was assessed in TILDA using The International Physical Activity Questionnaire (IPAQ) (28). This is a standardised measure which estimates habitual practice of physical activities. The short form of the IPAQ, which consists of 8 items 
estimating the time spent performing physical activities (from walking to moderate and vigorous exercise) and inactivity (time spent sitting) was used. The IPAQ classifies respondents as undertaking low, moderate or high levels of physical activity.

Overall, two thirds of older Irish adults report moderate (33\%) or high (34\%) levels of physical activity (Table 5.A26). Across all age groups, men are more active than women. For both men and women, the highest levels of physical activity are among adults aged 50 to 64 years, the lowest levels are reported in adults aged 75 and over. Regardless of age, individuals with higher education report higher levels of physical activity (Table 5.A27). An association between socio-economic status and exercise is observed; $40 \%$ of those in the lowest wealth quartile report low levels of physical activity compared to $25 \%$ in the wealthiest quartile (Table 5.A28).

\subsubsection{Primary prevention and screening}

Prevention and early treatment of many of the diseases and illnesses identified by screening can reduce morbidity and mortality. Identifying the factors which influence uptake of primary prevention and screening services will help to promote their use and may reduce health inequalities. TILDA respondents were asked if they had ever had a flu shot (influenza vaccination) or a blood test for cholesterol. Male respondents were asked if they had had a Prostate Specific Antigen (PSA) blood test for cancer. Female respondents were asked if they check their breasts regularly for lumps and if they had had a mammogram or x-ray of the breast to search for cancer.

\subsubsection{Uptake of medical tests}

Most $(83 \%)$ adults aged 75 years and over have had a flu vaccination. Awareness for screening for elevated cholesterol levels is also high, with $87.3 \%$ having had a blood test to assess cholesterol levels. There is no sex difference in uptake of either test (Table 5.A29). Older adults with primary or no education are more likely to have had a flu injection than those with secondary or third level education (Table 5.A30). There is evidence of a wealth gradient for uptake of the flu injection; adults aged 50-74 years in the lowest wealth quartile report higher levels of uptake than age matched counterparts in the highest wealth quartile (Table 5.A31). This may be because of reimbursement of GPs for administration of flu vaccination to patients who have a medical card, but this association needs to be explored in greater depth.

\subsubsection{Prostate cancer screening}

Almost three quarters of older men have been screened for prostate cancer, with the highest rates seen in those aged 65-74 years (80\%) (Table 5.A29). There is evidence of an educational gradient at all ages; men with primary or no education are less likely to screen for prostate cancer than men with second or third level education. For example, $71 \%$ of men aged 75 years and older with primary/no education have had a test for PSA levels compared to $83 \%$ of those with third level education (Table 
5.A30). There is also evidence of a wealth gradient, men in the lowest wealth quartile report substantially lower rates of prostate cancer screening than those in the highest quartile (64\% versus $81 \%$; Table 5.A31). A possible explanation for this is that screening is not reimbursed or subsidised.

\subsubsection{Breast cancer screening}

Awareness and uptake of screening for breast cancer is high, $67 \%$ of women regularly check their breasts for lumps and $73 \%$ have had a mammogram. There is evidence of a strong age gradient with women aged 50-64 years three times more likely to have had a mammogram than women aged 75 years and older ( $86 \%$ versus $34 \%$ ) (Table 5.A29). This is most likely attributable to the free State sponsored screening program for women aged between 50 and 65 years. An association with education is also observed; women with primary/no education are less likely to screen for breast cancer either by self-examination or mammogram than those with second/third level education. For example in women aged 75 years and older, only $29 \%$ of those with primary/no education had a mammogram in comparison with $54 \%$ of those with third level education (Table 5.A30). Women living in a rural area are more likely to check their breasts for lumps but less likely to have a mammogram compared to women from an urban area (Table 5.A32). This may be explained by geographic location of screening centres in urban areas. There is also evidence of a wealth gradient, women in the highest wealth quartile are more likely to have had a mammogram than women in the lowest quartile (89\% versus 63\%; Table 5.A31).

\subsection{Chronic debilitating conditions}

In older adults, early recognition of indicators of underlying health problems enable modification of risk factors and prevention of disability. In TILDA, these indicators are pain, incontinence and fear of falling.

\subsubsection{Pain}

Older adults have higher rates of chronic illness and disability (11). Pain is often a central component of chronic conditions and is associated with adverse health consequences and diminished quality of life.

TILDA respondents were asked if they are often troubled with pain, the severity of pain experienced, the treatment, control and location of pain as well as the impact of pain on daily functioning (household chores or work).

Overall $36 \%$ of older Irish adults are 'often troubled with pain' with the majority of these individuals reporting their pain as "moderate" or "severe" (Table 5.A33). Across all age categories, pain is more common in women than men. Back pain is the most common overall, affecting almost $15 \%$ of older Irish adults, with the highest 
rates evident in those aged 50-64 years (Figure 5.8). The prevalence of knee pain increases with age in women but peaks in men aged 65-74 years. Adults with primary or no education are more likely to report pain than those with a second or third level education (40\%; $34 \%$ and $31 \%$ respectively) (Table $5 . A 34)$. There is also clear evidence of a wealth gradient with adults in the lowest wealth quartile more likely to report pain than those in the wealthiest quartile ( $41 \%$ vs $30 \%$; Table $5 . A 35$ ).

Figure 5.8: Prevalence of pain by site, age and sex

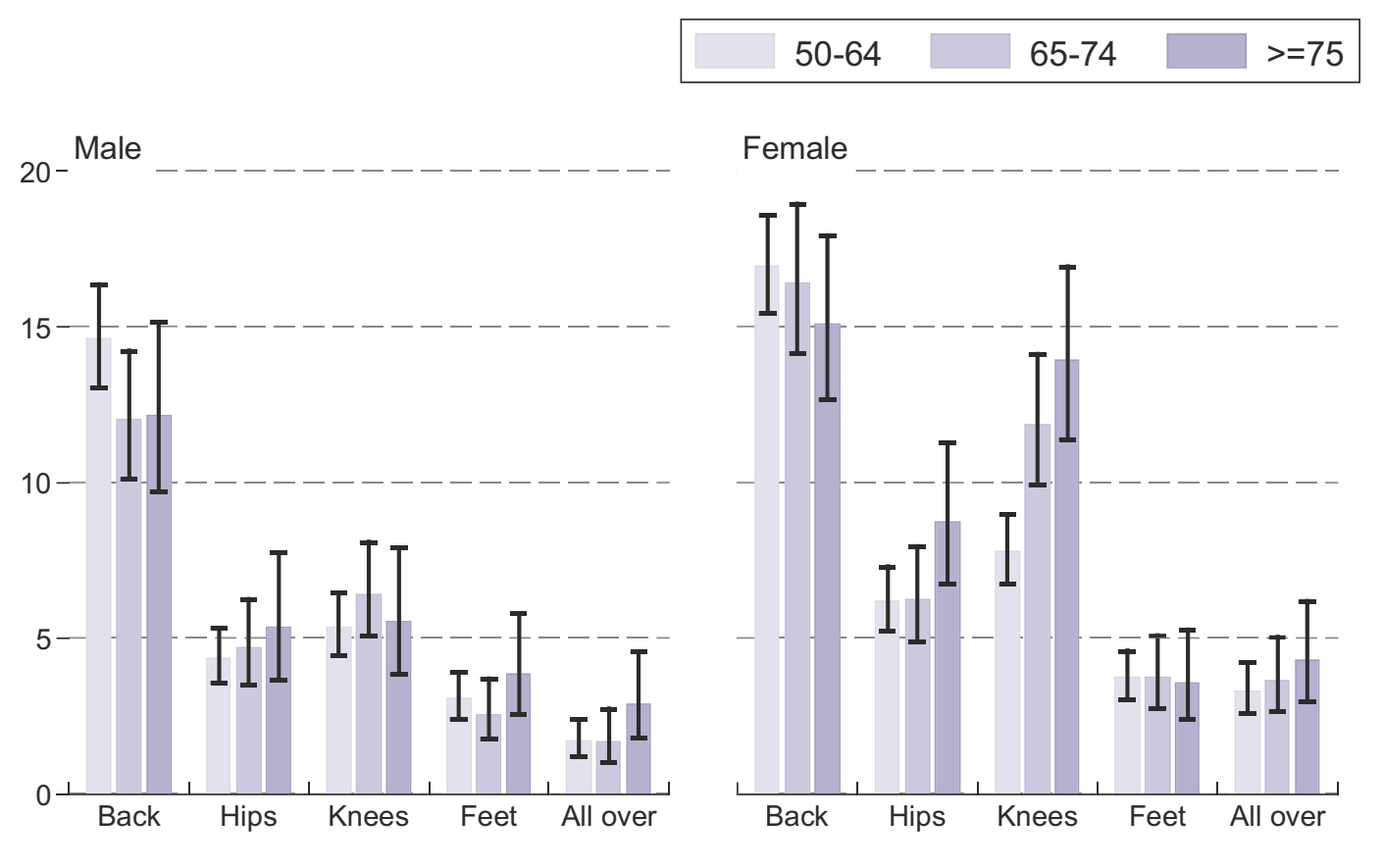

Note. $\mathrm{N}=8178$; Missing obs = 0; Error bars correspond to $95 \%$ confidence intervals

One in five adults aged between 50-64 years and one in four aged 75 years and older report that pain limits daily functioning (Table 5.A42). Women are more likely to report activity restriction than men. Older adults with primary or no education are almost twice as likely to report activity restriction as those with third level education ( $27.4 \%$ versus $16.3 \%$; Table $5 . A 43$ ). Similarly, individuals in the lowest wealth quartile are more likely to be limited by pain than those in the highest wealth quartile $(28.3 \%$ versus $13.9 \%$; Table 5.A44).

\subsubsection{Urinary incontinence}

Urinary incontinence is problematic for an individual and can also lead to many other problems and complications, particularly among older people. Incontinence causes people to avoid activities and interactions with others and can lead to isolation and depression (29). In addition, incontinence can increase the risk of falls when people attempt to reach the toilet before voiding (30). Despite affecting millions of older people, public awareness about incontinence is minimal, probably due to the nature of the condition and the 'taboo' surrounding it. 
TILDA respondents were asked questions relating to the prevalence and frequency of urinary incontinence as well as consequent activity restriction.

One in eight older Irish adults report urinary incontinence with three quarters of these adults reporting frequent urinary incontinence (more than once during the previous month) (Table 5.A36). The prevalence increases with age from $9 \%$ in those aged $50-64$ years, to $19 \%$ in those aged 75 years and older. At all ages, the prevalence is higher in women than men with very little evidence of either an educational or wealth gradient (Table 5.A37-5.A38).

Overall 3.2\% of the population report being limited in daily activities by urinary incontinence with women more than twice as likely to be limited as men $(4.2 \%$ versus $1.9 \%$ ) (Table 5.A42). While there does not appear to be an educational effect, there is a clear association with wealth, adults in the lowest wealth quartile report four times higher rates of activity limitation than those in the highest quartile $(5.7 \%$ versus $1.4 \%$ ) (Table 5.A43-5.A44).

\subsubsection{Fear of Falling}

Fear of falling (FOF) is a well recognised risk factor for falls. In an attempt to avoid fall-related morbidity and social embarrassment, many fearful older persons resort to activity restriction (31). Although in the short term curtailment of activities or avoidance may protect against falls, in the long term, activity restriction can diminish the physical and mental health of an older person and may further increase risk of future falls.

Fear of falling was measured in TILDA by asking respondents whether they are afraid of falling (yes or no), if so to what degree (somewhat afraid or very much afraid) and whether they limit their activities as a consequence of this fear.

One in four older Irish adults reports a fear of falling. The prevalence increases with age from $17 \%$ in those aged $50-64$ years up to $40 \%$ in those aged 75 years and older (Table 5.A39). At all ages, fear of falling is twice as common in women as men; for example $50 \%$ of women aged 75 years and older report a fear of falling compared to $27 \%$ of men of the same age. Thirty per cent adults with primary or no education report a fear of falling versus only $18 \%$ of those with third level education (Table 5.A40). There is also evidence of a wealth gradient with individuals in the lowest wealth quartile twice as likely to report a fear of falling as those in the highest quartile (Table 5.A41).

Overall $9.1 \%$ of older adults report that fear of falling limits daily activity. This rate is highest in those aged 75 years and older, where one in six restricts activity as a direct consequence of fear of falling. Women are twice as likely to restrict activity, as are those with primary or no education and those in the lowest wealth quartile (Table 5.A42-5.A44). 


\subsection{Medication Use and Polypharmacy}

Medication use in older adults requires particular attention both because of increasing numbers of medications and age-related physiological changes which predispose to side effects. The term 'polypharmacy' generally refers to the use of multiple medications (prescription and non-prescription) by a patient. Polypharmacy is widespread but is most common in the older population (32). Polypharmacy is associated with an increased risk of falls and fall-related injuries (33), delirium, decline in Activities of Daily Living (ADL's) and Instrumental Activities of Daily Living (IADL's) as well as increased mortality (34). A better understanding of medication use in older adults will inform future policy decisions on prescribing practices.

TILDA respondents were asked about all medication (prescription and non prescription) that they take on a regular basis (every day or every week). An inhome inventory of medication obtained by direct observation, was used as it is more reliable than self-report recall methods (35). We define 'polypharmacy' as the use of five or more medications.

Polypharmacy increases exponentially with age; from $12 \%$ in adults aged $50-64$ years to $41 \%$ in adults aged 75 years and older (Figure 5.9;Table 5.A45); rates are similar for men and women. Levels of polypharmacy are highest (30\%) in those with primary or no education, compared to those with third level education (15\%; Table 5.A46). Similarly, individuals in the lowest wealth quartile are more than twice as likely to report polypharmacy than individuals in the highest wealth quartile (31\% versus 14\%; Table 5.A47).

Older adults with medical cards are more than three times as likely to be taking more than five medications compared to adults without medical cover or with medical insurance ( $32 \%$ versus $9 \%$; Table $5 . A 48$ ). Although it is likely that some of this difference is caused by poorer health in those eligible for medical cards, preliminary analyses have shown that this association remains even after controlling for age and number of chronic illnesses (data not shown).

The risk of falls increases with increasing numbers of medications, from $15 \%$ in older adults not taking medications, up to $27 \%$ in those taking five or more medications (Table 5.A49). Education does not influence the association between polypharmacy and falls (Table 5.A50).

\subsection{Objective Measures of physical health}

Dedicated clinical research nurses conduct the objective health assessments in TILDA. The response rate to the health assessment is over $80 \%$ and all assessments will be completed by June 2011. For the purpose of this report, analyses are presented for the first 4572 cases. 
Figure 5.9: Number of medications taken by age and sex
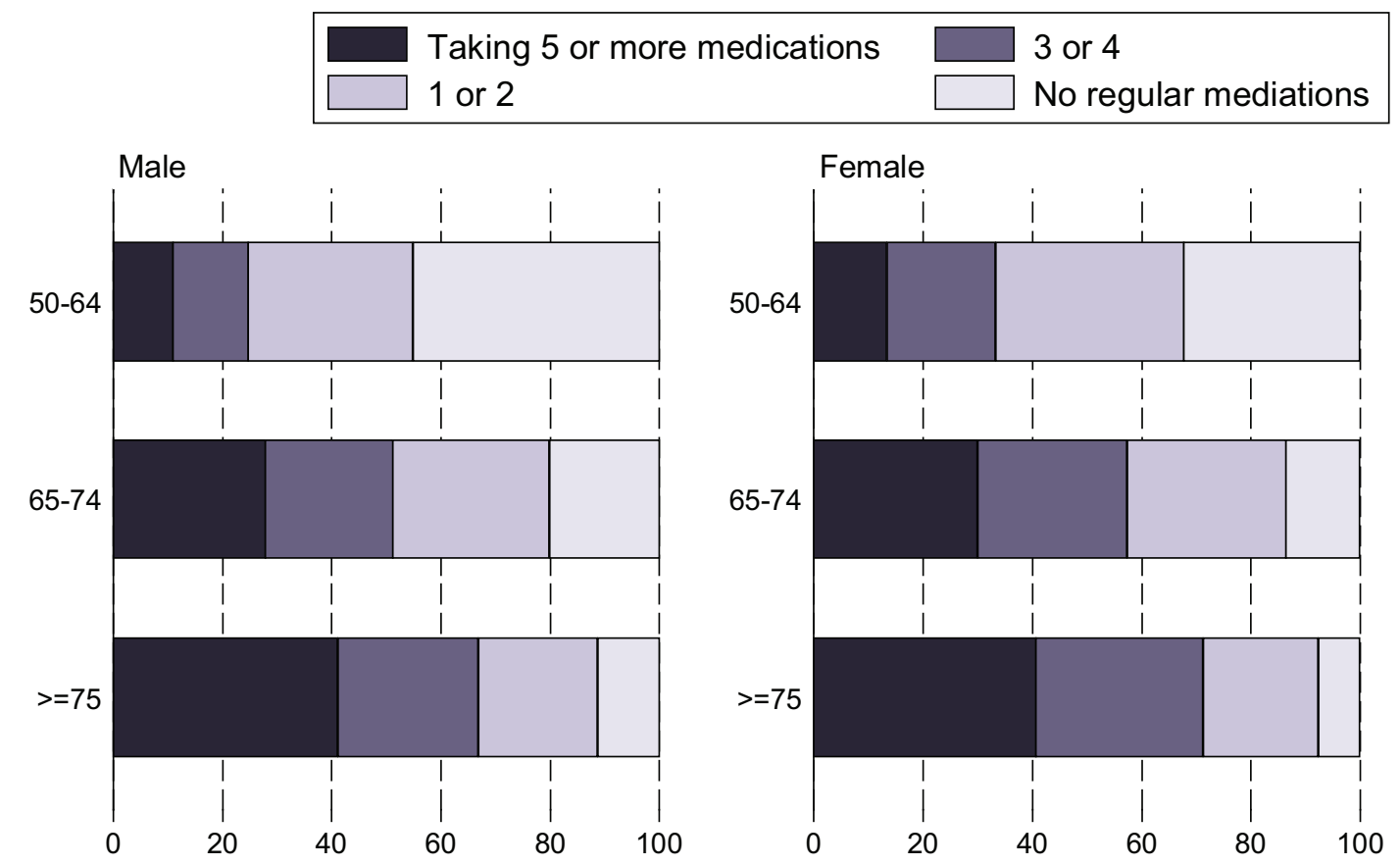

Note. $\mathrm{N}=8095 ;$ Missing obs $=83$

\subsubsection{Anthropometric measures and body mass index}

Obesity is a global health problem, affecting people of all ages (36). Obese people have increased mortality, although the relative risk of death associated with increasing body mass index (BMI) decreases with age (37). Obesity is associated with a number of conditions that interfere with health and well-being. These include the metabolic syndrome (obesity, insulin resistance, hypertension, gout, dislipidemia), diabetes, arthritis, pulmonary abnormalities, urinary incontinence, cataracts and cancers. Obesity exacerbates the age-related decline in physical function and impairs quality of life $(36,38)$. In contrast, being underweight is associated with a higher risk of anaemia and osteoporosis (39).

In TILDA, weight was measured using a SECA electronic floor scales. Height was measured using a SECA 240 wall mounted measuring rod. The respondent was asked to remove footwear, any heavy outer clothing and any head gear prior to the measurements. Body mass index (BMI) is calculated as the respondent's weight in kilograms divided by the square of their height in metres $\left(\mathrm{kg} / \mathrm{m}^{2}\right)$. The WHO classification system is used to categorise respondents as underweight (BMI $<18.5 \mathrm{~kg} /$ $\mathrm{m}^{2}$ ), Normal (BMI $\left.18.5-24.99 \mathrm{~kg} / \mathrm{m}^{2}\right)$, Overweight (BMI $25-29.99 \mathrm{~kg} / \mathrm{m}^{2}$ ) or Obese $(\geq$ $\left.30 \mathrm{~kg} / \mathrm{m}^{2}\right)(40)$. 
Three quarters of older Irish adults are overweight (44\%) or obese (34\%) with higher rates seen in men (Table 5.A51). Education is associated with BMI; $39 \%$ of older adults with primary or no education are obese compared to $29 \%$ with third level education (Table 5.A52). The association with wealth is similar, obesity rates are high in the lowest wealth quartile; for example $38 \%$ of adults aged 75 years and older in the lowest wealth quartile are obese compared to $17 \%$ of the same aged adults in the highest wealth quartile (Table 5.A53).

\subsubsection{Blood pressure}

Blood pressure was measured using the $\mathrm{OMRON}^{\mathrm{TM}}$ digital automatic blood pressure monitor with arm cuff (Model M10-IT). Three separate readings were taken one minute apart; the first two with the respondent seated and the third immediately after the respondent stood up. A mean value for seated blood pressure is created by averaging the first and second blood pressure readings. Blood pressure is categorised using the European Society of Cardiology (ESC) 2007 Guidelines for Cardiovascular Disease Prevention (41). Normal is categorised as systolic blood pressure (SBP) $<140 \mathrm{mmHg}$ and/or diastolic blood pressure (DBP) $<90 \mathrm{mmHg}$. High blood pressure (hypertension) is defined as SBP $\geq 140 \mathrm{mmHg}$ or $\mathrm{DBP} \geq 90 \mathrm{mmHg}$.

Nearly 1 in 4 older Irish adults (24\%) has objective evidence of hypertension according to the ESC guidelines. Rates are higher in men (25\%) than women (22\%). The highest rate of hypertension is in men aged $50-64$ years at $29 \%$ (Table $5 . A 54 a$ ). The association between education and objectively measured blood pressure is different for men and women. In women, third level education appears to be protective with lower levels of hypertension reported in this group ( $26 \%$ primary or no education; $22 \%$ second level education; $16 \%$ third level education). The opposite is seen in men for whom the highest prevalence of hypertension is in older adults with third level education (23\% primary/no education; $26 \%$ second level; $27 \%$ third level; Table 5.A54b). For both men and women the highest prevalence of hypertension is in adults belonging to the lowest wealth quartile (Table 5.A54c).

\subsubsection{Self report versus objective measurement}

Table 5.A55 presents the association between self-rated hypertension and objectively measured hypertension in older adults. Only $42 \%$ of older men who satisfied the ESC criteria for hypertension ${ }^{1}$ report a doctor's diagnosis of hypertension; $58 \%$ are therefore undiagnosed. A similar pattern is seen in women with hypertension in whom $49 \%$ of cases are undiagnosed.

1 The ESC criteria for hypertension recommend that blood pressure is measured during two or three separate visits separated by at least days or weeks. Blood pressure of TILDA respondents was measured three times but all three measurements were taken during a single health assessment, in common with similar epidemiological studies. 


\subsubsection{Osteoporosis}

In TILDA, the bone mass of a respondent's non-dominant foot was measured using quantitative ultrasound (Achilles Heel Ultrasound, Lunar, Madison, USA). The Achilles apparatus for heel evaluation measures both the broadband ultrasound attenuation (BUA) and the speed of sound (SOS), both of which provide an index of bone stiffness (SI). This parameter is a significantly better predictor of fracture than the BUA or the SOS alone (42). Osteoporosis is defined here by the 'Stiffness Index (SI)'. A respondent is considered to have osteoporosis if the $\mathrm{SI}$ is $\leq 65 \%$, osteopenia if the $\mathrm{SI}$ is between $65 \%$ and $86 \%$ and normal bone density if the $\mathrm{SI}$ is $>86 \%$ (43).

Overall $3 \%$ of men and $13 \%$ of women have objective evidence of osteoporosis. The prevalence increases with age from $8 \%$ in women aged $50-64$ years, to $34 \%$ in those aged 75 years and older (Table 5.A56a). An association with education is observed; $20 \%$ of women with primary/no education have objective evidence of osteoporosis compared to $11 \%$ of women with third level education (Table 5.A56b).

\subsubsection{Self report versus objective measurement}

Table 5.A57 presents the differences between self-rated osteoporosis and objectively measured osteoporosis in older adults. Only $34 \%$ of older women who have objective evidence of osteoporosis report a doctor's diagnosis of osteoporosis, $66 \%$ are therefore undiagnosed. The rate of under-diagnosis is even more striking in men; $100 \%$ of men with objective evidence of osteoporosis do not report a doctor's diagnosis of the condition.

\subsection{Conclusion}

This chapter has described the cross-sectional variations in disease prevalence and health behaviours, including differences between age groups, sex differences and the effect of education and wealth on observations. It has provided preliminary analyses of medication use and of some of the consequences of polypharmacy. As TILDA has both self-reported 'doctor diagnosed disease' and actual measurements of these diseases, we also presented preliminary comparisons of subjective and objective measures and evidence for underdiagnosis of some common conditions.

There is an age gradient for most cardiovascular and other disorders. Notable exceptions are lung disease, high cholesterol and cancer, which are most prevalent in adults aged between 65 and 74 years. Given that these are cross-sectional analyses, the distributions of diseases observed in the different age groups may be influenced by both cohort and survival effects. People born at different times may experience different environmental exposures which alter disease distributions. Longitudinal analysis will inform the relationship between age and disease prevalence in older adults. 
Some diseases vary in prevalence between men and women. For example hypertension, angina, and stroke are more common in men while osteoporosis, arthritis and high cholesterol are more common in women. Although women report far greater 'fear of falling', no difference in falls prevalence is observed between older men and women. In general, low levels of education are associated with higher disease prevalence except for urinary incontinence and cancer where no association is observed. Higher education is associated with better health screening, with the exception of the flu vaccination for which uptake is highest in individuals with primary or no education. This may be explained by reimbursement of GPs for vaccination of medical card holders. Breast screening is State funded for women aged between 50 and 64 years, this may explain the higher uptake in women in these age groups and in urban areas.

Some conditions are differently distributed by wealth, whereas others are not. The observed patterns by wealth may be influenced by cohort effects. Cardiovascular diseases in particular show linear trends, people in richer groups have less disease. There is no effect of wealth on cancer diagnosis or falls prevalence. Women in the richest group are far more likely to report a mammogram. Activity limitation associated with chronic conditions is more prevalent in individuals belonging to the poorest group.

Despite public information campaigns and efforts to increase awareness about the role of lifestyle factors in health, smoking and excessive alcohol consumption are common among older adults in Ireland, as are low levels of physical activity. Of particular concern is the high prevalence of several of these health-risk behaviours among those who are financially and educationally worse off.

TILDA uses directly observed information from individuals in their homes to establish estimates of medication use. The vast majority of older adults in Ireland use medications regularly and rates of polypharmacy are high. Overall 1 in 5 older adults takes five or more medications. This proportion rises to almost one in two of those aged 75 years and older. The risk of drug-drug interaction is therefore high. Future research will attempt to uncover the factors that contribute to polypharmacy and the risks associated with high medication use. Already our cross sectional analyses is yielding important information for policy makers and practitioners, by highlighting that older adults with medical cards are more than twice as likely to be taking polypharmacy as adults without cover or with medical insurance, thus possibly informing viable opportunities for improvement in drug safety among older adults.

The differences in self-reported hypertension and osteoporosis and measurements of same provides worrying evidence that under-diagnosis of these conditions is common and confirms the value of objective measurements in these types of studies. Although this lack of awareness is a significant concern, it is an opportunity both to influence policy and to evaluate the impact of policy changes in subsequent waves of TILDA. 


\section{References}

1. Marmot M, Ryff CD, Bumpass LL, Shipley M, Marks NF. Social inequalities in health: next questions and converging evidence. Soc Sci Med. 1997 Mar;44(6):90110.

2. Smith JP. Healthy bodies and thick wallets: the dual relation between health and economic status. J Econ Perspect. 1999 Spring;13(2):144-66.

3. Shulman LM, Pretzer-Aboff I, Anderson KE, Stevenson R, Vaughan CG, GruberBaldini AL, et al. Subjective report versus objective measurement of activities of daily living in Parkinson's disease. Mov Disord. 2006 Jun;21(6):794-9.

4. Morley JE, Flaherty JH. It's never too late: health promotion and illness prevention in older persons. J Gerontol A Biol Sci Med Sci. 2002 Jun;57(6):M338-42.

5. Benfante R, Reed D, Frank J. Does cigarette smoking have an independent effect on coronary heart disease incidence in the elderly? Am J Public Health. 1991 Jul;81(7):897-9.

6. Burns DM. Cigarette smoking among the elderly: disease consequences and the benefits of cessation. Am J Health Promot. 2000 Jul-Aug;14(6):357-61.

7. Moore AA, Hays RD, Greendale GA, Damesyn M, Reuben DB. Drinking habits among older persons: findings from the NHANES I Epidemiologic Followup Study (1982-84). National Health and Nutrition Examination Survey. J Am Geriatr Soc. 1999 Apr;47(4):412-6.

8. Mukamal KJ, Kuller LH, Fitzpatrick AL, Longstreth WT, Jr., Mittleman MA, Siscovick DS. Prospective study of alcohol consumption and risk of dementia in older adults. JAMA. 2003 Mar 19;289(11):1405-13.

9. Idler EL, Angel RJ. Self-rated health and mortality in the NHANES-I Epidemiologic Follow-up Study. Am J Public Health. 1990 Apr;80(4):446-52.

10. Central Statistics Office I. Principal Causes of Death in Ireland Cork2007; http:// www.cso.ie/statistics/principalcausesofdeath.htm].

11. Marmot M. Health, wealth and lifestyles of the older population in England: The 2002 English Longitudinal Study of Ageing. London: Institute for Fiscal Studies, December 2003; 2003; http://www.ifs.org.uk/elsa/report03/ch6.pdf].

12. Lewington $\mathrm{S}$. The importance of cholesterol, blood pressure and smoking for coronary heart disease. Eur Heart J. 2003 Oct;24(19):1703-4.

13. WHO. Global Health Risks: Mortality and burden of disease attributable to selected major risks. Geneva: WHO Press; 2009; http://www.who.int/healthinfo/ global_burden_disease/GlobalHealthRisks_report_full.pdf].

14. Issa SN, Sharma L. Epidemiology of osteoarthritis: an update. Curr Rheumatol Rep. 2006 Feb;8(1):7-15.

15. Reginster JY. The prevalence and burden of arthritis. Rheumatology (Oxford). 2002 Apr;41 Supp 1:3-6.

16. Fautrel $B$, Hilliquin $P$, Rozenberg $S$, Allaert FA, Coste $P$, Leclerc $A$, et al. Impact of osteoarthritis: results of a nationwide survey of 10,000 patients consulting for OA. Joint Bone Spine. 2005 May;72(3):235-40. 
17. Siris ES, Brenneman SK, Barrett-Connor E, Miller PD, Sajjan S, Berger ML, et al. The effect of age and bone mineral density on the absolute, excess, and relative risk of fracture in postmenopausal women aged 50-99: results from the National Osteoporosis Risk Assessment (NORA). Osteoporos Int. 2006;17(4):565-74.

18. Kanis JA, Johnell O, Oden A, Sembo I, Redlund-Johnell I, Dawson A, et al. Longterm risk of osteoporotic fracture in Malmo. Osteoporosis Int. 2000;11(8):669-74.

19. Nusbaum NJ. Aging and sensory senescence. South Med J. 1999 Mar;92(3):267-75.

20. Chia EM, Wang JJ, Rochtchina E, Mitchell P. Impact of multiple impairments on quality of life, hospitalisations and use of aged-care services. Med J Aust. 2006 May 1;184(9):478-9.

21. NCR. Cancer in Ireland 1994-2007: Annual Report of the National Cancer Registry. Dublin: National Cancer Registry; 2009; [http://www.ncri.ie/pubs/pubfiles/ summary_report_19942007.pdf].

22. Health Service Executive NCAOP, Department of Health and Children. Strategy to Prevent Falls and Fractures in Ireland's Ageing Population. 2008; [http://www. hse.ie/eng/services/Publications/services/Older/Strategy_to_Prevent_Falls_and_ Fractures_in_Ireland\%E2\%80\%99s_Ageing_Population_-_Full_report.pdf].

23. EU. EU citizens' attitudes towards alcohol. Brussels2010; [http://ec.europa.eu/ public_opinion/archives/ebs/ebs_331_en.pdf].

24. Mayfield D, McLeod G, Hall P. The CAGE questionnaire: validation of a new alcoholism screening instrument. Am J Psychiatry. 1974 Oct;131(10):1121-3.

25. Kitchens JM. Does this patient have an alcohol problem? JAMA. $1994 \mathrm{Dec}$ 14;272(22):1782-7.

26. Wagner EH, LaCroix AZ, Buchner DM, Larson EB. Effects of physical activity on health status in older adults. Observational studies. Annu Rev Public Health. 1992;13:451-68.

27. SLAN. SLAN 2007: Survey of Lifestyle, Attitudes and Nutrition in Ireland. Dublin: The Stationery Office, Dublin; 2007; [http://www.slan06.ie/SLAN2007MainReport. pdf].

28. Craig $C L$, Marshall $A L$, Sjostrom $M$, Bauman $A E$, Booth $M L$, Ainsworth $B E$, et al. International physical activity questionnaire: 12-country reliability and validity. Med Sci Sports Exerc. 2003 Aug;35(8):1381-95.

29. Hajjar RR. Psychosocial impact of urinary incontinence in the elderly population. Clin Geriatr Med. 2004 Aug;20(3):553-64, viii.

30. Chiarelli PE, Mackenzie LA, Osmotherly PG. Urinary incontinence is associated with an increase in falls: a systematic review. Aust J Physiother. 2009;55(2):89-95.

31. Deshpande N, Metter EJ, Bandinelli S, Lauretani F, Windham BG, Ferrucci L. Psychological, physical, and sensory correlates of fear of falling and consequent activity restriction in the elderly: the InCHIANTI study. Am J Phys Med Rehabil. 2008 May;87(5):354-62.

32. Haider SI, Johnell K, Thorslund M, Fastbom J. Trends in polypharmacy and potential drug-drug interactions across educational groups in elderly patients in Sweden for the period 1992 - 2002. Int J Clin Pharmacol Ther. 2007 Dec;45(12):643-53. 
33. Boyle N, Naganathan V, Cumming RG. Medication and falls: risk and optimization. Clin Geriatr Med. 2010 Nov;26(4):583-605.

34. Jyrkka J, Enlund H, Korhonen MJ, Sulkava R, Hartikainen S. Polypharmacy status as an indicator of mortality in an elderly population. Drugs Aging. 2009;26(12):1039-48.

35. Qato DM, Schumm LP, Johnson M, Mihai A, Lindau ST. Medication data collection and coding in a home-based survey of older adults. J Gerontol B Psychol Sci Soc Sci. 2009 Nov;64 Suppl 1:i86-93.

36. Kopelman PG. Obesity as a medical problem. Nature. 2000 Apr 6;404(6778):63543.

37. Calle EE, Thun MJ, Petrelli JM, Rodriguez C, Heath CW, Jr. Body-mass index and mortality in a prospective cohort of U.S. adults. N Engl J Med. 1999 Oct 7;341(15):1097-105.

38. Villareal DT, Apovian CM, Kushner RF, Klein S. Obesity in older adults: technical review and position statement of the American Society for Nutrition and NAASO, The Obesity Society. Am J Clin Nutr. 2005 Nov;82(5):923-34.

39. Coin A, Sergi G, Beninca P, Lupoli L, Cinti G, Ferrara L, et al. Bone mineral density and body composition in underweight and normal elderly subjects. Osteoporos Int. 2000;11(12):1043-50.

40. WHO. Physical status: the use and interpretation of anthropometry. Report of a WHO Expert Committe. Geneva1995.

41. Graham I, Atar D, Borch-Johnsen K, Boysen G, Burell G, Cifkova R, et al. European guidelines on cardiovascular disease prevention in clinical practice: executive summary. Fourth Joint Task Force of the European Society of Cardiology and other societies on cardiovascular disease prevention in clinical practice (constituted by representatives of nine societies and by invited experts). Eur J Cardiovasc Prev Rehabil. 2007 Sep;14 Suppl 2:E1-40.

42. Schott AM, Weill-Engerer S, Hans D, Duboeuf F, Delmas PD, Meunier PJ. Ultrasound discriminates patients with hip fracture equally well as dual energy X-ray absorptiometry and independently of bone mineral density. J Bone Miner Res. 1995 Feb;10(2):243-9.

43. Varenna M, Sinigaglia L, Adami S, Giannini S, Isaia G, Maggi S, et al. Association of quantitative heel ultrasound with history of osteoporotic fractures in elderly men: the ESOPO study. Osteoporos Int. 2005 Dec;16(12):1749-54. 


\section{Appendix 5A: Tables on physical and behavioural health of older Irish adults}

Table 5.A1: Self-rated health by age and sex

\begin{tabular}{|c|c|c|c|c|c|c|c|c|c|c|c|c|}
\hline & \multicolumn{2}{|c|}{ Excellent } & \multicolumn{2}{|c|}{ Very good } & \multicolumn{2}{|c|}{ Good } & \multicolumn{2}{|c|}{ Fair } & \multicolumn{2}{|c|}{ Poor } & \multirow{2}{*}{ Total } & \multirow{2}{*}{$\begin{array}{r}\text { Numbe } \\
\text { in } \\
\text { sample }\end{array}$} \\
\hline & $\%$ & $95 \% \mathrm{Cl}$ & $\%$ & $95 \% \mathrm{Cl}$ & $\%$ & $95 \% \mathrm{Cl}$ & $\%$ & $95 \% \mathrm{Cl}$ & $\%$ & $95 \% \mathrm{Cl}$ & & \\
\hline \multicolumn{13}{|l|}{ Male } \\
\hline $50-64$ & 15 & $(14-17)$ & 31 & $(29-34)$ & 32 & $(29-34)$ & 17 & $(16-19)$ & 4 & $(3-5)$ & 100 & 2080 \\
\hline $65-74$ & 12 & $(10-14)$ & 25 & $(22-28)$ & 35 & $(32-38)$ & 20 & $(18-23)$ & 8 & $(6-9)$ & 100 & 1070 \\
\hline$>=75$ & 9 & $(7-11)$ & 24 & $(20-27)$ & 36 & $(32-41)$ & 26 & $(22-30)$ & 6 & $(4-8)$ & 100 & 598 \\
\hline Total & 14 & (12-15) & 29 & $(27-30)$ & 33 & $(31-35)$ & 19 & $(18-21)$ & 5 & $(5-6)$ & 100 & 3748 \\
\hline \multicolumn{13}{|c|}{ Female } \\
\hline $50-64$ & 18 & $(17-20)$ & 29 & $(27-31)$ & 32 & $(30-34)$ & 15 & $(14-17)$ & 5 & $(4-6)$ & 100 & 2587 \\
\hline $65-74$ & 13 & $(11-15)$ & 26 & $(23-28)$ & 34 & $(31-37)$ & 21 & $(19-24)$ & 6 & $(5-8)$ & 100 & 1093 \\
\hline$>=75$ & 8 & $(6-10)$ & 24 & $(21-27)$ & 33 & $(29-37)$ & 28 & $(25-32)$ & 7 & $(5-9)$ & 100 & 749 \\
\hline Total & 15 & (14-16) & 27 & (26-29) & 33 & (31-34) & 19 & $(18-21)$ & 6 & $(5-7)$ & 100 & 4429 \\
\hline \multicolumn{13}{|l|}{ Total } \\
\hline $50-64$ & 17 & $(16-18)$ & 30 & $(29-32)$ & 32 & $(30-33)$ & 16 & $(15-18)$ & 5 & $(4-5)$ & 100 & 4667 \\
\hline $65-74$ & 12 & $(11-14)$ & 25 & $(23-27)$ & 35 & $(33-37)$ & 21 & $(19-23)$ & 7 & $(6-8)$ & 100 & 2163 \\
\hline$>=75$ & 8 & $(7-10)$ & 24 & $(21-26)$ & 34 & $(32-37)$ & 27 & $(25-30)$ & 7 & $(5-8)$ & 100 & 1347 \\
\hline Total & 14 & (13-15) & 28 & (27-29) & 33 & $(32-34)$ & 19 & $(18-20)$ & 6 & $(5-6)$ & 100 & 8177 \\
\hline
\end{tabular}

Note. $\mathrm{Cl}=$ confidence interval; Missing observations $=0.01 \%$ 
Table 5.A2: Self-rated health by age and education

\begin{tabular}{|c|c|c|c|c|c|c|c|c|c|c|c|}
\hline \multicolumn{2}{|c|}{ Excellent } & \multicolumn{2}{|c|}{ Very good } & \multicolumn{2}{|c|}{ Good } & \multicolumn{2}{|c|}{ Fair } & \multicolumn{2}{|c|}{ Poor } & \multicolumn{2}{|r|}{ Number } \\
\hline$\%$ & $95 \% \mathrm{Cl}$ & $\%$ & $95 \%$ Cl & $\%$ & $95 \% \mathrm{Cl}$ & $\%$ & $95 \% \mathrm{Cl}$ & $\%$ & $95 \% \mathrm{Cl}$ & & sample \\
\hline
\end{tabular}

Primary/none

\begin{tabular}{lllllllllllll}
$50-64$ & 9 & $(8-12)$ & 22 & $(20-25)$ & 34 & $(30-37)$ & 26 & $(23-29)$ & 9 & $(7-11)$ & 100 & 956 \\
$65-74$ & 9 & $(7-11)$ & 22 & $(19-25)$ & 34 & $(31-38)$ & 26 & $(23-29)$ & 9 & $(7-12)$ & 100 & 865 \\
$>=75$ & 5 & $(4-7)$ & 23 & $(20-26)$ & 33 & $(30-37)$ & 31 & $(28-35)$ & 8 & $(6-10)$ & 100 & 684 \\
\hline Total & 8 & $(7-9)$ & 22 & $(21-24)$ & 34 & $(32-36)$ & 28 & $(26-29)$ & 9 & $(8-10)$ & 100 & 2505 \\
\hline
\end{tabular}

\section{Secondary}

\begin{tabular}{lllllllllllll}
$50-64$ & 17 & $(15-19)$ & 32 & $(30-34)$ & 33 & $(31-35)$ & 14 & $(13-16)$ & 3 & $(3-4)$ & 100 & 2119 \\
$65-74$ & 14 & $(11-16)$ & 28 & $(25-31)$ & 37 & $(33-41)$ & 16 & $(14-19)$ & 5 & $(4-7)$ & 100 & 728 \\
$>=75$ & 11 & $(8-15)$ & 24 & $(21-28)$ & 38 & $(34-43)$ & 21 & $(18-25)$ & 5 & $(3-8)$ & 100 & 417 \\
\hline Total & 16 & $(14-17)$ & 30 & $(29-32)$ & 34 & $(33-36)$ & 15 & $(14-17)$ & 4 & $(3-5)$ & 100 & 3264
\end{tabular}

\section{Third/higher}

\begin{tabular}{lllllllllllll}
$50-64$ & 24 & $(22-26)$ & 35 & $(32-37)$ & 27 & $(25-30)$ & 11 & $(10-13)$ & 3 & $(2-4)$ & 100 & 1592 \\
$65-74$ & 22 & $(19-26)$ & 30 & $(27-34)$ & 30 & $(27-34)$ & 15 & $(12-18)$ & 3 & $(2-4)$ & 100 & 569 \\
$>=75$ & 21 & $(16-26)$ & 30 & $(25-37)$ & 32 & $(26-38)$ & 14 & $(10-20)$ & 3 & $(1-6)$ & 100 & 243 \\
\hline Total & 23 & $(21-25)$ & 34 & $(32-36)$ & 28 & $(26-30)$ & 12 & $(11-14)$ & 3 & $(2-3)$ & 100 & 2404 \\
\hline
\end{tabular}

\section{Total}

\begin{tabular}{lcccccccccccc}
$50-64$ & 17 & $(16-18)$ & 30 & $(29-32)$ & 32 & $(30-33)$ & 16 & $(15-18)$ & 5 & $(4-5)$ & 100 & 4667 \\
$65-74$ & 12 & $(11-14)$ & 25 & $(23-27)$ & 35 & $(33-37)$ & 21 & $(19-23)$ & 7 & $(6-8)$ & 100 & 2163 \\
$>=75$ & 8 & $(7-10)$ & 24 & $(21-26)$ & 34 & $(32-37)$ & 27 & $(25-30)$ & 7 & $(5-8)$ & 100 & 1347 \\
\hline Total & 14 & $(13-15)$ & 28 & $(27-29)$ & 33 & $(32-34)$ & 19 & $(18-20)$ & 6 & $(5-6)$ & 100 & 8177
\end{tabular}

Note. $\mathrm{Cl}=$ confidence interval; Missing observations $=0.01 \%$ 
Table 5.A3: Self-rated health by age and wealth

\begin{tabular}{|c|c|c|c|c|c|c|c|c|c|c|c|c|}
\hline & \multicolumn{2}{|c|}{ Excellent } & \multicolumn{2}{|c|}{ Very good } & \multicolumn{2}{|c|}{ Good } & \multicolumn{2}{|c|}{ Fair } & \multicolumn{2}{|c|}{ Poor } & \multirow{2}{*}{ Total } & \multirow{2}{*}{$\begin{array}{r}\text { Number } \\
\text { in } \\
\text { sample }\end{array}$} \\
\hline & $\%$ & $95 \% \mathrm{Cl}$ & $\%$ & $95 \% \mathrm{Cl}$ & $\%$ & $95 \% \mathrm{Cl}$ & $\%$ & $95 \% \mathrm{Cl}$ & $\%$ & $95 \% \mathrm{Cl}$ & & \\
\hline \multicolumn{13}{|c|}{ Lowest } \\
\hline $50-64$ & 10 & $(8-13)$ & 24 & $(20-28)$ & 31 & $(28-36)$ & 24 & $(20-28)$ & 11 & $(8-14)$ & 100 & 567 \\
\hline $65-74$ & 7 & $(5-11)$ & 22 & $(17-29)$ & 37 & $(31-44)$ & 25 & $(20-31)$ & 8 & $(5-12)$ & 100 & 243 \\
\hline$>=75$ & 4 & $(2-7)$ & 23 & $(17-31)$ & 29 & $(22-37)$ & 34 & $(27-42)$ & 10 & $(6-16)$ & 100 & 178 \\
\hline Total & 8 & $(6-10)$ & 23 & $(20-27)$ & 32 & $(29-36)$ & 27 & $(24-30)$ & 10 & $(8-12)$ & 100 & 988 \\
\hline \multicolumn{13}{|l|}{ 2nd } \\
\hline $50-64$ & 14 & $(11-17)$ & 28 & $(24-32)$ & 31 & $(27-35)$ & 20 & $(17-24)$ & 7 & $(5-10)$ & 100 & 586 \\
\hline $65-74$ & 13 & $(9-17)$ & 19 & $(14-24)$ & 43 & $(37-49)$ & 19 & $(14-24)$ & 8 & $(5-12)$ & 100 & 268 \\
\hline$>=75$ & 6 & $(3-12)$ & 29 & $(20-38)$ & 34 & $(25-44)$ & 23 & $(17-31)$ & 8 & $(4-15)$ & 100 & 145 \\
\hline Total & 12 & $(10-14)$ & 26 & (23-29) & 34 & $(31-38)$ & 20 & $(18-23)$ & 7 & (6-9) & 100 & 999 \\
\hline \multicolumn{13}{|l|}{ 3rd } \\
\hline $50-64$ & 16 & $(13-19)$ & 34 & $(30-38)$ & 35 & $(30-39)$ & 12 & $(9-15)$ & 4 & $(2-6)$ & 100 & 590 \\
\hline $65-74$ & 15 & $(11-21)$ & 28 & $(23-34)$ & 34 & $(28-41)$ & 18 & $(13-24)$ & 5 & $(3-9)$ & 100 & 262 \\
\hline$>=75$ & 11 & $(5-23)$ & 26 & $(17-37)$ & 37 & $(28-48)$ & 21 & $(15-30)$ & 4 & $(1-11)$ & 100 & 123 \\
\hline Total & 15 & $(12-18)$ & 31 & $(28-35)$ & 35 & $(32-38)$ & 15 & $(13-18)$ & 4 & (3-6) & 100 & 975 \\
\hline \multicolumn{13}{|c|}{ Highest } \\
\hline $50-64$ & 26 & $(22-30)$ & 35 & $(31-40)$ & 29 & $(25-33)$ & 9 & $(7-12)$ & 1 & $(0-2)$ & 100 & 634 \\
\hline $65-74$ & 23 & $(18-30)$ & 29 & $(24-36)$ & 32 & $(26-39)$ & 13 & $(9-19)$ & 1 & $(0-4)$ & 100 & 258 \\
\hline$>=75$ & 21 & $(14-32)$ & 26 & $(18-36)$ & 33 & $(23-44)$ & 13 & $(4-33)$ & 7 & $(4-13)$ & 100 & 95 \\
\hline Total & 25 & $(22-29)$ & 33 & $(30-37)$ & 30 & $(27-33)$ & 10 & $(8-13)$ & 2 & $(1-3)$ & 100 & 987 \\
\hline \multicolumn{13}{|l|}{ Total } \\
\hline $50-64$ & 17 & $(15-18)$ & 30 & $(29-32)$ & 32 & $(30-33)$ & 16 & $(15-18)$ & 5 & $(4-5)$ & 100 & 4667 \\
\hline $65-74$ & 12 & $(11-14)$ & 26 & $(24-28)$ & 34 & $(32-36)$ & 21 & $(19-23)$ & 7 & (6-9) & 100 & 2163 \\
\hline$>=75$ & 8 & $(7-10)$ & 24 & $(22-27)$ & 34 & $(31-37)$ & 28 & $(25-31)$ & 6 & $(5-8)$ & 100 & 1347 \\
\hline Total & 14 & (13-15) & 28 & $(27-29)$ & 33 & $(32-34)$ & 20 & $(19-21)$ & 6 & $(5-6)$ & 100 & 8177 \\
\hline
\end{tabular}

Note. $\mathrm{Cl}=$ confidence interval; Missing observations $=0.01 \%$ 
Table 5.A4: Cardiovascular risk factors by age and sex

\begin{tabular}{|c|c|c|c|c|c|c|}
\hline & \multicolumn{2}{|c|}{$\begin{array}{l}\text { High blood pressure } \\
\text { - self report }\end{array}$} & \multicolumn{2}{|c|}{$\begin{array}{c}\text { Abnormal Heart } \\
\text { Rhythm }\end{array}$} & \multicolumn{2}{|c|}{ High cholesterol } \\
\hline & $\%$ & $(95 \% \mathrm{Cl})$ & $\%$ & $(95 \% \mathrm{Cl})$ & $\%$ & $(95 \% \mathrm{CI})$ \\
\hline \multicolumn{7}{|l|}{ Male } \\
\hline $50-64$ & 29.9 & $(27.9-32.1)$ & 5.4 & $(4.5-6.5)$ & 36.5 & $(34.3-38.8)$ \\
\hline $65-74$ & 44.1 & $(40.9-47.3)$ & 10.2 & $(8.5-12.4)$ & 37.5 & $(34.4-40.6)$ \\
\hline$>=75$ & 47.9 & $(43.7-52.1)$ & 14.2 & $(11.4-17.6)$ & 28.5 & $(24.9-32.4)$ \\
\hline Total & 36.0 & (34.4-37.7) & 7.9 & (7.0-8.9) & 35.5 & (33.8-37.3) \\
\hline \multicolumn{7}{|c|}{ Female } \\
\hline $50-64$ & 29.5 & $(27.7-31.3)$ & 4.3 & $(3.5-5.2)$ & 36.5 & $(34.6-38.5)$ \\
\hline $65-74$ & 46.2 & $(43.1-49.3)$ & 7.0 & $(5.6-8.7)$ & 46.9 & $(43.6-50.1)$ \\
\hline$>=75$ & 57.5 & (53.9-61.1) & 11.3 & (9.1-13.9) & 38.5 & $(34.6-42.6)$ \\
\hline Total & 39.2 & (37.7-40.8) & 6.4 & $(5.6-7.2)$ & 39.3 & (37.7-41.0) \\
\hline \multicolumn{7}{|l|}{ Total } \\
\hline $50-64$ & 29.7 & $(28.4-31.1)$ & 4.9 & $(4.2-5.5)$ & 36.5 & $(35.0-38.1)$ \\
\hline $65-74$ & 45.2 & $(42.9-47.4)$ & 8.6 & (7.4-9.9) & 42.3 & (39.8-44.7) \\
\hline$>=75$ & 53.7 & $(50.7-56.6)$ & 12.4 & $(10.7-14.4)$ & 34.5 & $(31.6-37.5)$ \\
\hline Total & 37.7 & (36.6-38.9) & 7.1 & (6.5-7.7) & 37.5 & (36.2-38.8) \\
\hline
\end{tabular}


Table 5.A5: Cardiovascular risk factors by age and education

\begin{tabular}{|c|c|c|c|c|c|c|}
\hline & \multicolumn{2}{|c|}{$\begin{array}{c}\text { High blood pressure } \\
\text { - self report }\end{array}$} & \multicolumn{2}{|c|}{$\begin{array}{l}\text { Abnormal Heart } \\
\text { Rhythm }\end{array}$} & \multicolumn{2}{|c|}{ High cholesterol } \\
\hline & $\%$ & $(95 \% \mathrm{Cl})$ & $\%$ & $(95 \% \mathrm{Cl})$ & $\%$ & $(95 \% \mathrm{Cl})$ \\
\hline \multicolumn{7}{|c|}{ Primary/none } \\
\hline $50-64$ & 34.6 & $(31.6-37.7)$ & 4.9 & $(3.7-6.5)$ & 35.7 & $(32.5-39.1)$ \\
\hline $65-74$ & 49.0 & $(45.7-52.4)$ & 7.7 & $(6.1-9.8)$ & 39.6 & $(36.0-43.2)$ \\
\hline$>=75$ & 55.0 & $(51.0-58.9)$ & 11.8 & $(9.6-14.5)$ & 33.4 & $(29.6-37.4)$ \\
\hline Total & 45.4 & (43.3-47.4) & 7.9 & (6.9-9.1) & 36.1 & (33.9-38.4) \\
\hline \multicolumn{7}{|c|}{ Secondary } \\
\hline $50-64$ & 28.4 & $(26.5-30.4)$ & 4.9 & $(4.0-6.0)$ & 35.8 & $(33.6-38.0)$ \\
\hline $65-74$ & 41.7 & $(38.0-45.6)$ & 9.3 & (7.4-11.7) & 44.8 & $(41.1-48.7)$ \\
\hline$>=75$ & 50.5 & $(45.5-55.4)$ & 12.5 & $(9.7-16.0)$ & 33.9 & $(29.4-38.7)$ \\
\hline Total & 33.3 & $(31.7-35.0)$ & 6.6 & $(5.7-7.5)$ & 37.3 & (35.6-39.1) \\
\hline \multicolumn{7}{|c|}{ Third/higher } \\
\hline $50-64$ & 27.4 & $(25.3-29.6)$ & 4.6 & $(3.7-5.8)$ & 39.2 & $(36.7-41.7)$ \\
\hline $65-74$ & 40.6 & $(36.5-44.9)$ & 9.3 & $(7.2-12.1)$ & 45.2 & $(41.0-49.4)$ \\
\hline$>=75$ & 52.7 & (46.4-58.9) & 16.8 & $(12.6-22.2)$ & 45.2 & $(39.0-51.6)$ \\
\hline Total & 32.1 & $(30.3-34.0)$ & 6.6 & (5.7-7.7) & 40.8 & (38.8-42.9) \\
\hline \multicolumn{7}{|l|}{ Total } \\
\hline $50-64$ & 29.7 & $(28.4-31.1)$ & 4.9 & $(4.2-5.5)$ & 36.5 & $(35.0-38.1)$ \\
\hline $65-74$ & 45.2 & $(42.9-47.4)$ & 8.6 & $(7.4-9.9)$ & 42.3 & $(39.8-44.7)$ \\
\hline$>=75$ & 53.7 & $(50.7-56.6)$ & 12.4 & (10.7-14.4) & 34.5 & $(31.6-37.5)$ \\
\hline Total & 37.7 & (36.6-38.9) & 7.1 & (6.5-7.7) & 37.5 & (36.2-38.8) \\
\hline
\end{tabular}


Table 5.A6: Cardiovascular risk factors by age and wealth

\begin{tabular}{|c|c|c|c|c|c|c|}
\hline & \multicolumn{2}{|c|}{$\begin{array}{c}\text { High blood pressure - } \\
\text { self report }\end{array}$} & \multicolumn{2}{|c|}{$\begin{array}{l}\text { Abnormal Heart } \\
\text { Rhythm }\end{array}$} & \multicolumn{2}{|c|}{ High cholesterol } \\
\hline & $\%$ & $(95 \% \mathrm{Cl})$ & $\%$ & $(95 \% \mathrm{Cl})$ & $\%$ & (95\% CI) \\
\hline \multicolumn{7}{|c|}{ Lowest } \\
\hline $50-64$ & 31.5 & $(27.5-35.7)$ & 3.3 & $(1.9-5.4)$ & 29.3 & $(25.3-33.7)$ \\
\hline $65-74$ & 48.2 & $(41.2-55.3)$ & 8.4 & $(5.3-13.0)$ & 36.4 & $(29.5-43.9)$ \\
\hline$>=75$ & 51.9 & (44.1-59.6) & 11.0 & (7.0-16.9) & 25.8 & (19.1-34.0) \\
\hline Total & 40.5 & (37.0-44.1) & 6.4 & $(4.9-8.4)$ & 30.0 & (26.7-33.5) \\
\hline \multicolumn{7}{|l|}{ 2nd } \\
\hline $50-64$ & 32.9 & $(28.8-37.3)$ & 5.0 & $(3.4-7.3)$ & 37.8 & $(33.7-42.2)$ \\
\hline $65-74$ & 50.1 & $(43.5-56.6)$ & 10.1 & $(6.7-15.0)$ & 41.8 & $(35.3-48.6)$ \\
\hline$>=75$ & 53.4 & $(43.8-62.8)$ & 19.1 & (12.1-28.9) & 41.9 & $(32.0-52.6)$ \\
\hline Total & 41.1 & $(37.5-44.7)$ & 9.1 & (7.0-11.6) & 39.6 & $(36.0-43.4)$ \\
\hline \multicolumn{7}{|l|}{ 3rd } \\
\hline $50-64$ & 29.6 & (25.7-33.9) & 5.4 & $(3.7-7.7)$ & 39.1 & $(34.5-43.8)$ \\
\hline $65-74$ & 38.3 & $(31.9-45.0)$ & 10.5 & (6.9-15.5) & 46.1 & $(38.8-53.5)$ \\
\hline$>=75$ & 56.4 & $(46.1-66.2)$ & 16.4 & $(10.7-24.4)$ & 34.6 & $(24.6-46.1)$ \\
\hline Total & 36.0 & (32.4-39.9) & 8.4 & (6.7-10.5) & 40.1 & (36.5-43.8) \\
\hline \multicolumn{7}{|c|}{ Highest } \\
\hline $50-64$ & 27.2 & $(23.6-31.2)$ & 4.9 & $(3.4-7.0)$ & 42.2 & $(38.2-46.4)$ \\
\hline $65-74$ & 39.4 & $(32.5-46.7)$ & 6.7 & $(4.1-10.7)$ & 51.4 & $(43.9-58.7)$ \\
\hline$>=75$ & 48.2 & $(36.4-60.2)$ & 18.5 & $(10.6-30.4)$ & 38.4 & $(27.1-51.1)$ \\
\hline Total & 32.2 & (28.9-35.6) & 6.7 & $(5.0-8.8)$ & 43.9 & $(40.4-47.6)$ \\
\hline \multicolumn{7}{|l|}{ Total } \\
\hline $50-64$ & 29.7 & $(28.3-31.2)$ & 5.0 & $(4.3-5.7)$ & 36.8 & $(35.2-38.4)$ \\
\hline $65-74$ & 45.0 & $(42.6-47.4)$ & 8.7 & $(7.5-10.2)$ & 42.7 & $(40.2-45.3)$ \\
\hline$>=75$ & 54.4 & (51.1-57.6) & 11.8 & $(10.0-13.9)$ & 34.6 & $(31.4-38.0)$ \\
\hline Total & 38.9 & $(37.7-40.2)$ & 7.4 & $(6.8-8.1)$ & 37.7 & (36.2-39.1) \\
\hline
\end{tabular}


Table 5.A7: Prevalence of cardiovascular disease by age and sex

\begin{tabular}{|c|c|c|c|c|c|c|c|c|c|c|c|}
\hline & \multicolumn{2}{|c|}{ Angina } & \multicolumn{2}{|c|}{ Heart attack } & \multicolumn{2}{|c|}{ Heart failure } & \multicolumn{2}{|r|}{ TIA } & \multicolumn{2}{|c|}{ Diabetes } & \multirow{2}{*}{$\begin{array}{l}\text { Stroke } \\
\%(95 \% \mathrm{CI})\end{array}$} \\
\hline & $\%$ & (95\% CI) & $\%$ & $(95 \% \mathrm{Cl})$ & $\%$ & $(95 \% \mathrm{CI})$ & $\%$ & $(95 \% \mathrm{Cl})$ & $\%$ & $(95 \% \mathrm{Cl})$ & \\
\hline \multicolumn{12}{|l|}{ Male } \\
\hline $50-64$ & 3.3 & $(2.6-4.2)$ & 3.8 & $(3.0-4.7)$ & 1.2 & $(0.8-1.8)$ & 0.9 & $(0.6-1.5)$ & 7.2 & $(6.2-8.4)$ & 0.7 (0.4-1.1) \\
\hline $65-74$ & 10.4 & $(8.5-12.5)$ & 9.9 & (8.2-11.9) & 1.9 & $(1.2-3.0)$ & 2.5 & $(1.8-3.7)$ & 13.1 & $(11.2-15.3)$ & $3.2(2.3-4.6)$ \\
\hline$>=75$ & 13.9 & (11.4-16.9) & 15.3 & $(12.5-18.6)$ & 2.3 & $(1.3-4.2)$ & 4.7 & $(3.2-6.7)$ & 13.9 & $(11.2-17.1)$ & $4.4(3.0-6.5)$ \\
\hline Total & 6.6 & (5.8-7.4) & 7.0 & (6.2-7.9) & 1.5 & $(1.2-2.0)$ & 1.9 & $(1.5-2.4)$ & 9.6 & (8.7-10.6) & 1.8 (1.4-2.3) \\
\hline
\end{tabular}

Female

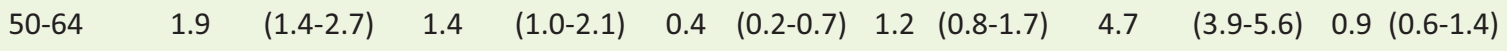

$\begin{array}{lllllllllllll}65-74 & 6.6 & (5.2-8.4) & 3.3 & (2.3-4.7) & 1.1 & (0.6-2.1) & 2.4 & (1.6-3.5) & 8.6 & (7.0-10.5) & 2.3 & (1.5-3.4)\end{array}$

>=75 $\quad 11.1 \quad(8.7-14.0) \quad 5.3 \quad(3.8-7.4) \quad 1.3 \quad(0.6-2.4) \quad 5.5 \quad(4.0-7.5) \quad 9.3 \quad(7.2-11.9) \quad 2.3 \quad(1.3-3.9)$

\begin{tabular}{llllllllllllll}
\hline Total & 4.9 & $(4.2-5.8)$ & 2.7 & $(2.2-3.3)$ & 0.7 & $(0.5-1.1)$ & 2.4 & $(1.9-2.9)$ & 6.5 & (5.8-7.4) & 1.5 & $(1.2-2.0)$
\end{tabular}

Total

$\begin{array}{lllllllllllll}50-64 & 2.6 & (2.2-3.2) & 2.6 & (2.1-3.2) & 0.8 & (0.6-1.1) & 1.1 & (0.8-1.4) & 6.0 & (5.3-6.7) & 0.8 & (0.6-1.1)\end{array}$

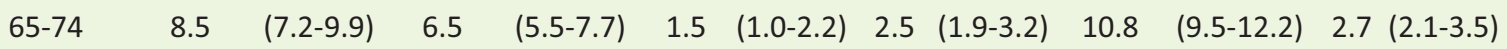

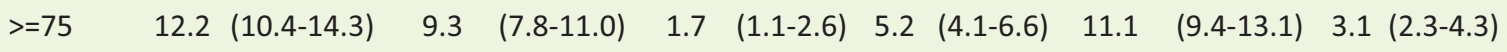

\begin{tabular}{lllllllllllll}
\hline Total & 5.7 & $(5.2-6.3)$ & 4.7 & $(4.3-5.3)$ & 1.1 & $(0.9-1.4)$ & 2.1 & $(1.8-2.5)$ & 8.0 & $(7.5-8.6)$ & 1.7 & $(1.4-2.0)$
\end{tabular}


Table 5.A8: Prevalence of cardiovascular disease by age and education

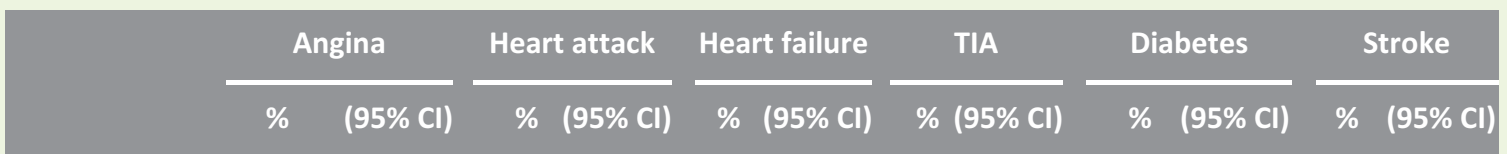

\section{Primary/none}

\begin{tabular}{|c|c|c|c|c|c|c|c|c|c|}
\hline $50-64$ & 4.7 & $(3.5-6.2)$ & $4.7 \quad(3.5-6.3)$ & 1.6 & $(1.0-2.7)$ & $1.1(0.6-2.0)$ & $8.4(6.8-10.3)$ & 1.1 & $(0.6-1.9)$ \\
\hline $65-74$ & 9.6 & $(7.7-11.8)$ & $7.0 \quad(5.5-9.0)$ & 1.5 & $(0.9-2.5)$ & $2.8(1.9-4.1)$ & $11.8(9.8-14.2)$ & 3.1 & $(2.1-4.5)$ \\
\hline$=75$ & 12.4 & $(10.0-15.3)$ & $9.3(7.3-11.8)$ & 1.7 & $(0.9-3.0)$ & 5.1 (3.7-7.0) & $11.8(9.5-14.5)$ & 3.5 & $(2.4-5.2)$ \\
\hline tal & 8.6 & (7.5-9.8) & $6.9 \quad(5.9-8.0)$ & 1.6 & $(1.2-2.2)$ & $2.9(2.3-3.6)$ & 10.5 (9.3-11.7) & 2.5 & (1.9-3.2) \\
\hline
\end{tabular}

\section{Secondary}

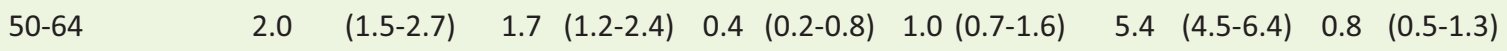

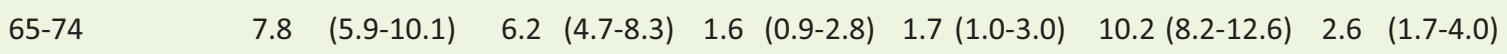

$>=75 \quad 12.5 \quad(9.5-16.3) \quad 10.0(7.5-13.3) \quad 1.9(1.0-3.8) \quad 5.3 \quad(3.5-7.8) \quad 10.9(8.3-14.3) \quad 2.4 \quad(1.3-4.7)$

\begin{tabular}{|c|c|c|c|c|c|c|}
\hline Toto & 4.2 & (3.6-5.0) & 3.5 & $(2.9-4.1)$ & $0.8 \quad(0.6-1$. & $1.6(1.2-2.1)$ \\
\hline
\end{tabular}

\section{Third/higher}

\begin{tabular}{|c|c|c|c|c|c|c|c|c|c|}
\hline $50-64$ & 1.8 & $(1.2-2.6)$ & $2.4 \quad(1.6-3.4)$ & 0.6 & $(0.3-1.2)$ & $1.1(0.6-1.8)$ & $4.7 \quad(3.7-5.9)$ & 0.6 & $(0.3-1.2)$ \\
\hline $65-74$ & 6.3 & $(4.6-8.7)$ & 5.6 (4.0-7.9) & 1.1 & $(0.4-2.6)$ & $3.2(2.0-4.9)$ & $9.0(6.9-11.5)$ & 1.8 & $(1.0-3.2)$ \\
\hline$>=75$ & 10.1 & $(6.8-14.8)$ & $7.1(4.6-10.9)$ & 1.3 & $(0.4-3.8)$ & $5.7(3.3-9.5)$ & $7.2(4.5-11.4)$ & 2.4 & $(1.1-5.2)$ \\
\hline Total & 3.4 & $(2.7-4.2)$ & 3.4 (2.7-4.3) & 0.8 & $(0.5-1.3)$ & $1.9(1.4-2.5)$ & $5.7 \quad(4.8-6.7)$ & 1.0 & $(0.7-1.4)$ \\
\hline \multicolumn{10}{|l|}{ Total } \\
\hline $50-64$ & 2.6 & $(2.2-3.2)$ & $2.6 \quad(2.1-3.2)$ & 0.8 & $(0.6-1.1)$ & $1.1(0.8-1.4)$ & $6.0 \quad(5.3-6.7)$ & 0.8 & $(0.6-1.1)$ \\
\hline $65-74$ & 8.5 & $(7.2-9.9)$ & $6.5 \quad(5.5-7.7)$ & 1.5 & $(1.0-2.2)$ & $2.5(1.9-3.2)$ & $10.8(9.5-12.2)$ & 2.7 & $(2.1-3.5)$ \\
\hline$>=75$ & 12.2 & $(10.4-14.3)$ & $9.3(7.8-11.0)$ & 1.7 & $(1.1-2.6)$ & $5.2(4.1-6.6)$ & $11.1(9.4-13.1)$ & 3.1 & $(2.3-4.3)$ \\
\hline Total & 5.7 & (5.2-6.3) & 4.7 (4.3-5.3) & 1.1 & $(0.9-1.4)$ & $2.1(1.8-2.5)$ & $8.0 \quad(7.5-8.6)$ & 1.7 & (1.4-2.0) \\
\hline
\end{tabular}


Table 5.A9: Prevalence of cardiovascular disease by age and wealth

\begin{tabular}{|c|c|c|c|c|c|c|c|c|c|c|c|c|}
\hline & \multicolumn{2}{|c|}{ Angina } & \multicolumn{2}{|c|}{ Heart attack } & \multicolumn{2}{|c|}{ Heart failure } & \multicolumn{2}{|r|}{ TIA } & \multicolumn{2}{|c|}{ Diabetes } & \multicolumn{2}{|r|}{ Stroke } \\
\hline & $\%$ & $(95 \% \mathrm{CI})$ & $\%$ & $(95 \% \mathrm{Cl})$ & $\%$ & (95\% Cl) & $\%$ & $(95 \% \mathrm{Cl})$ & $\%$ & $(95 \% \mathrm{Cl})$ & $\%$ & $(95 \% \mathrm{Cl})$ \\
\hline \multicolumn{13}{|c|}{ Lowest } \\
\hline $50-64$ & 4.3 & $(2.8-6.5)$ & 3.0 & $(1.8-5.1)$ & 1.2 & $(0.5-2.8)$ & 1.3 & $(0.6-2.5)$ & 7.5 & $(5.4-10.2)$ & 1.6 & $(0.8-3.1)$ \\
\hline $65-74$ & 9.5 & $(6.2-14.3)$ & 7.4 & $(4.8-11.3)$ & 2.2 & $(0.9-5.4)$ & 3.3 & $(1.7-6.4)$ & 11.0 & $(7.5-15.8)$ & 2.5 & $(1.2-5.2)$ \\
\hline$>=75$ & 15.1 & (10.4-21.6) & 9.8 & $(6.2-15.2)$ & 3.8 & $(1.8-7.9)$ & 4.1 & $(1.9-8.5)$ & 11.4 & $(7.2-17.5)$ & 2.9 & $(1.1-7.7)$ \\
\hline Total & 8.2 & (6.5-10.4) & 5.8 & $(4.3-7.6)$ & 2.1 & (1.3-3.3) & 2.4 & (1.6-3.7) & 9.3 & (7.5-11.4) & 2.1 & (1.3-3.4) \\
\hline \multicolumn{13}{|l|}{ 2nd } \\
\hline $50-64$ & 3.8 & $(2.3-6.0)$ & 4.1 & $(2.7-6.2)$ & 1.2 & $(0.5-2.9)$ & 1.5 & $(0.8-2.8)$ & 5.6 & $(4.0-7.8)$ & 1.1 & $(0.4-3.2)$ \\
\hline $65-74$ & 11.3 & $(7.6-16.6)$ & 8.2 & $(5.4-12.3)$ & 0.6 & $(0.1-2.9)$ & 2.7 & $(1.3-5.7)$ & 9.0 & $(5.5-14.4)$ & 2.6 & $(1.2-5.4)$ \\
\hline$>=75$ & 10.6 & $(6.3-17.3)$ & 10.3 & $(5.5-18.5)$ & 0.3 & $(0.0-2.6)$ & 7.2 & $(2.8-17.3)$ & 10.5 & $(6.0-17.8)$ & 7.8 & $(3.4-17.0)$ \\
\hline Total & 6.9 & $(5.3-9.0)$ & 6.3 & $(4.7-8.4)$ & 0.9 & (0.4-1.9) & 2.9 & $(1.7-5.0)$ & 7.4 & $(5.8-9.4)$ & 2.8 & $(1.6-4.8)$ \\
\hline \multicolumn{13}{|l|}{$3 r d$} \\
\hline $50-64$ & 1.2 & $(0.6-2.5)$ & 2.3 & $(1.2-4.3)$ & 0.9 & $(0.3-2.1)$ & 1.5 & $(0.7-3.4)$ & 3.7 & $(2.3-5.8)$ & 0.9 & $(0.4-2.1)$ \\
\hline $65-74$ & 6.9 & $(4.5-10.6)$ & 3.3 & $(1.7-6.1)$ & 0.8 & $(0.2-3.1)$ & 1.2 & $(0.4-3.8)$ & 11.7 & $(8.2-16.4)$ & 2.9 & $(1.4-5.9)$ \\
\hline$>=75$ & 12.9 & $(7.0-22.5)$ & 7.5 & $(3.9-14.0)$ & 2.3 & (0.5-10.5) & 4.4 & $(1.9-9.7)$ & 18.4 & $(10.9-29.3)$ & 1.7 & $(0.5-5.2)$ \\
\hline Total & 4.5 & (3.2-6.4) & 3.4 & $(2.3-5.0)$ & 1.1 & $(0.4-2.5)$ & 1.9 & $(1.1-3.2)$ & 8.0 & (6.1-10.4) & 1.5 & $(1.0-2.5)$ \\
\hline \multicolumn{13}{|c|}{ Highest } \\
\hline $50-64$ & 0.7 & $(0.3-1.6)$ & 2.0 & $(1.1-3.5)$ & 0.0 & - & 0.7 & $(0.3-2.0)$ & 3.5 & $(2.3-5.3)$ & 0.1 & $(0.0-0.7)$ \\
\hline $65-74$ & 6.5 & $(4.0-10.4)$ & 5.0 & $(2.9-8.6)$ & 0.2 & $(0.0-1.4)$ & 2.3 & $(1.1-5.1)$ & 7.0 & $(4.4-11.1)$ & 3.3 & $(1.5-7.0)$ \\
\hline$>=75$ & 9.4 & (4.1-20.0) & 6.5 & (3.1-13.0) & 0.0 & - & 5.8 & (2.3-13.8) & 6.1 & $(2.8-12.8)$ & 6.6 & $(2.9-14.1)$ \\
\hline Total & 2.9 & (1.9-4.3) & 3.1 & $(2.2-4.4)$ & 0.0 & $(0.0-0.3)$ & 1.6 & $(0.9-2.8)$ & 4.6 & (3.4-6.1) & 1.5 & $(0.9-2.6)$ \\
\hline \multicolumn{13}{|l|}{ Total } \\
\hline $50-64$ & 2.6 & $(2.1-3.1)$ & 2.5 & $(2.1-3.1)$ & 0.8 & $(0.6-1.2)$ & 1.1 & $(0.8-1.4)$ & 5.9 & $(5.2-6.6)$ & 0.9 & $(0.6-1.3)$ \\
\hline $65-74$ & 8.3 & (7.1-9.8) & 6.1 & (5.1-7.3) & 1.4 & $(0.9-2.1)$ & 2.4 & $(1.8-3.2)$ & 10.7 & (9.4-12.2) & 2.6 & $(2.0-3.4)$ \\
\hline$>=75$ & 11.4 & (9.6-13.6) & 8.5 & $(7.0-10.4)$ & 1.5 & $(0.9-2.3)$ & 5.4 & $(4.1-7.0)$ & 10.3 & $(8.5-12.4)$ & 3.3 & $(2.3-4.8)$ \\
\hline Total & 5.9 & (5.3-6.6) & 4.7 & $(4.2-5.3)$ & 1.1 & $(0.9-1.4)$ & 2.3 & $(2.0-2.8)$ & 8.0 & (7.4-8.7) & 1.8 & (1.5-2.3) \\
\hline
\end{tabular}


Table 5.A10: Non-cardiovascular chronic conditions by age and sex

\begin{tabular}{|c|c|c|c|c|c|c|c|c|c|}
\hline & \multirow{2}{*}{$\frac{\text { Lung disease }}{\%(95 \% \mathrm{Cl})}$} & \multirow{2}{*}{$\frac{\text { Cancer }}{\%(95 \% \mathrm{Cl})}$} & \multicolumn{2}{|c|}{ Arthritis } & \multicolumn{2}{|c|}{ Osteoporosis } & \multicolumn{2}{|c|}{ Hip fracture } & Wrist fracture \\
\hline & & & $\%$ & $(95 \% \mathrm{Cl})$ & $\%$ & $(95 \% \mathrm{Cl})$ & $\%$ & $(95 \% \mathrm{Cl})$ & $\% \quad(95 \% \mathrm{Cl})$ \\
\hline \multicolumn{10}{|l|}{ Male } \\
\hline $50-64$ & $3.0(2.3-3.9)$ & $3.5(2.8-4.4)$ & 15.3 & $(13.7-17.1)$ & 1.5 & $(1.1-2.2)$ & 3.4 & $(2.7-4.3)$ & $13.4(11.9-15.0)$ \\
\hline $65-74$ & $5.1(3.8-6.7)$ & 7.3 (5.9-9.1) & 27.7 & $(24.9-30.7)$ & 2.6 & $(1.8-3.7)$ & 4.3 & $(3.1-5.8)$ & $10.6 \quad(8.8-12.7)$ \\
\hline$>=75$ & 5.6 (3.9-7.9) & $8.9(6.8-11.6)$ & 33.4 & $(29.5-37.5)$ & 2.3 & $(1.3-3.9)$ & 5.5 & $(3.8-7.8)$ & $8.4 \quad(6.4-11.0)$ \\
\hline Total & 3.9 (3.3-4.6) & $5.3(4.6-6.0)$ & 21.0 & $(19.7-22.5)$ & 1.9 & $(1.5-2.4)$ & 3.9 & (3.3-4.7) & $12.0(10.9-13.2)$ \\
\hline \multicolumn{10}{|c|}{ Female } \\
\hline $50-64$ & $4.0(3.3-4.9)$ & $5.8(4.9-6.9)$ & 23.8 & $(22.2-25.5)$ & 12.5 & 11.2-13.9) & 2.1 & $(1.5-2.9)$ & $(7.5-9.7)$ \\
\hline $65-74$ & $5.6(4.3-7.3)$ & $10.1(8.4-12.1)$ & 42.6 & (39.4-45.7) & 19.1 & 16.8-21.6) & 2.6 & $(1.8-3.8)$ & 13.5 (11.5-15.9) \\
\hline$>=75$ & $4.4(3.1-6.3)$ & $6.1(4.5-8.1)$ & 50.4 & $(46.5-54.2)$ & 22.4 & 19.4-25.8) & 7.5 & $(5.7-9.9)$ & $17.2(14.6-20.1)$ \\
\hline Total & $4.5(3.8-5.2)$ & $6.8(6.1-7.7)$ & 33.7 & $(32.2-35.3)$ & 16.1 & $15.0-17.3)$ & 3.4 & $(2.8-4.1)$ & $11.5(10.5-12.6)$ \\
\hline \multicolumn{10}{|l|}{ Total } \\
\hline $50-64$ & $3.5(3.0-4.1)$ & $4.7(4.1-5.3)$ & 19.6 & $(18.4-20.8)$ & 7.0 & $(6.3-7.8)$ & 2.8 & $(2.2-3.4)$ & $11.0(10.1-12.0)$ \\
\hline $65-74$ & $5.3(4.4-6.5)$ & $8.8(7.6-10.1)$ & 35.3 & $(33.1-37.6)$ & 11.0 & $(9.7-12.5)$ & 3.4 & $(2.7-4.4)$ & $12.1(10.6-13.7)$ \\
\hline$>=75$ & $4.9(3.8-6.3)$ & $7.2(5.9-8.8)$ & 43.6 & $(40.7-46.5)$ & 14.4 & 12.5-16.5) & 6.7 & $(5.3-8.4)$ & 13.7 (11.9-15.7) \\
\hline Total & 4.2 (3.7-4.7) & 6.1 (5.6-6.7) & 27.6 & $(26.5-28.8)$ & 9.3 & (8.7-10.0) & 3.6 & $(3.1-4.2)$ & $11.7(11.0-12.5)$ \\
\hline
\end{tabular}


Table 5.A11: Prevalence of non-cardiovascular chronic conditions by age and education

\begin{tabular}{|c|c|c|c|c|c|c|c|c|c|c|c|}
\hline & \multicolumn{2}{|c|}{ Lung disease } & \multicolumn{2}{|r|}{ Cancer } & Arthritis & \multicolumn{2}{|c|}{ Osteoporosis } & \multicolumn{2}{|c|}{ Hip fracture } & \multicolumn{2}{|c|}{ Wrist fracture } \\
\hline & $\%$ & $(95 \% \mathrm{CI})$ & $\%$ & $(95 \% \mathrm{Cl})$ & $\% \quad(95 \% \mathrm{CI})$ & $\%$ & $(95 \% \mathrm{Cl})$ & $\%$ & $(95 \% \mathrm{Cl})$ & $\%$ & $(95 \% \mathrm{Cl})$ \\
\hline \multicolumn{12}{|c|}{ Primary/none } \\
\hline $50-64$ & 5.7 & $(4.4-7.4)$ & 4.4 & (3.4-5.9) & $23.3(20.6-26.1)$ & 6.9 & $(5.5-8.5)$ & 3.7 & $(2.6-5.1)$ & 11.4 & $(9.5-13.7)$ \\
\hline $65-74$ & 5.7 & $(4.3-7.5)$ & 9.1 & $(7.3-11.4)$ & $36.7(33.4-40.2)$ & 9.4 & $(7.6-11.7)$ & 4.6 & $(3.4-6.3)$ & 10.8 & $(8.6-13.3)$ \\
\hline$>=75$ & 5.1 & (3.7-7.1) & 6.5 & $(4.9-8.6)$ & $44.0(40.1-48.0)$ & 13.6 & $(11.2-16.4)$ & 7.4 & $(5.5-9.9)$ & 14.0 & $(11.6-16.7)$ \\
\hline Total & 5.5 & $(4.7-6.5)$ & 6.5 & (5.6-7.6) & $33.8(31.9-35.8)$ & 9.7 & $(8.6-11.0)$ & 5.1 & $(4.2-6.2)$ & 12.0 & $(10.7-13.5)$ \\
\hline \multicolumn{12}{|c|}{ Secondary } \\
\hline $50-64$ & 2.8 & $(2.2-3.7)$ & 4.7 & $(3.9-5.7)$ & $17.9(16.3-19.6)$ & 7.3 & $(6.2-8.5)$ & 2.9 & $(2.3-3.8)$ & 11.6 & $(10.4-13.0)$ \\
\hline $65-74$ & 5.7 & $(4.2-7.6)$ & 8.7 & $(6.9-10.9)$ & $34.5(31.0-38.1)$ & 11.7 & $(9.4-14.3)$ & 2.3 & $(1.4-3.8)$ & 13.2 & (10.9-15.9) \\
\hline$>=75$ & 4.8 & $(3.1-7.2)$ & 8.5 & $(6.1-11.8)$ & $43.4(38.7-48.4)$ & 16.2 & $(13.0-20.0)$ & 5.9 & $(4.0-8.6)$ & 13.3 & $(10.3-17.0)$ \\
\hline Total & 3.6 & (3.0-4.3) & 5.9 & $(5.2-6.7)$ & $23.8(22.3-25.4)$ & 9.1 & (8.1-10.1) & 3.1 & $(2.6-3.8)$ & 12.1 & $(11.0-13.3)$ \\
\hline \multicolumn{12}{|c|}{ Third/higher } \\
\hline $50-64$ & 2.5 & $(1.8-3.4)$ & 4.7 & (3.8-5.9) & $19.2(17.3-21.2)$ & 6.6 & $(5.6-7.9)$ & 1.4 & $(0.9-2.1)$ & 9.0 & $(7.7-10.6)$ \\
\hline $65-74$ & 3.2 & $(2.0-5.0)$ & 7.6 & $(5.6-10.0)$ & $32.8(29.0-36.9)$ & 14.9 & $(12.2-18.0)$ & 2.1 & $(1.2-3.8)$ & 13.5 & $(11.0-16.5)$ \\
\hline$>=75$ & 3.7 & $(1.9-6.9)$ & 9.0 & $(6.0-13.2)$ & $42.1(35.9-48.5)$ & 14.8 & $(10.8-20.0)$ & 3.8 & $(2.0-7.1)$ & 13.2 & (9.5-18.1) \\
\hline Total & 2.7 & $(2.1-3.5)$ & 5.6 & $(4.8-6.6)$ & $23.8(22.1-25.6)$ & 8.9 & (7.9-10.1) & 1.7 & $(1.2-2.4)$ & 10.2 & (9.1-11.5) \\
\hline \multicolumn{12}{|l|}{ Total } \\
\hline $50-64$ & 3.5 & $(3.0-4.1)$ & 4.7 & (4.1-5.3) & $19.6(18.4-20.8)$ & 7.0 & $(6.3-7.8)$ & 2.8 & $(2.2-3.4)$ & 11.0 & $(10.1-12.0)$ \\
\hline $65-74$ & 5.3 & $(4.4-6.5)$ & 8.8 & $(7.6-10.1)$ & $35.3(33.1-37.6)$ & 11.0 & $(9.7-12.5)$ & 3.4 & $(2.7-4.4)$ & 12.1 & $(10.6-13.7)$ \\
\hline$>=75$ & 4.9 & $(3.8-6.3)$ & 7.2 & $(5.9-8.8)$ & $43.6(40.7-46.5)$ & 14.4 & $(12.5-16.5)$ & 6.7 & $(5.3-8.4)$ & 13.7 & $(11.9-15.7)$ \\
\hline Total & 4.2 & (3.7-4.7) & 6.1 & (5.6-6.7) & $27.6(26.5-28.8)$ & 9.3 & (8.7-10.0) & 3.6 & (3.1-4.2) & 11.7 & $(11.0-12.5)$ \\
\hline
\end{tabular}


Table 5.A12: Prevalence of non-cardiovascular chronic conditions by age and wealth

\begin{tabular}{|c|c|c|c|c|c|c|c|c|c|c|}
\hline & \multicolumn{2}{|c|}{ Lung disease } & Cancer & Arthritis & \multicolumn{2}{|c|}{ Osteoporosis } & \multicolumn{2}{|c|}{ Hip fracture } & \multicolumn{2}{|c|}{ Wrist fracture } \\
\hline & $\%$ & (95\% CI) & $\%(95 \% \mathrm{Cl})$ & $\% \quad(95 \% \mathrm{Cl})$ & $\%$ & $(95 \% \mathrm{CI})$ & $\%$ & $(95 \% \mathrm{CI})$ & $\%$ & $(95 \% \mathrm{Cl})$ \\
\hline \multicolumn{11}{|c|}{ Lowest } \\
\hline $50-64$ & 6.2 & $(4.4-8.7)$ & $4.3(2.8-6.4)$ & 19.9 (16.3-24.0) & 6.6 & $(4.8-9.2)$ & 3.4 & $(2.1-5.7)$ & 14.3 & $(11.4-17.7)$ \\
\hline $65-74$ & 7.7 & $(4.5-12.7)$ & $8.8(5.5-13.8)$ & $40.0(33.4-47.0)$ & 11.1 & $(7.2-16.8)$ & 1.9 & $(0.7-5.1)$ & 10.8 & $(7.0-16.3)$ \\
\hline$>=75$ & 6.3 & $(3.0-12.7)$ & $7.3(3.9-13.3)$ & $48.4(40.7-56.1)$ & 16.8 & $(11.3-24.2)$ & 7.6 & $(4.4-12.7)$ & 17.5 & $(11.6-25.5)$ \\
\hline Total & 6.5 & $(4.9-8.6)$ & $6.0(4.5-8.1)$ & $31.6(28.5-34.9)$ & 10.2 & $(8.2-12.7)$ & 4.2 & $(3.0-5.9)$ & 14.4 & $(11.8-17.4)$ \\
\hline \multicolumn{11}{|l|}{ 2nd } \\
\hline $50-64$ & 4.6 & $(3.1-6.8)$ & $4.0(2.5-6.1)$ & 23.9 (20.3-27.9) & 7.2 & $(5.2-9.7)$ & 2.4 & $(1.3-4.2)$ & 10.5 & $(8.2-13.3)$ \\
\hline $65-74$ & 6.6 & $(3.7-11.5)$ & $9.5(6.3-14.1)$ & $38.2(32.1-44.6)$ & 9.9 & $(6.4-15.1)$ & 3.0 & $(1.5-6.0)$ & 9.4 & $(6.4-13.4)$ \\
\hline$>=75$ & 7.0 & $(3.3-14.2)$ & $5.3(2.5-11.0)$ & $43.8(34.5-53.6)$ & 13.5 & $(8.1-21.7)$ & 5.6 & $(2.7-11.3)$ & 13.0 & $(8.0-20.5)$ \\
\hline Total & 5.6 & $(4.1-7.6)$ & 5.5 (4.2-7.2) & $31.5(28.2-35.0)$ & 9.2 & $(7.2-11.5)$ & 3.2 & $(2.2-4.7)$ & 10.8 & $(8.8-13.2)$ \\
\hline \multicolumn{11}{|l|}{ 3rd } \\
\hline $50-64$ & 1.7 & $(0.9-3.2)$ & $5.6(4.0-7.8)$ & 19.3 (16.1-22.9) & 7.8 & $(5.8-10.3)$ & 3.3 & $(1.9-5.5)$ & 7.8 & $(5.8-10.4)$ \\
\hline $65-74$ & 4.9 & $(2.7-8.7)$ & $5.4(3.1-9.0)$ & $34.0(28.3-40.2)$ & 13.0 & $(8.8-18.8)$ & 1.9 & $(0.8-4.6)$ & 10.0 & $(6.8-14.5)$ \\
\hline$>=75$ & 5.2 & $(2.1-12.2)$ & $12.2(7.2-19.9)$ & $40.8(31.6-50.8)$ & 13.4 & $(7.8-21.9)$ & 4.6 & $(2.0-10.3)$ & 17.3 & $(10.2-27.8)$ \\
\hline Total & 3.0 & $(2.0-4.5)$ & $6.6(5.0-8.6)$ & $26.2(23.3-29.3)$ & 9.9 & $(8.0-12.2)$ & 3.2 & $(2.0-4.9)$ & 9.8 & $(7.9-12.1)$ \\
\hline \multicolumn{11}{|c|}{ Highest } \\
\hline $50-64$ & 2.2 & $(1.2-3.9)$ & $4.2(2.8-6.3)$ & $20.0(16.8-23.6)$ & 5.0 & $(3.4-7.2)$ & 1.9 & $(1.0-3.7)$ & 8.4 & $(6.4-11.0)$ \\
\hline $65-74$ & 3.7 & $(1.8-7.6)$ & $9.2(5.8-14.3)$ & $24.3(18.6-31.1)$ & 9.3 & (6.1-13.9) & 4.0 & $(1.8-8.8)$ & 11.1 & $(7.6-16.1)$ \\
\hline$>=75$ & 3.5 & $(1.2-9.8)$ & $5.9(3.0-11.1)$ & $35.4(24.5-48.1)$ & 15.8 & $(9.6-25.0)$ & 0.0 & - & 15.9 & $(6.8-32.8)$ \\
\hline Total & 2.7 & $(1.7-4.0)$ & 5.5 (4.2-7.3) & $22.5(19.7-25.6)$ & 7.0 & (5.6-8.9) & 2.2 & $(1.3-3.6)$ & 9.8 & $(7.8-12.2)$ \\
\hline \multicolumn{11}{|l|}{ Total } \\
\hline $50-64$ & 3.7 & $(3.1-4.4)$ & $4.9(4.3-5.6)$ & $19.8(18.6-21.2)$ & 7.2 & $(6.5-8.0)$ & 3.1 & $(2.4-3.9)$ & 10.8 & (9.9-11.9) \\
\hline $65-74$ & 5.6 & $(4.5-6.8)$ & $8.4(7.2-9.8)$ & $36.3(33.8-38.8)$ & 11.3 & $(9.9-12.9)$ & 3.7 & $(2.8-5.0)$ & 12.1 & $(10.5-13.9)$ \\
\hline$>=75$ & 4.7 & $(3.6-6.2)$ & $6.6(5.2-8.2)$ & $44.2(40.9-47.6)$ & 14.1 & (12.0-16.5) & 7.2 & $(5.5-9.3)$ & 15.0 & $(12.7-17.5)$ \\
\hline Total & 4.4 & (3.8-4.9) & 6.1 (5.5-6.7) & $29.4(28.1-30.8)$ & 9.8 & (9.0-10.6) & 4.2 & (3.6-4.9) & 12.1 & $(11.2-13.1)$ \\
\hline
\end{tabular}


Table 5.A13: Prevalence of sensory impairment and eye disease by age and sex

\begin{tabular}{|c|c|c|c|c|c|c|c|c|c|c|}
\hline & \multicolumn{2}{|c|}{$\begin{array}{c}\text { Self-reported } \\
\text { poor vision }\end{array}$} & \multicolumn{2}{|c|}{$\begin{array}{l}\text { Self-reported } \\
\text { poor hearing }\end{array}$} & \multicolumn{2}{|c|}{ ARMD } & \multicolumn{2}{|c|}{ Cataracts } & \multicolumn{2}{|c|}{ Glaucoma } \\
\hline & $\%$ & $(95 \% \mathrm{Cl})$ & $\%$ & $(95 \% \mathrm{Cl})$ & $\%$ & $(95 \% \mathrm{Cl})$ & $\%$ & $(95 \% \mathrm{Cl})$ & $\%$ & $(95 \% \mathrm{Cl})$ \\
\hline \multicolumn{11}{|l|}{ Male } \\
\hline $50-64$ & 9.6 & $(8.3-11.0)$ & 15.2 & $(13.7-16.9)$ & 0.4 & $(0.2-0.8)$ & 2.7 & $(2.1-3.5)$ & 1.2 & $(0.8-1.8)$ \\
\hline $65-74$ & 8.8 & $(7.0-10.8)$ & 19.1 & $(16.5-22.0)$ & 1.4 & $(0.9-2.3)$ & 9.0 & $(7.5-10.8)$ & 3.1 & $(2.2-4.3)$ \\
\hline$>=75$ & 17.3 & $(14.2-21.0)$ & 30.6 & $(26.7-34.8)$ & 3.3 & $(2.1-5.1)$ & 30.0 & $(26.2-34.1)$ & 5.2 & $(3.6-7.3)$ \\
\hline Total & 10.6 & (9.5-11.7) & 18.5 & $(17.1-20.0)$ & 1.1 & $(0.8-1.4)$ & 8.3 & (7.5-9.3) & 2.3 & $(1.8-2.8)$ \\
\hline
\end{tabular}

Female

\begin{tabular}{lrrrrrrrrrr}
$50-64$ & 8.4 & $(7.2-9.8)$ & 6.7 & $(5.8-7.8)$ & 1.4 & $(1.0-1.9)$ & 4.2 & $(3.5-5.0)$ & 1.7 & $(1.2-2.3)$ \\
$65-74$ & 10.8 & $(9.0-12.9)$ & 14.6 & $(12.5-17.1)$ & 2.1 & $(1.4-3.2)$ & 14.8 & $(12.8-17.2)$ & 2.4 & $(1.6-3.5)$ \\
$>=75$ & 20.4 & $(17.4-23.8)$ & 23.6 & $(20.5-27.0)$ & 5.0 & $(3.6-6.9)$ & 39.0 & $(35.4-42.8)$ & 5.3 & $(3.8-7.3)$ \\
\hline Total & 11.5 & $(10.4-12.7)$ & 12.1 & $(11.0-13.2)$ & 2.3 & $(1.9-2.9)$ & 14.0 & $(12.9-15.1)$ & 2.6 & $(2.1-3.2)$ \\
\hline Total & & & & & & & & & & \\
$50-64$ & 9.0 & $(8.1-10.0)$ & 11.0 & $(10.0-12.0)$ & 0.9 & $(0.6-1.2)$ & 3.4 & $(2.9-4.0)$ & 1.5 & $(1.1-1.9)$ \\
$65-74$ & 9.8 & $(8.5-11.3)$ & 16.8 & $(15.1-18.7)$ & 1.8 & $(1.3-2.5)$ & 12.0 & $(10.6-13.5)$ & 2.7 & $(2.1-3.5)$ \\
$>=75$ & 19.2 & $(16.9-21.7)$ & 26.4 & $(23.9-29.1)$ & 4.3 & $(3.3-5.7)$ & 35.4 & $(32.7-38.2)$ & 5.2 & $(4.1-6.6)$ \\
\hline Total & 11.0 & $(10.2-11.9)$ & 15.2 & $(14.2-16.1)$ & 1.7 & $(1.4-2.1)$ & 11.3 & $(10.5-12.1)$ & 2.4 & $(2.1-2.8)$
\end{tabular}


Table 5.A14: Prevalence of sensory impairment and eye disease by age and education

\begin{tabular}{|c|c|c|c|c|}
\hline $\begin{array}{l}\text { Self-reported } \\
\text { poor vision }\end{array}$ & $\begin{array}{l}\text { Self-reported } \\
\text { poor hearing }\end{array}$ & ARMD & Cataracts & Glaucoma \\
\hline (95\% CI) & (95\% Cl) & (95\% CI) & $(95 \% \mathrm{Cl})$ & (95\% Cl) \\
\hline
\end{tabular}

\section{Primary/none}

\begin{tabular}{llllllllll}
$50-64$ & 15.6 & $(13.3-18.1)$ & $15.6(13.4-18.0)$ & 1.1 & $(0.6-1.9)$ & 4.2 & $(3.1-5.6)$ & 1.8 & $(1.1-3.0)$ \\
$65-74$ & 13.4 & $(11.4-15.8)$ & $18.9(16.3-22.0)$ & 1.3 & $(0.7-2.3)$ & 11.1 & $(9.1-13.3)$ & 2.3 & $(1.5-3.5)$ \\
$>=75$ & 23.7 & $(20.6-27.2)$ & $29.8(26.3-33.5)$ & 4.0 & $(2.7-5.9)$ & $38.0(34.6-41.6)$ & 5.7 & $(4.2-7.7)$ \\
\hline Total & 17.5 & $(16.0-19.1)$ & $21.0(19.3-22.9)$ & 2.0 & $(1.5-2.7)$ & $16.9(15.4-18.5)$ & 3.2 & $(2.6-4.0)$ \\
\hline
\end{tabular}

\section{Secondary}

\begin{tabular}{lrrrrrrrrrr}
$50-64$ & 7.6 & $(6.5-8.8)$ & 10.0 & $(8.8-11.3)$ & 0.9 & $(0.6-1.4)$ & 3.0 & $(2.3-3.8)$ & 1.4 & $(0.9-2.0)$ \\
$65-74$ & 6.4 & $(4.8-8.5)$ & $15.3(12.8-18.2)$ & 2.2 & $(1.4-3.6)$ & 11.5 & $(9.5-13.9)$ & 3.1 & $(2.1-4.5)$ \\
$>=75$ & 11.5 & $(8.7-15.0)$ & $21.5(17.7-25.9)$ & 4.6 & $(2.9-7.0)$ & $30.7(26.2-35.6)$ & 4.9 & $(3.1-7.5)$ \\
\hline Total & 7.7 & $(6.8-8.8)$ & $12.2(11.1-13.4)$ & 1.6 & $(1.2-2.0)$ & 7.5 & $(6.7-8.5)$ & 2.1 & $(1.6-2.6)$
\end{tabular}

\section{Third/higher}

\begin{tabular}{lrrrrrrrrrr}
$50-64$ & 5.1 & $(4.1-6.4)$ & 8.2 & $(6.9-9.8)$ & 0.5 & $(0.3-1.0)$ & 3.6 & $(2.8-4.7)$ & 1.2 & $(0.8-1.9)$ \\
$65-74$ & 6.0 & $(4.2-8.4)$ & $13.5(10.9-16.7)$ & 2.5 & $(1.5-4.1)$ & $16.3(13.4-19.8)$ & 3.2 & $(2.0-4.9)$ \\
$>=75$ & 7.8 & $(4.9-12.2)$ & $15.2(11.2-20.3)$ & 6.3 & $(3.6-10.6)$ & $30.4(24.5-37.0)$ & 3.3 & $(1.7-6.4)$ \\
\hline Total & 5.5 & $(4.6-6.6)$ & 9.8 & $(8.7-11.1)$ & 1.4 & $(1.0-1.9)$ & 8.4 & $(7.3-9.7)$ & 1.8 & $(1.3-2.4)$ \\
\hline Total & & & & & & & & & & \\
$50-64$ & 9.0 & $(8.1-10.0)$ & $11.0(10.0-12.0)$ & 0.9 & $(0.6-1.2)$ & 3.4 & $(2.9-4.0)$ & 1.5 & $(1.1-1.9)$ \\
$65-74$ & 9.8 & $(8.5-11.3)$ & $16.8(15.1-18.7)$ & 1.8 & $(1.3-2.5)$ & $12.0(10.6-13.5)$ & 2.7 & $(2.1-3.5)$ \\
$>=75$ & 19.2 & $(16.9-21.7)$ & $26.4(23.9-29.1)$ & 4.3 & $(3.3-5.7)$ & $35.4(32.7-38.2)$ & 5.2 & $(4.1-6.6)$ \\
\hline Total & 11.0 & $(10.2-11.9)$ & $15.2(14.2-16.1)$ & 1.7 & $(1.4-2.1)$ & $11.3(10.5-12.1)$ & 2.4 & $(2.1-2.8)$
\end{tabular}


Table 5.A15: Prevalence of sensory impairment and eye disease by age and wealth

\begin{tabular}{|c|c|c|c|c|c|c|c|}
\hline \multirow{3}{*}{ Lowest } & $\begin{array}{l}\text { Self-reported } \\
\text { poor vision }\end{array}$ & \multicolumn{2}{|c|}{$\begin{array}{l}\text { Self-reported } \\
\text { poor hearing }\end{array}$} & \multicolumn{2}{|c|}{ ARMD } & Cataracts & Glaucoma \\
\hline & $\% \quad(95 \% \mathrm{Cl})$ & $\%$ & $(95 \% \mathrm{Cl})$ & $\%$ & $(95 \% \mathrm{Cl})$ & $\% \quad(95 \% \mathrm{Cl})$ & $(95 \% \mathrm{Cl})$ \\
\hline & & & & & & & \\
\hline $50-64$ & $15.7(12.4-19.6)$ & 12.5 & (9.8-16.0) & 1.3 & $(0.6-2.6)$ & $3.2 \quad(2.0-4.9)$ & $(1.2-3.7)$ \\
\hline $65-74$ & $11.3 \quad(7.2-17.3)$ & 16.4 & $(11.7-22.6)$ & 5.2 & $(2.9-9.2)$ & $14.9(11.2-19.7)$ & $(1.3-6.1)$ \\
\hline$>=75$ & $27.1(20.6-34.8)$ & 30.3 & $(23.5-38.0)$ & 7.6 & $(4.1-13.5)$ & 39.9 (31.8-48.5) & $6.2(3.3-11.3)$ \\
\hline Total & $17.7(14.6-21.2)$ & 18.0 & $(15.0-21.4)$ & 3.8 & $(2.5-5.6)$ & 15.3 (12.8-18.1) & 3.3 (2.3-4.8) \\
\hline \multicolumn{8}{|l|}{ 2nd } \\
\hline $50-64$ & $10.4 \quad(8.1-13.4)$ & 13.4 & $(10.7-16.6)$ & 1.7 & $(0.9-3.4)$ & $3.9 \quad(2.5-6.0)$ & $(0.6-2.9)$ \\
\hline $65-74$ & $10.2(6.8-15.0)$ & 20.4 & $(15.4-26.5)$ & 0.5 & $(0.1-3.5)$ & 14.0 (10.1-18.9) & $2.3 \quad(1.1-4.8)$ \\
\hline >=75 & $21.8(14.3-31.8)$ & 31.3 & $(22.0-42.3)$ & 3.1 & (0.6-14.5) & $33.9(24.8-44.4)$ & $7.0(3.7-12.6)$ \\
\hline Total & $12.7(10.3-15.6)$ & 18.7 & $(15.6-22.1)$ & 1.7 & $(0.8-3.5)$ & $12.3 \quad(9.7-15.5)$ & $2.7 \quad(1.8-4.1)$ \\
\hline \multicolumn{8}{|l|}{ 3rd } \\
\hline $50-64$ & $8.3 \quad(6.2-10.9)$ & 9.9 & $(7.6-12.7)$ & 0.5 & $(0.2-1.5)$ & $3.8 \quad(2.3-6.1)$ & $(0.9-3.4)$ \\
\hline $65-74$ & $4.6 \quad(2.6-8.0)$ & 16.8 & $(12.5-22.2)$ & 1.9 & $(0.8-4.4)$ & $8.3 \quad(5.2-12.8)$ & $4.2 \quad(2.3-7.6)$ \\
\hline$>=75$ & $14.9 \quad(8.8-24.1)$ & 21.0 & $(14.1-30.1)$ & 5.9 & $(2.6-12.7)$ & $37.8(27.5-49.4)$ & $8.9(4.6-16.5)$ \\
\hline Total & $8.4 \quad(6.6-10.6)$ & 13.4 & (11.1-15.9) & 1.7 & $(1.0-3.0)$ & $10.3 \quad(7.9-13.3)$ & $(2.4-5.1)$ \\
\hline \multicolumn{8}{|c|}{ Highest } \\
\hline $50-64$ & $5.0 \quad(3.3-7.4)$ & 8.8 & $(6.7-11.7)$ & 0.7 & $(0.2-1.9)$ & $2.9 \quad(1.7-4.9)$ & $(0.7-2.8)$ \\
\hline $65-74$ & $6.6 \quad(3.5-12.1)$ & 11.7 & (8.1-16.5) & 1.3 & $(0.5-3.3)$ & $8.6 \quad(5.8-12.7)$ & $(1.7-6.2)$ \\
\hline$>=75$ & $7.9 \quad(3.2-18.5)$ & 13.7 & $(7.5-23.7)$ & 6.7 & $(2.4-17.3)$ & $24.5(16.0-35.7)$ & $(1.5-8.4)$ \\
\hline Total & $5.6 \quad(4.1-7.7)$ & 10.0 & (8.1-12.3) & 1.5 & $(0.8-2.7)$ & (4.9-8.4) & (1.4-3.1) \\
\hline \multicolumn{8}{|l|}{ Total } \\
\hline $50-64$ & $8.8 \quad(7.8-9.8)$ & 10.7 & $(9.8-11.8)$ & 0.8 & $(0.6-1.1)$ & $(3.0-4.1)$ & $(1.1-1.9)$ \\
\hline $65-74$ & 10.2 (8.7-11.9) & 17.0 & $(15.2-19.0)$ & 1.8 & $(1.3-2.6)$ & $12.4(10.9-14.1)$ & $(2.1-3.4)$ \\
\hline$>=75$ & $20.2(17.6-23.0)$ & 27.0 & $(24.0-30.2)$ & 4.4 & $(3.3-6.0)$ & $35.3(32.4-38.4)$ & $(3.9-6.5)$ \\
\hline Total & $11.7(10.8-12.7)$ & 15.9 & $(14.8-17.0)$ & 1.9 & $(1.5-2.3)$ & $12.9(12.0-13.8)$ & $(2.2-3.0)$ \\
\hline
\end{tabular}


Table 5.A16: Difficulty following a conversation with 1 person by age and sex

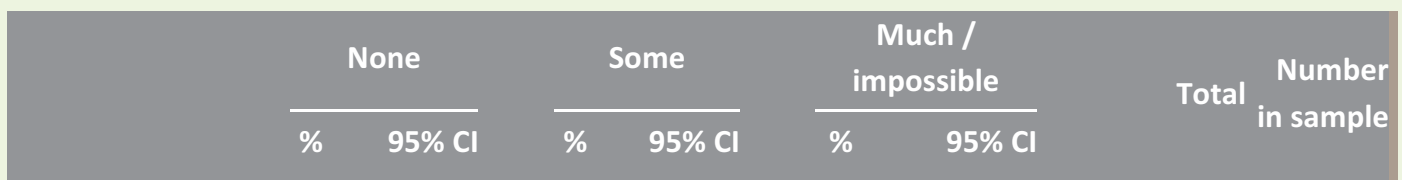

Male

\begin{tabular}{lcccccccc}
$50-64$ & 95 & $(94-96)$ & 5 & $(4-6)$ & 1 & $(0-1)$ & 100 & 2081 \\
$65-74$ & 90 & $(88-92)$ & 9 & $(7-11)$ & 1 & $(0-2)$ & 100 & 1070 \\
$>=75$ & 81 & $(77-84)$ & 18 & $(14-22)$ & 1 & $(1-3)$ & 100 & 598 \\
\hline Total & 91 & $(90-92)$ & 8 & $(7-9)$ & 1 & $(1-1)$ & 100 & 3749
\end{tabular}

\section{Female}

\begin{tabular}{lcccccccc}
$50-64$ & 97 & $(96-98)$ & 3 & $(2-3)$ & 1 & $(0-1)$ & 100 & 2587 \\
$65-74$ & 94 & $(92-95)$ & 5 & $(4-7)$ & 1 & $(0-2)$ & 100 & 1093 \\
$>=75$ & 88 & $(85-91)$ & 9 & $(7-12)$ & 3 & $(2-4)$ & 100 & 749 \\
\hline Total & 94 & $(93-95)$ & 5 & $(4-6)$ & 1 & $(1-2)$ & 100 & 4429 \\
\hline Total & & & & & & & & \\
$50-64$ & 96 & $(95-97)$ & 4 & $(3-4)$ & 1 & $(0-1)$ & 100 & 4668 \\
$65-74$ & 92 & $(91-94)$ & 7 & $(6-8)$ & 1 & $(1-1)$ & 100 & 2163 \\
$>=75$ & 86 & $(83-88)$ & 12 & $(10-15)$ & 2 & $(1-3)$ & 100 & 1347 \\
\hline Total & 93 & $(92-93)$ & 6 & $(6-7)$ & 1 & $(1-1)$ & 100 & 8178
\end{tabular}

Note. $\mathrm{Cl}=$ confidence interval; Missing observations $=0.00 \%$ 
Table 5.A17: Number of falls in the last year by age and sex

\begin{tabular}{|c|c|c|c|c|c|c|c|c|}
\hline & \multicolumn{2}{|c|}{ None } & \multicolumn{2}{|c|}{ One } & \multicolumn{2}{|c|}{ Two or more } & \multirow{2}{*}{ Total } & \multirow{2}{*}{$\begin{array}{l}\text { Number } \\
\text { in sample }\end{array}$} \\
\hline & $\%$ & $95 \% \mathrm{Cl}$ & $\%$ & $95 \% \mathrm{Cl}$ & $\%$ & $95 \% \mathrm{Cl}$ & & \\
\hline \multicolumn{9}{|l|}{ Male } \\
\hline $50-64$ & 83 & $(81-84)$ & 10 & $(9-12)$ & 7 & $(6-8)$ & 100 & 2080 \\
\hline $65-74$ & 83 & $(80-85)$ & 10 & $(8-13)$ & 7 & $(6-9)$ & 100 & 1069 \\
\hline$>=75$ & 77 & $(73-80)$ & 16 & $(13-19)$ & 7 & $(5-10)$ & 100 & 598 \\
\hline Total & 82 & $(80-83)$ & 11 & $(10-12)$ & 7 & $(6-8)$ & 100 & 3747 \\
\hline \multicolumn{9}{|c|}{ Female } \\
\hline $50-64$ & 82 & $(81-84)$ & 11 & $(10-13)$ & 6 & $(5-7)$ & 100 & 2587 \\
\hline $65-74$ & 78 & $(76-81)$ & 14 & $(12-16)$ & 8 & $(6-9)$ & 100 & 1093 \\
\hline$>=75$ & 74 & $(71-78)$ & 15 & $(12-18)$ & 11 & $(8-13)$ & 100 & 749 \\
\hline Total & 80 & (79-81) & 13 & $(12-14)$ & 7 & $(7-8)$ & 100 & 4429 \\
\hline \multicolumn{9}{|l|}{ Total } \\
\hline $50-64$ & 83 & $(81-84)$ & 11 & $(10-12)$ & 7 & $(6-8)$ & 100 & 4667 \\
\hline $65-74$ & 81 & $(79-82)$ & 12 & $(11-14)$ & 7 & $(6-8)$ & 100 & 2162 \\
\hline$>=75$ & 75 & $(73-78)$ & 15 & $(13-17)$ & 9 & $(8-11)$ & 100 & 1347 \\
\hline Total & 81 & $(80-82)$ & 12 & $(11-13)$ & 7 & $(7-8)$ & 100 & 8176 \\
\hline
\end{tabular}

Note. $\mathrm{Cl}=$ confidence interval; Missing observations $=0.02 \%$ 
Table 5.A18: Number of falls in the last year by age and education

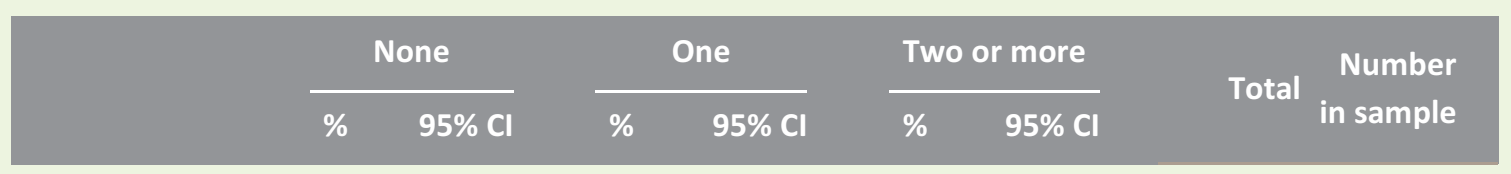

Primary/none

\begin{tabular}{lllllllll}
$50-64$ & 80 & $(78-83)$ & 11 & $(9-13)$ & 9 & $(7-11)$ & 100 & 957 \\
$65-74$ & 81 & $(78-83)$ & 12 & $(10-14)$ & 8 & $(6-10)$ & 100 & 865 \\
$>=75$ & 77 & $(73-80)$ & 14 & $(11-17)$ & 9 & $(7-12)$ & 100 & 684 \\
\hline Total & 79 & $(78-81)$ & 12 & $(11-13)$ & 9 & $(8-10)$ & 100 & 2506 \\
\hline
\end{tabular}

Secondary

\begin{tabular}{lcccccccc}
$50-64$ & 84 & $(82-85)$ & 10 & $(9-11)$ & 6 & $(5-7)$ & 100 & 2118 \\
$65-74$ & 82 & $(79-85)$ & 12 & $(10-15)$ & 6 & $(5-8)$ & 100 & 728 \\
$>=75$ & 71 & $(67-76)$ & 18 & $(14-22)$ & 11 & $(8-14)$ & 100 & 417 \\
\hline Total & 82 & $(81-83)$ & 11 & $(10-12)$ & 7 & $(6-8)$ & 100 & 3263 \\
\hline
\end{tabular}

\section{Third/higher}

\begin{tabular}{lcccccccc}
$50-64$ & 82 & $(80-84)$ & 12 & $(11-14)$ & 6 & $(5-7)$ & 100 & 1592 \\
$65-74$ & 77 & $(73-80)$ & 14 & $(12-17)$ & 9 & $(7-11)$ & 100 & 568 \\
$>=75$ & 77 & $(72-82)$ & 18 & $(14-24)$ & 5 & $(3-8)$ & 100 & 243 \\
\hline Total & 81 & $(79-82)$ & 13 & $(12-14)$ & 6 & $(5-7)$ & 100 & 2403 \\
\hline Total & & & & & & & 100 & 4667 \\
$50-64$ & 83 & $(81-84)$ & 11 & $(10-12)$ & 7 & $(6-8)$ & 100 & 2162 \\
$65-74$ & 81 & $(79-82)$ & 12 & $(11-14)$ & 7 & $(6-8)$ & 100 & 1347 \\
$>=75$ & 75 & $(73-78)$ & 15 & $(13-17)$ & 9 & $(8-11)$ & 100 & 8176 \\
\hline Total & 81 & $(80-82)$ & 12 & $(11-13)$ & 7 & $(7-8)$ & & 100 \\
\hline
\end{tabular}

Note. $\mathrm{Cl}=$ confidence interval; Missing observations $=0.02 \%$ 
Table 5.A19: Number of falls in the past year by age and wealth

\begin{tabular}{|c|c|c|c|c|c|c|c|c|}
\hline & \multicolumn{2}{|c|}{ None } & \multicolumn{2}{|c|}{ One } & \multicolumn{2}{|c|}{ Two or more } & \multirow{2}{*}{ Total } & \multirow{2}{*}{$\begin{array}{r}\text { Number in } \\
\text { sample }\end{array}$} \\
\hline & $\%$ & $95 \% \mathrm{Cl}$ & $\%$ & $95 \% \mathrm{Cl}$ & $\%$ & $95 \% \mathrm{Cl}$ & & \\
\hline \multicolumn{9}{|c|}{ Lowest } \\
\hline $50-64$ & 79 & $(75-83)$ & 10 & $(7-13)$ & 11 & $(9-14)$ & 100 & 567 \\
\hline $65-74$ & 80 & $(74-86)$ & 13 & $(9-18)$ & 7 & $(4-11)$ & 100 & 243 \\
\hline$>=75$ & 75 & $(68-82)$ & 14 & $(9-21)$ & 11 & $(7-16)$ & 100 & 178 \\
\hline Total & 78 & $(75-81)$ & 11 & $(9-14)$ & 10 & $(8-13)$ & 100 & 988 \\
\hline \multicolumn{9}{|l|}{ 2nd } \\
\hline $50-64$ & 86 & $(83-89)$ & 7 & $(6-10)$ & 6 & $(4-9)$ & 100 & 586 \\
\hline $65-74$ & 82 & $(77-87)$ & 10 & $(7-15)$ & 7 & $(5-11)$ & 100 & 268 \\
\hline$>=75$ & 77 & $(68-84)$ & 16 & $(10-25)$ & 7 & $(4-12)$ & 100 & 145 \\
\hline Total & 83 & $(80-86)$ & 10 & $(8-12)$ & 7 & $(5-9)$ & 100 & 999 \\
\hline \multicolumn{9}{|l|}{ 3rd } \\
\hline $50-64$ & 83 & $(80-86)$ & 10 & $(8-13)$ & 7 & $(5-10)$ & 100 & 590 \\
\hline $65-74$ & 84 & $(79-88)$ & 9 & $(6-13)$ & 7 & $(5-11)$ & 100 & 262 \\
\hline$>=75$ & 69 & $(57-78)$ & 20 & $(12-33)$ & 11 & $(6-19)$ & 100 & 123 \\
\hline Total & 81 & (78-84) & 11 & (9-14) & 8 & $(6-10)$ & 100 & 975 \\
\hline \multicolumn{9}{|c|}{ Highest } \\
\hline $50-64$ & 81 & $(77-84)$ & 13 & $(10-16)$ & 6 & $(4-9)$ & 100 & 634 \\
\hline $65-74$ & 78 & $(71-83)$ & 16 & $(12-22)$ & 6 & $(4-10)$ & 100 & 258 \\
\hline$>=75$ & 69 & $(58-79)$ & 20 & $(13-30)$ & 11 & $(5-20)$ & 100 & 95 \\
\hline Total & 79 & $(76-82)$ & 14 & $(12-17)$ & 7 & $(5-9)$ & 100 & 987 \\
\hline \multicolumn{9}{|l|}{ Total } \\
\hline $50-64$ & 83 & $(82-84)$ & 10 & $(9-11)$ & 7 & $(6-7)$ & 100 & 4667 \\
\hline $65-74$ & 81 & $(79-82)$ & 12 & $(11-14)$ & 7 & $(6-9)$ & 100 & 2162 \\
\hline$>=75$ & 76 & $(73-79)$ & 15 & $(13-17)$ & 9 & $(8-11)$ & 100 & 1347 \\
\hline Total & 81 & $(80-82)$ & 12 & $(11-13)$ & 7 & (7-8) & 100 & 8176 \\
\hline
\end{tabular}

Note. $\mathrm{Cl}=$ confidence interval; Missing observations $=0.02 \%$ 
Table 5.A20: Smoking history by age and sex

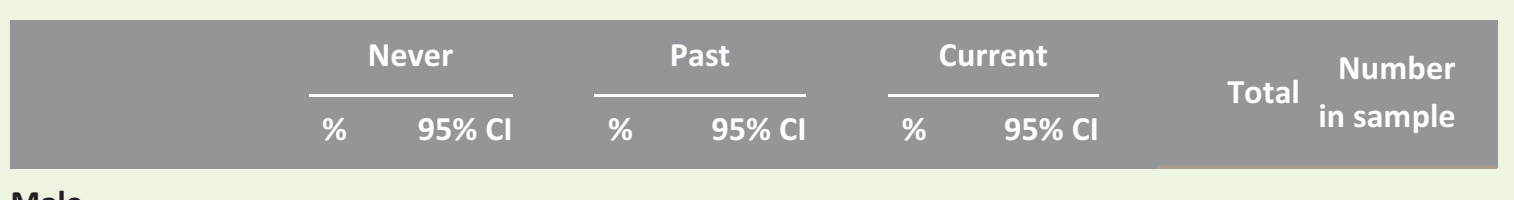

\section{Male}

\begin{tabular}{lllllllll}
$50-64$ & 38 & $(36-40)$ & 40 & $(37-42)$ & 22 & $(20-24)$ & 100 & 2080 \\
$65-74$ & 31 & $(28-34)$ & 53 & $(50-57)$ & 16 & $(14-18)$ & 100 & 1070 \\
$>=75$ & 31 & $(27-36)$ & 55 & $(50-59)$ & 14 & $(11-17)$ & 100 & 598 \\
\hline Total & 35 & $(34-37)$ & 45 & $(43-47)$ & 19 & $(18-21)$ & 100 & 3748 \\
\hline
\end{tabular}

\section{Female}

\begin{tabular}{lllllllll}
$50-64$ & 46 & $(44-48)$ & 31 & $(29-33)$ & 24 & $(22-26)$ & 100 & 2587 \\
$65-74$ & 53 & $(50-56)$ & 30 & $(27-32)$ & 17 & $(15-20)$ & 100 & 1093 \\
$>=75$ & 57 & $(53-61)$ & 33 & $(29-37)$ & 10 & $(7-12)$ & 100 & 749 \\
\hline Total & 50 & $(48-52)$ & 31 & $(29-32)$ & 19 & $(18-21)$ & 100 & 4429 \\
\hline Total & & & & & & & 100 & 4667 \\
$50-64$ & 42 & $(40-44)$ & 35 & $(34-37)$ & 23 & $(22-24)$ & 100 & 2163 \\
$65-74$ & 42 & $(40-44)$ & 41 & $(39-43)$ & 17 & $(15-18)$ & 100 & 1347 \\
$>=75$ & 47 & $(44-50)$ & 42 & $(39-45)$ & 11 & $(10-13)$ & 100 & 8177 \\
\hline Total & 43 & $(42-44)$ & 38 & $(36-39)$ & 19 & $(18-20)$ & 100 \\
\hline
\end{tabular}

Note. $\mathrm{Cl}=$ confidence interval; Missing observations $=0.01 \%$ 
Table 5.A21: Smoking history by age and education

\begin{tabular}{|c|c|c|c|c|c|c|c|c|}
\hline & \multicolumn{2}{|c|}{ Never } & \multicolumn{2}{|c|}{ Past } & \multicolumn{2}{|c|}{ Current } & \multirow{2}{*}{ Total } & \multirow{2}{*}{$\begin{array}{l}\text { Number } \\
\text { in sample }\end{array}$} \\
\hline & $\%$ & $95 \% \mathrm{Cl}$ & $\%$ & $95 \% \mathrm{Cl}$ & $\%$ & $95 \% \mathrm{Cl}$ & & \\
\hline \multicolumn{9}{|c|}{ Primary/none } \\
\hline $50-64$ & 32 & $(28-35)$ & 36 & $(32-39)$ & 33 & $(29-36)$ & 100 & 956 \\
\hline $65-74$ & 40 & $(37-43)$ & 41 & $(38-44)$ & 19 & $(17-22)$ & 100 & 865 \\
\hline$>=75$ & 45 & $(41-50)$ & 42 & $(38-46)$ & 13 & $(11-16)$ & 100 & 684 \\
\hline Total & 38 & $(36-41)$ & 39 & $(37-41)$ & 22 & $(20-24)$ & 100 & 2505 \\
\hline \multicolumn{9}{|c|}{ Secondary } \\
\hline $50-64$ & 44 & $(42-46)$ & 34 & $(31-36)$ & 22 & $(21-24)$ & 100 & 2119 \\
\hline $65-74$ & 44 & $(40-47)$ & 41 & $(37-44)$ & 15 & $(13-18)$ & 100 & 728 \\
\hline$>=75$ & 54 & (49-59) & 38 & $(33-43)$ & 8 & $(5-11)$ & 100 & 417 \\
\hline Total & 45 & $(43-47)$ & 35 & (34-37) & 20 & $(18-21)$ & 100 & 3264 \\
\hline
\end{tabular}

\section{Third/higher}

\begin{tabular}{lllllllll}
$50-64$ & 49 & $(46-51)$ & 38 & $(35-40)$ & 14 & $(12-15)$ & 100 & 1592 \\
$65-74$ & 46 & $(42-50)$ & 43 & $(39-48)$ & 10 & $(8-13)$ & 100 & 569 \\
$>=75$ & 40 & $(34-46)$ & 50 & $(44-56)$ & 10 & $(7-15)$ & 100 & 243 \\
\hline Total & 47 & $(45-49)$ & 40 & $(38-42)$ & 13 & $(11-14)$ & 100 & 2404 \\
\hline Total & & & & & & & 100 & 4667 \\
$50-64$ & 42 & $(40-44)$ & 35 & $(34-37)$ & 23 & $(22-24)$ & 100 & 2163 \\
$65-74$ & 42 & $(40-44)$ & 41 & $(39-43)$ & 17 & $(15-18)$ & 100 & 1347 \\
$>=75$ & 47 & $(44-50)$ & 42 & $(39-45)$ & 11 & $(10-13)$ & 100 & 8177 \\
\hline Total & 43 & $(42-44)$ & 38 & $(36-39)$ & 19 & $(18-20)$ & & 100
\end{tabular}

Note. $\mathrm{Cl}=$ confidence interval; Missing observations $=0.01 \%$ 
Table 5.A22: Smoking history by age and wealth

\begin{tabular}{|c|c|c|c|c|c|c|c|}
\hline \multicolumn{2}{|c|}{ Never } & \multicolumn{2}{|c|}{ Past } & \multicolumn{2}{|c|}{ Current } & \multirow{2}{*}{ Total } & \multirow{2}{*}{$\begin{array}{l}\text { Number } \\
\text { in sample }\end{array}$} \\
\hline$\%$ & $95 \% \mathrm{Cl}$ & $\%$ & $95 \% \mathrm{Cl}$ & $\%$ & $95 \% \mathrm{Cl}$ & & \\
\hline
\end{tabular}

\section{Lowest}

\begin{tabular}{|c|c|c|c|c|c|c|c|c|}
\hline $50-64$ & 28 & $(24-32)$ & 27 & $(23-32)$ & 45 & $(40-50)$ & 100 & 567 \\
\hline $65-74$ & 36 & $(30-42)$ & 43 & $(37-49)$ & 22 & $(17-28)$ & 100 & 243 \\
\hline$>=75$ & 42 & $(35-50)$ & 42 & $(35-50)$ & 16 & $(11-22)$ & 100 & 178 \\
\hline Total & 33 & $(30-37)$ & 35 & $(31-38)$ & 32 & $(28-36)$ & 100 & 988 \\
\hline \multicolumn{9}{|l|}{ 2nd } \\
\hline $50-64$ & 36 & $(32-41)$ & 37 & $(33-42)$ & 26 & $(23-30)$ & 100 & 586 \\
\hline $65-74$ & 43 & $(37-50)$ & 42 & $(35-48)$ & 15 & $(11-21)$ & 100 & 268 \\
\hline$>=75$ & 47 & $(38-57)$ & 42 & $(32-51)$ & 11 & $(7-18)$ & 100 & 145 \\
\hline Total & 40 & $(36-44)$ & 39 & $(35-43)$ & 21 & $(18-24)$ & 100 & 999 \\
\hline \multicolumn{9}{|l|}{$3 r d$} \\
\hline $50-64$ & 43 & $(39-48)$ & 42 & $(38-47)$ & 15 & $(12-18)$ & 100 & 590 \\
\hline $65-74$ & 43 & $(36-51)$ & 44 & $(37-51)$ & 13 & $(9-18)$ & 100 & 262 \\
\hline$>=75$ & 47 & $(36-58)$ & 42 & $(32-53)$ & 11 & $(6-21)$ & 100 & 123 \\
\hline Total & 44 & $(40-48)$ & 42 & (39-46) & 14 & $(11-16)$ & 100 & 975 \\
\hline \multicolumn{9}{|c|}{ Highest } \\
\hline $50-64$ & 50 & $(46-54)$ & 37 & $(33-41)$ & 13 & $(10-17)$ & 100 & 634 \\
\hline $65-74$ & 51 & $(44-58)$ & 41 & $(34-48)$ & 8 & $(5-12)$ & 100 & 258 \\
\hline$>=75$ & 43 & $(31-56)$ & 41 & $(30-54)$ & 15 & $(6-34)$ & 100 & 95 \\
\hline Total & 50 & $(46-53)$ & 38 & $(35-42)$ & 12 & $(10-15)$ & 100 & 987 \\
\hline \multicolumn{9}{|l|}{ Total } \\
\hline $50-64$ & 43 & $(41-45)$ & 35 & $(33-36)$ & 22 & $(21-24)$ & 100 & 4667 \\
\hline $65-74$ & 43 & $(41-46)$ & 41 & $(39-43)$ & 16 & $(14-18)$ & 100 & 2163 \\
\hline$>=75$ & 48 & $(45-51)$ & 41 & $(38-44)$ & 11 & $(9-13)$ & 100 & 1347 \\
\hline Total & 44 & $(43-46)$ & 38 & (36-39) & 18 & (17-19) & 100 & 8177 \\
\hline
\end{tabular}

Note. $\mathrm{Cl}=$ confidence interval; Missing observations $=0.01 \%$ 
Table 5.A23: Problematic alcohol use and diagnosed substance abuse by age and sex

\begin{tabular}{|c|c|c|c|c|}
\hline & \multicolumn{2}{|c|}{$\begin{array}{c}\text { Alcohol Problem - } \\
\text { Objective }\end{array}$} & \multicolumn{2}{|c|}{$\begin{array}{l}\text { Diagnosed Alcohol } \\
\text { or Substance Abuse }\end{array}$} \\
\hline & $\%$ & $(95 \% \mathrm{Cl})$ & $\%$ & $(95 \% \mathrm{Cl})$ \\
\hline \multicolumn{5}{|l|}{ Male } \\
\hline $50-64$ & 8.6 & $(7.3-10.2)$ & 3.2 & $(2.4-4.2)$ \\
\hline $65-74$ & 6.0 & $(4.5-8.0)$ & 3.9 & $(2.9-5.4)$ \\
\hline$>=75$ & 2.4 & $(1.2-4.5)$ & 0.7 & $(0.3-1.8)$ \\
\hline Total & 7.0 & $(6.1-8.2)$ & 3.0 & (2.4-3.7) \\
\hline \multicolumn{5}{|c|}{ Female } \\
\hline $50-64$ & 4.0 & $(3.2-5.1)$ & 1.0 & $(0.7-1.6)$ \\
\hline $65-74$ & 1.5 & $(0.8-2.8)$ & 0.5 & $(0.2-1.3)$ \\
\hline$>=75$ & 0.6 & $(0.2-2.1)$ & 0.1 & $(0.0-0.6)$ \\
\hline Total & 2.7 & (2.2-3.4) & 0.7 & $(0.5-1.0)$ \\
\hline \multicolumn{5}{|l|}{ Total } \\
\hline $50-64$ & 6.3 & $(5.5-7.2)$ & 2.1 & $(1.6-2.7)$ \\
\hline $65-74$ & 3.7 & $(2.8-4.8)$ & 2.2 & $(1.6-3.0)$ \\
\hline$>=75$ & 1.3 & $(0.7-2.3)$ & 0.3 & $(0.1-0.8)$ \\
\hline Total & 4.8 & $(4.2-5.4)$ & 1.8 & (1.5-2.2) \\
\hline
\end{tabular}


Table 5.A24: Problematic alcohol use and diagnosed substance abuse by age and education

\begin{tabular}{|cccc|}
$\begin{array}{c}\text { Alcohol Problem - } \\
\text { Objective }\end{array}$ & \multicolumn{2}{c|}{$\begin{array}{c}\text { Diagnosed Alcohol } \\
\text { or Substance Abuse }\end{array}$} \\
\hline$\%$ & $(95 \% \mathrm{CI})$ & $\%$ & $(95 \% \mathrm{Cl})$ \\
\hline
\end{tabular}

Primary/none

\begin{tabular}{lllll}
$50-64$ & 5.5 & $(3.9-7.7)$ & 3.3 & $(2.2-5.0)$ \\
$65-74$ & 4.4 & $(3.0-6.5)$ & 2.6 & $(1.7-4.0)$ \\
$>=75$ & 1.4 & $(0.6-2.9)$ & 0.2 & $(0.1-1.0)$ \\
\hline Total & 3.9 & $(3.0-5.0)$ & 2.1 & $(1.6-2.8)$ \\
\hline
\end{tabular}

Secondary

\begin{tabular}{lllll}
$50-64$ & 7.1 & $(6.0-8.5)$ & 1.6 & $(1.2-2.3)$ \\
$65-74$ & 2.7 & $(1.7-4.4)$ & 1.6 & $(0.9-2.7)$ \\
$>=75$ & 1.1 & $(0.3-3.3)$ & 0.3 & $(0.0-1.8)$ \\
\hline Total & 5.7 & $(4.8-6.7)$ & 1.5 & $(1.1-2.0)$
\end{tabular}

Third/higher

\begin{tabular}{lllll}
$50-64$ & 5.3 & $(4.1-6.8)$ & 1.5 & $(1.0-2.4)$ \\
$65-74$ & 3.7 & $(2.3-5.9)$ & 2.0 & $(1.1-3.6)$ \\
$>=75$ & 1.5 & $(0.5-4.6)$ & 1.5 & $(0.6-3.9)$ \\
\hline Total & 4.7 & $(3.7-5.8)$ & 1.6 & $(1.1-2.3)$ \\
\hline Total & & & & \\
$50-64$ & 6.3 & $(5.5-7.2)$ & 2.1 & $(1.6-2.7)$ \\
$65-74$ & 3.7 & $(2.8-4.8)$ & 2.2 & $(1.6-3.0)$ \\
$>=75$ & 1.3 & $(0.7-2.3)$ & 0.3 & $(0.1-0.8)$ \\
\hline Total & 4.8 & $(4.2-5.4)$ & 1.8 & $(1.5-2.2)$ \\
\hline
\end{tabular}


Table 5.A25: Problematic alcohol use and diagnosed substance abuse by age and wealth

\begin{tabular}{|c|c|c|c|c|}
\hline & \multicolumn{2}{|c|}{$\begin{array}{c}\text { Alcohol Problem - } \\
\text { Objective }\end{array}$} & \multicolumn{2}{|c|}{$\begin{array}{l}\text { Diagnosed Alcohol } \\
\text { or Substance Abuse }\end{array}$} \\
\hline & $\%$ & (95\% Cl) & $\%$ & $(95 \% \mathrm{Cl})$ \\
\hline \multicolumn{5}{|c|}{ Lowest } \\
\hline $50-64$ & 7.8 & $(5.2-11.5)$ & 4.5 & $(2.9-7.0)$ \\
\hline $65-74$ & 5.5 & $(2.9-10.3)$ & 1.9 & $(0.8-4.4)$ \\
\hline$>=75$ & 1.9 & $(0.6-6.0)$ & 0.4 & $(0.1-2.9)$ \\
\hline Total & 5.8 & $(4.1-8.1)$ & 2.9 & $(2.0-4.3)$ \\
\hline \multicolumn{5}{|l|}{ 2nd } \\
\hline $50-64$ & 7.2 & $(5.0-10.4)$ & 3.0 & $(1.8-5.0)$ \\
\hline $65-74$ & 2.3 & $(1.0-5.2)$ & 2.7 & $(1.3-5.6)$ \\
\hline$>=75$ & 2.7 & $(0.7-10.2)$ & 0.4 & $(0.1-1.5)$ \\
\hline Total & 5.2 & $(3.8-7.2)$ & 2.4 & $(1.6-3.6)$ \\
\hline \multicolumn{5}{|l|}{ 3rd } \\
\hline $50-64$ & 5.2 & $(3.4-7.8)$ & 0.8 & $(0.3-2.2)$ \\
\hline $65-74$ & 2.9 & $(1.2-6.8)$ & 1.0 & $(0.3-3.3)$ \\
\hline$>=75$ & 0.9 & $(0.1-6.0)$ & 0.6 & $(0.1-4.2)$ \\
\hline Total & 4.0 & $(2.7-5.8)$ & 0.8 & $(0.4-1.7)$ \\
\hline \multicolumn{5}{|c|}{ Highest } \\
\hline $50-64$ & 6.6 & $(4.8-9.2)$ & 0.9 & $(0.3-2.1)$ \\
\hline $65-74$ & 2.5 & $(1.1-5.4)$ & 1.9 & $(0.7-5.2)$ \\
\hline$>=75$ & 0.0 & - & 0.0 & - \\
\hline Total & 5.0 & (3.7-6.8) & 1.0 & $(0.5-1.9)$ \\
\hline \multicolumn{5}{|l|}{ Total } \\
\hline $50-64$ & 5.8 & $(5.0-6.7)$ & 1.9 & $(1.5-2.4)$ \\
\hline $65-74$ & 3.2 & $(2.4-4.2)$ & 2.0 & $(1.5-2.8)$ \\
\hline$>=75$ & 1.2 & $(0.6-2.3)$ & 0.2 & $(0.1-0.5)$ \\
\hline Total & 4.2 & (3.7-4.8) & 1.5 & (1.2-1.9) \\
\hline
\end{tabular}


Table 5.A26: Physical activity by age and sex

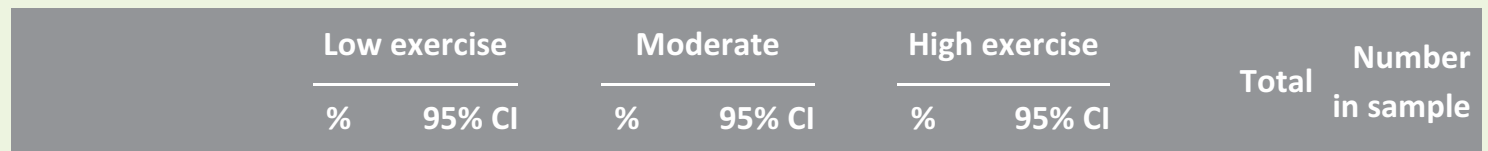

Male

\begin{tabular}{lllllllll}
$50-64$ & 23 & $(21-25)$ & 29 & $(27-31)$ & 48 & $(45-50)$ & 100 & 2059 \\
$65-74$ & 25 & $(22-28)$ & 37 & $(34-41)$ & 38 & $(34-41)$ & 100 & 1060 \\
$>=75$ & 42 & $(37-46)$ & 31 & $(27-35)$ & 28 & $(24-32)$ & 100 & 592 \\
\hline Total & 26 & $(25-28)$ & 31 & $(30-33)$ & 42 & $(40-45)$ & 100 & 3711 \\
\hline
\end{tabular}

Female

\begin{tabular}{lllllllll}
$50-64$ & 32 & $(30-34)$ & 36 & $(34-38)$ & 32 & $(29-34)$ & 100 & 2556 \\
$65-74$ & 40 & $(36-43)$ & 35 & $(32-38)$ & 26 & $(23-29)$ & 100 & 1092 \\
$>=75$ & 59 & $(55-63)$ & 30 & $(27-34)$ & 11 & $(9-14)$ & 100 & 742 \\
\hline Total & 39 & $(38-41)$ & 35 & $(33-36)$ & 26 & $(24-28)$ & 100 & 4390 \\
\hline Total & 28 & $(26-29)$ & 33 & $(31-34)$ & 40 & $(38-42)$ & 100 & 4615 \\
$50-64$ & 32 & $(30-35)$ & 36 & $(34-39)$ & 31 & $(29-34)$ & 100 & 2152 \\
$65-74$ & 52 & $(49-55)$ & 30 & $(28-33)$ & 18 & $(15-20)$ & 100 & 1334 \\
$>=75$ & 33 & $(32-35)$ & 33 & $(32-34)$ & 34 & $(32-36)$ & 100 & 8101 \\
\hline Total & & & & & & & \\
\hline
\end{tabular}

Note. $\mathrm{Cl}=$ confidence interval; Missing observations $=0.94 \%$ 
Table 5.A27: Physical activity by age and education

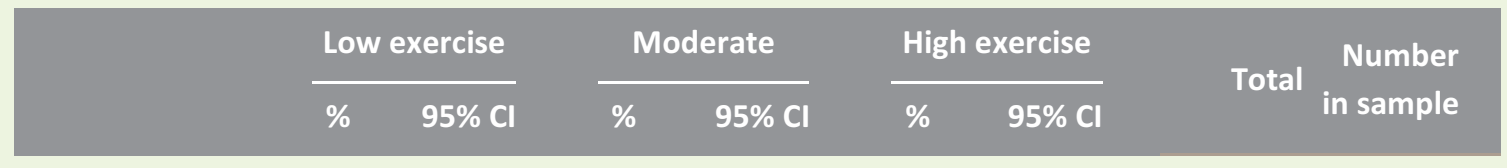

\section{Primary/none}

\begin{tabular}{|c|c|c|c|c|c|c|c|c|}
\hline $50-64$ & 30 & $(27-33)$ & 33 & $(30-36)$ & 38 & $(34-41)$ & 100 & 947 \\
\hline $65-74$ & 34 & $(31-38)$ & 36 & $(32-40)$ & 30 & $(27-34)$ & 100 & 859 \\
\hline$>=75$ & 55 & (51-59) & 29 & $(25-32)$ & 16 & $(13-20)$ & 100 & 678 \\
\hline Total & 39 & $(37-41)$ & 32 & $(30-34)$ & 29 & $(26-31)$ & 100 & 2484 \\
\hline \multicolumn{9}{|c|}{ Secondary } \\
\hline $50-64$ & 28 & $(26-30)$ & 31 & $(29-33)$ & 41 & $(38-44)$ & 100 & 2091 \\
\hline $65-74$ & 33 & $(29-37)$ & 36 & $(33-40)$ & 31 & $(27-35)$ & 100 & 724 \\
\hline$>=75$ & 50 & $(45-55)$ & 32 & $(28-37)$ & 18 & $(14-22)$ & 100 & 412 \\
\hline Total & 31 & (29-33) & 32 & $(30-34)$ & 37 & (34-39) & 100 & 3227 \\
\hline \multicolumn{9}{|c|}{ Third/higher } \\
\hline $50-64$ & 24 & $(22-27)$ & 36 & (34-39) & 39 & $(36-42)$ & 100 & 1577 \\
\hline $65-74$ & 25 & $(21-29)$ & 36 & $(33-41)$ & 39 & $(34-43)$ & 100 & 568 \\
\hline$>=75$ & 36 & $(31-42)$ & 36 & $(31-43)$ & 27 & $(22-33)$ & 100 & 241 \\
\hline Total & 26 & $(24-28)$ & 36 & (34-38) & 38 & $(36-40)$ & 100 & 2386 \\
\hline \multicolumn{9}{|l|}{ Total } \\
\hline $50-64$ & 28 & $(26-29)$ & 33 & $(31-34)$ & 40 & $(38-42)$ & 100 & 4615 \\
\hline $65-74$ & 32 & $(30-35)$ & 36 & $(34-39)$ & 31 & $(29-34)$ & 100 & 2152 \\
\hline$>=75$ & 52 & $(49-55)$ & 30 & $(28-33)$ & 18 & $(15-20)$ & 100 & 1334 \\
\hline Total & 33 & (32-35) & 33 & (32-34) & 34 & $(32-36)$ & 100 & 8101 \\
\hline
\end{tabular}

Note. $\mathrm{Cl}=$ confidence interval; Missing observations $=0.94 \%$ 
Table 5.A28: Physical activity by age and wealth

\begin{tabular}{|c|c|c|c|c|c|c|c|c|}
\hline & \multicolumn{2}{|c|}{ Low exercise } & \multicolumn{2}{|c|}{ Moderate } & \multicolumn{2}{|c|}{ High exercise } & \multirow{2}{*}{ Total } & \multirow{2}{*}{$\begin{array}{l}\text { Number } \\
\text { in sample }\end{array}$} \\
\hline & $\%$ & $95 \% \mathrm{Cl}$ & $\%$ & $95 \% \mathrm{Cl}$ & $\%$ & $95 \% \mathrm{Cl}$ & & \\
\hline \multicolumn{9}{|c|}{ Lowest } \\
\hline $50-64$ & 31 & $(27-35)$ & 37 & $(32-42)$ & 33 & $(28-38)$ & 100 & 562 \\
\hline $65-74$ & 39 & $(32-45)$ & 43 & $(36-51)$ & 18 & $(13-25)$ & 100 & 242 \\
\hline$>=75$ & 60 & $(52-68)$ & 28 & $(21-36)$ & 12 & $(8-19)$ & 100 & 178 \\
\hline Total & 40 & $(36-44)$ & 36 & $(31-41)$ & 24 & $(20-28)$ & 100 & 982 \\
\hline
\end{tabular}

2nd

\begin{tabular}{lllllllll}
$50-64$ & 30 & $(26-34)$ & 34 & $(30-38)$ & 36 & $(32-41)$ & 100 & 583 \\
$65-74$ & 38 & $(32-44)$ & 36 & $(31-42)$ & 26 & $(21-32)$ & 100 & 268 \\
$>=75$ & 59 & $(48-68)$ & 30 & $(21-40)$ & 11 & $(7-17)$ & 100 & 145 \\
\hline Total & 37 & $(34-42)$ & 34 & $(31-37)$ & 29 & $(25-32)$ & 100 & 996 \\
\hline
\end{tabular}

3rd

\begin{tabular}{lllllllll}
$50-64$ & 29 & $(25-34)$ & 32 & $(28-36)$ & 39 & $(34-44)$ & 100 & 585 \\
$65-74$ & 30 & $(25-37)$ & 34 & $(27-40)$ & 36 & $(29-44)$ & 100 & 262 \\
$>=75$ & 46 & $(34-58)$ & 34 & $(25-45)$ & 20 & $(12-31)$ & 100 & 123 \\
\hline Total & 32 & $(28-36)$ & 33 & $(29-36)$ & 35 & $(31-39)$ & 100 & 970 \\
\hline
\end{tabular}

Highest

\begin{tabular}{lllllllll}
$50-64$ & 23 & $(20-28)$ & 34 & $(30-39)$ & 42 & $(37-47)$ & 100 & 633 \\
$65-74$ & 23 & $(17-30)$ & 39 & $(32-46)$ & 38 & $(31-46)$ & 100 & 257 \\
$>=75$ & 37 & $(24-51)$ & 31 & $(21-42)$ & 33 & $(23-45)$ & 100 & 95 \\
\hline Total & 25 & $(21-28)$ & 35 & $(32-39)$ & 40 & $(36-44)$ & 100 & 985 \\
\hline
\end{tabular}

Total

\begin{tabular}{lllllllll}
$50-64$ & 28 & $(26-30)$ & 33 & $(31-34)$ & 39 & $(37-42)$ & 100 & 4615 \\
$65-74$ & 34 & $(32-36)$ & 35 & $(32-37)$ & 31 & $(29-34)$ & 100 & 2152 \\
$>=75$ & 54 & $(50-57)$ & 30 & $(27-33)$ & 17 & $(15-20)$ & 100 & 1334 \\
\hline Total & 35 & $(34-37)$ & 32 & $(31-34)$ & 32 & $(31-34)$ & 100 & 8101
\end{tabular}

Note. $\mathrm{Cl}=$ confidence interval; Missing observations $=0.94 \%$ 
Table 5.A29: Flu vaccination and medical screening by age and sex

\begin{tabular}{|c|c|c|c|c|c|c|c|c|c|c|}
\hline & \multicolumn{2}{|c|}{ Flu jab } & \multicolumn{2}{|c|}{$\begin{array}{l}\text { Cholesterol } \\
\text { test }\end{array}$} & \multicolumn{2}{|c|}{$\begin{array}{c}\text { Prostate cancer } \\
\text { test }\end{array}$} & \multicolumn{2}{|c|}{$\begin{array}{l}\text { Checks breast } \\
\text { for lumps }\end{array}$} & \multicolumn{2}{|c|}{ Mammogram } \\
\hline & $\%$ & $(95 \% \mathrm{CI})$ & $\%$ & $(95 \% \mathrm{CI})$ & $\%$ & $(95 \% \mathrm{Cl})$ & $\%$ & $(95 \% \mathrm{Cl})$ & $\%$ & (95\% Cl) \\
\hline \multicolumn{11}{|l|}{ Male } \\
\hline $50-64$ & 31 & $(29-33)$ & 85 & $(84-87)$ & 69 & $(67-71)$ & & & & \\
\hline $65-74$ & 67 & (64-70) & 92 & $(90-94)$ & 80 & $(77-83)$ & & & & \\
\hline$>=75$ & 84 & $(81-87)$ & 90 & $(87-92)$ & 76 & $(72-79)$ & & & & \\
\hline Total & 48 & $(46-50)$ & 88 & (86-89) & 73 & $(71-75)$ & & & & \\
\hline \multicolumn{11}{|c|}{ Female } \\
\hline $50-64$ & 34 & $(32-36)$ & 85 & $(83-86)$ & & & 73 & $(71-75)$ & 86 & $(85-88)$ \\
\hline $65-74$ & 67 & $(64-70)$ & 91 & (89-93) & & & 67 & $(64-70)$ & 77 & (74-79) \\
\hline$>=75$ & 83 & $(80-86)$ & 88 & $(85-90)$ & & & 50 & $(46-54)$ & 34 & $(31-38)$ \\
\hline Total & 52 & (50-54) & 87 & $(86-88)$ & & & 67 & (65-68) & 73 & $(71-75)$ \\
\hline \multicolumn{11}{|l|}{ Total } \\
\hline $50-64$ & 33 & $(31-34)$ & 85 & $(84-86)$ & & & & & & \\
\hline $65-74$ & 67 & $(65-69)$ & 92 & $(90-93)$ & & & & & & \\
\hline$>=75$ & 83 & $(81-85)$ & 89 & $(87-91)$ & & & & & & \\
\hline Total & 50 & $(49-51)$ & 87 & $(86-88)$ & & & & & & \\
\hline
\end{tabular}


Table 5.A30: Flu vaccination and medical screening by age and education

\begin{tabular}{|c|c|c|c|c|c|c|c|c|c|c|}
\hline & \multicolumn{2}{|c|}{ Flu jab } & \multicolumn{2}{|c|}{$\begin{array}{c}\text { Cholesterol } \\
\text { test }\end{array}$} & \multicolumn{2}{|c|}{$\begin{array}{l}\text { Checks breast } \\
\text { for lumps } \\
\text { (female only) }\end{array}$} & \multicolumn{2}{|c|}{$\begin{array}{l}\text { Mammogram } \\
\text { (female only) }\end{array}$} & \multicolumn{2}{|c|}{$\begin{array}{l}\text { Prostate } \\
\text { cancer test } \\
\text { (male only) }\end{array}$} \\
\hline & $\%$ & (95\% Cl) & $\%$ & $(95 \% \mathrm{CI})$ & $\%$ & $\begin{array}{r}(95 \% \\
\mathrm{Cl})\end{array}$ & $\%$ & (95\% Cl) & $\%$ & $\begin{array}{r}(95 \% \\
\mathrm{CI})\end{array}$ \\
\hline \multicolumn{11}{|c|}{ Primary/none } \\
\hline $50-64$ & 40 & $(36-43)$ & 84 & $(81-86)$ & 74 & $(70-78)$ & 83 & $(79-86)$ & 64 & (59-69) \\
\hline $65-74$ & 70 & $(67-74)$ & 91 & (89-93) & 66 & $(61-70)$ & 73 & $(68-77)$ & 77 & $(72-81)$ \\
\hline$>=75$ & 82 & $(79-85)$ & 87 & $(84-90)$ & 50 & $(45-55)$ & 29 & $(25-34)$ & 71 & (66-76) \\
\hline Total & 62 & $(60-64)$ & 87 & $(85-88)$ & 63 & $(60-65)$ & 60 & (57-63) & 70 & (67-73) \\
\hline \multicolumn{11}{|c|}{ Secondary } \\
\hline $50-64$ & 28 & $(26-30)$ & 85 & $(83-86)$ & 73 & $(70-76)$ & 87 & (84-89) & 69 & $(66-72)$ \\
\hline $65-74$ & 64 & $(60-67)$ & 92 & $(90-94)$ & 70 & $(65-74)$ & 78 & $(74-82)$ & 83 & $(78-87)$ \\
\hline$>=75$ & 86 & $(82-89)$ & 92 & $(90-95)$ & 51 & $(45-57)$ & 41 & $(36-47)$ & 85 & $(78-90)$ \\
\hline Total & 41 & $(40-43)$ & 87 & (85-88) & 70 & $(68-72)$ & 79 & $(77-81)$ & 73 & (70-75) \\
\hline \multicolumn{11}{|c|}{ Third/higher } \\
\hline $50-64$ & 35 & $(32-37)$ & 88 & $(87-90)$ & 72 & $(69-75)$ & 89 & $(87-91)$ & 75 & (72-79) \\
\hline $65-74$ & 65 & (61-69) & 93 & $(90-95)$ & 67 & $(61-72)$ & 83 & $(78-87)$ & 88 & $(83-91)$ \\
\hline$>=75$ & 85 & $(80-89)$ & 91 & $(87-94)$ & 50 & $(41-58)$ & 54 & $(44-63)$ & 83 & $(75-89)$ \\
\hline Total & 45 & $(43-47)$ & 89 & (88-91) & 69 & $(66-71)$ & 84 & $(82-86)$ & 78 & $(75-81)$ \\
\hline \multicolumn{11}{|l|}{ Total } \\
\hline $50-64$ & 33 & $(31-34)$ & 85 & $(84-86)$ & 73 & $(71-75)$ & 86 & $(85-88)$ & 69 & (67-71) \\
\hline $65-74$ & 67 & $(65-69)$ & 92 & $(90-93)$ & 67 & $(64-70)$ & 77 & (74-79) & 80 & $(77-83)$ \\
\hline$>=75$ & 83 & $(81-85)$ & 89 & $(87-91)$ & 50 & $(46-54)$ & 34 & $(31-38)$ & 76 & (72-79) \\
\hline Total & 50 & $(49-51)$ & 87 & $(86-88)$ & 67 & $(65-68)$ & 73 & $(71-75)$ & 73 & (71-75) \\
\hline
\end{tabular}


Table 5.A31: Flu vaccination and medical screening by age and wealth

\begin{tabular}{|c|c|c|c|c|c|c|c|c|c|c|}
\hline & \multicolumn{2}{|c|}{ Flu jab } & \multicolumn{2}{|c|}{$\begin{array}{c}\text { Cholesterol } \\
\text { test }\end{array}$} & \multicolumn{2}{|c|}{$\begin{array}{l}\text { Checks breast } \\
\text { for lumps } \\
\text { (female only) }\end{array}$} & \multicolumn{2}{|c|}{$\begin{array}{l}\text { Mammogram } \\
\text { (female only) }\end{array}$} & \multicolumn{2}{|c|}{$\begin{array}{l}\text { Prostate } \\
\text { cancer test } \\
\text { (male only) }\end{array}$} \\
\hline & $\%$ & $(95 \% \mathrm{Cl})$ & $\%$ & $(95 \% \mathrm{Cl})$ & $\%$ & $(95 \% \mathrm{CI})$ & $\%$ & $(95 \% \mathrm{Cl})$ & $\%$ & $(95 \% \mathrm{CI})$ \\
\hline \multicolumn{11}{|c|}{ Lowest } \\
\hline $50-64$ & 37 & $(33-41)$ & 78 & $(73-82)$ & 70 & $(63-76)$ & 77 & $(71-81)$ & 52 & $(45-59)$ \\
\hline $65-74$ & 72 & $(64-79)$ & 91 & $(86-94)$ & 72 & $(62-80)$ & 69 & $(58-79)$ & 77 & $(66-85)$ \\
\hline$>=75$ & 87 & $(79-91)$ & 87 & $(80-91)$ & 58 & $(48-69)$ & 36 & $(27-47)$ & 84 & $(72-91)$ \\
\hline Total & 57 & (53-61) & 83 & $(79-86)$ & 67 & (61-72) & 63 & $(57-68)$ & 64 & $(58-69)$ \\
\hline \multicolumn{11}{|l|}{ 2nd } \\
\hline $50-64$ & 33 & $(29-37)$ & 85 & $(81-87)$ & 71 & $(65-77)$ & 84 & $(78-88)$ & 67 & $(61-72)$ \\
\hline $65-74$ & 71 & $(65-77)$ & 91 & $(87-94)$ & 65 & $(56-73)$ & 70 & $(60-79)$ & 80 & $(72-86)$ \\
\hline$>=75$ & 75 & (64-83) & 94 & (88-97) & 41 & $(29-55)$ & 26 & $(18-38)$ & 70 & $(56-81)$ \\
\hline Total & 51 & $(47-54)$ & 88 & $(86-90)$ & 62 & (57-67) & 66 & $(61-71)$ & 70 & $(65-74)$ \\
\hline \multicolumn{11}{|l|}{$3 r d$} \\
\hline $50-64$ & 33 & $(29-38)$ & 90 & $(87-93)$ & 74 & $(69-79)$ & 91 & $(87-94)$ & 71 & $(65-77)$ \\
\hline $65-74$ & 66 & $(58-73)$ & 89 & $(84-93)$ & 64 & (54-73) & 82 & $(73-89)$ & 81 & $(72-87)$ \\
\hline$>=75$ & 86 & $(78-92)$ & 98 & (94-99) & 42 & $(27-60)$ & 47 & $(31-63)$ & 79 & $(66-87)$ \\
\hline Total & 50 & $(46-54)$ & 91 & (89-93) & 66 & $(61-71)$ & 82 & $(76-87)$ & 74 & (70-79) \\
\hline \multicolumn{11}{|c|}{ Highest } \\
\hline $50-64$ & 29 & $(25-33)$ & 88 & $(85-91)$ & 77 & $(71-81)$ & 91 & (87-94) & 78 & $(73-83)$ \\
\hline $65-74$ & 56 & $(49-64)$ & 95 & (91-98) & 70 & $(58-79)$ & 92 & $(84-96)$ & 87 & $(79-92)$ \\
\hline$>=75$ & 80 & $(68-89)$ & 89 & $(79-95)$ & 42 & $(25-61)$ & 64 & $(46-79)$ & 82 & $(65-92)$ \\
\hline Total & 40 & (37-44) & 90 & $(88-92)$ & 72 & (66-76) & 89 & $(85-92)$ & 81 & $(76-84)$ \\
\hline \multicolumn{11}{|l|}{ Total } \\
\hline $50-64$ & 33 & (31-34) & 85 & $(84-86)$ & 73 & $(71-75)$ & 86 & (84-87) & 69 & $(66-71)$ \\
\hline $65-74$ & 67 & $(65-69)$ & 91 & $(90-93)$ & 68 & $(65-71)$ & 75 & $(71-78)$ & 80 & $(76-83)$ \\
\hline$>=75$ & 83 & (81-85) & 88 & $(86-90)$ & 49 & $(45-53)$ & 30 & $(27-34)$ & 74 & $(70-78)$ \\
\hline Total & 53 & $(51-54)$ & 87 & (86-88) & 65 & (64-67) & 68 & $(66-70)$ & 72 & (70-74) \\
\hline
\end{tabular}


Table 5.A32: Breast cancer screening behaviour by age and area of residence

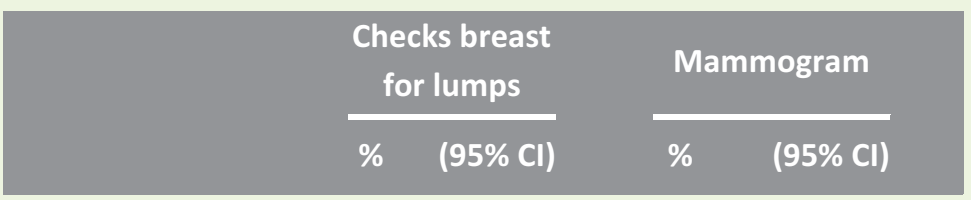

Dublin city or county

\begin{tabular}{lllll}
$50-64$ & 70 & $(66-73)$ & 89 & $(86-91)$ \\
$65-74$ & 60 & $(54-66)$ & 91 & $(86-94)$ \\
$>=75$ & 39 & $(32-47)$ & 48 & $(40-56)$ \\
\hline Total & 61 & $(58-64)$ & 81 & $(78-84)$
\end{tabular}

\section{Another town or city}

\begin{tabular}{lllll}
$50-64$ & 71 & $(67-75)$ & 87 & $(84-90)$ \\
$65-74$ & 65 & $(60-71)$ & 77 & $(72-82)$ \\
$>=75$ & 52 & $(45-59)$ & 33 & $(27-40)$ \\
\hline Total & 66 & $(63-69)$ & 74 & $(71-77)$
\end{tabular}

\begin{tabular}{lllll}
\hline A rural area & & & & \\
$50-64$ & 76 & $(73-78)$ & 85 & $(82-87)$ \\
$65-74$ & 73 & $(68-77)$ & 69 & $(64-73)$ \\
$>=75$ & 54 & $(48-59)$ & 29 & $(24-34)$ \\
\hline Total & 70 & $(68-72)$ & 69 & $(66-71)$ \\
\hline Total & 73 & $(71-75)$ & 86 & $(85-88)$ \\
$50-64$ & 67 & $(64-70)$ & 77 & $(74-79)$ \\
$65-74$ & 50 & $(46-54)$ & 34 & $(31-38)$ \\
$>=75$ & 67 & $(65-68)$ & 73 & $(71-75)$ \\
\hline Total & & & & \\
\hline
\end{tabular}


Table 5.A33: Prevalence and severity of pain by age and sex

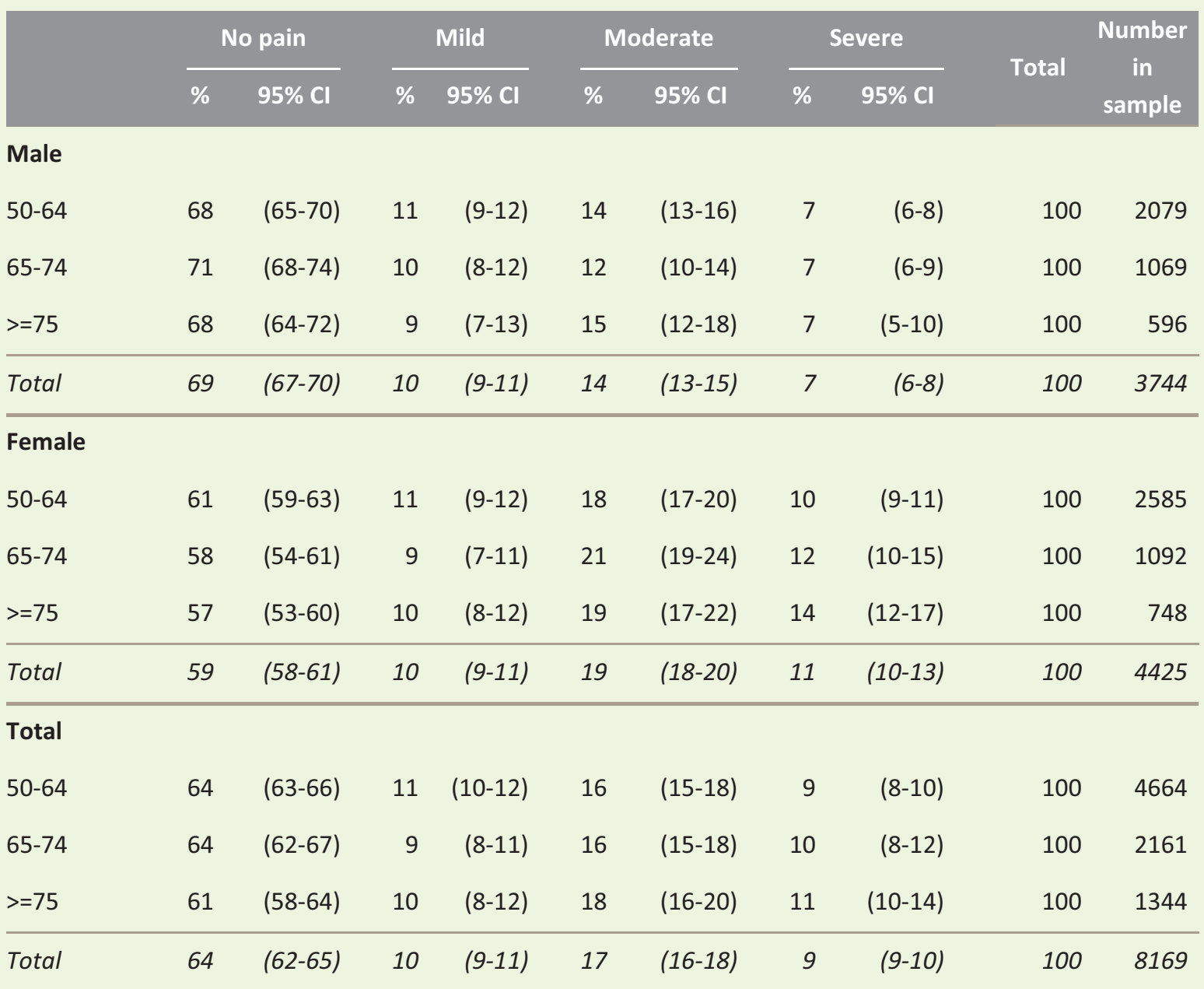

Note. $\mathrm{Cl}=$ confidence interval; Missing observations $=0.11 \%$ 
Table 5.A34: Prevalence and severity of pain by age and education

\begin{tabular}{|c|c|c|c|c|c|c|c|c|c|}
\hline \multicolumn{2}{|c|}{ No pain } & \multicolumn{2}{|c|}{ Mild } & \multicolumn{2}{|c|}{ Moderate } & \multicolumn{2}{|c|}{ Severe } & \multirow{2}{*}{ Total } & \multirow{2}{*}{$\begin{array}{c}\text { Number } \\
\text { in } \\
\text { sample }\end{array}$} \\
\hline$\%$ & $95 \% \mathrm{Cl}$ & $\%$ & $95 \% \mathrm{Cl}$ & $\%$ & $95 \% \mathrm{Cl}$ & $\%$ & $95 \% \mathrm{Cl}$ & & \\
\hline
\end{tabular}

\section{Primary/none}

\begin{tabular}{|c|c|c|c|c|c|c|c|c|c|c|}
\hline $50-64$ & 58 & $(55-62)$ & 10 & $(8-12)$ & 18 & $(16-21)$ & 14 & $(11-16)$ & 100 & 956 \\
\hline $65-74$ & 59 & $(56-63)$ & 10 & $(8-12)$ & 18 & $(15-20)$ & 13 & $(10-15)$ & 100 & 864 \\
\hline$>=75$ & 60 & $(56-64)$ & 10 & $(8-12)$ & 16 & $(13-19)$ & 14 & $(12-17)$ & 100 & 683 \\
\hline Total & 59 & $(57-61)$ & 10 & $(9-11)$ & 17 & $(16-19)$ & 13 & $(12-15)$ & 100 & 2503 \\
\hline \multicolumn{11}{|c|}{ Secondary } \\
\hline $50-64$ & 65 & $(62-67)$ & 11 & $(10-12)$ & 17 & $(15-19)$ & 7 & $(6-9)$ & 100 & 2118 \\
\hline $65-74$ & 69 & $(66-73)$ & 8 & $(6-10)$ & 15 & $(13-18)$ & 8 & $(6-10)$ & 100 & 727 \\
\hline$>=75$ & 62 & $(56-67)$ & 9 & $(7-12)$ & 22 & $(19-27)$ & 7 & $(5-10)$ & 100 & 417 \\
\hline Total & 65 & $(63-67)$ & 10 & (9-11) & 17 & $(16-19)$ & 7 & $(6-8)$ & 100 & 3262 \\
\hline \multicolumn{11}{|c|}{ Third/higher } \\
\hline $50-64$ & 70 & $(68-72)$ & 11 & $(9-13)$ & 13 & $(12-15)$ & 6 & $(5-7)$ & 100 & 1590 \\
\hline $65-74$ & 68 & $(65-72)$ & 10 & $(8-13)$ & 16 & $(14-20)$ & 5 & $(4-8)$ & 100 & 569 \\
\hline$>=75$ & 67 & $(61-73)$ & 11 & $(8-16)$ & 16 & $(12-22)$ & 5 & $(3-9)$ & 100 & 241 \\
\hline Total & 70 & $(67-72)$ & 11 & $(9-12)$ & 14 & (13-16) & 6 & $(5-7)$ & 100 & 2400 \\
\hline \multicolumn{11}{|l|}{ Total } \\
\hline $50-64$ & 64 & $(63-66)$ & 11 & $(10-12)$ & 16 & $(15-18)$ & 9 & $(8-10)$ & 100 & 4664 \\
\hline $65-74$ & 64 & $(62-67)$ & 9 & $(8-11)$ & 16 & $(15-18)$ & 10 & $(8-12)$ & 100 & 2161 \\
\hline$>=75$ & 61 & $(58-64)$ & 10 & $(8-12)$ & 18 & $(16-20)$ & 11 & $(10-14)$ & 100 & 1344 \\
\hline Total & 64 & (62-65) & 10 & (9-11) & 17 & (16-18) & 9 & (9-10) & 100 & 8169 \\
\hline
\end{tabular}

Note. $\mathrm{Cl}=$ confidence interval; Missing observations $=0.11 \%$ 
Table 5.A35: Prevalence and severity of pain by age and wealth

\begin{tabular}{|c|c|c|c|c|c|c|c|c|c|c|}
\hline & \multicolumn{2}{|c|}{ No pain } & \multicolumn{2}{|c|}{ Mild } & \multicolumn{2}{|c|}{ Moderate } & \multicolumn{2}{|c|}{ Severe } & \multirow{2}{*}{ Total } & \multirow{2}{*}{$\begin{array}{l}\text { Number } \\
\text { in } \\
\text { sample }\end{array}$} \\
\hline & $\%$ & $95 \% \mathrm{Cl}$ & $\%$ & $95 \% \mathrm{Cl}$ & $\%$ & $95 \% \mathrm{Cl}$ & $\%$ & $95 \% \mathrm{Cl}$ & & \\
\hline \multicolumn{11}{|c|}{ Lowest } \\
\hline $50-64$ & 56 & $(50-61)$ & 10 & $(8-14)$ & 19 & $(16-23)$ & 15 & $(12-18)$ & 100 & 567 \\
\hline $65-74$ & 65 & $(59-71)$ & 5 & $(3-10)$ & 19 & $(14-24)$ & 11 & $(7-16)$ & 100 & 243 \\
\hline$>=75$ & 59 & $(51-66)$ & 7 & $(4-12)$ & 15 & $(11-21)$ & 19 & $(12-28)$ & 100 & 178 \\
\hline Total & 59 & (54-63) & 8 & $(6-11)$ & 18 & $(16-21)$ & 15 & $(12-18)$ & 100 & 988 \\
\hline \multicolumn{11}{|l|}{ 2nd } \\
\hline $50-64$ & 61 & $(57-65)$ & 10 & $(8-13)$ & 19 & $(15-22)$ & 10 & $(8-13)$ & 100 & 586 \\
\hline $65-74$ & 61 & $(55-68)$ & 8 & $(5-13)$ & 19 & $(15-24)$ & 11 & $(8-17)$ & 100 & 268 \\
\hline$>=75$ & 62 & $(51-71)$ & 11 & $(5-23)$ & 15 & $(10-23)$ & 12 & (7-19) & 100 & 145 \\
\hline Total & 61 & $(58-65)$ & 10 & $(8-13)$ & 18 & $(16-21)$ & 11 & $(9-13)$ & 100 & 999 \\
\hline \multicolumn{11}{|l|}{$3 r d$} \\
\hline $50-64$ & 66 & $(62-70)$ & 11 & $(9-14)$ & 17 & $(14-21)$ & 6 & $(5-9)$ & 100 & 590 \\
\hline $65-74$ & 65 & $(59-71)$ & 10 & $(7-16)$ & 17 & $(13-22)$ & 8 & $(5-12)$ & 100 & 262 \\
\hline$>=75$ & 63 & $(53-72)$ & 11 & $(6-18)$ & 17 & $(11-26)$ & 9 & $(4-18)$ & 100 & 122 \\
\hline Total & 65 & $(62-68)$ & 11 & $(9-13)$ & 17 & (14-20) & 7 & $(6-9)$ & 100 & 974 \\
\hline \multicolumn{11}{|c|}{ Highest } \\
\hline $50-64$ & 69 & $(65-73)$ & 14 & $(11-17)$ & 13 & $(10-16)$ & 4 & $(3-6)$ & 100 & 634 \\
\hline $65-74$ & 77 & $(69-83)$ & 7 & $(4-12)$ & 11 & $(8-16)$ & 5 & $(2-11)$ & 100 & 258 \\
\hline$>=75$ & 63 & $(49-76)$ & 9 & $(4-18)$ & 18 & (11-29) & 10 & $(3-33)$ & 100 & 95 \\
\hline Total & 70 & $(67-74)$ & 12 & $(10-14)$ & 13 & $(11-16)$ & 5 & (3-7) & 100 & 987 \\
\hline \multicolumn{11}{|l|}{ Total } \\
\hline $50-64$ & 64 & $(63-66)$ & 10 & $(9-12)$ & 17 & $(15-18)$ & 9 & $(8-10)$ & 100 & 4664 \\
\hline $65-74$ & 64 & $(62-67)$ & 10 & $(8-11)$ & 16 & $(14-18)$ & 10 & $(9-12)$ & 100 & 2161 \\
\hline$>=75$ & 61 & $(58-64)$ & 10 & $(8-12)$ & 18 & $(16-21)$ & 11 & $(9-14)$ & 100 & 1344 \\
\hline Total & 64 & $(62-65)$ & 10 & $(9-11)$ & 17 & $(16-18)$ & 10 & $(9-10)$ & 100 & 8169 \\
\hline
\end{tabular}

Note. $\mathrm{Cl}=$ confidence interval; Missing observations $=0.11 \%$ 
Table 5.A36: Prevalence of urinary incontinence by age and sex

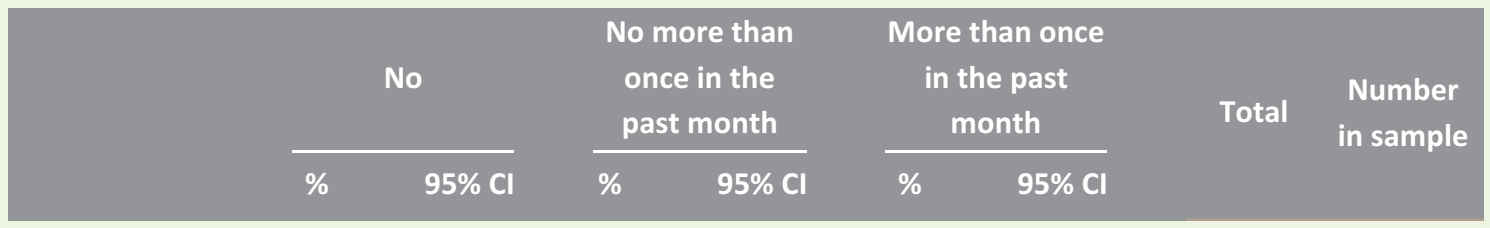

Male

\begin{tabular}{lllllllll}
$50-64$ & 96 & $(95-97)$ & 1 & $(1-1)$ & 3 & $(2-4)$ & 100 & 2080 \\
$65-74$ & 92 & $(91-94)$ & 2 & $(1-3)$ & 5 & $(4-7)$ & 100 & 1068 \\
$>=75$ & 87 & $(84-90)$ & 4 & $(3-7)$ & 8 & $(6-11)$ & 100 & 595 \\
\hline Total & 94 & $(93-95)$ & 2 & $(1-2)$ & 4 & $(4-5)$ & 100 & 3743 \\
\hline
\end{tabular}

Female

\begin{tabular}{lllllllll}
$50-64$ & 84 & $(83-86)$ & 4 & $(3-5)$ & 12 & $(11-13)$ & 100 & 2578 \\
$65-74$ & 81 & $(78-83)$ & 6 & $(4-7)$ & 14 & $(12-16)$ & 100 & 1087 \\
$>=75$ & 78 & $(75-81)$ & 3 & $(2-5)$ & 19 & $(16-22)$ & 100 & 746 \\
\hline Total & 82 & $(81-83)$ & 4 & $(3-5)$ & 14 & $(13-15)$ & 100 & 4411 \\
\hline Total & & & & & & & & \\
$50-64$ & 90 & $(89-91)$ & 2 & $(2-3)$ & 7 & $(7-8)$ & 100 & 4658 \\
$65-74$ & 86 & $(85-88)$ & 4 & $(3-5)$ & 10 & $(8-11)$ & 100 & 2155 \\
$>=75$ & 82 & $(79-84)$ & 4 & $(3-5)$ & 15 & $(13-17)$ & 100 & 1341 \\
\hline Total & 88 & $(87-89)$ & 3 & $(3-3)$ & 9 & $(9-10)$ & 100 & 8154
\end{tabular}

Note. $\mathrm{Cl}=$ confidence interval; Missing observations $=0.29 \%$ 
Table 5.A37: Prevalence of urinary incontinence by age and education

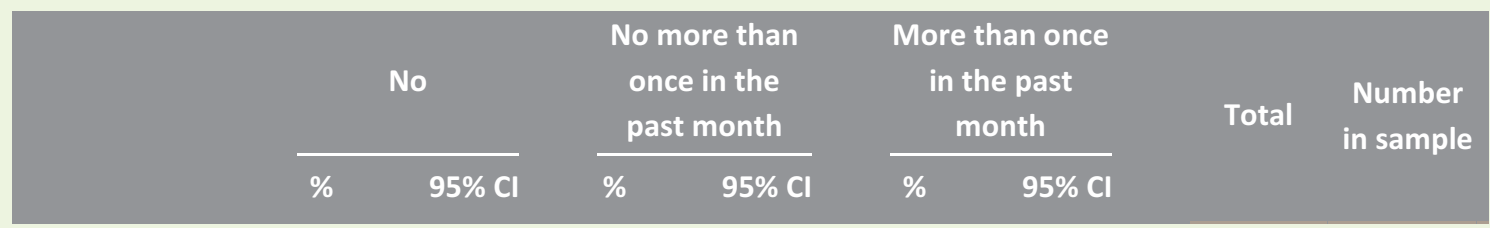

Primary/none

\begin{tabular}{lllllllll}
$50-64$ & 88 & $(86-90)$ & 2 & $(1-3)$ & 10 & $(8-12)$ & 100 & 952 \\
$65-74$ & 86 & $(84-89)$ & 4 & $(3-5)$ & 10 & $(8-12)$ & 100 & 860 \\
$>=75$ & 82 & $(79-85)$ & 4 & $(2-6)$ & 14 & $(12-17)$ & 100 & 678 \\
\hline Total & 86 & $(84-87)$ & 3 & $(3-4)$ & 11 & $(10-13)$ & 100 & 2490 \\
\hline
\end{tabular}

\begin{tabular}{|c|c|c|c|c|c|c|c|c|}
\hline \multicolumn{9}{|c|}{ Secondary } \\
\hline $50-64$ & 91 & $(90-92)$ & 2 & $(1-3)$ & 7 & $(6-8)$ & 100 & 2116 \\
\hline $65-74$ & 87 & $(84-89)$ & 4 & $(3-6)$ & 9 & $(7-12)$ & 100 & 725 \\
\hline$>=75$ & 81 & $(77-85)$ & 4 & $(2-6)$ & 15 & $(12-19)$ & 100 & 417 \\
\hline Total & 89 & $(88-90)$ & 3 & $(2-3)$ & 8 & $(7-9)$ & 100 & 3258 \\
\hline \multicolumn{9}{|c|}{ Third/higher } \\
\hline $50-64$ & 90 & $(88-91)$ & 3 & $(3-4)$ & 7 & $(6-8)$ & 100 & 1590 \\
\hline $65-74$ & 86 & $(83-89)$ & 4 & $(2-6)$ & 10 & $(8-13)$ & 100 & 569 \\
\hline$>=75$ & 82 & $(76-86)$ & 4 & $(2-8)$ & 14 & $(10-19)$ & 100 & 243 \\
\hline Total & 88 & (87-90) & 4 & $(3-4)$ & 8 & (7-9) & 100 & 2402 \\
\hline \multicolumn{9}{|l|}{ Total } \\
\hline $50-64$ & 90 & $(89-91)$ & 2 & $(2-3)$ & 7 & $(7-8)$ & 100 & 4658 \\
\hline $65-74$ & 86 & $(85-88)$ & 4 & $(3-5)$ & 10 & $(8-11)$ & 100 & 2155 \\
\hline$>=75$ & 82 & $(79-84)$ & 4 & $(3-5)$ & 15 & $(13-17)$ & 100 & 1341 \\
\hline Total & 88 & (87-89) & 3 & (3-3) & 9 & (9-10) & 100 & 8154 \\
\hline
\end{tabular}

Note. $\mathrm{Cl}=$ confidence interval; Missing observations $=0.29 \%$ 
Table 5.A38: Prevalence of urinary incontinence by age and wealth

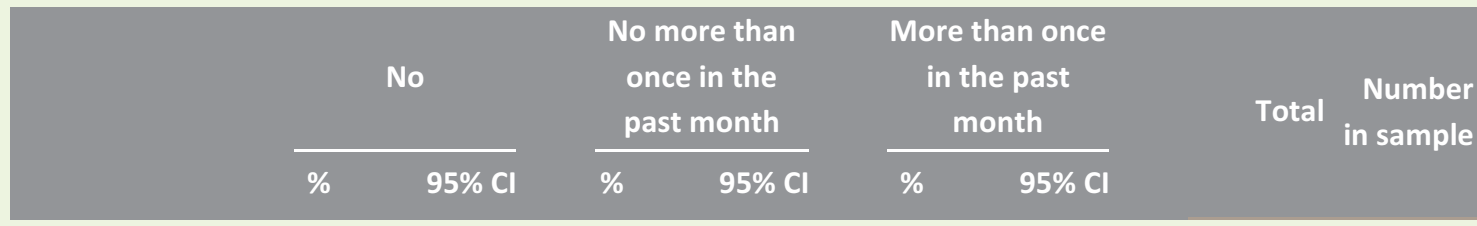

\begin{tabular}{|c|c|c|c|c|c|c|c|c|}
\hline \multicolumn{9}{|c|}{ Lowest } \\
\hline $50-64$ & 89 & $(86-92)$ & 2 & $(1-4)$ & 9 & $(7-12)$ & 100 & 567 \\
\hline $65-74$ & 87 & $(82-92)$ & 4 & $(2-7)$ & 9 & $(5-14)$ & 100 & 243 \\
\hline$>=75$ & 77 & $(68-84)$ & 4 & $(2-9)$ & 19 & $(13-27)$ & 100 & 177 \\
\hline Total & 86 & $(82-88)$ & 3 & $(2-4)$ & 11 & (9-15) & 100 & 987 \\
\hline \multicolumn{9}{|l|}{ 2nd } \\
\hline $50-64$ & 90 & $(88-93)$ & 3 & $(2-4)$ & 7 & $(5-10)$ & 100 & 585 \\
\hline $65-74$ & 86 & $(82-90)$ & 5 & $(3-8)$ & 9 & $(6-13)$ & 100 & 268 \\
\hline$>=75$ & 78 & $(67-85)$ & 4 & $(1-11)$ & 19 & $(12-29)$ & 100 & 145 \\
\hline Total & 87 & (84-89) & 3 & $(2-5)$ & 10 & $(8-13)$ & 100 & 998 \\
\hline \multicolumn{9}{|l|}{ 3rd } \\
\hline $50-64$ & 89 & $(86-91)$ & 2 & $(1-3)$ & 9 & $(7-12)$ & 100 & 589 \\
\hline $65-74$ & 85 & (79-89) & 4 & $(2-7)$ & 11 & $(8-16)$ & 100 & 262 \\
\hline$>=75$ & 85 & $(76-91)$ & 5 & $(2-11)$ & 10 & $(5-18)$ & 100 & 123 \\
\hline Total & 87 & (85-89) & 3 & $(2-4)$ & 10 & $(8-12)$ & 100 & 974 \\
\hline \multicolumn{9}{|c|}{ Highest } \\
\hline $50-64$ & 89 & $(86-92)$ & 3 & $(2-5)$ & 7 & $(5-10)$ & 100 & 634 \\
\hline $65-74$ & 90 & $(85-93)$ & 2 & $(1-6)$ & 8 & $(5-12)$ & 100 & 258 \\
\hline$>=75$ & 82 & $(72-89)$ & 3 & $(1-9)$ & 15 & $(8-25)$ & 100 & 95 \\
\hline Total & 89 & $(86-91)$ & 3 & $(2-4)$ & 8 & $(6-11)$ & 100 & 987 \\
\hline \multicolumn{9}{|l|}{ Total } \\
\hline $50-64$ & 90 & $(89-91)$ & 2 & $(2-3)$ & 8 & $(7-9)$ & 100 & 4658 \\
\hline $65-74$ & 86 & (84-88) & 4 & $(3-5)$ & 10 & $(9-12)$ & 100 & 2155 \\
\hline$>=75$ & 81 & $(78-83)$ & 3 & $(2-5)$ & 16 & $(13-19)$ & 100 & 1341 \\
\hline Total & 87 & (86-88) & 3 & $(3-3)$ & 10 & $(9-11)$ & 100 & 8154 \\
\hline
\end{tabular}

Note. $\mathrm{Cl}=$ confidence interval; Missing observations $=0.29 \%$ 
Table 5.A39: Prevalence of fear of falling by age and sex

\begin{tabular}{|c|c|c|c|c|c|c|c|c|}
\hline & \multicolumn{2}{|c|}{ Not afraid } & \multicolumn{2}{|c|}{$\begin{array}{l}\text { Somewhat } \\
\text { afraid }\end{array}$} & \multicolumn{2}{|c|}{ Very afraid } & \multirow{2}{*}{ Total } & \multirow{2}{*}{$\begin{array}{l}\text { Number } \\
\text { in sample }\end{array}$} \\
\hline & $\%$ & $95 \% \mathrm{Cl}$ & $\%$ & $95 \% \mathrm{Cl}$ & $\%$ & $95 \% \mathrm{Cl}$ & & \\
\hline \multicolumn{9}{|l|}{ Male } \\
\hline $50-64$ & 90 & [89-92] & 7 & [6-9] & 2 & {$[2-3]$} & 100 & 2081 \\
\hline $65-74$ & 85 & [82-87] & 12 & [10-14] & 4 & [3-5] & 100 & 1069 \\
\hline$>=75$ & 74 & [70-77] & 20 & [17-23] & 7 & [5-9] & 100 & 597 \\
\hline Total & 86 & [85-88] & 10 & [9-11] & 3 & [3-4] & 100 & 3747 \\
\hline \multicolumn{9}{|c|}{ Female } \\
\hline $50-64$ & 75 & [73-77] & 19 & [17-21] & 6 & [5-7] & 100 & 2587 \\
\hline $65-74$ & 63 & [60-66] & 27 & [24-30] & 10 & [8-12] & 100 & 1092 \\
\hline$>=75$ & 50 & [47-54] & 34 & [30-37] & 16 & [13-19] & 100 & 749 \\
\hline Total & 67 & [65-69] & 24 & [23-25] & 9 & [8-10] & 100 & 4428 \\
\hline \multicolumn{9}{|l|}{ Total } \\
\hline $50-64$ & 83 & [81-84] & 13 & [12-14] & 4 & [4-5] & 100 & 4668 \\
\hline $65-74$ & 74 & [71-76] & 20 & [18-22] & 7 & [6-8] & 100 & 2161 \\
\hline$>=75$ & 60 & [57-63] & 28 & [26-31] & 12 & [10-14] & 100 & 1346 \\
\hline Total & 76 & [75-77] & 17 & [16-18] & 6 & [6-7] & 100 & 8175 \\
\hline
\end{tabular}

Note. $\mathrm{Cl}=$ confidence interval; Missing observations $=0.04 \%$ 
Table 5.A40: Prevalence of fear of falling by age and education

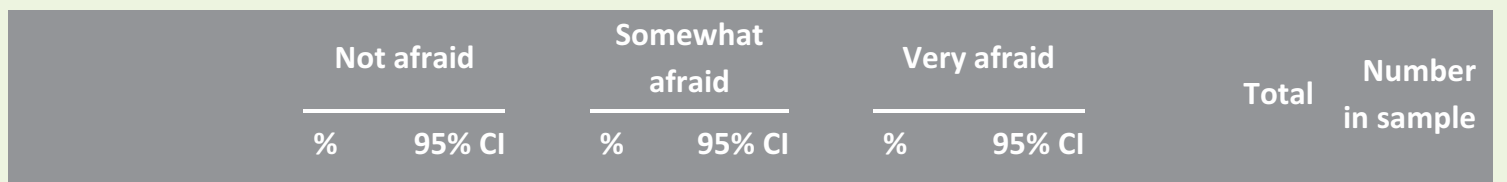

\section{Primary/none}

\begin{tabular}{|c|c|c|c|c|c|c|c|c|}
\hline $50-64$ & 77 & [74-80] & 15 & [13-18] & 7 & [6-9] & 100 & 957 \\
\hline $65-74$ & 72 & [69-75] & 20 & [17-23] & 8 & [6-10] & 100 & 864 \\
\hline$>=75$ & 59 & [55-63] & 28 & [25-31] & 13 & $\begin{array}{r}{[11-} \\
16]\end{array}$ & 100 & 684 \\
\hline Total & 70 & [68-72] & 21 & [19-22] & 9 & [8-11] & 100 & 2505 \\
\hline \multicolumn{9}{|c|}{ Secondary } \\
\hline $50-64$ & 84 & [82-85] & 13 & [11-14] & 3 & [3-4] & 100 & 2119 \\
\hline $65-74$ & 75 & [71-78] & 19 & [17-23] & 6 & {$[4-8]$} & 100 & 728 \\
\hline$>=75$ & 59 & [54-64] & 30 & [26-35] & 11 & [8-14] & 100 & 416 \\
\hline Total & 79 & [78-81] & 16 & [15-17] & 5 & [4-6] & 100 & 3263 \\
\hline \multicolumn{9}{|c|}{ Third/higher } \\
\hline $50-64$ & 86 & [84-87] & 12 & [10-13] & 3 & {$[2-3]$} & 100 & 1592 \\
\hline $65-74$ & 76 & [72-79] & 20 & [17-24] & 4 & [3-6] & 100 & 568 \\
\hline$>=75$ & 68 & [61-74] & 25 & [20-31] & 7 & [4-11] & 100 & 243 \\
\hline Total & 82 & [81-84] & 15 & [13-16] & 3 & [3-4] & 100 & 2403 \\
\hline \multicolumn{9}{|l|}{ Total } \\
\hline $50-64$ & 83 & [81-84] & 13 & [12-14] & 4 & [4-5] & 100 & 4668 \\
\hline $65-74$ & 74 & [71-76] & 20 & [18-22] & 7 & [6-8] & 100 & 2161 \\
\hline$>=75$ & 60 & [57-63] & 28 & [26-31] & 12 & $\begin{array}{r}{[10-} \\
14]\end{array}$ & 100 & 1346 \\
\hline Total & 76 & [75-77] & 17 & [16-18] & 6 & [6-7] & 100 & 8175 \\
\hline
\end{tabular}

Note. $\mathrm{Cl}=$ confidence interval; Missing observations $=0.04 \%$ 
Table 5.A41: Prevalence of fear of falling by age and wealth

\begin{tabular}{|c|c|c|c|c|c|c|c|c|}
\hline & \multicolumn{2}{|c|}{ Not afraid } & \multicolumn{2}{|c|}{ Somewhat afraid } & \multicolumn{2}{|c|}{ Very afraid } & \multirow{2}{*}{ Total } & \multirow{2}{*}{$\begin{array}{r}\text { Number in } \\
\text { sample }\end{array}$} \\
\hline & $\%$ & $95 \% \mathrm{Cl}$ & $\%$ & $95 \% \mathrm{Cl}$ & $\%$ & $95 \% \mathrm{Cl}$ & & \\
\hline \multicolumn{9}{|c|}{ Lowest } \\
\hline $50-64$ & 76 & $(72-80)$ & 14 & $(11-18)$ & 10 & $(7-13)$ & 100 & 567 \\
\hline $65-74$ & 78 & $(70-84)$ & 15 & $(10-22)$ & 7 & $(4-12)$ & 100 & 243 \\
\hline$>=75$ & 54 & $(45-63)$ & 27 & $(20-34)$ & 19 & $(13-28)$ & 100 & 178 \\
\hline Total & 71 & $(66-75)$ & 18 & $(15-21)$ & 12 & $(9-15)$ & 100 & 988 \\
\hline \multicolumn{9}{|l|}{ 2nd } \\
\hline $50-64$ & 80 & $(76-83)$ & 16 & $(13-19)$ & 5 & $(3-7)$ & 100 & 586 \\
\hline $65-74$ & 74 & $(68-79)$ & 21 & $(17-27)$ & 5 & $(3-8)$ & 100 & 268 \\
\hline$>=75$ & 62 & $(53-71)$ & 27 & $(20-36)$ & 10 & $(6-17)$ & 100 & 145 \\
\hline Total & 75 & (71-78) & 19 & $(17-22)$ & 6 & $(4-8)$ & 100 & 999 \\
\hline \multicolumn{9}{|l|}{$3 r d$} \\
\hline $50-64$ & 85 & $(81-88)$ & 11 & $(8-14)$ & 4 & $(3-7)$ & 100 & 590 \\
\hline $65-74$ & 79 & $(73-84)$ & 16 & $(12-22)$ & 5 & $(3-9)$ & 100 & 262 \\
\hline$>=75$ & 68 & (59-76) & 26 & $(19-36)$ & 6 & $(3-11)$ & 100 & 123 \\
\hline Total & 81 & $(78-83)$ & 15 & $(12-17)$ & 5 & $(3-6)$ & 100 & 975 \\
\hline \multicolumn{9}{|c|}{ Highest } \\
\hline $50-64$ & 88 & $(85-90)$ & 11 & $(8-14)$ & 2 & $(1-3)$ & 100 & 634 \\
\hline $65-74$ & 80 & $(73-86)$ & 17 & $(12-23)$ & 3 & $(1-9)$ & 100 & 258 \\
\hline$>=75$ & 58 & $(44-70)$ & 36 & $(24-50)$ & 6 & $(2-14)$ & 100 & 95 \\
\hline Total & 83 & $(80-86)$ & 15 & $(12-18)$ & 2 & $(1-4)$ & 100 & 987 \\
\hline \multicolumn{9}{|l|}{ Total } \\
\hline $50-64$ & 82 & $(81-83)$ & 14 & $(12-15)$ & 4 & $(4-5)$ & 100 & 4668 \\
\hline $65-74$ & 72 & (69-74) & 21 & $(19-23)$ & 8 & $(6-9)$ & 100 & 2161 \\
\hline$>=75$ & 58 & $(55-62)$ & 29 & $(26-32)$ & 13 & $(11-15)$ & 100 & 1346 \\
\hline Total & 74 & (73-76) & 19 & $(18-20)$ & 7 & $(6-8)$ & 100 & 8175 \\
\hline
\end{tabular}

Note. $\mathrm{Cl}=$ confidence interval; Missing observations $=0.04 \%$ 
Table 5.A42: Activity limitation due to incontinence, pain and fear of falling by age and sex

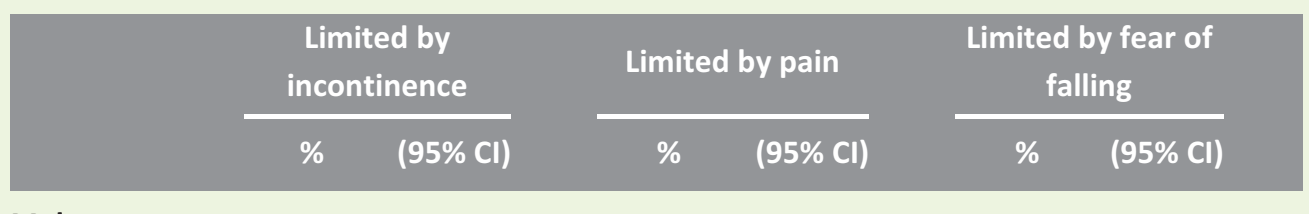

\section{Male}

\begin{tabular}{lcccccc}
$50-64$ & 1.3 & $(0.9-2.0)$ & 18.9 & $(17.0-20.9)$ & 3.7 & $(2.9-4.6)$ \\
$65-74$ & 1.9 & $(1.3-3.0)$ & 16.2 & $(13.8-18.9)$ & 5.5 & $(4.2-7.2)$ \\
$>=75$ & 3.7 & $(2.3-5.8)$ & 21.7 & $(17.8-26.2)$ & 11.9 & $(8.9-15.7)$ \\
\hline Total & 1.9 & $(1.5-2.5)$ & 18.8 & $(17.3-20.4)$ & 5.7 & $(4.8-6.7)$ \\
\hline
\end{tabular}

Female

\begin{tabular}{lllllll}
$50-64$ & 3.5 & $(2.8-4.3)$ & 22.2 & $(20.4-24.1)$ & 7.3 & $(6.3-8.6)$ \\
$65-74$ & 4.7 & $(3.5-6.3)$ & 24.9 & $(22.1-27.8)$ & 12.4 & $(10.2-15.0)$ \\
$>=75$ & 5.3 & $(3.8-7.4)$ & 28.2 & $(24.5-32.2)$ & 19.9 & $(16.9-23.3)$ \\
\hline Total & 4.2 & $(3.6-5.0)$ & 24.4 & $(22.9-25.9)$ & 11.8 & $(10.6-13.0)$ \\
\hline Total & & & & & & \\
$50-64$ & 2.5 & $(2.0-3.0)$ & 20.7 & $(19.3-22.1)$ & 5.6 & $(4.9-6.5)$ \\
$65-74$ & 3.5 & $(2.7-4.4)$ & 20.9 & $(19.0-23.0)$ & 9.3 & $(7.8-11.0)$ \\
$>=75$ & 4.7 & $(3.6-6.2)$ & 25.9 & $(23.1-28.9)$ & 17.1 & $(14.8-19.6)$ \\
\hline Total & 3.2 & $(2.8-3.7)$ & 21.9 & $(20.8-23.1)$ & 9.1 & $(8.3-10.0)$ \\
\hline
\end{tabular}


Table 5.A43: Activity limitation due to incontinence, pain and fear of falling by age and education

\begin{tabular}{|c|c|c|c|c|c|c|}
\hline & \multicolumn{2}{|c|}{$\begin{array}{l}\text { Limited by } \\
\text { incontinence }\end{array}$} & \multicolumn{2}{|c|}{ Limited by pain } & \multicolumn{2}{|c|}{$\begin{array}{l}\text { Limited by fear of } \\
\text { falling }\end{array}$} \\
\hline & $\%$ & $(95 \% \mathrm{Cl})$ & $\%$ & $(95 \% \mathrm{Cl})$ & $\%$ & $(95 \% \mathrm{Cl})$ \\
\hline \multicolumn{7}{|c|}{ Primary/none } \\
\hline $50-64$ & 3.6 & $(2.5-5.1)$ & 28.8 & $(25.8-32.0)$ & 8.3 & $(6.6-10.4)$ \\
\hline $65-74$ & 3.6 & $(2.5-5.1)$ & 24.2 & $(21.1-27.7)$ & 10.1 & $(7.9-12.9)$ \\
\hline$>=75$ & 4.5 & $(3.1-6.5)$ & 28.6 & $(24.9-32.6)$ & 17.3 & $(14.3-20.8)$ \\
\hline Total & 4.0 & (3.2-4.9) & 27.4 & (25.4-29.6) & 12.3 & $(10.7-14.0)$ \\
\hline \multicolumn{7}{|c|}{ Secondary } \\
\hline $50-64$ & 2.1 & $(1.6-2.8)$ & 18.9 & $(17.1-20.9)$ & 5.0 & (4.1-6.1) \\
\hline $65-74$ & 3.1 & $(2.0-4.8)$ & 17.8 & $(15.0-21.0)$ & 9.3 & $(7.2-11.8)$ \\
\hline$>=75$ & 5.2 & $(3.1-8.4)$ & 22.3 & $(18.2-26.9)$ & 17.8 & $(14.0-22.4)$ \\
\hline Total & 2.7 & $(2.2-3.4)$ & 19.1 & $(17.6-20.7)$ & 7.5 & $(6.6-8.6)$ \\
\hline \multicolumn{7}{|c|}{ Third/higher } \\
\hline $50-64$ & 2.2 & $(1.6-3.0)$ & 15.8 & $(13.9-18.0)$ & 4.2 & $(3.3-5.5)$ \\
\hline $65-74$ & 4.2 & $(2.7-6.4)$ & 18.1 & $(15.1-21.6)$ & 6.6 & (4.7-9.2) \\
\hline$>=75$ & 5.1 & $(2.6-9.7)$ & 15.6 & $(11.0-21.5)$ & 13.3 & (8.8-19.6) \\
\hline Total & 2.9 & $(2.3-3.7)$ & 16.3 & $(14.7-18.0)$ & 5.8 & $(4.7-7.0)$ \\
\hline \multicolumn{7}{|l|}{ Total } \\
\hline $50-64$ & 2.5 & $(2.0-3.0)$ & 20.7 & $(19.3-22.1)$ & 5.6 & $(4.9-6.5)$ \\
\hline $65-74$ & 3.5 & $(2.7-4.4)$ & 20.9 & $(19.0-23.0)$ & 9.3 & $(7.8-11.0)$ \\
\hline$>=75$ & 4.7 & $(3.6-6.2)$ & 25.9 & (23.1-28.9) & 17.1 & $(14.8-19.6)$ \\
\hline Total & 3.2 & $(2.8-3.7)$ & 21.9 & $(20.8-23.1)$ & 9.1 & (8.3-10.0) \\
\hline
\end{tabular}


Table 5.A44: Activity limitation due to incontinence, pain and fear of falling by age and wealth

\begin{tabular}{|c|c|c|c|c|c|c|}
\hline & \multicolumn{2}{|c|}{$\begin{array}{l}\text { Limited by } \\
\text { incontinence }\end{array}$} & \multicolumn{2}{|c|}{ Limited by pain } & \multicolumn{2}{|c|}{$\begin{array}{l}\text { Limited by fear of } \\
\text { falling }\end{array}$} \\
\hline & $\%$ & $(95 \% \mathrm{Cl})$ & $\%$ & $(95 \% \mathrm{Cl})$ & $\%$ & $(95 \% \mathrm{CI})$ \\
\hline \multicolumn{7}{|c|}{ Lowest } \\
\hline $50-64$ & 4.6 & $(3.0-6.9)$ & 28.8 & $(24.3-33.8)$ & 9.7 & (7.3-12.9) \\
\hline $65-74$ & 6.1 & $(3.4-10.8)$ & 22.7 & $(17.2-29.3)$ & 9.0 & $(5.5-14.4)$ \\
\hline$>=75$ & 7.5 & $(4.1-13.2)$ & 31.9 & $(25.3-39.4)$ & 23.0 & $(16.5-31.1)$ \\
\hline Total & 5.7 & $(4.2-7.7)$ & 28.3 & $(24.7-32.1)$ & 13.0 & $(10.3-16.2)$ \\
\hline \multicolumn{7}{|l|}{ 2nd } \\
\hline $50-64$ & 2.3 & $(1.3-4.1)$ & 26.7 & $(23.0-30.8)$ & 6.3 & $(4.6-8.7)$ \\
\hline $65-74$ & 3.5 & $(1.8-6.8)$ & 23.1 & $(17.9-29.2)$ & 6.4 & $(3.6-10.9)$ \\
\hline$>=75$ & 5.7 & $(2.3-13.6)$ & 26.0 & $(18.5-35.3)$ & 16.7 & $(10.8-25.0)$ \\
\hline Total & 3.3 & $(2.1-5.0)$ & 25.7 & $(22.7-29.1)$ & 8.5 & (6.6-10.7) \\
\hline \multicolumn{7}{|l|}{$3 r d$} \\
\hline $50-64$ & 3.1 & $(2.0-4.9)$ & 18.3 & $(15.0-22.2)$ & 4.1 & $(2.6-6.3)$ \\
\hline $65-74$ & 2.1 & $(1.0-4.6)$ & 14.0 & $(10.2-18.9)$ & 5.9 & $(3.5-9.9)$ \\
\hline$>=75$ & 1.5 & $(0.3-6.4)$ & 25.9 & $(17.8-36.0)$ & 9.5 & (5.7-15.7) \\
\hline Total & 2.6 & $(1.8-3.8)$ & 18.5 & (15.9-21.4) & 5.4 & $(4.0-7.1)$ \\
\hline \multicolumn{7}{|c|}{ Highest } \\
\hline $50-64$ & 1.0 & $(0.4-2.3)$ & 13.8 & $(10.8-17.5)$ & 3.1 & $(2.0-4.8)$ \\
\hline $65-74$ & 1.9 & $(0.7-5.2)$ & 11.4 & $(7.3-17.3)$ & 6.9 & $(3.7-12.6)$ \\
\hline$>=75$ & 2.9 & $(0.8-9.5)$ & 19.7 & $(9.4-36.8)$ & 8.7 & $(4.0-18.0)$ \\
\hline Total & 1.4 & $(0.8-2.5)$ & 13.9 & $(11.2-17.1)$ & 4.6 & (3.3-6.4) \\
\hline \multicolumn{7}{|l|}{ Total } \\
\hline $50-64$ & 2.5 & $(2.0-3.0)$ & 20.7 & $(19.3-22.1)$ & 5.6 & $(4.9-6.5)$ \\
\hline $65-74$ & 3.5 & $(2.7-4.4)$ & 20.9 & $(19.0-23.0)$ & 9.3 & $(7.8-11.0)$ \\
\hline$>=75$ & 4.7 & $(3.6-6.2)$ & 25.9 & (23.1-28.9) & 17.1 & $(14.8-19.6)$ \\
\hline Total & 3.2 & $(2.8-3.7)$ & 21.9 & $(20.8-23.1)$ & 9.1 & (8.3-10.0) \\
\hline
\end{tabular}


Table 5.A45: Number of regular medications used by age and sex

\begin{tabular}{|c|c|c|c|c|c|c|c|c|c|c|}
\hline & \multicolumn{2}{|c|}{$\begin{array}{l}\text { No regular } \\
\text { medications }\end{array}$} & \multicolumn{2}{|c|}{$1-2$} & \multicolumn{2}{|r|}{$3-4$} & \multicolumn{2}{|c|}{$\begin{array}{c}5 \text { or more } \\
\text { medications }\end{array}$} & \multirow{2}{*}{ Total } & \multirow{2}{*}{$\begin{array}{r}\text { Number } \\
\text { in } \\
\text { sample }\end{array}$} \\
\hline & $\%$ & $95 \% \mathrm{Cl}$ & $\%$ & $95 \% \mathrm{Cl}$ & $\%$ & $95 \% \mathrm{Cl}$ & $\%$ & $95 \% \mathrm{Cl}$ & & \\
\hline \multicolumn{11}{|l|}{ Male } \\
\hline $50-64$ & 45 & $(43-47)$ & 30 & $(28-32)$ & 14 & $(12-15)$ & 11 & $(10-12)$ & 100 & 2067 \\
\hline $65-74$ & 20 & $(18-23)$ & 29 & $(26-32)$ & 23 & $(21-26)$ & 28 & $(25-31)$ & 100 & 1056 \\
\hline$>=75$ & 11 & $(9-14)$ & 22 & $(19-26)$ & 26 & $(22-29)$ & 41 & $(37-45)$ & 100 & 591 \\
\hline Total & 34 & $(32-36)$ & 29 & $(27-30)$ & 18 & (17-19) & 19 & $(18-21)$ & 100 & 3714 \\
\hline \multicolumn{11}{|c|}{ Female } \\
\hline $50-64$ & 32 & $(30-34)$ & 34 & $(32-36)$ & 20 & $(18-22)$ & 13 & $(12-15)$ & 100 & 2572 \\
\hline $65-74$ & 14 & $(12-16)$ & 29 & $(26-32)$ & 27 & $(25-30)$ & 30 & $(27-33)$ & 100 & 1085 \\
\hline$>=75$ & 8 & $(6-10)$ & 21 & $(18-24)$ & 31 & $(27-34)$ & 41 & $(37-45)$ & 100 & 724 \\
\hline Total & 23 & $(22-24)$ & 30 & $(29-32)$ & 24 & $(23-25)$ & 23 & $(21-24)$ & 100 & 4381 \\
\hline \multicolumn{11}{|l|}{ Total } \\
\hline $50-64$ & 39 & $(37-40)$ & 32 & $(31-34)$ & 17 & $(16-18)$ & 12 & $(11-13)$ & 100 & 4639 \\
\hline $65-74$ & 17 & $(15-19)$ & 29 & $(27-31)$ & 25 & $(23-27)$ & 29 & $(27-31)$ & 100 & 2141 \\
\hline$>=75$ & 9 & $(8-11)$ & 21 & $(19-24)$ & 29 & $(26-31)$ & 41 & $(38-44)$ & 100 & 1315 \\
\hline Total & 28 & (27-29) & 30 & (29-31) & 21 & $(20-22)$ & 21 & $(20-22)$ & 100 & 8095 \\
\hline
\end{tabular}

Note. $\mathrm{Cl}=$ confidence interval; Missing observations $=1.01 \%$ 
Table 5.A46: Number of regular medications used by age and education

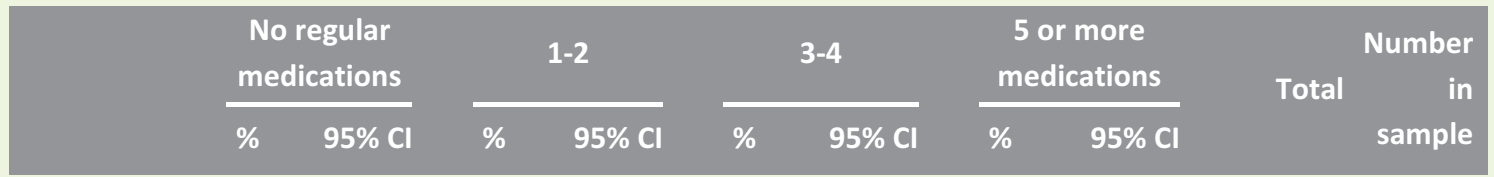

\section{Primary/none}

\begin{tabular}{lllllllllll}
$50-64$ & 32 & $(29-35)$ & 31 & $(28-34)$ & 19 & $(17-22)$ & 18 & $(16-21)$ & 100 & 943 \\
$65-74$ & 14 & $(12-17)$ & 28 & $(25-31)$ & 26 & $(23-29)$ & 32 & $(29-36)$ & 100 & 854 \\
$>=75$ & 9 & $(7-11)$ & 21 & $(18-24)$ & 29 & $(26-33)$ & 41 & $(37-46)$ & 100 & 663 \\
\hline Total & 19 & $(18-21)$ & 27 & $(25-29)$ & 24 & $(23-26)$ & 30 & $(28-32)$ & 100 & 2460
\end{tabular}

Secondary

\begin{tabular}{lrrrrrrrrrr}
$50-64$ & 41 & $(39-43)$ & 32 & $(30-34)$ & 17 & $(15-19)$ & 10 & $(9-12)$ & 100 & 2111 \\
$65-74$ & 20 & $(17-23)$ & 29 & $(26-33)$ & 24 & $(21-27)$ & 27 & $(24-31)$ & 100 & 719 \\
$>=75$ & 9 & $(7-13)$ & 22 & $(18-26)$ & 28 & $(24-32)$ & 41 & $(36-45)$ & 100 & 409 \\
\hline Total & 34 & $(32-36)$ & 30 & $(29-32)$ & 19 & $(18-21)$ & 17 & $(15-18)$ & 100 & 3239
\end{tabular}

\section{Third/higher}

\begin{tabular}{rrrrrrrrrrr}
$50-64$ & 41 & $(38-43)$ & 35 & $(32-37)$ & 15 & $(13-17)$ & 10 & $(8-11)$ & 100 & 1585 \\
$65-74$ & 19 & $(15-22)$ & 32 & $(28-36)$ & 28 & $(24-31)$ & 22 & $(19-26)$ & 100 & 567 \\
$>=75$ & 12 & $(8-16)$ & 24 & $(19-29)$ & 27 & $(21-32)$ & 38 & $(32-45)$ & 100 & 241 \\
\hline Total & 34 & $(32-36)$ & 33 & $(31-35)$ & 18 & $(17-20)$ & 15 & $(13-16)$ & 100 & 2393
\end{tabular}

\begin{tabular}{|c|c|c|c|c|c|c|c|c|c|c|}
\hline \multicolumn{11}{|l|}{ Total } \\
\hline $50-64$ & 39 & $(37-40)$ & 32 & $(31-34)$ & 17 & $(16-18)$ & 12 & $(11-13)$ & 100 & 4639 \\
\hline $65-74$ & 17 & $(15-19)$ & 29 & $(27-31)$ & 25 & $(23-27)$ & 29 & $(27-31)$ & 100 & 2141 \\
\hline$>=75$ & 9 & $(8-11)$ & 21 & $(19-24)$ & 29 & $(26-31)$ & 41 & $(38-44)$ & 100 & 1315 \\
\hline Total & 28 & (27-29) & 30 & $(29-31)$ & 21 & $(20-22)$ & 21 & $(20-22)$ & 100 & 8095 \\
\hline
\end{tabular}

Note. $\mathrm{Cl}=$ confidence interval; Missing observations $=1.01 \%$ 
Table 5.A47: Number of regular medications used by age and wealth

\begin{tabular}{|c|c|c|c|c|c|c|c|c|c|c|}
\hline & \multicolumn{2}{|c|}{$\begin{array}{l}\text { No regular } \\
\text { medications }\end{array}$} & \multicolumn{2}{|c|}{$1-2$} & \multicolumn{2}{|c|}{$3-4$} & \multicolumn{2}{|c|}{$\begin{array}{l}5 \text { or more } \\
\text { medications }\end{array}$} & \multirow{2}{*}{ Total } & \multirow{2}{*}{$\begin{array}{r}\text { Number } \\
\text { in } \\
\text { sample }\end{array}$} \\
\hline & $\%$ & $95 \% \mathrm{Cl}$ & $\%$ & $95 \% \mathrm{Cl}$ & $\%$ & $95 \% \mathrm{Cl}$ & $\%$ & $95 \% \mathrm{Cl}$ & & \\
\hline \multicolumn{11}{|c|}{ Lowest } \\
\hline $50-64$ & 35 & $(30-39)$ & 30 & $(26-34)$ & 17 & $(14-21)$ & 18 & $(15-22)$ & 100 & 566 \\
\hline $65-74$ & 15 & $(12-20)$ & 25 & $(20-31)$ & 24 & $(18-30)$ & 36 & $(30-42)$ & 100 & 240 \\
\hline$>=75$ & 7 & $(4-11)$ & 16 & $(10-24)$ & 26 & $(20-34)$ & 51 & $(41-60)$ & 100 & 176 \\
\hline Total & 23 & $(20-26)$ & 25 & (23-28) & 21 & $(18-24)$ & 31 & (27-34) & 100 & 982 \\
\hline \multicolumn{11}{|l|}{ 2nd } \\
\hline $50-64$ & 35 & $(31-40)$ & 29 & $(25-33)$ & 21 & $(17-25)$ & 15 & $(12-19)$ & 100 & 585 \\
\hline $65-74$ & 12 & $(8-16)$ & 28 & $(22-34)$ & 29 & $(23-36)$ & 31 & $(25-38)$ & 100 & 267 \\
\hline$>=75$ & 8 & $(4-14)$ & 21 & $(13-32)$ & 27 & $(20-37)$ & 43 & $(34-54)$ & 100 & 143 \\
\hline Total & 24 & $(21-28)$ & 27 & $(24-30)$ & 24 & $(21-27)$ & 25 & $(21-28)$ & 100 & 995 \\
\hline \multicolumn{11}{|l|}{$3 r d$} \\
\hline $50-64$ & 35 & $(31-40)$ & 33 & $(29-37)$ & 20 & $(17-24)$ & 12 & $(9-15)$ & 100 & 587 \\
\hline $65-74$ & 19 & $(15-25)$ & 31 & $(24-38)$ & 22 & $(17-28)$ & 28 & $(23-35)$ & 100 & 260 \\
\hline$>=75$ & 4 & $(2-8)$ & 26 & $(18-35)$ & 26 & $(17-38)$ & 45 & $(35-56)$ & 100 & 121 \\
\hline Total & 26 & $(23-30)$ & 31 & (28-35) & 21 & (19-24) & 21 & $(18-24)$ & 100 & 968 \\
\hline \multicolumn{11}{|c|}{ Highest } \\
\hline $50-64$ & 41 & $(37-46)$ & 34 & (30-39) & 17 & $(13-20)$ & 8 & $(6-11)$ & 100 & 632 \\
\hline $65-74$ & 20 & $(15-26)$ & 36 & $(30-43)$ & 23 & $(18-29)$ & 21 & $(16-27)$ & 100 & 257 \\
\hline$>=75$ & 10 & $(5-18)$ & 31 & $(19-46)$ & 21 & $(14-32)$ & 39 & $(28-50)$ & 100 & 95 \\
\hline Total & 33 & $(30-37)$ & 34 & (31-38) & 18 & $(16-21)$ & 14 & $(12-17)$ & 100 & 984 \\
\hline \multicolumn{11}{|l|}{ Total } \\
\hline $50-64$ & 38 & $(37-40)$ & 32 & (31-34) & 17 & $(16-18)$ & 12 & $(11-13)$ & 100 & 4639 \\
\hline $65-74$ & 16 & $(15-18)$ & 29 & $(27-32)$ & 25 & $(23-27)$ & 29 & $(27-31)$ & 100 & 2141 \\
\hline$>=75$ & 9 & $(7-10)$ & 22 & $(19-25)$ & 29 & $(27-32)$ & 40 & $(37-44)$ & 100 & 1315 \\
\hline Total & 27 & $(25-28)$ & 29 & $(28-30)$ & 22 & $(21-23)$ & 22 & $(21-24)$ & 100 & 8095 \\
\hline
\end{tabular}

Note. $\mathrm{Cl}=$ confidence interval; Missing observations $=1.01 \%$ 
Table 5.A48: Number of regular medications used by age and medical insurance cover

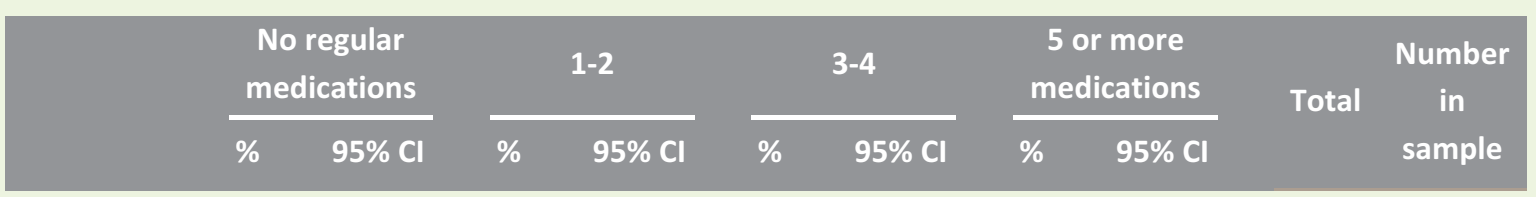

\section{Not covered}

\begin{tabular}{lllllllllll}
$50-64$ & 51 & $(47-55)$ & 28 & $(25-31)$ & 13 & $(11-16)$ & 8 & $(6-10)$ & 100 & 702 \\
$65-74$ & 30 & $(22-38)$ & 34 & $(26-44)$ & 19 & $(13-27)$ & 17 & $(11-25)$ & 100 & 123 \\
$>=75$ & 51 & $(20-81)$ & 30 & $(8-69)$ & 0 & - & 19 & $(4-54)$ & 100 & 8 \\
\hline Total & 48 & $(45-52)$ & 29 & $(26-32)$ & 14 & $(12-16)$ & 9 & $(7-11)$ & 100 & 833
\end{tabular}

\section{Medical insurance only}

\begin{tabular}{lrrrrrrrrrr}
$50-64$ & 42 & $(40-45)$ & 35 & $(33-37)$ & 15 & $(14-17)$ & 7 & $(6-8)$ & 100 & 2521 \\
$65-74$ & 22 & $(19-26)$ & 35 & $(31-39)$ & 23 & $(20-27)$ & 20 & $(17-23)$ & 100 & 663 \\
$>=75$ & 6 & $(3-14)$ & 23 & $(16-33)$ & 33 & $(24-43)$ & 38 & $(28-48)$ & 100 & 88 \\
\hline Total & 38 & $(36-40)$ & 35 & $(33-37)$ & 17 & $(16-19)$ & 10 & $(9-11)$ & 100 & 3272
\end{tabular}

\section{Medical card only}

\begin{tabular}{lrrrrrrrrrr}
$50-64$ & 28 & $(25-31)$ & 29 & $(26-32)$ & 21 & $(18-23)$ & 22 & $(20-25)$ & 100 & 1118 \\
$65-74$ & 14 & $(12-17)$ & 24 & $(21-27)$ & 25 & $(22-29)$ & 36 & $(33-40)$ & 100 & 764 \\
$>=75$ & 8 & $(6-11)$ & 22 & $(19-26)$ & 28 & $(25-32)$ & 41 & $(37-45)$ & 100 & 701 \\
\hline Total & 18 & $(17-20)$ & 26 & $(24-27)$ & 24 & $(23-26)$ & 32 & $(30-34)$ & 100 & 2583
\end{tabular}

\section{Dual cover}

\begin{tabular}{lllllllllll}
$50-64$ & 22 & $(17-28)$ & 33 & $(28-39)$ & 24 & $(20-30)$ & 21 & $(16-26)$ & 100 & 294 \\
$65-74$ & 12 & $(10-15)$ & 29 & $(25-33)$ & 28 & $(25-32)$ & 30 & $(27-34)$ & 100 & 590 \\
$>=75$ & 10 & $(7-13)$ & 19 & $(16-23)$ & 29 & $(25-33)$ & 42 & $(37-47)$ & 100 & 517 \\
\hline Total & 14 & $(12-16)$ & 26 & $(24-29)$ & 28 & $(25-30)$ & 32 & $(30-35)$ & 100 & 1401
\end{tabular}

\begin{tabular}{|c|c|c|c|c|c|c|c|c|c|c|}
\hline \multicolumn{11}{|l|}{ Total } \\
\hline $50-64$ & 39 & $(37-40)$ & 32 & $(31-34)$ & 17 & $(16-18)$ & 12 & $(11-13)$ & 100 & 4639 \\
\hline $65-74$ & 17 & $(15-19)$ & 29 & $(27-31)$ & 25 & $(23-27)$ & 29 & $(27-31)$ & 100 & 2141 \\
\hline$>=75$ & 9 & $(8-11)$ & 21 & $(19-24)$ & 29 & $(26-31)$ & 41 & $(38-44)$ & 100 & 1315 \\
\hline Total & 28 & (27-29) & 30 & $(29-31)$ & 21 & $(20-22)$ & 21 & $(20-22)$ & 100 & 8095 \\
\hline
\end{tabular}

Note. $\mathrm{Cl}=$ confidence interval; Missing observations $=1.01 \%$ 
Table 5.A49: Number of falls in the last year by medication use and age

\begin{tabular}{|c|c|c|c|c|c|c|c|c|}
\hline & \multicolumn{2}{|c|}{$\begin{array}{l}\text { Two or more } \\
\text { falls in past } \\
\text { year }\end{array}$} & \multicolumn{2}{|c|}{ One } & \multicolumn{2}{|c|}{ None } & \multirow[t]{2}{*}{ Total } & \multirow{2}{*}{$\begin{array}{l}\text { Number } \\
\text { in sample }\end{array}$} \\
\hline & $\%$ & $95 \% \mathrm{Cl}$ & $\%$ & $95 \% \mathrm{Cl}$ & $\%$ & $95 \% \mathrm{Cl}$ & & \\
\hline \multicolumn{9}{|l|}{$50-64$} \\
\hline 0 medications & 5 & $(4-6)$ & 10 & $(9-12)$ & 85 & $(83-87)$ & 100 & 1787 \\
\hline 1-2 medications & 6 & $(5-7)$ & 11 & $(10-13)$ & 83 & $(81-85)$ & 100 & 1523 \\
\hline 3-4 medications & 8 & $(6-10)$ & 12 & $(10-15)$ & 80 & $(77-83)$ & 100 & 783 \\
\hline$>=5$ medications & 13 & $(10-16)$ & 9 & $(7-12)$ & 78 & $(74-81)$ & 100 & 545 \\
\hline Total & 7 & $(6-8)$ & 11 & $(10-12)$ & 83 & (81-84) & 100 & 4638 \\
\hline \multicolumn{9}{|l|}{$65-74$} \\
\hline 0 medications & 5 & $(3-8)$ & 10 & $(7-14)$ & 85 & $(81-88)$ & 100 & 369 \\
\hline 1-2 medications & 5 & $(3-7)$ & 12 & $(10-15)$ & 83 & $(80-86)$ & 100 & 626 \\
\hline 3-4 medications & 7 & $(5-10)$ & 11 & $(8-14)$ & 82 & $(79-85)$ & 100 & 548 \\
\hline$>=5$ medications & 11 & $(9-14)$ & 15 & $(12-19)$ & 73 & $(70-77)$ & 100 & 597 \\
\hline Total & 7 & $(6-9)$ & 12 & $(11-14)$ & 80 & $(78-82)$ & 100 & 2140 \\
\hline \multicolumn{9}{|l|}{$>=75$} \\
\hline 0 medications & 4 & $(2-11)$ & 10 & $(6-17)$ & 85 & $(77-91)$ & 100 & 127 \\
\hline 1-2 medications & 5 & $(3-8)$ & 15 & $(11-20)$ & 81 & $(75-85)$ & 100 & 287 \\
\hline 3-4 medications & 8 & $(6-12)$ & 16 & $(13-21)$ & 75 & $(70-80)$ & 100 & 368 \\
\hline$>=5$ medications & 13 & $(10-17)$ & 17 & $(13-20)$ & 70 & $(66-74)$ & 100 & 533 \\
\hline Total & 9 & $(8-11)$ & 16 & $(13-18)$ & 75 & (73-78) & 100 & 1315 \\
\hline \multicolumn{9}{|l|}{ Total } \\
\hline 0 medications & 5 & $(4-6)$ & 10 & $(9-11)$ & 85 & $(83-87)$ & 100 & 2283 \\
\hline 1-2 medications & 5 & $(5-6)$ & 12 & $(11-13)$ & 83 & $(81-84)$ & 100 & 2436 \\
\hline 3-4 medications & 8 & $(6-9)$ & 13 & $(11-15)$ & 79 & $(77-81)$ & 100 & 1699 \\
\hline$>=5$ medications & 13 & $(11-14)$ & 14 & $(12-16)$ & 74 & $(71-76)$ & 100 & 1675 \\
\hline Total & 7 & $(7-8)$ & 12 & $(11-13)$ & 81 & $(80-82)$ & 100 & 8093 \\
\hline
\end{tabular}

Note. $\mathrm{Cl}=$ confidence interval; Missing observations $=0.02 \%$ 
Table 5.A50: Number of falls in the last year by medication use and education

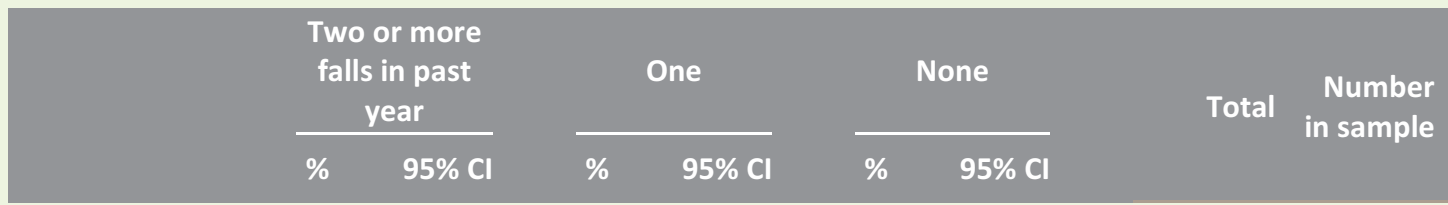

\section{Primary/none}

\begin{tabular}{|c|c|c|c|c|c|c|c|c|}
\hline 0 medications & 5 & $(3-7)$ & 11 & $(8-14)$ & 84 & $(81-88)$ & 100 & 472 \\
\hline 1-2 medications & 5 & $(4-7)$ & 11 & $(9-14)$ & 84 & $(80-86)$ & 100 & 673 \\
\hline 3-4 medications & 9 & $(7-11)$ & 12 & $(10-16)$ & 79 & $(75-82)$ & 100 & 593 \\
\hline$>=5$ medications & 14 & $(11-16)$ & 14 & $(12-17)$ & 72 & $(69-76)$ & 100 & 722 \\
\hline Total & 9 & $(7-10)$ & 12 & $(11-14)$ & 79 & $(77-81)$ & 100 & 2460 \\
\hline \multicolumn{9}{|l|}{ Secondary } \\
\hline 0 medications & 5 & $(4-6)$ & 9 & $(8-11)$ & 86 & $(84-88)$ & 100 & 1042 \\
\hline 1-2 medications & 6 & $(5-8)$ & 12 & $(10-14)$ & 82 & $(80-85)$ & 100 & 971 \\
\hline 3-4 medications & 7 & $(6-10)$ & 12 & $(10-15)$ & 81 & $(77-84)$ & 100 & 644 \\
\hline$>=5$ medications & 11 & $(9-14)$ & 13 & $(11-16)$ & 76 & $(72-79)$ & 100 & 581 \\
\hline Total & 7 & $(6-8)$ & 11 & $(10-12)$ & 82 & $(81-83)$ & 100 & 3238 \\
\hline \multicolumn{9}{|l|}{ Third/higher } \\
\hline 0 medications & 5 & $(4-7)$ & 11 & $(9-13)$ & 84 & $(81-86)$ & 100 & 769 \\
\hline 1-2 medications & 4 & $(3-6)$ & 14 & $(11-16)$ & 82 & $(79-85)$ & 100 & 790 \\
\hline 3-4 medications & 6 & $(4-9)$ & 16 & $(13-20)$ & 78 & $(74-81)$ & 100 & 461 \\
\hline$>=5$ medications & 12 & $(9-16)$ & 13 & $(10-17)$ & 75 & (70-79) & 100 & 372 \\
\hline Total & 6 & $(5-7)$ & 13 & $(12-15)$ & 81 & (79-82) & 100 & 2392 \\
\hline \multicolumn{9}{|l|}{ Total } \\
\hline 0 medications & 5 & $(4-6)$ & 10 & $(9-11)$ & 85 & $(83-87)$ & 100 & 2283 \\
\hline 1-2 medications & 5 & $(5-6)$ & 12 & $(11-13)$ & 83 & $(81-84)$ & 100 & 2436 \\
\hline 3-4 medications & 8 & $(6-9)$ & 13 & $(11-15)$ & 79 & $(77-81)$ & 100 & 1699 \\
\hline$>=5$ medications & 13 & $(11-14)$ & 14 & $(12-16)$ & 74 & $(71-76)$ & 100 & 1675 \\
\hline Total & 7 & $(7-8)$ & 12 & (11-13) & 81 & $(80-82)$ & 100 & 8093 \\
\hline
\end{tabular}

Note. $\mathrm{Cl}=$ confidence interval; Missing observations $=0.02 \%$ 
Table 5.A51: Distribution of BMI by age and sex

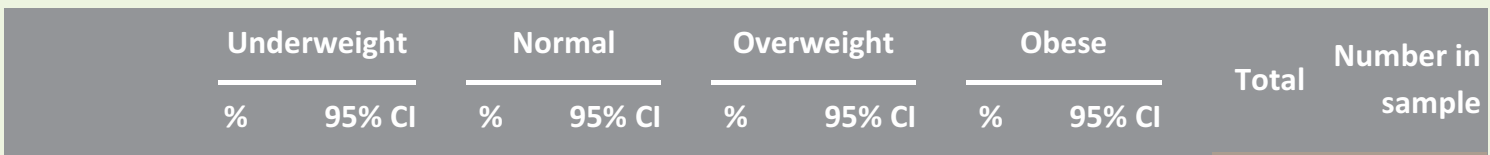

Male

\begin{tabular}{lllllllllll}
$50-64$ & 0 & $(0-1)$ & 16 & $(13-18)$ & 48 & $(45-51)$ & 36 & $(34-39)$ & 100 & 1169 \\
$65-74$ & 1 & $(0-2)$ & 14 & $(11-17)$ & 47 & $(43-51)$ & 39 & $(35-43)$ & 100 & 591 \\
$>=75$ & 0 & $(0-3)$ & 17 & $(13-23)$ & 46 & $(39-52)$ & 37 & $(31-43)$ & 100 & 262 \\
\hline Total & 0 & $(0-1)$ & 15 & $(14-17)$ & 47 & $(45-50)$ & 37 & $(35-39)$ & 100 & 2022
\end{tabular}

\section{Female}

\begin{tabular}{lllllllllll}
$50-64$ & 1 & $(0-1)$ & 28 & $(26-31)$ & 40 & $(38-43)$ & 31 & $(28-34)$ & 100 & 1439 \\
$65-74$ & 1 & $(0-2)$ & 26 & $(22-29)$ & 40 & $(35-44)$ & 34 & $(30-38)$ & 100 & 592 \\
$>=75$ & 1 & $(0-3)$ & 29 & $(24-35)$ & 42 & $(36-48)$ & 28 & $(23-34)$ & 100 & 295 \\
\hline Total & 1 & $(0-1)$ & 28 & $(26-30)$ & 40 & $(38-43)$ & 31 & $(29-33)$ & 100 & 2326 \\
\hline
\end{tabular}

\section{Total}

\begin{tabular}{lllllllllll}
$50-64$ & 0 & $(0-1)$ & 22 & $(20-24)$ & 44 & $(42-46)$ & 34 & $(32-36)$ & 100 & 2608 \\
$65-74$ & 1 & $(0-1)$ & 20 & $(18-22)$ & 43 & $(40-46)$ & 36 & $(33-39)$ & 100 & 1183 \\
$>=75$ & 1 & $(0-2)$ & 24 & $(20-28)$ & 43 & $(39-48)$ & 32 & $(28-36)$ & 100 & 557 \\
\hline Total & 0 & $(0-1)$ & 22 & $(20-23)$ & 44 & $(42-45)$ & 34 & $(33-36)$ & 100 & 4348
\end{tabular}

Note. $\mathrm{Cl}=$ confidence interval; Missing observations $=46.83 \%$ 
Table 5.A52: Distribution of BMI by age and education

\begin{tabular}{|c|c|c|c|c|c|c|c|c|c|}
\hline \multicolumn{2}{|c|}{ Underweight } & \multicolumn{2}{|c|}{ Normal } & \multicolumn{2}{|c|}{ Overweight } & \multicolumn{2}{|c|}{ Obese } & \multirow{2}{*}{ Total } & \multirow{2}{*}{$\begin{array}{r}\text { Number in } \\
\text { sample }\end{array}$} \\
\hline$\%$ & $95 \% \mathrm{Cl}$ & $\%$ & $95 \% \mathrm{Cl}$ & $\%$ & $95 \% \mathrm{Cl}$ & $\%$ & $95 \% \mathrm{Cl}$ & & \\
\hline
\end{tabular}

\section{Primary/none}

\begin{tabular}{|c|c|c|c|c|c|c|c|c|c|c|}
\hline $50-64$ & 1 & $(0-2)$ & 19 & $(15-24)$ & 39 & $(34-44)$ & 41 & $(37-46)$ & 100 & 451 \\
\hline $65-74$ & 0 & $(0-2)$ & 17 & $(14-21)$ & 41 & $(36-46)$ & 42 & $(37-47)$ & 100 & 410 \\
\hline$>=75$ & 1 & $(0-3)$ & 21 & $(16-27)$ & 47 & $(40-53)$ & 32 & $(26-38)$ & 100 & 242 \\
\hline Total & 1 & $(0-1)$ & 19 & $(16-21)$ & 42 & $(38-45)$ & 39 & $(36-42)$ & 100 & 1103 \\
\hline \multicolumn{11}{|c|}{ Secondary } \\
\hline $50-64$ & 0 & $(0-1)$ & 21 & $(19-24)$ & 46 & $(43-49)$ & 33 & $(30-35)$ & 100 & 1187 \\
\hline $65-74$ & 1 & $(0-3)$ & 21 & $(18-26)$ & 44 & $(39-48)$ & 34 & $(29-38)$ & 100 & 410 \\
\hline$>=75$ & 1 & $(0-4)$ & 27 & $(21-33)$ & 39 & $(32-45)$ & 34 & $(28-41)$ & 100 & 193 \\
\hline Total & 1 & $(0-1)$ & 22 & $(20-24)$ & 45 & $(43-47)$ & 33 & (31-35) & 100 & 1790 \\
\hline \multicolumn{11}{|c|}{ Third/higher } \\
\hline $50-64$ & 0 & $(0-1)$ & 25 & $(23-28)$ & 45 & $(42-48)$ & 30 & $(27-33)$ & 100 & 970 \\
\hline $65-74$ & 1 & $(0-2)$ & 24 & $(20-29)$ & 48 & $(42-53)$ & 28 & $(23-32)$ & 100 & 363 \\
\hline$>=75$ & 0 & (.-.) & 36 & $(28-45)$ & 38 & $(30-46)$ & 26 & $(20-35)$ & 100 & 121 \\
\hline Total & 0 & $(0-1)$ & 26 & (24-28) & 45 & $(42-47)$ & 29 & $(27-32)$ & 100 & 1454 \\
\hline \multicolumn{11}{|l|}{ Total } \\
\hline $50-64$ & 0 & $(0-1)$ & 22 & $(20-24)$ & 44 & $(42-46)$ & 34 & $(32-36)$ & 100 & 2608 \\
\hline $65-74$ & 1 & $(0-1)$ & 20 & $(18-22)$ & 43 & $(40-46)$ & 36 & $(33-39)$ & 100 & 1183 \\
\hline$>=75$ & 1 & $(0-2)$ & 24 & $(20-28)$ & 43 & $(39-48)$ & 32 & $(28-36)$ & 100 & 557 \\
\hline Total & 0 & $(0-1)$ & 22 & $(20-23)$ & 44 & $(42-45)$ & 34 & $(33-36)$ & 100 & 4348 \\
\hline
\end{tabular}

Note. $\mathrm{Cl}=$ confidence interval; Missing observations $=46.83 \%$ 
Table 5.A53: Distribution of BMI by age and wealth

\begin{tabular}{|c|c|c|c|c|c|c|c|c|c|c|}
\hline & \multicolumn{2}{|c|}{ Underweight } & \multicolumn{2}{|c|}{ Normal } & \multicolumn{2}{|c|}{ Overweight } & \multicolumn{2}{|c|}{ Obese } & \multirow{2}{*}{ Total } & \multirow{2}{*}{$\begin{array}{l}\text { Number } \\
\text { in sample }\end{array}$} \\
\hline & $\%$ & $95 \% \mathrm{Cl}$ & $\%$ & $95 \% \mathrm{Cl}$ & $\%$ & $95 \% \mathrm{Cl}$ & $\%$ & $95 \% \mathrm{Cl}$ & & \\
\hline \multicolumn{11}{|l|}{$50-64$} \\
\hline Lowest & 0 & $(0-3)$ & 25 & $(19-31)$ & 41 & $(35-48)$ & 34 & $(27-41)$ & 100 & 242 \\
\hline 2nd & 0 & $(0-2)$ & 17 & $(13-21)$ & 42 & $(36-47)$ & 41 & $(36-47)$ & 100 & 338 \\
\hline $3 r d$ & 0 & - & 18 & $(15-23)$ & 47 & $(42-52)$ & 35 & $(30-41)$ & 100 & 358 \\
\hline Highest & 0 & - & 25 & $(20-29)$ & 49 & $(43-54)$ & 27 & $(22-32)$ & 100 & 432 \\
\hline Total & 0 & $(0-1)$ & 21 & $(19-23)$ & 45 & $(42-48)$ & 34 & (31-37) & 100 & 1370 \\
\hline \multicolumn{11}{|l|}{$65-74$} \\
\hline Lowest & 3 & $(1-10)$ & 21 & $(14-28)$ & 41 & $(32-51)$ & 35 & $(26-45)$ & 100 & 108 \\
\hline 2nd & 0 & $(0-3)$ & 25 & $(17-35)$ & 33 & $(26-42)$ & 41 & $(32-51)$ & 100 & 128 \\
\hline $3 r d$ & 1 & $(0-5)$ & 22 & $(15-30)$ & 45 & $(38-53)$ & 32 & $(25-40)$ & 100 & 172 \\
\hline Highest & 0 & - & 25 & $(18-33)$ & 46 & $(38-54)$ & 30 & $(22-39)$ & 100 & 162 \\
\hline Total & 1 & $(0-3)$ & 23 & $(19-27)$ & 42 & $(38-46)$ & 34 & (30-39) & 100 & 570 \\
\hline \multicolumn{11}{|l|}{$>=75$} \\
\hline Lowest & 0 & - & 17 & $(10-28)$ & 45 & $(31-60)$ & 38 & $(23-55)$ & 100 & 58 \\
\hline 2nd & 2 & $(0-14)$ & 29 & $(17-45)$ & 43 & $(29-59)$ & 26 & $(15-40)$ & 100 & 68 \\
\hline $3 r d$ & 0 & - & 26 & $(14-43)$ & 45 & $(32-59)$ & 29 & $(19-41)$ & 100 & 75 \\
\hline Highest & 0 & - & 58 & $(41-73)$ & 26 & $(15-40)$ & 17 & $(8-33)$ & 100 & 46 \\
\hline Total & 1 & $(0-5)$ & 28 & $(22-36)$ & 42 & (34-51) & 29 & $(22-37)$ & 100 & 247 \\
\hline \multicolumn{11}{|l|}{ Total } \\
\hline Lowest & 1 & $(0-3)$ & 22 & $(18-27)$ & 42 & $(37-47)$ & 35 & $(30-41)$ & 100 & 408 \\
\hline 2nd & 1 & $(0-2)$ & 21 & $(17-25)$ & 40 & $(36-45)$ & 38 & $(34-43)$ & 100 & 534 \\
\hline $3 r d$ & 0 & $(0-1)$ & 20 & $(17-25)$ & 46 & $(42-50)$ & 33 & $(29-37)$ & 100 & 605 \\
\hline Highest & 0 & - & 27 & $(23-31)$ & 46 & $(42-51)$ & 27 & $(23-31)$ & 100 & 640 \\
\hline Total & 0 & $(0-1)$ & 22 & (21-24) & 44 & $(41-46)$ & 33 & (31-36) & 100 & 2187 \\
\hline
\end{tabular}

Note. $\mathrm{Cl}=$ confidence interval; Missing observations $=46.83 \%$ 
Table 5.A54a: Prevalence of objectively measured hypertension by age and sex

\begin{tabular}{|c|c|c|c|c|c|c|}
\hline & \multicolumn{2}{|c|}{ Male } & \multicolumn{2}{|c|}{ Female } & \multicolumn{2}{|c|}{ Total } \\
\hline & $\%$ & $(95 \% \mathrm{Cl})$ & $\%$ & $(95 \% \mathrm{Cl})$ & $\%$ & $(95 \% \mathrm{Cl})$ \\
\hline \multicolumn{7}{|c|}{ Age group } \\
\hline $50-64$ & 29 & $(26-32)$ & 23 & $(20-25)$ & 26 & $(24-28)$ \\
\hline $65-74$ & 21 & $(17-25)$ & 23 & $(20-27)$ & 22 & $(19-25)$ \\
\hline$>=75$ & 17 & $(12-23)$ & 21 & $(16-27)$ & 19 & $(16-24)$ \\
\hline Total & 25 & $(23-27)$ & 22 & (21-24) & 24 & (22-25) \\
\hline
\end{tabular}

Table 5.A54b: Prevalence of objectively measured hypertension by education and sex

\begin{tabular}{|c|c|c|c|c|c|c|}
\hline & \multicolumn{2}{|c|}{ Male } & \multicolumn{2}{|c|}{ Female } & \multicolumn{2}{|c|}{ Total } \\
\hline & $\%$ & $(95 \% \mathrm{Cl})$ & $\%$ & $(95 \% \mathrm{Cl})$ & $\%$ & $(95 \% \mathrm{Cl})$ \\
\hline \multicolumn{7}{|l|}{ Education } \\
\hline Primary/none & 23 & $(20-27)$ & 26 & $(23-31)$ & 25 & $(22-28)$ \\
\hline Secondary & 26 & $(23-29)$ & 22 & $(19-25)$ & 24 & $(22-26)$ \\
\hline Third/higher & 27 & $(23-31)$ & 16 & (14-19) & 22 & $(19-24)$ \\
\hline Total & 25 & $(23-27)$ & 22 & (21-24) & 24 & $(22-25)$ \\
\hline
\end{tabular}

Table 5.A54c: Prevalence of objectively measured hypertension by wealth and sex

\begin{tabular}{|c|c|c|c|c|c|c|}
\hline & \multicolumn{2}{|c|}{ Male } & \multicolumn{2}{|c|}{ Female } & \multicolumn{2}{|c|}{ Total } \\
\hline & $\%$ & $(95 \% \mathrm{Cl})$ & $\%$ & $(95 \% \mathrm{Cl})$ & $\%$ & $(95 \% \mathrm{CI})$ \\
\hline \multicolumn{7}{|c|}{ Wealth quartile } \\
\hline Lowest & 34 & $(28-41)$ & 25 & $(19-32)$ & 30 & $(25-35)$ \\
\hline 2nd & 20 & $(15-26)$ & 25 & $(20-32)$ & 23 & $(19-27)$ \\
\hline $3 r d$ & 24 & $(19-29)$ & 22 & $(17-27)$ & 23 & $(19-27)$ \\
\hline Highest & 25 & $(21-31)$ & 23 & $(18-28)$ & 24 & $(21-28)$ \\
\hline Total & 25 & $(23-27)$ & 22 & $(21-24)$ & 24 & $(22-25)$ \\
\hline
\end{tabular}


Table 5.A55: Proportion of the population with a diagnosis of hypertension by objective measure of blood pressure in men and women aged 50 and over

\begin{tabular}{|c|c|c|c|c|c|c|}
\hline & \multicolumn{2}{|c|}{ Not diagnosed } & \multicolumn{2}{|c|}{ Diagnosed } & \multirow{2}{*}{ Total } & \multirow{2}{*}{$\begin{array}{c}\text { Number in } \\
\text { sample }\end{array}$} \\
\hline & $\%$ & $95 \% \mathrm{Cl}$ & $\%$ & $95 \% \mathrm{Cl}$ & & \\
\hline \multicolumn{7}{|l|}{ Male } \\
\hline Not hypertensive & 67 & $(64-70)$ & 33 & $(30-36)$ & 100 & 1513 \\
\hline Hypertensive & 58 & $(53-62)$ & 42 & $(38-47)$ & 100 & 510 \\
\hline Total & 65 & $(62-67)$ & 35 & (33-38) & 100 & 2023 \\
\hline \multicolumn{7}{|l|}{ Female } \\
\hline Not hypertensive & 64 & $(62-67)$ & 36 & $(33-38)$ & 100 & 1838 \\
\hline Hypertensive & 49 & $(45-54)$ & 51 & $(46-55)$ & 100 & 488 \\
\hline Total & 61 & (59-63) & 39 & $(37-41)$ & 100 & 2326 \\
\hline \multicolumn{7}{|l|}{ Total } \\
\hline Not hypertensive & 66 & $(64-67)$ & 34 & $(33-36)$ & 100 & 3351 \\
\hline Hypertensive & 54 & $(51-57)$ & 46 & $(43-49)$ & 100 & 998 \\
\hline Total & 63 & (61-64) & 37 & (36-39) & 100 & 4349 \\
\hline
\end{tabular}

Note. $\mathrm{Cl}=$ confidence interval; Missing observations $=0.00 \%$ 
Table 5.A56a: Prevalence of objectively measured osteoporosis by age and sex

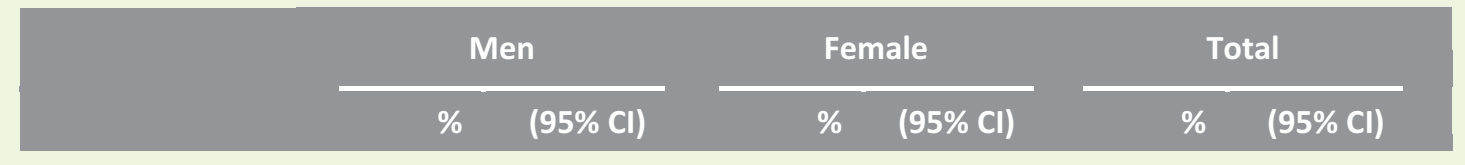

\begin{tabular}{lrrrrrr} 
Age group & & & & & \\
$50-64$ & 2 & $(1-3)$ & $(6-9)$ & 5 & $(4-6)$ \\
$65-74$ & 5 & $(4-8)$ & 18 & $(15-21)$ & 12 & $(10-14)$ \\
$>=75$ & 3 & $(1-7)$ & 34 & $(27-42)$ & 21 & $(16-26)$ \\
\hline Total & 3 & $(2-4)$ & 13 & $(11-15)$ & 8 & $(6-9)$ \\
\hline
\end{tabular}

Table 5.A56b: Prevalence of objectively measured osteoporosis by education and sex

\begin{tabular}{|c|c|c|c|c|c|c|}
\hline & \multicolumn{2}{|c|}{ Men } & \multicolumn{2}{|c|}{ Female } & \multicolumn{2}{|c|}{ Total } \\
\hline & $\%$ & $(95 \% \mathrm{Cl})$ & $\%$ & $(95 \% \mathrm{Cl})$ & $\%$ & $(95 \% \mathrm{Cl})$ \\
\hline \multicolumn{7}{|l|}{ Education } \\
\hline Primary/none & 4 & $(2-6)$ & 20 & $(16-24)$ & 11 & $(9-14)$ \\
\hline Secondary & 3 & $(2-4)$ & 11 & $(9-13)$ & 7 & $(6-8)$ \\
\hline Third/higher & 2 & $(1-3)$ & 11 & $(9-13)$ & 6 & $(5-8)$ \\
\hline Total & 3 & $(2-4)$ & 13 & (11-15) & 8 & $(6-9)$ \\
\hline
\end{tabular}

Table 5.A56c: Prevalence of objectively measured osteoporosis by wealth quartile and sex

\begin{tabular}{|c|c|c|c|c|c|c|}
\hline & \multicolumn{2}{|c|}{ Men } & \multicolumn{2}{|c|}{ Female } & \multicolumn{2}{|c|}{ Total } \\
\hline & $\%$ & $(95 \% \mathrm{Cl})$ & $\%$ & $(95 \% \mathrm{Cl})$ & $\%$ & $(95 \% \mathrm{Cl})$ \\
\hline \multicolumn{7}{|c|}{ Wealth quartile } \\
\hline Lowest & 4 & $(2-9)$ & 13 & $(9-20)$ & 9 & $(6-13)$ \\
\hline 2nd & 3 & $(2-6)$ & 15 & $(10-21)$ & 9 & $(6-12)$ \\
\hline $3 r d$ & 2 & $(1-5)$ & 11 & $(8-16)$ & 7 & $(5-9)$ \\
\hline Highest & 2 & $(1-5)$ & 11 & $(8-16)$ & 6 & $(5-8)$ \\
\hline Total & 3 & $(2-4)$ & 13 & $(11-15)$ & 8 & $(6-9)$ \\
\hline
\end{tabular}


Table 5.A57: Proportion of the population with a diagnosis of osteoporosis by objective measure of bone density in men and women aged 50 and over

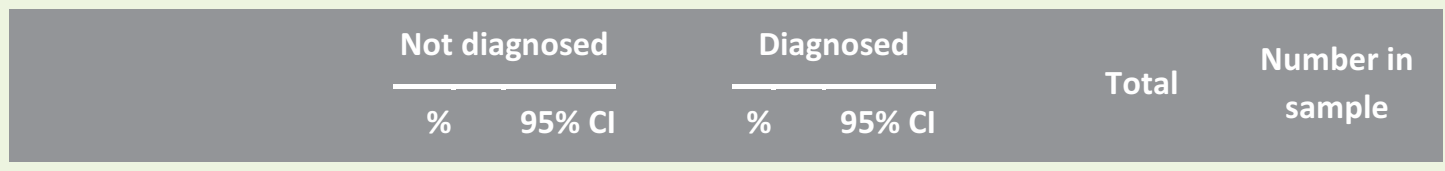

Male

\begin{tabular}{|c|c|c|c|c|c|c|}
\hline Normal bone stiffness & 98 & $(97-99)$ & 2 & $(1-3)$ & 100 & 1231 \\
\hline Osteopenia & 97 & $(95-99)$ & 3 & $(1-5)$ & 100 & 504 \\
\hline Osteoporosis & 100 & - & 0 & - & 100 & 49 \\
\hline Total & 98 & (97-99) & 2 & $(1-3)$ & 100 & 1784 \\
\hline \multicolumn{7}{|l|}{ Female } \\
\hline Normal bone stiffness & 91 & $(88-93)$ & 9 & $(7-12)$ & 100 & 744 \\
\hline Osteopenia & 80 & $(78-83)$ & 20 & $(17-22)$ & 100 & 1084 \\
\hline Osteoporosis & 66 & $(59-72)$ & 34 & $(28-41)$ & 100 & 255 \\
\hline Total & 82 & $(80-84)$ & 18 & $(16-20)$ & 100 & 2083 \\
\hline \multicolumn{7}{|l|}{ Total } \\
\hline Normal bone stiffness & 96 & $(95-97)$ & 4 & $(3-5)$ & 100 & 1975 \\
\hline Osteopenia & 86 & $(84-88)$ & 14 & $(12-16)$ & 100 & 1588 \\
\hline Osteoporosis & 72 & $(66-77)$ & 28 & $(23-34)$ & 100 & 304 \\
\hline Total & 90 & (89-91) & 10 & (9-11) & 100 & 3867 \\
\hline
\end{tabular}

Note. $\mathrm{Cl}=$ confidence interval; Missing observations $=0.00 \%$ 


\section{Mental Health And Cognitive Function}

Claire O'Regan, Hilary Cronin and Rose Anne Kenny

\section{Contents}

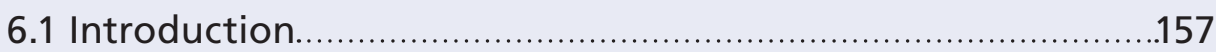

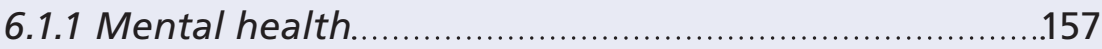

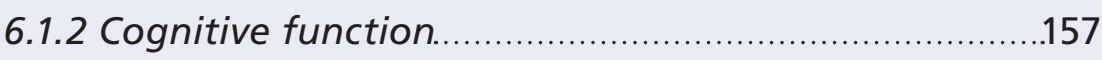

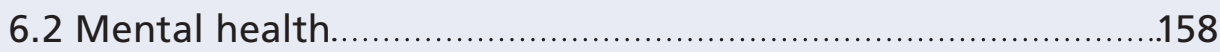

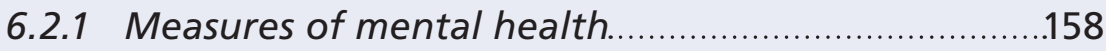

6.2.2 Self-rated mental health ......................................159

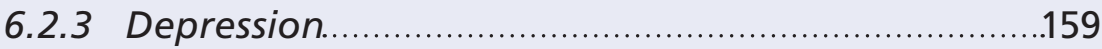

6.2.4 Depression and disability.......................................161

6.2.5 Depression and sensory impairment .........................162

6.2.6 Depression and health behaviours...........................162

6.2.7 Depression, polypharmacy and falls........................162

6.2.8 Economic consequences of depression......................165

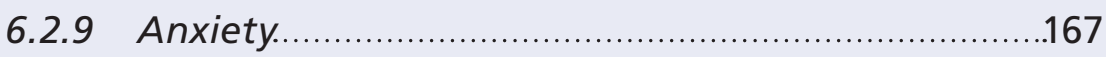

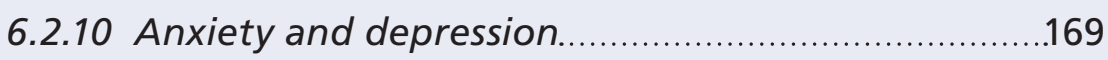

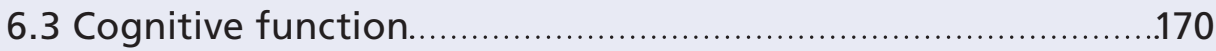

6.3.1 Measures of cognitive function .............................170

6.3.2 Self-rated memory .............................................171

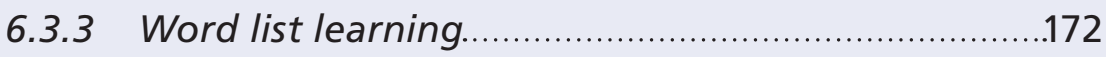

6.3.4 Prospective memory............................................173

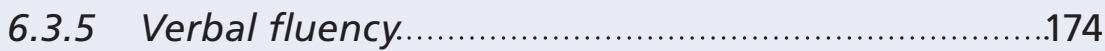

6.3.6 Global cognitive function......................................175

6.3.7 Cognitive impairment and employment................176

6.3.8 Cognitive impairment and activities of daily living .............................................179

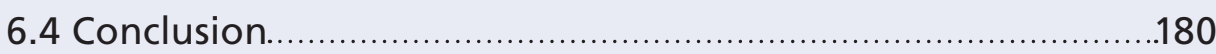




\section{Mental Health And Cognitive Function}

Key findings

- Depression is common among older adults in Ireland, with $10 \%$ of the population reporting clinically significant depressive symptoms with a further $18 \%$ reporting 'sub-threshold' levels of depression.

- Anxiety is more common than depression among older adults; $13 \%$ report clinically significant anxiety symptoms while $29 \%$ report sub-threshold levels of anxiety.

- There is evidence of under-diagnosis and hence under-treatment of depression and anxiety; $78 \%$ of older adults with objective evidence of depression do not report a doctor's diagnosis of depression. Similarly, $85 \%$ of older adults with objective evidence of anxiety do not report a doctor's diagnosis of anxiety.

- Depression is associated with disability. Nearly two-thirds of older adults with depression have a longstanding illness or disability compared to one-third of people who are depression free.

- Depression is associated with increased medication use. Of people aged 75 and over with depression, $56 \%$ are taking five or more medications compared to $36 \%$ of adults without depression.

- Older adults with depression have extremely low rates of labour force participation. Of adults aged 50-64 without depression, $60 \%$ are in employment compared to $30 \%$ of older adults with depression.

- Health service utilisation is increased in people with depression. Depressed adults aged 75 and over have an average of 7 visits to their GP in the past year compared to an average of 4 visits among the non-depressed older population.

- Cognitive impairment rises sharply with age. Of adults aged 80 and over, $35 \%$ have cognitive impairment compared to $4 \%$ of adults aged between 50 and 64 .

- There was a high level of memory impairment in the sample, particularly in the older groups. Of adults aged 80 and over, $42 \%$ forgot to carry out an action they had earlier been instructed to perform raising concerns about activities such as remembering to take medication, pay bills or take safety precautions. 


\subsection{Introduction}

\subsubsection{Mental health}

The promotion and protection of good mental health in old age is becoming a major societal concern. Good mental health is associated with greater economic success, better social relationships and reduced risk of physical illness. In addition it has a significant impact on a person's performance in the labour market. Individuals with poor mental health are less attached to the labour force, work fewer hours, lose more work days, and earn lower wages (1).

In Ireland, estimates suggest that the overall economic cost of mental health problems is $€ 3$ billion per annum; only cardiovascular disease is likely to contribute more to the overall burden of illness. Mental health care budgets have historically been determined on the basis of past precedent and political judgement rather than on the basis of an objective measure of population health needs (2). That is still the case, in part because ongoing accurate information on prevalence is not always available to inform resource allocation. Against this background this chapter reports on the prevalence of common mental health disorders in older adults and variations in prevalence between groups defined by a range of health, social and economic characteristics that have been previously associated with adult psychiatric morbidity.

\subsubsection{Cognitive function}

Cognitive function refers to an individual's perceptions, memory, thinking, reasoning and awareness. Along with physical decline, decline in cognitive function is a hallmark of ageing and is predictive of mortality (3). Independence in later life is as much determined by cognitive ability as by physical ability (4). Among older adults a broad spectrum of cognitive capability exists with dementia at one extreme and normal cognitive function at the other. Adequate cognitive functioning is required to perform simple activities of daily living such as dressing and bathing and more complex tasks such as managing money, paying bills and taking medications. Cognitive function also affects an individual's ability to work and plays a role in retirement planning and decisions around pensions and savings. The estimated cost of care for dementia in the UK today exceeds that of cancer, stroke and heart disease combined (5). Therefore, modifiable risk factors and early interventions to prevent cognitive decline and dementia are key priorities for policy-makers and for societies.

Despite its importance, the implications of declining cognitive functioning on older persons' daily lives are complex and not well understood. One reason is the lack of adequate data sources from which to derive population-based estimates of the prevalence and consequences of cognitive impairment. With an anticipated exponential expansion of the population that will develop dementia and the resulting costs to society, it is increasingly important to investigate and understand the mechanisms that promote optimal cognitive function in old age. This chapter 
describes variation in cognitive function between age groups and between men and women. In addition the effect of education and the association between cognitive performance, employment and activities of daily living are explored. Over subsequent waves TILDA's capacity to identify determinants of successful cognitive ageing will inform prevention strategies to ensure optimal health and to prevent or delay cognitive impairment in old age.

\subsection{Mental health}

\subsubsection{Measures of mental health}

Measures of mental health presented in this chapter include self-rated emotional health, diagnosed mental illness and measures of symptomatic anxiety and depression, the most common mental health disorders affecting older people. Specifically:

- Respondents rated their own emotional health directly using a global rating of emotional health as excellent, very good, good, fair, or poor.

- For diagnosed mental illness, respondents were asked whether a doctor had ever told them that they had any emotional, nervous or psychiatric problems.

- Center for Epidemiologic Studies Depression Scale (CES-D) - The 20 item CES-D scale (6) was administered during the CAPI and was used to estimate the prevalence of depression. The CES-D measures the degree to which respondents have experienced a wide variety of depressive symptoms within the past week. Each of the 20 items is measured on a four point scale leading to a total score of 60 . A cutoff score of $\geq 16$ is used to determine clinically significant (case level) depressive symptoms. Case level is indicative of depressive symptomatology. While the categorisation of specific subtypes and severity levels of depression is important for diagnostic purposes in older adults, it is increasingly important to recognise that any depressive symptoms that impair health, cognition or activities of daily living are clinically significant. This approach is especially relevant in older adults whose cognition and functional ability may be seriously impaired by a relatively small number of depressive symptoms. For this reason subthreshold symptom levels of depression are also presented in this report. In line with previous literature these are defined as those respondents who reported between 8-15 symptoms on the CES-D (7).

- Hospital Anxiety and Depression Scale -Anxiety subscale (HADS-A) - This seven item scale was included in the self-completion questionnaire to measure current anxiety symptomatology. It generates a total score of 21 . Borderline anxiety is defined as a score between 8-10 while a cutoff score $\geq 11$ is used to determine clinically significant (case level) anxiety. 


\subsubsection{Self-rated mental health}

Self-rated mental health is useful for monitoring the general mental health of the population. It is associated with a wide range of mental morbidity measures and captures individuals' perceptions of mental health, which have implications for service use and treatment compliance.

Overall, $90 \%$ of the older population rate their emotional health as excellent ( $25 \%)$, very good $(35 \%)$ or good $(30 \%)$, however a substantial proportion $(11 \%)$ rate their emotional health as fair or poor (Table 6.A1). Women tend to report lower levels of emotional health compared to men and no difference in self-rated emotional health across age groups is observed (Figure 6.1). Higher education is associated with better self-rated emotional health although the effect is not as great as was observed for self-rated physical health in chapter 5 . Of adults aged $\geq 75$ years with third level education, $94 \%$ rate their health as excellent, very good or good compared to $86 \%$ of those with primary or no education.

Figure 6.1: Self-rated emotional health by age, sex and education

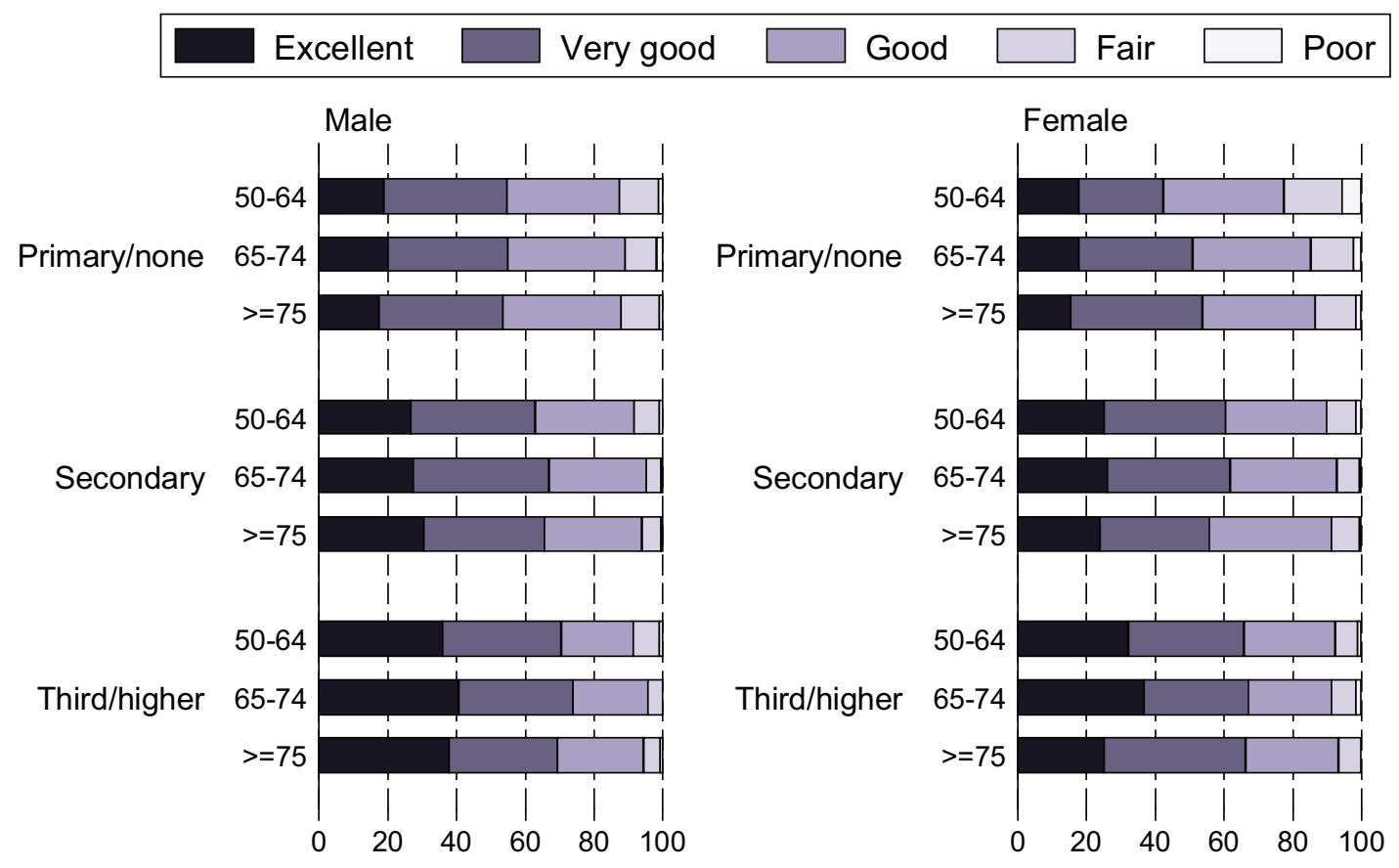

Note. $\mathrm{N}=8173 ;$ Missing obs $=5$

\subsubsection{Depression}

Depression is the most prevalent mental health condition in the older population and a leading cause of disability. Depression in late life is a recognised phenomenon but research suggests that depression is both under-recognised and under-treated 
in older adults. Not only has depression a profound impact on quality of life but it is associated with an increased risk of mortality from suicide and vascular disease (8). Although much research has been undertaken into depressive disorders, most of the literature focuses on younger adults. The effects of ageing on the brain, the physiological and behavioural consequences of depression, and the impact of other diseases common in the elderly, make late-life depression a distinct entity requiring its own body of research.

\subsubsection{Prevalence of depressive symptoms and diagnosed depression}

Based on the CES-D, $10 \%$ of respondents reported clinically significant depressive symptoms while $18 \%$ reported sub-threshold depression. In contrast only $5 \%$ of respondents reported a doctor's diagnosis of depression. These figures highlight the under-diagnosis of depression in older Irish adults (Table 6.A2). Only $22 \%$ of respondents who were depressed according to the CES-D reported a doctor's diagnosis of depression. An unmet need for mental health services may, therefore, be experienced by up to $78 \%$ of adults aged 50 and older with depression.

This large unmet need for diagnosis and treatment reflects the nature of the disorder in older adults. Depression occurs in a complex medical and psychosocial context where signs and symptoms are frequently attributed to "normal ageing", vascular disease, dementia, or any of a host of other age-associated afflictions. Psychosocial factors such as loss, combined with declines in physical health and sensory impairment, can also divert attention from a diagnosis of depression. In addition older people are less likely to report sadness, depressed mood or worthlessness, which are often considered hallmarks of the diagnosis of depression.

\subsubsection{Age, sex, education and wealth}

One of the most consistent findings in psychiatric epidemiology is the higher prevalence of depression among women. Rates of depression have been consistently shown to be higher in older women than in older men, but the sex difference is narrower in older people compared to the twofold difference seen across the rest of the adult lifespan. The relationship with age is also complex. Results from international studies show that the prevalence of major depression appears to diminish as people get older, however the incidence of 'sub-threshold' or 'minor' depression increases steadily with advancing age and rises steeply among those older than 80 years $(9,10)$.

Our results show that women are much more likely than men to suffer from depression (Table 6.A2). Overall, $13 \%$ of women reported case level depression, compared with $7 \%$ of men. Similarly, $20 \%$ of women reported sub-threshold depression, compared with $15 \%$ of men. The prevalence of case level depression was highest in the 50-64 year age group (11\%) and decreases with advancing years, yet the prevalence of sub-threshold depression was highest in the oldest age group 
(21\%). As previously mentioned this pattern is consistent with findings from other international studies. Figure 6.2 presents the prevalence of depression by sex, age and education. For men and women in all age categories low education is associated with higher prevalence of depression. An association with wealth is also observed. Of adults in the lowest wealth quartile, $17 \%$ have case level depression compared to $4 \%$ in the highest wealth quartile (Table 6.A3).

Figure 6.2: Prevalence of depression by sex, age and education

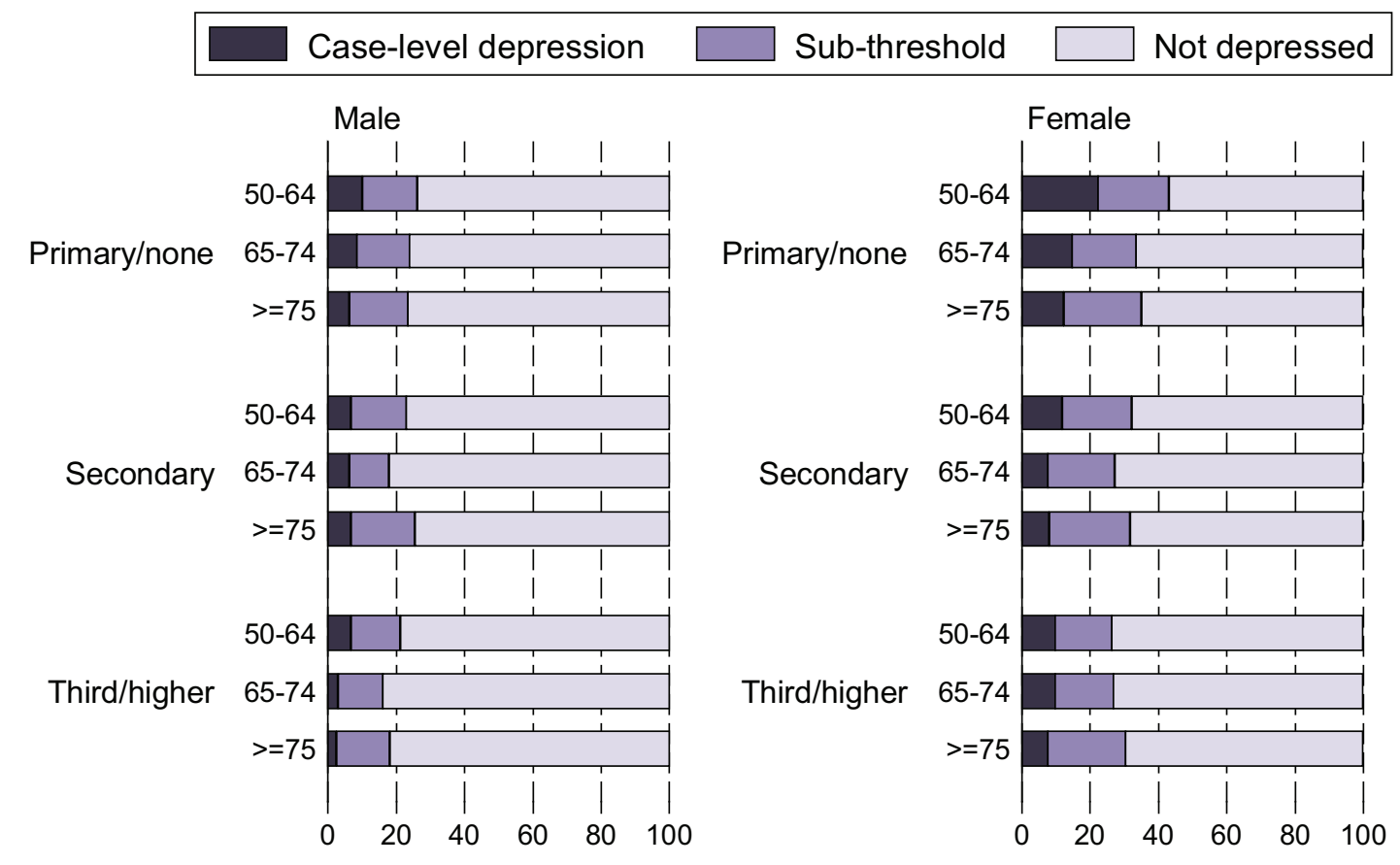

Note. $\mathrm{N}=8044 ;$ Missing obs $=134$

\subsubsection{Depression and disability}

There is a strong bi-directional relationship between depression and disability. Current evidence suggests that late-life depression promotes disability, and that disability increases the risk of depression. Depression leaves older adults vulnerable to disability regardless of the presence of medical illness, and depression is projected to be the second leading cause of disability worldwide by 2020 (11).

Respondents in TILDA were asked whether they have any longstanding illness, disability or infirmity that has troubled them or that is likely to affect them over a period of time (including mental health problems). If the answer was yes, they were then asked whether the illness limited their activities in any way. From the answers to these questions a variable was derived to indicate the presence of a limiting longstanding illness. 
Table 6.A4 shows the prevalence of disability by depression and sex. A clear association is observed. Nearly two-thirds of respondents with depression had a longstanding illness or disability compared to one-third of people who were depression free. The association between depression and activity limitation is stronger than the association with the presence of disease or disability; $52 \%$ of adults with case level depression had a limiting longstanding illness compared to $17 \%$ of people without depression. The association between depression and disability is similar in men and women. The absolute number of people with a disability in Ireland is likely to rise as the number of older people increases, therefore, understanding the causal link between depression and disability is important and a key focus of future waves of the study. This information will have considerable implications for health and social care providers.

\subsubsection{Depression and sensory impairment}

The prevalence of vision or hearing loss is expected to increase as the population ages. A strong association has been found between loss of vision and depression, with less consistent or weaker relationships between hearing loss and depression (12). TILDA respondents rated their vision (using glasses or contact lens) and hearing (with or without hearing aid) directly using a rating of excellent, very good, good, fair, or poor.

Figure 6.3 presents the association between depression, sensory function and age. A substantially larger proportion of persons with visual and hearing impairment experience depression than is observed in the general population. Of people with poor eyesight, $32 \%$ had case level depression compared to $6 \%$ of people with excellent vision. A similar pattern is seen for hearing. Of people with poor hearing, $26 \%$ had case level depression compared to $8 \%$ of people with excellent hearing.

\subsubsection{Depression and health behaviours}

\subsubsection{Exercise}

Several studies have revealed a direct relationship between physical inactivity and higher levels of depressive symptoms, however, many of these studies have focused on younger adults. The importance of studying these variables in older adults is highlighted by data suggesting age differences in the relationship between exercise and depression (13). Chapter 5 provides detail on how physical activity was assessed in TILDA.

Figure 6.4 presents the prevalence of physical activity by depression, age and sex. In all age groups a strong association between depression and low physical activity is observed. Overall, $47 \%$ of older adults with case level depression had low physical activity levels. This compares to $29 \%$ in non-depressed older adults (Table 6.A5). Depressed older women are more physically inactive than depressed older men. 
Figure 6.3: Depression by sensory function

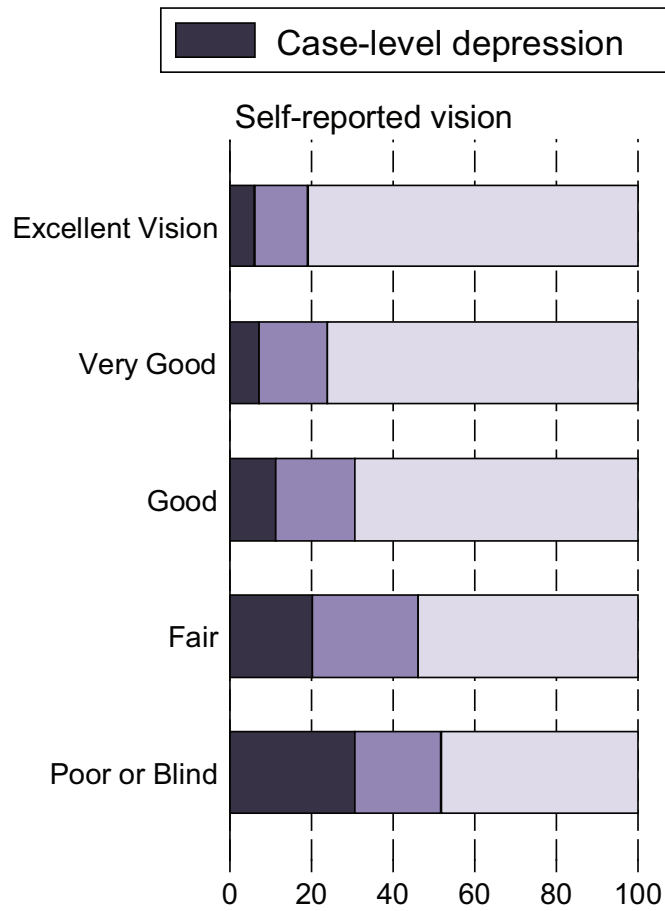

\section{Sub-threshold $\square$ Not depressed}

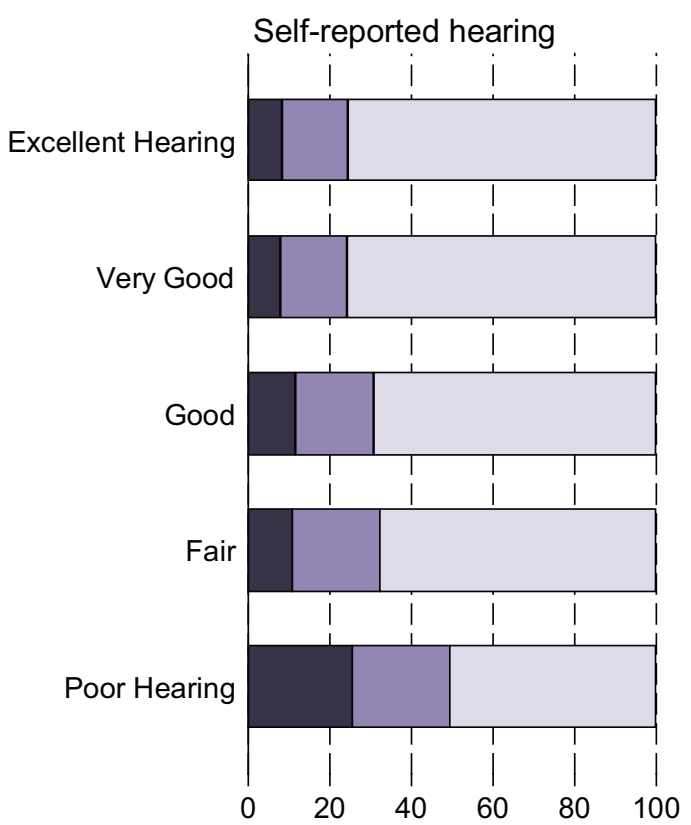

Figure 6.4 Physical activity by depression, age and sex

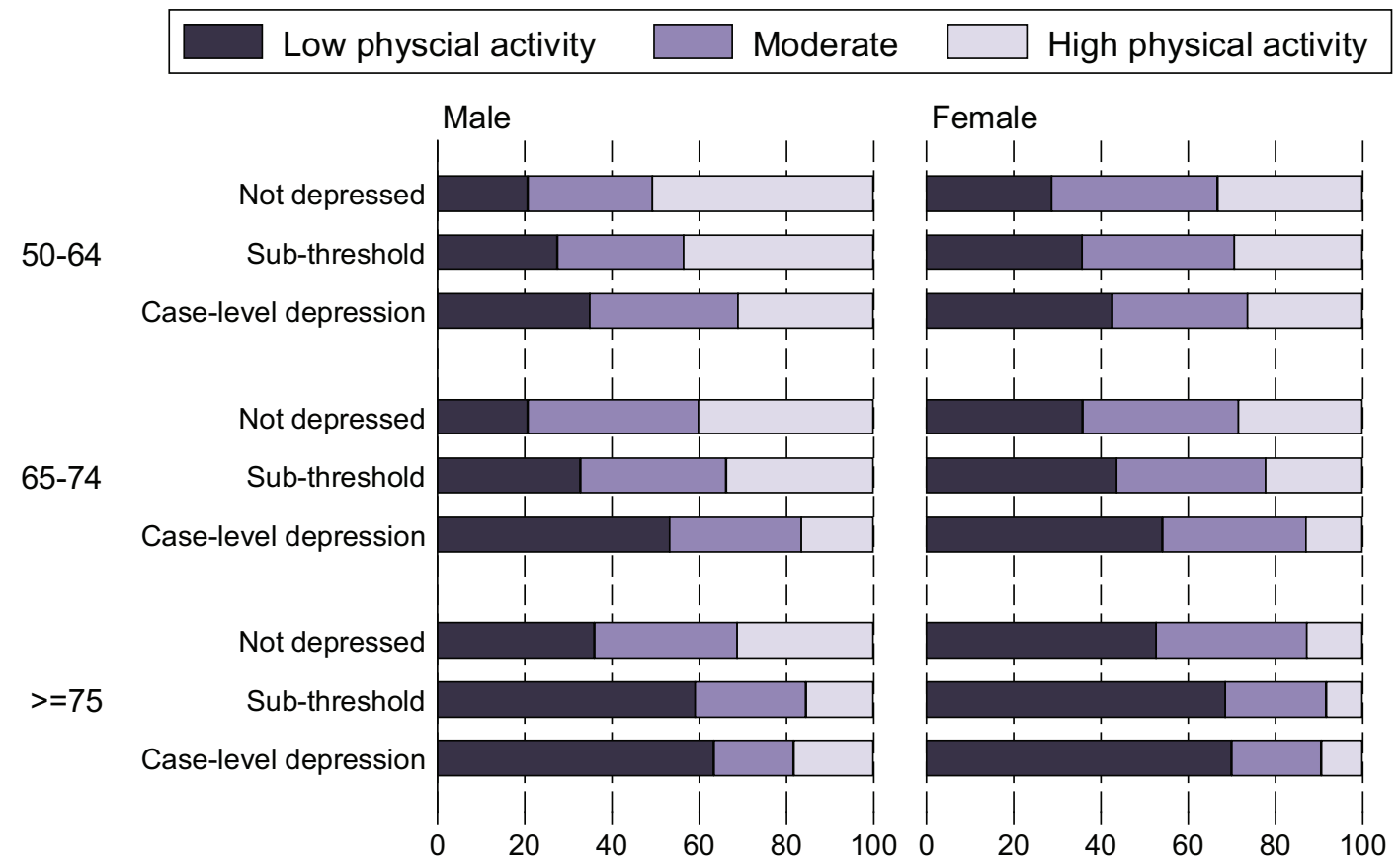

Note. $\mathrm{N}=7974 ;$ Missing obs $=204$ 
Although these associations do not prove causation, they suggest that increased physical activity is associated with lower levels of depressive symptoms among older adults. Future waves of TILDA will provide insights into the potential causal role of physical activity in reducing depression. The type, frequency, intensity, and duration of exercise that is most effective in treating depression in older adults is as yet unknown, so further research in this area is important. In addition, the in-depth assessment of psychological and physiological factors in TILDA will be invaluable in identifying mediators of the relationship between exercise and depression.

\subsubsection{Sleep}

Sleep disturbance is known to be a risk factor for depression among older adults (14).

Research on sleep has traditionally examined the effects of sleep quantity; however, a more recent distinction additionally incorporates sleep quality. Prospective studies have shown that insomnia, which was previously conceptualised as a symptom of depression, often precedes the onset of depression. The wider consequences of poor sleep quality include increased risk of falls, poor cognitive function and decreased quality of life $(15,16)$.

To examine sleep quality in TILDA, respondents were asked how often they had trouble falling asleep and how often they had trouble with waking up too early and not being able to fall asleep again. Response options were most of the time, sometimes, rarely or never. Table 6.1 presents the prevalence of sleep disruption by age. Our data suggest that ageing is not necessarily associated with poor or disrupted sleep as similar levels of sleep disruption are reported in all age groups.

Table 6.1: Prevalence of sleep disruption by age

\begin{tabular}{|l|rr|rr|}
\hline & \multicolumn{3}{|c|}{ Trouble falling asleep } & \multicolumn{3}{|c|}{$\begin{array}{c}\text { Trouble with waking } \\
\text { up too early }\end{array}$} \\
& $\%$ & $(95 \% \mathrm{Cl})$ & $\%$ & $(95 \% \mathrm{Cl})$ \\
\hline $\mathbf{5 0 - 6 4}$ & 10.7 & $(9.7-11.7)$ & 16.3 & $(15.1-17.5)$ \\
\hline $\mathbf{6 5 - 7 4}$ & 11.5 & $(10.1-13.0)$ & 16.3 & $(14.6-18.1)$ \\
\hline $\mathbf{> = 7 5}$ & 11.5 & $(9.8-13.6)$ & 17.3 & $(15.1-19.8)$ \\
\hline Total & 11.0 & $(10.3-11.8)$ & 16.5 & $(15.5-17.5)$ \\
\hline
\end{tabular}

Depressed older adults have far greater disruption in sleep quality than the general population. Of respondents with depression, 33\% had trouble falling asleep compared to $7 \%$ without depression. Similarly, $38 \%$ of respondents with depression had trouble waking up too early compared to $12 \%$ without depression (Table 6.A6). It is currently not possible to examine the direction of association for any of the 
observations made however, data from future waves of the study will allow us to examine these associations in greater depth and identify causal relationships that are potentially modifiable.

\subsubsection{Depression, polypharmacy and falls}

As discussed in Chapter 5, polypharmacy is defined as the use of five or more drugs, including prescribed, over-the-counter, and complementary medicines. Older adults with depression are at increased risk of polypharmacy owing to the presence of comorbid medical conditions. The risk of falls is increased with polypharmacy (see Chapter 5) and depression. This association is partly due to the comorbidity for which the multiple medications are prescribed.

Figure 6.5a presents the association between polypharmacy, depression, age and sex. Regardless of age, older adults with depression have higher rates of polypharmacy compared to older adults who are depression free. Of people aged 75 and over with case level depression, $56 \%$ are taking five or more medications compared to $36 \%$ of adults without depression. The association between falls, polypharmacy, depression and age can be seen in Figure $6.5 \mathrm{~b}$. Overall $36 \%$ of respondents with both case level depression and polypharmacy fell in the past year compared to $25 \%$ of respondents with case level depression and no polypharmacy. Future waves of the study will explore whether it is the specific drugs prescribed to treat depression (e.g. psychotropics) or polypharmacy per se that increase the risk of falls, with the ultimate aim of identifying modifiable risk factors for falls in depressed older adults.

\subsubsection{Economic consequences of depression}

\subsubsection{Employment}

A major economic consequence of poor mental health is the effect on labour market participation. This is reflected in lost employment, absenteeism, lost productivity and premature retirement. Figure 6.6 presents the association between employment, depression and age. Respondents with depression have extremely low rates of labour force participation compared to the non-depressed older population. In the preretirement age category (those aged $50-64$ ) $60 \%$ of respondents without depression are in employment compared to $30 \%$ of respondents with case level depression (Table 6.A7). While the direction of this effect is difficult to ascertain using this cross-sectional data, it is likely that a bi-directional association exists with depression being more likely to lead to removal from the labour market and continuation of employment into old age protecting against depression. 
Figure 6.5a: Polypharmacy (regularly taking five or more medications) by depression, age and sex

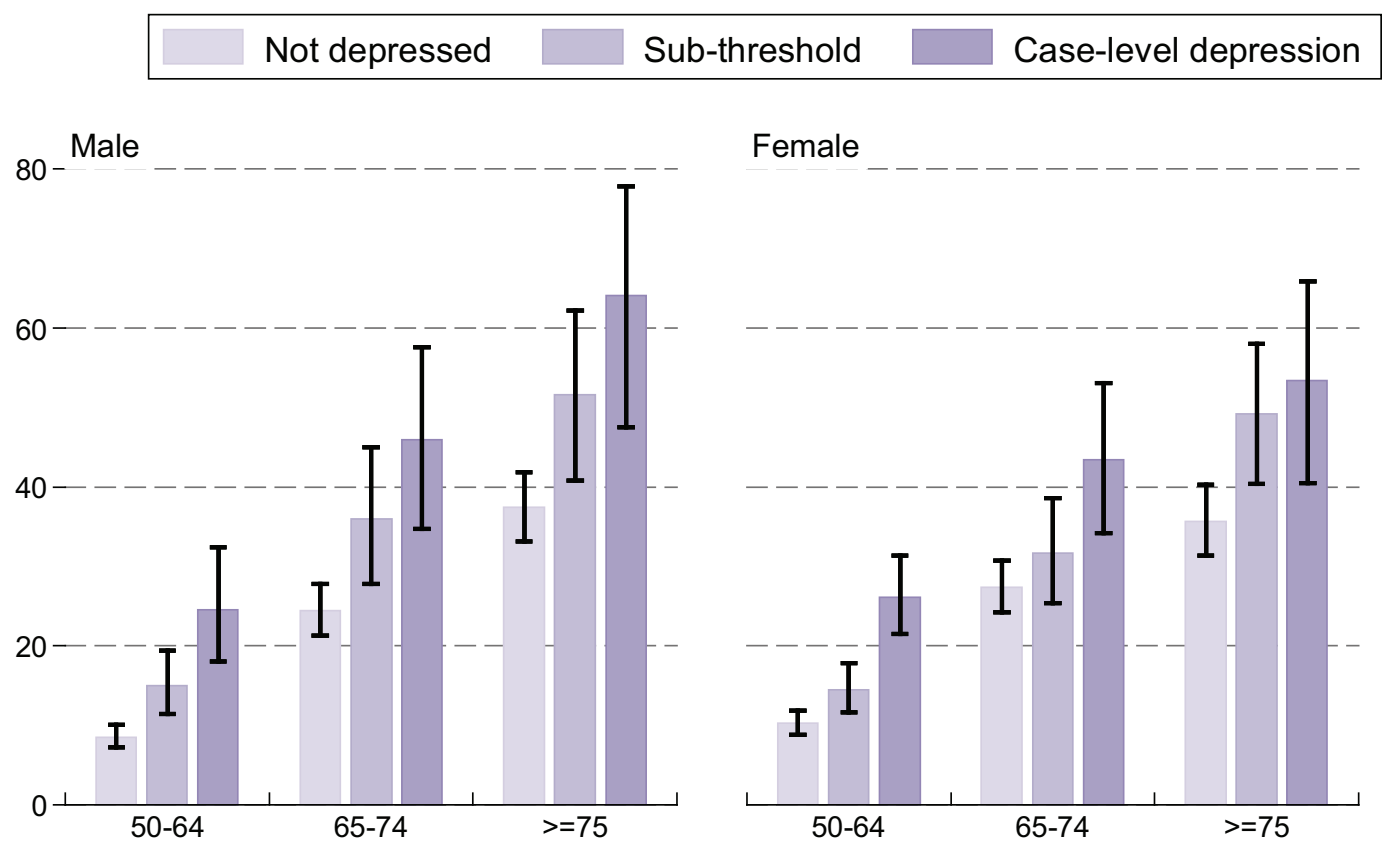

Note. $\mathrm{N}=7968$; Missing obs $=210$; Error bars correspond to $95 \%$ confidence intervals

Figure 6.5b: Percentage of the population who fell in the last year by depression, polypharmacy and age

$<5$ medications $\square>=5$ medications

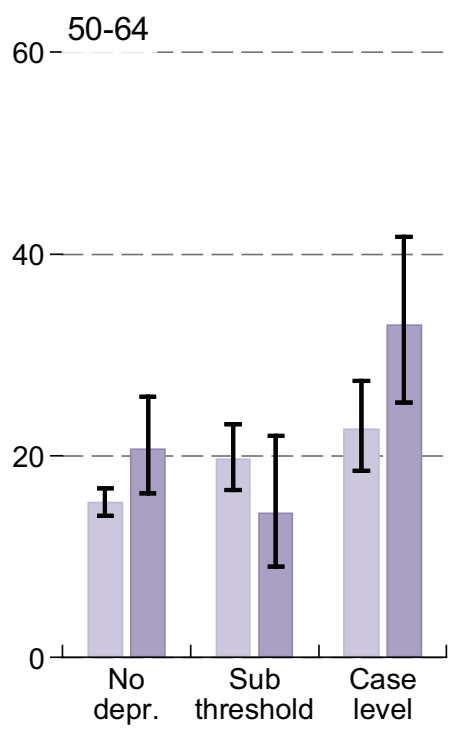

65-74

$>=75$

Note. $\mathrm{N}=7967$; Missing obs $=211$; Error bars correspond to $95 \%$ confidence intervals 
Figure 6.6 Percentage of the population currently at work by depression, age and sex

\begin{tabular}{|l|l|l|l}
\hline Not depressed & Sub-threshold $\square$ Case-level depression
\end{tabular}

$$
80^{-} \text {Male }
$$

Female
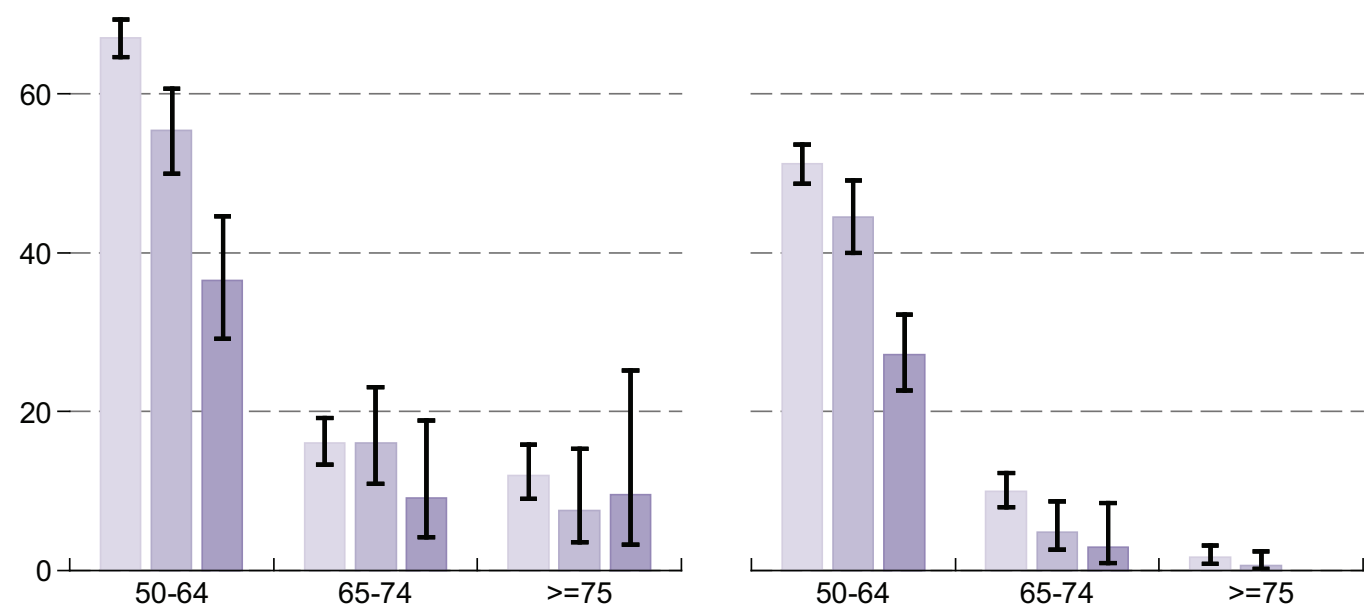

Note. $\mathrm{N}=8047$; Missing obs $=131$; Error bars correspond to $95 \%$ confidence intervals

\subsubsection{Depression and health service utilisation}

Depression is associated with increased health service utilisation in older adults (17). In all age groups utilisation of GP services is far greater among depressed adults Figure 6.7). Respondents aged 75 and over with case level depression had an average of 7 visits to their GP in the past year. This compares to an average of 5 visits among the non-depressed older population (Table 6.A8). The opportunity for increased recognition and treatment of depression by primary care providers, therefore, exists given the high number of times depressed older adults attend their GP. As depression is often under-diagnosed, patients may continue to visit their GP without getting adequate treatment for their problem. Over utilisation of health services may therefore be a consequence and an indicator of undiagnosed depression.

\subsubsection{Anxiety}

\subsubsection{Prevalence of anxiety symptoms and diagnosed anxiety}

Anxiety is a general term for several disorders that cause nervousness, fear, apprehension, and worrying. These disorders affect how people feel and behave, and they can manifest as physical symptoms. Mild anxiety is vague and unsettling, while severe anxiety can be extremely debilitating, and have a serious impact on daily life. Research on the course and treatment of anxiety in older adults lags behind that of other mental conditions such as depression and Alzheimer's disease, yet recent evidence suggests that anxiety is at least as common as depression in older adults (18). 
Figure 6.7: GP visits by depression age and sex

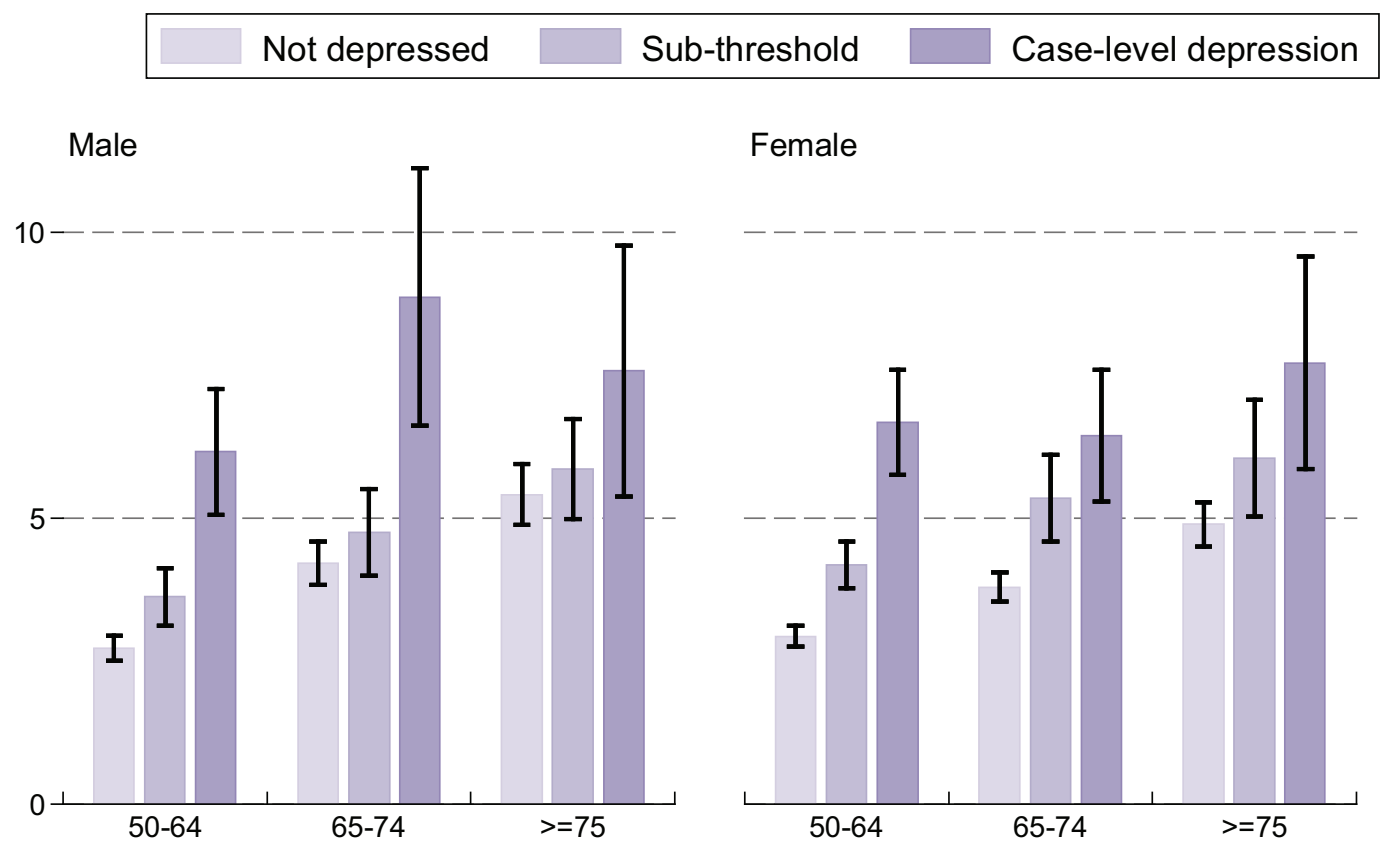

Note. $\mathrm{N}=8037$; Missing obs $=141$; Error bars correspond to $95 \%$ confidence intervals

Figure 6.8 presents the prevalence of anxiety by age, sex and education. Overall, $13 \%$ of respondents experienced case level anxiety symptoms while $29 \%$ reported sub-threshold levels of anxiety. In contrast only $5 \%$ of respondents reported a doctor's diagnosis of anxiety suggesting a marked under-diagnosis of anxiety in older Irish adults. Only $15 \%$ of people who were classified as anxious according to the HADS-A reported a doctor's diagnosis of anxiety.

\subsubsection{Age, sex, education and wealth}

Similar to the patterns for depression, women are more likely than men to suffer from anxiety (Table 6.A9). Overall, $15 \%$ of women reported case level anxiety, compared with $11 \%$ of men. Similarly, $30 \%$ of women reported sub-threshold anxiety, compared with $27 \%$ of men. The prevalence of case level and sub-threshold anxiety was highest in the 50-64 year age group and decreases with advancing years. This is different to the pattern observed for depression where the prevalence of subthreshold depression was highest in people aged 75 and older. For men and women in all age categories low education is associated with higher prevalence of anxiety (Table 6.A10). An association with wealth is also observed. Of adults in the lowest wealth quartile $17 \%$ have case level anxiety compared to $9 \%$ in the highest wealth quartile (Table 6.A11). 
Figure 6.8 Anxiety by age, sex and education

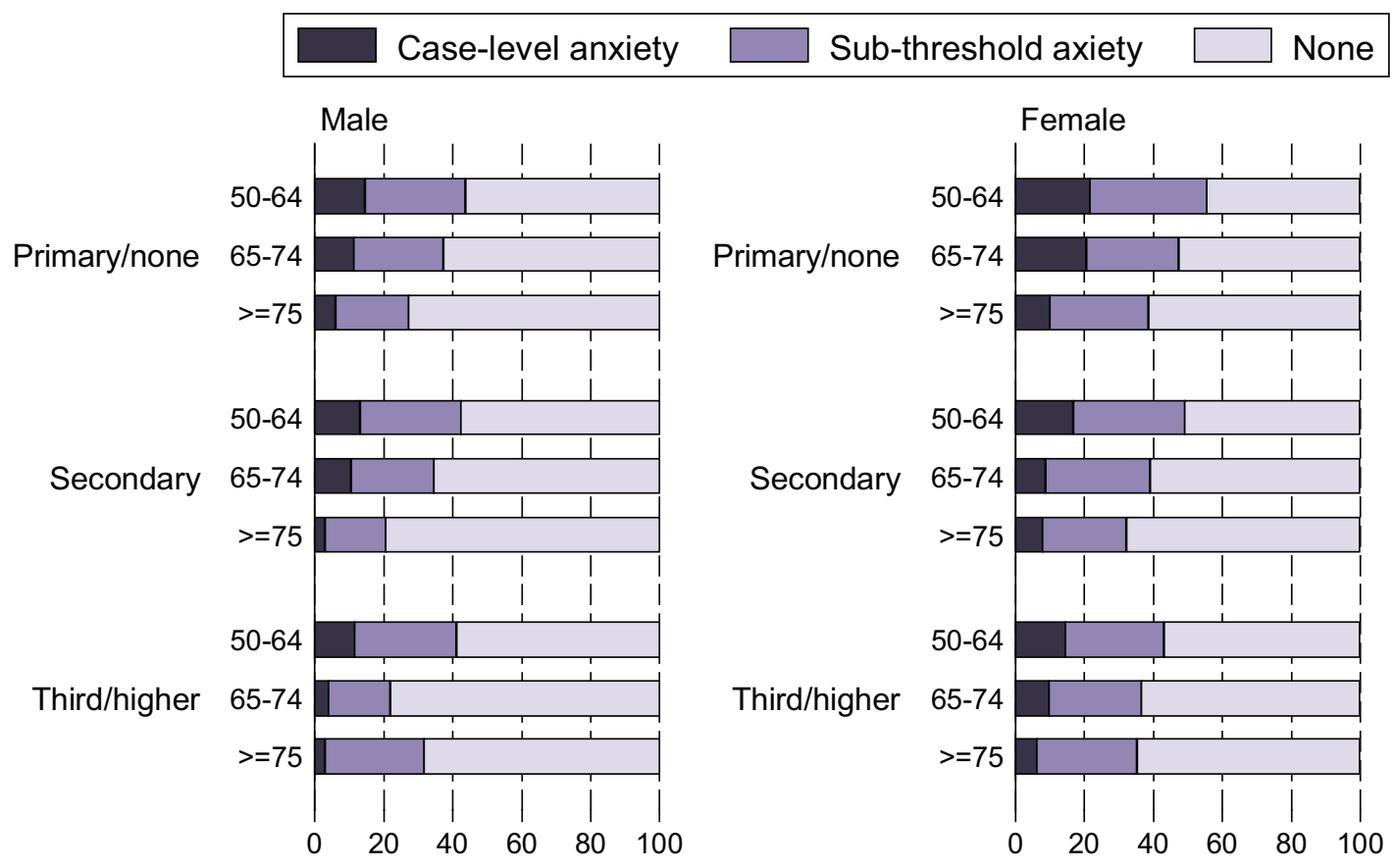

Note. $\mathrm{N}=6031 ;$ Missing obs $=231$

\subsubsection{Anxiety and depression}

There has been growing interest and concern about the high rates of co-occurring anxiety and depression (comorbidity), now clearly documented in both epidemiologic and clinical studies. The presence of comorbid depression and anxiety has a negative impact on prognosis, including elevated rates of suicide, greater severity of the primary disorder, greater impairments in social and occupational functioning, and poorer response to treatment (19).

The suicidal ideation indicator in TILDA is an item taken from the Euro-D scale (20). Respondents are asked 'in the past month, have you felt that you would rather be dead?'. Response options are: 'yes' participant has mentioned passive suicidal ideation versus 'no', no passive suicidal ideation mentioned.

Table 6.A12a and 6.A12b presents the prevalence of co-occurring anxiety and depression. Comorbidity is highly prevalent in the older Irish population. Of older adults with case level depression, $48 \%$ have co-occurring case level anxiety while $36 \%$ of people with case level anxiety have co-occurring case level depression. Figure 6.9 presents the association between suicidal ideation and disability by anxiety, depression and age. The additional risk associated with comorbidity can be clearly seen. Of people with both depression and anxiety, $66 \%$ have a longstanding illness or disability. This compared to $60 \%$ of people with depression only and $44 \%$ of people with anxiety only. The association is even more marked for suicide ideation. Of older adults with both depression and anxiety, 30\% reported suicidal feelings, compared to $16 \%$ with depression and $5 \%$ with anxiety (Table 6.A13). 
Figure 6.9: Disability and suicidal ideation by anxiety, depression and age

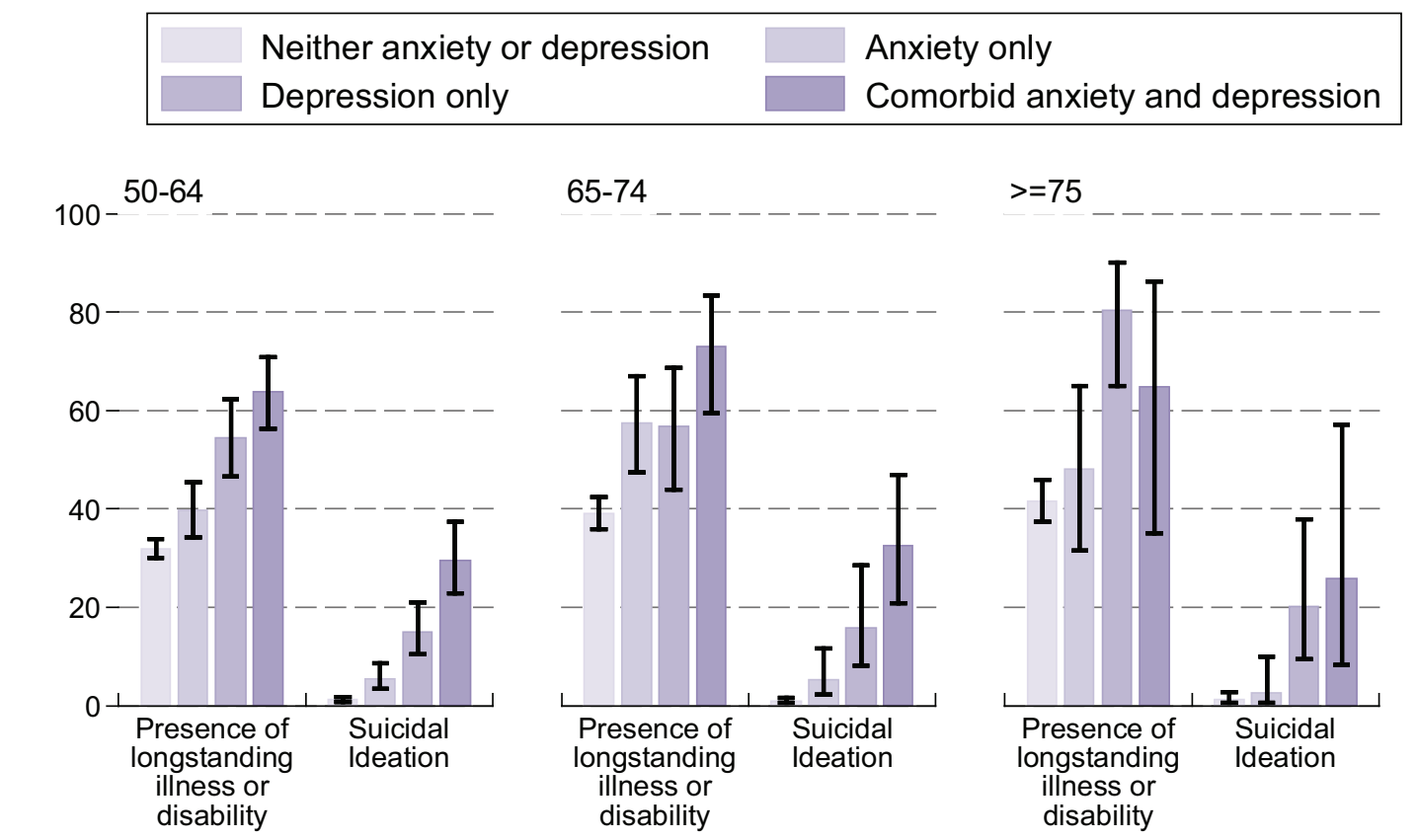

Note. $\mathrm{N}=5935$; Missing obs $=327$; Error bars correspond to $95 \%$ confidence intervals

\subsection{Cognitive function}

Changes in cognitive function are common in normal ageing and occur across the life-span. Cognitive decline is characterised by impairments in memory and decisionmaking ability including planning, organisation and mental flexibility. As well as day-to-day difficulties, important decisions about retirement, health, housing and finances may also be compromised in cognitively impaired older adults. A full understanding of how individuals make the economic, social and lifestyle decisions associated with retirement requires an assessment of key aspects of cognitive function along with information about the factors that influence its maintenance or decline.

The cognitive processes that are examined in this chapter include learning and memory, executive function, and global cognitive function. Given the primacy of memory in age-related cognitive impairment, memory assessment comprises measures of both self-rated memory, immediate recall and prospective memory.

\subsubsection{Measures of cognitive function}

Self-rated memory: This measure provides an indication of whether the respondent is worried about their memory. Respondents are asked to rate whether their memory at the present time is excellent, very good, good, fair or poor. 
Word-list learning: This is a test of verbal learning and recall, in which 10 common words are presented orally and the participant is asked to remember them. Recall is tested immediately after the words are presented.

Prospective memory: Sometimes referred to as 'remembering to remember', prospective memory concerns memory for future actions. Early in the cognitive assessment session, respondents were informed about an action that they should carry out at an appropriate time, later in the session. They were told that they would need to carry out the action without being reminded. The task was to remember to write their initials in the top left-hand corner of the page attached to the clipboard, when later handed the clipboard. When the appropriate point in the session was reached for the respondent to carry out the action, the interviewer waited for five seconds to see if the respondent performed the correct action without a prompt. If they failed to carry out the action spontaneously, the interviewer reminded them that they were going to do something, and recorded what the respondent then did. A correct response requires the respondent to carry out the correct action without being reminded.

Executive Function: Word-finding (verbal fluency) is a test of how quickly respondents can think of words from a particular category, in this case, naming as many different animals as possible in one minute. Successful performance on this test requires self-initiated activity, organisation and abstraction (categorising animals into groups such as domestic, wild, birds, dogs), and mental flexibility (moving to a new category when no more animals come to mind from a previous category).

Global Cognitive Function: The mini-mental state examination (MMSE) is a brief 30-point test that is used to screen for cognitive impairment (21). It is commonly used in clinical practice to screen for dementia. It is also used to estimate the severity of cognitive impairment at a given point in time and to follow the course of cognitive changes in an individual over time. It assesses orientation, recall, attention, calculation language abilities and visuospatial ability.

\subsubsection{Self-rated memory}

Insight into one's own cognitive abilities is important as memory complaints in older adults predict future objective cognitive decline. Table 6.A14 presents selfreported memory by age and sex. Overall, $82 \%$ of people aged 50 and over perceive their memory as excellent $(12 \%)$, very good (31\%) or good $(39 \%) .17 \%$ perceive their memory as fair (14\%) or poor (3\%). Self-reported poor memory increases with age and no difference in memory performance is reported between men and women. Low education is associated with poor memory. This association is most pronounced in the 50-64 year age group where $21 \%$ of older adults with primary or no education rated their memory as fair or poor compared to $8 \%$ of those with third level education (Table 6.A15). Wealth is associated with people's perception of their memory particularly in the oldest old. In the lowest wealth quartile $27 \%$ of people 
aged 75 and over rated their memory as fair or poor compared to $11 \%$ in the highest wealth quartile (Table 6.A16)

Figure 6.10: Self-reported memory by age and sex

\begin{tabular}{|l|l|}
\hline Primary/none $\square$ Secondary $\square$ Third/higher \\
\hline
\end{tabular}

40- Male

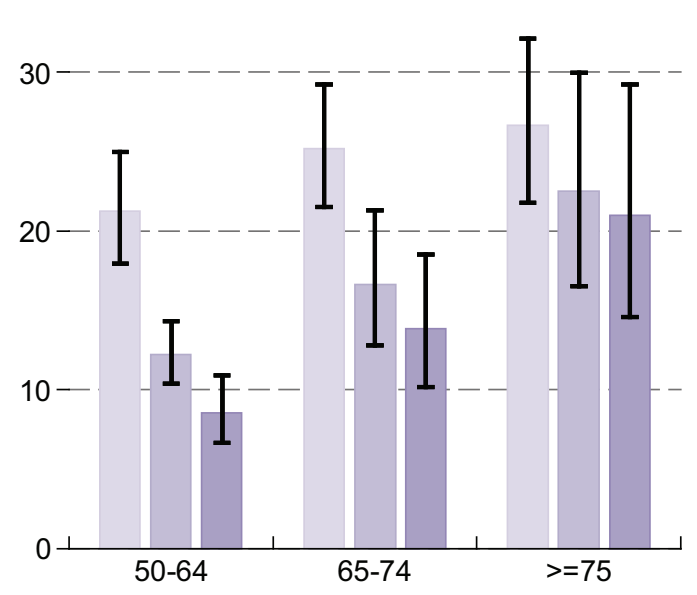

Female

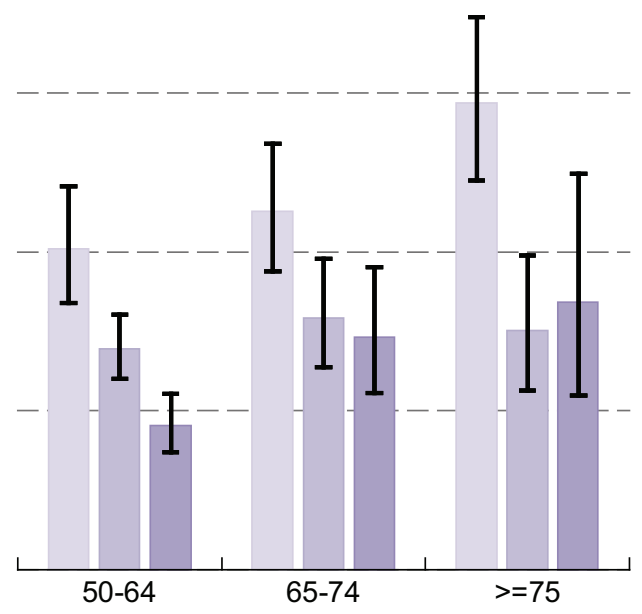

Note. $\mathrm{N}=8171$; Missing obs = 7; Error bars correspond to $95 \%$ confidence intervals

\subsubsection{Word list learning}

This task is important as it assesses people's ability to remember events occurring in the past few minutes. Table 6.2 presents the mean number of words (out of a maximum of ten) recalled by age and sex. A marked age-related impairment of memory for the ten-word list is observed in men and women. Adults aged 50-59 on average remembered 2 more words than adults aged 80 and over. Older women have marginally better recall than older men.

Table 6.2: Mean number of words recalled by age and sex

\begin{tabular}{|l|r|r|r|r|rr|} 
& \multicolumn{2}{|c|}{ Male } & \multicolumn{2}{c|}{ Female } & \multicolumn{2}{c|}{ Total } \\
& Mean & $95 \% \mathrm{Cl}$ & Mean & $95 \% \mathrm{Cl}$ & Mean & $95 \% \mathrm{Cl}$ \\
\hline $\mathbf{5 0 - 5 9}$ & 6.0 & $(5.9-6.1)$ & 6.2 & $(6.1-6.3)$ & 6.1 & $(6.0-6.2)$ \\
\hline $\mathbf{6 0 - 6 4}$ & 5.6 & $(5.5-5.8)$ & 5.9 & $(5.8-6.1)$ & 5.8 & $(5.7-5.9)$ \\
\hline $\mathbf{6 5 - 6 9}$ & 5.4 & $(5.2-5.5)$ & 5.7 & $(5.5-5.8)$ & 5.5 & $(5.4-5.6)$ \\
\hline $\mathbf{7 0 - 7 9}$ & 4.7 & $(4.6-4.9)$ & 4.9 & $(4.8-5.0)$ & 4.8 & $(4.7-4.9)$ \\
\hline$>=80$ & 4.0 & $(3.7-4.2)$ & 4.1 & $(3.9-4.3)$ & 4.0 & $(3.9-4.2)$ \\
\hline Total & 5.5 & $(5.4-5.5)$ & 5.6 & $(5.5-5.7)$ & 5.5 & $(5.5-5.6)$ \\
\hline
\end{tabular}


Figure 6.11 shows the mean number of words recalled by age and education. In all age groups people with higher education have better immediate recall. Adults aged 75 and over with third level education have similar recall to adults aged between 50 and 64 with primary or no education.

Figure 6.11: Immediate recall (mean) by age and education

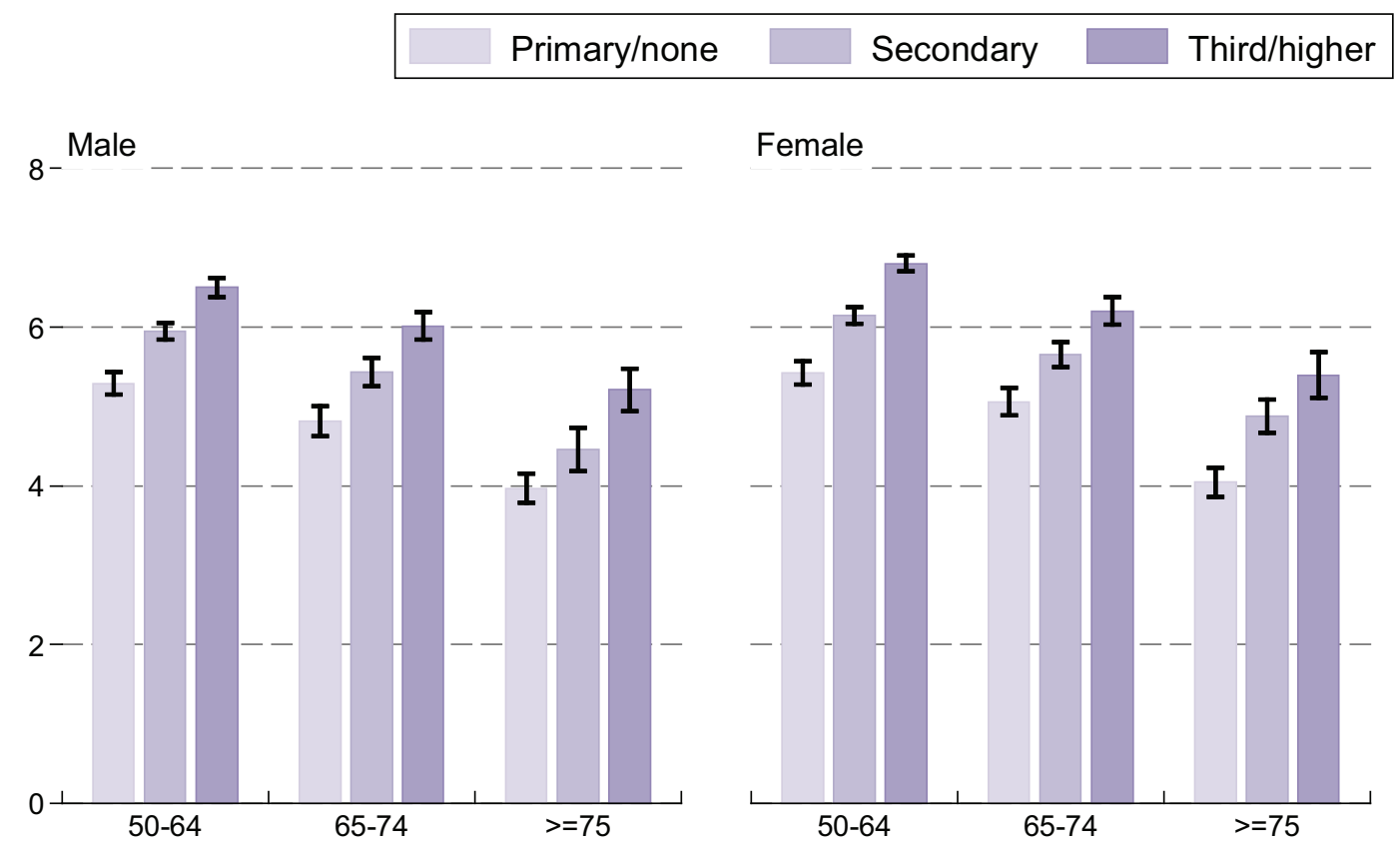

Note. $\mathrm{N}=8153$; Missing obs $=25$; Error bars correspond to $95 \%$ confidence intervals

\subsubsection{Prospective memory}

Table 6.3 presents performance on the prospective memory task by age and sex. Age differences are particularly marked on the prospective memory test, which assesses the respondent's ability to remember to carry out an instruction given earlier in the session without being reminded. Adults aged 80 and over have a failure rate almost four times higher than adults aged 60 and under (42\% versus $11 \%$ ). Prospective memory is slightly worse in older men compared to older women.

Figure 6.12 shows the percent age of people who failed the prospective memory task by age, sex and education. In all age groups individuals with low levels of education performed worse on the prospective memory task. The association was most pronounced for those aged 80 and over, $45 \%$ of people with primary education failed the task compared to $26 \%$ of with third level education (Table 6.A17). 
Table 6.3: Percentage who failed prospective memory task by age and sex

\begin{tabular}{|l|r|r|r|r|rr|} 
& \multicolumn{2}{|c|}{ Male } & \multicolumn{2}{c|}{ Female } & \multicolumn{3}{c|}{ Total } \\
& $\%$ & $(95 \% \mathrm{Cl})$ & $\%$ & $(95 \% \mathrm{Cl})$ & $\%$ & $(95 \% \mathrm{Cl})$ \\
\hline $\mathbf{5 0 - 5 9}$ & 12.5 & $(10.7-14.4)$ & 10.3 & $(8.7-12.0)$ & 11.4 & $(10.1-12.8)$ \\
\hline $\mathbf{6 0 - 6 4}$ & 15.0 & $(12.2-18.3)$ & 12.0 & $(9.8-14.7)$ & 13.5 & $(11.6-15.7)$ \\
\hline $\mathbf{6 5 - 6 9}$ & 20.8 & $(17.4-24.6)$ & 17.8 & $(14.9-21.3)$ & 19.3 & $(17.0-21.8)$ \\
\hline $\mathbf{7 0 - 7 9}$ & 27.0 & $(23.4-31.0)$ & 26.4 & $(23.1-30.0)$ & 26.7 & $(23.9-29.6)$ \\
\hline$>=80$ & 41.3 & $(34.9-48.0)$ & 41.9 & $(36.6-47.5)$ & 41.7 & $(37.3-46.2)$ \\
\hline Total & 18.8 & $(17.2-20.4)$ & 18.3 & $(16.8-19.8)$ & 18.5 & $(17.3-19.8)$ \\
\hline
\end{tabular}

Figure 6.12: Prospective memory task (\% failed) by age, sex and education

\begin{tabular}{|l|l|}
\hline Primary/none & Secondary $\square$ Third/higher \\
\hline
\end{tabular}

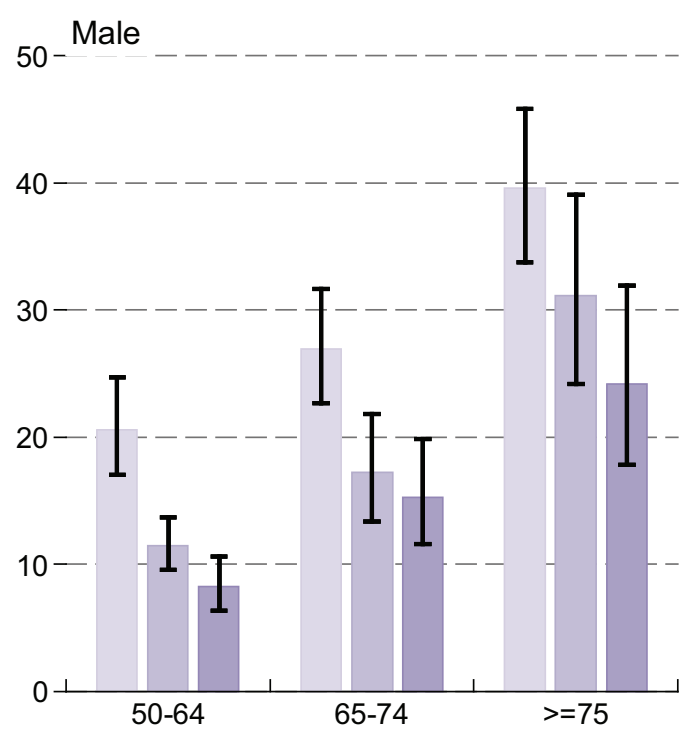

Female

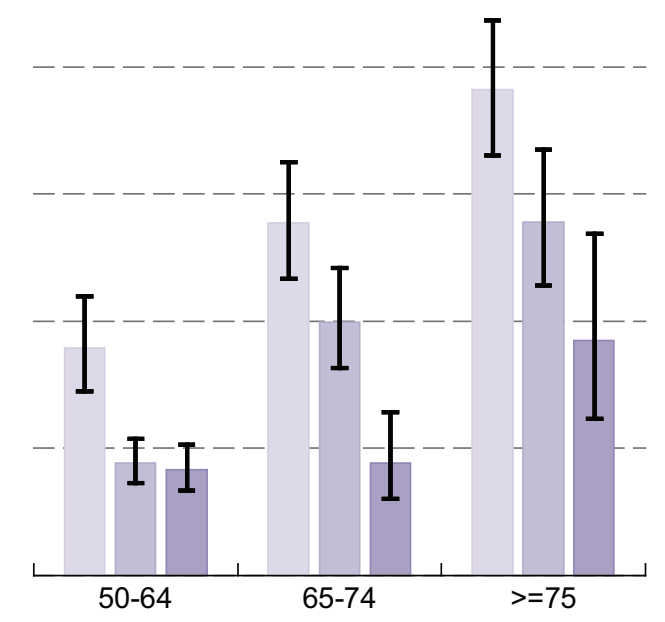

Note. $\mathrm{N}=8174 ;$ Missing obs $=4$; Error bars correspond to $95 \%$ confidence intervals

\subsubsection{Verbal fluency}

Verbal fluency tasks provide measures of a number of executive processes, including self-initiated activity, categorisation and mental flexibility. These processes regulate an individual's ability to organise thoughts and activities, prioritise tasks, manage time efficiently, and make decisions. The number of different animal names generated on the verbal fluency task ranged from 0 to 50, with an overall mean of 20. There was a large effect of age on fluency scores (Table 6.4). Adults aged 60 and under produced an average of 22 different animal names, compared to an average of 16 words in adults aged 80 and over. Verbal fluency decreases steadily with age in both men and women. Older men had better verbal fluency than older women (Table 6.4 ). 
Table 6.4 Verbal fluency (mean number of animals named) by age and sex

\begin{tabular}{|l|r|r|r|r|rr|} 
& \multicolumn{2}{|c|}{ Male } & \multicolumn{2}{c|}{ Female } & \multicolumn{2}{l}{ Total } \\
& Mean & $95 \% \mathrm{Cl}$ & Mean & $95 \% \mathrm{Cl}$ & Mean & $95 \% \mathrm{Cl}$ \\
\hline $\mathbf{5 0 - 5 9}$ & 21.7 & $(21.2-22.1)$ & 21.5 & $(21.1-21.9)$ & 21.6 & $(21.2-22.0)$ \\
\hline $\mathbf{6 0 - 6 4}$ & 20.9 & $(20.3-21.5)$ & 20.3 & $(19.8-20.8)$ & 20.6 & $(20.1-21.0)$ \\
\hline $\mathbf{6 5 - 6 9}$ & 19.9 & $(19.3-20.6)$ & 18.9 & $(18.2-19.5)$ & 19.4 & $(18.9-19.9)$ \\
\hline $\mathbf{7 0 - 7 9}$ & 18.3 & $(17.8-18.8)$ & 17.3 & $(16.8-17.8)$ & 17.7 & $(17.3-18.1)$ \\
\hline $\mathbf{> = 8 0}$ & 16.4 & $(15.6-17.1)$ & 14.2 & $(13.6-14.9)$ & 15.0 & $(14.5-15.6)$ \\
\hline Total & 20.3 & $(19.9-20.6)$ & 19.3 & $(19.0-19.7)$ & 19.8 & $(19.5-20.1)$ \\
\hline
\end{tabular}

Figure 6.13: Verbal fluency (mean) by age, sex and education

\begin{tabular}{|l|l|}
\hline Primary/none & Secondary $\square$ Third/higher \\
\hline
\end{tabular}
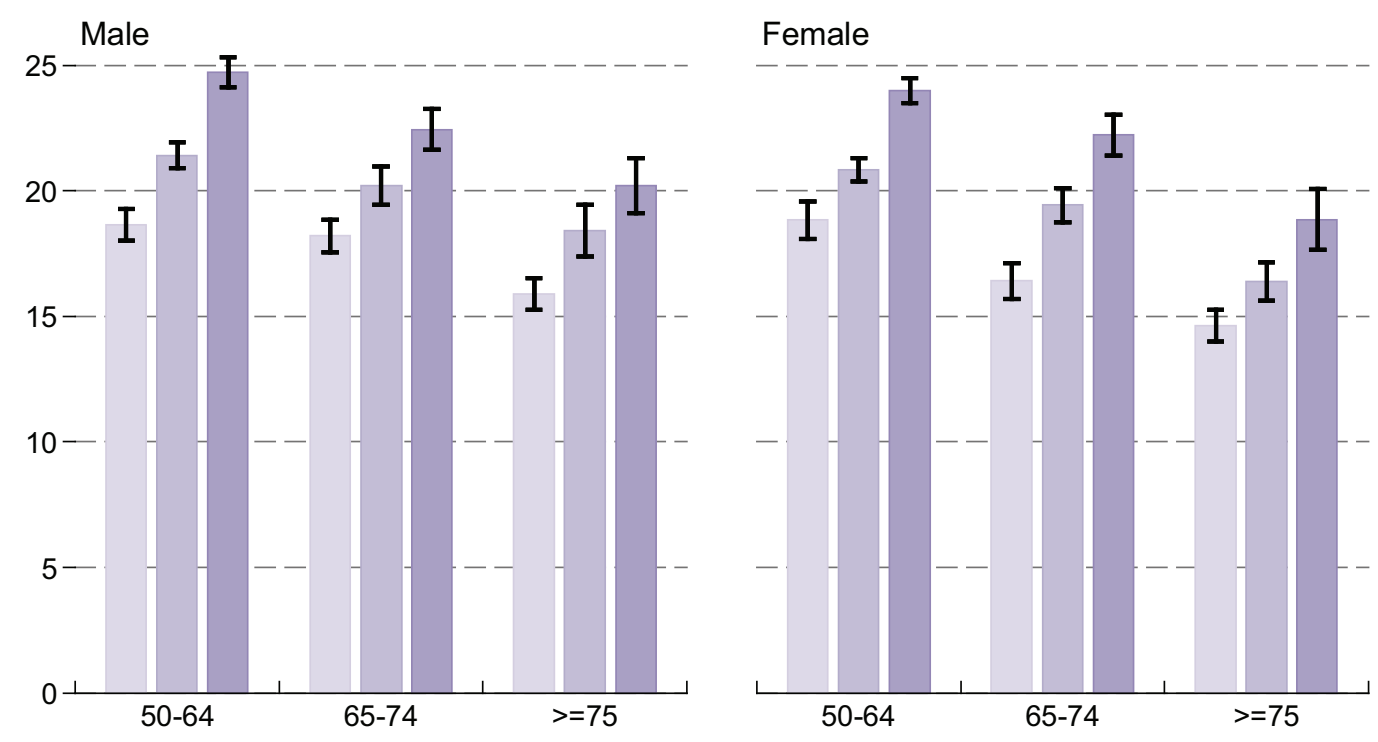

Note. $\mathrm{N}=8133$; Missing obs $=45$; Error bars correspond to $95 \%$ confidence intervals

Figure 6.13 presents the mean number of animals named on the verbal fluency task by age, sex and education. In all age groups higher education was associated with better verbal fluency. The effect of education was consistent across all age groups. For example adults aged 80 and over with third level education generated 4 more words than adults of the same age with primary or no education (Table 6.A18).

\subsubsection{Global cognitive function}

Cognitive impairment (not dementia) has been receiving increased clinical and research attention during the last several years. Mild Cognitive Impairment ( $\mathrm{MCl})$ is a diagnosis given to individuals who have cognitive impairments beyond that expected for age and education, but that do not constitute a diagnosis of dementia. 
It is considered to be the boundary or transitional stage between normal ageing and dementia. Although $\mathrm{MCl}$ can present with a variety of symptoms, when memory loss is the predominant symptom it is termed "amnestic $\mathrm{MCl}$ " and is a recognised risk factor for dementia (22).

TILDA employed the MMSE to assess global cognitive function and identify the presence of cognitive impairment in older adults. Scores on the MMSE range from 0 to 30, with scores of 26 or higher considered normal and scores of less than 15 indicating severe impairment. Here we define 'mild cognitive impairment' $(\mathrm{MCl})$ as a score between 20 and 25, with 'moderate impairment' corresponding to a score less than 20.

People with known or suspected dementia were not recruited at baseline by TILDA thus as expected very few people are classified with moderate or severe cognitive impairment in our study. Table 6.5 presents levels of cognitive function by age and sex. The proportion with normal cognitive functioning is markedly reduced with age. For example, $96 \%$ of men aged 50-59 have normal function compared to $69 \%$ of men aged 80 and over. At all ages men and women had similar levels of cognitive impairment.

Figure 6.14 and table 6.A19 show the proportion of people who have cognitive impairment (MMSE<25) by age, sex and education. A marked association between cognitive impairment and low levels of education is observed. For example, $47 \%$ of adults aged 80 and over with primary education have cognitive impairment. This compares to just $17 \%$ of adults aged 80 and over with third level education. Although it is difficult to exclude all other explanations, this finding provides evidence toward the strong protective effect of education against cognitive impairment, an association which will be explored more fully in future TILDA analyses.

\subsubsection{Cognitive impairment and employment}

Cognitive function is important for a person's employment prospects, and it is possible that continuing employment past retirement age preserves cognitive function. The association between cognitive impairment and employment status is shown in Figure 6.15. Unemployed older adults performed worse on all measures of cognition. For example, $41 \%$ of adults aged 50-64 who are unemployed had poor recall compared with $31 \%$ of employed people of the same age (Table 6.A21).

Figure 6.16 presents the association between cognitive impairment, age and wealth. A consistent association between cognitive impairment and the lowest wealth quartile is observed for all measures of cognitive function. Of adults aged 64 and under in the lowest wealth quartile, $47 \%$ had poor recall compared to $25 \%$ of adults 
Table 6.5: Global cognitive function by age and sex

\begin{tabular}{|c|c|c|c|c|c|c|c|c|}
\hline & \multicolumn{2}{|c|}{$\begin{array}{c}\text { Normal cognitive } \\
\text { function } \\
\text { (MMSE 26-30) }\end{array}$} & \multicolumn{2}{|c|}{$\begin{array}{c}\text { Mild } \\
\text { impairment } \\
\text { (MMSE 20-25) }\end{array}$} & \multicolumn{2}{|c|}{$\begin{array}{l}\text { Moderate } \\
\text { impairment } \\
\text { (MMSE <20) }\end{array}$} & \multirow[b]{2}{*}{ Total } & \multirow{2}{*}{$\begin{array}{l}\text { Number } \\
\text { in } \\
\text { sample }\end{array}$} \\
\hline & $\%$ & $95 \% \mathrm{Cl}$ & $\%$ & $95 \% \mathrm{Cl}$ & $\%$ & $95 \% \mathrm{Cl}$ & & \\
\hline \multicolumn{9}{|l|}{ Male } \\
\hline $50-59$ & 96 & $(94-97)$ & 4 & $(3-6)$ & 0 & $(0-1)$ & 100 & 819 \\
\hline $60-64$ & 94 & $(90-96)$ & 5 & $(3-9)$ & 1 & $(0-3)$ & 100 & 351 \\
\hline $65-69$ & 89 & $(85-93)$ & 9 & $(6-13)$ & 2 & $(1-4)$ & 100 & 337 \\
\hline 70-79 & 82 & $(77-86)$ & 16 & $(13-20)$ & 2 & $(1-4)$ & 100 & 412 \\
\hline$>=80$ & 69 & $(59-77)$ & 25 & $(18-35)$ & 6 & $(2-14)$ & 100 & 105 \\
\hline Total & 91 & $(89-92)$ & 8 & $(7-10)$ & 1 & $(1-2)$ & 100 & 2024 \\
\hline \multicolumn{9}{|c|}{ Female } \\
\hline $50-59$ & 94 & $(92-96)$ & 5 & $(4-7)$ & 1 & $(0-2)$ & 100 & 985 \\
\hline $60-64$ & 94 & $(91-96)$ & 6 & $(4-9)$ & 0 & - & 100 & 455 \\
\hline $65-69$ & 92 & $(88-94)$ & 8 & $(5-11)$ & 0 & $(0-3)$ & 100 & 348 \\
\hline 70-79 & 83 & (79-87) & 15 & $(12-19)$ & 2 & $(1-4)$ & 100 & 410 \\
\hline$>=80$ & 62 & $(53-71)$ & 31 & $(23-40)$ & 7 & $(3-14)$ & 100 & 132 \\
\hline Total & 90 & $(88-91)$ & 9 & $(8-11)$ & 1 & $(1-2)$ & 100 & 2330 \\
\hline \multicolumn{9}{|l|}{ Total } \\
\hline $50-59$ & 95 & $(94-96)$ & 4 & $(4-6)$ & 0 & $(0-1)$ & 100 & 1804 \\
\hline $60-64$ & 94 & $(92-95)$ & 6 & $(4-8)$ & 0 & $(0-1)$ & 100 & 806 \\
\hline $65-69$ & 91 & (88-93) & 8 & $(6-11)$ & 1 & $(0-2)$ & 100 & 685 \\
\hline 70-79 & 82 & $(79-85)$ & 16 & $(13-19)$ & 2 & $(1-3)$ & 100 & 822 \\
\hline$>=80$ & 65 & $(58-71)$ & 29 & $(23-35)$ & 6 & $(4-11)$ & 100 & 237 \\
\hline Total & 90 & $(89-91)$ & 9 & $(8-10)$ & 1 & $(1-2)$ & 100 & 4354 \\
\hline
\end{tabular}

Note. $\mathrm{Cl}=$ confidence interval; Missing observations $=0.56 \%$ 
of the same age in the highest wealth quartile. Longitudinal analyses using later waves of TILDA will allow exploration of the possible mechanisms underlying these associations to be fully explored.

Figure 6.14: Cognitive impairment (MMSE<25) by age and education

\begin{tabular}{|l|l|l|}
\hline Primary/none $\square$ Secondary $\square$ Third/higher \\
\hline
\end{tabular}
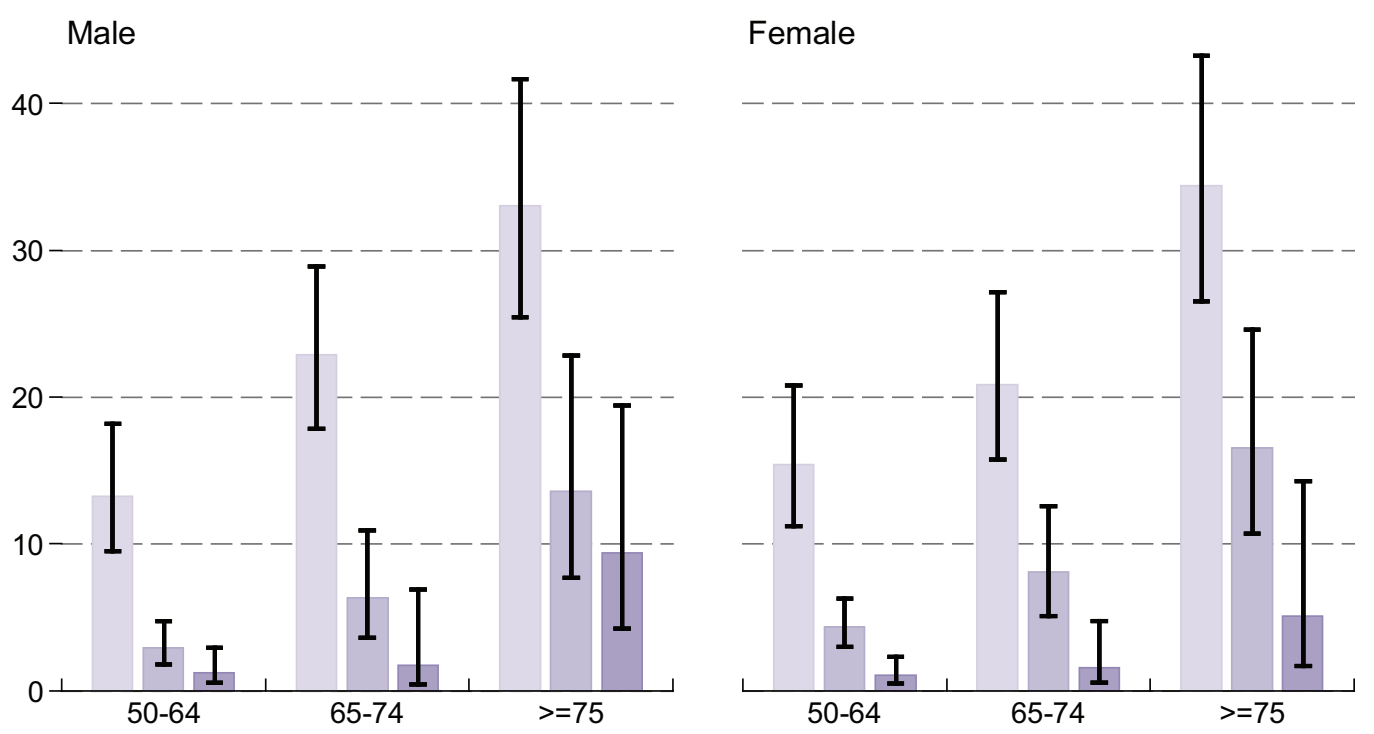

Note. $\mathrm{N}=4360$; Missing obs $=3818$; Error bars correspond to $95 \%$ confidence intervals

Figure 6.15 Cognitive impairment (MMSE<25) by age and employment

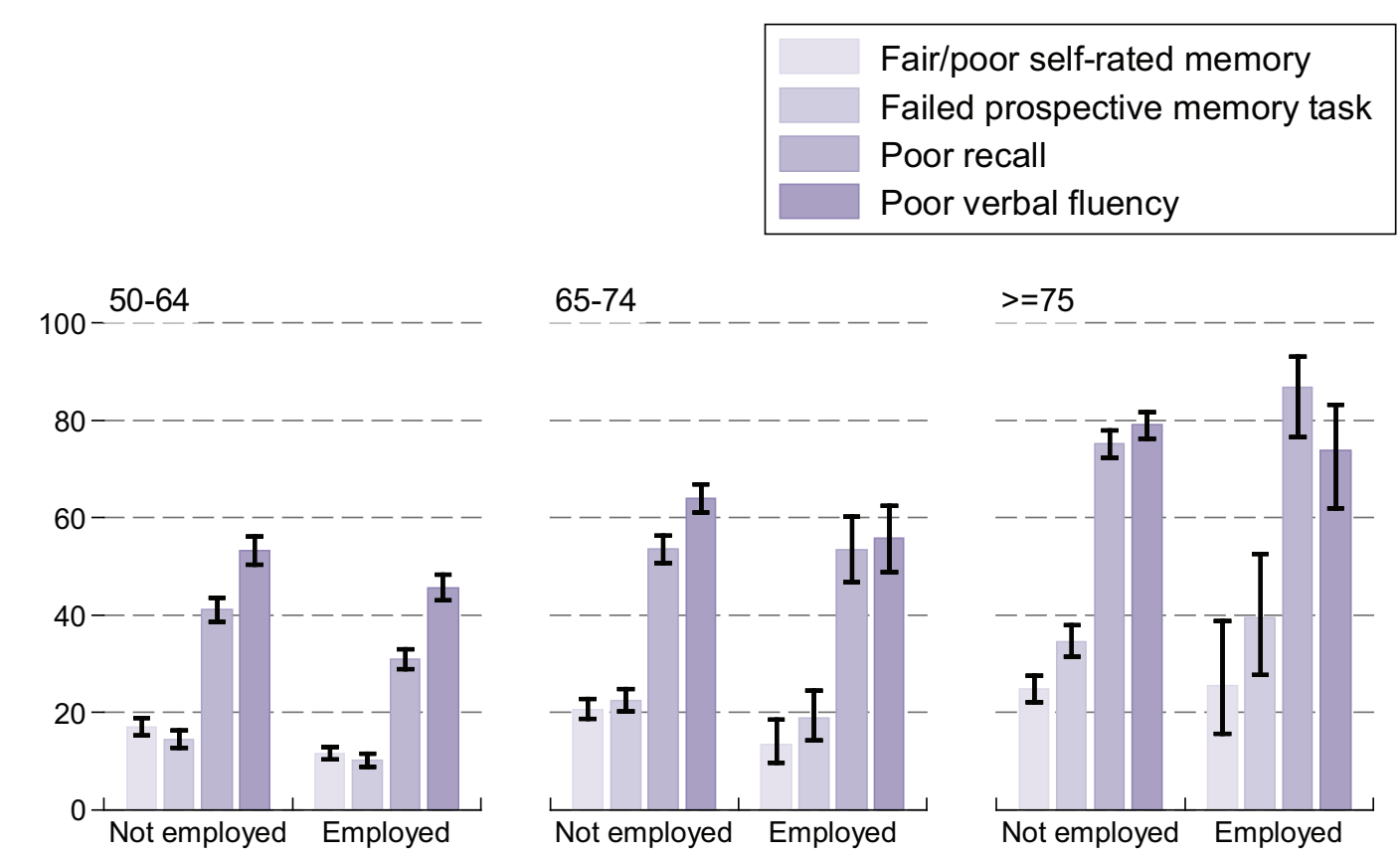

Note. $\mathrm{N}=8119$; Missing obs = 59; Error bars correspond to $95 \%$ confidence intervals 
Figure 6.16: Cognitive impairment by age and wealth

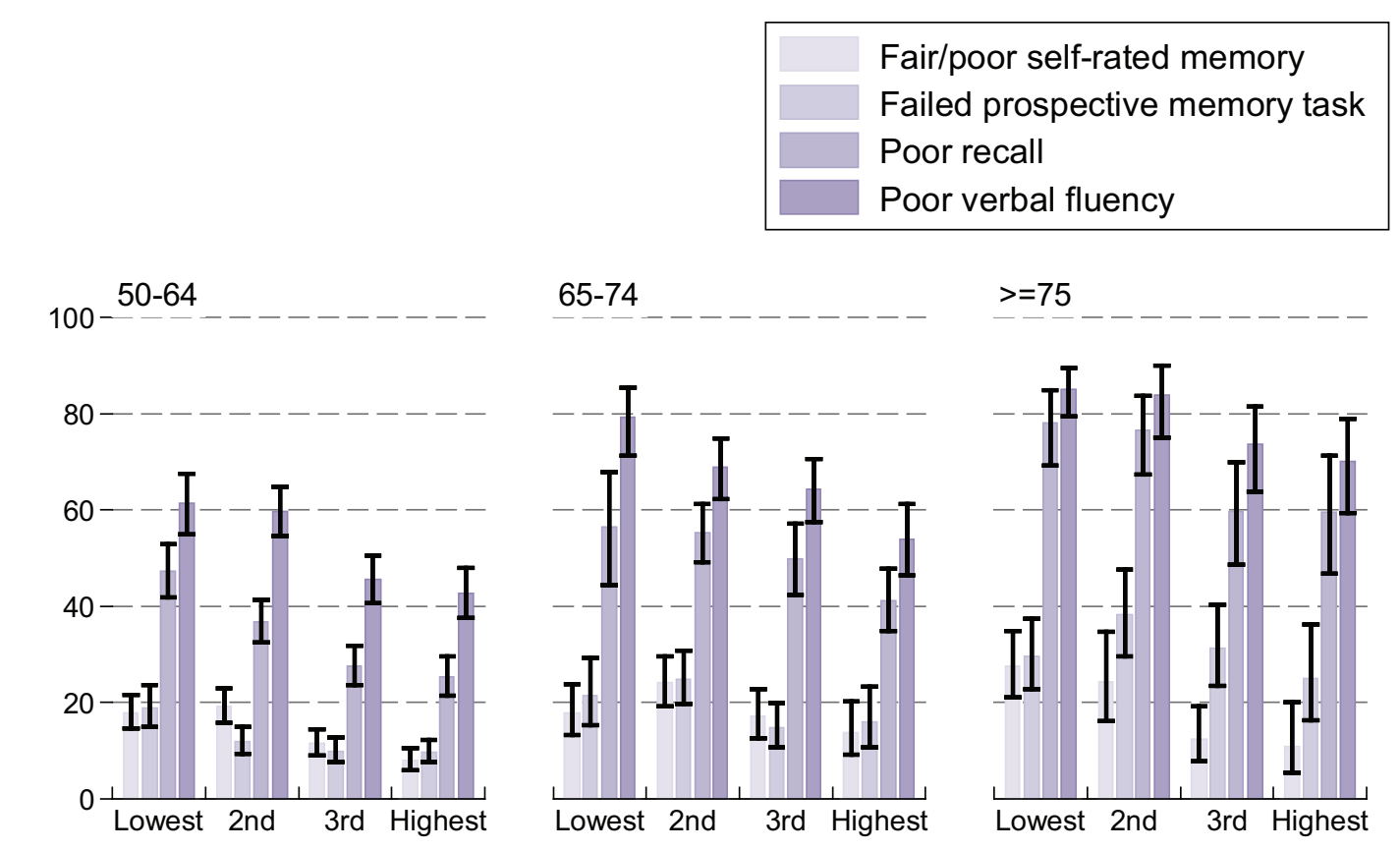

Note. $\mathrm{N}=3924$; Missing obs $=4254$; Error bars correspond to $95 \%$ confidence intervals

\subsubsection{Cognitive impairment and activities of daily living}

The association between cognitive impairment and basic and instrumental activities of daily living (ADL/IADL) is presented in Table 6.5. Older adults with disability have far greater levels of cognitive impairment compared to older adults without disability. The association between IADL disability and poor verbal fluency is especially striking. IADL disability measures competency in activities critical to independent living in older adult's i.e. managing money, shopping, telephone use and taking medications correctly. Of older adults with IADL disability, 80\% have impaired executive function (as measured by verbal fluency). Impairments in executive functions impact the ability to perform such tasks as planning, prioritising, organizing, paying attention and remembering details. Although those with disability are older and would therefore be expected to have lower cognitive function, this association remains strong even when controlling for age. These results highlight the importance of identifying cognitive risk factors for function decline and confirm the social and economic impact conferred by levels of cognitive impairment that may not be clinically apparent and will not meet the clinical criteria for dementia. 
Table 6.5: Cognitive impairment by disability level

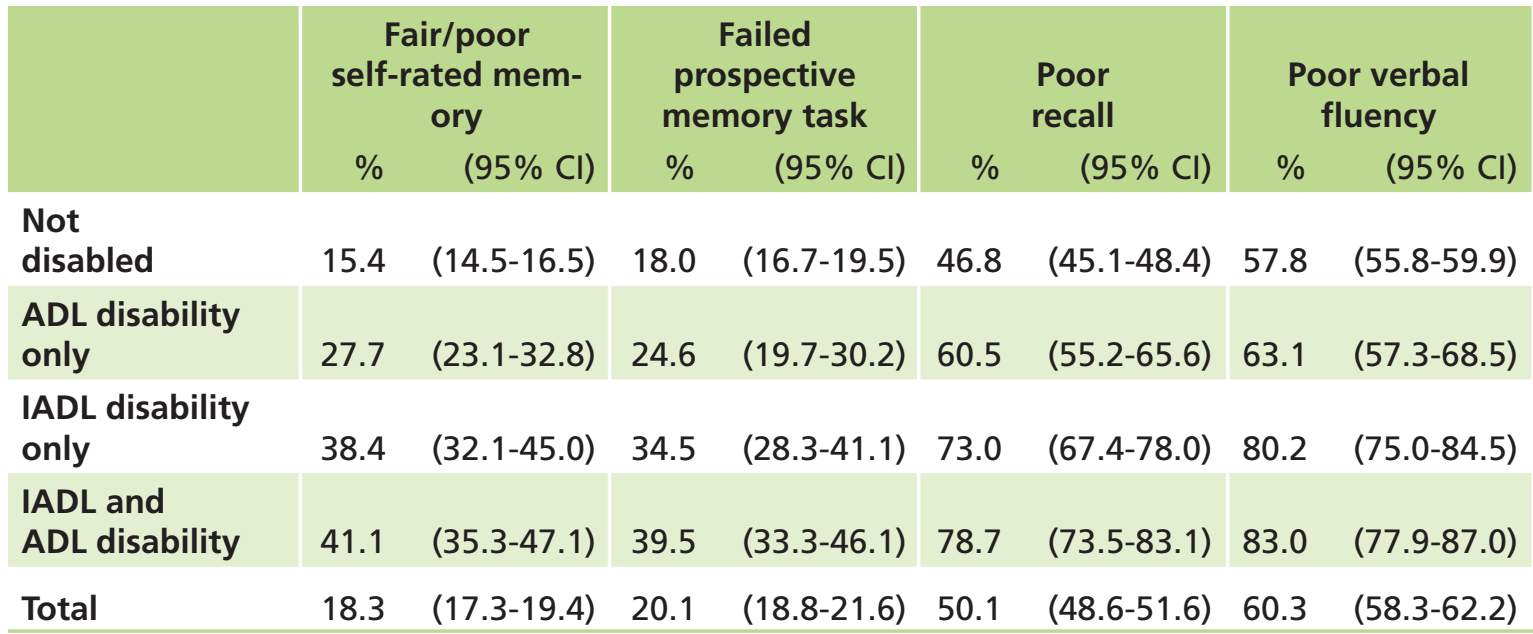

\subsection{Conclusions}

Given the rapid ageing of the Irish population, the potential public health burden of late-life mental health disorders will also grow, emphasising the importance of continued epidemiologic monitoring of the mental health status of older adults. There is a high prevalence of undiagnosed and therefore untreated depression and anxiety in the older Irish population. This represents a serious public health concern as older adults with depressive symptoms are at increased risk for subsequent functional and cognitive impairment, psychological distress and suicide. The need to manage these conditions is emphasised by the overwhelming effect of depression on employment status, disability and health service utilisation.

The results presented in this chapter show clear associations between depression and several risk factors that are potentially modifiable (e.g., sleep, exercise, sensory impairment, and polypharmacy). Effective recognition and treatment of these risk factors may be associated with functional improvement that may alleviate the economic burden of these disorders. Increased recognition of the high prevalence of co-occurring depression and anxiety is required since this is associated with increased levels of disability and suicidal ideation. A high prevalence of sub-threshold depression and anxiety was observed in our sample. These milder symptom levels are clearly significant in older adults as they have a marked negative impact on measures of health, employment and health service utilisation.

Cognitive capability or impairment of function is a key marker of population health and independence at all ages. TILDA provides the most comprehensive nationally representative data on cognitive function in older adults. This chapter has described variation in cognitive function between age groups and between men and women, and the effects of education on cognitive performance. 
The observed high levels of prospective memory impairment is particularly alarming, since a very high percentage of older people live alone, and may be at increased risk of forgetting to carry out important actions such as taking medication, locking doors or paying bills. The negative impact of cognitive performance on activities of daily living (both ADL and IADL) is also worrying. Limitations in these abilities have economic consequences in the form of reduced efficiency in taking care of financial affairs and increased expenditures associated with formal health care and informal personal assistance. Recognition of cognitive risk factors for functional decline and early signs of functional impairment are, therefore, hugely important in older adults and are key priorities for future waves of the study.

The consistent finding that those with the highest education and greatest levels of wealth have the best cognition provides evidence that cognitive impairment may disproportionately affect those from the less privileged social classes, as well as suggesting that education and mental activity may be a way to protect against cognitive decline. These associations will be fully explored in future TILDA analyses.

\section{References}

1. Cornwell K, Forbes C, Inder B, Meadows G. Mental illness and its effects on labour market outcomes. J Ment Health Policy Econ. 2009 Sep;12(3):107-18.

2. O'Shea E, Kennelly B. The economics of mental health care in Ireland: Irish Centre for Social Gerontology and Department of Economics, NUI Galway 2008.

3. Dewey ME, Saz P. Dementia, cognitive impairment and mortality in persons aged 65 and over living in the community: a systematic review of the literature. Int J Geriatr Psychiatry. 2001 Aug;16(8):751-61.

4. Greiner PA, Snowdon DA, Schmitt FA. The loss of independence in activities of daily living: the role of low normal cognitive function in elderly nuns. Am J Public Health. 1996 Jan;86(1):62-6.

5. Ramon Luengo-Fernandez JL, Alasta ir Gray. Dementia 2010. The economic burden of dementia and associated research funding in the United Kingdom: University of Oxford for the Alzheimer's Research Trust 2010.

6. Radloff LS. The CES-D scale: A self-report depression scale for research in the general population. Applied Psychological Measurement. 1977;1:385-401.

7. Vahia IV, Meeks TW, Thompson WK, Depp CA, Zisook S, Allison M, et al. Subthreshold depression and successful aging in older women. Am J Geriatr Psychiatry. 2010 Mar; 18(3):212-20.

8. Fiske A, Wetherell JL, Gatz M. Depression in older adults. Annu Rev Clin Psychol. 2009;5:363-89.

9. Hasin DS, Goodwin RD, Stinson FS, Grant BF. Epidemiology of major depressive disorder: results from the National Epidemiologic Survey on Alcoholism and Related Conditions. Arch Gen Psychiatry. 2005 Oct;62(10):1097-106.

10. Blazer DG. Depression in late life: review and commentary. J Gerontol A Biol Sci Med Sci. 2003 Mar;58(3):249-65. 
11. Murray CJ, Lopez AD. Regional patterns of disability-free life expectancy and disability-adjusted life expectancy: Global Burden of Disease Study. Lancet. 1997 May 10;349(9062):1347-52.

12. Capella-McDonnall ME. The effects of single and dual sensory loss on symptoms of depression in the elderly. Int J Geriatr Psychiatry. 2005 Sep;20(9):855-61.

13. Fukukawa Y, Nakashima C, Tsuboi S, Kozakai R, Doyo W, Niino N, et al. Age differences in the effect of physical activity on depressive symptoms. Psychol Aging. 2004 Jun;19(2):346-51.

14. Cole MG, Dendukuri N. Risk factors for depression among elderly community subjects: a systematic review and meta-analysis. Am J Psychiatry. 2003 Jun;160(6):1147-56.

15. Banks Jea, Lessof C, Nazroo J, Rogers N, Stafford M, Steptoe A. Financial circumstances, health and well-being of the older population in England: THE 2008 ENGLISH LONGITUDINAL STUDY OF AGEING (Wave 4). london2010.

16. Stone KL, Ancoli-Israel S, Blackwell T, Ensrud KE, Cauley JA, Redline S, et al. Actigraphy-measured sleep characteristics and risk of falls in older women. Arch Intern Med. 2008 Sep 8;168(16):1768-75.

17. Roelands M, Van Oyen H, Depoorter A, Baro F, Van Oost P. Are cognitive impairment and depressive mood associated with increased service utilisation in community-dwelling elderly people? Health Soc Care Community. 2003 Jan;11(1):1-9.

18. Singleton N, Bumpstead R, O'Brien M, Lee A, Meltzer H. Psychiatric morbidity among adults living in private households, 2000. Int Rev Psychiatry. 2003 FebMay;15(1-2):65-73.

19. Hirschfeld RM. The Comorbidity of Major Depression and Anxiety Disorders: Recognition and Management in Primary Care. Prim Care Companion J Clin Psychiatry. 2001 Dec;3(6):244-54.

20. Prince MJ, Reischies F, Beekman AT, Fuhrer R, Jonker C, Kivela SL, et al. Development of the EURO-D scale--a European, Union initiative to compare symptoms of depression in 14 European centres. Br J Psychiatry. 1999 Apr;174:330-8.

21. Folstein MF FS, McHugh PR. "Mini-mental state". A practical method for grading the cognitive state of patients for the clinician. Journal Psychiatriac Research. 1975;12(3):189-98.

22. DeCarli C. Mild cognitive impairment: prevalence, prognosis, aetiology, and treatment. Lancet Neurol. 2003 Jan;2(1):15-21. 


\section{Appendix 6A - Tables on mental health and cognitive function}

\section{Table 6.A1: Self-rated emotional health by age and education}

\begin{tabular}{|c|c|c|c|c|c|c|c|c|c|c|c|}
\hline & ellent & & y good & & ood & & Fair & & oor & & Number \\
\hline$\%$ & $95 \% \mathrm{Cl}$ & $\%$ & $95 \% \mathrm{Cl}$ & $\%$ & $95 \% \mathrm{Cl}$ & $\%$ & $95 \% \mathrm{Cl}$ & $\%$ & $95 \% \mathrm{Cl}$ & & sample \\
\hline
\end{tabular}

\section{Primary/none}

\begin{tabular}{lllllllllllll}
$50-64$ & 18 & $(16-21)$ & 31 & $(27-34)$ & 34 & $(31-37)$ & 14 & $(12-16)$ & 3 & $(2-5)$ & 100 & 957 \\
$65-74$ & 19 & $(16-22)$ & 34 & $(30-38)$ & 34 & $(31-38)$ & 11 & $(9-13)$ & 2 & $(1-3)$ & 100 & 865 \\
$>=75$ & 16 & $(13-20)$ & 37 & $(34-42)$ & 33 & $(29-38)$ & 12 & $(9-15)$ & 1 & $(1-3)$ & 100 & 684 \\
\hline Total & 18 & $(16-20)$ & 34 & $(31-36)$ & 34 & $(31-36)$ & 12 & $(11-14)$ & 2 & $(2-3)$ & 100 & 2506 \\
\hline
\end{tabular}

\section{Secondary}

\begin{tabular}{lllllllllllll}
$50-64$ & 26 & $(24-28)$ & 36 & $(34-38)$ & 29 & $(27-31)$ & 8 & $(7-9)$ & 1 & $(1-2)$ & 100 & 2119 \\
$65-74$ & 27 & $(23-30)$ & 37 & $(34-41)$ & 30 & $(26-33)$ & 6 & $(4-8)$ & 1 & $(0-1)$ & 100 & 727 \\
$>=75$ & 26 & $(22-31)$ & 33 & $(28-38)$ & 33 & $(28-38)$ & 7 & $(5-10)$ & 0 & $(0-2)$ & 100 & 417 \\
\hline Total & 26 & $(24-28)$ & 36 & $(34-38)$ & 30 & $(28-31)$ & 7 & $(7-8)$ & 1 & $(1-2)$ & 100 & 3263
\end{tabular}

\section{Third/higher}

\begin{tabular}{lllllllllllll}
$50-64$ & 34 & $(31-37)$ & 34 & $(32-37)$ & 24 & $(22-26)$ & 7 & $(6-9)$ & 1 & $(1-2)$ & 100 & 1592 \\
$65-74$ & 39 & $(35-43)$ & 32 & $(28-36)$ & 23 & $(20-27)$ & 6 & $(4-8)$ & 1 & $(0-2)$ & 100 & 569 \\
$>=75$ & 31 & $(25-38)$ & 37 & $(31-43)$ & 26 & $(21-32)$ & 6 & $(4-10)$ & 0 & $(0-3)$ & 100 & 243 \\
\hline Total & 35 & $(32-37)$ & 34 & $(32-36)$ & 24 & $(22-26)$ & 7 & $(6-8)$ & 1 & $(1-1)$ & 100 & 2404 \\
\hline
\end{tabular}

\section{Total}

\begin{tabular}{lllllllllllll}
$50-64$ & 26 & $(24-28)$ & 34 & $(33-36)$ & 29 & $(27-31)$ & 9 & $(8-10)$ & 2 & $(1-2)$ & 100 & 4668 \\
$65-74$ & 25 & $(22-27)$ & 35 & $(32-37)$ & 31 & $(29-33)$ & 8 & $(7-9)$ & 1 & $(1-2)$ & 100 & 2162 \\
$>=75$ & 20 & $(18-23)$ & 36 & $(33-39)$ & 33 & $(30-36)$ & 10 & $(8-12)$ & 1 & $(1-2)$ & 100 & 1346 \\
\hline Total & 25 & $(23-26)$ & 35 & $(33-36)$ & 30 & $(29-32)$ & 9 & $(8-10)$ & 2 & $(1-2)$ & 100 & 8176
\end{tabular}

Note. $\mathrm{Cl}=$ confidence interval; Missing observations $=0.02 \%$ 
Table 6.A2: Prevalence of depression by age and sex

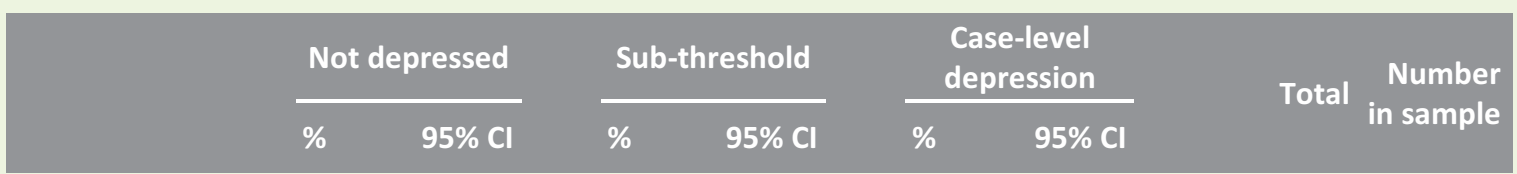

\section{Male}

\begin{tabular}{lllllllll}
$50-64$ & 77 & $(75-79)$ & 16 & $(14-17)$ & 8 & $(7-9)$ & 100 & 2062 \\
$65-74$ & 79 & $(76-82)$ & 14 & $(12-16)$ & 7 & $(5-9)$ & 100 & 1046 \\
$>=75$ & 77 & $(73-80)$ & 17 & $(14-21)$ & 6 & $(4-8)$ & 100 & 588 \\
\hline Total & 77 & $(76-79)$ & 15 & $(14-17)$ & 7 & $(6-8)$ & 100 & 3696
\end{tabular}

\section{Female}

\begin{tabular}{lllllllll}
$50-64$ & 67 & $(64-69)$ & 20 & $(18-21)$ & 14 & $(12-16)$ & 100 & 2549 \\
$65-74$ & 70 & $(67-73)$ & 19 & $(16-22)$ & 11 & $(9-13)$ & 100 & 1074 \\
$>=75$ & 66 & $(62-70)$ & 23 & $(20-26)$ & 11 & $(9-14)$ & 100 & 728 \\
\hline Total & 67 & $(65-69)$ & 20 & $(19-22)$ & 13 & $(11-14)$ & 100 & 4351 \\
\hline Total & & & & & & & 100 & 4611 \\
$50-64$ & 72 & $(70-73)$ & 18 & $(16-19)$ & 11 & $(10-12)$ & 100 & 2120 \\
$65-74$ & 74 & $(72-77)$ & 16 & $(15-18)$ & 9 & $(8-11)$ & 100 & 1316 \\
$>=75$ & 71 & $(67-73)$ & 21 & $(18-23)$ & 9 & $(7-11)$ & 100 & 8047 \\
\hline Total & 72 & $(71-74)$ & 18 & $(17-19)$ & 10 & $(9-11)$ & & 100 \\
\hline
\end{tabular}

Note. $\mathrm{Cl}=$ confidence interval; Missing observations $=1.60 \%$ 
Table 6.A3: Prevalence of depression by age and wealth

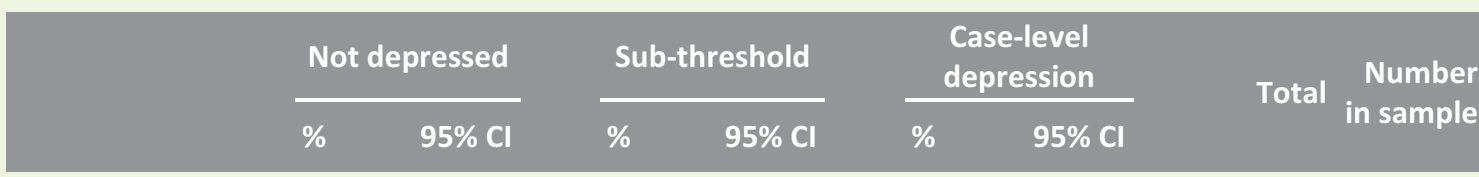

\section{Lowest}

\begin{tabular}{lllllllll}
$50-64$ & 56 & $(51-62)$ & 22 & $(18-26)$ & 22 & $(18-27)$ & 100 & 556 \\
$65-74$ & 70 & $(61-77)$ & 19 & $(13-26)$ & 12 & $(8-17)$ & 100 & 240 \\
$>=75$ & 68 & $(59-75)$ & 22 & $(15-31)$ & 10 & $(6-16)$ & 100 & 177 \\
\hline Total & 62 & $(57-67)$ & 21 & $(18-25)$ & 17 & $(14-20)$ & 100 & 973 \\
\hline
\end{tabular}

2nd

\begin{tabular}{lllllllll}
$50-64$ & 68 & $(64-73)$ & 18 & $(14-21)$ & 14 & $(11-18)$ & 100 & 578 \\
$65-74$ & 76 & $(69-81)$ & 15 & $(11-20)$ & 10 & $(6-14)$ & 100 & 264 \\
$>=75$ & 62 & $(52-71)$ & 27 & $(19-37)$ & 11 & $(6-18)$ & 100 & 143 \\
\hline Total & 69 & $(65-72)$ & 19 & $(16-22)$ & 12 & $(10-15)$ & 100 & 985 \\
\hline
\end{tabular}

3rd

\begin{tabular}{lllllllll}
$50-64$ & 73 & $(68-77)$ & 19 & $(15-22)$ & 9 & $(7-11)$ & 100 & 585 \\
$65-74$ & 74 & $(66-80)$ & 18 & $(13-24)$ & 9 & $(6-13)$ & 100 & 257 \\
$>=75$ & 73 & $(61-83)$ & 21 & $(13-32)$ & 6 & $(3-11)$ & 100 & 123 \\
\hline Total & 73 & $(69-76)$ & 19 & $(16-22)$ & 8 & $(7-10)$ & 100 & 965 \\
\hline
\end{tabular}

Highest

\begin{tabular}{lllllllll}
$50-64$ & 79 & $(76-82)$ & 16 & $(13-19)$ & 5 & $(3-7)$ & 100 & 631 \\
$65-74$ & 85 & $(79-89)$ & 13 & $(9-18)$ & 2 & $(1-5)$ & 100 & 255 \\
$>=75$ & 76 & $(64-86)$ & 18 & $(10-30)$ & 6 & $(3-12)$ & 100 & 94 \\
\hline Total & 80 & $(77-83)$ & 15 & $(13-18)$ & 4 & $(3-6)$ & 100 & 980 \\
\hline Total & 72 & $(70-74)$ & 17 & $(16-19)$ & 11 & $(10-12)$ & 100 & 4611 \\
$50-64$ & 75 & $(72-77)$ & 16 & $(14-18)$ & 9 & $(8-11)$ & 100 & 2120 \\
$65-74$ & 71 & $(67-74)$ & 21 & $(18-24)$ & 8 & $(7-10)$ & 100 & 1316 \\
$>=75$ & 72 & $(71-74)$ & 18 & $(17-19)$ & 10 & $(9-11)$ & 100 & 8047 \\
\hline Total & & & & & & &
\end{tabular}

Note. $\mathrm{Cl}=$ confidence interval; Missing observations $=1.60 \%$ 
Table 6.A4: Prevalence of disability by depression and sex

\begin{tabular}{lllllllll}
\multicolumn{2}{c}{$\begin{array}{c}\text { No long term } \\
\text { illness }\end{array}$} & & & \multicolumn{2}{c}{$\begin{array}{c}\text { Long term } \\
\text { illness }\end{array}$} & & $\begin{array}{c}\text { Limiting long } \\
\text { term illness }\end{array}$
\end{tabular}

\section{Male}

\begin{tabular}{|c|c|c|c|c|c|c|c|c|}
\hline Not depressed & 69 & $(67-71)$ & 14 & $(13-16)$ & 17 & $(15-18)$ & 100 & 2877 \\
\hline Sub-threshold & 54 & $(49-58)$ & 14 & $(11-17)$ & 32 & $(28-36)$ & 100 & 563 \\
\hline $\begin{array}{l}\text { Case-level } \\
\text { depression }\end{array}$ & 36 & $(31-43)$ & 11 & $(7-15)$ & 53 & $(46-59)$ & 100 & 254 \\
\hline Total & 64 & $(62-66)$ & 14 & $(13-15)$ & 22 & $(20-23)$ & 100 & 3694 \\
\hline \multicolumn{9}{|l|}{ Female } \\
\hline Not depressed & 66 & $(64-68)$ & 16 & $(15-18)$ & 18 & $(16-19)$ & 100 & 2974 \\
\hline Sub-threshold & 53 & $(49-57)$ & 15 & $(13-18)$ & 32 & $(28-35)$ & 100 & 851 \\
\hline $\begin{array}{l}\text { Case-level } \\
\text { depression }\end{array}$ & 36 & $(32-41)$ & 12 & $(9-15)$ & 52 & $(47-56)$ & 100 & 523 \\
\hline Total & 59 & $(58-61)$ & 16 & $(14-17)$ & 25 & $(24-26)$ & 100 & 4348 \\
\hline \multicolumn{9}{|l|}{ Total } \\
\hline Not depressed & 67 & $(66-69)$ & 15 & $(14-17)$ & 17 & $(16-18)$ & 100 & 5851 \\
\hline Sub-threshold & 53 & $(50-57)$ & 15 & $(13-17)$ & 32 & $(29-35)$ & 100 & 1414 \\
\hline $\begin{array}{l}\text { Case-level } \\
\text { depression }\end{array}$ & 36 & $(33-40)$ & 11 & $(9-14)$ & 52 & $(48-56)$ & 100 & 777 \\
\hline Total & 62 & $(60-63)$ & 15 & (14-16) & 23 & $(22-25)$ & 100 & 8042 \\
\hline
\end{tabular}

Note. $\mathrm{Cl}=$ confidence interval; Missing observations $=0.06 \%$ 
Table 6.A5 Physical activity by depression and age

\begin{tabular}{cllllll}
\multicolumn{2}{c}{$\begin{array}{c}\text { Low physcial } \\
\text { activity }\end{array}$} & & \multicolumn{2}{c}{ Moderate } & & $\begin{array}{c}\text { High physical } \\
\text { activity }\end{array}$
\end{tabular}

\section{0-64}

\begin{tabular}{|c|c|c|c|c|c|c|c|c|}
\hline Not depressed & 24 & $(23-26)$ & 33 & $(31-35)$ & 43 & $(40-45)$ & 100 & 3283 \\
\hline Sub-threshold & 32 & $(29-35)$ & 32 & $(29-36)$ & 36 & $(32-40)$ & 100 & 794 \\
\hline $\begin{array}{l}\text { Case-level } \\
\text { depression }\end{array}$ & 40 & $(35-45)$ & 32 & $(28-36)$ & 28 & $(24-33)$ & 100 & 484 \\
\hline Total & 27 & $(26-29)$ & 33 & $(31-34)$ & 40 & $(38-42)$ & 100 & 4561 \\
\hline \multicolumn{9}{|l|}{$65-74$} \\
\hline Not depressed & 28 & $(25-31)$ & 37 & $(35-40)$ & 35 & $(31-38)$ & 100 & 1589 \\
\hline Sub-threshold & 39 & $(34-45)$ & 34 & $(29-40)$ & 27 & $(22-33)$ & 100 & 340 \\
\hline $\begin{array}{l}\text { Case-level } \\
\text { depression }\end{array}$ & 54 & $(46-61)$ & 32 & $(26-39)$ & 14 & $(10-20)$ & 100 & 181 \\
\hline Total & 32 & $(30-34)$ & 36 & (34-39) & 31 & (29-34) & 100 & 2110 \\
\hline \multicolumn{9}{|l|}{$>=75$} \\
\hline Not depressed & 45 & $(42-49)$ & 34 & $(30-37)$ & 21 & $(18-24)$ & 100 & 932 \\
\hline Sub-threshold & 65 & $(59-71)$ & 24 & $(19-30)$ & 11 & $(7-15)$ & 100 & 265 \\
\hline $\begin{array}{l}\text { Case-level } \\
\text { depression }\end{array}$ & 68 & $(58-77)$ & 20 & $(13-29)$ & 12 & $(7-20)$ & 100 & 106 \\
\hline Total & 52 & $(48-55)$ & 30 & $(28-33)$ & 18 & $(16-21)$ & 100 & 1303 \\
\hline \multicolumn{9}{|l|}{ Total } \\
\hline Not depressed & 29 & $(27-31)$ & 34 & $(33-36)$ & 37 & $(35-39)$ & 100 & 5804 \\
\hline Sub-threshold & 41 & $(38-43)$ & 31 & $(28-33)$ & 29 & $(26-32)$ & 100 & 1399 \\
\hline $\begin{array}{l}\text { Case-level } \\
\text { depression }\end{array}$ & 47 & $(43-51)$ & 30 & $(27-33)$ & 23 & $(19-26)$ & 100 & 771 \\
\hline Total & 33 & (31-34) & 33 & $(32-35)$ & 34 & $(32-36)$ & 100 & 7974 \\
\hline
\end{tabular}

Note. $\mathrm{Cl}=$ confidence interval; Missing observations $=0.94 \%$ 
Table 6.A6 Prevalence of sleep disruption by depression and age

\begin{tabular}{|c|c|c|c|c|}
\hline & \multicolumn{2}{|c|}{ Trouble falling asleep } & \multicolumn{2}{|c|}{ Waking too early } \\
\hline & $\%$ & $(95 \% \mathrm{Cl})$ & $\%$ & (95\% CI) \\
\hline \multicolumn{5}{|l|}{$50-64$} \\
\hline Not depressed & 5.7 & $(4.9-6.6)$ & 10.8 & (9.7-12.0) \\
\hline Sub-threshold & 16.4 & (13.7-19.4) & 24.1 & $(21.0-27.4)$ \\
\hline $\begin{array}{l}\text { Case-level } \\
\text { depression }\end{array}$ & 34.9 & (30.6-39.6) & 39.9 & $(35.4-44.5)$ \\
\hline Total & 10.7 & (9.7-11.7) & 16.3 & (15.1-17.5) \\
\hline \multicolumn{5}{|l|}{$65-74$} \\
\hline Not depressed & 7.6 & $(6.3-9.1)$ & 12.5 & (10.9-14.4) \\
\hline Sub-threshold & 20.3 & $(16.2-25.1)$ & 22.6 & $(18.4-27.5)$ \\
\hline $\begin{array}{l}\text { Case-level } \\
\text { depression }\end{array}$ & 27.6 & $(20.8-35.6)$ & 35.5 & $(28.4-43.2)$ \\
\hline Total & 11.5 & (10.1-13.0) & 16.3 & $(14.6-18.1)$ \\
\hline \multicolumn{5}{|l|}{$>=75$} \\
\hline Not depressed & 8.2 & $(6.5-10.3)$ & 14.4 & $(12.1-17.0)$ \\
\hline Sub-threshold & 14.5 & $(10.5-19.8)$ & 19.5 & $(14.8-25.2)$ \\
\hline $\begin{array}{l}\text { Case-level } \\
\text { depression }\end{array}$ & 30.9 & (22.4-40.9) & 35.7 & $(26.8-45.6)$ \\
\hline Total & 11.5 & (9.8-13.6) & 17.3 & $(15.1-19.8)$ \\
\hline \multicolumn{5}{|l|}{ Total } \\
\hline Not depressed & 6.6 & (5.9-7.3) & 11.9 & $(11.0-12.8)$ \\
\hline Sub-threshold & 16.8 & $(14.8-19.1)$ & 22.8 & $(20.4-25.4)$ \\
\hline $\begin{array}{l}\text { Case-level } \\
\text { depression }\end{array}$ & 32.8 & $(29.2-36.5)$ & 38.3 & $(34.6-42.0)$ \\
\hline Total & 11.0 & (10.3-11.8) & 16.5 & $(15.5-17.5)$ \\
\hline
\end{tabular}


Table 6.A7 Employment by age and depression

\begin{tabular}{cccccccc}
\multicolumn{2}{c}{ Employed } & & \multicolumn{2}{c}{ Retired } & & \multicolumn{2}{c}{ Other (coded) } \\
\cline { 1 - 2 } & $95 \% \mathrm{Cl}$ & & $\%$ & $95 \% \mathrm{Cl}$ & & $\%$ & $95 \% \mathrm{Cl}$
\end{tabular}$\quad$ Total $\begin{gathered}\text { Number } \\
\text { in sample }\end{gathered}$

\section{$50-64$}

\begin{tabular}{|c|c|c|c|c|c|c|c|c|}
\hline Not depressed & 60 & $(58-61)$ & 13 & $(12-14)$ & 27 & $(26-29)$ & 100 & 3316 \\
\hline Sub-threshold & 49 & $(46-53)$ & 11 & $(9-13)$ & 40 & $(36-43)$ & 100 & 806 \\
\hline $\begin{array}{l}\text { Case-level } \\
\text { depression }\end{array}$ & 30 & $(26-35)$ & 12 & $(10-16)$ & 57 & $(52-62)$ & 100 & 489 \\
\hline Total & 55 & $(53-56)$ & 12 & (11-14) & 33 & (31-34) & 100 & 4611 \\
\hline \multicolumn{9}{|l|}{$65-74$} \\
\hline Not depressed & 13 & $(11-15)$ & 67 & $(65-70)$ & 20 & $(18-22)$ & 100 & 1595 \\
\hline Sub-threshold & 9 & $(7-13)$ & 67 & $(61-72)$ & 24 & $(19-29)$ & 100 & 343 \\
\hline $\begin{array}{l}\text { Case-level } \\
\text { depression }\end{array}$ & 5 & $(3-10)$ & 66 & $(58-72)$ & 29 & $(23-37)$ & 100 & 182 \\
\hline Total & 12 & $(10-13)$ & 67 & $(65-69)$ & 21 & $(19-23)$ & 100 & 2120 \\
\hline \multicolumn{9}{|l|}{$>=75$} \\
\hline Not depressed & 6 & $(5-8)$ & 71 & $(67-74)$ & 23 & $(20-27)$ & 100 & 942 \\
\hline Sub-threshold & 3 & $(1-6)$ & 64 & $(57-71)$ & 33 & $(27-40)$ & 100 & 268 \\
\hline $\begin{array}{l}\text { Case-level } \\
\text { depression }\end{array}$ & 3 & $(1-8)$ & 57 & $(47-67)$ & 40 & $(30-51)$ & 100 & 106 \\
\hline Total & 5 & $(4-7)$ & 68 & $(65-71)$ & 27 & $(24-30)$ & 100 & 1316 \\
\hline \multicolumn{9}{|l|}{ Total } \\
\hline Not depressed & 39 & $(37-41)$ & 36 & $(35-38)$ & 25 & $(24-26)$ & 100 & 5853 \\
\hline Sub-threshold & 31 & $(29-34)$ & 34 & $(31-37)$ & 35 & $(32-38)$ & 100 & 1417 \\
\hline $\begin{array}{l}\text { Case-level } \\
\text { depression }\end{array}$ & 21 & $(18-24)$ & 31 & $(27-35)$ & 48 & $(44-52)$ & 100 & 777 \\
\hline Total & 36 & (34-37) & 35 & (34-37) & 29 & $(28-30)$ & 100 & 8047 \\
\hline
\end{tabular}

Note. $\mathrm{Cl}=$ confidence interval; Missing observations $=0.00 \%$ 


\section{Table 6.A8 Healthcare utilisation by depression and age}

\begin{tabular}{|c|c|c|c|c|}
\hline & \multicolumn{2}{|c|}{ GP visits in past year } & \multicolumn{2}{|c|}{$\begin{array}{c}\text { Number of reported } \\
\text { medications }\end{array}$} \\
\hline & Mean $(95 \% \mathrm{Cl})$ & $\mathbf{N}$ & Mean $(95 \% \mathrm{Cl})$ & $\mathbf{N}$ \\
\hline \multicolumn{5}{|l|}{$50-64$} \\
\hline Not depressed & $2.82(2.67,2.97)$ & 3299 & $1.56(1.49,1.64)$ & 3299 \\
\hline Sub-threshold & $3.93(3.60,4.25)$ & 799 & $2.09(1.92,2.27)$ & 799 \\
\hline $\begin{array}{l}\text { Case-level } \\
\text { depression }\end{array}$ & $6.52(5.77,7.26)$ & 481 & $3.13(2.86,3.39)$ & 481 \\
\hline \multicolumn{5}{|l|}{$65-74$} \\
\hline Not depressed & $4.00(3.76,4.24)$ & 1578 & $3.00(2.87,3.14)$ & 1578 \\
\hline Sub-threshold & $5.10(4.58,5.63)$ & 340 & $3.74(3.42,4.06)$ & 340 \\
\hline $\begin{array}{l}\text { Case-level } \\
\text { depression }\end{array}$ & $7.34(6.22,8.47)$ & 179 & $4.52(4.06,4.98)$ & 179 \\
\hline \multicolumn{5}{|l|}{$>=75$} \\
\hline Not depressed & $5.17(4.84,5.50)$ & 920 & $3.85(3.66,4.05)$ & 920 \\
\hline Sub-threshold & $5.89(5.13,6.65)$ & 258 & $4.89(4.48,5.30)$ & 258 \\
\hline $\begin{array}{l}\text { Case-level } \\
\text { depression }\end{array}$ & $7.72(6.15,9.29)$ & 105 & $5.35(4.75,5.95)$ & 105 \\
\hline \multicolumn{5}{|l|}{ Total } \\
\hline Not depressed & $3.52(3.39,3.64)$ & 5797 & $2.31(2.23,2.38)$ & 5797 \\
\hline Sub-threshold & $4.58(4.30,4.85)$ & 1397 & $3.01(2.85,3.18)$ & 1397 \\
\hline $\begin{array}{l}\text { Case-level } \\
\text { depression }\end{array}$ & $6.88(6.27,7.50)$ & 765 & $3.78(3.55,4.01)$ & 765 \\
\hline
\end{tabular}


Table 6.A9 Anxiety by age and sex

\begin{tabular}{|c|c|c|c|c|c|c|c|c|}
\hline & \multicolumn{2}{|c|}{ None } & \multicolumn{2}{|c|}{$\begin{array}{l}\text { Sub-threshold } \\
\text { anxiety }\end{array}$} & \multicolumn{2}{|c|}{$\begin{array}{c}\text { Case-level } \\
\text { anxiety }\end{array}$} & \multirow{2}{*}{ Total } & \multirow{2}{*}{$\begin{array}{r}\text { Number } \\
\text { in sample }\end{array}$} \\
\hline & $\%$ & $95 \% \mathrm{Cl}$ & $\%$ & $95 \% \mathrm{Cl}$ & $\%$ & $95 \% \mathrm{Cl}$ & & \\
\hline \multicolumn{9}{|l|}{ Male } \\
\hline $50-64$ & 58 & $(55-60)$ & 29 & $(27-32)$ & 13 & $(11-15)$ & 100 & 1554 \\
\hline $65-74$ & 66 & $(62-69)$ & 24 & $(21-27)$ & 10 & $(8-13)$ & 100 & 815 \\
\hline$>=75$ & 74 & $(69-78)$ & 21 & $(17-26)$ & 5 & $(3-8)$ & 100 & 408 \\
\hline Total & 62 & $(60-64)$ & 27 & $(25-29)$ & 11 & $(10-13)$ & 100 & 2777 \\
\hline \multicolumn{9}{|c|}{ Female } \\
\hline $50-64$ & 51 & $(49-53)$ & 32 & $(29-34)$ & 17 & $(16-19)$ & 100 & 1967 \\
\hline $65-74$ & 58 & (54-61) & 28 & $(25-31)$ & 14 & $(12-17)$ & 100 & 821 \\
\hline$>=75$ & 63 & $(58-68)$ & 28 & $(23-33)$ & 9 & $(6-13)$ & 100 & 468 \\
\hline Total & 55 & $(53-57)$ & 30 & $(28-32)$ & 15 & (14-16) & 100 & 3256 \\
\hline \multicolumn{9}{|l|}{ Total } \\
\hline $50-64$ & 54 & $(52-56)$ & 30 & $(29-32)$ & 15 & $(14-17)$ & 100 & 3521 \\
\hline $65-74$ & 62 & $(59-64)$ & 26 & (24-29) & 12 & $(10-14)$ & 100 & 1636 \\
\hline$>=75$ & 68 & $(64-71)$ & 25 & $(22-29)$ & 7 & $(6-10)$ & 100 & 876 \\
\hline Total & 58 & $(57-60)$ & 29 & $(27-30)$ & 13 & (12-14) & 100 & 6033 \\
\hline
\end{tabular}

Note. $\mathrm{Cl}=$ confidence interval; Missing observations $=26.23 \%$ 
Table 6.A10 Anxiety by age and education

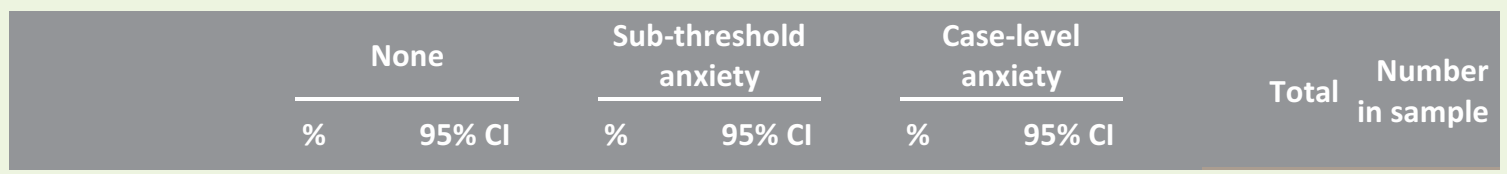

\section{Primary/none}

\begin{tabular}{lcccccccc}
$50-64$ & 51 & $(46-55)$ & 31 & $(28-35)$ & 18 & $(15-21)$ & 100 & 624 \\
$65-74$ & 58 & $(54-62)$ & 26 & $(23-30)$ & 16 & $(13-19)$ & 100 & 590 \\
$>=75$ & 66 & $(60-71)$ & 26 & $(21-31)$ & 8 & $(6-12)$ & 100 & 393 \\
\hline Total & 58 & $(55-60)$ & 28 & $(26-31)$ & 14 & $(13-16)$ & 100 & 1607 \\
\hline Secondary & & & & & & & 100 & 1623 \\
$50-64$ & 54 & $(52-57)$ & 31 & $(28-33)$ & 15 & $(13-17)$ & 100 & 571 \\
$65-74$ & 63 & $(59-67)$ & 28 & $(24-31)$ & 10 & $(7-12)$ & 100 & 294 \\
$>=75$ & 72 & $(67-77)$ & 22 & $(18-27)$ & 6 & $(4-9)$ & 100 \\
\hline Total & 58 & $(56-60)$ & 29 & $(27-31)$ & 13 & $(12-15)$ & 100 & 2488
\end{tabular}

\section{Third/higher}

\begin{tabular}{lllllllll}
$50-64$ & 58 & $(55-61)$ & 29 & $(27-32)$ & 13 & $(11-15)$ & 100 & 1274 \\
$65-74$ & 71 & $(66-74)$ & 22 & $(19-26)$ & 7 & $(5-10)$ & 100 & 475 \\
$>=75$ & 67 & $(59-73)$ & 29 & $(23-36)$ & 4 & $(2-9)$ & 100 & 187 \\
\hline Total & 61 & $(59-63)$ & 28 & $(26-30)$ & 11 & $(10-13)$ & 100 & 1936 \\
\hline Total & & & & & & & 100 & 3521 \\
$50-64$ & 54 & $(52-56)$ & 30 & $(29-32)$ & 15 & $(14-17)$ & 100 & 1636 \\
$65-74$ & 62 & $(59-64)$ & 26 & $(24-29)$ & 12 & $(10-14)$ & 100 & 876 \\
$>=75$ & 68 & $(64-71)$ & 25 & $(22-29)$ & 7 & $(6-10)$ & 100 & 6033 \\
\hline Total & 58 & $(57-60)$ & 29 & $(27-30)$ & 13 & $(12-14)$ & 100 \\
\hline
\end{tabular}

Note. $\mathrm{Cl}=$ confidence interval; Missing observations $=26.23 \%$ 
Table 6.A11 Anxiety by age and wealth

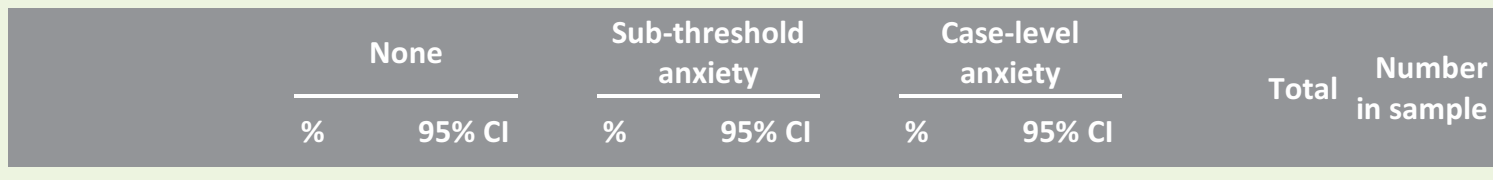

\section{Lowest}

\begin{tabular}{lllllllll}
$50-64$ & 48 & $(41-54)$ & 31 & $(26-37)$ & 22 & $(17-27)$ & 100 & 378 \\
$65-74$ & 55 & $(47-62)$ & 29 & $(23-36)$ & 17 & $(11-24)$ & 100 & 183 \\
$>=75$ & 63 & $(52-73)$ & 29 & $(20-40)$ & 8 & $(4-15)$ & 100 & 112 \\
\hline Total & 53 & $(48-58)$ & 30 & $(26-34)$ & 17 & $(14-21)$ & 100 & 673 \\
\hline 2nd & & & & & & & 100 & 465 \\
$50-64$ & 50 & $(46-55)$ & 32 & $(27-36)$ & 18 & $(14-22)$ & 100 & 200 \\
$65-74$ & 61 & $(53-68)$ & 25 & $(19-32)$ & 14 & $(9-21)$ & 100 & 102 \\
$>=75$ & 67 & $(53-79)$ & 28 & $(17-43)$ & 4 & $(1-12)$ & 100 \\
\hline Total & 56 & $(52-60)$ & 30 & $(26-34)$ & 14 & $(12-17)$ & 100 & 767 \\
\hline
\end{tabular}

3rd

\begin{tabular}{lllllllll}
$50-64$ & 56 & $(51-60)$ & 30 & $(25-34)$ & 15 & $(12-18)$ & 100 & 491 \\
$65-74$ & 60 & $(52-67)$ & 32 & $(25-39)$ & 9 & $(5-14)$ & 100 & 221 \\
$>=75$ & 70 & $(59-79)$ & 25 & $(17-36)$ & 5 & $(2-12)$ & 100 & 93 \\
\hline Total & 59 & $(55-62)$ & 30 & $(26-33)$ & 12 & $(10-14)$ & 100 & 805 \\
\hline
\end{tabular}

Highest

\begin{tabular}{lllllllll}
$50-64$ & 59 & $(54-63)$ & 31 & $(27-35)$ & 10 & $(8-14)$ & 100 & 520 \\
$65-74$ & 73 & $(66-79)$ & 23 & $(17-29)$ & 4 & $(2-9)$ & 100 & 216 \\
$>=75$ & 60 & $(48-70)$ & 35 & $(26-45)$ & 6 & $(2-17)$ & 100 & 78 \\
\hline Total & 62 & $(58-66)$ & 29 & $(26-33)$ & 9 & $(7-11)$ & 100 & 814 \\
\hline Total & & & & & & & 100 & 3521 \\
$50-64$ & 64 & $(52-56)$ & 31 & $(29-32)$ & 15 & $(14-17)$ & 100 & 1636 \\
$65-74$ & $(60-65)$ & 26 & $(24-28)$ & 12 & $(10-14)$ & 100 & 876 \\
$>=75$ & 67 & $(63-72)$ & 25 & $(21-30)$ & 7 & $(5-10)$ & 100 & 6033 \\
\hline Total & 59 & $(57-60)$ & 28 & $(27-30)$ & 13 & $(12-14)$ & & 100 \\
\hline
\end{tabular}

Note. $\mathrm{Cl}=$ confidence interval; Missing observations $=26.23 \%$ 
Table 6.A12 (a) Prevalence of comorbid anxiety by level of depression

\begin{tabular}{|c|c|c|c|c|c|c|c|c|}
\hline & \multicolumn{2}{|c|}{ None } & \multicolumn{2}{|c|}{$\begin{array}{c}\text { Sub-threshold } \\
\text { anxiety }\end{array}$} & \multicolumn{2}{|c|}{$\begin{array}{l}\text { Case-level } \\
\text { anxiety }\end{array}$} & \multirow{2}{*}{ Total } & \multirow{2}{*}{$\begin{array}{l}\text { Number } \\
\text { in sample }\end{array}$} \\
\hline & $\%$ & $95 \% \mathrm{Cl}$ & $\%$ & $95 \% \mathrm{Cl}$ & $\%$ & $95 \% \mathrm{Cl}$ & & \\
\hline Not depressed & 68 & $(66-69)$ & 26 & $(24-27)$ & 6 & $(6-7)$ & 100 & 4416 \\
\hline Sub-threshold & 43 & $(40-46)$ & 37 & $(34-40)$ & 20 & $(18-23)$ & 100 & 1020 \\
\hline Case-level depre & $n 16$ & $(13-19)$ & 36 & $(32-41)$ & 48 & $(43-52)$ & 100 & 512 \\
\hline Total & 59 & $(57-60)$ & 29 & $(27-30)$ & 13 & $(12-14)$ & 100 & 5948 \\
\hline
\end{tabular}

Note. $\mathrm{Cl}=$ confidence interval; Missing observations $=26.23 \%$

Table 6.A12 (b) Prevalence of comorbid depression by level of anxiety

\begin{tabular}{|c|c|c|c|c|c|c|c|c|}
\hline & \multicolumn{2}{|c|}{ Not depressed } & \multicolumn{2}{|c|}{ Sub-threshold } & \multicolumn{2}{|c|}{$\begin{array}{c}\text { Case-level } \\
\text { depression }\end{array}$} & \multirow{2}{*}{ Total } & \multirow{2}{*}{$\begin{array}{r}\text { Number in } \\
\text { sample }\end{array}$} \\
\hline & $\%$ & $95 \% \mathrm{Cl}$ & $\%$ & $95 \% \mathrm{Cl}$ & $\%$ & $95 \% \mathrm{Cl}$ & & \\
\hline None & 84 & $(82-86)$ & 13 & $(12-15)$ & 3 & $(2-3)$ & 100 & 3545 \\
\hline $\begin{array}{l}\text { Sub-threshold } \\
\text { anxiety }\end{array}$ & 65 & $(62-68)$ & 22 & $(20-25)$ & 12 & $(11-14)$ & 100 & 1677 \\
\hline Case-level anxiety & 37 & $(33-41)$ & 27 & $(24-31)$ & 36 & $(32-40)$ & 100 & 726 \\
\hline Total & 73 & $(71-74)$ & 18 & (16-19) & 10 & $(9-11)$ & 100 & 5948 \\
\hline
\end{tabular}

Note. $\mathrm{Cl}=$ confidence interval; Missing observations $=1.60 \%$ 
Table 6.A13 Suicidal ideation and disability by anxiety, depression and age.

\begin{tabular}{|c|c|c|c|c|}
\hline & \multicolumn{2}{|c|}{$\begin{array}{c}\text { Presence of longstanding } \\
\text { illness or disability }\end{array}$} & \multicolumn{2}{|c|}{ Suicidal Ideation } \\
\hline & $\%$ & $(95 \% \mathrm{Cl})$ & $\%$ & (95\% Cl) \\
\hline \multicolumn{5}{|l|}{$50-64$} \\
\hline Neither anxiety or depression & 31.9 & $(30.0-33.8)$ & 1.2 & $(0.8-1.8)$ \\
\hline Anxiety only & 39.7 & $(34.2-45.4)$ & 5.5 & $(3.4-8.7)$ \\
\hline Depression only & 54.5 & $(46.5-62.3)$ & 15.0 & $(10.4-21.1)$ \\
\hline Comorbid anxiety and depression & 63.9 & $(56.2-70.8)$ & 29.6 & $(22.8-37.5)$ \\
\hline Total & 35.6 & $(33.7-37.5)$ & 3.9 & (3.3-4.7) \\
\hline \multicolumn{5}{|l|}{$65-74$} \\
\hline Neither anxiety or depression & 39.1 & $(35.9-42.4)$ & 1.0 & $(0.6-1.7)$ \\
\hline Anxiety only & 57.5 & $(47.3-67.1)$ & 5.2 & $(2.2-11.8)$ \\
\hline Depression only & 56.8 & $(43.8-68.8)$ & 15.8 & $(8.0-28.6)$ \\
\hline Comorbid anxiety and depression & 73.0 & $(59.3-83.4)$ & 32.5 & $(20.8-47.0)$ \\
\hline Total & 42.7 & $(39.6-45.8)$ & 3.2 & $(2.3-4.4)$ \\
\hline \multicolumn{5}{|l|}{$>=75$} \\
\hline Neither anxiety or depression & 41.5 & $(37.3-45.9)$ & 1.3 & $(0.6-2.8)$ \\
\hline Anxiety only & 48.0 & $(31.2-65.3)$ & 2.6 & $(0.6-10.3)$ \\
\hline Depression only & 80.4 & $(64.6-90.2)$ & 20.2 & $(9.5-38.0)$ \\
\hline Comorbid anxiety and depression & 64.8 & $(34.9-86.4)$ & 25.8 & $(8.2-57.4)$ \\
\hline Total & 44.7 & $(40.5-48.9)$ & 3.0 & $(1.9-4.8)$ \\
\hline \multicolumn{5}{|l|}{ Total } \\
\hline Neither anxiety or depression & 35.3 & $(33.6-37.1)$ & 1.2 & $(0.9-1.6)$ \\
\hline Anxiety only & 44.4 & $(39.6-49.3)$ & 5.1 & $(3.4-7.5)$ \\
\hline Depression only & 60.1 & $(53.6-66.2)$ & 16.2 & $(12.1-21.3)$ \\
\hline Comorbid anxiety and depression & 65.8 & $(59.3-71.8)$ & 29.9 & $(24.0-36.6)$ \\
\hline Total & 38.8 & (37.1-40.5) & 3.6 & (3.1-4.2) \\
\hline
\end{tabular}




\section{Table 6.A14 Self-reported memory by age and sex}

\begin{tabular}{|c|c|c|c|c|c|c|c|c|c|c|c|c|}
\hline & \multicolumn{2}{|c|}{ Excellent } & \multicolumn{2}{|c|}{ Very good } & \multicolumn{2}{|c|}{ Good } & \multicolumn{2}{|r|}{ Fair } & \multicolumn{2}{|r|}{ Poor } & \multirow{2}{*}{ Total } & \multirow{2}{*}{$\begin{array}{c}\text { Number } \\
\text { in } \\
\text { sample }\end{array}$} \\
\hline & $\%$ & $95 \% \mathrm{Cl}$ & $\%$ & $95 \% \mathrm{Cl}$ & $\%$ & $95 \% \mathrm{Cl}$ & $\%$ & $95 \% \mathrm{Cl}$ & $\%$ & $95 \% \mathrm{Cl}$ & & \\
\hline \multicolumn{13}{|l|}{ Male } \\
\hline $50-64$ & 16 & $(14-18)$ & 33 & $(31-36)$ & 37 & $(35-39)$ & 11 & $(9-12)$ & 3 & $(2-4)$ & 100 & 2080 \\
\hline $65-74$ & 10 & $(8-12)$ & 31 & $(28-35)$ & 38 & $(35-41)$ & 17 & $(15-20)$ & 4 & $(3-5)$ & 100 & 1070 \\
\hline$>=75$ & 5 & $(4-8)$ & 26 & $(22-30)$ & 43 & $(39-47)$ & 21 & $(18-25)$ & 4 & $(3-6)$ & 100 & 598 \\
\hline Total & 13 & (12-14) & 32 & (30-34) & 38 & $(36-40)$ & 14 & (13-15) & 3 & $(3-4)$ & 100 & 3748 \\
\hline
\end{tabular}

\section{Female}

\begin{tabular}{lllllllllllll}
$50-64$ & 15 & $(13-16)$ & 35 & $(33-37)$ & 36 & $(34-38)$ & 12 & $(11-14)$ & 2 & $(2-3)$ & 100 & 2585 \\
$65-74$ & 9 & $(7-11)$ & 27 & $(25-30)$ & 45 & $(42-48)$ & 16 & $(14-18)$ & 3 & $(2-5)$ & 100 & 1093 \\
$>=75$ & 5 & $(4-7)$ & 23 & $(20-26)$ & 47 & $(43-51)$ & 20 & $(16-23)$ & 5 & $(3-7)$ & 100 & 749 \\
\hline Total & 11 & $(10-12)$ & 31 & $(29-32)$ & 41 & $(39-42)$ & 15 & $(13-16)$ & 3 & $(2-4)$ & 100 & 4427
\end{tabular}

\section{Total}

\begin{tabular}{lllllllllllll}
$50-64$ & 15 & $(14-16)$ & 34 & $(33-36)$ & 37 & $(35-38)$ & 11 & $(11-12)$ & 3 & $(2-3)$ & 100 & 4665 \\
$65-74$ & 9 & $(8-11)$ & 29 & $(27-32)$ & 42 & $(39-44)$ & 16 & $(15-18)$ & 3 & $(3-4)$ & 100 & 2163 \\
$>=75$ & 5 & $(4-7)$ & 24 & $(22-27)$ & 46 & $(43-49)$ & 20 & $(18-23)$ & 5 & $(3-6)$ & 100 & 1347 \\
\hline Total & 12 & $(11-13)$ & 31 & $(30-32)$ & 39 & $(38-41)$ & 14 & $(13-15)$ & 3 & $(3-4)$ & 100 & 8175
\end{tabular}

Note. $\mathrm{Cl}=$ confidence interval; Missing observations $=0.04 \%$ 


\section{Table 6.A15 Self-reported memory by age and education}

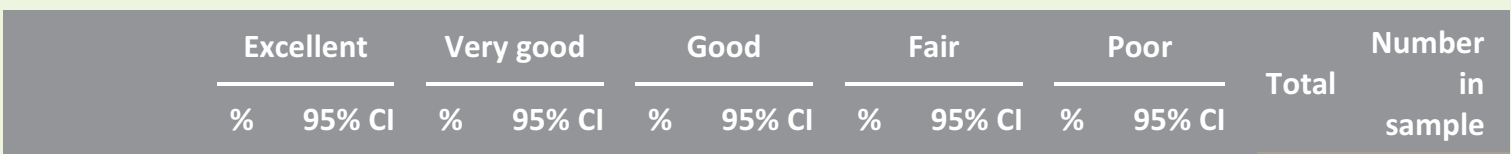

\section{Primary/none}

\begin{tabular}{lcccccccccccc}
$50-64$ & 11 & $(9-13)$ & 28 & $(25-31)$ & 41 & $(38-44)$ & 16 & $(14-19)$ & 5 & $(3-6)$ & 100 & 956 \\
$65-74$ & 7 & $(5-9)$ & 26 & $(23-29)$ & 44 & $(40-47)$ & 20 & $(17-22)$ & 4 & $(3-6)$ & 100 & 865 \\
$>=75$ & 3 & $(2-5)$ & 22 & $(19-26)$ & 46 & $(42-50)$ & 23 & $(20-27)$ & 5 & $(4-7)$ & 100 & 684 \\
\hline Total & 7 & $(6-8)$ & 25 & $(24-27)$ & 43 & $(41-45)$ & 19 & $(18-21)$ & 5 & $(4-6)$ & 100 & 2505 \\
\hline
\end{tabular}

\section{Secondary}

\begin{tabular}{lcccccccccccc}
$50-64$ & 14 & $(12-15)$ & 36 & $(34-38)$ & 37 & $(35-39)$ & 11 & $(10-12)$ & 2 & $(2-3)$ & 100 & 2117 \\
$65-74$ & 10 & $(8-13)$ & 32 & $(28-36)$ & 42 & $(38-45)$ & 14 & $(11-16)$ & 3 & $(2-4)$ & 100 & 728 \\
$>=75$ & 8 & $(6-12)$ & 27 & $(23-31)$ & 47 & $(42-52)$ & 15 & $(12-19)$ & 3 & $(1-5)$ & 100 & 417 \\
\hline Total & 13 & $(11-14)$ & 34 & $(32-36)$ & 39 & $(37-41)$ & 12 & $(11-13)$ & 2 & $(2-3)$ & 100 & 3262 \\
\hline
\end{tabular}

\section{Third/higher}

\begin{tabular}{lcccccccccccc}
$50-64$ & 23 & $(21-26)$ & 37 & $(35-40)$ & 31 & $(28-33)$ & 7 & $(6-9)$ & 1 & $(1-2)$ & 100 & 1592 \\
$65-74$ & 15 & $(12-18)$ & 36 & $(32-40)$ & 35 & $(31-39)$ & 12 & $(10-15)$ & 2 & $(1-3)$ & 100 & 569 \\
$>=75$ & 11 & $(8-17)$ & 31 & $(25-37)$ & 39 & $(33-45)$ & 14 & $(10-20)$ & 4 & $(2-8)$ & 100 & 243 \\
\hline Total & 21 & $(19-23)$ & 36 & $(34-38)$ & 32 & $(30-34)$ & 9 & $(8-10)$ & 2 & $(1-2)$ & 100 & 2404 \\
\hline Total & & & & & & & & & & & & \\
$50-64$ & 15 & $(14-16)$ & 34 & $(33-36)$ & 37 & $(35-38)$ & 11 & $(11-12)$ & 3 & $(2-3)$ & 100 & 4665 \\
$65-74$ & 9 & $(8-11)$ & 29 & $(27-32)$ & 42 & $(39-44)$ & 16 & $(15-18)$ & 3 & $(3-4)$ & 100 & 2163 \\
$>=75$ & 5 & $(4-7)$ & 24 & $(22-27)$ & 46 & $(43-49)$ & 20 & $(18-23)$ & 5 & $(3-6)$ & 100 & 1347 \\
\hline Total & 12 & $(11-13)$ & 31 & $(30-32)$ & 39 & $(38-41)$ & 14 & $(13-15)$ & 3 & $(3-4)$ & 100 & 8175 \\
\hline
\end{tabular}

Note. $\mathrm{Cl}=$ confidence interval; Missing observations $=0.04 \%$ 
Table 6.A16 Self-reported memory by age and wealth

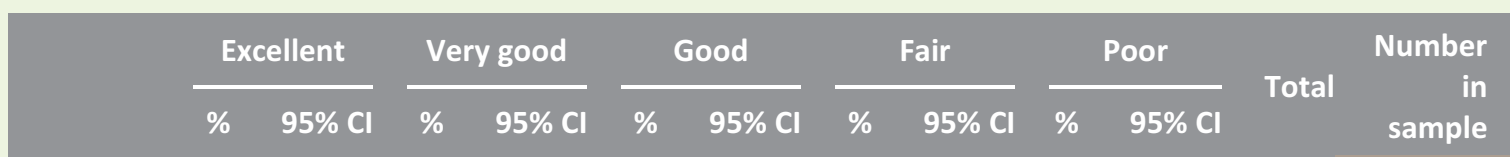

\section{Lowest}

\begin{tabular}{lcccccccccccc}
$50-64$ & 10 & $(7-12)$ & 35 & $(31-41)$ & 37 & $(33-42)$ & 14 & $(11-17)$ & 4 & $(3-7)$ & 100 & 567 \\
$65-74$ & 6 & $(3-9)$ & 32 & $(25-41)$ & 44 & $(37-52)$ & 15 & $(11-21)$ & 3 & $(1-6)$ & 100 & 243 \\
$>=75$ & 5 & $(3-9)$ & 22 & $(16-30)$ & 46 & $(39-53)$ & 19 & $(14-27)$ & 8 & $(4-17)$ & 100 & 178 \\
\hline Total & 7 & $(6-9)$ & 31 & $(27-36)$ & 41 & $(37-45)$ & 15 & $(13-18)$ & 5 & $(3-7)$ & 100 & 988 \\
\hline 2nd & & & & & & & & & & & & \\
$50-64$ & 11 & $(9-14)$ & 32 & $(28-37)$ & 38 & $(34-41)$ & 15 & $(13-19)$ & 4 & $(2-6)$ & 100 & 586 \\
$65-74$ & 9 & $(6-13)$ & 27 & $(22-34)$ & 40 & $(33-46)$ & 21 & $(16-26)$ & 3 & $(1-6)$ & 100 & 268 \\
$>=75$ & 4 & $(2-10)$ & 21 & $(15-29)$ & 50 & $(41-60)$ & 18 & $(12-26)$ & 7 & $(3-13)$ & 100 & 145 \\
\hline Total & 9 & $(8-12)$ & 29 & $(26-32)$ & 41 & $(38-44)$ & 17 & $(15-20)$ & 4 & $(3-6)$ & 100 & 999 \\
\hline
\end{tabular}

3rd

\begin{tabular}{lcccccccccccc}
$50-64$ & 16 & $(13-20)$ & 35 & $(31-39)$ & 37 & $(33-41)$ & 9 & $(7-12)$ & 2 & $(1-4)$ & 100 & 590 \\
$65-74$ & 9 & $(6-13)$ & 33 & $(27-40)$ & 41 & $(35-47)$ & 14 & $(10-19)$ & 4 & $(2-7)$ & 100 & 262 \\
$>=75$ & 8 & $(3-20)$ & 29 & $(21-38)$ & 51 & $(40-62)$ & 12 & $(8-19)$ & 0 & $(.-)$. & 100 & 123 \\
\hline Total & 13 & $(11-16)$ & 33 & $(30-37)$ & 40 & $(37-44)$ & 11 & $(9-13)$ & 2 & $(1-3)$ & 100 & 975 \\
\hline
\end{tabular}

Highest

\begin{tabular}{lcccccccccccc}
$50-64$ & 21 & $(18-24)$ & 40 & $(36-44)$ & 32 & $(28-36)$ & 8 & $(6-10)$ & 0 & $(0-1)$ & 100 & 634 \\
$65-74$ & 12 & $(8-17)$ & 39 & $(32-47)$ & 35 & $(29-42)$ & 13 & $(9-20)$ & 0 & $(0-3)$ & 100 & 258 \\
$>=75$ & 8 & $(4-16)$ & 29 & $(20-41)$ & 51 & $(38-64)$ & 10 & $(4-19)$ & 1 & $(0-5)$ & 100 & 95 \\
\hline Total & 17 & $(15-20)$ & 38 & $(35-42)$ & 35 & $(31-38)$ & 9 & $(7-12)$ & 0 & $(0-1)$ & 100 & 987 \\
\hline Total & & & & & & & & & & & & \\
$50-64$ & 15 & $(14-16)$ & 34 & $(33-36)$ & 37 & $(35-38)$ & 12 & $(11-13)$ & 3 & $(2-3)$ & 100 & 4665 \\
$65-74$ & 9 & $(8-10)$ & 29 & $(27-31)$ & 42 & $(40-44)$ & 17 & $(15-19)$ & 4 & $(3-5)$ & 100 & 2163 \\
$>=75$ & 5 & $(4-7)$ & 24 & $(21-26)$ & 46 & $(43-49)$ & 20 & $(18-23)$ & 5 & $(4-7)$ & 100 & 1347 \\
\hline Total & 11 & $(11-12)$ & 31 & $(29-32)$ & 40 & $(39-41)$ & 15 & $(14-16)$ & 3 & $(3-4)$ & 100 & 8175 \\
\hline
\end{tabular}

Note. $\mathrm{Cl}=$ confidence interval; Missing observations $=0.04 \%$ 
Table 6.A17 Proportion failed prospective memory task by age and education

\begin{tabular}{|c|c|c|c|c|c|c|c|c|}
\hline & \multicolumn{2}{|c|}{ Primary/none } & \multicolumn{2}{|c|}{ Secondary } & \multicolumn{2}{|c|}{ Third/higher } & \multicolumn{2}{|c|}{ Total } \\
\hline & $\%$ & $(95 \% \mathrm{Cl})$ & $\%$ & $(95 \% \mathrm{Cl})$ & $\%$ & $(95 \% \mathrm{Cl})$ & $\%$ & $(95 \% \mathrm{Cl})$ \\
\hline $50-59$ & 19.2 & $(15.7-23.2)$ & 9.8 & $(8.4-11.6)$ & 8.3 & $(6.7-10.1)$ & 11.4 & $(10.1-12.8)$ \\
\hline $60-64$ & 19.6 & $(15.8-24.0)$ & 10.9 & $(8.5-13.8)$ & 8.3 & (6.1-11.4) & 13.5 & $(11.6-15.7)$ \\
\hline $65-69$ & 24.6 & $(20.6-29.2)$ & 15.4 & $(12.4-19.0)$ & 12.1 & $(9.0-16.0)$ & 19.3 & $(17.0-21.8)$ \\
\hline 70-79 & 31.5 & $(27.5-35.7)$ & 23 & $(19.3-27.2)$ & 14.3 & $(11.0-18.4)$ & 26.7 & $(23.9-29.6)$ \\
\hline$>=80$ & 44.6 & $(39.0-50.4)$ & 37.4 & $(30.6-44.7)$ & 25.9 & $(17.6-36.3)$ & 41.7 & $(37.3-46.2)$ \\
\hline Total & 27.8 & $(25.6-30.3)$ & 13.8 & $(12.5-15.2)$ & 10.1 & $(8.9-11.5)$ & 18.5 & $(17.3-19.8)$ \\
\hline
\end{tabular}

Table 6.A18 Verbal fluency (mean number of animals named) by age and education

\begin{tabular}{|c|c|c|c|c|c|c|c|c|}
\hline & \multicolumn{2}{|c|}{ Primary/none } & \multicolumn{2}{|c|}{ Secondary } & \multicolumn{2}{|c|}{ Third/higher } & \multicolumn{2}{|c|}{ Total } \\
\hline & Mean & $95 \% \mathrm{Cl}$ & Mean & $95 \% \mathrm{Cl}$ & Mean & $95 \% \mathrm{Cl}$ & Mean & $95 \% \mathrm{C}$ \\
\hline $50-59$ & 18.8 & $(18.2-19.5)$ & 21.3 & $(20.9-21.7)$ & 24.5 & $(24.0-25.0)$ & 21.6 & $(21.2-22.0)$ \\
\hline $60-64$ & 18.6 & $(17.9-19.3)$ & 20.7 & $(20.0-21.3)$ & 24 & $(23.3-24.7)$ & 20.6 & $(20.1-21.0)$ \\
\hline $65-69$ & 17.9 & $(17.3-18.6)$ & 19.9 & $(19.2-20.6)$ & 22.8 & $(22.0-23.5)$ & 19.4 & (18.9-19.9) \\
\hline $70-79$ & 16.3 & $(15.8-16.9)$ & 19 & $(18.4-19.6)$ & 20.9 & $(20.2-21.6)$ & 17.7 & $(17.3-18.1)$ \\
\hline$>=80$ & 14.3 & $(13.7-15.0)$ & 15.9 & $(15.0-16.7)$ & 19.3 & $(18.0-20.7)$ & 15 & $(14.5-15.6)$ \\
\hline Total & 16.2 & (15.7-16.8) & 20.1 & (19.6-20.5) & 23.1 & (22.5-23.7) & 19.1 & (18.8-19.5) \\
\hline
\end{tabular}

Table 6.A19 Proportion with cognitive impairment (MMSE<25) by age and education

\begin{tabular}{|c|c|c|c|c|c|c|c|c|}
\hline & \multicolumn{2}{|c|}{ Primary/none } & \multicolumn{2}{|c|}{ Secondary } & \multicolumn{2}{|c|}{ Third/higher } & \multicolumn{2}{|c|}{ Total } \\
\hline & $\%$ & $(95 \% \mathrm{Cl})$ & $\%$ & $(95 \% \mathrm{Cl})$ & $\%$ & $(95 \% \mathrm{Cl})$ & $\%$ & $(95 \% \mathrm{Cl})$ \\
\hline $50-59$ & 16.9 & $(12.3-22.7)$ & 3.5 & $(2.4-5.1)$ & 1.5 & $(0.8-3.1)$ & 5.2 & $(4.0-6.7)$ \\
\hline $60-64$ & 12.2 & (8.4-17.6) & 4.2 & $(2.4-7.2)$ & 0.7 & $(0.2-2.8)$ & 6 & $(4.4-8.1)$ \\
\hline $65-69$ & 19.4 & $(14.5-25.5)$ & 4.5 & $(2.2-9.0)$ & 2.3 & $(0.9-5.5)$ & 10.3 & $(7.9-13.4)$ \\
\hline 70-79 & 27.6 & $(22.1-34.0)$ & 11.7 & $(8.0-16.6)$ & 1.2 & $(0.4-3.8)$ & 18.1 & (14.9-21.9) \\
\hline$>=80$ & 47.1 & $(37.0-57.5)$ & 27.8 & $(18.0-40.3)$ & 16.7 & $(8.0-31.5)$ & 40 & (32.5-47.9) \\
\hline Total & 24.3 & $(21.5-27.2)$ & 6 & $(4.8-7.4)$ & 1.9 & $(1.3-2.8)$ & 11.3 & (10.1-12.6) \\
\hline
\end{tabular}


Table 6.A20 Global Cognitive function by age and sex

\begin{tabular}{|c|c|c|c|c|c|c|c|c|}
\hline & \multicolumn{2}{|c|}{$\begin{array}{l}\text { Normal } \\
\text { Cognitive } \\
\text { Function } \\
\end{array}$} & \multicolumn{2}{|c|}{$\begin{array}{c}\text { Mild } \\
\text { impairment }\end{array}$} & \multicolumn{2}{|c|}{$\begin{array}{c}\text { Moderate } \\
\text { impairment }\end{array}$} & \multirow[t]{2}{*}{ Total } & \multirow[t]{2}{*}{$\begin{array}{r}\text { Number } \\
\text { in sample }\end{array}$} \\
\hline & $\%$ & $95 \% \mathrm{Cl}$ & $\%$ & $95 \% \mathrm{Cl}$ & $\%$ & $95 \% \mathrm{Cl}$ & & \\
\hline \multicolumn{9}{|l|}{ Male } \\
\hline $50-59$ & 96 & (94-97) & 4 & $(3-6)$ & 0 & $(0-1)$ & 100 & 819 \\
\hline $60-64$ & 94 & $(90-96)$ & 5 & $(3-9)$ & 1 & $(0-3)$ & 100 & 351 \\
\hline $65-69$ & 89 & $(85-93)$ & 9 & $(6-13)$ & 2 & $(1-4)$ & 100 & 337 \\
\hline 70-79 & 82 & $(77-86)$ & 16 & $(13-20)$ & 2 & $(1-4)$ & 100 & 412 \\
\hline$>=80$ & 69 & (59-77) & 25 & $(18-35)$ & 6 & $(2-14)$ & 100 & 105 \\
\hline Total & 91 & (89-92) & 8 & $(7-10)$ & 1 & $(1-2)$ & 100 & 2024 \\
\hline \multicolumn{9}{|c|}{ Female } \\
\hline $50-59$ & 94 & $(92-96)$ & 5 & $(4-7)$ & 1 & $(0-2)$ & 100 & 985 \\
\hline $60-64$ & 94 & $(91-96)$ & 6 & $(4-9)$ & 0 & (.-.) & 100 & 455 \\
\hline $65-69$ & 92 & $(88-94)$ & 8 & $(5-11)$ & 0 & $(0-3)$ & 100 & 348 \\
\hline 70-79 & 83 & $(79-87)$ & 15 & $(12-19)$ & 2 & $(1-4)$ & 100 & 410 \\
\hline$>=80$ & 62 & $(53-71)$ & 31 & $(23-40)$ & 7 & $(3-14)$ & 100 & 132 \\
\hline Total & 90 & (88-91) & 9 & $(8-11)$ & 1 & $(1-2)$ & 100 & 2330 \\
\hline \multicolumn{9}{|l|}{ Total } \\
\hline $50-59$ & 95 & $(94-96)$ & 4 & $(4-6)$ & 0 & $(0-1)$ & 100 & 1804 \\
\hline $60-64$ & 94 & $(92-95)$ & 6 & $(4-8)$ & 0 & $(0-1)$ & 100 & 806 \\
\hline $65-69$ & 91 & $(88-93)$ & 8 & $(6-11)$ & 1 & $(0-2)$ & 100 & 685 \\
\hline 70-79 & 82 & $(79-85)$ & 16 & $(13-19)$ & 2 & $(1-3)$ & 100 & 822 \\
\hline$>=80$ & 65 & $(58-71)$ & 29 & $(23-35)$ & 6 & $(4-11)$ & 100 & 237 \\
\hline Total & 90 & (89-91) & 9 & $(8-10)$ & 1 & $(1-2)$ & 100 & 4354 \\
\hline
\end{tabular}

Note. $\mathrm{Cl}=$ confidence interval; Missing observations $=46.67 \%$ 
Table 6.A21 Cognitive impairment by age and employment

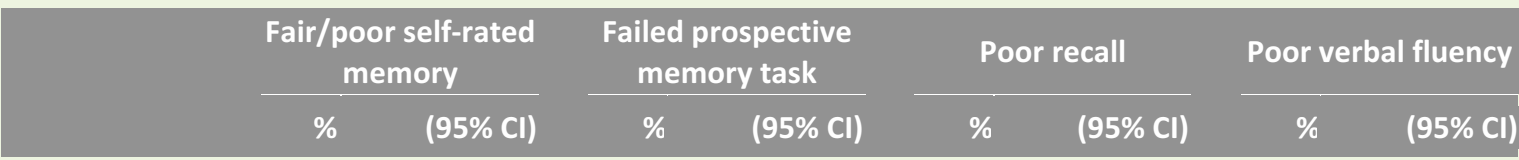

50-64

\begin{tabular}{lcccccccc} 
Not employed & 16.9 & $(15.3-18.8)$ & 14.3 & $(12.6-16.2)$ & 41.1 & $(38.7-43.6)$ & 53.3 & $(50.4-56.1)$ \\
Employed & 11.6 & $(10.4-13.0)$ & 10.1 & $(8.8-11.5)$ & 30.9 & $(28.9-33.0)$ & 45.6 & $(42.9-48.2)$ \\
\hline Total & 14.0 & $(13.0-15.1)$ & 12.0 & $(10.9-13.3)$ & 35.6 & $(33.9-37.3)$ & 49.1 & $(46.8-51.3)$ \\
\hline
\end{tabular}

$65-74$

\begin{tabular}{lcccccccc} 
Not employed & 20.6 & $(18.6-22.8)$ & 22.4 & $(20.2-24.7)$ & 53.6 & $(50.7-56.4)$ & 64.0 & $(61.0-66.9)$ \\
Employed & 13.4 & $(9.6-18.5)$ & 18.8 & $(14.2-24.4)$ & 53.5 & $(46.7-60.2)$ & 55.7 & $(48.7-62.5)$ \\
\hline Total & 19.8 & $(17.9-21.7)$ & 22.0 & $(19.9-24.2)$ & 53.6 & $(50.9-56.2)$ & 63.0 & $(60.1-65.8)$ \\
\hline$>=75$ & & & & & & & & \\
Not employed & 24.7 & $(22.0-27.6)$ & 34.6 & $(31.4-37.9)$ & 75.2 & $(72.3-77.9)$ & 79.1 & $(76.3-81.6)$ \\
Employed & 25.5 & $(15.6-38.8)$ & 39.4 & $(27.5-52.8)$ & 86.8 & $(76.5-93.1)$ & 73.9 & $(61.7-83.2)$ \\
\hline Total & 24.8 & $(22.1-27.6)$ & 34.8 & $(31.6-38.2)$ & 75.8 & $(73.0-78.4)$ & 78.8 & $(76.1-81.2)$
\end{tabular}

Total

\begin{tabular}{lcccccccc} 
Not employed & 20.2 & $(19.0-21.5)$ & 22.3 & $(20.8-23.9)$ & 54.2 & $(52.4-55.9)$ & 63.6 & $(61.5-65.7)$ \\
Employed & 12.1 & $(10.9-13.4)$ & 11.5 & $(10.2-13.0)$ & 34.2 & $(32.1-36.2)$ & 47.1 & $(44.6-49.7)$ \\
\hline Total & 17.3 & $(16.4-18.3)$ & 18.5 & $(17.3-19.8)$ & 47.0 & $(45.6-48.5)$ & 57.7 & $(55.8-59.7)$
\end{tabular}


Table 6.A22 Cognitive impairment by age and wealth

\begin{tabular}{|c|c|c|c|c|c|c|c|c|}
\hline & \multicolumn{2}{|c|}{$\begin{array}{c}\text { Fair/poor self-rated } \\
\text { memory }\end{array}$} & \multicolumn{2}{|c|}{$\begin{array}{l}\text { Failed prospective } \\
\text { memory task }\end{array}$} & \multicolumn{2}{|c|}{ Poor recall } & \multicolumn{2}{|c|}{ Poor verbal fluency } \\
\hline & $\%$ & $(95 \% \mathrm{Cl})$ & $\%$ & $(95 \% \mathrm{Cl})$ & $\%$ & $(95 \% \mathrm{Cl})$ & $\%$ & $(95 \% \mathrm{CI})$ \\
\hline \multicolumn{9}{|l|}{$50-64$} \\
\hline Lowest & 17.8 & $(14.6-21.5)$ & 18.9 & $(15.0-23.6)$ & 47.3 & $(41.8-52.9)$ & 61.4 & $(54.9-67.5)$ \\
\hline $2 n d$ & 19.1 & $(15.8-22.9)$ & 11.8 & $(9.3-15.0)$ & 36.8 & $(32.4-41.4)$ & 59.8 & $(54.5-64.8)$ \\
\hline $3 r d$ & 11.5 & $(9.0-14.5)$ & 9.9 & $(7.6-12.7)$ & 27.5 & $(23.5-31.8)$ & 45.6 & $(40.7-50.6)$ \\
\hline Highest & 7.9 & $(5.9-10.4)$ & 9.7 & $(7.6-12.2)$ & 25.3 & $(21.5-29.6)$ & 42.7 & $(37.6-48.0)$ \\
\hline Total & 14.3 & $(12.8-15.8)$ & 12.6 & $(11.0-14.3)$ & 34.3 & $(32.0-36.7)$ & 52.7 & $(49.6-55.7)$ \\
\hline \multicolumn{9}{|l|}{$65-74$} \\
\hline Lowest & 17.9 & (13.1-23.9) & 21.5 & $(15.3-29.4)$ & 56.5 & $(44.3-68.0)$ & 79.2 & $(71.2-85.5)$ \\
\hline 2nd & 24.1 & $(19.2-29.7)$ & 24.8 & $(19.7-30.9)$ & 55.2 & $(49.0-61.2)$ & 68.9 & (62.1-74.9) \\
\hline $3 r d$ & 17.1 & $(12.6-22.9)$ & 14.7 & $(10.7-20.0)$ & 49.8 & $(42.4-57.3)$ & 64.3 & $(57.5-70.7)$ \\
\hline Highest & 13.7 & $(9.1-20.2)$ & 16.0 & $(10.6-23.3)$ & 41.1 & (34.7-47.9) & 53.9 & $(46.4-61.2)$ \\
\hline Total & 18.6 & (16.1-21.4) & 19.6 & (16.9-22.7) & 51.3 & (47.1-55.5) & 67.4 & (63.3-71.2) \\
\hline \multicolumn{9}{|l|}{$>=75$} \\
\hline Lowest & 27.4 & $(20.9-35.1)$ & 29.6 & $(22.6-37.7)$ & 78.1 & (69.1-85.0) & 85.1 & $(79.4-89.4)$ \\
\hline $2 n d$ & 24.2 & $(16.0-35.0)$ & 38.2 & $(29.5-47.8)$ & 76.5 & $(67.2-83.8)$ & 83.9 & $(74.8-90.1)$ \\
\hline $3 r d$ & 12.4 & $(7.8-19.2)$ & 31.3 & $(23.4-40.4)$ & 59.7 & $(48.5-70.1)$ & 73.6 & $(63.7-81.6)$ \\
\hline Highest & 10.8 & $(5.4-20.3)$ & 24.9 & $(16.2-36.3)$ & 59.5 & $(46.5-71.3)$ & 70.0 & $(59.2-79.0)$ \\
\hline Total & 21.5 & (17.0-26.9) & 32.1 & $(27.3-37.3)$ & 71.7 & $(66.8-76.2)$ & 80.7 & (76.7-84.1) \\
\hline \multicolumn{9}{|l|}{ Total } \\
\hline Lowest & 20.3 & $(17.4-23.6)$ & 22.2 & $(18.6-26.4)$ & 57.3 & (51.1-63.3) & 71.5 & (66.1-76.4) \\
\hline $2 n d$ & 21.3 & $(18.3-24.7)$ & 20.2 & $(17.3-23.6)$ & 49.0 & $(45.6-52.5)$ & 66.8 & $(63.0-70.4)$ \\
\hline $3 r d$ & 13.0 & $(11.0-15.4)$ & 14.5 & $(12.3-17.1)$ & 38.2 & (34.4-42.1) & 54.7 & $(50.7-58.6)$ \\
\hline Highest & 9.5 & $(7.6-11.8)$ & 12.7 & (10.4-15.3) & 32.4 & (29.1-35.9) & 48.1 & $(43.7-52.6)$ \\
\hline Total & 16.6 & $(15.2-18.2)$ & 17.9 & (16.2-19.6) & 45.2 & (43.1-47.4) & 61.3 & (58.7-63.9) \\
\hline
\end{tabular}




\section{Health And Social Care Utilisation}

\section{Charles Normand, Yumiko Kamiya, Virpi Timonen and Brendan Whelan}

\section{Contents}

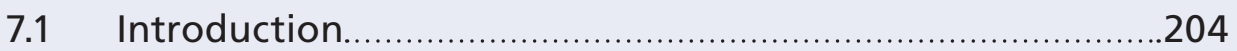

7.2 Medical card and health insurance coverage ....................205

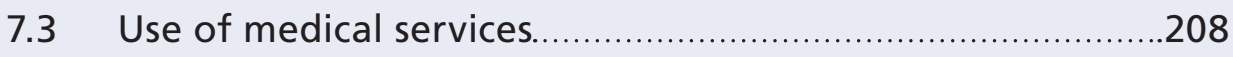

7.4 Utilisation of other state care services ….........................213

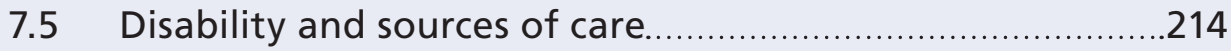

7.6 Prevalence of impairments in ADL and IADL by age and sex

7.7 State provision of meals, home help, and personal care.

7.8 Primary source of help for those with disability......

7.9. Conclusions. 


\section{Health And Social Care Utilisation}

\section{Key findings}

- Nearly all (97\%) of those aged 80 or over have medical cards that exempt them from paying fees for primary care and hospital care. This compares with $91 \%$ for people in their 70 s and $30 \%$ of those in their 50 s.

- Nearly $60 \%$ of people between 50 and 69 have private medical insurance, dropping to $46 \%$ for those in their 70 s and $32 \%$ of those over 80 .

- The likelihood of being a user of GP care rises slightly with age, but is similar for all those over 70 .

- The likelihood of having a hospital admission is similar for different ages over 60, but the length of stay increases slightly with age, and people over 80 are lower users of outpatient services than those in their 60s and 70s.

- The prevalence of disabilities rises with age from less than $10 \%$ of those between 50 and 64 to nearly $30 \%$ of those over 75 .

- People with impairments in activities of daily living (ADL) and instrumental activities of daily living (IADL) receive on average 118 hours of help per month.

- The most common primary helper for this group is the recipients' spouse, this represents a large contribution by older adults into the care of older adults.

- Only 3.5\% of people over 50 receive state provided home help services.

- Of those with both ADL and IADL impairments, $12 \%$ do not receive formal or informal help and these people constitute a potentially very vulnerable group.

\subsection{Introduction}

Access to health services depends both on medical need and the presence or absence of financial or other barriers. Some medical needs are related to age - in particular it is common for older people to have one or more chronic conditions, and the treatment and care of these conditions may be complicated by frailty or multimorbidity. This first analysis of the patterns of use of health services looks in particular at the roles of age and eligibility status on use of services. We begin by considering the usage of the main healthcare services - general practitioners (GPs) and hospitals and then go on to deal with formal and informal social care.

Entitlement to health care that is free or subsidised at the point of use in Ireland ('Entitlement Status') falls into four main categories - those with rights only to 
the main state funded services, those who have supplementary private insurance, those with medical cards (which give free access in primary and community care, exemption from co-payments in public hospitals and free drugs) and those with both private insurance and medical cards. The entitlements for those with private medical insurance vary depending on the policy that is chosen, but generally allow quicker access to some hospital services and exemption from co-payments in hospitals. Uptake of full medical cards is close to $100 \%$ of those who meet the criteria. The income threshold for medical cards is higher for those over 70 . There is a small additional category - a card giving rights to free GP care but not the other benefits, called the GP visit card. This is available for people with incomes up to $50 \%$ above the medical card limit. The uptake of the GP visit card is much lower than for the medical card but accurate data on the uptake are not available.

In this section those with main state cover only are described as having 'no additional cover', and those with both private insurance and medical cards are described as having 'dual cover'.

The TILDA survey data have been weighted to be fully representative of the older population. However, the survey in the first wave did not include those who are in residential care. Although this covers only around $2 \%$ of those over 50 , it represents a larger proportion of those in older age categories and people in residential care typically have more chronic disease. This means that the findings may understate to a small extent the use of health services, particularly in the older part of the over 50 s population. It is popularly believed that the ageing of the population will significantly increase the demands on the health sector. Studies in several countries have questioned the importance of age, and point to the large increase in use of services in the last six months of life (1). The data from TILDA presented in this chapter support the finding that age alone is not a particularly important determinant of health service utilisation.

\subsection{Medical card and health insurance coverage - the patterns of entitlement to health services free at the point of use in Ireland}

Health services in Ireland are funded mainly from taxation, which provides around around $80 \%$ of total health spending (2). However, nearly half of the population has supplementary private insurance that mainly covers in-patient services, and contributes around $8 \%$ of total health care resources. Most of the population pay out-of-pocket for primary and community services and for drugs (up to a monthly maximum), and this represents around $12 \%$ of total health care expenditure (2). These services are free for those with medical cards. 
Table 7.1 shows the pattens of health care coverage for those over 50 by age group. Entitlements are issued on the basis of income (and in a few cases particular health needs) but were available to all people over the age of 70 from 2001 to 2008 . For the purposes of presenting these numbers, the small proportion (less than $5 \%$ of card holders over 50 years of age) with GP visit cards are included in the medical card category.

Table 7.1: Health care entitlement status by age

\begin{tabular}{|c|c|c|c|c|c|c|c|c|c|c|c|c|c|c|}
\hline & & $\begin{array}{l}\text { Not } \\
\text { Jvered }\end{array}$ & & $\begin{array}{l}\text { lealth } \\
\text { urance } \\
\text { only }\end{array}$ & $\stackrel{\mathrm{M}}{\mathrm{Ca}}$ & $\begin{array}{l}\text { edical } \\
\text { d only }\end{array}$ & & $\begin{array}{l}\text { Dual } \\
\text { Eover }\end{array}$ & Total & & $\begin{array}{l}\text { All } \\
\text { edical } \\
\text {-ards }\end{array}$ & $\begin{array}{l}\text { All } \\
\text { Ins }\end{array}$ & $\begin{array}{l}\text { Health } \\
\text { urance }\end{array}$ & $\begin{array}{l}\text { Number } \\
\text { in } \\
\text { Sample }\end{array}$ \\
\hline & $\%$ & $95 \% \mathrm{Cl}$ & $\%$ & $95 \% \mathrm{Cl}$ & $\%$ & $95 \% \mathrm{Cl}$ & $\%$ & $95 \% \mathrm{Cl}$ & & $\%$ & $95 \% \mathrm{Cl}$ & $\%$ & $95 \% \mathrm{Cl}$ & $\%$ \\
\hline $50-59$ & 19 & $(17-20)$ & 51 & $(49-53)$ & 25 & $(23-27)$ & 5 & $(4-6)$ & 100 & 30 & $(28-33)$ & 56 & $(54-59)$ & 3271 \\
\hline $60-64$ & 10 & $(9-12)$ & 50 & $(47-53)$ & 31 & $(28-34)$ & 9 & $(7-11)$ & 100 & 40 & $(36-43)$ & 59 & $(56-62)$ & 1393 \\
\hline $65-69$ & 10 & $(8-12)$ & 41 & $(37-44)$ & 33 & $(30-36)$ & 17 & $(14-19)$ & 100 & 49 & $(46-53)$ & 57 & $(54-62)$ & 1197 \\
\hline 70-79 & 1 & $(1-2)$ & 8 & $(7-9)$ & 53 & $(49-56)$ & 38 & $(35-41)$ & 100 & 91 & $(89-92)$ & 46 & $(43-50)$ & 168 \\
\hline$>=80$ & 0 & $(0-1)$ & 3 & $(2-4)$ & 68 & $(64-72)$ & 29 & $(25-33)$ & 100 & 97 & $(95-98)$ & 32 & $(28-36)$ & 63 \\
\hline Total & 11 & $(10-12)$ & 37 & $(35-38)$ & 36 & $(35-38)$ & 16 & $(15-17)$ & 100 & 52 & $(52-54)$ & 53 & $(51-55)$ & 8172 \\
\hline
\end{tabular}

Some interesting patterns can be found. Despite the recent decision to withdraw the automatic entitlement to medical cards from those over 70, it remains the case that over $90 \%$ of those between 70 and 79 retained the cards, and almost all of those over 80 still have medical cards. Dual cover is rare in those between 50 and 59 but is more common in those in their 70 s.

Those between 50 and 59 have similar entitlements to those estimated for people under 50 (2), although there is a slightly higher proportion with private health insurance. Around $60 \%$ of people in their 60 s have private insurance - suggesting there may be a cohort entering the older age groups who have had and retain private cover. For those between 60 and 69 there is no apparent effect of the statutory retirement age on the proportions with private insurance but the proportion having dual cover is higher in those between 65 and 69 . Private insurance cover for those over 80 is much lower at $32 \%$.

Entitlement status may provide some insight into the patterns of health service use reported on the next page. To explore this in more detail it is necessary to look at entitlement status, age and socio-economic status, all of which affect use of health and social care. Table 7.2 shows the patterns of those with private insurance, those with medical cards (including those with dual cover) and those with neither. 
Table 7.2: Characteristics of the population aged 50 and over by entitlement status

\begin{tabular}{|c|c|c|c|c|}
\hline & $\begin{array}{c}\text { Not } \\
\text { covered } \\
\%\end{array}$ & $\begin{array}{l}\text { Medical } \\
\text { card } \\
\\
\%\end{array}$ & $\begin{array}{r}\text { Medical } \\
\text { insurance } \\
\%\end{array}$ & $\begin{array}{r}\text { Total } \\
\\
\%\end{array}$ \\
\hline \multicolumn{5}{|l|}{ Gender } \\
\hline Male & 57 & 43 & 52 & 48 \\
\hline Female & 43 & 57 & 48 & 52 \\
\hline \multicolumn{5}{|c|}{ Highest education achieved } \\
\hline Primary/none & 34 & 55 & 15 & 38 \\
\hline Secondary & 52 & 35 & 52 & 43 \\
\hline Third/higher & 15 & 9 & 33 & 19 \\
\hline \multicolumn{5}{|l|}{ Household type } \\
\hline Living alone & 16 & 32 & 12 & 23 \\
\hline Living with spouse only & 30 & 39 & 40 & 38 \\
\hline Living with others & 54 & 29 & 48 & 39 \\
\hline \multicolumn{5}{|l|}{ Employment status } \\
\hline At work & 61 & 14 & 59 & 35 \\
\hline Retired & 12 & 48 & 24 & 35 \\
\hline Other & 26 & 38 & 18 & 29 \\
\hline \multicolumn{5}{|l|}{ Self-rated physical health } \\
\hline Excellent & 15 & 9 & 22 & 14 \\
\hline Very good & 29 & 22 & 35 & 28 \\
\hline Good & 35 & 34 & 31 & 33 \\
\hline Fair & 17 & 26 & 10 & 19 \\
\hline Poor & 3 & 8 & 2 & 6 \\
\hline
\end{tabular}

The patterns are not surprising. Those with no additional entitlements typically report themselves as healthier than those with medical cards, but slightly less healthy than those with private insurance only. They are likely to be working and to have at least secondary education.

Those with medical cards are generally older, are least likely to be in good health, and are much less likely to be working. The majority of those with medical cards have only primary education, which is partly explained by their age. They are also the most likely group to be living alone.

Those with private insurance have the highest levels of education, are likely to be working and have the best self-rated health. They are the least likely to be living alone. Although complex causal relationships may underlie these figures it is clear that private insurance cover is concentrated in the part of the over 50 population with the lowest needs for care, as it is in the population as a whole (2). 
Table 7.3 shows the patterns of self-rated health by age group. As expected this shows some decline in health status with age, but most people still consider themselves in good health in each age group.

Table 7.3: Self-rated health status by age

\begin{tabular}{|c|c|c|c|c|c|c|c|c|c|c|c|c|}
\hline & \multicolumn{2}{|c|}{ Excellent } & \multicolumn{2}{|c|}{ Very Good } & \multicolumn{2}{|c|}{ Good } & \multicolumn{2}{|c|}{ Fair } & \multicolumn{2}{|c|}{ Poor } & \multirow[t]{2}{*}{ Total } & \multirow{2}{*}{$\begin{array}{l}\text { Number } \\
\text { in } \\
\text { sample }\end{array}$} \\
\hline & $\%$ & $95 \% \mathrm{Cl}$ & $\%$ & $95 \% \mathrm{Cl}$ & $\%$ & $95 \% \mathrm{Cl}$ & $\%$ & $95 \% \mathrm{Cl}$ & $\%$ & $95 \% \mathrm{Cl}$ & & \\
\hline $50-59$ & 18 & $(17-20)$ & 30 & $(29-32)$ & 31 & $(30-33)$ & 16 & $(15-17)$ & 4 & $(4-5)$ & 100 & 3273 \\
\hline $60-64$ & 14 & $(12-16)$ & 30 & $(28-33)$ & 33 & $(30-35)$ & 18 & $(16-20)$ & 6 & $(4-7)$ & 100 & 1394 \\
\hline $65-69$ & 13 & $(11-15)$ & 25 & $(22-28)$ & 35 & $(32-38)$ & 20 & $(18-23)$ & 7 & $(5-8)$ & 100 & 1198 \\
\hline 70-79 & 10 & $(8-11)$ & 24 & $(21-26)$ & 35 & $(33-38)$ & 25 & $(23-27)$ & 7 & $(6-8)$ & 100 & 1681 \\
\hline$>=80$ & 9 & $(7-11)$ & 26 & $(23-30)$ & 33 & $(29-37)$ & 25 & $(22-29)$ & 7 & $(5-9)$ & 100 & 631 \\
\hline Total & 14 & $(13-15)$ & 28 & $(27-29)$ & 33 & $(32-34)$ & 19 & $(18-20)$ & 6 & $(5-6)$ & 100 & 8177 \\
\hline
\end{tabular}

Note. $\mathrm{Cl}=$ confidence interval; Missing observations $=0.01 \%$

When these are collapsed into two categories - good and poor - the proportions declaring themselves to be in good health fall from $79 \%$ of those in their 50 s to $68 \%$ for those in their 80s.

\subsection{Use of medical services}

Table 7.4 shows the patterns of use of different types of health services by entitlement status and self-rated health. The percentages are for those who used the services at least once in the previous year. For the purposes of this presentation the five categories of self-rated health have been collapsed into two - those who consider their health good or better, and those who consider their health to be fair or poor. 
Table 7.4: Percentage of persons who utilised different types of healthcare, classified by entitlement status and self-rated health

\begin{tabular}{|c|c|c|c|c|c|c|c|c|}
\hline & \multicolumn{2}{|c|}{ GP visit } & \multicolumn{2}{|c|}{$\begin{array}{l}\text { Outpatient Clinic } \\
\text { Attendance }\end{array}$} & \multicolumn{2}{|c|}{$\begin{array}{l}\text { Emergency } \\
\text { Department } \\
\text { Attendance }\end{array}$} & \multicolumn{2}{|c|}{$\begin{array}{l}\text { Hospital } \\
\text { Admission }\end{array}$} \\
\hline & $\%$ & $95 \% \mathrm{Cl}$ & $\%$ & $95 \% \mathrm{Cl}$ & $\%$ & $95 \% \mathrm{Cl}$ & $\%$ & $95 \% \mathrm{Cl}$ \\
\hline \multicolumn{9}{|l|}{ Good health } \\
\hline Not covered & 71.1 & $(67.3-74.7)$ & 26.1 & $(22.7-29.8)$ & 11.2 & $(9.0-13.9)$ & 4.6 & $(3.2-6.5)$ \\
\hline Medical insurance & 80.9 & $(79.1-82.5)$ & 33.4 & $(31.4-35.5)$ & 10.2 & $(9.0-11.5)$ & 8.3 & $(7.3-9.4)$ \\
\hline Medical card & 91.6 & $(90.4-92.7)$ & 35.3 & $(33.2-37.4)$ & 12.0 & $(10.8-13.2)$ & 10.7 & $(9.6-11.9)$ \\
\hline Total & 84.6 & $(83.5-85.6)$ & 33.4 & $(31.9-34.9)$ & 11.1 & $(10.3-12.0)$ & 9.0 & $(8.3-9.7)$ \\
\hline \multicolumn{9}{|l|}{ Poor health } \\
\hline Not covered & 86.7 & $(80.3-91.2)$ & 51.8 & $(44.2-59.3)$ & 21.2 & $(15.3-28.5)$ & 11.2 & $(7.0-17.3)$ \\
\hline Medical insurance & 92.5 & $(89.2-94.9)$ & 62.3 & $(57.0-67.3)$ & 23.4 & $(19.4-28.0)$ & 22.4 & $(18.5-26.9)$ \\
\hline Medical card & 97.6 & $(96.5-98.4)$ & 61.3 & $(58.3-64.2)$ & 27.7 & $(25.1-30.6)$ & 26.8 & $(24.3-29.4)$ \\
\hline Total & 95.7 & $(94.6-96.6)$ & 60.7 & $(58.1-63.1)$ & 26.4 & $(24.2-28.6)$ & 24.6 & $(22.5-26.8)$ \\
\hline \multicolumn{9}{|l|}{ Total } \\
\hline Not covered & 74.3 & $(71.0-77.3)$ & 31.3 & $(28.1-34.7)$ & 13.2 & $(11.0-15.8)$ & 5.9 & $(4.4-7.8)$ \\
\hline Medical insurance & 82.3 & $(80.7-83.8)$ & 36.9 & $(35.0-39.0)$ & 11.8 & $(10.6-13.0)$ & 10.1 & $(9.0-11.2)$ \\
\hline Medical card & 93.7 & $(92.8-94.5)$ & 44.3 & $(42.5-46.2)$ & 17.5 & $(16.2-18.8)$ & 16.3 & $(15.2-17.5)$ \\
\hline Total & 87.4 & $(86.5-88.2)$ & 40.2 & $(38.8-41.6)$ & 14.9 & $(14.1-15.8)$ & 12.9 & $(12.1-13.7)$ \\
\hline
\end{tabular}

People with no additional cover and those with private insurance only are similar in terms of the age distribution, and the likelihood of being employed. However, those with private insurance are wealthier and have higher levels of education and are on average in better health. The expectation might, therefore, be that those with private insurance would make less use of health services than those with no additional cover. The opposite is the case for all types of care as discussed in more detail below. Those with medical cards are in general the oldest and sickest part of the over 50 population, and as would be expected are the highest users of services in all categories.

The most interesting comparisons are for those who declare themselves as being in poor health, where failure to access services may be more serious. For those in poor health, having a medical card makes attendance at the GP more likely. For those without medical cards, the deterrent effect of paying the full cost fee (reported in most cases to be $€ 50$ per visit) appears to be stronger in the no additional cover group than the private insurance group (probably due to the generally lower 
incomes of those with no additional cover compared to those with private insurance only).

Those in poor health with no additional cover are also less likely to go to the emergency department which may in part be because without a GP referral this incurs a $€ 100$ fee. Similarly, those with no additional cover are less likely to go to outpatient services, which again require referral by a GP or hospital doctor. In some cases it is likely that those with private insurance are going to private outpatient appointments, where getting an appointment is usually easier and waiting times are typically shorter. This suggests that for outpatient services there are more barriers to access for those with no additional cover than for the rest of the population.

Those in poor health who have a medical card are most likely to have a hospital admission, and those with no additional entitlements are the least likely. The higher rates of inpatient admission for those with private insurance compared to those with no additional cover may be because those with insurance can opt to go to private hospitals where thresholds for admission are sometimes lower than in public hospitals.

Table 7.5 shows the patterns of use of health services classified by age group and self -rated health. Again the figures shown refer to the percentage who availed of the service in question at least once in the past year. Although it is widely believed that age is a major factor in the use of services, a more complicated pattern emerges. 
Table 7.5: Percentage of persons who utilised different types of healthcare, classified by age group and self-rated health

\begin{tabular}{|c|c|c|c|c|c|c|c|}
\hline \multicolumn{2}{|c|}{ GP visit } & \multicolumn{2}{|c|}{$\begin{array}{c}\text { Outpatient } \\
\text { Clinic Attendance }\end{array}$} & \multicolumn{2}{|c|}{$\begin{array}{l}\text { Emergency } \\
\text { Department } \\
\text { Attendance }\end{array}$} & \multicolumn{2}{|c|}{$\begin{array}{l}\text { Hospital } \\
\text { Admission }\end{array}$} \\
\hline$\%$ & $95 \% \mathrm{Cl}$ & $\%$ & $95 \% \mathrm{Cl}$ & $\%$ & $95 \% \mathrm{Cl}$ & $\%$ & $95 \% \mathrm{Cl}$ \\
\hline
\end{tabular}

Good health

\begin{tabular}{|l|r|r|r|r|r|r|r|r|}
\hline $50-59$ & 77.4 & $(75.6-79.2)$ & 29.4 & $(27.5-31.4)$ & 10.3 & $(9.1-11.6)$ & 7.2 & $(6.3-8.3)$ \\
\hline $60-69$ & 86.8 & $(85.0-88.4)$ & 36.5 & $(34.1-38.9)$ & 11.7 & $(10.2-13.3)$ & 9.3 & $(8.0-10.6)$ \\
\hline $70-79$ & 93.3 & $(91.7-94.6)$ & 37.9 & $(35.0-40.9)$ & 11.7 & $(10.0-13.8)$ & 11.8 & $(10.0-13.8)$ \\
\hline$>=80$ & 95.3 & $(92.7-97.0)$ & 32.6 & $(28.1-37.5)$ & 11.8 & $(9.1-15.2)$ & 10.8 & $(8.2-14.1)$ \\
\hline Total & 84.6 & $(83.5-85.7)$ & 33.4 & $(31.9-34.9)$ & 11.1 & $(10.3-12.0)$ & 9.0 & $(8.3-9.7)$ \\
\hline
\end{tabular}

Poor health

\begin{tabular}{|l|l|l|l|l|l|l|l|l|}
\hline $50-59$ & 93.6 & $(91.3-95.3)$ & 60.5 & $(56.5-64.4)$ & 28.5 & $(24.9-32.5)$ & 23.3 & $(20.0-27.0)$ \\
\hline $60-69$ & 96.4 & $(94.5-97.6)$ & 63.9 & $(59.9-67.8)$ & 25.1 & $(21.7-28.8)$ & 23.8 & $(20.4-27.6)$ \\
\hline $70-79$ & 97.8 & $(95.8-98.8)$ & 63.8 & $(58.8-68.5)$ & 27.3 & $(23.2-31.8)$ & 26.9 & $(23.0-31.2)$ \\
\hline$>=80$ & 95.7 & $(91.6-97.8)$ & 45.3 & $(37.8-53.0)$ & 21.6 & $(16.2-28.3)$ & 25.2 & $(19.4-31.9)$ \\
\hline Total & 95.7 & $(94.6-96.6)$ & 60.7 & $(58.1-63.1)$ & 26.4 & $(24.2-28.6)$ & 24.6 & $(22.5-26.8)$ \\
\hline Total & & & & & & & & \\
\hline $50-59$ & 80.7 & $(79.1-82.1)$ & 35.7 & $(33.9-37.5)$ & 14.0 & $(12.7-15.3)$ & 10.5 & $(9.4-11.7)$ \\
\hline $60-69$ & 89.2 & $(87.8-90.5)$ & 43.3 & $(41.2-45.5)$ & 15.0 & $(13.6-16.6)$ & 12.9 & $(11.6-14.3)$ \\
\hline $70-79$ & 94.7 & $(93.5-95.7)$ & 46.1 & $(43.4-48.8)$ & 16.7 & $(14.8-18.7)$ & 16.6 & $(14.8-18.5)$ \\
\hline$>=80$ & 95.4 & $(93.4-96.9)$ & 36.7 & $(32.7-40.8)$ & 14.9 & $(12.3-18.1)$ & 15.4 & $(12.8-18.5)$ \\
\hline Total & 87.4 & $(86.5-88.2)$ & 40.2 & $(38.8-41.6)$ & 14.9 & $(14.1-15.8)$ & 12.9 & $(12.1-13.7)$ \\
\hline
\end{tabular}

For those in poor health, there is very little apparent effect of age on the likelihood of using GP services or having a hospital admission. Use of outpatient services is only slightly higher for the 70-79 age group compared to the 50-59 age group, and those over 80 are the least likely to be users of outpatient services. There is only a small increase in the likelihood of having a hospital admission between those in their 50s and 60 s and those in their 70s, and there is no difference in the likelihood of using hospital inpatient services between those aged 70-79 and those over 80 . 
For those who consider themselves to be in good health the patterns are broadly similar, with GP visits rising slowly with age, but no difference between those in their 70 s and those over 80 . There is no change in the rate of attendance at emergency departments with age. The likelihood of using outpatient services rises between those in their 50s and those in their 60s, but then peaks and falls. There is an increase overall in hospital admissions from the 50 s to the 70 s, but this is also small, and mainly reflects the larger numbers who report that they are in poor health (see Table 7.3).

There is also evidence that those in older age categories who are hospitalised spend more days in hospital. Table 7.6 shows patterns of number of days in hospital for those hospitalised, and the greater number of long stays in those over 80 suggests that these include many whose discharge is delayed by lack of suitable alternative care. Although those over 80 are less likely to have a hospital admission than those between 70 and 79, the longer stays means that the bed days (and therefore the likely cost) are similar. It is interesting, however, to note that for all age groups there are some people with long stays, and in all age categories at least $10 \%$ of those hospitalised spent 20 days or more in hospital.

Table 7.6: Number of nights in hospital for those hospitalised in the past year, classified by age

\begin{tabular}{|c|c|c|c|c|c|c|c|c|c|c|c|c|c|c|c|c|}
\hline & \multirow{2}{*}{\multicolumn{2}{|c|}{$\begin{array}{l}\text { 1-4 Nights } \\
\% \quad 95 \% \mathrm{Cl}\end{array}$}} & \multirow{2}{*}{$\begin{array}{l}5-9 \\
\%\end{array}$} & \multirow{2}{*}{$\begin{array}{l}\text { Nights } \\
95 \% \mathrm{Cl}\end{array}$} & \multicolumn{2}{|c|}{$\begin{array}{c}10-1 \\
\text { Nights } 4\end{array}$} & \multicolumn{2}{|c|}{$\begin{array}{r}15-19 \\
\text { Nights }\end{array}$} & \multicolumn{2}{|c|}{$\begin{array}{c}20-29 \\
\text { Nights }\end{array}$} & \multicolumn{2}{|c|}{$\begin{array}{r}30-39 \\
\text { Nights }\end{array}$} & \multicolumn{2}{|c|}{$\begin{array}{c}40+ \\
\text { Nights }\end{array}$} & \multirow[t]{2}{*}{ Total } & \multirow[t]{2}{*}{$\begin{array}{c}\text { Number } \\
\text { in } \\
\text { sample }\end{array}$} \\
\hline & & & & & $\%$ & $95 \% \mathrm{Cl}$ & $\%$ & $95 \% \mathrm{Cl}$ & $\%$ & $95 \% \mathrm{Cl}$ & $\%$ & $95 \% \mathrm{Cl}$ & $\%$ & $95 \% \mathrm{Cl}$ & & \\
\hline 50-59 & 54 & $(48-60)$ & 25 & $(20-30)$ & 9 & $(7-13)$ & 2 & $(1-4)$ & 5 & (3-8) & 2 & $(1-4)$ & 3 & $(1-4)$ & 100 & 334 \\
\hline 60-64 & 44 & $(36-52)$ & 27 & $(20-35)$ & 15 & $(10-21)$ & 5 & $(2-10)$ & 5 & $(2-10)$ & 1 & $(0-5)$ & 4 & $(0-5)$ & 100 & 160 \\
\hline $65-69$ & 43 & $(36-51)$ & 35 & $(27-43)$ & 10 & $(6-16)$ & 1 & $(0-4)$ & 7 & $(4-12)$ & 2 & $(1-6)$ & 2 & $(1-6)$ & 100 & 171 \\
\hline $70-79$ & 40 & $(34-46)$ & 25 & $(20-31)$ & 14 & $(10-19)$ & 4 & $(2-7)$ & 8 & $(5-12)$ & 3 & $(2-7)$ & 6 & $(2-7)$ & 100 & 282 \\
\hline$>=80$ & 35 & $(25-46)$ & 25 & $(17-35)$ & 16 & $(10-25)$ & 3 & $(1-8)$ & 10 & $(5-18)$ & 5 & $(2-12)$ & 6 & $(2-12)$ & 100 & 96 \\
\hline Total & 45 & $(42-48)$ & 27 & $(24-30)$ & 12 & $(10-14)$ & 3 & $(2-4)$ & 7 & $(5-8)$ & 3 & $(2-4)$ & 4 & $(2-4)$ & 100 & 1043 \\
\hline
\end{tabular}

Note: $\mathrm{Cl}=$ confidence interval; Missing observations $=0.29 \%$

What is striking is the small difference in number of days in hospital for those hospitalised between those in their 70s and those in their $80 \mathrm{~s}$. The survey does not include those normally resident in nursing homes or hospital. Those normally in residential care are likely to display different patterns of service use since they are typically more dependent, but may also be less vulnerable since some of the support they need is available within the nursing home or hospital. 


\subsection{Utilisation of other state care services}

We now turn to care services other than those provided by GPs and hospitals.

Respondents were asked which other state services they had utilised in the past year, excluding services where the respondent had paid more than a nominal amount. Table 7.7 shows how these other state provided health and social care services are utilised by people over 50 . The utilisation rates vary from $13 \%$ for optician services to less than $1 \%$ for speech and language therapy, social workers and respite services. There is a strong age gradient: about $31 \%$ of the youngest age group avail of at least one of the services listed compared with $60 \%$ of those aged 80 or over. It is still striking that as many as $40 \%$ of the oldest age group did not avail of any of the services in the past year. The final column of the table shows the percentage of respondents receiving each service who reported that they were satisfied with it. The levels of satisfaction are very high.

Table 7.7: Percentage of the population availing of different social services in the past year, classified by age, and percentage satisfied with the service

\begin{tabular}{|c|c|c|c|c|c|c|}
\hline & $\begin{array}{l}\text { Age } \\
\text { group } \\
50-59 \\
\%\end{array}$ & $\begin{array}{r}\text { Age } \\
\text { group } \\
60-69 \\
\%\end{array}$ & $\begin{array}{r}\text { Age } \\
\text { group } \\
\text { 70-79 } \\
\%\end{array}$ & $\begin{array}{r}\begin{array}{c}\text { Age } \\
\text { group } \\
>=80 \\
\%\end{array}\end{array}$ & $\begin{array}{r}\text { Total } \\
\%\end{array}$ & $\begin{array}{l}\text { Satisfied } \\
\text { with } \\
\text { service } \\
\%\end{array}$ \\
\hline Public Health or Community Nurse & 2.2 & 3.7 & 11.8 & 24.9 & 6.6 & 90 \\
\hline Occupational therapy & 0.9 & 1.3 & 2.2 & 3.2 & 1.5 & 93 \\
\hline Chiropody services & 1.3 & 2.2 & 9.8 & 15.6 & 4.5 & 88 \\
\hline Physiotherapy services & 3.9 & 5.1 & 7 & 6.9 & 5.2 & 88 \\
\hline Speech and language therapist & 0.2 & 0.2 & 0.4 & 0.2 & 0.2 & 93 \\
\hline Social work services & 0.3 & 0.1 & 0.4 & 0 & 0.3 & 89 \\
\hline Psychological/counselling services & 1.4 & 0.5 & 0.6 & 0.1 & 0.8 & 94 \\
\hline Home help & 0.5 & 1.3 & 6.2 & 19.2 & 3.5 & 94 \\
\hline Personal care attendant & 0.1 & 0.2 & 0.9 & 3.3 & 0.6 & 95 \\
\hline Meals-on-Wheels & 0.1 & 0.3 & 2.4 & 3.3 & 0.9 & 94 \\
\hline Day centre services & 0.3 & 0.6 & 1.6 & 6.8 & 1.2 & 97 \\
\hline Optician service & 7.9 & 10.7 & 20.9 & 18.5 & 12.3 & 96 \\
\hline Dental services & 9.8 & 11.6 & 12.0 & 8.7 & 10.7 & 92 \\
\hline Hearing services & 0.8 & 1.4 & 2.9 & 5.3 & 1.8 & 86 \\
\hline Dietician services & 1.1 & 1.6 & 2.3 & 0.3 & 1.5 & 95 \\
\hline Respite services & 0.2 & 0.3 & 0.8 & 1.1 & 0.5 & 90 \\
\hline
\end{tabular}




\subsection{Disability and sources of care}

The following section broadens the definition of care to cover help received from both formal and informal sources. Informal help refers to unpaid assistance offered by family, friends, and neighbours. Formal services refer to various paid services, whether provided by the state or by private or non-profit organisations, such as those considered in the preceding section. We focus in particular on the relationship between care received and care need, as indicated by two widely used measures of one's capacity to carry out normal daily activities. The overall prevalence of disability is first discussed and we then go on to consider the relationship between disability and three of the state provided formal services mentioned above. The final section examines the extent and sources of informal care and how receipt of care varies with disability type.

\subsection{Prevalence of impairments in ADL and IADL by age and sex}

This section describes the prevalence of disability in the Irish population aged 50 and over. Disability is here defined as difficulty in carrying out normal daily activities, referred to as activities of daily living (ADL) and instrumental activities of daily living (IADL). ADL are the basic tasks of everyday life that pertain to personal care, such as eating, bathing, dressing, toileting, and moving about. The original ADL scale was developed by Katz and colleagues (3) who described ADL as 'activities which people perform habitually and universally'. IADL are activities performed by a person in order to live independently in a community setting, such as managing money, shopping, using the telephone, housekeeping, preparing meals, and taking medications correctly. The IADL scale used in TILDA is derived from a set of validated questions developed by Lawton and Brody (4).

Table 7.8 shows the proportions of the population with limitations in ADL only, IADL only and having both ADL and IADL limitations. Overall, $12 \%$ of men and $14 \%$ of women aged 50 and over have at least one such disability. There is a clear age gradient as the prevalence is greater at older ages and in each age group, women are more likely to have limitations than men. The prevalence of limitations in the oldest age group is $23 \%$ for men ( $9 \%$ with ADL only, $6 \%$ with IADL only and $8 \%$ with IADL and ADL difficulties), while for women it is $32 \%$ ( $6 \%$ with ADL only, $12 \%$ with IADL only and $14 \%$ with IADL and ADL difficulties). 
Table 7.8: Prevalence of disability by age and sex

\begin{tabular}{|c|c|c|c|c|c|c|c|c|c|c|}
\hline & \multicolumn{2}{|c|}{ Not disabled } & \multicolumn{2}{|c|}{$\begin{array}{c}\text { ADL disability } \\
\text { only }\end{array}$} & \multicolumn{2}{|c|}{$\begin{array}{l}\text { IADL disability } \\
\text { only }\end{array}$} & \multicolumn{2}{|c|}{$\begin{array}{c}\text { IADL and } \\
\text { ADL disability }\end{array}$} & \multirow{2}{*}{ Total } & \multirow{2}{*}{$\begin{array}{l}\text { Number } \\
\text { in sample }\end{array}$} \\
\hline & $\%$ & $95 \% \mathrm{Cl}$ & $\%$ & $95 \% \mathrm{Cl}$ & $\%$ & $95 \% \mathrm{Cl}$ & $\%$ & $95 \% \mathrm{Cl}$ & & \\
\hline \multicolumn{11}{|l|}{ Male } \\
\hline $50-64$ & 92 & (91-93) & 4 & $(4-5)$ & 2 & $(1-3)$ & 2 & $(1-2)$ & 100 & 2,081 \\
\hline $65-74$ & 88 & $(86-90)$ & 7 & $(5-9)$ & 2 & $(1-3)$ & 3 & $(2-5)$ & 100 & 1,070 \\
\hline$>=75$ & 77 & $(73-80)$ & 9 & $(7-12)$ & 6 & $(4-8)$ & 8 & $(6-11)$ & 100 & 598 \\
\hline Total & 89 & $(87-90)$ & 6 & $(5-7)$ & 3 & $(2-3)$ & 3 & $(2-4)$ & 100 & 3,749 \\
\hline \multicolumn{11}{|c|}{ Female } \\
\hline $50-64$ & 92 & $(90-93)$ & 3 & $(2-4)$ & 3 & $(2-4)$ & 3 & $(2-3)$ & 100 & 2,587 \\
\hline $65-74$ & 87 & $(85-89)$ & 5 & $(4-7)$ & 4 & $(3-5)$ & 4 & $(3-5)$ & 100 & 1,093 \\
\hline$>=75$ & 68 & $(65-72)$ & 6 & $(4-8)$ & 12 & $(10-15)$ & 14 & $(11-17)$ & 100 & 749 \\
\hline Total & 86 & $(84-87)$ & 4 & $(3-5)$ & 5 & $(4-6)$ & 5 & $(5-6)$ & 100 & 4,429 \\
\hline \multicolumn{11}{|l|}{ Total } \\
\hline $50-64$ & 92 & $(91-93)$ & 4 & (3-4) & 2 & $(2-3)$ & 2 & $(2-3)$ & 100 & 4,668 \\
\hline $65-74$ & 87 & $(86-89)$ & 6 & $(5-7)$ & 3 & $(2-4)$ & 4 & $(3-5)$ & 100 & 2,163 \\
\hline$>=75$ & 72 & $(69-74)$ & 7 & (6-9) & 10 & $(8-12)$ & 11 & $(10-14)$ & 100 & 1,347 \\
\hline Total & 87 & $(86-88)$ & 5 & $(4-5)$ & 4 & (3-4) & 4 & $(4-5)$ & 100 & 8,178 \\
\hline
\end{tabular}

Note: $\mathrm{Cl}=$ confidence interval; Missing observations $=0.00 \%$

\subsection{State provision of meals, home help, and personal care}

This section examines the proportions of community living older people who receive three types of state-provided home services: home helps (also referred to as home care workers whose tasks are mainly oriented to household tasks i.e., help with IADL); meals services (most commonly meals-on-wheels) and the services provided by personal care attendants (typically help with ADL and some nursing).

Table 7.7 showed that 3.5\% of older people received home help services in the past year, while $1 \%$ of the population had the help of a state-provided personal care attendant and around $1 \%$ received meals on wheels. Figure 7.1 illustrates this use by the reported level of disability. Some use of services in the past year was made by individuals with no reported impairments in ADLs or IADLs. This may reflect the temporary nature of the impairment that led to the allocation of the service, or that the service had been provided on the basis of a judgement including factors other than an individual's disability. Among those with impairments in both ADLs and 
IADLs, these services were used by $24 \%, 8 \%$ and $5 \%$ of people respectively.

Figure 7.1: Percentage of the population receiving home help service, meals on wheels and personal care attendant services by level of disability

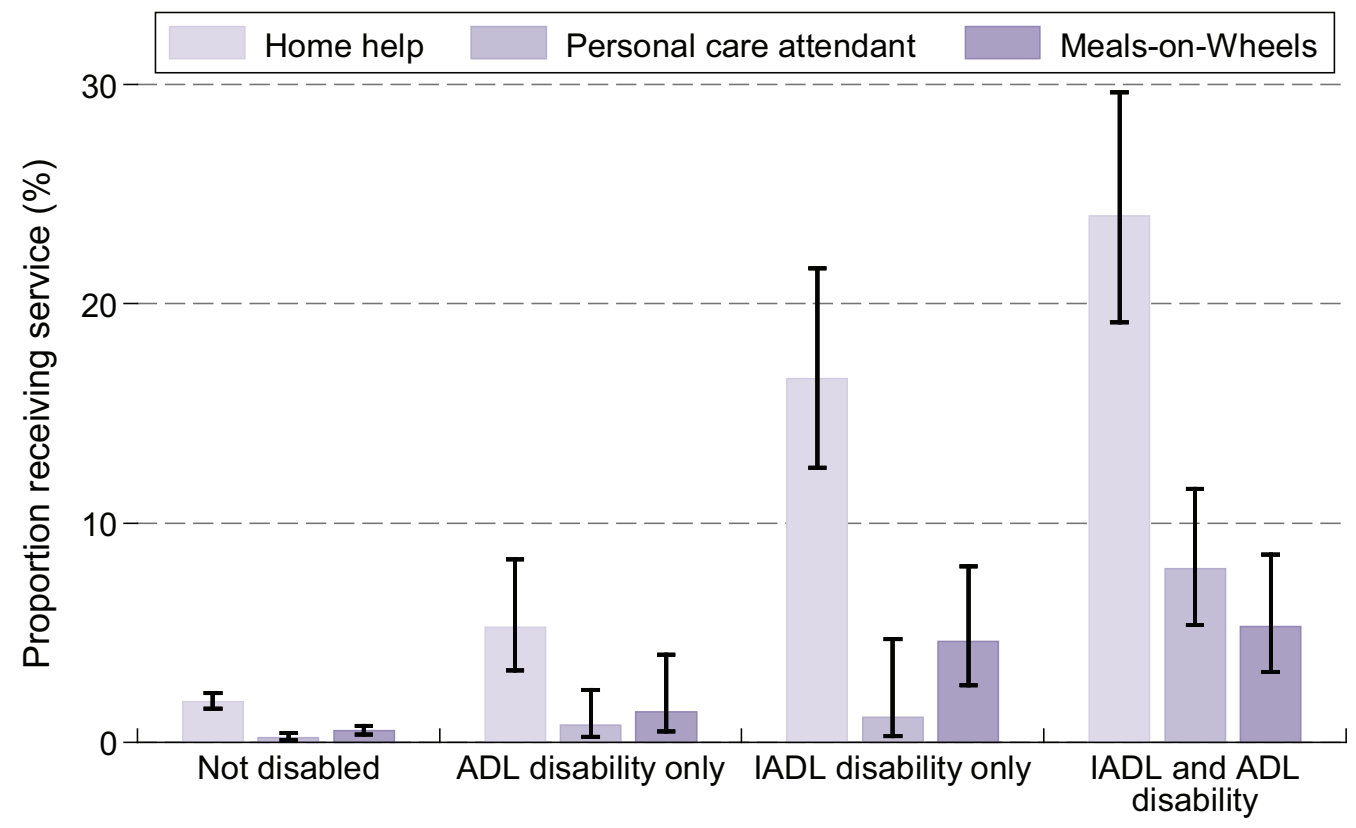

Note. $\mathrm{N}=8178$; Missing obs = 0; Error bars correspond to $95 \%$ confidence intervals

\subsection{Primary source of help for those with disability}

TILDA respondents with disabilities were asked to identify up to twelve formal and informal helpers, and to specify which of these was their primary carer. Of those with only ADL limitations, $83 \%$ did not receive any help, $13 \%$ were primarily helped by their spouse, $3.5 \%$ by a child, and $0.5 \%$ by a non-family member. The proportion of those who did not receive any help is high, but it should be noted that $80 \%$ of those with only ADL difficulties reported 'difficulties with dressing, including putting on shoes'. The fact that they did not report any difficulties with IADL suggests that these individuals have difficulties for example in bending down to put on shoes or lacing them, but no major problems that would impact on their ability to live independently.

Of those with IADL limitations, $26 \%$ received no help, $28 \%$ were primarily helped by a spouse, $26 \%$ by a child, $5 \%$ by relatives other than spouse and children, and $14 \%$ by non-family members. For those with combined IADL and ADL limitations, $12 \%$ did not receive any help, 33\% were primarily helped by a spouse, $31 \%$ by children, $3 \%$ by other relatives, and $20 \%$ by non-family members. 
The category "non-family members" includes both informal carers such as neighbours and friends and formal carers such as those paid privately, those paid by the state and those provided by non-profit bodies. The relatively low numbers in this "non-family" category emphasises the heavy predominance of informal sources, and in particular spouses and children in providing care for older people.

\subsection{Conclusions}

The patterns of entitlements and use of health services shows some influence of entitlement on use of services, and some effects of age, but overall it is clear that age has only modest effects on patterns of service use compared to self-reported health status. Despite the widely held belief that ageing will lead to large increases in the demands for hospital care which will be hard to accommodate, the evidence from TILDA suggests that increased demands will be modest, and will be driven primarily by the health of the population as opposed to the age structure. As found in other studies $(1,5)$ the most pressing effects of ageing are likely to be on demands for a range of community-based health and social care services.

As the population ages, planning for formal and informal care becomes a major policy issue. The results presented above show that $12 \%$ of men and $14 \%$ of women aged 50 and over have at least one limitation in daily activities. For those with limitations in daily and instrumental daily activities, the principal source of help is family members.

The severity of impairments in instrumental and daily activities is associated with the number of hours of care. Preliminary analysis suggests that people with both ADL and IADL difficulties receive on average 118 hours of help per month (data not shown) and this will be the focus of detailed further investigation. As the most common primary helper for this group is the care recipient's spouse, this represents a large contribution by older adults into the care of other older adults, a finding that calls for further research and policy interventions for the growing number of older carers (6).

For only $5 \%$ of people with ADL difficulties only, $13 \%$ of people with IADL difficulties only and $20 \%$ of people with both ADL and IADL the primary source of personal care was a non-family member. Some of these helpers are friends and neighbours, and some are formal (i.e. paid) care workers. The $12 \%$ who do not receive any help from formal or informal sources despite having both ADL and IADL difficulties constitute a potentially very vulnerable group, and further analysis of TILDA data will enable us to characterise this population, with the view to enabling the planning of services targeted at them.

Only a minority of older people with ADL and IADL difficulties receive formal care from the State, such as home help and meals-on-wheels. Four per cent of people over 50 received some state-provided home help services in the past year. 
A full examination of the relationship between need for care and the factors that determine the allocation of services in the population is beyond the scope of this report but will be the subject of future analyses.

\section{References}

1. Mcgrail K, Green B, Barer ML, Evans RG, Hertzman C, Normand C. Age, costs of acute and long-term care and proximity to death: evidence for 1987-88 and 199495 in British Columbia. Age Ageing. 2000 ;29(3):249-253.

2. Report of the Expert Group on Resource Allocation and Financing in the Health Sector (Ruane Report). Dublin: DOHC; 2010.

3. Katz S, Ford AB, Moskowitz RW, Jackson BA, Jaffe MW. Studies of illness in the aged, the index of ADL: A standardized measure of biological and psychosocial function. JAMA. 1963 21;185:914-919.

4. Lawton MP, Brody EM. Assessment of Older People: Self-Maintaining and Instrumental Activities of Daily Living. The Gerontologist. 1969;9(3 Part 1):179 $-186$.

5. Werblow A, Felder S, Zweifel P. Population ageing and health care expenditure: a school of "red herrings"? Health Econ. 2007 Oct;16(10):1109-1126.

6. Wren M-A. The Older Carer [Internet]. SPARC; 2010. Available from: http://sparc. tcd.ie/docs/The_Older_Carer.pdf 


\section{Retirement And Labour Market Participation}

Irene Mosca and Alan Barrett

\section{Contents}

8.1 Introduction

8.2 Labour market status of older adults in Ireland: an overview.

8.3 Determinants of labour market status of men and women aged 50 to 64

8.4 Labour market status of men and women aged 65 to 74

8.5 Working conditions of employees

aged 50 and above

8.5.1 Workplace discrimination 230

8.5.2 Hours at work and wind-down 230

8.5.3 Expected retirement age. 231

8.5.4 Pension coverage. 233

8.6 Conclusions .235 


\section{Retirement And Labour Market Participation}

\section{Key findings}

- Among those aged 50 to $64,62 \%$ of men and $46 \%$ of women are at work compared to $16 \%$ of men and $8 \%$ of women aged 65 to 74 .

- Of men aged 65 to $74,82 \%$ describe themselves as retired, compared to $52 \%$ of women. However, $36 \%$ of women aged 65 to 74 report that they are 'looking after home or family'.

- For those below the State Pension Age:

- Labour supply of older adults aged 50 to 64 in Ireland is concentrated amongst the healthiest, most educated, wealthiest and most satisfied with life.

- For example, $53 \%$ of men and $28 \%$ of women with primary or no education are employed, compared to $70 \%$ of men and $62 \%$ of women with tertiary or higher education.

- In the poorest quartile of this population, $34 \%$ of women and $38 \%$ of men are at work compared to $59 \%$ of women and $71 \%$ of men in the richest quartile.

- The average number of hours worked decreases as workers move closer to age 65 , suggesting some form of 'wind-down' in advance of retirement.

- Around $25 \%$ of male and female employees expect to retire before state pension age (65). Retirement expectations are different for different education groups, with the more highly educated expecting to retire earlier.

- Of female employees, $41 \%$ are not covered by an occupational, PRSA (Personal Retirement Savings Account) or private pension scheme compared to $20 \%$ of male employees.

- Pension coverage varies by group. Among higher professionals, $78 \%$ are covered by an occupational pension, compared to $32 \%$ of unskilled workers.

- Of those currently at work, $96 \%$ of women and $98 \%$ of men report that they are not affected by any kind of workplace discrimination.

\subsection{Introduction}

Labour market participation of older people is important from the perspective of the individual and the macroeconomy. At an individual level, participation in the labour market can be associated with increased resources and enhanced levels of life satisfaction if work is a source of positive social contact and engagement. At 
the level of the macroeconomy, higher levels of participation among older people translate into a bigger labour force and so increased output ${ }^{1}$. If higher participation is combined with the later payment of pensions, reductions in pensions can be achieved. Increasing the labour market participation of older people is increasingly viewed as a prerequisite for tackling the long-run costs associated with population ageing and this policy objective is reflected in the National Pensions Framework (1). Given this context, it is important to understand the patterns and determinants of labour market participation among those aged 50 and over in Ireland.

This chapter examines the issue of labour market participation from a number of perspectives. Section 8.2 provides a general overview of the labour market status of individuals aged 50 to 64 and aged 65 to 74 in Ireland. The extent to which patterns of employment of men and women aged 50 to 64 and 65 to 74 vary with health, education, wealth and life satisfaction is explored in detail in Sections 8.3 and 8.4. Section 8.5 explores the working conditions for older people in Ireland. Among the issues investigated are workplace discrimination, the pattern of hours worked by age, expectations regarding retirement age and pension coverage. Section 8.6 provides some conclusions.

\subsection{Labour market status of older adults in Ireland: an overview}

Self-reported labour market status reflects individuals' perceptions about their role in the labour market. TILDA respondents are asked to choose the status that best describes their current situation, including: retired; employed (including unpaid work in family business, temporarily away from work, or participating in an apprenticeship or an employment programme such as Community Employment); self-employed; unemployed; permanently sick or disabled; looking after home or family; in education or training; and other. If they answer "other", they are asked to specify their status in more details. Most respondents answering "other" do not see themselves as falling in one single category. For example, they are working for a few hours per week, are not in good health but do not see themselves as permanently sick or disabled and are caring for a family member.

Table 8.1 shows that the distribution of men and women in: employment, retirement, looking after family or home, and falling into the other category varies significantly by sex and age group. For the purpose of this analysis, the other category includes those who regard themselves as being unemployed, permanently sick or disabled, in education and training and other. (For a more detailed breakdown, see Table A8.1).

Of those aged 50 to $64,62 \%$ of men and $46 \%$ of women are at work. This is similar to findings from the 2004 wave of the Survey of Health and Retirement in Europe

1 At a time of recession, it might be argued that the demand for labour is below supply and so additional supply, through higher participation, will not lead to an increase in output. While there might be some truth in this argument, the argument here applies over the longer term during which time periods of excess labour demand may also apply. 
(SHARE), which show that the employment rate for men aged between 50 and 65 is $62 \%$ compared to $43 \%$ for women for the ten European countries studied (2).

As expected, the proportion of men and women at work decreases significantly with age. Between the ages of 65 and $74,16 \%$ of men and $8 \%$ of women are in employment, while $82 \%$ of men and $52 \%$ of women report themselves as retired. Another $36 \%$ of women aged 65 to 74 are looking after home or family, while men almost never describe themselves as such. The vastly different proportions of men and women who report being retired most likely reflects a difference in perception of retirement as opposed to a substantive difference across the sexes.

Among men aged 75 and over, $11 \%$ are still employed, with farmers making up most of this group (84\%).

Table 8.1: Labour market status by sex and age group

\begin{tabular}{|c|c|c|c|c|c|c|c|c|c|}
\hline \multicolumn{2}{|c|}{ Employed } & \multicolumn{2}{|c|}{ Retired } & \multicolumn{2}{|c|}{$\begin{array}{l}\text { Looking after } \\
\text { family/home }\end{array}$} & \multicolumn{2}{|c|}{ Other } & \multirow{2}{*}{ Total } & \multirow{2}{*}{$\begin{array}{l}\text { Number in } \\
\text { sample }\end{array}$} \\
\hline$\%$ & $95 \% \mathrm{Cl}$ & $\%$ & $95 \% \mathrm{Cl}$ & $\%$ & $95 \% \mathrm{Cl}$ & $\%$ & $95 \% \mathrm{Cl}$ & & \\
\hline
\end{tabular}

Male

\begin{tabular}{|c|c|c|c|c|c|c|c|c|c|c|}
\hline $50-64$ & 62 & $(60-65)$ & 14 & $(12-15)$ & 1 & $(1-2)$ & 23 & $(21-25)$ & 100 & 2081 \\
\hline $65-74$ & 16 & $(14-19)$ & 82 & $(79-84)$ & 0 & $(0-1)$ & 2 & $(1-3)$ & 100 & 107 \\
\hline$>=75$ & 11 & $(8-14)$ & 87 & $(84-90)$ & 0 & $(0-1)$ & 2 & $(1-3)$ & 100 & \\
\hline Total & 44 & $(42-45)$ & 41 & $(39-43)$ & 1 & $(1-1)$ & 15 & $(13-16)$ & 100 & \\
\hline
\end{tabular}

Female

\begin{tabular}{|c|c|c|c|c|c|c|c|c|c|c|}
\hline $50-64$ & 46 & $(44-49)$ & 11 & $(10-13)$ & 27 & $(25-29)$ & 16 & $(14-17)$ & 100 & 2587 \\
\hline $65-74$ & 8 & $(7-10)$ & 52 & $(49-56)$ & 36 & $(32-39)$ & 4 & $(3-5)$ & 100 & 1093 \\
\hline$>=75$ & 1 & $(1-2)$ & 55 & $(50-59)$ & 40 & $(35-44)$ & 4 & $(3-6)$ & 100 & 749 \\
\hline Total & 28 & $(27-30)$ & 30 & $(28-32)$ & 31 & $(29-33)$ & 10 & $(9-12)$ & 100 & 4429 \\
\hline
\end{tabular}

Total

\begin{tabular}{|c|c|c|c|c|c|c|c|c|c|c|}
\hline 50-64 & 54 & $(53-56)$ & 12 & $(11-14)$ & 14 & $(13-15)$ & 19 & $(18-21)$ & 100 & 4668 \\
\hline $65-74$ & 12 & $(10-14)$ & 67 & $(64-69)$ & 18 & $(17-20)$ & 3 & $(2-4)$ & 100 & 2163 \\
\hline$>=75$ & 5 & $(4-7)$ & 68 & (64-71) & 24 & $(21-27)$ & 3 & $(2-4)$ & 100 & 1347 \\
\hline Total & 36 & $(34-37)$ & 35 & $(34-37)$ & 17 & $(16-18)$ & 12 & $(12-13)$ & 100 & 8178 \\
\hline
\end{tabular}

Note. $\mathrm{Cl}=$ confidence interval; Missing observations $=0.00 \%$ 


\subsection{Determinants of labour market status of men and women aged 50 to 64}

Table 8.1 showed that $62 \%$ of men and $46 \%$ of women aged 50 to 64 are currently at work. Self-employment is more common among men ( $41 \%$ of those at work) than women (12\%, see section 8.5.2). The drivers of employment at older ages are complex. Previous studies have suggested that determinants of employment of older people include: mental and physical health; level of education; wage opportunities; type of employment; overall wealth; financial incentives in both public and private pension schemes; preferences for work; job satisfaction; and family responsibilities or arrangements. The extent to which employment status is associated with health, education, wealth and life satisfaction in those aged 50-64 is described below.

\subsubsection{Employment and health}

Health strongly affects an individual's ability and willingness to work at older ages. Several international studies have shown that there is a strong positive association between health and employment $(3,4)$. The 2004 wave of SHARE has shown that the employment rate of European individuals aged 50 and above is much lower for people who report having a disease or severe restrictions in activities of daily living or perceiving themselves to have poor health $(2,5)$. Also, results from the 2002 wave of the ELSA survey have shown that self-reported employment status is lower for individuals in poorer health. For example, English men before State Pension Age (SPA) who report being in excellent, very good or good health are between 35 and 40 percentage points more likely to be active than those who are in fair or poor health $(6$, p.130).

TILDA respondents are asked to rate their health on a five-point scale (excellent, very good, good, fair, poor). For the purpose of this analysis, three groups are identified: (a) those claiming to be in excellent, very good or good health; and (b) those reporting fair health; and (c) those claiming to be in poor health.

Figure 8.1 suggests that health is very strongly correlated with employment for those aged 50-64, with people reporting their health as poor very unlikely to be in employment. Focusing firstly on men, $69 \%$ of those in excellent, very good or good health are employed. For men in fair and poor health, the employment rate is $43 \%$ and $17 \%$, respectively. For women, a similar pattern holds. Among women in excellent, very good or good health, $52 \%$ are employed but for women in fair and poor health, only $30 \%$ and $9 \%$ are employed, respectively. 
Figure 8.1: Proportion of the population aged 50-64 at work by self-rated health status and sex

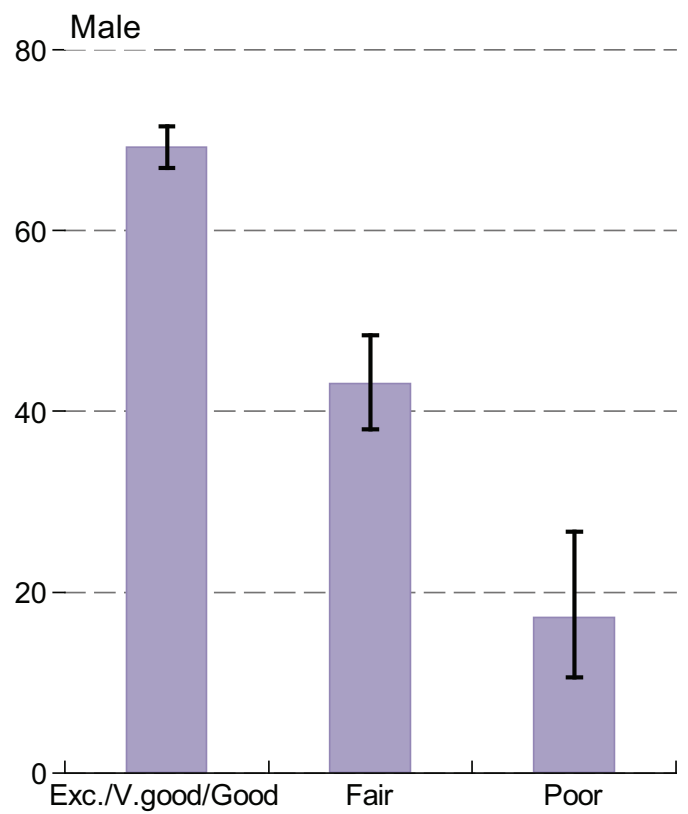

\section{Female}

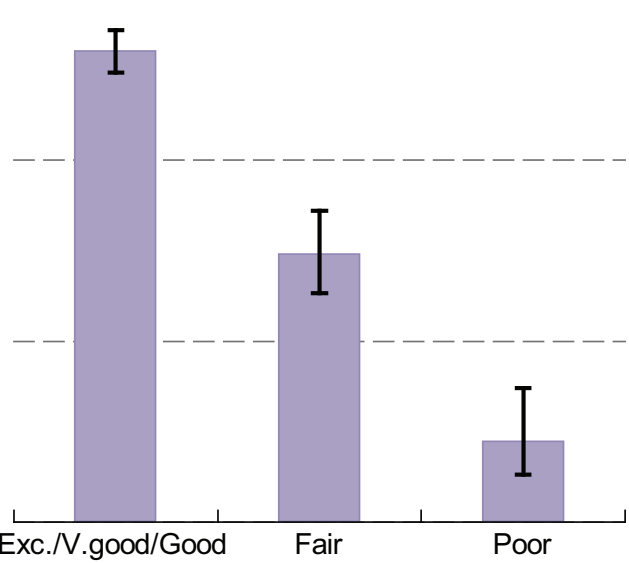

Note. $\mathrm{N}=4667$; Missing obs = 1; Error bars correspond to $95 \%$ confidence intervals

\subsubsection{Employment and education}

Previous studies suggest that there is a positive association between education and employment. For example, Kakwij and Vermeulen (7) used the first wave of SHARE data and found that all other things being equal, the higher the level of education an individual has, the higher is the probability of labour market participation. Avendano, Jürges, and Mackenbach (8) used Wave 1 and 2 of SHARE and found that low educational attainment is associated with a lower probability of being employed in all European regions. Haider and Loughran (9) used the 1991-1999 waves of the Current Population Survey and the 1998 wave of the HRS survey to investigate the labour market status of Americans aged 50 and above. They found that labour force participation is higher at higher levels of education at all ages, ranging from $23 \%$ for dropouts to $62 \%$ for those with more than a college level education (p. 10).

In TILDA, education is measured by the highest level of formal education achieved. Irish-specific levels are reclassified into three categories: primary/none (not complete or primary or equivalent), secondary (intermediate/junior/group certificate or equivalent and leaving certificate or equivalent) and third/higher (diploma/ certificate, primary degree and postgraduate/higher degree).

Figure 8.2 shows that a clear education gradient exists: more educated respondents are more likely to be in employment between the ages of 50 and 64, and the 
strength of the association appears particularly strong for women. Looking at men first, the proportion who are employed rises from $53 \%$ for those with primary education to $65 \%$ for those with secondary education and to $70 \%$ for the third level group. For women, this employment-education gradient starts at $28 \%$, increases to $47 \%$ for those with second level education and then increases to $62 \%$ for those with third level education.

Figure 8.2: Employment rate by educational attainment and sex in those aged 50-64

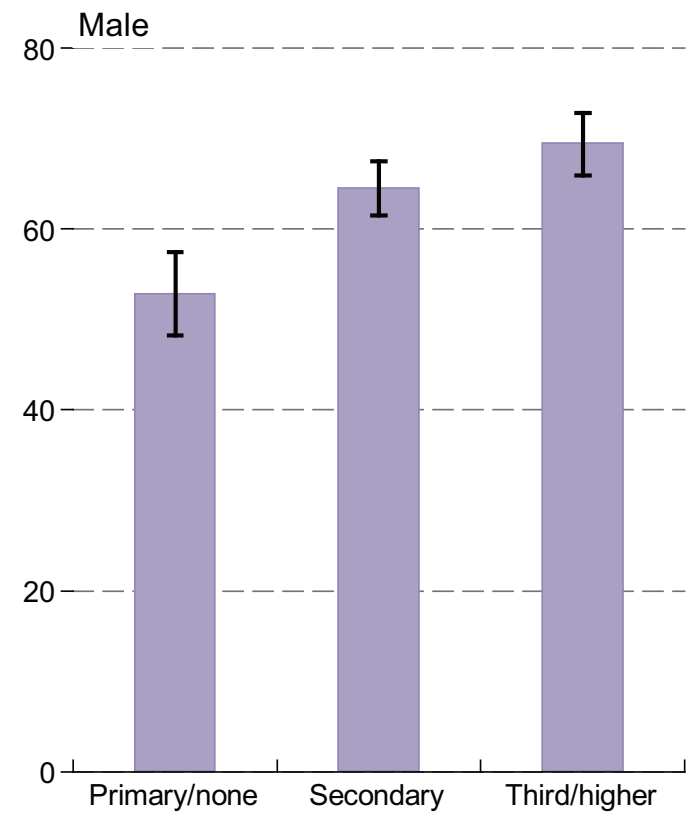

Female

Note. $\mathrm{N}=4668$; Missing obs = 0; Error bars correspond to $95 \%$ confidence intervals

\subsubsection{Employment and wealth}

The association between wealth and labour market status has also been widely investigated in the literature. It is possible that older people choose to remain at work because of poor financial circumstances, however, Haider and Loughran (9) found that the wealthiest Americans are more likely to be working than the poorest at all ages, and that the difference in labour force participation between the richest and poorest groups (quintiles) increases with age. Banks and Casanova (6) investigated the relationship between inactivity and wealth of English men aged 50 to 64 . Contrary to Haider and Loughran (9), they found that inactivity rates exhibit a U-shaped pattern by wealth. Looking across five wealth quintiles, the lowest two wealth groups are most likely to be inactive, but not retired. The highest two wealth groups are most likely to inactive and retired, while those in the middle of the wealth distribution are most likely to be at work. They also found that the association between inactivity and wealth flattens considerably at older ages, with men remaining in work being concentrated at either extreme of the wealth distribution (i.e., in the poorest or richest quintile). 
TILDA respondents are asked to provide information on their gross assets, including self-valuation of: current residence, properties other than current residence; cars; savings; other financial assets; and other assets including businesses and land. For the purpose of this analysis, wealth is defined as the sum of gross assets and respondents are divided in wealth quartiles.

Figure 8.3 shows that there is a consistent positive association between employment and wealth, especially for women. Of women who fall in the poorest quartile, $34 \%$ are in employment, compared to $41 \%$ in the second quartile, $46 \%$ in the third quartile and $59 \%$ in the richest quartile. Of men who fall in the poorest quartile, $38 \%$ are in employment, compared to $50 \%$ in the second quartile and $71 \%$ in both the third and richest quartiles.

Figure 8.3: Employment rate by wealth quartile and sex in those aged 50-64

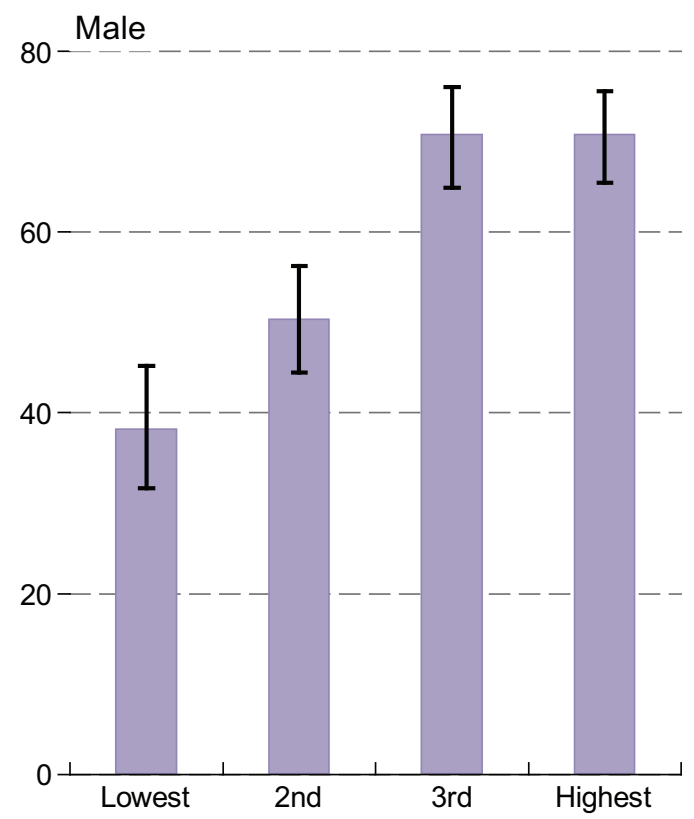

Female

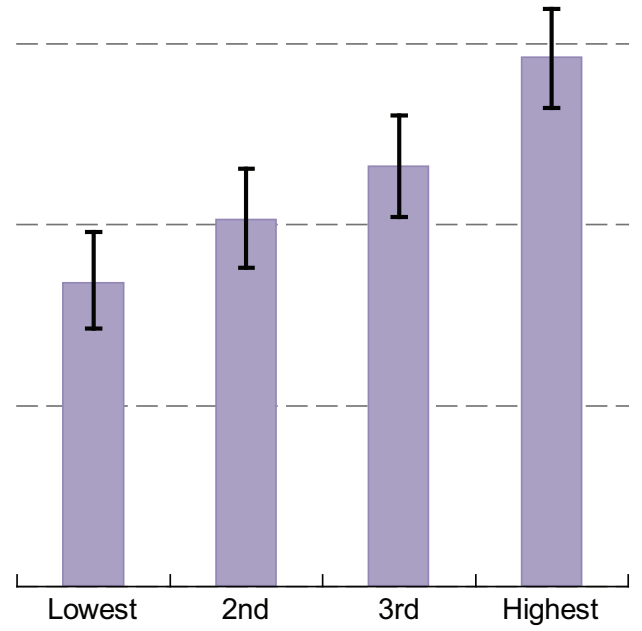

Note. $\mathrm{N}=2377$; Missing obs $=2291$; Error bars correspond to $95 \%$ confidence intervals

\subsubsection{Employment and life satisfaction}

Previous studies have suggested that working to an older age has positive physical and psychological effects. This may be due to work being an opportunity for active engagement $(10,11)$. Calvo (12) exploited the longitudinal dimension of the Health and Retirement Survey (HRS) and found that longer working lives have beneficial effects on individuals' physical and psychological well-being. However, the type of job undertaken was found to be a critical factor, with undesirable jobs washing out the potential favourable effects of work. On the other hand, results from SHARE suggest that contented employees tend to work longer. Individual responsibility 
and professional recognition also act as incentives to postpone retirement (13. p.8). Calvo, Haverstick, and Sass (14) studied the HRS cohort of respondents who were fully employed in 1992 and fully retired by 2004. They found that what matters for individuals' happiness is not the type of transition to retirement (e.g. gradual versus full retirement) but whether the transition is perceived as chosen or imposed.

TILDA respondents are asked whether they agree or disagree with the statement "I am satisfied with my life". Alternatives are presented on a show card ranging from one (strongly agree) to seven (strongly disagree). Around $80 \%$ of male respondents aged 50 to 64 give a response of one or two. Around $10 \%$ give a response of three and the remaining $10 \%$ give a response of four or above. Hence, the following three categories are identified: a) one-two (high); three (medium); and four and above (low).

Figure 8.4 shows an association between life satisfaction and employment. The rate of employment among the most satisfied men is $66 \%$; amongst the least satisfied it is $43 \%$. For women, the corresponding figures are $50 \%$ and $31 \%$.

Figure 8.4: Employment rate by life satisfaction and sex in those aged 50-64

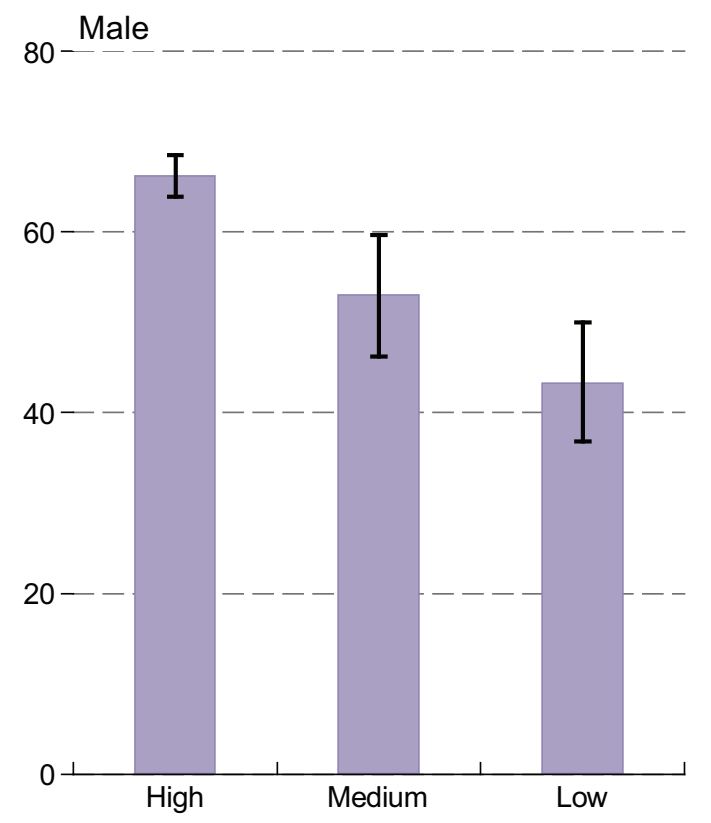
Female

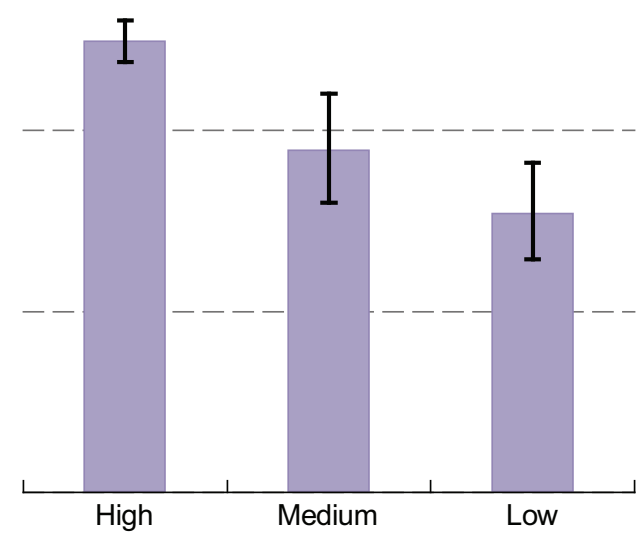

Note. $\mathrm{N}=4663$; Missing obs $=5$; Error bars correspond to $95 \%$ confidence intervals

In summary, labour supply of older adults aged 50 to 64 in Ireland is concentrated amongst the healthiest, most educated, wealthiest and most satisfied members of the population. 


\subsection{Labour market status of men and women aged 65 to 74}

The following section describes the labour market status of men and women aged 65 to 74 and hence already beyond the state pension age (SPA). Table 8.1 showed that for this group, most men are retired ( $82 \%)$ and the majority of women are either retired or looking after home or family (52\% and $36 \%$, respectively). Of those at work ( $16 \%$ of all men, $8 \%$ of all women), $73 \%$ of men are self-employed and $27 \%$ are employees. These compare to $31 \%$ and $69 \%$, respectively, for women.

Previous international studies including ELSA and HRS have shown that some retired men and women still undertake some paid work. Although reporting themselves as retired, such individuals still show some attachment to the labour market. In the TILDA sample, $4 \%$ of both men and women aged 65 to 74 report themselves to be retired but have done at least one hour of paid work in the previous week. These are defined as "retired but working". For these respondents, the transition out of work is not complete. For this reason, it is appropriate to include them with those who give their main status as being employed.

Similarly to those aged between 50 and 64, there is an association between health and employment. Of men who report being in excellent, very good or good health, $22 \%$ are working or retired but working, compared to $12 \%$ of those who claim to be in fair or poor health. The corresponding figures for women are $12 \%$ and $5 \%$, respectively.

Compared to those aged 50-64, differences across the three educational groups do not hold for men, but are still clear-cut for women. Figure 8.5 shows that $6 \%$ of women aged 65 to 74 with primary or no education are still at work, compared to $12 \%$ for those with secondary education and $17 \%$ for those with third or higher education.

Figure 8.6 shows that there is an association between employment and wealth for men aged 65-74, but not for women. Of men aged 65 to 74 who fall in the poorest group, $5 \%$ are in employment, compared to $13 \%$ in the second quartile, $20 \%$ in the third quartile and $26 \%$ in the wealthiest group. Also, the vast majority (73\%) of men aged 65 to 74 who are still at work are self-employed whereas most women (69\%) are employees, suggesting significant differences in the reasons for continuing to work between men and women in this age group. Finally, in contrast with those aged between 50 and 64, there is no association between employment and life satisfaction for those aged 65 to 74 .

To sum up, labour supply of individuals aged 65 to 74 in Ireland seems to be concentrated amongst healthiest men and women, wealthiest men and most educated women. 
Figure 8.5: Employment rate by educational attainment and sex in those aged 65-74

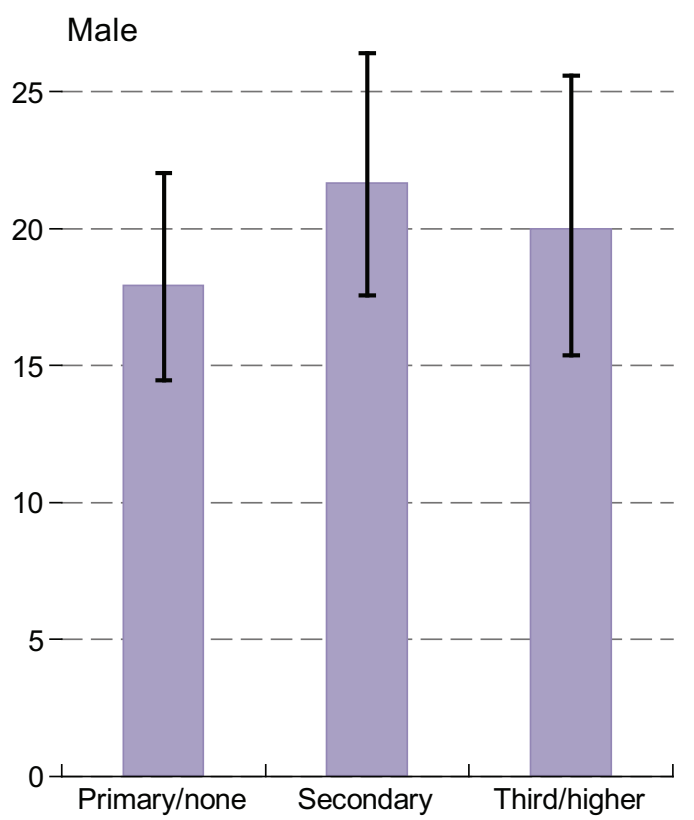

Female

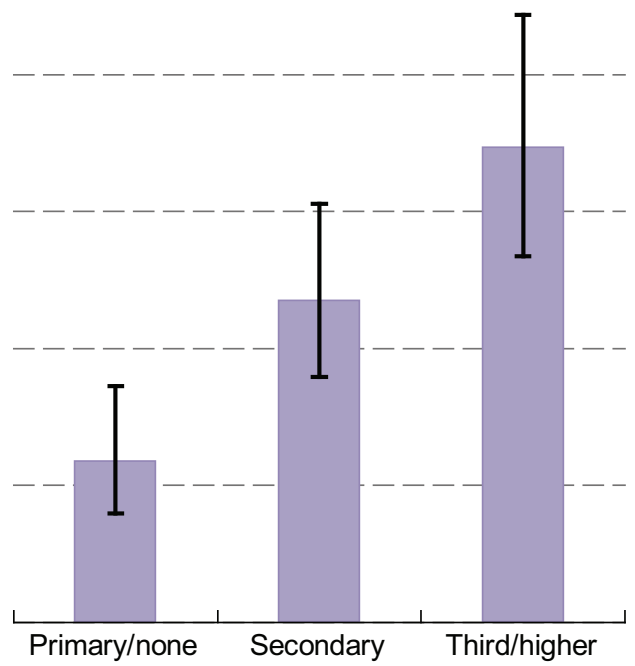

Note. $\mathrm{N}=2162 ;$ Missing obs $=1$; Error bars correspond to $95 \%$ confidence intervals

Figure 8.6: Employment rate by wealth quartile and sex in those aged 65-74

$$
\text { 40 Male }
$$

Female
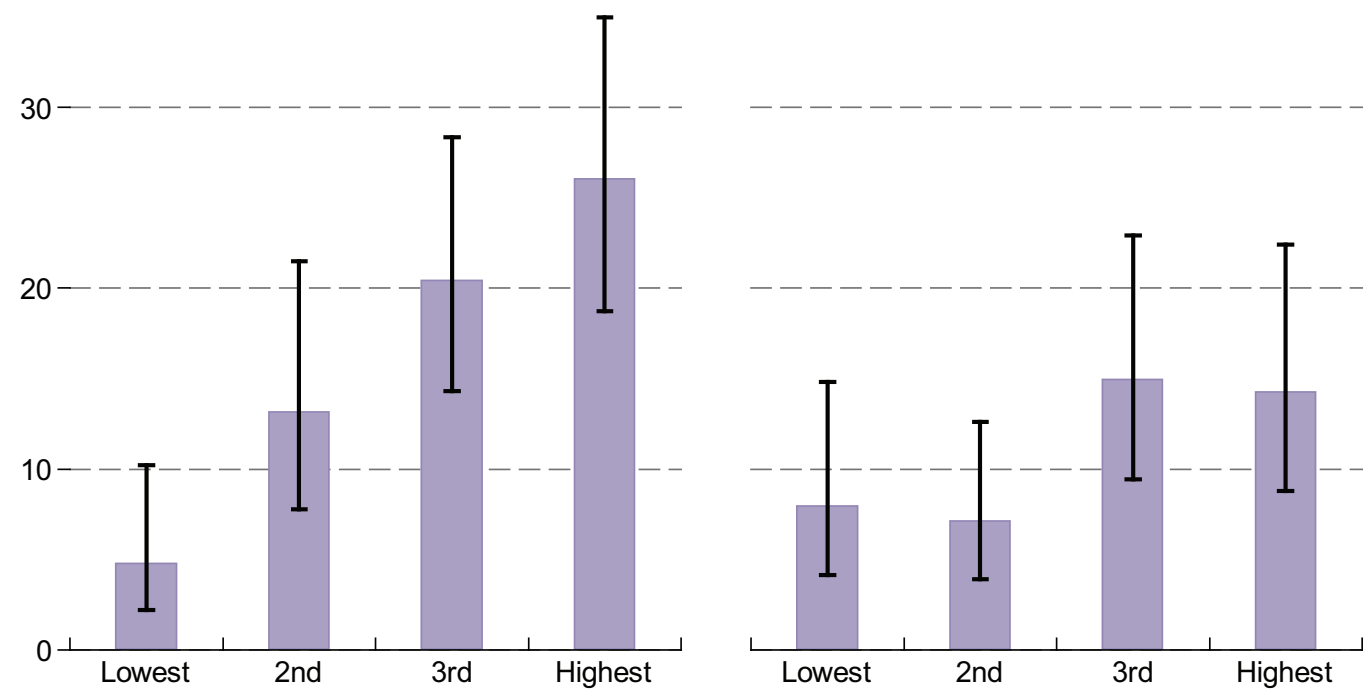

Note. $\mathrm{N}=1032$; Missing obs $=1131$; Error bars correspond to $95 \%$ confidence intervals 


\subsection{Working conditions of employees aged 50 and above}

Here the working conditions of all older employees in Ireland are discussed. Particular issues investigated are: workplace discrimination; the pattern of hours worked by age; expected retirement age; and pension coverage.

\subsubsection{Workplace discrimination}

TILDA respondents currently in employment are asked whether over the past twelve months they have been subjected to discrimination linked to: sex; age; nationality; ethnic background; religion; disability; and sexual orientation. Very few older people are affected by discrimination at work: $97.6 \%$ of men and $96.4 \%$ of women who are at work report that they are not being affected by any kind of workplace discrimination.

\subsubsection{Hours at work and wind-down}

Individuals may change their attitudes about work and compensation as they age. Haider and Loughran (9) found that older Americans work fewer weeks and fewer hours than their younger counterparts and that the median wage decreases with age for both full and part-time workers, regardless of their level of education. SHARE and ELSA have shown that more women work part-time than men, and that both men and women over 65 are more likely to work part time than their younger counterparts. $(6,15)$.

Figure 8.7 explores the issue of "wind-down" by looking at the relative proportions of men and women who are in part-time work divided into four different age groups: (a) 50-54; (b) 55-59; (c) 60-64; and (d) 65+. Following ELSA and SHARE, a part-time worker is defined as an individual working for less than 30 hours per week (excluding meal breaks but including any paid or unpaid overtime). If a respondent has more than one job, both main and subsidiary jobs are taken into account. Only respondents who report themselves to be employed are included (self-employed are excluded).

Men and women approaching the State Pension Age (SPA) (i.e. those aged 6064) and after SPA (aged 65+) are more likely to be working part-time than their younger counterparts (aged 50-54 and 55-59): 7\% of men aged 50-54 work part-time, compared to $23 \%$ of men aged $60-64$ and $31 \%$ of men aged $65+$. The corresponding figures for women are $48 \%, 56 \%$ and $71 \%$, respectively.

The issue of working time can be investigated more closely by looking at the average number of hours spent at work in the same age groups: (a) 50-54; (b) 55-59; (c) 60-64; and (d) $65+$. Table 8.2 shows that the average number of hours worked decreases across the groups of men and women as they move closer to age 65 , especially for men. 
Figure 8.7 : Proportion of employees working part time by age and sex
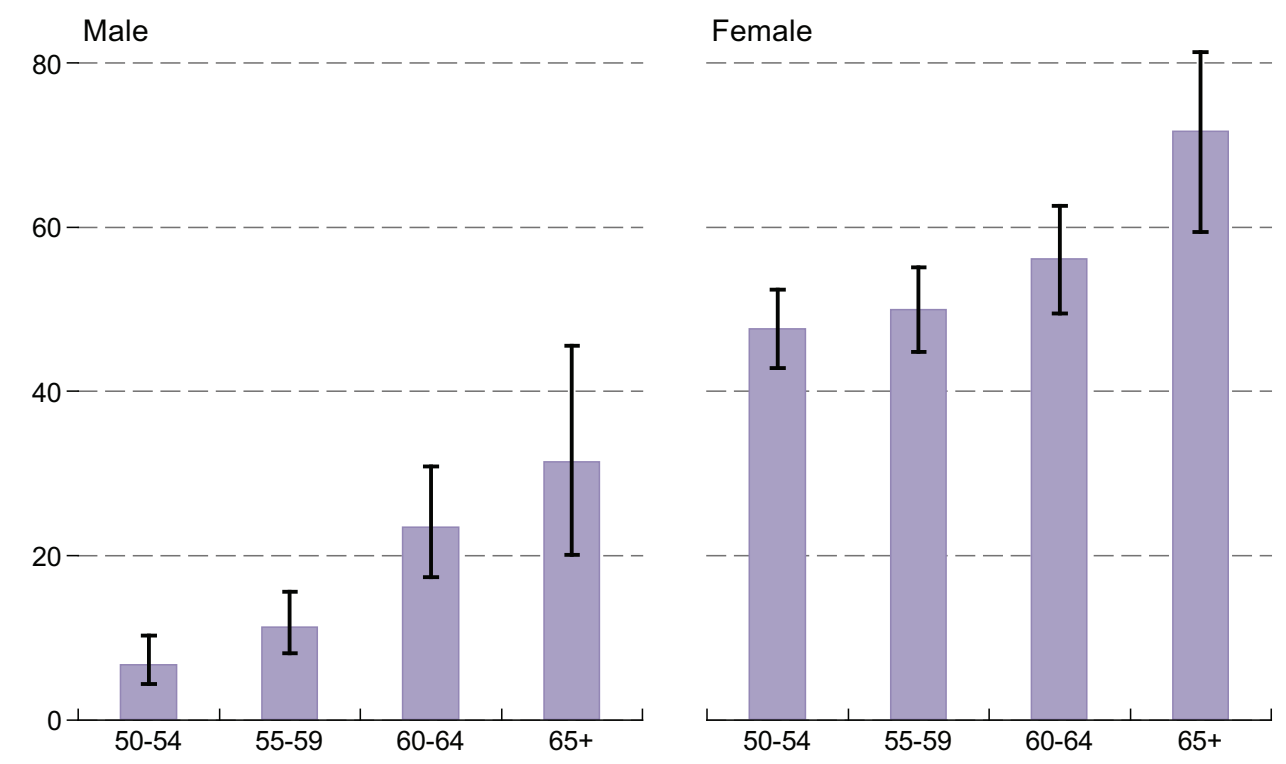

Note. $\mathrm{N}=2037$; Missing obs = 9; Error bars correspond to $95 \%$ confidence intervals

For men, the average number of hours worked is similar before and after reaching age 65 (37 for men aged 60-64 compared to 36 for men aged 65+). However, far fewer men work after this age and there is likely to be a "composition effect" caused by the characteristics of this group. For women, the number of hours worked decreases significantly after reaching age 65, shifting from 27 for women aged 60 to 64 to 21 for women aged 65 and above.

Table 8.2: Weekly average number of hours spent at work by sex and age group, employees only

\begin{tabular}{|l|rr|rr|} 
& \multicolumn{2}{|c|}{ Men } & \multicolumn{2}{c|}{ Women } \\
& Mean & $95 \% \mathrm{Cl}$ & Mean & $95 \% \mathrm{Cl}$ \\
\hline $\mathbf{5 0 - 5 4}$ & 43 & $(42,44)$ & 29 & $(28,30)$ \\
\hline $\mathbf{5 5 - 5 9}$ & 42 & $(40,44)$ & 28 & $(27,30)$ \\
\hline $\mathbf{6 0 - 6 4}$ & 37 & $(35,40)$ & 27 & $(25,29)$ \\
\hline $65+$ & 36 & $(31,42)$ & 21 & $(18,24)$
\end{tabular}

Note. $\mathrm{Cl}=$ confidence interval; $\mathrm{N}=2037$; missing $=9$

\subsubsection{Expected Retirement Age}

As noted in the introduction to this chapter, a central theme in the economics of ageing is the desirability of extending working lives/postponing retirement so that 
the pressures on state pensions systems can be alleviated. In Ireland, a recent policy initiative which aims to achieve these objectives was contained in the National Pensions Framework (1). Under proposals contained in that document, the state pension age will be increased gradually to 68 years over a period of time. Starting in 2014 , the state pension age will be increased by one year to 66. It will subsequently be raised to 67 in 2021 and to 68 in 2028. In this context, it is important to explore the age at which those currently at work expect to retire.

TILDA respondents are asked to state the age at which they plan to retire. The question is asked not only to those currently employed (including employees and self-employed), but also to those who are unemployed or in education or training. However, only employees aged 50 to 64 are included in the present analysis.

Figure 8.8 shows that male and female employees have different expectations. Among employees, $43 \%$ of men and $36 \%$ of women expect to retire at age 65 , the current state pension age. $25 \%$ of men and $26 \%$ of women plan to retire before state pension age (50-64), whereas $15 \%$ of men and $10 \%$ of women plan to continue working after reaching the current state pension age (66+). Also, women are more uncertain about the age at which they will retire: $13 \%$ of women and $6 \%$ of men do not know when they will retire. Interestingly, $16 \%$ of women and $11 \%$ of men do not plan to retire.

Figure 8.8: Expected retirement age by sex, employees aged 50-64

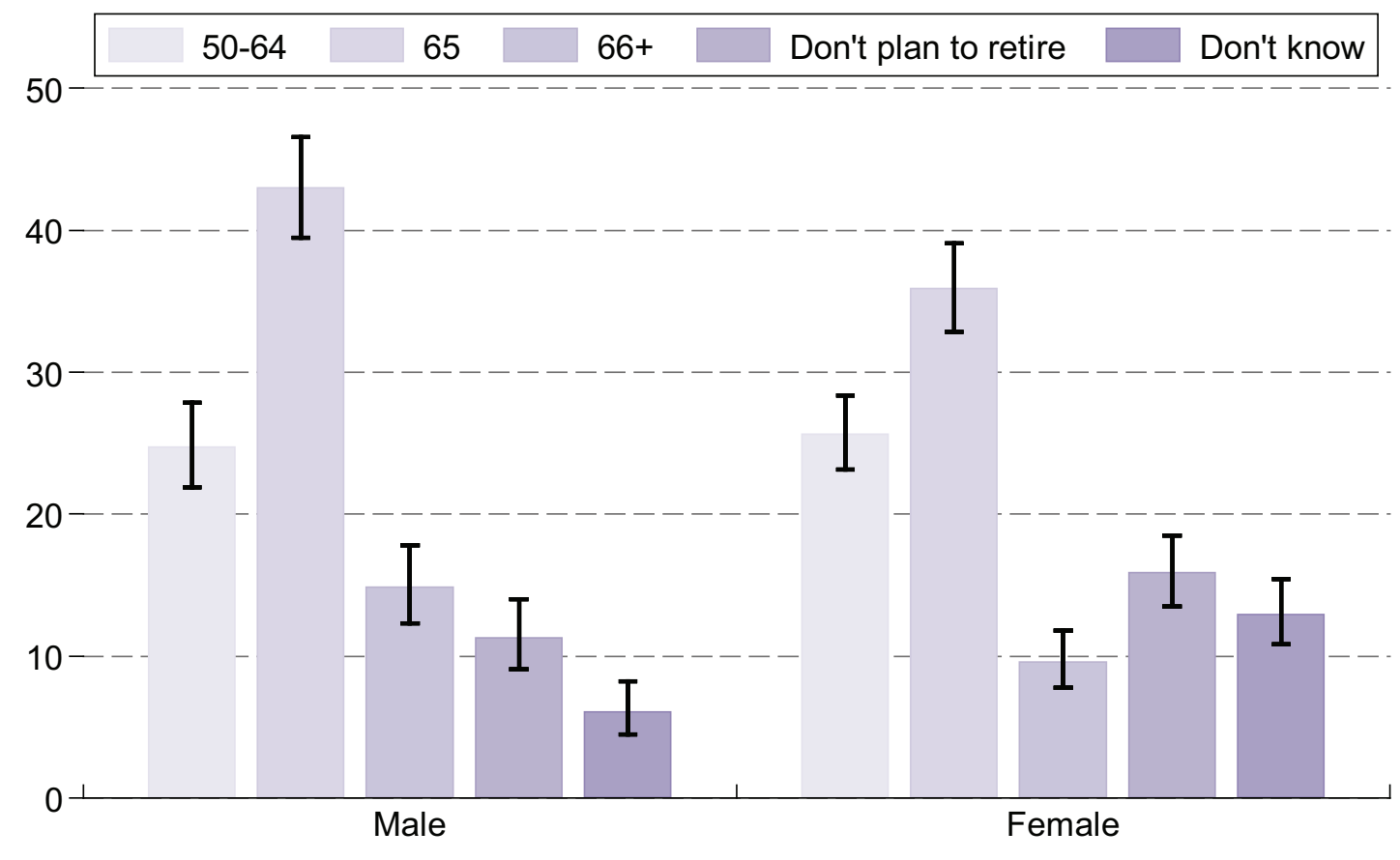

Note. $\mathrm{N}=1915$; Missing obs = 0; Error bars correspond to 95\% confidence intervals 
Figure 8.9 shows that expectations are different for different education groups, with the more highly educated expecting to retire earlier. For example, $7 \%$ of men and $9 \%$ of women with primary or no education expect to retire before SPA, compared to $37 \%$ of men and $38 \%$ of women with tertiary or higher education. Similarly, $17 \%$ of men and $26 \%$ of women with primary or no education do not plan to retire, compared to $10 \%$ of men and $11 \%$ of women with tertiary or higher education. For more details, see Table A8.2.

Figure 8.9: Expected retirement age by educational attainment and sex, employees aged $50-64$

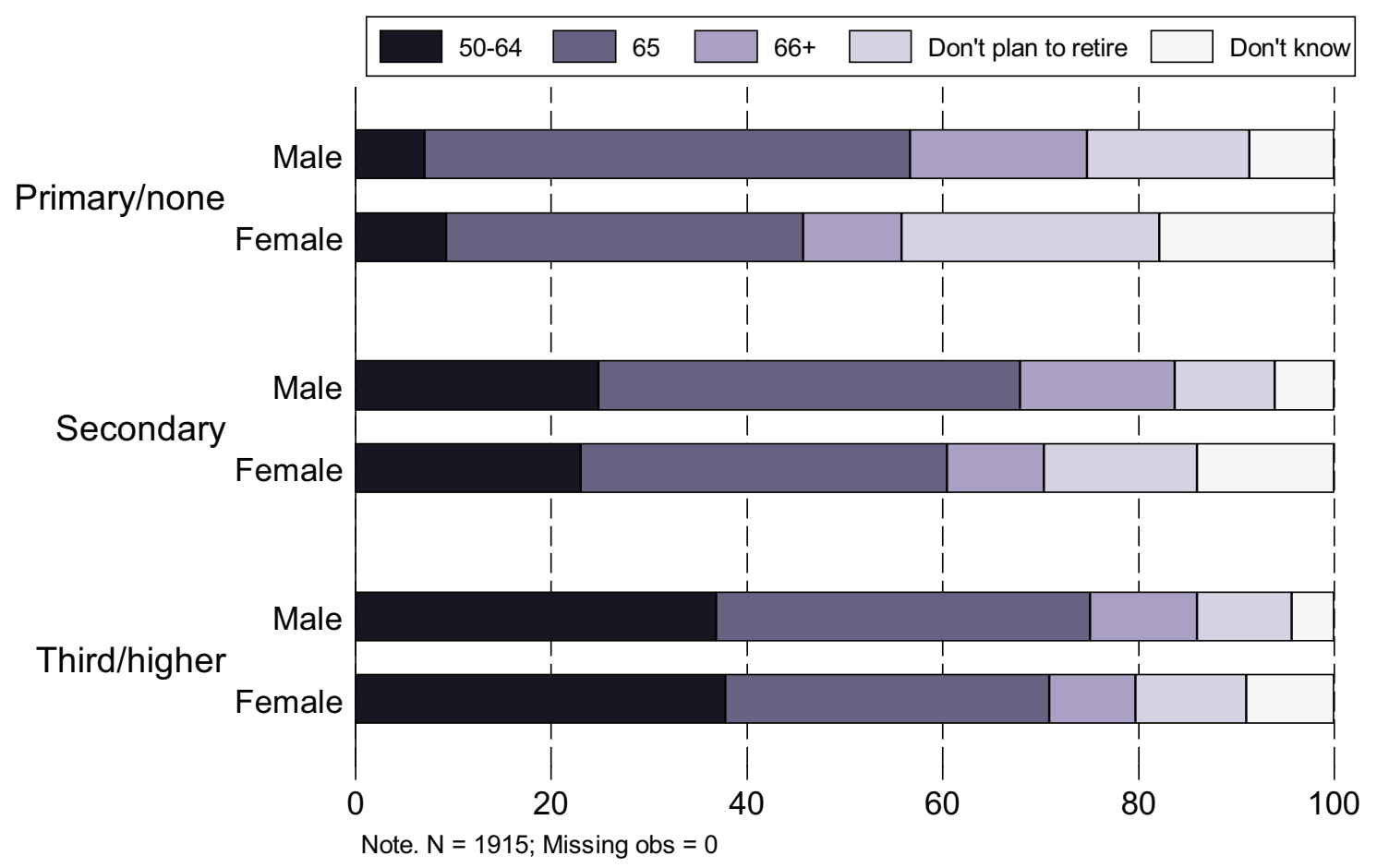

\subsubsection{Pension coverage}

Another objective of the National Pensions Framework is to ensure increased pension coverage beyond the state pension. TILDA respondents working in both the private sector and public sector were asked whether they are covered by an occupational pension scheme organised by their current or previous employer, a Personal Retirement Saving Account (PRSA) organised through their current employer, or another kind of personal pension scheme.

Figure 8.10 shows the proportions of male and female employees aged 50 to 64 who are: a) covered by an occupational pension scheme; b) covered by a PRSA or another kind of personal pension scheme; $c$ ) not covered by any of these. If respondents are covered by both an occupational and personal pension scheme, they are classed as having an occupational pension. 
Echoing results from a special module of the Quarterly National Household Survey (16), TILDA shows that female employees aged 50 to 64 are less likely to be covered by occupational and private pension schemes than their male counterparts. Amongst women at work, $41 \%$ are not covered by an occupational, PRSA or private pension scheme compared to $20 \%$ of men. Women are also less likely to be covered by an occupational pension scheme (52\% compared to $68 \%$ for men).

Figure 8.10: Pension coverage and sex, employees aged 50-64

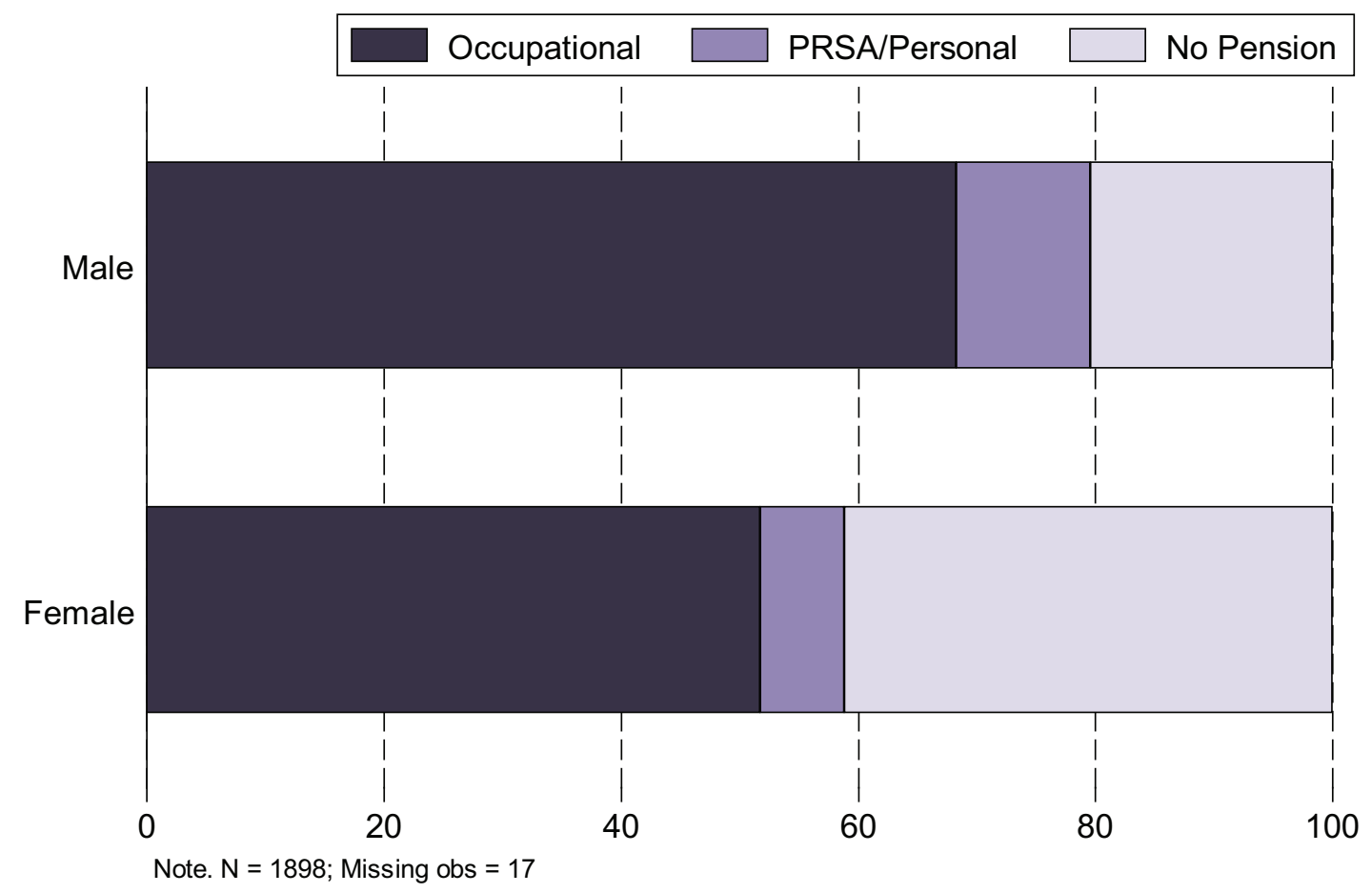

Private sector employees who are covered by an occupational pension scheme with their current employer are then asked if this is a defined contribution or defined benefit scheme. Defined benefit schemes provide the employee with a pension "promise" of a certain percentage of an employee's final salary. Defined contribution schemes offer a pension determined by the level of contributions invested into a fund, its investment performance and the charges levied. Public sector employees are asked the name of the scheme they are covered by (e.g., main civil service pension scheme and pension schemes of members of the Garda, armed forces or university teaching and research staff). For the purpose of this analysis, public sector employees who are covered by an occupational pension scheme are considered as covered by a defined benefit scheme. Of those covered by an occupational pension scheme with their current employer, $74 \%$ of men and $85 \%$ of women are covered by a defined benefit scheme. $26 \%$ of men and $15 \%$ of women are covered by a defined contribution scheme. 
Figure 8.11 shows that pension coverage varies significantly by socio-economic group. For example, $74 \%$ of managers and $78 \%$ of higher professionals are covered by an occupational pension, compared to $48 \%$ of semi-skilled and $32 \%$ of unskilled workers. For more details, see Table A8.3.

Figure 8.11: Pension coverage by socio-economic group, employees aged 50-64

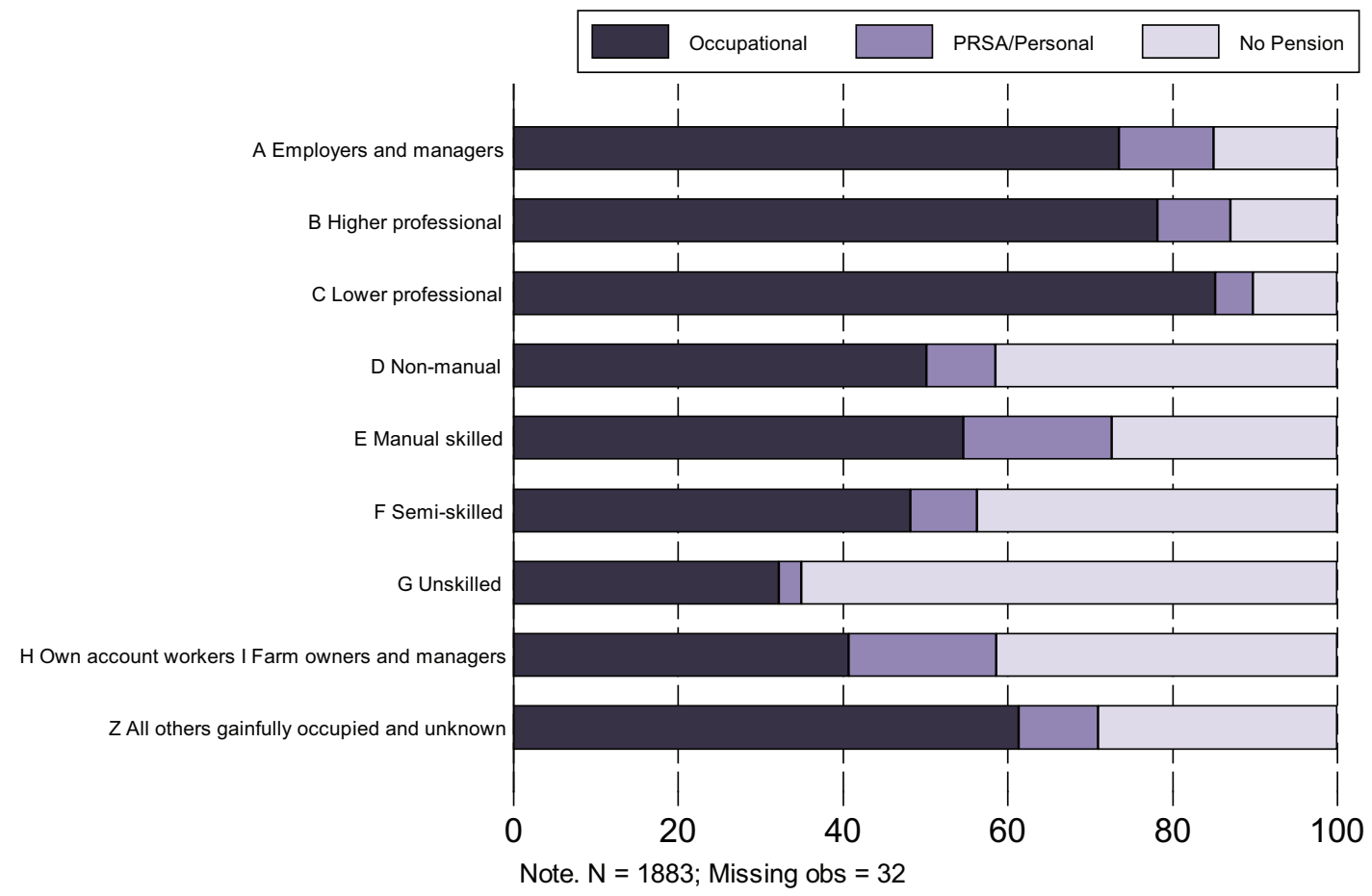

\subsection{Conclusions}

More educated, healthier, wealthier and more satisfied older adults are more likely to be at work. While it is tempting to draw inferences about causation, plausible arguments can be made in the case of each factor as to why causal relationships with employment could run in either direction. Better health allows people to remain at work for longer but it is also possible that work contributes to mental and physical health through its impact on social interaction or physical activity. Chapter 6 also shows that respondents with depression have extremely low rates of labour force participation compared to the general population. As with many other dimensions of TILDA, the longitudinal component of the study will be vital in developing insights into these causal links.

The results show both positive and negative aspects of the labour market situations of older employees. On the positive side, little evidence was found of widespread discrimination on the grounds of age. It was also found that average hours worked decline for older groups, thereby suggesting that some form of "wind-down" in 
advance of retirement may be occurring for some people. On the negative side, the analysis has also shown that one in five male employees and two in five female employees aged 50-64 are not covered by any form of pension.

While the findings presented here shed light on a range of aspects of the labour market situation of older adults, the real value of TILDA will emerge when the data from wave 2 and subsequent waves are available. As the later waves become available, it will be possible to track trends in the variables of interest. It will also be possible to establish causal relationships including for example, the extent to which good health leads people to work longer or working longer leads to good health. By identifying factors that assist longer and more fulfilling working lives, TILDA will allow for the development of carefully designed policy interventions.

\section{References}

1. Department of Social and Family Affairs. National Pensions Framework. Dublin: The Stationery Office; 2010.

2. Barnay T, Debrand T. Effects of health on the labour force participation of older persons in Europe. Health Econ Letters. 2006;109.

3. Currie J, Madrian BC. Health, health insurance and the labor market. In:

Ashenfelter O, Card D, editors. Handbook of Labor Economics. Amsterdam: North Holland; 1999. p. 3309-3416.

4. Lumsdaine $\mathrm{R}$, Mitchell $\mathrm{O}$. New developments in the economic analysis of retirement. In: Ashenfelter O, Card D, editors. Handbook of Labor Economics (3). Amsterdam: North Holland; 1999.

5. Alavinia SM, Burdorf A. Unemployment and retirement and ill-health: a crosssectional analysis across European countries. Int Arch Occup Environ Health. 2008;82:39-45.

6. Banks J, Casanova M. Work and retirement. In: Marmot M, Banks J, Blundell R, Lessof C, Nazroo J, editors. Health, wealth and lifestyles of the older population in England: the 2002 English Longitudinal Study Of Ageing; 2003. p. 127-142.

7. Kalwij A, Vermeulen F. Health and labour force participation of older people in Europe: what do objective health indicators add to the analysis?. Health Econ. 2007;17(5): 619-638.

8. Avendano $\mathrm{M}$, Jürges $\mathrm{H}$, Mackenbach JP. Educational level and changes in health across Europe: longitudinal results from SHARE. J EUR SOC POLICY. 2009;19(301).

9. Haider S, Loughran D. Elderly labor supply: work or play?, RAND Labor and population program working paper 01-09, Santa Monica, CA. 2001

10. Atchley RC. Continuity and adaptation in aging: creating positive experiences. Baltimore, MD: Johns Hopkins University Press; 1999.

11. Rowe JW, Kahn R. Successful aging. New York: Pantheon; 1998.

12. Calvo E. Does working longer make people healthier and happier? MPRA Paper No. 5606. 2006. Available from: http://mpra.ub.uni-muenchen.de/5606/ 
13. SHARE. 50+ in Europe - Summary of initial results. 2006. Available from: http://www.share-project.org/t3/share/fileadmin/pdf_selected_results/English.pdf

14. Calvo E, Haverstick K, Sass SA. Gradual retirement, sense of control and retirees' happiness. RES AGING. 2009;31(112).

15. Brugiavini, A, Croda E, Mariuzzo F. Labour force participation of the older adults: unused capacity?. In: Börsch-Supan A, Brugiavini A, Jürges H, Mackenbach J, Siegrist J, Weber G, editors. Health, ageing and retirement in Europe - first results from the Survey of Health, Ageing and Retirement in Europe; 2005. p. 236-240.

16. Central Statistics Office. Quarterly National Household Survey Pensions Update: Quarter 12007 and Quarter 1 2008, Dublin, CSO. 2008. 


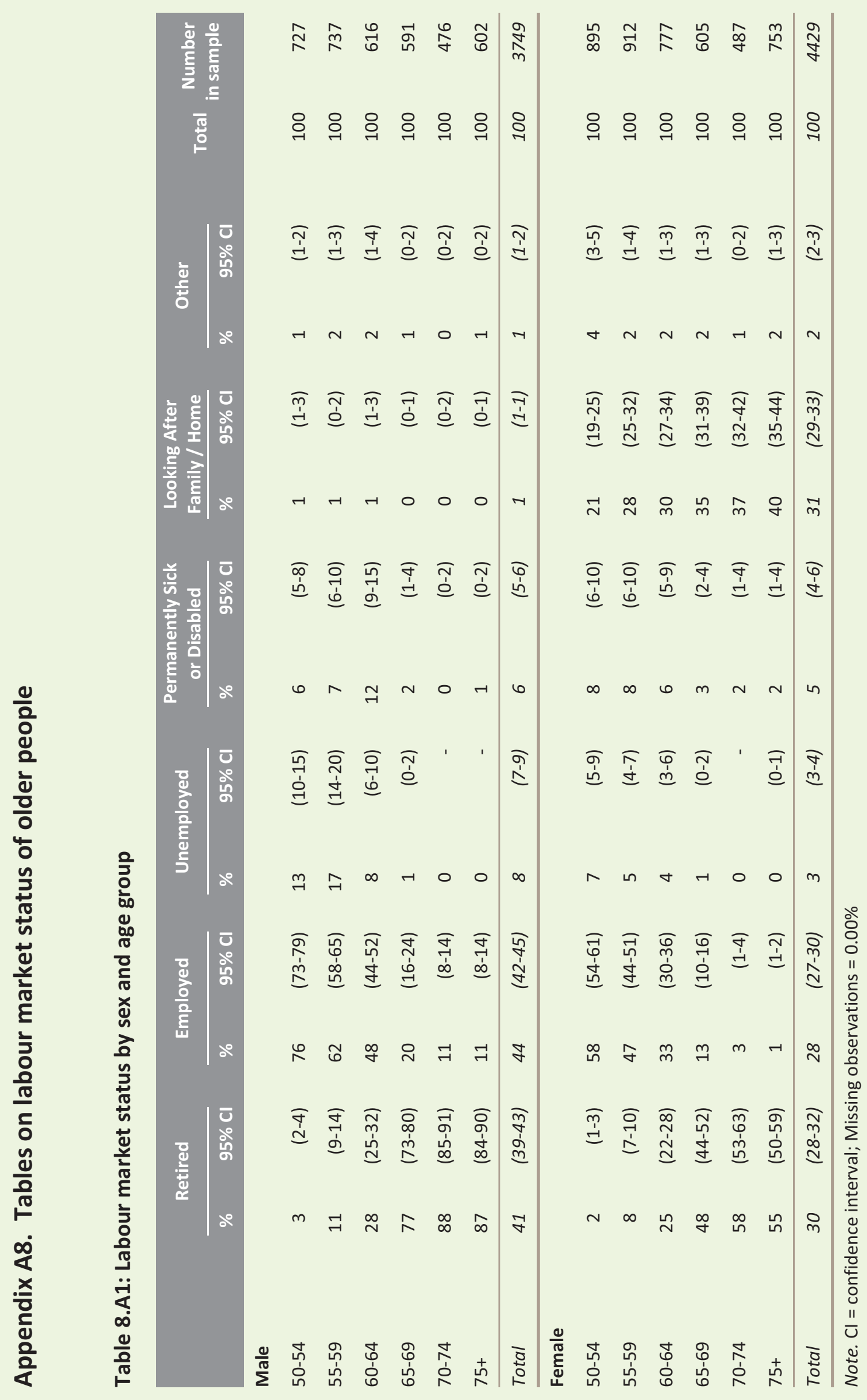




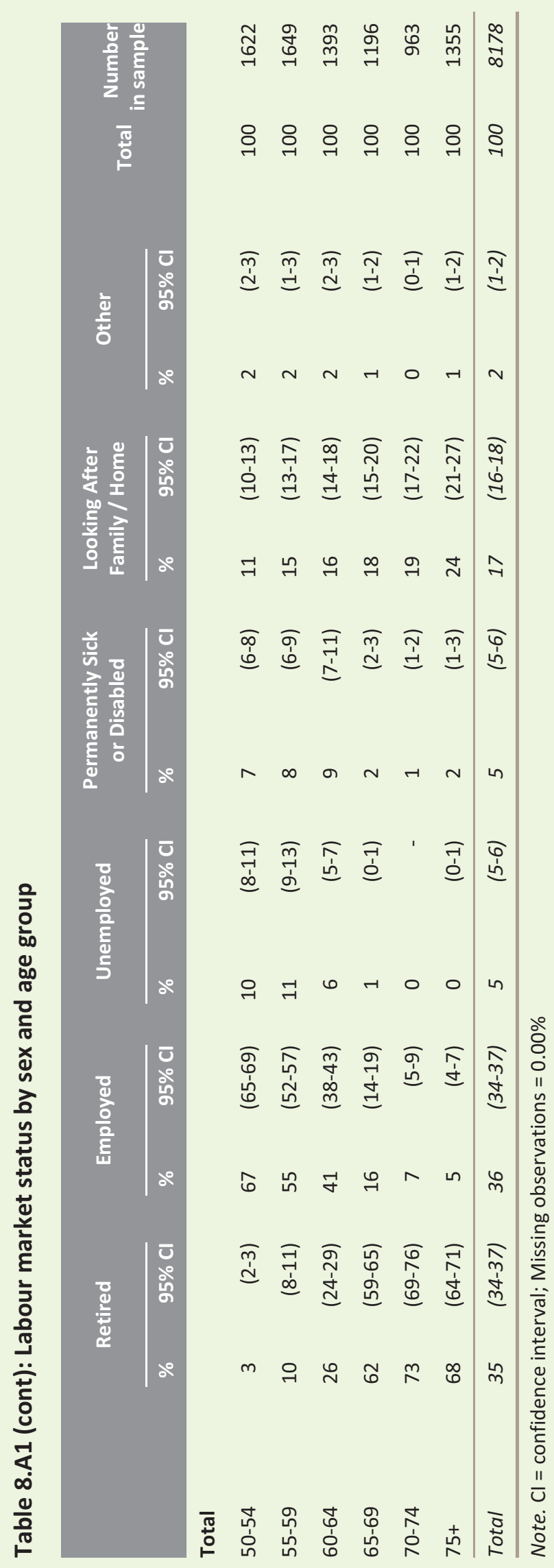




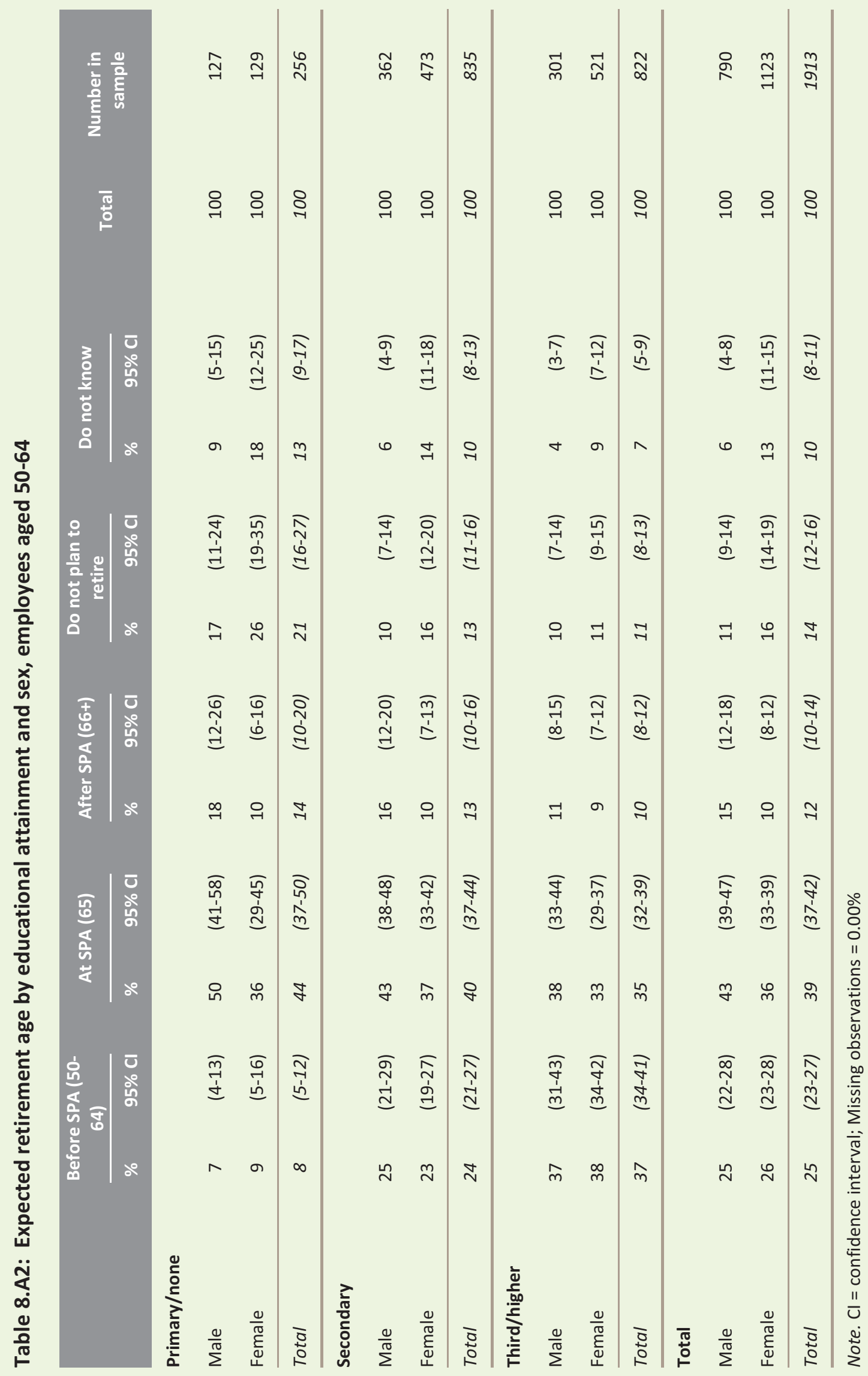




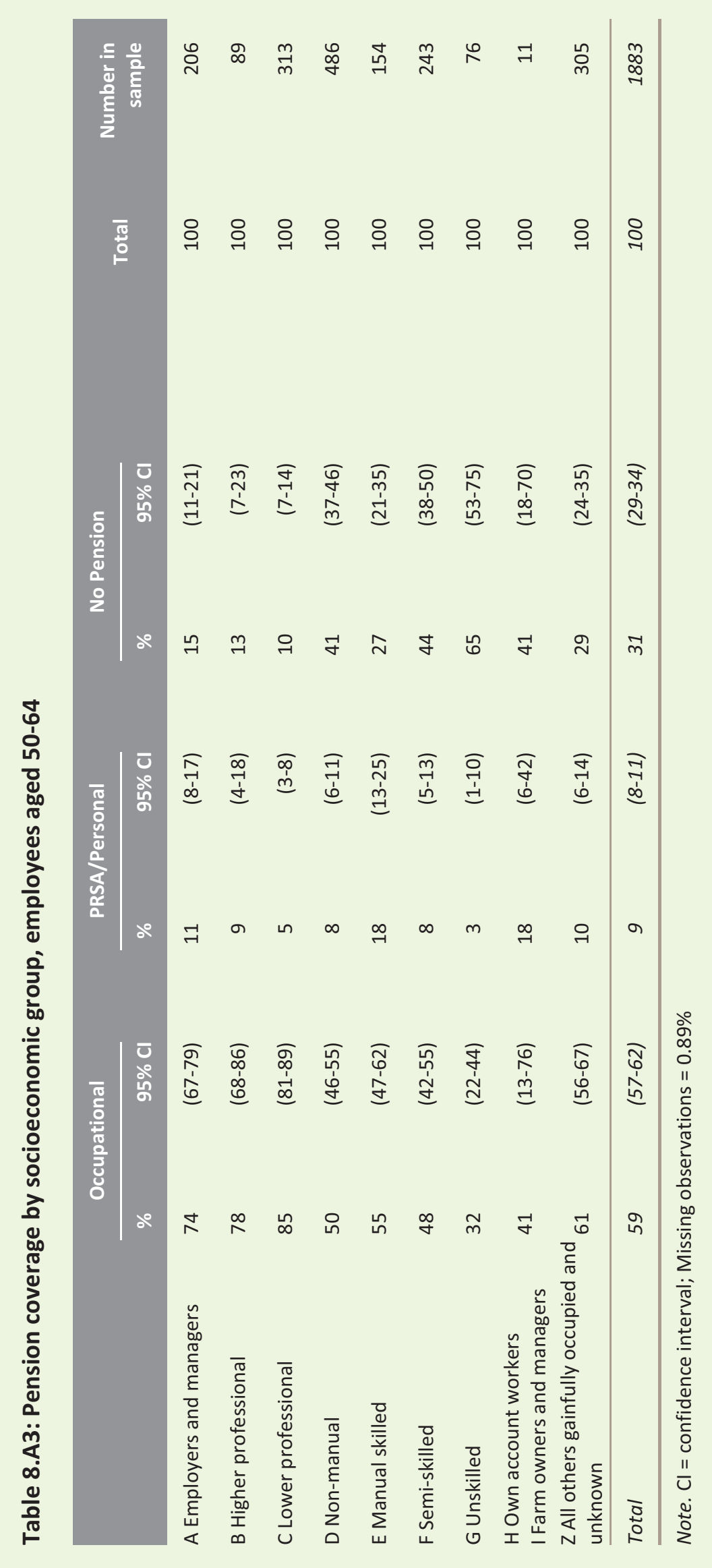




\title{
Income And Asset Levels Of Older People
}

\author{
Vincent O' Sullivan and Richard Layte
}

\section{Contents}

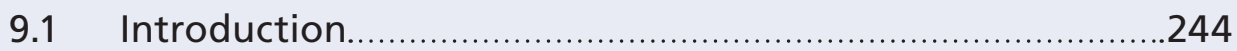

9.2 Calculation of income and other technical issues..............246

9.3 The distribution of income in the population aged 50 and over.

9.4 Explaining variability in the incomes of older people......

9.4.1 Income by age groups 250

9.4.2 Household composition and number of workers in household..

9.4.3 Income by years of service of retirees........................252

9.4.4 Income by years since retirement...........................2252

9.4.5 Income by former occupation of retirees.................254

9.5 Sources of income

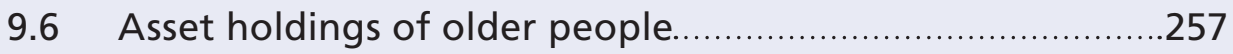

9.6.1 Housing tenure and house valuations .........................257

9.6.2 Ownership of property other than
current residence...............................................259

9.6.3 Savings and other financial assets..........................260

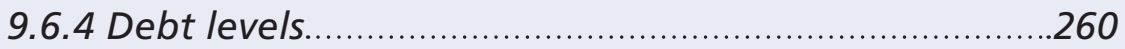

9.6.5 Assets and income levels............................................261

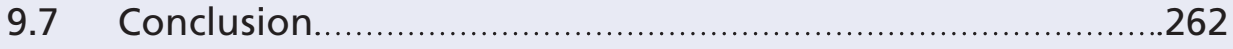




\section{Income And Asset Levels Of Older People}

\section{Key findings}

- The average weekly household disposable income is $€ 767$ but around half live on under $€ 400$ per week.

- About one in eight older people have weekly disposable incomes of $€ 1,000$ or more.

- Older people who had professional or managerial jobs have significantly higher incomes in retirement than the general population largely due to occupational pension schemes and higher levels of financial assets.

- State pensions are the most important source of income among older people in Ireland and make up around two-thirds of gross income for those aged 65 and over.

- Around $26 \%$ depend on state transfers as their sole source of income.

- A majority (about 70\%) own their home and have finished paying off their mortgage. The median self-valuation of current residence is $€ 300,000$ for those with tertiary education. This is just under twice the median self-reported house value amongst those with only primary education.

- Savings and financial assets (other than property) vary with level of education from an average of $€ 14,000$ for those with primary education to $€ 60,000$ for those with tertiary education.

\subsection{Introduction}

Before the establishment of social welfare systems in Western European countries around the beginning of the 20th century, increasing age was often associated with vulnerability to poverty as the ability to work waned and incomes fell. Charles Booth's key insight from his survey of 'Life and Labour of the People in London' (1) was that the onset of old age and inability to work was the primary cause of poverty in that period and this contributed to the Old Age Pensions Act in Britain in 1908. State pensions changed this completely and with the wider availability of occupational pensions in the second half of the last century, older age is no longer as marked by low income and poverty. Nonetheless, retirement from work is still associated with a reduction in income and, for many in Irish society, dependency on the state pension. The incomes of older people tend, therefore, to be lower than incomes in the younger population and income variation among older people compared to the younger population is lower (2). 
Recent Irish governments have increased state pension rates more steeply than the rates of other social welfare payments and pension rates have been protected so far in the recent recession. This has meant that the real incomes of older people increased significantly over the economic boom. At the same time though, wage incomes have been growing faster than state pensions leading to a growing gap between the incomes of pensioners and those in paid work $(3,4)$. Variation in income among older people in Ireland is lower than among younger age groups, but some older people are better-off than others. The main income of a majority of older people is the state pension but an increasing proportion of older people have an occupational or private sector pension as well. These vary in value, depending on the person's life and work history. To understand this variation it is necessary to understand the way in which education, work life mobility and Irish history interact. People who left school before the advent of free secondary education in Ireland (1967) were far more likely to leave with a primary education only and far less likely to enter third level education (5). As average levels of education have increased so has the necessity of higher education for the attainment of higher occupational and professional positions (6). This means that level of educational attainment has become increasingly important for incomes in old age and the probability of having an occupational pension.

Studies of quality of life across a large number of countries consistently show that a person's level of income and material resources strongly affects their overall satisfaction with life and well-being $(7,8)$. This chapter shows how income varies across the older population in Ireland and what factors may influence this. This chapter unfolds as follows: section 9.2 describes the calculation of disposable income used in the sections that follow; section 9.3 describes the average level of income among people aged 50 and over in Ireland. This section also examines variation in the household incomes of older people in Ireland and how this compares to the distribution of income in the general population as found in the EU Survey on Income and Living Conditions (EU-SILC). Section 9.4 analyses the factors that explain the distribution of income across the households in the TILDA survey such as the level of current employment in the household and the occupational position of its members before retirement. Section 9.5 examines the composition of income packaging found among the TILDA sample, i.e. the combination of employment, social welfare and occupational pension income typical across households and how this varies by other factors. Section 9.6 examines the level and type of financial assets held among TILDA households in terms of home ownership, estimated house values and other financial assets/liabilities. 


\subsection{Calculation of income and other technical issues}

The measure of gross income used in this chapter is the sum of current labour income, pension income, social transfers, asset income and income from irregular sources.

Labour income consists of employee income from the respondent's main job in the past 12 months including all types of overtime, commission, bonuses, share options and so on. Labour income also includes the gross profit from self-employment (coded to zero for losses) for self-employed people as well as pre-tax farm income for those engaged in farming. Pension income is made up of both regular and lump sum income from occupational and private schemes. Social welfare payments made to the respondent, income from assets and irregular income (for example, redundancy payments, gambling winnings) are also included in our measure of gross income.

Disposable income, net of taxes and social insurance contributions was calculated taking into account household structure, pension contributions, tax credits and other aspects of the tax system.

To take household size into account when measuring living standards, household disposable income is equivalised. Equivalisation creates a weighted average of household income for household members. The weights take economies of scale in consumption into account. For example, a single person, living on their own would generally require less electricity than a two person household. However, one would expect the single person's electricity consumption to be more than half as much as the couple's. Different equivalisation weighting schemes are used across the world, however this chapter uses the scheme commonly used in Ireland where the head of household is assigned a value of 1 , all subsequent adults are each assigned a value of 0.66 and children are assigned a value of 0.33 . These values are summed together to form an equivalating factor and the total household disposable income is then divided by the equivalating factor to give equivalised disposable income.

There are two major drawbacks in the approach taken to estimating household income. Firstly, the individual gross incomes of household members other than the respondent (and their partner, if they have one) are not observed. Typically, these earners would be the adult children of the respondent. Therefore, household income may be understated. It is difficult to estimate the degree of understatement. However it should be noted that about one-third of households have at least one child living at home. Of those households with children living at home, about two-thirds have at least one child working. Unfortunately, we cannot take their contribution to household income into account.

Secondly, where the partner of a respondent has decided not to participate in the survey, one cannot observe their income and thus cannot calculate either gross or disposable household income. This applies to about 1600 respondents who had to 
be excluded from the analysis in this chapter. In about $60 \%$ of these cases, the nonparticipating partner is male. It is not possible to discern the extent to which this non-response biases the results. However, it should be noted that the educational attainment of people whose spouse did not respond is nearly identical to the educational attainment of those where their spouse did respond. This suggests that the non-response is more likely to be at random and have less of a bias on the results than if the non-response were non-random.

A further 3000 individuals were excluded as these respondents and/or their spouses had not given enough information for their disposable income to be accurately calculated. The process for calculating disposable income requires information from the respondents. For example, respondents must give responses in relation to different sources of income or their living arrangements. If they or their spouses refuse to answer a question or do not know the answer, it is not possible to calculate their after-tax disposable income. The cost of having an accurate estimate of disposable income is that observations with missing information have to be set aside in the analysis.

In the interests of having internally valid results, the tables and figures used in Chapter 9 are based on a fixed sample size with complete information on all of the variables (income related and otherwise) considered. Thus the relationships found in different tables or graphs in this chapter are based on the same sample and are not conditional on the availability non-missing data.

Table 9.1 shows a comparison of mean disposable income for certain sub-groups as measured by TILDA and EU-SILC. It should be noted that the EU-SILC data refers to 2009 and TILDA was collected during late 2009 and during all of 2010. The average disposable income for all groups is higher in EU-SILC. This is to be expected as the economy contracted over time.

\subsection{The distribution of income in the population aged 50 and over}

Figure 9.1 shows the distribution of disposable household income measured in Euro per week; the incomes of people aged 50 and over estimated using TILDA is represented by the columns in the chart and the population aged 25 to 49, using data drawn from the EU-SILC survey, is represented by the line across the chart.

EU-SILC is the EU reference source for comparative statistics on income distribution and living conditions. The survey is carried out on an annual basis in 31 European Countries. The Irish survey is carried out by the Central Statistics Office on a nationally representative sample of 6000 households in Ireland. Most of the questions relating to income that are used in TILDA are the same as those in EU-SILC. 
Table 9.1: Mean disposable income of adults aged 65 and over (Euro per week). A comparison of EU SILC and TILDA

\begin{tabular}{lccc}
\multicolumn{2}{c}{$\begin{array}{c}\text { EU SILC } 2009 \\
\text { Mean }\end{array}$} & Mean & TILDA \\
\hline $\begin{array}{l}\text { Average Annual Disposable Household Income* } \\
\text { 65-74 }\end{array}$ & 652 & 630 & $(543-717)$ \\
\hline 75 and over & 477 & 378 & $(353-403)$ \\
\hline All 65 and over & 572 & 506 & $(458-553)$ \\
\hline Average Annual Disposable Equivalised Income** & & \\
\hline $65-74$ & 429 & 456 & $(392-519)$ \\
\hline 75 and over & 354 & 308 & $(285-330)$ \\
\hline All 65 and over & 398 & 389 & $(351-428)$ \\
\hline
\end{tabular}

*Averaged over Households **Averaged over Individuals

Note: The 50-64 age group are not included in this table.

A large proportion of households including people aged 50 and over (around 29\%) have incomes between $€ 201$ and $€ 300$ per week with the second most common group at $€ 401$ to $€ 500$ per week. These groups represent the large proportion of the older population on contributory and non-contributory state pensions. In 2010, the year in which the majority of the data were collected, the contributory old age pension was a maximum of $€ 230$ which when combined with the dependent person's allowance of $€ 206$ in that year produces the two big groups in the distribution.

The vast majority of those over the age of 65 in Ireland receive these pensions, and so incomes are more homogeneous among older people than among the younger population where sources of income are more varied.

The average household disposable income of people aged 50 and above is $€ 767$ per week, significantly below the $€ 995$ of those aged 25 to 49 in 2009 (the last year for which income data from EU-SILC are available at the time of writing). This is unsurprising given that the largest income categories among the younger population in Figure 9.1 are those between $€ 601$ and $€ 1,000$ a week compared to the big groupings between $€ 201$ and $€ 500$ among older people. However, this does not mean that all older people in Ireland are dependent upon the state pension. Figure 9.1 shows that $13 \%$ of those aged 50 and above have a net or disposable income of more than $€ 1000$ a week and that $4 \%$ have a disposable income of $€ 2,000$ or more a week.

What implications does the distribution of income among older people have for the proportion at risk of experiencing income poverty? Since being 'at risk of poverty' in Ireland is measured relative to a poverty threshold set at $60 \%$ of median 
individual income (that is $60 \%$ of the person's income who is half way up the income distribution of the general population if all incomes were ranked), this depends upon the position of older people relative to younger age groups. According to the 2009 SILC survey (9) just under $10 \%$ of people aged $65+$ were at risk of income poverty compared to $12 \%$ among those aged between 18 and 65 . However, as shown in (9), the proportion at risk of poverty has decreased significantly from 30\% in 2003. The decrease has occurred largely because old age pensions rose faster than other benefits in the mid-2000s and have not subsequently decreased unlike employment incomes and other social welfare benefits. In 2009 the 'at risk of income poverty' line for a single person was $€ 231$, down from $€ 239$ in 2008. Stable state pension levels combined with falling incomes in the working age population have dramatically lowered the proportion of older people at risk of poverty ${ }^{1}$.

Figure 9.1: The distribution of disposable household income (Euro per week)

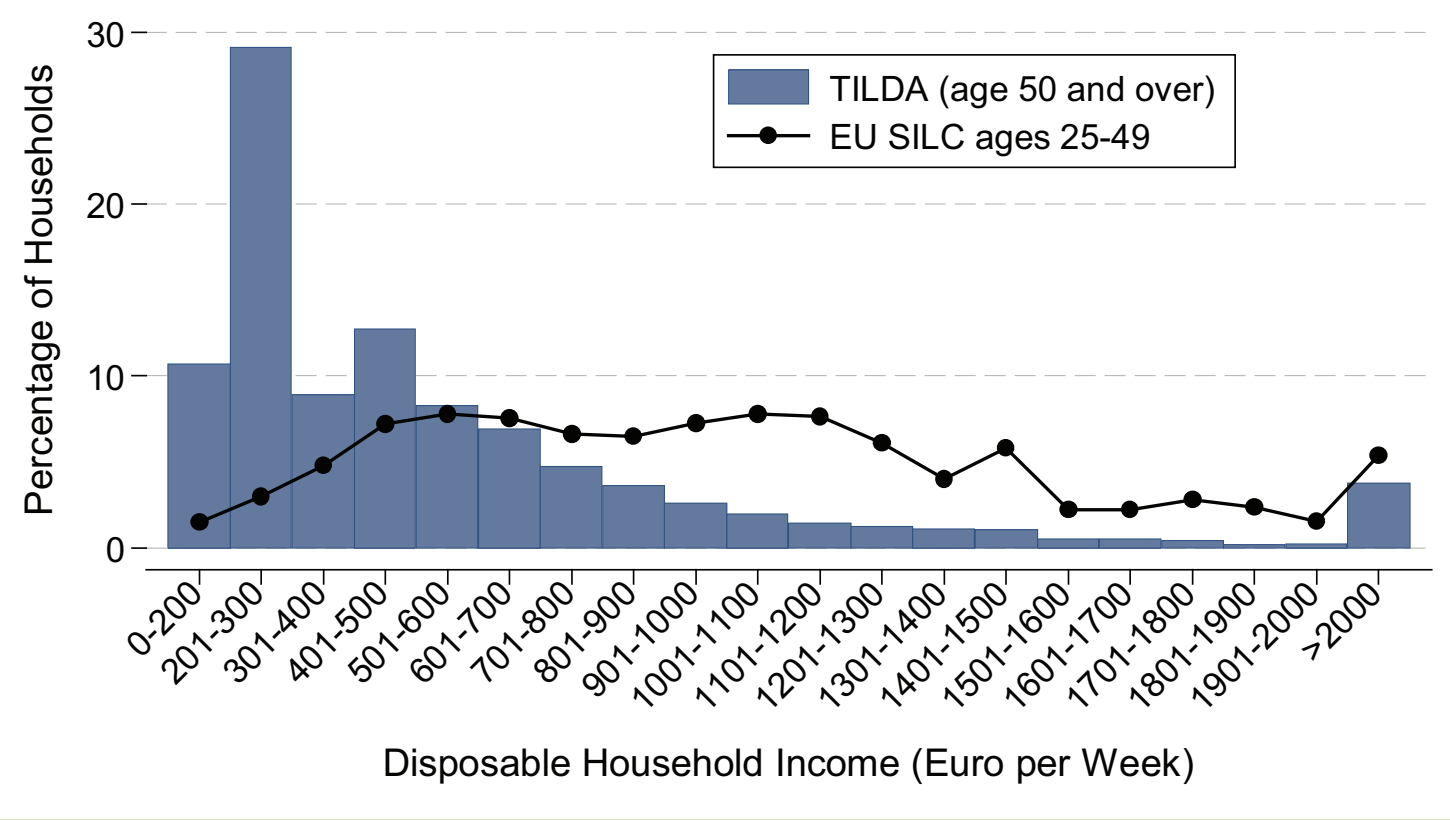

\subsection{Explaining variability in the incomes of older people}

Section 9.3 showed that there was less income variability among people aged $50+$ compared to those aged 18 to 49 because of the importance of the old age pension among this group. Nonetheless, the incomes of older people do vary and TILDA can provide insights into the factors that explain this.

1 It is not possible to carry out a direct analysis of the 'at risk of poverty' rate using TILDA alone. This is because the threshold is defined as $60 \%$ of the median income from the general population in the year in which the data are observed. This is not available in TILDA. 


\subsubsection{Income by age groups}

Figure 9.2 shows the median household (un-equivalised) and equivalised disposable income by the age of the respondent. Median weekly household disposable income declines from $€ 558$ amongst those aged $50-64$ to $€ 321$ for those aged 75 or over. However, when income is equivalised the gap between age groups is much reduced. The median equivalised income for those aged $50-64$ is $€ 290$, the median for those aged $65-74$ is $€ 315$ and the median for those aged 75 or over is $€ 259$. The medians for equivalised income between the different groups are very similar because equivalisation produces a per household member measure of income. Given that older age groups are more likely to be living on their own (for example, if their partner has passed away) and younger age groups are more likely to have children still living with them, the equivalised amounts are very similar despite the unequivalised amount being different.

Figure 9.2: Median household income and equivalised income by age (Euro per week)

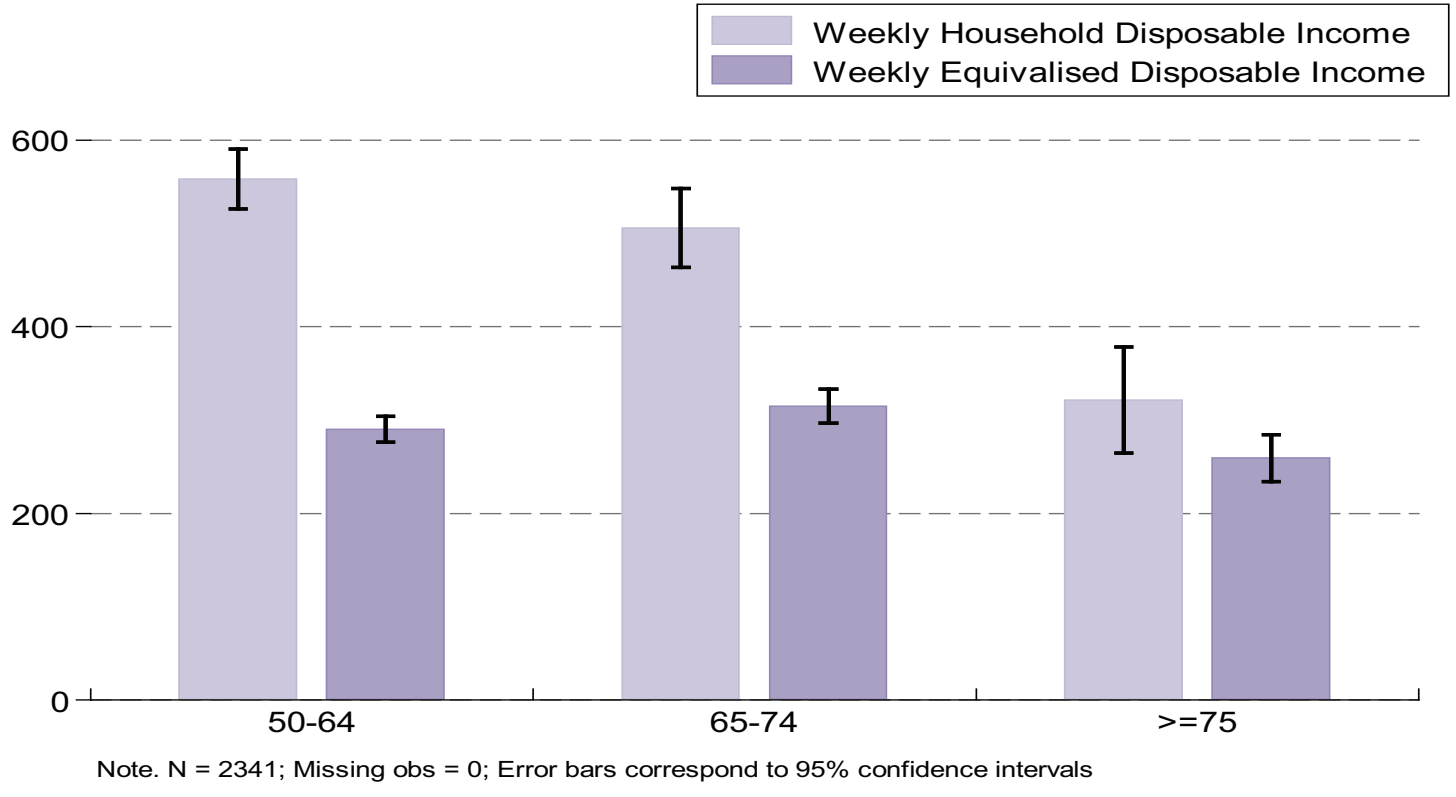

Figure 9.3 shows how the relationship between income and age varies by education. The largest absolute decline in income amongst older age groups is greatest for those with tertiary education where median household disposable income is $€ 922$ for those aged 50-64 and is €624 for those aged 75 and over. Expressing income of those aged 75 and over as a percentage of those aged $50-64$, there is a $33 \%$ decline in income for those with tertiary education. This is approximately the same as the relative decline in incomes between those aged 50-64 (€386) and those aged 75 and over $(€ 255)$ for those with primary education. For those with secondary education, the median household disposable income for those aged 50-64 is $€ 591$ and for those aged 75 and over it is $€ 474$. 
Figure 9.3: Median household income and equivalised income by age (Euro per week)

Weekly Household Disposable Income Weekly Equivalised Disposable Income

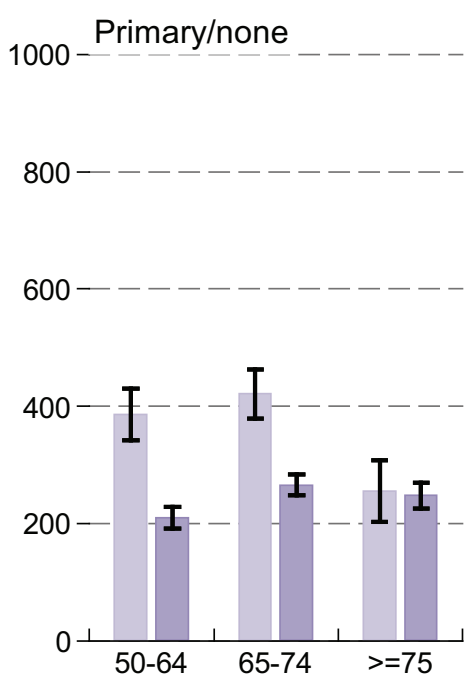

Secondary

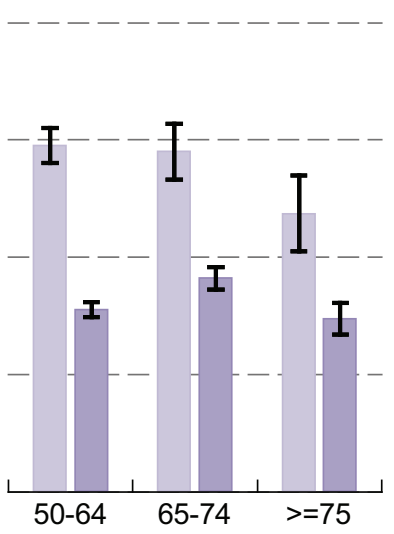

Third/higher

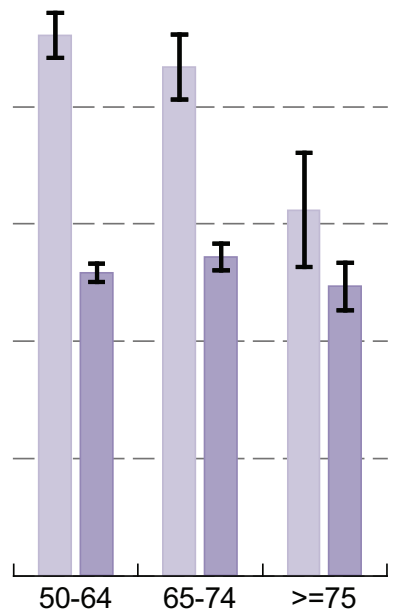

Note. $\mathrm{N}=2341$; Missing obs $=0$; Error bars correspond to $95 \%$ confidence intervals

Once again, equivalisation significantly reduces the differences in median incomes across different age groups due to the different composition of households. This is true for each education group. For those with primary education, equivalised income ranges between $€ 210$ and $€ 266$ depending on age group. For those with secondary education, median equivalised income ranges between $€ 296$ and $€ 364$. For those with tertiary education, median equivalised income ranges between $€ 494$ and $€ 543$ depending on age group.

\subsubsection{The number working in household}

Figure 9.4 shows that one of the primary drivers of household income is the number of adults in the household who are working. Controlling for the number of adults in the household through equivalisation of incomes, couple households where one partner works have higher incomes than those where neither works. However, single households where the householder works and couple households where both work have significantly higher incomes. Interestingly there does not appear to be large differences in income between single men and single women conditional on their work status. 
Figure 9.4: Median equivalised disposable household income by household type (Euro per week)

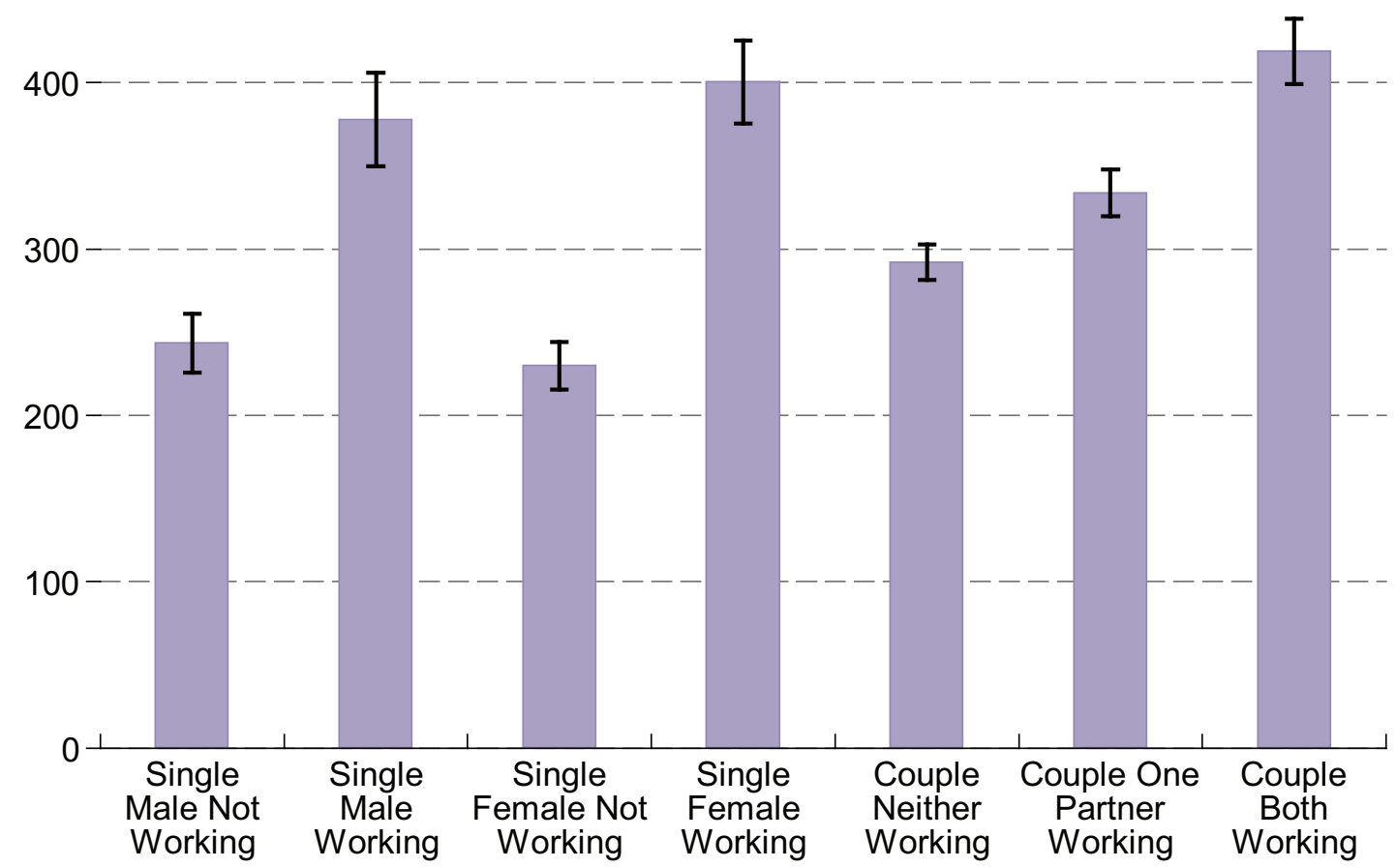

Note. $\mathrm{N}=2341$; Missing obs = 0; Error bars correspond to $95 \%$ confidence intervals

\subsubsection{Income by years of service of retirees}

State and occupational pension income will vary in proportion to years of service whilst working. Figure 9.5 shows that the equivalised household income of retirees does not increase significantly between those who never worked or those who worked for up to 30 years but is significantly higher for those who worked between 31 and 40 years. The fall in incomes among those with $41+$ years of service reflects the fact that these individuals left school earlier and had lower occupational attainment on average than those with 31 to 40 years of service.

\subsubsection{Income by years since retirement}

Time since retirement is also important as shown in Figure 9.6. Those most recently retired have the highest household incomes, partially because they are likely to have working spouses in the household but also because levels of savings and lump sum payments are depleted over time. Figure 9.6 suggests that the rate of depletion stabilises roughly 10 years after retirement. 
Figure 9.5: Median equivalised disposable income of retirees only by years of service (Euro per week)

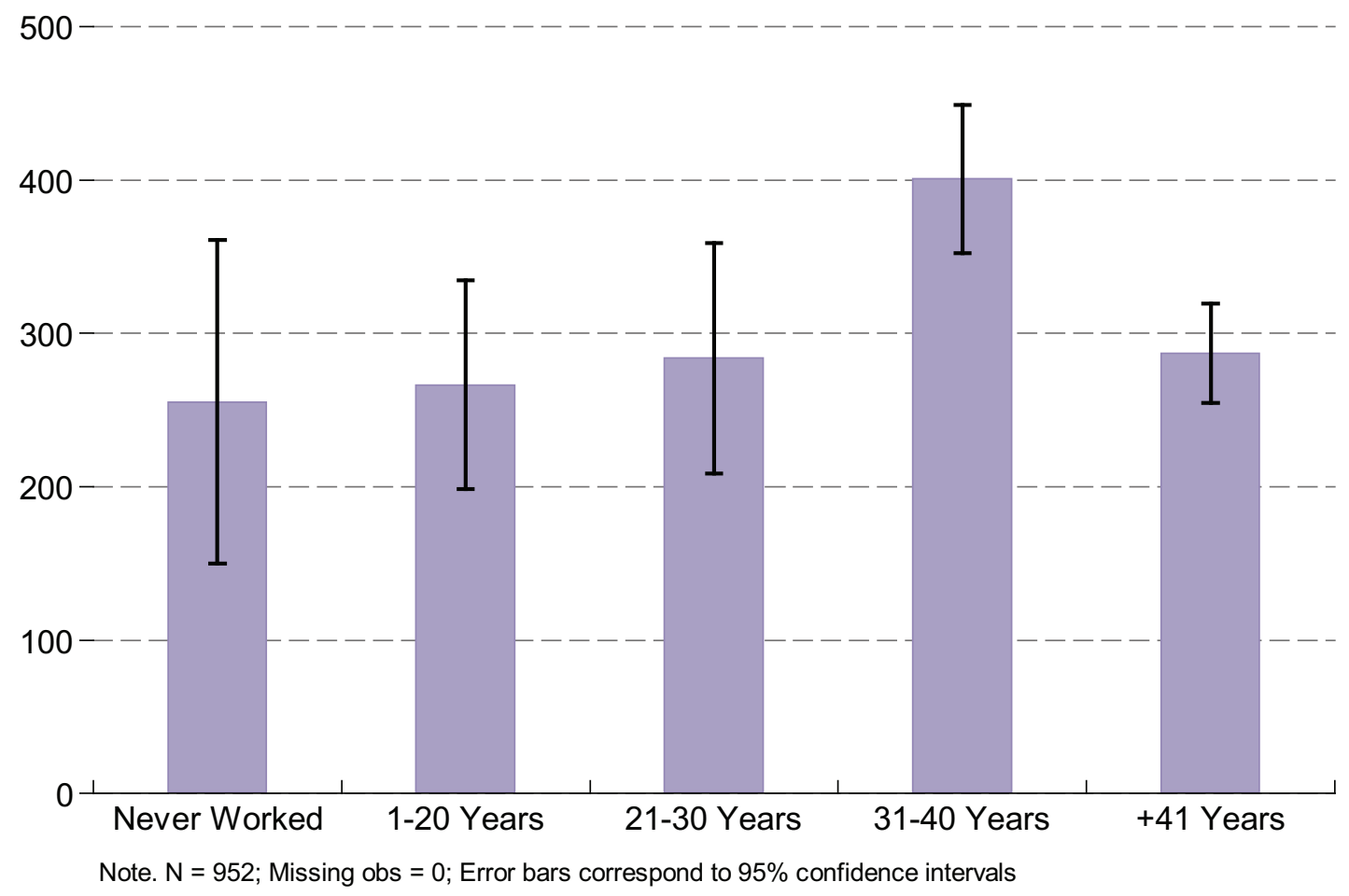

Figure 9.6: Median equivalised disposable income of retirees only by years since retirement (Euro per week)

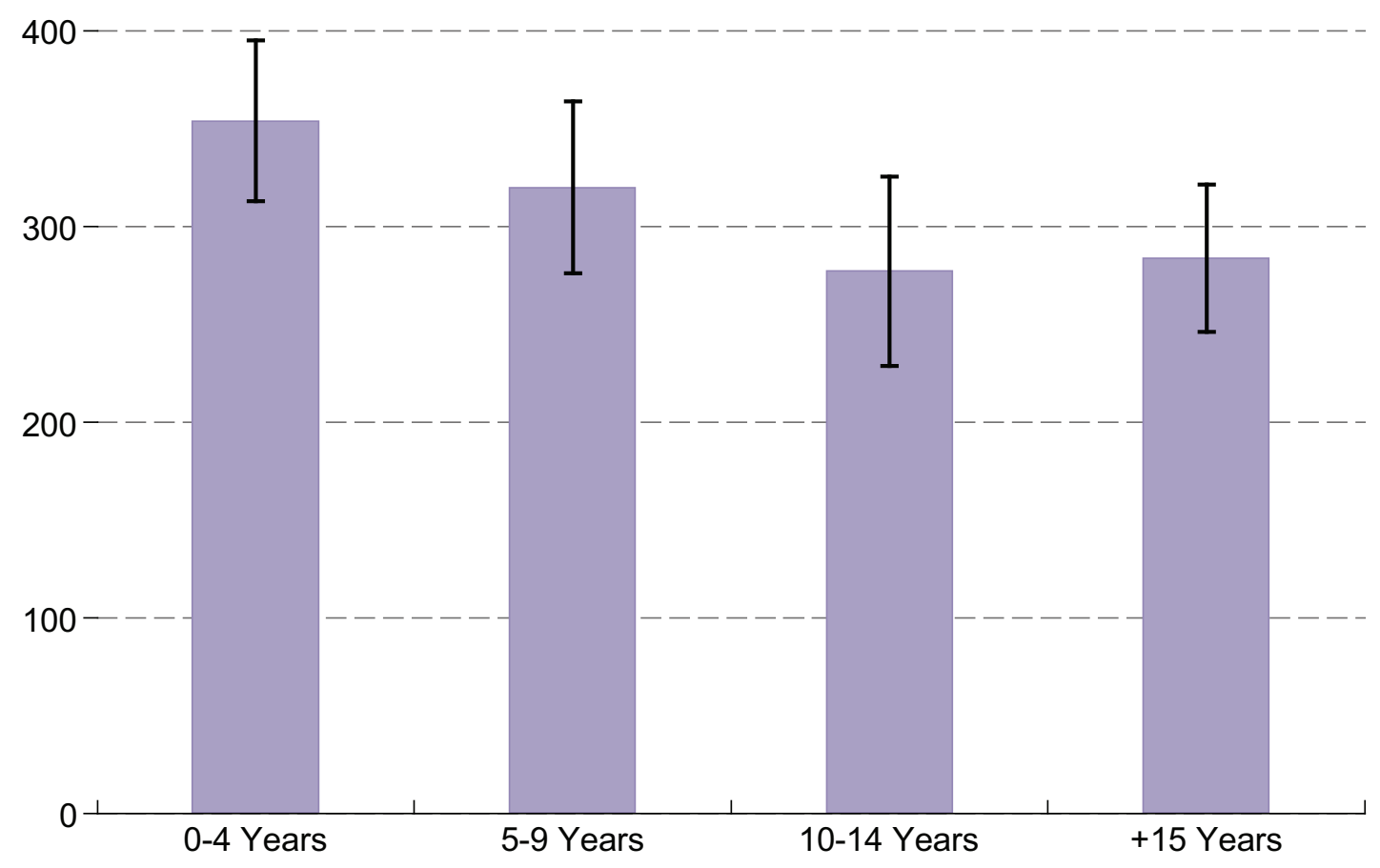

Note. $\mathrm{N}=952$; Missing obs = 0; Error bars correspond to $95 \%$ confidence intervals 


\subsubsection{Income by former occupation and level of education of retirees}

The previous section demonstrated that time elapsed since retirement and years of working before retirement influence post-retirement income. The type of job that the person had during their period in paid employment may also affect pension income and savings. The effect of socio-economic group (SEG) on income in retirement is shown in Figure 9.7. Having been in a profession or in a managerial position is associated with the highest income levels in retirement with income lower in those who had a manual occupation compared to non-manual occupations. Although the median income of the previously self-employed is lower than the median income of manual employees, the confidence interval is wider because of the larger variability among this group. For example, the group includes the selfemployed plumber or electrician alongside the owner of a company with a thousand employees. The large standard error for those previously self-employed could also be explained by the small number of observations in this category which arose as currently retired respondents had to volunteer, unprompted by the questionnaire, that they were self-employed rather than be asked about self-employment directly as is the case with respondents currently working.

Figure 9.7: Median equivalised disposable income of retirees only by socioeconomic group of their former occupation (Euro per week)

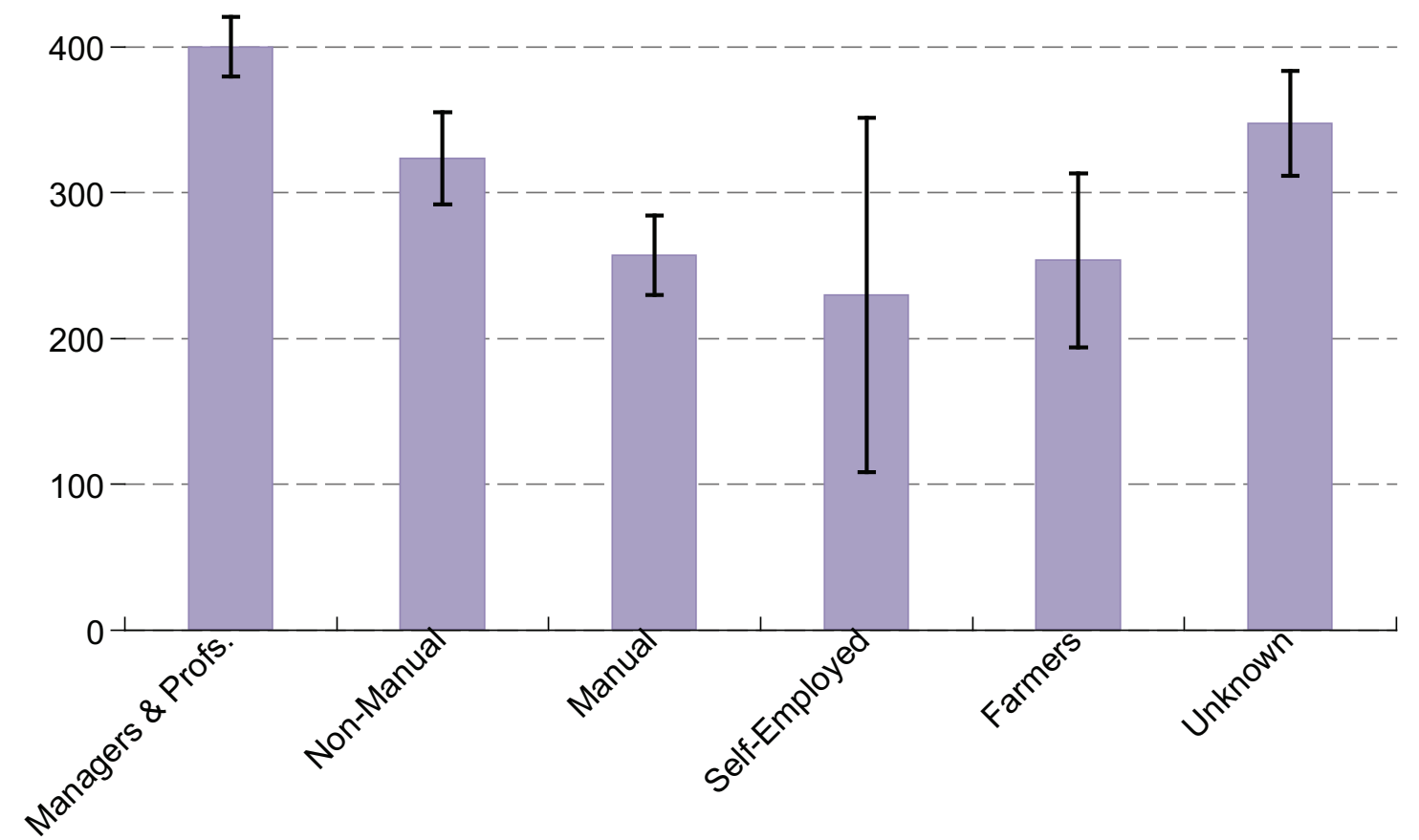

Note. $\mathrm{N}=952$; Missing obs = 0; Error bars correspond to $95 \%$ confidence intervals 
Consistent with the higher pension incomes seen in professional groups, it was also found that the median equivalised disposable income of those with tertiary (third level) education is $€ 552$, which is significantly higher than those with primary (€254) or secondary education (€322).

\subsection{Sources of income}

TILDA respondents were asked about the different sources that made up their overall income. Respondents were asked about levels of income from various sources, and each of these was classified as being labour income, social welfare, state pension or occupational pension. Figure 9.8 gives the proportion of each household's 'income package' made from different sources by the age and educational attainment of the individual. Looking across the different educational levels, income from paid work or 'labour income' makes up a majority of the total income of those aged less than 65. Pension incomes contribute to total income here because some respondents will have retired partners. Among those aged 65-74 the proportion of income from state pensions is over $60 \%$ and increases to over $75 \%$ among those aged 75 and over. The proportion of income from state pensions decreases with increasing educational attainment.

Figure 9.8: The distribution of sources of gross household income by age and education

Labour Income
State Pension

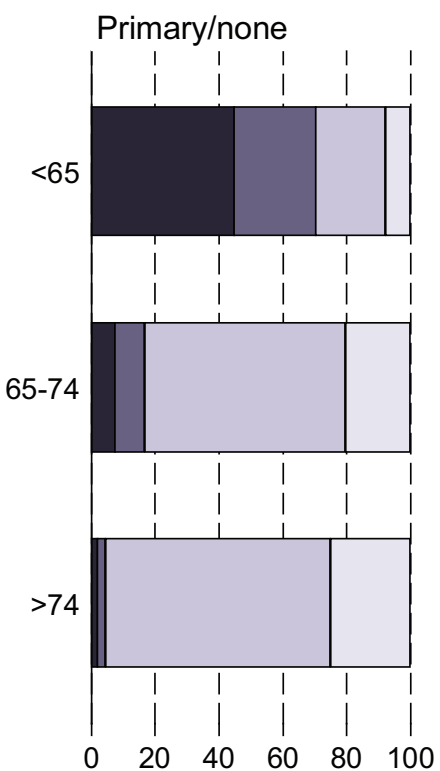

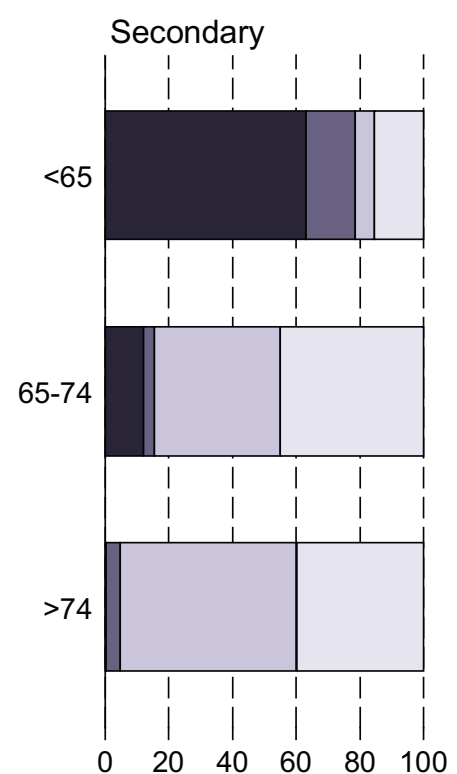

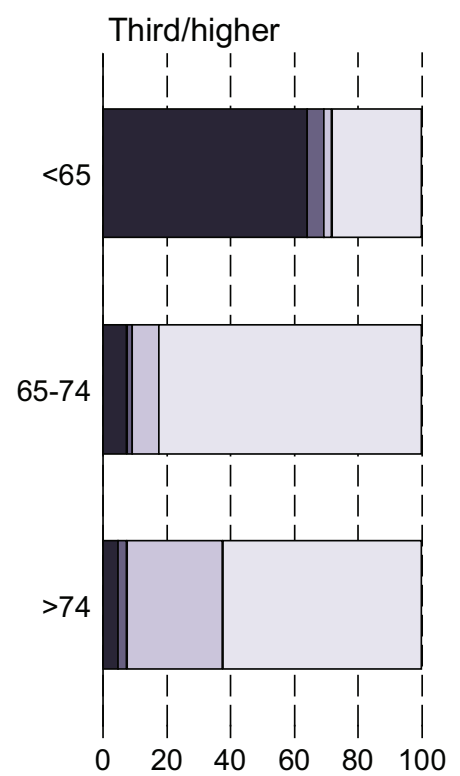


As level of education increases, the proportion of income from occupational pensions (including public sector pensions) or private pensions also increases, reaching over $70 \%$ of the total among those aged $65+$ with third level education. As described earlier, these groups are more likely to have had professional and managerial occupations that generally include an occupational pension although the proportion has been falling in recent years (10). It is also important to note that the measure of income used in this chapter includes lump sum payments so the proportion of income coming from occupational pensions would be high for those who have such a pension.

Figure 9.9 shows the proportion, by age group and highest educational attainment, of those whose only source of income comes from state transfers. Here, state transfers include the contributory and the non-contributory state pensions as well as other state assistances, allowances and benefits. It is striking that, regardless of age group, the proportion of those who depend solely on state transfers is considerably higher amongst the least educated group. In that group, around $35 \%$ of people aged 50-64 have state transfers as their only source of income. This rises to just over half for those aged 75 years and older. For those with secondary education, the proportion solely depending on state transfers in each age group is less than half that of the corresponding age group with primary education. For those with tertiary education, the proportion of those with only state transfers as a source of income is $6 \%$ for the youngest and middle age group and rises to $12 \%$ for the oldest group.

Figure 9.9 Proportion (\%) by age and education of those whose sole source of income comes from state transfers

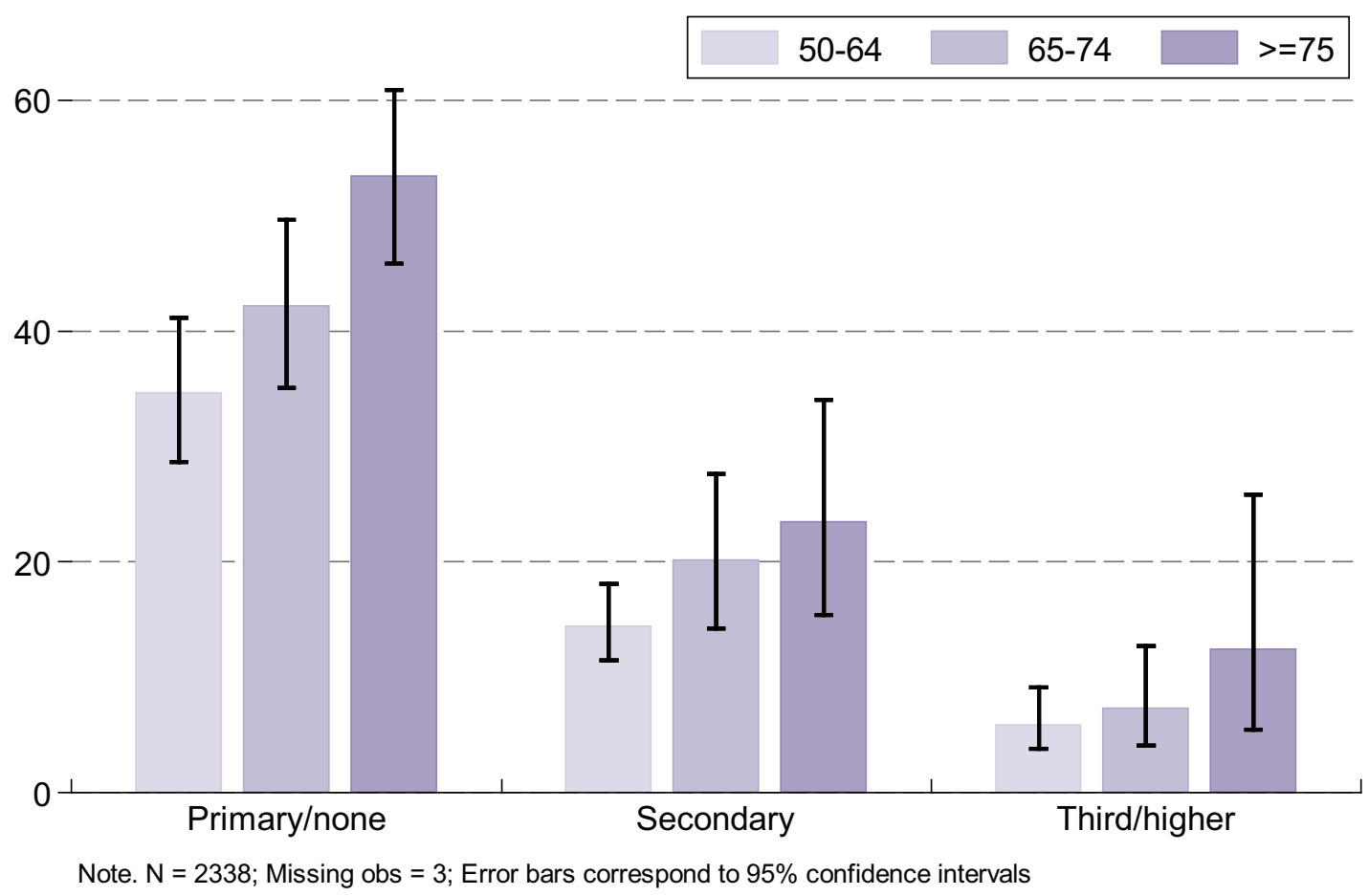




\subsection{Asset holdings of older people}

TILDA has collected information on the asset holdings of older people in Ireland. Income levels and asset holding are both key economic variables. However, for older people, assets are particularly important. As people withdraw from the labour market as they age, they may need to rely on savings and other asset holdings, in addition to any pension entitlements, to maintain their standard of living into the future. Savings and other assets can also provide a financial buffer to deal with adverse unexpected events such as a serious illness requiring expensive treatment. A final motive for holding assets could be to provide financial assistance to family members or indeed, to provide an inheritance to family members or others. This subsection first examines housing tenure and self-valuations of current residences and then moves on to discuss other forms of asset wealth as well as debt. It concludes with a brief discussion of the relationship between assets and income.

\subsubsection{Housing tenure and house valuations}

As can be seen in Figure 9.10, the majority of older people own their own home outright. This finding is constant across education groups. A significant minority ( $16 \%$ to $32 \%$ depending on education level) of those aged less than 65 are still paying off a mortgage but this proportion becomes negligible amongst those aged over 65 . This is true regardless of education level. The proportion renting on the private market is very small (3\%-6\%) across different age and education groups. The "Other" category includes individuals living in the homes of their children. The proportion in this group is small (on average about $2 \%$ ) but is largest amongst the very oldest age groups ( $5 \%-7 \%$ amongst those aged 75 and over). The proportion of respondents renting from local authorities is concentrated amongst those who left education after primary school ( $9 \%-25 \%$ depending on age group) and is under $10 \%$ for other education groups.

Information on the self-valuations of property was collected by TILDA, however, it should be noted that at the time of data collection the property market was falling or stagnant and so the valuations of respondents may not have been an accurate reflection of the actual current value of their homes. The likelihood that a person makes any or an accurate prediction of the value of their home may depend on a number of factors. For example, if the respondent has adult children who bought a home in recent years, they may be more aware of the state of the property market.

Keeping in mind the issue of the difficulty of valuation of homes in the current economic climate, the median self-valuation is $€ 200,000$ amongst those who own their own home (including those paying off mortgages). Figure 9.11 shows how this varies by education level: the median for those with tertiary education is $€ 300,000$ and the median for those with primary education is $€ 170,000$ and for those with secondary education the median is $€ 200,000$. 
Figure 9.10: Housing tenure by age group and highest educational attainment

\begin{tabular}{|ll|}
\hline Owned Outright & $\square$ Paying Mortgage $\square$ Private Rental \\
$\square$ Local Authority & $\square$ Other
\end{tabular}
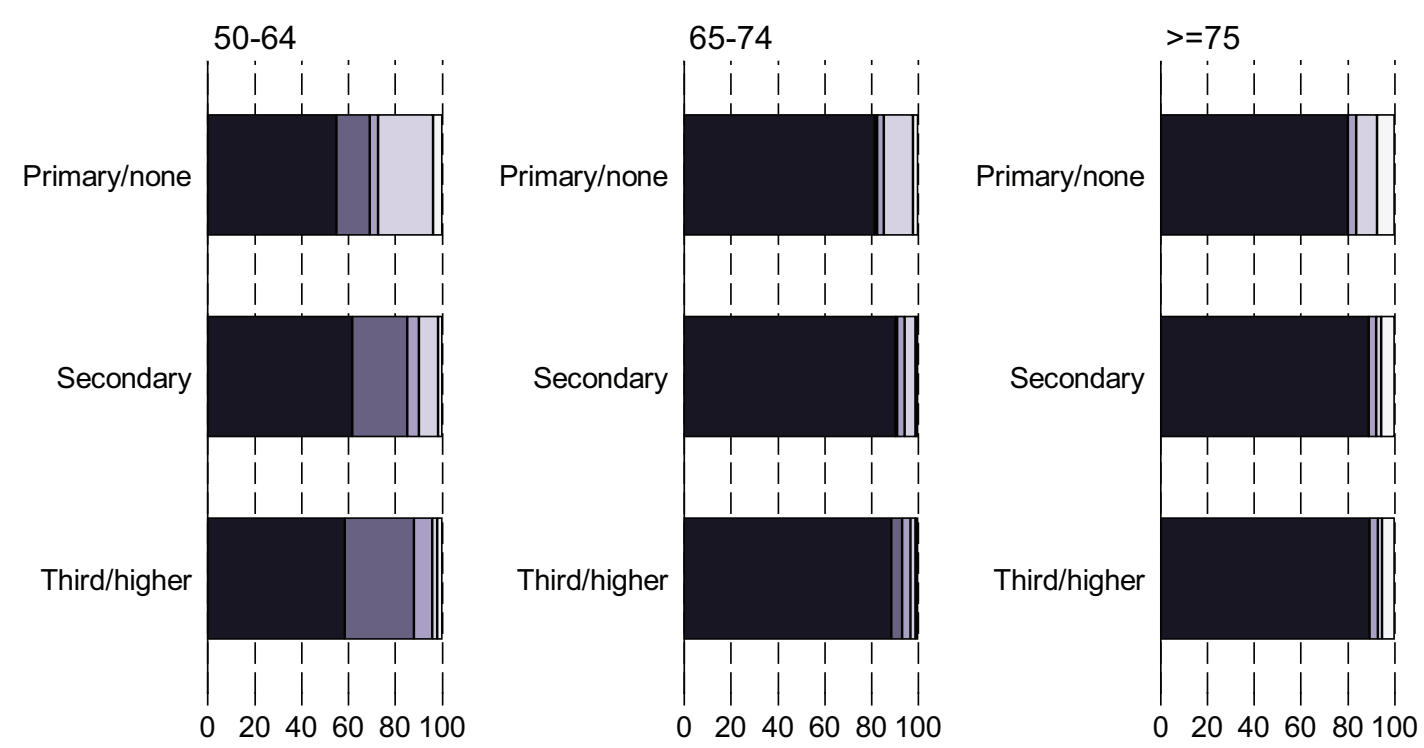

Note. $\mathrm{N}=2341$; Missing obs $=0$

Figure 9.11: Median of current valuations of private residence by highest educational attainment

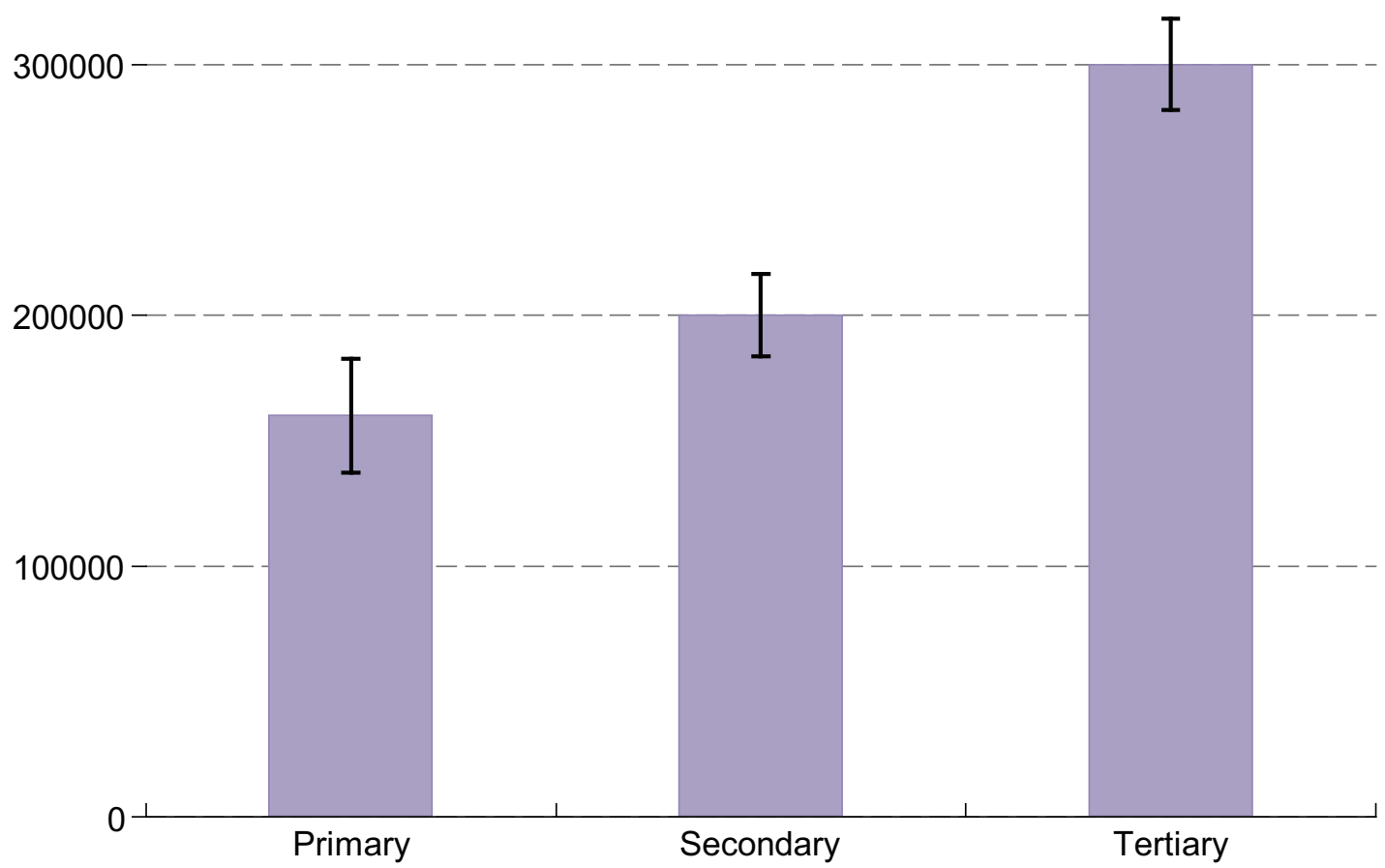

Note. $\mathrm{N}=1935$; Missing obs = 0; Error bars correspond to $95 \%$ confidence intervals 


\subsubsection{Ownership of property other than current residence}

Around $13 \%$ of older people own a residential property that is not their main residence. Property other than current residence includes houses, apartments and holiday homes but excludes time shares. The proportion owning property other than their current residence varies considerably over education groups. Figure 9.12 shows that around $30 \%$ of those with tertiary education own at least one such property compared with $15 \%$ for those with secondary level education and just $5 \%$ for those with primary education.

Figure 9.12: Proportion with property other than current residence, debt or savings by highest educational attainment

Any Property Other than Current Residence

Any Savings $\quad$ Any Debt

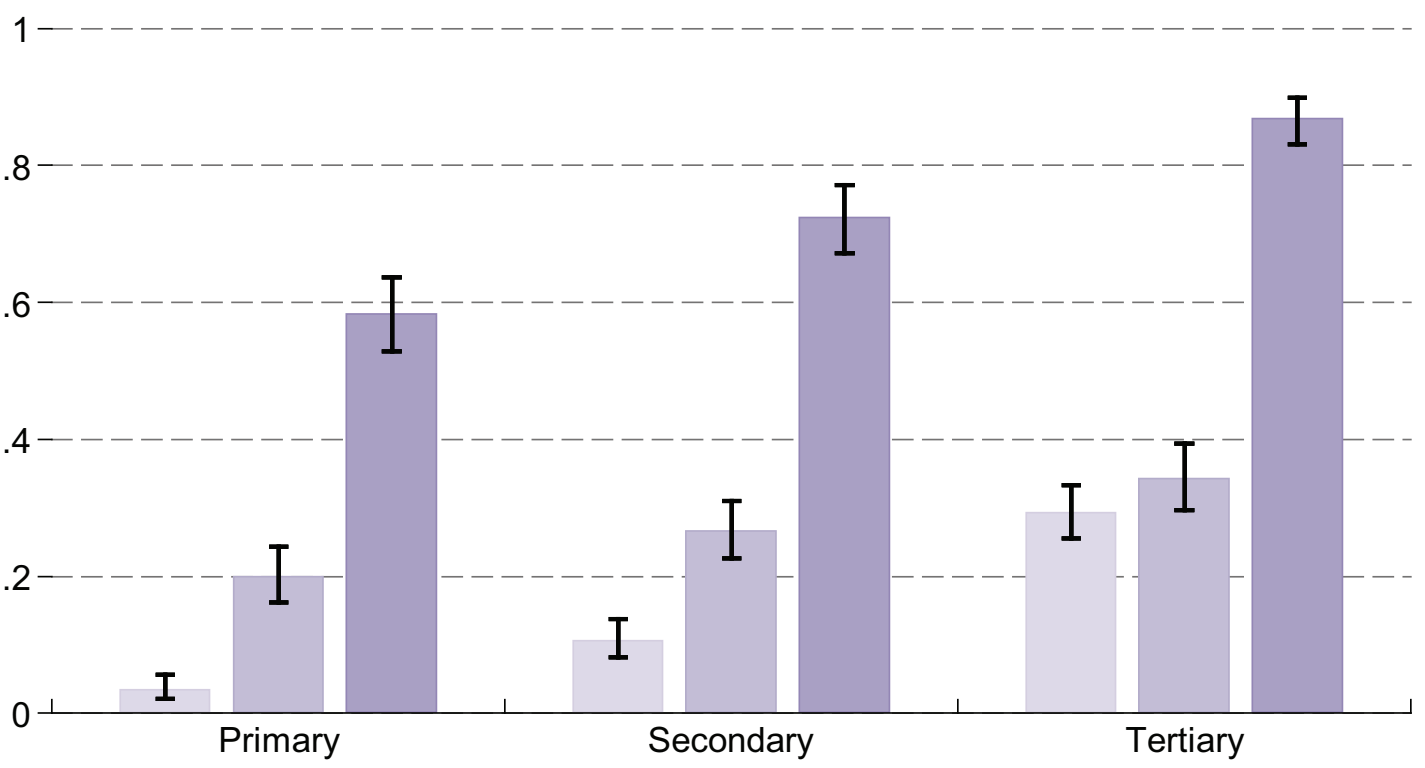

Note. $\mathrm{N}=2341$; Missing obs $=0$; Error bars correspond to $95 \%$ confidence intervals

Although the date at which respondents purchased the property is not known nor the price they purchased at, it is probable that at least some invested during the property bubble and are possibly in negative equity. The problem of negative equity may, therefore, not be confined to younger people and may even be more problematic for older people who may have been planning to cash in on their property investments in the near future and cannot sit out the property slump in the same way that younger people can. The median self-estimated value of properties other than current residence is $€ 200,000$. Figure 9.13 shows that the median varies across education group with the median property value of the primary educated group being $€ 180,000$ (the very wide confidence interval reflecting the small number of observations in this group), $€ 180,000$ for those with secondary education and $€ 250,000$ for those with tertiary education. 
Figure 9.13: Median value of property (other than current residence) by highest educational attainment (Euro)

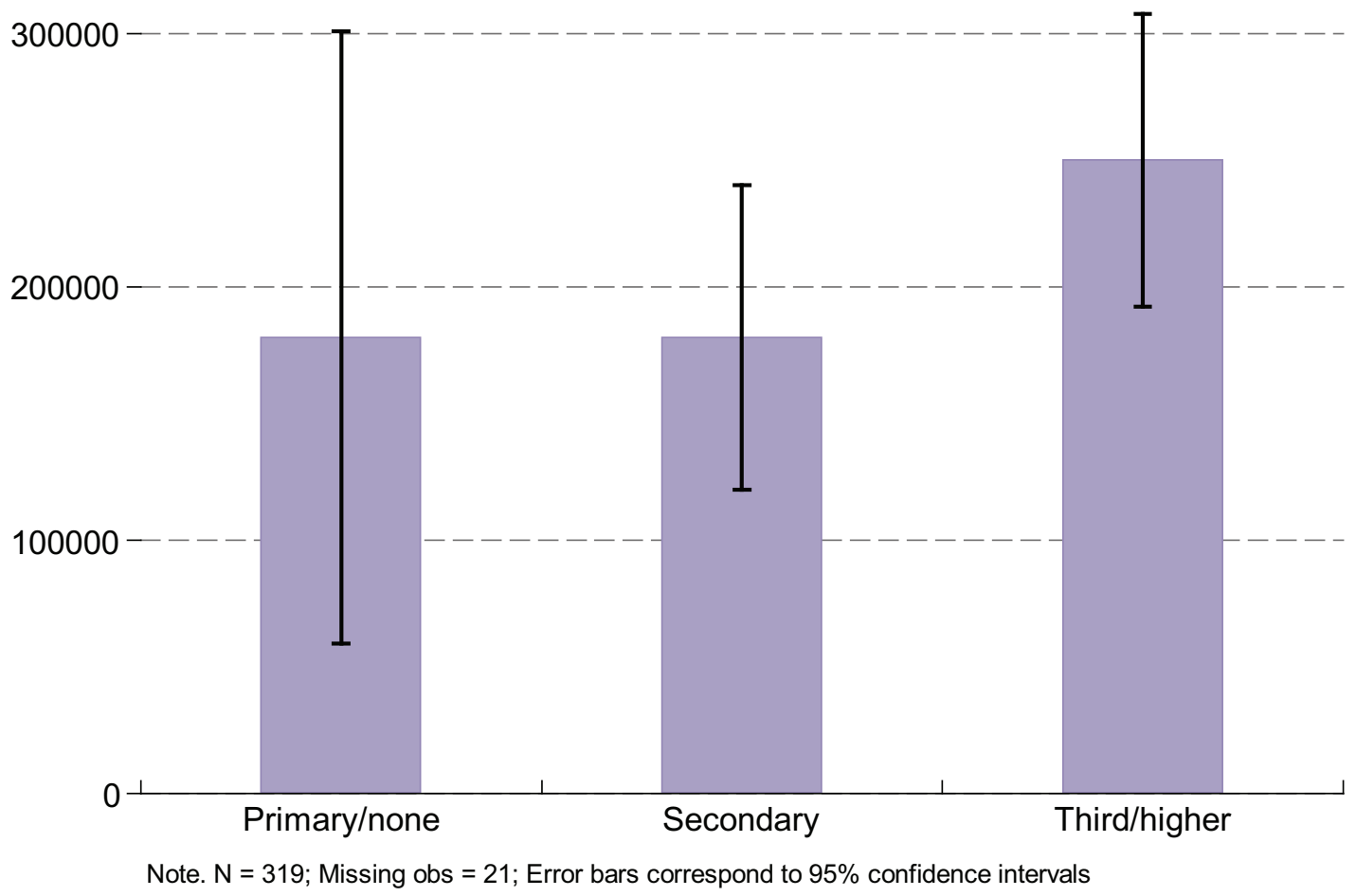

\subsubsection{Savings levels among older households}

Figure 9.12 also shows that the proportion of those with any savings (held in savings or deposit accounts) or other financial assets (including bonds, mutual funds or shares, but excluding future pension entitlement) is just under $60 \%$ of people with primary education, around $76 \%$ for those with secondary education and around $85 \%$ for those with tertiary education. Figure 9.14 shows that the median level of wealth holdings varies by the highest level of educational attainment within the household. Households with primary education have median holdings of $€ 14,000$, less than half of the holdings of older people with secondary education $(€ 30,000)$ and less than a quarter of the median savings of those with tertiary education $(€ 60,000)$.

\subsubsection{Debt levels}

Figure 9.12 also shows that roughly one-fifth of the older population have some debt that does not include mortgages on their primary residences. TILDA respondents were asked their level of debt on property other than current residence, debt on cars and other vehicles, overdue bills (phone, electricity, heating), overdue credit cards/store card bills, other loans (from bank, building society or other financial institution), debts to relatives or friends and so on. Figure 9.15 shows that the 
probability of a household having debt differs by the level of education: households that have higher levels of education are more likely to be in debt. Around a fifth of those with primary education are in debt. Around $28 \%$ of those with secondary education are in debt and about a third of those with tertiary education are in debt. Figure 9.15 shows that conditional on being in debt, the median level of debt for those with primary education is $€ 6,000$ and the median level for those with either secondary or tertiary education is $€ 10,000$.

Figure 9.14: Median level of savings or other financial assets by highest educational attainment (Euros)

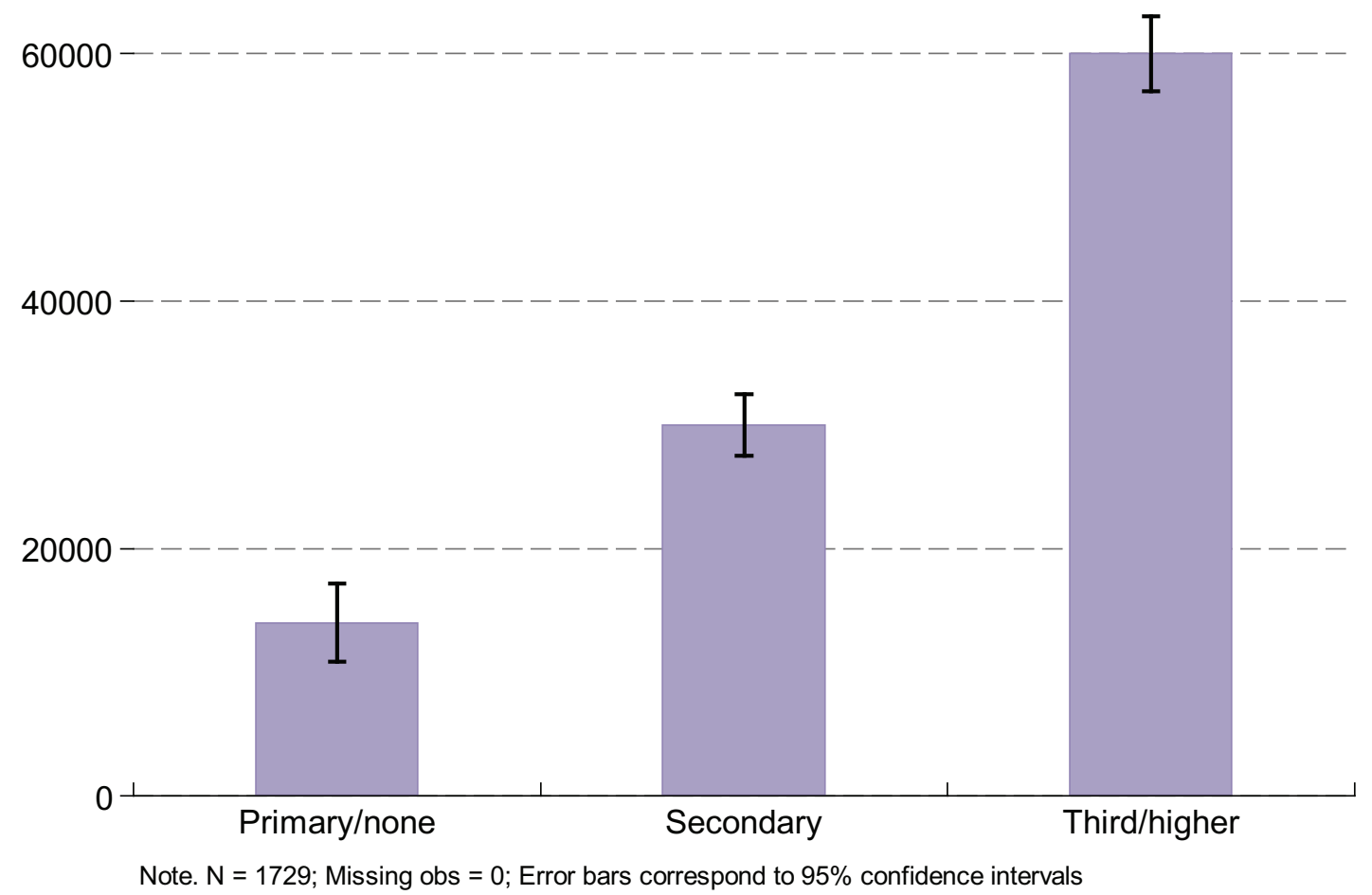

\subsubsection{Relationship between income and assets}

There is widespread belief that older people are 'income poor but asset rich' compared with younger people. Unfortunately, it is not possible to compare asset holdings by income levels of older people with those of younger people due to lack of a comparable dataset on younger people. However, an analysis of TILDA alone is still informative. Figure 9.16 shows the relationship between income and net assets. For each income group, median net assets are positive (or zero in the case of assets other than current residence for the lowest income group). Figure 9.16 shows that individuals with higher weekly disposable income have higher asset holdings. However, the relationship is less pronounced when we count the value of owneroccupied property alone, to the exclusion of second or subsequent homes. The median value of owner occupied residential property net of mortgage for the lowest income group is around $€ 100,000$. This rises to over $€ 330,000$ for the highest income 
group. However, when we look at other types of assets (that is, not the value of the respondent's home) the relationship is different. Asset holdings still rise with income level, but it is important to note that the median net asset holding for those in the lowest income group, while still positive, is very small (c. $€ 3,000)$.

Figure 9.15: Median level of debt by highest educational attainment (Euro)

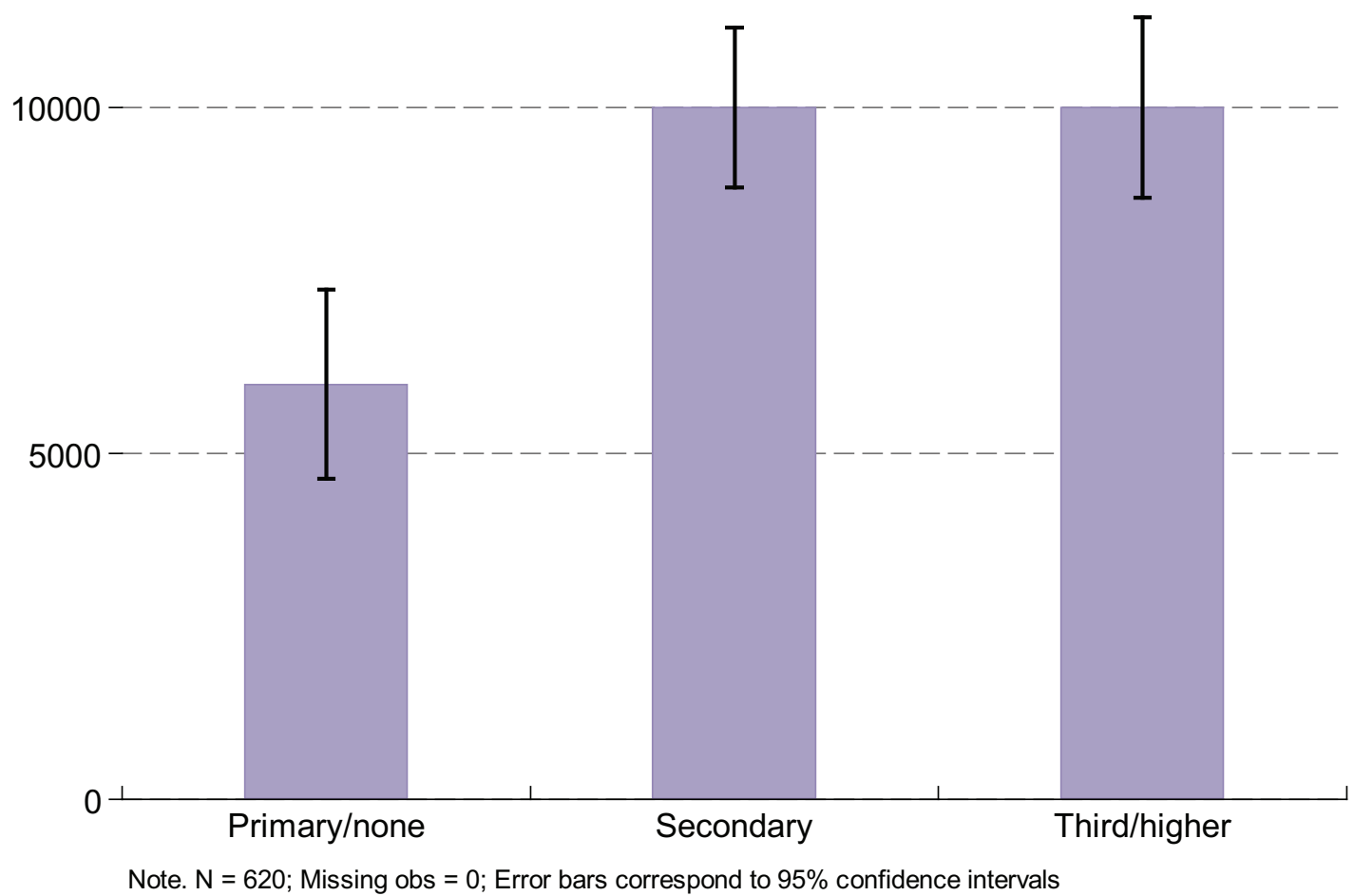

\subsection{Conclusions}

This chapter has focused on income, wealth and assets among older people in Ireland and examined some of the factors that influence the distribution of these variables across older people. Age, educational attainment, household structure, labour supply and occupation are all related to income levels and asset holdings.

There is considerable heterogeneity amongst old people in terms of income. While 1 in 8 people aged 50 or over have an income of $€ 1,000$ or more a week, around $30 \%$ live on between $€ 201$ and $€ 300$. Educational attainment is a stronger determinant of income than age within this group and a very large proportion of those with primary education are dependent on state transfers as their only source of income. Thus a 'one size fits all' approach to social welfare policy would ignore that different groups would be affected differently by policy changes. 
Figure 9.16: Median net assets by level of weekly household disposable income (Euro)

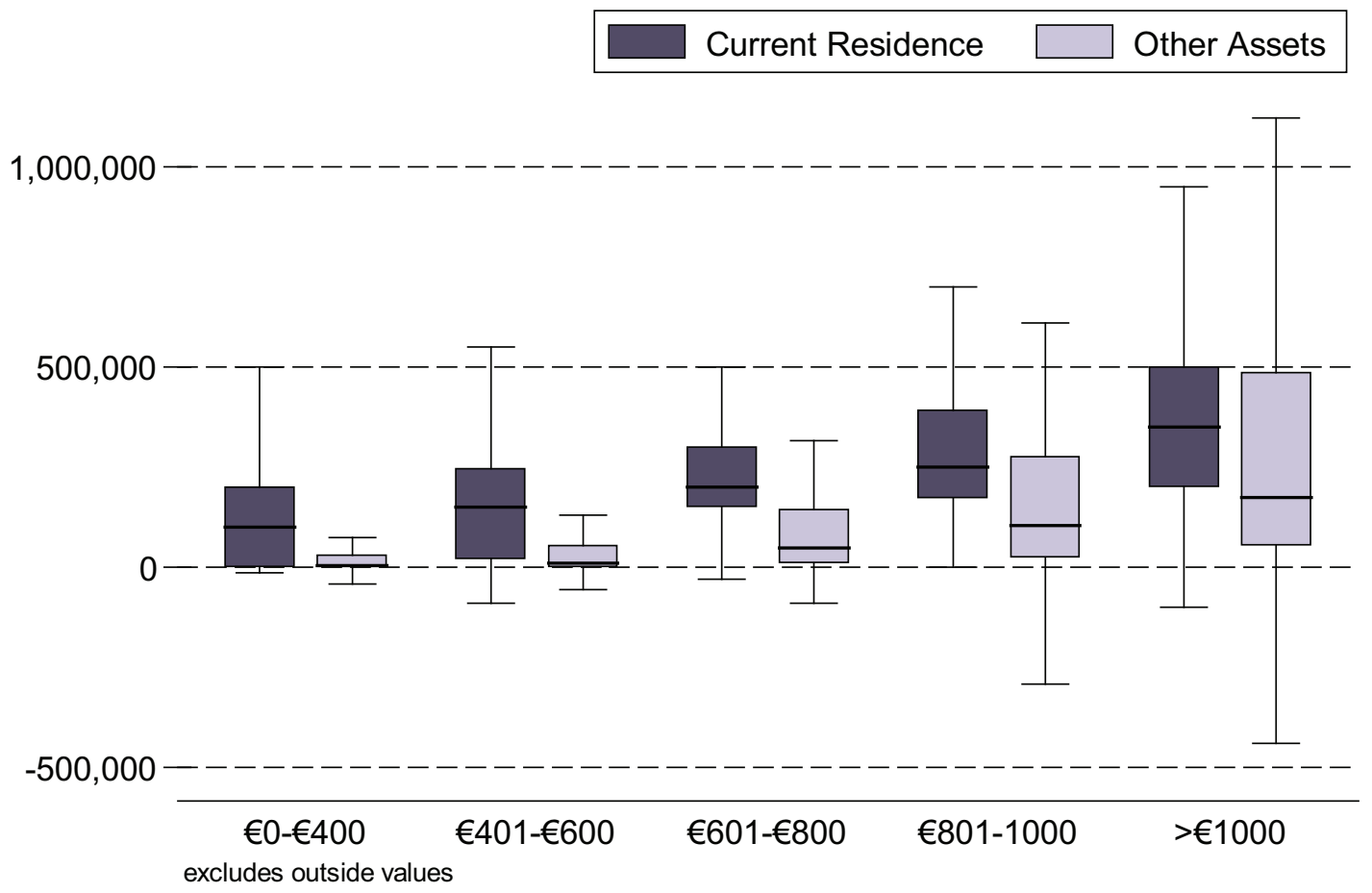

With respect to home ownership, there is less heterogeneity between education groups, with the vast majority owning their own home. However, the self-valuations of these homes vary by education level and there is diversity amongst older people with respect to owning other types of assets. Those with higher educational attainment are much more likely to have bought a property other than their own home and may realise losses as a result of their investment over the next number of years. At least some of these second or subsequent homes could have been bought during the housing boom using life savings or pension lump sums. Due to their age, this group of better educated older people may not have the option of waiting for property prices to rise again when there is a resolution to the current banking and property crisis.

This chapter highlights that certain groups of people aged 50 and over are in a more precarious financial position than others. In particular, those with lower socioeconomic status (measured here by level of education) are in a much less comfortable position in relation to wealth. They have lower incomes and are much less likely to have savings or other liquid financial assets that could be drawn from during old age. 


\section{References}

1. Booth, C. 1903. Life and Labour of the People in London: London.

2. Layte, R, T. Fahey, and C. T Whelan. 1999. Income Deprivation and Well-Being Among Older Irish People. National Council on Ageing and Older People.

3. Layte, R. \& Whelan, C. T. 2004. Class Transformation and Trends in Social Fluidity in the Republic of Ireland 1973 to 1994. In R.Breen (Ed.), Social Mobility in Europe. Oxford University Press.

4. Nolan, B. \& Maitre, B. 2008. Economic Growth and Income Inequality. In T.Fahey, H. Russell, \& C. T. Whelan (Eds.), Quality of Life in Ireland: The Social Impact of Economic Boom (pp. 27-42). New York: Springer.

5. Smyth, E. \& Hannan, D. F. 2000. Education and Inequality. In B.Nolan, P. J. O'Connell, \& C. T. Whelan (Eds.), Bust to Boom? The Irish Experience of Growth and Inequality (pp. 109-126). Dublin: Institute of Public Administration.

6. Whelan, C. T. \& Layte, R. 2002. Late Industrialisation and the Increased Merit Selection Hypothesis: Ireland as a Test Case. European Sociological Review.

7. Watson, D, Pichler, F, and Wallace, C. Subjective Well-Being in Europe. 2010. Luxembourg, Office for Official Publications of the European Communities. Second European Quality of Life Survey. Ref Type: Serial (Book,Monograph)

8. Layte, R, Maître, B, and Whelan, C. T. Living Conditions, Social Exclusion and Mental Well-Being. 2010. Luxembourg, Office for Official Publications of the European Communities. Second European Quality of Life Survey. Ref Type: Report

9. CSO. Survey of Income and Living Conditions (SILC) 2009. 2010. Dublin, The Stationery Office. Ref Type: Report

10. Hughes, G and B. Nolan. 2000. Comparative and Segmented Labour Markets and Exclusion from Retirement Income. In Policy Measures for Low-wage Employment in Europe. Edited by W. Salverda, C. Lucifora, and B. Nolan.Edward Elgar Publishing Ltd. 


\section{Quality Of Life And Beliefs About Ageing}

Hannah McGee, Karen Morgan, Anne Hickey, Helen Burke and George Savva

\section{Contents}

10.1 Introduction

10.2 Quality of life of older adults:

an overview.

10.2.1 Quality of life: overall results.

10.2.2 Quality of life by key demographics factors

10.3 Beliefs about ageing: an overview.

274

10.3.1 Beliefs about ageing:

overall results.

10.3.2 Beliefs about ageing

by key demographic factors

10.4 Conclusions.

282 


\section{Quality of Life and Beliefs about Ageing}

\section{Key findings}

- The older population as a whole experience a high quality of life. The mean score for older people on the CASP-19 quality of life scale is 42.7 , representing $75 \%$ of the total possible score of 57 .

- The best quality of life is experienced by older people with the highest asset wealth.

- The group of older people who have the lowest quality of life, by a considerable margin, are those who rate their health as fair or poor (scoring 36.3 on CASP-19).

- Older people on the whole perceive the ageing process positively, believing they have considerable control over the positive experiences of ageing, but less over the negative aspects.

- The wealthiest and the most educated older people perceive ageing most positively.

- People in the oldest age category (75+ years) have the most negative perceptions of ageing.

\subsection{Introduction}

With increases in life expectancy, delayed onset of morbidity, and higher expectations for old age, interest in well-being in later life and how to achieve it has intensified. 'Successful ageing' has come to the fore as a goal for the ageing population. While an agreed definition of successful ageing remains elusive, there is broad agreement that core constituents include physical health and functioning, psychological wellbeing, and social functioning and participation (1). As the older population surges both in absolute and relative numbers, well-being in old age has also become a focus for policy-makers as a key indicator of the physical and psychological health, social integration and economic security of the older community.

Despite the adverse changes that occur with increasing age, older people typically report high levels of well-being. Most feel younger than their actual age and maintain a sense of confidence and purpose. In the HeSSOP (Health and Social Services for Older People) surveys of older people in Ireland, conducted in 2000 and 2004, over three-quarters of community-dwelling older people scored high on morale $(2,3)$. In fact, older people are more likely to report satisfaction with their lives than younger people (4). Old age, it appears, brings with it an ability to adapt to age- 
related changes and stresses. One study found, for example, that physical decline did not have an impact on older people's satisfaction with life, suggesting that they regard it as a normal and relatively acceptable part of ageing (5). Moreover, older people recognise benefits in old age, such as increased wisdom and maturity, with opportunities for growth and lessening of demands upon them. Research has come to emphasise that ageing is highly specific to each individual, which implies that the pathway of old age is not predetermined. While growing older unavoidably entails losses, some individuals cope better with these losses than others. With this in mind, this chapter aims to shed some light on the personal, material and social circumstances that influence how well people cope.

To assess the well-being of the older population in Ireland, this chapter looks at quality of life as measured in TILDA. While quality of life is a concept difficult to disentangle from well-being itself, it has come to be regarded as a distinct dimension of well-being. Beliefs about ageing are also examined to provide insights into how the older population perceives the process of growing older.

\subsection{Quality of life of older adults: an overview}

Quality of life is widely accepted as an indicator of successful ageing, and it is monitored as a means of measuring the effectiveness of social policies, welfare programmes, and health care. For this reason, quality of life is increasingly assessed in population surveys of older people, and findings have been encouraging. A study by Bowling and colleagues based on four Omnibus Surveys in Britain found that over $80 \%$ of people aged 65 years and over reported good quality of life (6). The first wave of the English Longitudinal Study of Ageing (ELSA) found that quality of life increased from the age of 50 years and peaked at 68 years; from there it gradually declined and by 86 years had reached the same level as at 50 years (7).

The lack of conceptual clarity around quality of life has been a source of considerable debate, and one of the more significant challenges in quality of life research has been defining the term. While it is recognised as complex and multifaceted, in attempting to quantify it much research conflates quality of life with the factors that influence it, such as health in particular. Older people themselves most commonly define successful ageing by reference to good health and functioning, although these aspects are rarely mentioned in isolation (1), and research on older people has often used health as a proxy measure for quality of life. Reducing quality of life simply to health is likely to distort the representation of old age, however, as it is not uncommon for older people to have serious illness or disability and yet to rate their quality of life as good. In the study by Bowling and colleagues already noted, 62\% of participants who had fairly severe or severe restrictions in daily living nevertheless reported good quality of life (6). In HeSSO-P I, 78\% of participants rated their quality of life as good or very good, but only $14 \%$ had been free from any medical condition in the preceding year (2). 
TILDA uses a measure of quality of life (CASP-19) developed for use in older age, which has been adopted in other longitudinal studies of ageing, including ELSA $(7,8)$. CASP-19 is based on a model that conceptualises quality of life as needs satisfaction, thereby distinguishing quality of life from the factors that influence it (9). The model classifies needs into four domains:

- Control - the ability to actively participate in one's environment (e.g., 'My age prevents me from doing the things I would like to').

- Autonomy - the right of the individual to be free from the unwanted interference of others (e.g., 'I can do the things that I want to do').

- Self-realisation - the fulfilment of one's potential (e.g., 'I feel that life is full of opportunities').

- Pleasure - the sense of happiness or enjoyment derived from engaging with life (e.g., 'I look forward to each day').

Control and autonomy are included as they are prerequisites for an individual's free participation in society. By including self-realisation and pleasure, the model captures the active and self-reflexive aspects of living that bring reward and happiness to people in later life.

The CASP-19 domains are represented by 19 statements, which are presented to participants as part of the self-completion questionnaire. Participants are asked to indicate how often (often, sometimes, not often, or never) each statement applies to them. Responses are scored from 0 to 3 and the mean scores for each domain and a total mean score are calculated. The total score could range from 0 , representing a complete absence of quality of life, to 57 , representing total satisfaction. The maximum score on the control domain is 12; on the three other domains, it is 15.

\subsubsection{Quality of life: overall results}

In TILDA the mean score for quality of life on CASP-19 is 42.7 (Table 10.1), representing $75 \%$ of the total score. This is a very positive finding indicating that, overall, the older population experiences high levels of quality of life. The first wave of ELSA in 2002 reported a similar score, 42.5, for the older population in England (7). However, by the fourth wave in 2008, this score had fallen to 40.7 . In terms of the CASP-19 domains, TILDA respondents reported particularly high scores on the pleasure domain, with relatively lower scores on the control domain. The high score on the pleasure domain suggests that Irish older people derive considerable enjoyment from life, with $85 \%$ reporting that they often enjoy the things they do, while $81 \%$ often look forward to each day. 
Table 10.1: Mean CASP-19 scores in TILDA with ELSA scores for comparison

\begin{tabular}{|l|r|r|r|r|r|}
\hline & $\begin{array}{c}\text { TILDA } \\
\text { mean } \\
\text { score }\end{array}$ & $\mathbf{9 5 \% ~ C l}$ & $\begin{array}{c}\text { Mean } \\
\text { score as \% } \\
\text { of total }\end{array}$ & $\begin{array}{c}\text { ELSA } \\
\text { mean } \\
\text { score }\end{array}$ & $\begin{array}{c}\text { ELSA } \\
\text { S.D. }\end{array}$ \\
\hline Total (0-57) & 42.7 & $42.5-42.9$ & 75 & 40.7 & 8.9 \\
\hline Control (0-12) & 7.1 & $7.1-7.2$ & 59 & 7.6 & 2.5 \\
\hline Autonomy (0-15) & 10.8 & $10.7-10.9$ & 72 & 10.2 & 2.7 \\
\hline Pleasure (0-15) & 13.8 & $13.7-13.8$ & 92 & 13.1 & 2.4 \\
\hline Self-realisation (0-15) & 10.8 & $10.7-10.9$ & 72 & 9.9 & 3.2 \\
\hline
\end{tabular}

Older people are also independent and fulfilled to a large extent, reflected in the relatively high scores on the autonomy and self-realisation domains. Over $90 \%$ feel that they can at least sometimes do the things they want to do, and over $80 \%$ feel that life is 'sometimes' or 'often' full of opportunities. At the same time, family and financial constraints put pressure on their ability to be independent: $30 \%$ feel that family responsibilities can prevent them from doing what they want to do, while $55 \%$ indicate that they are 'sometimes' or 'often' prevented from doing what they want to do by shortage of money.

The lowest relative score is in the control domain, which indicates that older people's needs are least met in relation to engagement with their environment. Over onethird (35\%) feel that their age at least sometimes prevents them from doing the things they would like to do, while $23 \%$ at least sometimes feel left out of things.

ELSA wave 4 also recorded the highest domain score in the pleasure domain (13.1) and lowest in the control domain (7.6). The main divergence between the Irish and English studies was in the self-realisation score, which in ELSA was notably lower at 9.9, compared with 10.8 in TILDA.

\subsubsection{Quality of life by demographic factors}

Many factors influence the quality of life of older people. The importance of health has already been noted. The material conditions of life also have a determining influence. Well-being in later life is associated with higher socio-economic status, financial security and better education (10). ELSA found that scores on CASP-19 were $22 \%$ higher in the wealthiest than the poorest quintile of the population (8). Social integration also plays a key role: quality of life improves with having trusting relationships and social contact $(7,10)$. In this section, variation in quality of life with age, gender, education, self-rated health status, wealth, living arrangements and residential location are examined. 
Age: Quality of life increases between $50-64$ years and $65-74$ years ( 42.5 and 43.3 respectively), followed by a decline to the lowest level at 75 years and over (41.3) (Table 10.2). A similar drop in quality of life at 75+ years was recorded by wave 4 of ELSA, with a marginal difference in scores between the two younger age groups in that study (50-64 years, 41.2; 65-74 years, 41.3; 75+ years, 38.4).

Table 10.2: Mean CASP-19 scores by age

\begin{tabular}{|c|c|c|c|c|c|c|}
\hline & \multicolumn{2}{|c|}{$50-64$ years } & \multicolumn{2}{|c|}{$65-74$ years } & \multicolumn{2}{|c|}{$75+$ years } \\
\hline & Mean & $95 \% \mathrm{Cl}$ & Mean & $95 \% \mathrm{Cl}$ & Mean & $95 \% \mathrm{Cl}$ \\
\hline Total & 42.5 & $42.2-42.8$ & 43.3 & $42.8-43.7$ & 41.3 & $40.7-41.9$ \\
\hline Control & 7.5 & $7.4-7.6$ & 7.0 & $6.9-7.1$ & 5.9 & $5.8-6.1$ \\
\hline Autonomy & 10.5 & $10.3-10.6$ & 11.2 & $11.0-11.3$ & 11.2 & $11.0-11.3$ \\
\hline Pleasure & 13.5 & $13.5-13.6$ & 13.9 & $13.8-14.0$ & 13.9 & $13.8-14.0$ \\
\hline Self-realisation & 10.8 & $10.7-10.9$ & 11.0 & $10.8-11.2$ & 10.0 & $9.8-10.3$ \\
\hline
\end{tabular}

In the individual domains, the overall pattern is not replicated. There is no difference between the 65-74 year olds and those aged 75 years and over in autonomy and pleasure, but both groups score higher than those aged 50-64 years. For example, $89 \%$ of people aged $65-74$ years and $88 \%$ of people aged $75+$ years often enjoy the things they do, compared with $82 \%$ of those aged 50-64 years. On the other hand, it is this youngest group that has the greatest sense of control over its environment, while those aged 75 years and over have the least. More than two-thirds (68\%) of people aged 75 years and over feel that their age prevents them from doing what they would like to at least sometimes, compared with $43 \%$ of those aged $65-74$ years and $22 \%$ of those aged $50-64$ years. In terms of self-realisation, the two younger age categories experience a similar degree of fulfilment, while those aged 75+ years experience less.

Comparing the TILDA data with ELSA domain scores by age (Table 10.3), at each age interval older people in England had higher scores on the control domain but lower scores on the autonomy, pleasure and self-realisation domains, indicating more ability to participate but less sense of independence and less ability to derive enjoyment and fulfilment from their lives. 
Table 10.3: Mean CASP-19 scores by age in ELSA

\begin{tabular}{|c|c|c|c|c|c|c|}
\hline & \multicolumn{2}{|c|}{$<=64$ years } & \multicolumn{2}{|c|}{$65-74$ years } & \multicolumn{2}{|c|}{$>=75$ years } \\
\hline & Mean & S.D. & Mean & S.D. & Mean & S.D. \\
\hline Total & 41.2 & 9.2 & 41.3 & 8.4 & 38.4 & 8.2 \\
\hline Control & 8.0 & 2.4 & 7.6 & 2.4 & 6.4 & 2.4 \\
\hline Autonomy & 10.1 & 2.8 & 10.4 & 2.7 & 10.2 & 2.5 \\
\hline Pleasure & 12.9 & 2.4 & 13.3 & 2.2 & 13.1 & 2.3 \\
\hline Self-realisation & 10.1 & 3.1 & 10.0 & 3.0 & 8.7 & 3.2 \\
\hline
\end{tabular}

Sex: Women, with a score of 42.6 on CASP-19, experience a slightly better quality of life than men, who score 42.3 (Table 10.4). ELSA also reported little difference between the sexes in waves 1 and $4(7,8)$; scores for wave 4 were 40.6 for men and 40.8 for women, with this variation not statistically significant. A separate survey of a sample of 263 people aged 65-74 years in Britain similarly found no significant difference between men and women on CASP-19 scores (11). Other research on gender disparities in quality of life does not concur with these results, however. HeSSOP-I found that older women had a lower quality of life than older men (2). A meta-analysis of 300 studies that used various measures of subjective well-being (12) concluded that older women experienced significantly lower levels of well-being than older men, with widowhood and lower financial resources, both of which are more common amongst women, suggested as possible explanations.

Table 10.4: Mean scores on CASP-19 domains by sex, with ELSA scores for comparison

\begin{tabular}{|c|c|c|c|c|c|c|c|c|}
\hline & \multicolumn{4}{|c|}{ Men } & \multicolumn{4}{|c|}{ Women } \\
\hline & \multicolumn{2}{|c|}{ TILDA } & \multicolumn{2}{|c|}{ ELSA } & \multicolumn{2}{|c|}{ TILDA } & \multicolumn{2}{|c|}{ ELSA } \\
\hline & Mean & $95 \% \mathrm{Cl}$ & Mean & S.D. & Mean & $95 \% \mathrm{Cl}$ & Mean & S.D. \\
\hline Total & 42.3 & $42.0-42.6$ & 40.6 & 8.9 & 42.6 & $42.3-43.0$ & 40.8 & 8.8 \\
\hline Control & 7.2 & $7.1-7.2$ & 7.7 & 2.5 & 7.1 & $7.0-7.2$ & 7.8 & 2.5 \\
\hline Autonomy & 10.8 & $10.6-10.9$ & 10.1 & 2.7 & 10.7 & $10.6-10.8$ & 10.2 & 2.7 \\
\hline Pleasure & 13.6 & $13.5-13.7$ & 12.9 & 2.4 & 13.8 & $13.7-13.8$ & 13.1 & 2.3 \\
\hline Self-realisation & 10.6 & $10.5-10.8$ & 9.9 & 3.2 & 10.8 & $10.7-10.9$ & 9.8 & 3.2 \\
\hline
\end{tabular}

Examining the separate quality-of-life domains indicates no differences between men and women in terms of control and autonomy, although women derive greater pleasure from life and attain greater self-realisation than men. The domain patterns also show considerable divergence from ELSA wave 4 data. Older men in England score higher than their male counterparts in Ireland on the control domain, but lower on the other three domains. Older women in England likewise score higher on the control domain, but lower on autonomy, pleasure and self-realisation, than older women in Ireland. 
Education: Quality of life increases in the older population with level of education; those with a tertiary education have the best quality of life, while those who have primary or no education have the poorest (Table 10.5). This pattern is mirrored in three domains: control, pleasure and self-realisation, suggesting that having more education equips people with a greater confidence in their ability to determine the path of old age and to experience satisfaction and fulfilment as they age. No significant differences exist, however, in feelings of autonomy among the different groups.

Table 10.5: Mean CASP-19 scores by education

\begin{tabular}{|l|r|r|rr|rr|}
\hline & \multicolumn{2}{|c|}{ Primary/None } & \multicolumn{2}{c|}{ Secondary } & \multicolumn{2}{c|}{ Tertiary } \\
& Mean & $95 \% \mathrm{Cl}$ & Mean & $95 \% \mathrm{Cl}$ & Mean & $95 \% \mathrm{Cl}$ \\
\hline Total & 41.4 & $41.0-41.8$ & 42.7 & $42.4-43.0$ & 43.9 & $43.6-44.2$ \\
\hline Control & 6.6 & $6.5-6.7$ & 7.3 & $7.3-7.4$ & 7.6 & $7.6-7.7$ \\
\hline Autonomy & 10.7 & $10.5-10.8$ & 10.7 & $10.6-10.9$ & 10.9 & $10.7-11.0$ \\
\hline Pleasure & 13.6 & $13.5-13.7$ & 13.7 & $13.6-13.8$ & 13.9 & $13.8-14.0$ \\
\hline Self-realisation & 10.3 & $10.1-10.4$ & 10.8 & $10.7-10.9$ & 11.4 & $11.3-11.6$ \\
\hline
\end{tabular}

Self-rated health status: Older people who rate their health as fair or poor have the lowest quality of life score in the survey (36.3), a score substantially worse than those who rate their health as excellent or good (43.6) (Table 10.6). This difference in quality of life occurs in all four domains of need. This finding confirms previous research findings, which have consistently found that poor perceived health is associated with lower quality of life among older people $(5,6)$.

Table 10.6: Mean CASP-19 scores by self-rated health status

\begin{tabular}{l|rr|rr} 
& \multicolumn{2}{|c|}{ Excellent/Good } & \multicolumn{3}{c}{ Fair/Poor } \\
& Mean & $95 \% \mathrm{Cl}$ & Mean & $95 \% \mathrm{Cl}$ \\
\hline Total & 43.6 & $43.4-43.8$ & 36.3 & $35.7-37.0$ \\
\hline Control & 7.3 & $7.3-7.4$ & 6.1 & $5.9-6.2$ \\
\hline Autonomy & 11.1 & $11.0-11.2$ & 8.8 & $8.6-9.0$ \\
\hline Pleasure & 13.9 & $13.8-13.9$ & 12.7 & $12.5-13.0$ \\
\hline Self-realisation & 11.2 & $11.1-11.2$ & 8.5 & $8.2-8.8$ \\
\hline
\end{tabular}


Wealth: Quality of life increases consistently with wealth (Table 10.7). The largest differences between the wealthiest and the least wealthy occur in the control and self-realisation domains, which suggests that wealth particularly enhances a sense of power to influence one's environment and to achieve one's goals. Scores between the groups increase more gradually from least wealthy to most wealthy in the autonomy and pleasure domains, but it is still the wealthiest whose needs are most satisfied in these domains.

Table 10.7: Mean CASP-19 scores by wealth category

\begin{tabular}{|l|r|r|r|r|r|r|r|r|}
\hline & \multicolumn{2}{|c|}{ Lowest } & \multicolumn{2}{c|}{$2^{\text {nd }}$} & \multicolumn{2}{l|}{$3^{\text {rd }}$} & \multicolumn{2}{l}{ Highest } \\
& Mean & $95 \% \mathrm{Cl}$ & Mean & $95 \% \mathrm{Cl}$ & Mean & $95 \% \mathrm{Cl}$ & Mean & $95 \% \mathrm{Cl}$ \\
\hline Total & 40.9 & $40.0-41.8$ & 41.5 & $40.8-42.1$ & 43.2 & $42.6-43.8$ & 44.6 & $44.1-45.2$ \\
\hline Control & 6.7 & $6.5-6.9$ & 6.8 & $6.6-7.0$ & 7.4 & $7.2-7.5$ & 7.7 & $7.5-7.8$ \\
\hline Autonomy & 10.2 & $9.9-10.5$ & 10.5 & $10.3-10.8$ & 10.9 & $10.7-11.1$ & 11.3 & $11.1-11.5$ \\
\hline Pleasure & 13.4 & $13.1-13.6$ & 13.6 & $13.4-13.8$ & 13.9 & $13.8-14.0$ & 14.0 & $13.9-14.2$ \\
\hline Self-realisation & 10.3 & $10.0-10.6$ & 10.4 & $10.2-10.7$ & 11.0 & $10.8-11.3$ & 11.5 & $11.3-11.7$ \\
\hline
\end{tabular}

Living arrangements: Older people who live with a spouse have a better quality of life than those who live alone or live with others (Table 10.8), although the picture becomes more nuanced when the scores on the domains are examined. The overall finding is replicated in the scores for the pleasure and self-realisation domains, suggesting that older people who live with a spouse experience greater pleasure and fulfilment in life. Those who live alone have the greatest sense of autonomy but the lowest sense of control, suggesting paradoxically that they feel more free to act as they wish but less able to participate in their environment. Older people who live with others have the strongest feeling of control of the three groups.

Table 10.8: Mean CASP-19 scores by living arrangements

\begin{tabular}{|l|r|r|r|r|r|r|} 
& \multicolumn{2}{|c|}{ Living alone } & \multicolumn{2}{c|}{ Living with spouse } & \multicolumn{2}{c|}{ Living with others } \\
& Mean & $95 \% \mathrm{Cl}$ & Mean & $95 \% \mathrm{Cl}$ & Mean & $95 \% \mathrm{Cl}$ \\
\hline Total & 42.1 & $41.6-42.6$ & 43.2 & $42.8-43.5$ & 42.0 & $41.6-42.3$ \\
\hline Control & 6.9 & $6.7-7.0$ & 7.1 & $7.0-7.2$ & 7.3 & $7.2-7.4$ \\
\hline Autonomy & 11.3 & $11.1-11.4$ & 10.9 & $10.8-11.1$ & 10.3 & $10.1-10.4$ \\
\hline Pleasure & 13.5 & $13.4-13.6$ & 13.9 & $13.8-14.0$ & 13.6 & $13.5-13.7$ \\
\hline Self-realisation & 10.2 & $10.0-10.4$ & 11.1 & $11.0-11.2$ & 10.7 & $10.5-10.8$ \\
\hline
\end{tabular}


Residential location: No significant variation exists in overall quality of life based on place of residence, nor in the individual domains of need, except that older people living in Dublin city or county score higher in control than people living in other cities and towns and in rural locations (Table 10.9).

Table 10.9: Mean CASP-19 scores by residential location

\begin{tabular}{|l|rr|rr|r|r|} 
& \multicolumn{2}{|c|}{ Dublin city/county } & \multicolumn{2}{c|}{ Other city/town } & \multicolumn{3}{c}{ Rural } \\
& Mean & $95 \% \mathrm{Cl}$ & Mean & $95 \% \mathrm{Cl}$ & Mean & $95 \% \mathrm{Cl}$ \\
\hline Total & 42.7 & $42.2-43.2$ & 42.2 & $41.8-42.6$ & 42.5 & $42.2-42.8$ \\
\hline Control & 7.3 & $7.2-7.4$ & 7.1 & $7.0-7.2$ & 7.1 & $7.0-7.2$ \\
\hline Autonomy & 10.7 & $10.6-10.9$ & 10.7 & $10.5-10.8$ & 10.8 & $10.7-10.9$ \\
\hline Pleasure & 13.6 & $13.5-13.8$ & 13.6 & $13.5-13.7$ & 13.8 & $13.7-13.8$ \\
\hline Self-realisation & 10.7 & $10.5-10.9$ & 10.6 & $10.5-10.8$ & 10.8 & $10.7-10.9$ \\
\hline
\end{tabular}

\subsection{Beliefs about ageing: an overview}

Self-perceptions of ageing is a new area of research, and studies on this theme have so far been limited. The area merits investigation, however, as holding a positive perception of ageing is one aspect of successful ageing. Beliefs about ageing have been found to influence the well-being and health of the older population. Older people who perceive ageing positively are more likely to engage in preventive health behaviour, have fewer functional limitations and live longer (13-15). The Healthy Ageing Research Programme (HARP) in Ireland found that negative perceptions of ageing were associated with poorer quality of life among community-dwelling older people (16). While positive perceptions of ageing are challenged by the pervasive negative stereotypes of old age in society, most older people resist these negative stereotypes in their self-perceptions (17). ELSA concluded that perceptions of ageing were generally positive among the older population in England, but that older people also thought society did not fully share that view (18).

Any measure of beliefs about ageing must capture the multifaceted nature of the ageing process, taking account of both positive and negative aspects of older people's views. TILDA uses the Ageing Perceptions Questionnaire (APQ) (19) to capture these views of ageing. This instrument is derived from Leventhal's selfregulation model (SRM), which offers a framework for viewing and assessing the impact of illness on the individual (20). The APQ posits that ageing, like illness, is a stressor that places demands upon an individual's resources for adaptation and coping. Following the SRM, it assumes that an individual forms a representation of ageing to make sense of and respond to the process. Underlying this representation are logical themes or dimensions. In this study, the APQ was used to quantitatively assess ageing perceptions across four dimensions: 
(1) Timeline - awareness of ageing and variation in experience of the process over time. There are two sub-dimensions: timeline-chronic (the extent to which awareness of one's age or ageing is constant, e.g., 'I always classify myself as old') and timelinecyclical (the extent to which one experiences variation in awareness of ageing, e.g., 'I go through phases of feeling old').

(2) Consequences - beliefs about the positive and negative impacts of ageing on one's life. There are two sub-dimensions: consequences-positive (awareness of the benefits of ageing, e.g. 'As I get older I get wiser') and consequences-negative (awareness of the downsides of ageing, e.g., 'Getting older makes everything a lot harder for me').

(3) Control - beliefs about one's power over both the positive and negative aspects of ageing. Here, too, there are two sub-dimensions: control-positive (perceived control over positive experiences of ageing, e.g. 'The quality of my social life in later years depends on me.') and control-negative (perceived control over negative experiences of ageing, e.g. 'How mobile I am in later life is not up to me').

(4) Emotional representations - emotional responses to ageing, (e.g., 'I get depressed when I think about getting older').

The APQ captures these four dimensions in 32 statements about ageing. Participants are asked to indicate the extent to which they agree or disagree with each statement (strongly disagree, disagree, neither agree nor disagree, agree or strongly agree). Responses are scored from 1 to 5 and the mean score for each domain is calculated. The centre of each scale is therefore 3, indicating neither agreeing nor disagreeing with the statements. Higher scores indicate greater endorsement of the specific perception. For the purposes of illustration with reference to specific statements, responses have been re-categorised into three categories: agree, neither agree nor disagree, and disagree.

The APQ is a new instrument and while it has been adopted recently in a number of international studies, data from those studies is not yet available for comparison with the results presented in this chapter. Findings from wave 1 of TILDA will provide significant new information on this important topic internationally. 


\subsubsection{Beliefs about ageing: overall results}

Scores on each dimension of the APQ are shown in Table 10.10. Looking first at older people's awareness of ageing, scores on the timeline dimension suggest that variation in the awareness of ageing (measured by timeline-cyclical) is slightly more common among older people than constant consciousness of it (measured by timeline-chronic). However, both scores (2.66 and 2.70) are close to the centre of the scale, 'neither agree nor disagree', with a score of 3, which indicates that older people perceive ageing to be chronic and cyclical to some extent but do not perceive it to be strongly one or the other. By way of illustration, the strongest endorsement of timeline-cyclical by participants is agreement that their awareness of getting older comes and goes in cycles (42\%), while the strongest endorsement of timeline-chronic is agreement that they are always aware of the fact that they are getting older (48\%). At the same time, $60 \%$ do not agree that they go through phases of viewing themselves as old (timeline-cyclical), while just $14 \%$ always classify themselves as old (timeline-chronic).

Table 10.10: Mean scores on APQ sub-dimensions

\begin{tabular}{|l|c|c|}
\hline APQ Dimension & Mean & $95 \% \mathrm{Cl}$ \\
\hline Timeline-chronic & 2.66 & $2.63-2.69$ \\
\hline Timeline-cyclical & 2.70 & $2.67-2.72$ \\
\hline Emotional representations & 2.31 & $2.28-2.33$ \\
\hline Control-positive & 3.93 & $3.92-3.95$ \\
\hline Control-negative & 3.10 & $3.07-3.13$ \\
\hline Consequences-positive & 3.78 & $3.76-3.81$ \\
\hline Consequences-negative & 2.91 & $2.88-2.94$ \\
\hline
\end{tabular}

The highest dimensional score (3.93) occurs in the control-positive dimension, indicating that older people in large part believe they have control over the positive experiences of ageing. For example, $87 \%$ believe that they can determine to live life to the full, and $84 \%$ believe that they can determine the positive aspects of ageing. However, participants also score relatively highly in the control-negative dimension (3.10); this suggests that they assume considerable control over negative aspects of ageing, too. For instance, $56 \%$ disagree that they have no control over the impact of ageing on their social life. There is less assumption of control over negative experiences than over positive experiences $-60 \%$ agree, for instance, that they cannot control slowing down with age (control-negative). 
A high mean score on the consequences-positive dimension (3.78) suggests that a majority of older people acknowledge the positive aspects of ageing. For instance, $86 \%$ agree that they appreciate things more, while $72 \%$ feel that they continue to grow as a person. The lower score on the consequences-negative dimension (2.91) indicates that the negative aspects of ageing have less of an impact, although a substantial proportion of older people do acknowledge these aspects. Over half $(53 \%)$, for instance, feel that age restricts what they can do, but a much smaller proportion, $28 \%$, feel that they do not cope so well with problems that arise.

The low score on the emotional representation dimension suggests that older people do not have strong emotional responses to ageing. For this reason, this dimension will not be examined further in this chapter.

\subsubsection{Beliefs about ageing by key demographic factors}

Personal circumstances undoubtedly influence an individual's views on ageing. Steverink and colleagues (2001) established associations between a positive personal experience of ageing and better health, higher education, less loneliness and higher income, indicating that adapting to ageing is easier when a person is advantaged in life (5). The same study also demonstrated that positive views of ageing decline and negative views increase with age. This section examines how beliefs about ageing vary in the older Irish population with age, gender, education, self-rated health status, wealth, living arrangements and residential location.

Age: As age increases, older people become more persistently aware of their ageing, while the recurrence of reminders of their ageing also increases (Table 10.11).

However, while those in the 50-64 years and 65-74 years age groups perceive their ageing more intermittently, in the 75+ years age group ageing is perceived more as a constant. Looking at participants' responses to individual statements, $7 \%$ of the 50 64 years group and $14 \%$ of $65-74$ years group always classify themselves as old, while $38 \%$ of people aged $75+$ years do so.

Table 10.11: Mean scores on APQ sub-dimensions by age

\begin{tabular}{|l|r|r|r|r|r|r|} 
& \multicolumn{2}{|c|}{$50-64$ years } & \multicolumn{2}{c|}{$65-74$ years } & \multicolumn{2}{c|}{$75+$ years } \\
\hline APQ Dimension & Mean & $95 \% \mathrm{Cl}$ & Mean & $95 \% \mathrm{Cl}$ & Mean & $95 \% \mathrm{Cl}$ \\
\hline Timeline-chronic & 2.53 & $2.49-2.56$ & 2.69 & $2.64-2.74$ & 3.10 & $3.03-3.16$ \\
\hline Timeline-cyclical & 2.60 & $2.57-2.63$ & 2.75 & $2.71-2.80$ & 2.92 & $2.86-2.98$ \\
\hline Control-positive & 3.98 & $3.95-4.00$ & 3.92 & $3.89-3.95$ & 3.78 & $3.74-3.83$ \\
\hline Control-negative & 3.28 & $3.25-3.31$ & 2.99 & $2.94-3.03$ & 2.66 & $2.60-2.73$ \\
\hline Consequences-positive & 3.83 & $3.80-3.85$ & 3.71 & $3.67-3.75$ & 3.69 & $3.64-3.75$ \\
\hline Consequences-negative & 2.68 & $2.65-2.72$ & 3.01 & $2.97-3.06$ & 3.50 & $3.44-3.56$ \\
\hline
\end{tabular}


Perceptions of control over the positive aspects of ageing decline between 50-64-year-olds and 65-74-year-olds, but decline more in the 75+ years age group. The perceived sense of control over the negative aspects of ageing is less for all age groups and drops markedly from the youngest to the oldest. This perception is reflected, for example, by $31 \%$ of $50-64$-year-olds endorsing the view that their mobility in later life is not dependent on themselves, compared with $44 \%$ of 64-75-year-olds and $56 \%$ of those aged $75+$ years. While perception of the positive consequences of ageing declines between the ages of 50-64 years and 65-74 years, it remains more steady between the latter group and the 75+ years age group. However, perception of negative consequences rises substantially with each age group. Overall, the results in relation to age suggest that as age progresses, older people become more aware of their ageing and the negative consequences of the process, while at the same time feeling they have less influence over those consequences.

Sex: Some differences are evident in the ageing perceptions of men and women, as illustrated in Table 10.12. Women tend to perceive ageing more as cyclical, whereas men are more likely to perceive it as chronic. For example, $32 \%$ of women agree that they go through phases of feeling old, compared with $24 \%$ of men; $45 \%$ of men, meanwhile, are always aware of their age, compared with $37 \%$ of women.

Table 10.12: Mean scores on APQ sub-dimensions by sex

\begin{tabular}{|l|c|c|c|c|}
\hline & \multicolumn{2}{|c|}{ Men } & \multicolumn{3}{c|}{ Women } \\
\hline APQ Dimension & Mean & $95 \%$ C.I. & Mean & $95 \%$ C.I. \\
\hline Timeline-chronic & 2.72 & $2.69-2.76$ & 2.60 & $2.57-2.64$ \\
\hline Timeline-cyclical & 2.61 & $2.58-2.64$ & 2.77 & $2.73-2.80$ \\
\hline Control-positive & 3.91 & $3.89-3.94$ & 3.95 & $3.93-3.97$ \\
\hline Control-negative & 3.09 & $3.05-3.12$ & 3.12 & $3.09-3.16$ \\
\hline Consequences-positive & 3.74 & $3.72-3.77$ & 3.81 & $3.78-3.84$ \\
\hline Consequences-negative & 2.95 & $2.91-2.99$ & 2.85 & $2.81-2.89$ \\
\hline
\end{tabular}

Women have a stronger perception of control over the positive aspects of the ageing process, but the difference between men and women in relation to control of the negative aspects is marginal. There is also variance in how the sexes perceive the consequences of ageing, with women perceiving the positive consequences more strongly than men, while men perceive the negative consequences more keenly. For example, $75 \%$ of women agree that they continue to grow as a person, compared with $70 \%$ of men, while $53 \%$ of men agree they can take part in fewer activities, compared with $43 \%$ of women. 
Education: Perceptions of ageing both as chronic and cyclical decrease as level of education increases, but those with the lowest level of education tend to view it more as chronic, while those with secondary or tertiary education view ageing more as cyclical (Table 10.13). Perceptions of control in both the positive and negative sub-dimensions increase with level of education, most sharply between those in the primary/none and secondary categories in the control-negative dimension. Endorsement of the positive aspects of ageing increases by relatively small increments with education level, while endorsement of the negative aspects of ageing is much greater among those with the lowest level of education, compared with those in the other two categories. Taken together these findings indicate that older people with a lower level of education perceive ageing and their ability to cope with it more negatively than those with more education.

Table 10.13: Mean scores on APQ sub-dimensions by education

\begin{tabular}{|l|c|c|c|c|c|c|}
\hline & \multicolumn{2}{|c|}{ Primary/None } & \multicolumn{2}{c|}{ Secondary } & \multicolumn{2}{c|}{ Tertiary } \\
\hline APQ Dimension & Mean & $95 \%$ C.I. & Mean & $95 \%$ C.I. & Mean & $95 \%$ C.I. \\
\hline Timeline-chronic & 2.85 & $2.80-2.90$ & 2.57 & $2.54-2.61$ & 2.51 & $2.47-2.54$ \\
\hline Timeline-cyclical & 2.79 & $2.74-2.83$ & 2.65 & $2.62-2.69$ & 2.59 & $2.55-2.63$ \\
\hline Control-positive & 3.84 & $3.80-3.87$ & 3.95 & $3.93-3.97$ & 4.07 & $4.04-4.09$ \\
\hline Control-negative & 2.80 & $2.75-2.85$ & 3.20 & $3.17-3.24$ & 3.47 & $3.44-3.51$ \\
\hline Consequences-positive & 3.71 & $3.67-3.75$ & 3.79 & $3.77-3.82$ & 3.86 & $3.83-3.89$ \\
\hline Consequences-negative & 3.15 & $3.09-3.20$ & 2.79 & $2.75-2.82$ & 2.69 & $2.65-2.73$ \\
\hline
\end{tabular}

Self-rated health status: Scores in both the timeline-chronic and timeline-cyclical dimensions are higher among older people who rate their health as fair or poor than those who rate their health as excellent or good, as illustrated in Table 10.14. On the other hand, those with excellent or good health have a greater perception of control over both the positive and negative aspects of ageing, and are more likely to endorse the positive aspects of ageing, while those with poor self-rated health are much more aware of the negative aspects of ageing. Results in relation to health status overall indicate that poor self-rated health is associated with greater awareness of ageing and its drawbacks, together with less sense of control over the process. 
Table 10.14: Mean scores on APQ sub-dimensions by self-rated health status

\begin{tabular}{|l|cc|c|c|} 
& \multicolumn{2}{c|}{ Excellent/Good } & \multicolumn{3}{c|}{ Fair/Poor } \\
\hline APQ Dimension & Mean & $95 \%$ C.I. & Mean & $95 \%$ C.I. \\
\hline Timeline-chronic & 2.59 & $2.56-2.61$ & 3.04 & $2.98-3.11$ \\
\hline Timeline-cyclical & 2.63 & $2.60-2.65$ & 3.02 & $2.95-3.09$ \\
\hline Control-positive & 3.95 & $3.94-3.97$ & 3.82 & $3.77-3.87$ \\
\hline Control-negative & 3.18 & $3.15-3.21$ & 2.73 & $2.66-2.79$ \\
\hline Consequences-positive & 3.79 & $3.77-3.81$ & 3.71 & $3.66-3.77$ \\
\hline Consequences-negative & 2.80 & $2.77-2.83$ & 3.41 & $3.34-3.47$
\end{tabular}

Wealth: Perceptions of ageing as a whole become more positive as wealth increases (Table 10.15). The greatest differences between wealth categories are in the controlnegative and consequences-negative sub-dimensions. In the control-negative subdimension scores fall steadily from the wealthiest group to the least wealthy group. No significant differences exist among groups in perceptions of the beneficial aspects of ageing, but awareness of its downsides is highest in the lowest wealth group and then falls across each subsequent category, reaching the lowest point in the wealthiest group.

Table 10.15: Mean scores on APQ sub-dimensions by wealth

\begin{tabular}{lrrrrrrrrr} 
& \multicolumn{2}{c}{ Lowest } & \multicolumn{2}{c}{$2^{\text {nd }}$} & \multicolumn{3}{c}{$3^{\text {rd }}$} & \multicolumn{2}{c}{ Highest } \\
& Mean & $95 \%$ C.I. & Mean & $95 \%$ C.I. & Mean & $95 \%$ C.I. & Mean & $95 \%$ C.I. \\
\hline Timeline-chronic & 2.76 & $2.68-2.84$ & 2.71 & $2.64-2.79$ & 2.61 & $2.54-2.67$ & 2.46 & $2.39-2.52$ \\
\hline Timeline-cyclical & 2.82 & $2.74-2.90$ & 2.71 & $2.64-2.78$ & 2.66 & $2.59-2.73$ & 2.57 & $2.50-2.63$ \\
\hline Control-positive & 3.89 & $3.84-3.95$ & 3.92 & $3.87-3.96$ & 3.99 & $3.95-4.04$ & 4.02 & $3.98-4.06$ \\
\hline Control-negative & 2.92 & $2.84-3.00$ & 3.03 & $2.95-3.10$ & 3.24 & $3.16-3.31$ & 3.39 & $3.33-3.45$ \\
\hline Consequences-positive & 3.77 & $3.70-3.83$ & 3.76 & $3.71-3.82$ & 3.80 & $3.75-3.85$ & 3.83 & $3.77-3.88$ \\
\hline Consequences-negative & 3.05 & $2.97-3.14$ & 2.97 & $2.89-3.05$ & 2.80 & $2.73-2.86$ & 2.65 & $2.58-2.72$
\end{tabular}

Living arrangements: Table 10.16 shows that scores in both the timeline-chronic and timeline-cyclical dimensions are higher among those who live alone than those who live with a spouse or with others. While there are no significant differences in the control-positive sub-dimension, perceptions of control over the negative aspects of ageing are lowest among older people who live alone, increase among those who live with a spouse, and are highest among those who live with others. A similar pattern is evident in relation to awareness of the benefits of ageing: those who live with others perceive the positive aspects of ageing most strongly, while those who live alone perceive the benefits most weakly. A reverse pattern emerges on examining perceptions of the drawbacks of ageing: people who live alone are most 
aware of the negative aspects of ageing, while those who live with others are least aware. These findings imply that older people who live alone hold the least positive perceptions of ageing, while those who live with others hold the most positive.

Table 10.16: Mean scores on APQ sub-dimensions by living arrangements

\begin{tabular}{|l|r|r|r|r|r|r|}
\hline & \multicolumn{2}{|c|}{ Living alone } & \multicolumn{2}{c|}{ Living with spouse } & \multicolumn{2}{c|}{ Living with others } \\
\hline APQ Dimension & Mean & $95 \% \mathrm{Cl}$ & Mean & $95 \% \mathrm{Cl}$ & Mean & $95 \% \mathrm{Cl}$ \\
\hline Timeline-chronic & 2.80 & $2.74-2.86$ & 2.62 & $2.59-2.66$ & 2.62 & $2.58-2.66$ \\
\hline Timeline-cyclical & 2.79 & $2.73-2.84$ & 2.67 & $2.63-2.71$ & 2.66 & $2.62-2.70$ \\
\hline Control-positive & 3.90 & $3.87-3.94$ & 3.94 & $3.91-3.96$ & 3.94 & $3.92-3.97$ \\
\hline Control-negative & 2.95 & $2.89-3.00$ & 3.09 & $3.05-3.14$ & 3.21 & $3.16-3.25$ \\
\hline Consequences-positive & 3.74 & $3.69-3.78$ & 3.76 & $3.73-3.80$ & 3.82 & $3.78-3.85$ \\
\hline Consequences-negative & 3.10 & $3.04-3.16$ & 2.91 & $2.86-2.95$ & 2.78 & $2.74-2.82$ \\
\hline
\end{tabular}

Residential location: There is minor variation in perceptions of ageing between people in different residential locations in a number of sub-dimensions (Table 10.17). The most notable geographical differences occur in the control-negative sub-dimension, where scores fall as location progresses from Dublin city/county to other city/town to rural. Variation based on place of residence also exists in the consequences-negative sub-dimension, with scores rising from Dublin city/county to other city/town to rural location. The results as a whole indicate that the more rural the place of residence, the less control people feel over the negative experiences of ageing and the more aware they are of the disadvantages of ageing.

Table 10.17: Mean scores on APQ sub-dimensions by residential location

\begin{tabular}{|l|c|c|c|c|c|c|}
\hline & \multicolumn{2}{|c|}{ Dublin city/county } & \multicolumn{2}{c|}{ Other city/town } & \multicolumn{2}{c}{ Rural } \\
\hline APQ Dimension & Mean & $95 \% \mathrm{Cl}$ & Mean & $95 \% \mathrm{Cl}$ & Mean & $95 \% \mathrm{Cl}$ \\
\hline Timeline-chronic & 2.59 & $2.54-2.64$ & 2.65 & $2.60-2.70$ & 2.70 & $2.66-2.74$ \\
\hline Timeline-cyclical & 2.71 & $2.66-2.76$ & 2.70 & $2.65-2.75$ & 2.68 & $2.64-2.71$ \\
\hline Control-positive & 3.97 & $3.94-4.00$ & 3.96 & $3.93-3.99$ & 3.90 & $3.87-3.93$ \\
\hline Control-negative & 3.27 & $3.21-3.32$ & 3.13 & $3.08-3.18$ & 3.02 & $2.98-3.06$ \\
\hline Consequences-positive & 3.75 & $3.71-3.80$ & 3.79 & $3.75-3.83$ & 3.78 & $3.75-3.81$ \\
\hline Consequences-negative & 2.80 & $2.75-2.85$ & 2.88 & $2.83-2.93$ & 2.96 & $2.91-3.00$ \\
\hline
\end{tabular}




\subsection{Conclusions}

Older men and women in Ireland report good quality of life, although differences exist when wealth (quality of life increases with level of asset wealth); age (those aged 65-74 years have the highest levels of quality of life compared with their older and younger counterparts); level of education (quality of life increases with education); and the person's own rating of their health (poorer self-rated health is associated with poorer quality of life) are considered. Older people express favourable views on the ageing process overall, acknowledging the positive aspects of ageing more than the negative aspects. The oldest age group and older adults who rate their health poorly perceive ageing and their ability to cope with it more negatively.

Remarkable consistency is notable between quality of life and ageing belief. Older people are confident in their ability to fulfil their potential according to the quality of life measure, and believe that they have considerable control over both the favourable and the unfavourable aspects of ageing on the ageing perception measure. Clear social divisions are evident, however, in the experience of old age, where certain groups, namely those with most wealth, better education and better self-rated health, age more successfully than others. Poor self-perceived health, on the other hand, is a strong marker for a more negative experience of ageing and perception of the process, along with greater age, less education and less wealth.

Findings from this first wave of TILDA provide a positive picture of ageing in Ireland overall, with high levels of quality of life reported and generally positive perceptions of ageing. However, a decline is evident when those in the oldest age category are considered, those with least education, those with least wealth and, most notably, those reporting poorer self-rated health. Further exploration of possible relationships between these key variables (quality of life and ageing perceptions) and aspects of health status, health policy, health service use and funding of this use, social inclusion and support, and psychological well-being will provide important additional explanatory information on findings in this chapter. Important differences between findings of wave 1 of TILDA and wave 4 of ELSA require further exploration. Information from future waves of TILDA will equally provide a key dimension in examining predictors of successful ageing, reflected in positive perceptions of getting older and ultimately a better quality of life. 


\section{References}

1. Bowling A, Dieppe P. What is successful ageing and who should define it? BMJ. 2005 Dec 24;331(7531):1548-51.

2. Garavan R, Winder R, McGee H. Health and Social Services for Older People (HeSSOP): Consulting older people on health and social services - A survey of service use, experiences and needs. Dublin: National Council on ageing and older people; 2001. Report No.: 64.

3. O'Hanlon A, McGee M, Barker M, Garavan R, Hickey A, Conroy R, O'Neill, D. Hessop-2 : Health and Social Services for Older People II : Changing profiles from 2000 to 2004. Dublin: National Council on Ageing and Older People 2005. Report No.: 96.

4. Strine TW, Chapman DP, Balluz LS, Moriarty DG, Mokdad AH. The associations between life satisfaction and health-related quality of life, chronic illness, and health behaviors among U.S. community-dwelling adults. J Community Health. 2008 Feb;33(1):40-50.

5. Steverink N, Westerhof GJ, Bode C, Dittmann-Kohli F. The personal experience of aging, individual resources, and subjective well-being. J Gerontol B Psychol Sci Soc Sci. 2001 Nov;56(6):364-73.

6. Bowling A, Seetai S, Morris R, Ebrahim S. Quality of life among older people with poor functioning. The influence of perceived control over life. Age Ageing. 2007 May;36(3):310-5.

7. Netuveli G, Wiggins RD, Hildon Z, Montgomery SM, Blane D. Quality of life at older ages: evidence from the English longitudinal study of aging (wave 1). J Epidemiol Community Health. 2006 Apr;60(4):357-63.

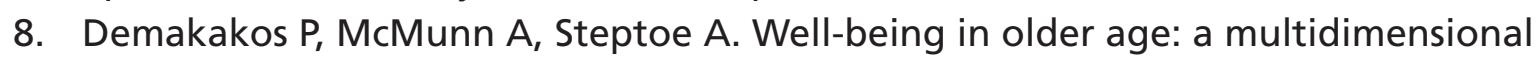
perspective. In: Banks J, Lessof C, Nazroo J, Rogers N, Stafford M, Steptoe A, editors. Financial Circumstances, Health and Well-being of the Older Population in England. London: Institute for Fiscal Studies; 2010.

9. Hyde M, Wiggins RD, Higgs $P$, Blane DB. A measure of quality of life in early old age: the theory, development and properties of a needs satisfaction model (CASP19). Aging Ment Health. 2003 May;7(3):186-94.

10. Pinquart M, Sorensen S. Influences of socioeconomic status, social network, and competence on subjective well-being in later life: a meta-analysis. Psychol Aging. 2000 Jun;15(2):187-224.

11. Wiggins R, Higgs $P$, Hyde M, Blane D. Quality of life in the third age: key predictors of the CASP-19 measure. Ageing and Society. 2004;24:693-708.

12. Pinquart $M$, Sorensen $S$. Gender differences in self-concept and psychological well-being in old age: a meta-analysis. J Gerontol B Psychol Sci Soc Sci. 2001 Jul;56(4):195-213.

13. Levy BR, Myers LM. Preventive health behaviors influenced by self-perceptions of aging. Prev Med. 2004 Sep;39(3):625-9. 
14. Levy BR, Slade MD, KasI SV. Longitudinal benefit of positive self-perceptions of aging on functional health. J Gerontol B Psychol Sci Soc Sci. 2002 Sep;57(5):40917.

15. Levy BR, Slade MD, Kunkel SR, Kasl SV. Longevity increased by positive selfperceptions of aging. J Pers Soc Psychol. 2002 Aug;83(2):261-70.

16. Hickey A, O'Hanlon A, McGee H. Quality of life in community-dwelling older people in Ireland: Association with ageing perceptions, physical health and psychological well-being. Irish Journal of Psychology. 2010;31(3-4):135-50.

17. Pinquart M. Good news about the effects of bad old-age stereotypes. Exp Aging Res. 2002 Jul-Sep;28(3):317-36.

18. Demakakos P, Hacker E, Gjonca E. Perceptions of Ageing. Retirement, health and relationships of the older population in England: The 2004 English Longitudinal Study of Ageing. London: The Institute for Fiscal Studies; 2006.

19. Barker M, O'Hanlon A, McGee HM, Hickey A, Conroy RM. Cross-sectional validation of the Aging Perceptions Questionnaire: a multidimensional instrument for assessing self-perceptions of aging. BMC Geriatr. 2007;7:9.

20. Leventhal $H$, Nerenz $D$, Steele D. Illness representations and coping with health threats. In: Baum A, Taylor S, Singer J, editors. Handbook of Psychology and Health. New Jersey: Lawrence Erlbaum Associates; 1984. p. 219-52 


\section{Appendix for Chapter 10: Quality of Life and Beliefs about Ageing}

Table 10.A1: Responses to CASP-19 statements

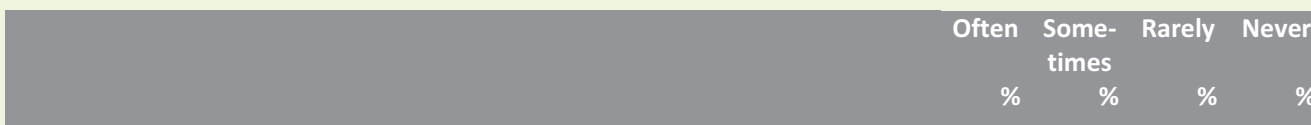

\section{Control}

1 My age prevents me from doing the things I would like to

$\begin{array}{rrrr}8.9 & 26.2 & 26.9 & 38.0 \\ 6.5 & 24.1 & 29.8 & 39.6 \\ 54.7 & 30.1 & 9.0 & 6.2 \\ 4.8 & 18.2 & 28.7 & 48.3\end{array}$

2 I feel that what happens to me is out of my control

3 I feel free to plan for the future

4 I feel left out of things

\section{Autonomy}

5 I can do the things that I want to do

$\begin{array}{llll}66.1 & 26.5 & 4.5 & 2.9\end{array}$

6 Family responsibilities prevent me from doing what I want to do

7 I feel that I can please myself what I do

$\begin{array}{llll}65.7 & 27.4 & 4.4 & 2.5\end{array}$

8 My health stops me from doing things I want to do

$\begin{array}{llll}11.5 & 23.2 & 21.1 & 44.2\end{array}$

9 Shortage of money stops me from doing things I want to do

\section{Pleasure}

\begin{tabular}{|c|c|c|c|c|c|}
\hline 10 & I look forward to each day & 80.7 & 16.5 & 1.7 & 1.1 \\
\hline 11 & I feel that my life has meaning & 76.5 & 18.7 & 2.7 & 2.1 \\
\hline 12 & I enjoy the things that I do & 84.6 & 13.9 & 1.2 & 0.3 \\
\hline 13 & I enjoy being in the company of others & 78.0 & 20.0 & 1.5 & 0.5 \\
\hline 14 & On balance, I look back on my life with a sense of happiness & 68.6 & 26.0 & 4.1 & 1.3 \\
\hline \multicolumn{6}{|c|}{ Self-realisation } \\
\hline 15 & I feel full of energy these days & 32.5 & 51.1 & 12.7 & 3.7 \\
\hline 16 & I choose to do things that I have never done before & 15.5 & 41.0 & 30.4 & 13.2 \\
\hline 17 & I feel satisfied with the way my life has turned out & 60.4 & 32.3 & 5.0 & 2.3 \\
\hline 18 & I feel that life is full of opportunities & 40.6 & 41.6 & 13.9 & 3.9 \\
\hline 19 & I feel that the future looks good for me & 46.5 & 41.0 & 9.4 & 3.1 \\
\hline
\end{tabular}




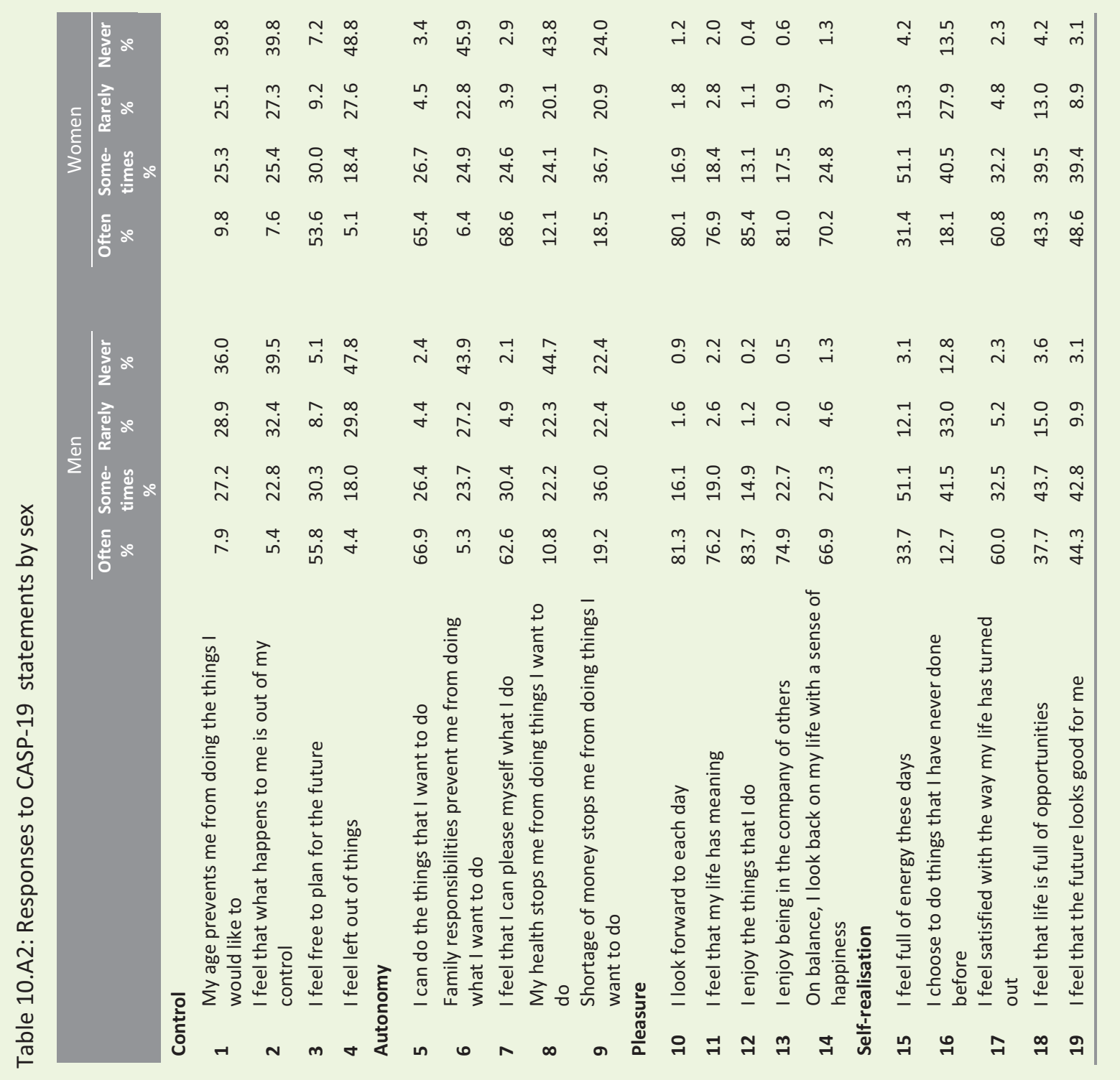




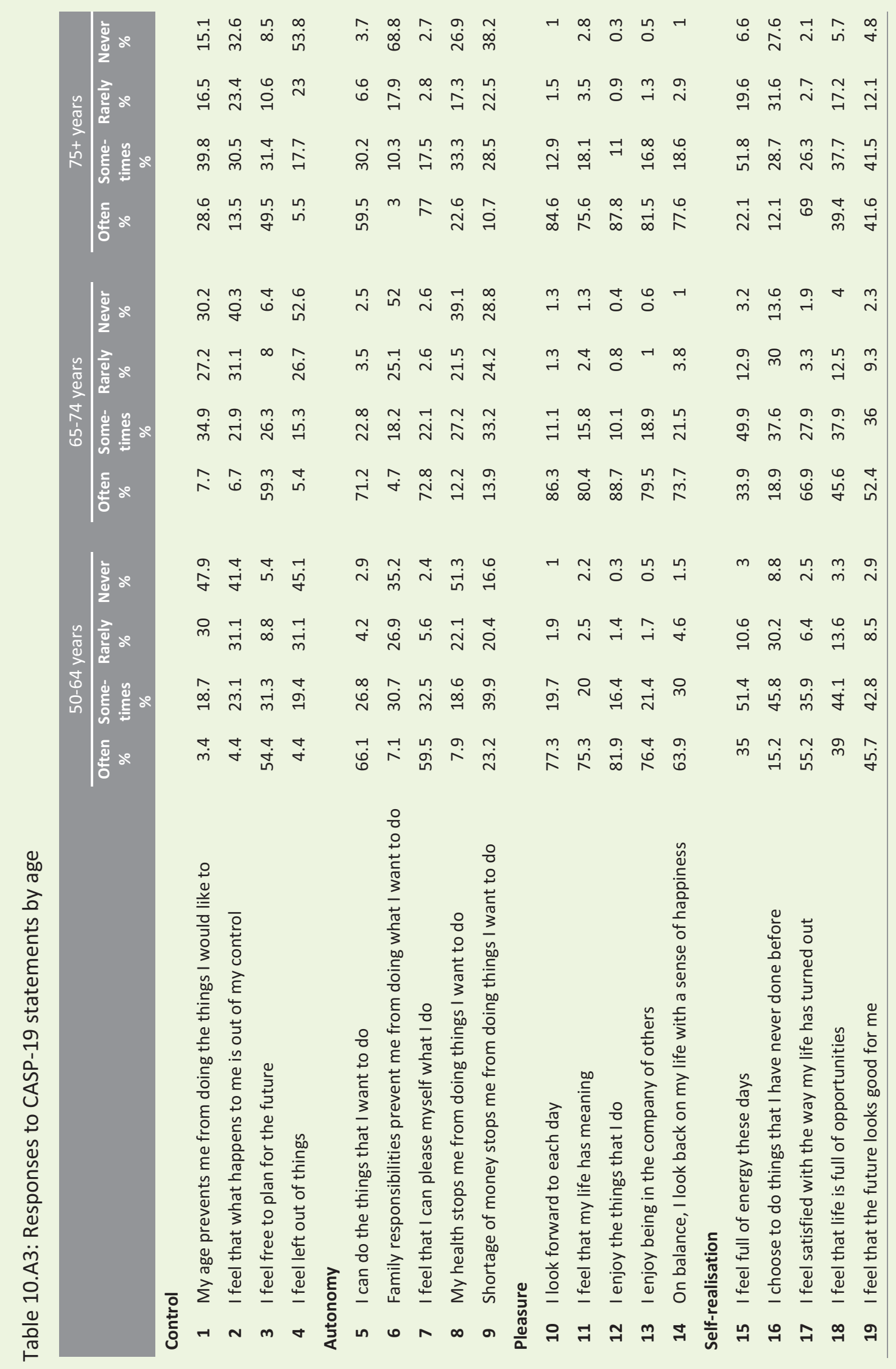


Table 10.A4: Responses to APQ statements

\begin{tabular}{|c|c|c|c|c|}
\hline & & $\begin{array}{r}\text { Disagree } \\
\%\end{array}$ & $\begin{array}{c}\text { Neither } \\
\text { agree nor } \\
\text { disagree } \\
\%\end{array}$ & $\begin{array}{r}\text { Agree } \\
\%\end{array}$ \\
\hline \multicolumn{5}{|c|}{ Timeline-chronic } \\
\hline & I am conscious of getting older all of the time & 38.6 & 24.3 & 37.1 \\
\hline & I am always aware of my age & 39.5 & 19.5 & 41 \\
\hline & I always classify myself as old & 71.3 & 14.8 & 13.8 \\
\hline & I am always aware of the fact that I am getting older & 34.7 & 17.5 & 47.8 \\
\hline & I feel my age in everything that I do & 67 & 16.3 & 16.7 \\
\hline \multicolumn{5}{|c|}{ Timeline-cyclical } \\
\hline & I go through cycles in which my experience of ageing gets better and worse & 39.1 & 31.3 & 29.6 \\
\hline & My awareness of getting older comes and goes in cycles & 35.7 & 21.9 & 42.4 \\
\hline & I go through phases of feeling old & 53.5 & 18 & 28.5 \\
\hline & My awareness of getting older changes a great deal from day to day & 56 & 21.6 & 22.5 \\
\hline 32 & I go through phases of viewing myself as being old & 60.1 & 16.7 & 23.2 \\
\hline \multicolumn{5}{|c|}{ Control-positive } \\
\hline & The quality of my social life in later years depends on me & 7.6 & 10.1 & 82.3 \\
\hline & The quality of my relationships with others in later life depends on me & 6.3 & 9.8 & 83.9 \\
\hline & Whether I continue living life to the full depends on me & 5.8 & 7.7 & 86.5 \\
\hline & As I get older there is much I can do to maintain my independence & 6.3 & 11.1 & 82.7 \\
\hline & Whether getting older has positive sides to it depends on me & 5.1 & 10.6 & 84.3 \\
\hline \multicolumn{5}{|c|}{ Control-negative } \\
\hline & Slowing down with age is not something I can control & 24.6 & 15.6 & 59.8 \\
\hline & How mobile I am in later life is not up to me & 47 & 14.7 & 38.3 \\
\hline & I have no control over whether I lose vitality or zest for life as I age & 55.3 & 15.4 & 29.3 \\
\hline & I have no control over the effects which getting older has on my social life & 56.4 & 15.3 & 28.3 \\
\hline \multicolumn{5}{|c|}{ Consequences-positive } \\
\hline & As I get older I get wiser & 14.1 & 21.8 & 64.2 \\
\hline & As I get older I continue to grow as a person & 8.3 & 19.3 & 72.4 \\
\hline & As I get older I appreciate things more & 5.1 & 8.9 & 86 \\
\hline \multicolumn{5}{|c|}{ Consequences-negative } \\
\hline & Getting older restricts the things that I can do & 30.4 & 16.3 & 53.3 \\
\hline & Getting older makes me less independent & 51.1 & 17.4 & 31.5 \\
\hline & Getting older makes everything a lot harder for me & 47.8 & 22.7 & 29.5 \\
\hline & As I get older I can take part in fewer activities & 34.4 & 17.4 & 48.2 \\
\hline 20 & As I get older I do not cope as well with problems that arise & 52.9 & 18.8 & 28.3 \\
\hline \multicolumn{5}{|c|}{ Emotional representations } \\
\hline 9 & I get depressed when I think about how ageing might affect the things that I can do & 56.2 & 20.1 & 23.7 \\
\hline 13 & I get depressed when I think about the effect that getting older might have on my social life & 62.5 & 21.1 & 16.4 \\
\hline 25 & I get depressed when I think about getting older & 70.6 & 16.2 & 13.1 \\
\hline 26 & I worry about the effects that getting older may have on my relationships with others & 67.2 & 17.3 & 15.5 \\
\hline 29 & I feel angry when I think about getting older & 79.2 & 13.6 & 7.3 \\
\hline
\end{tabular}




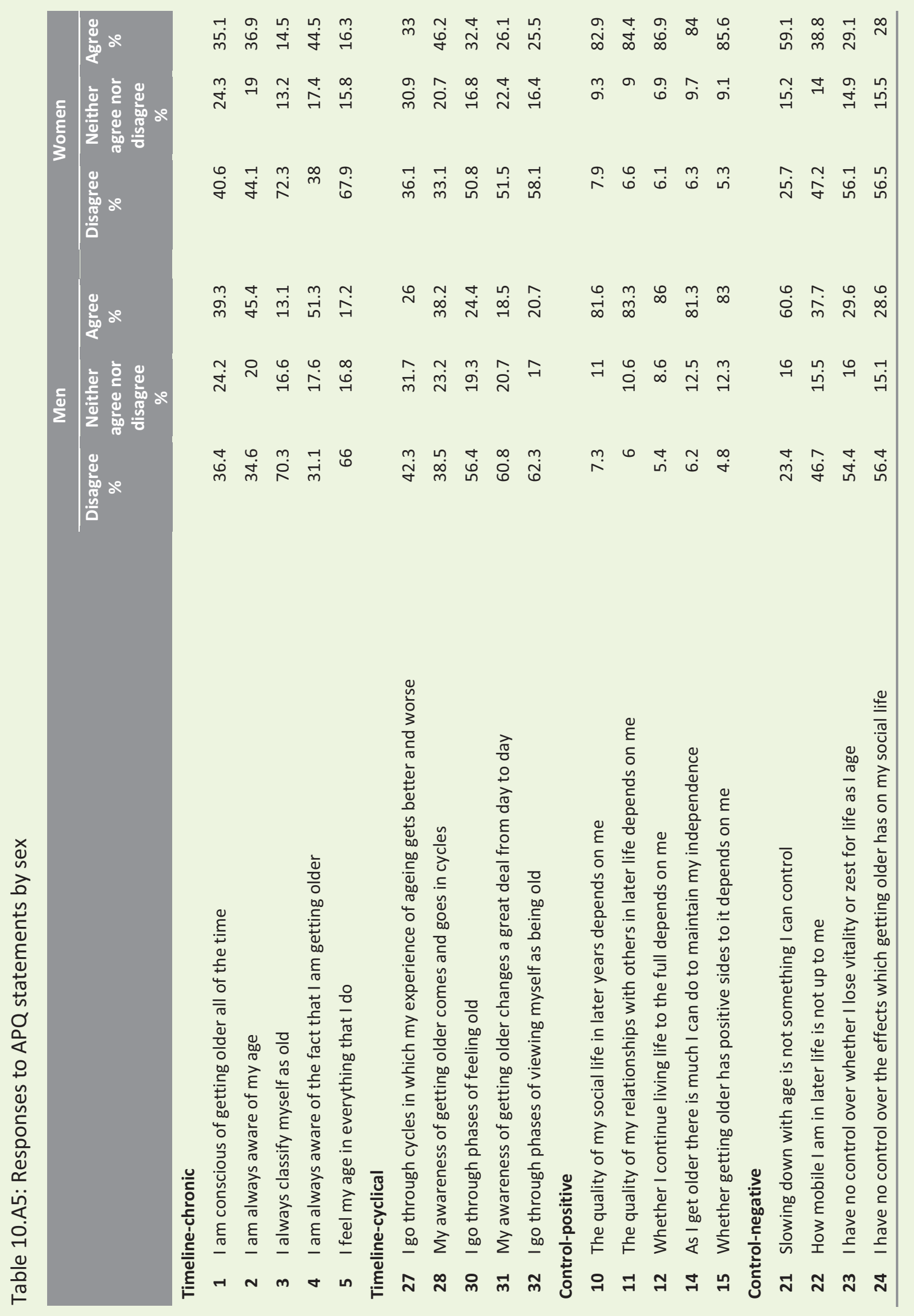




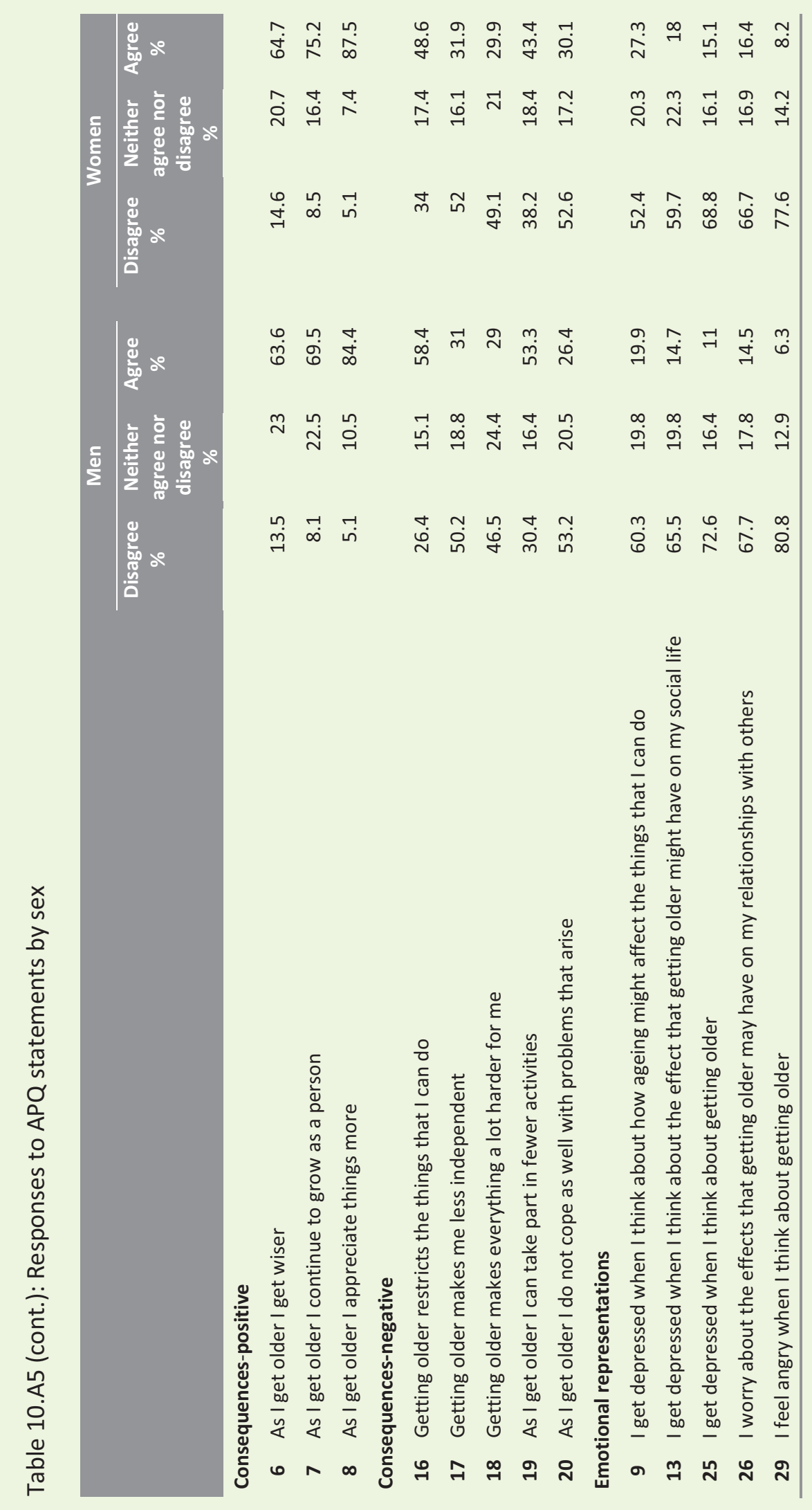




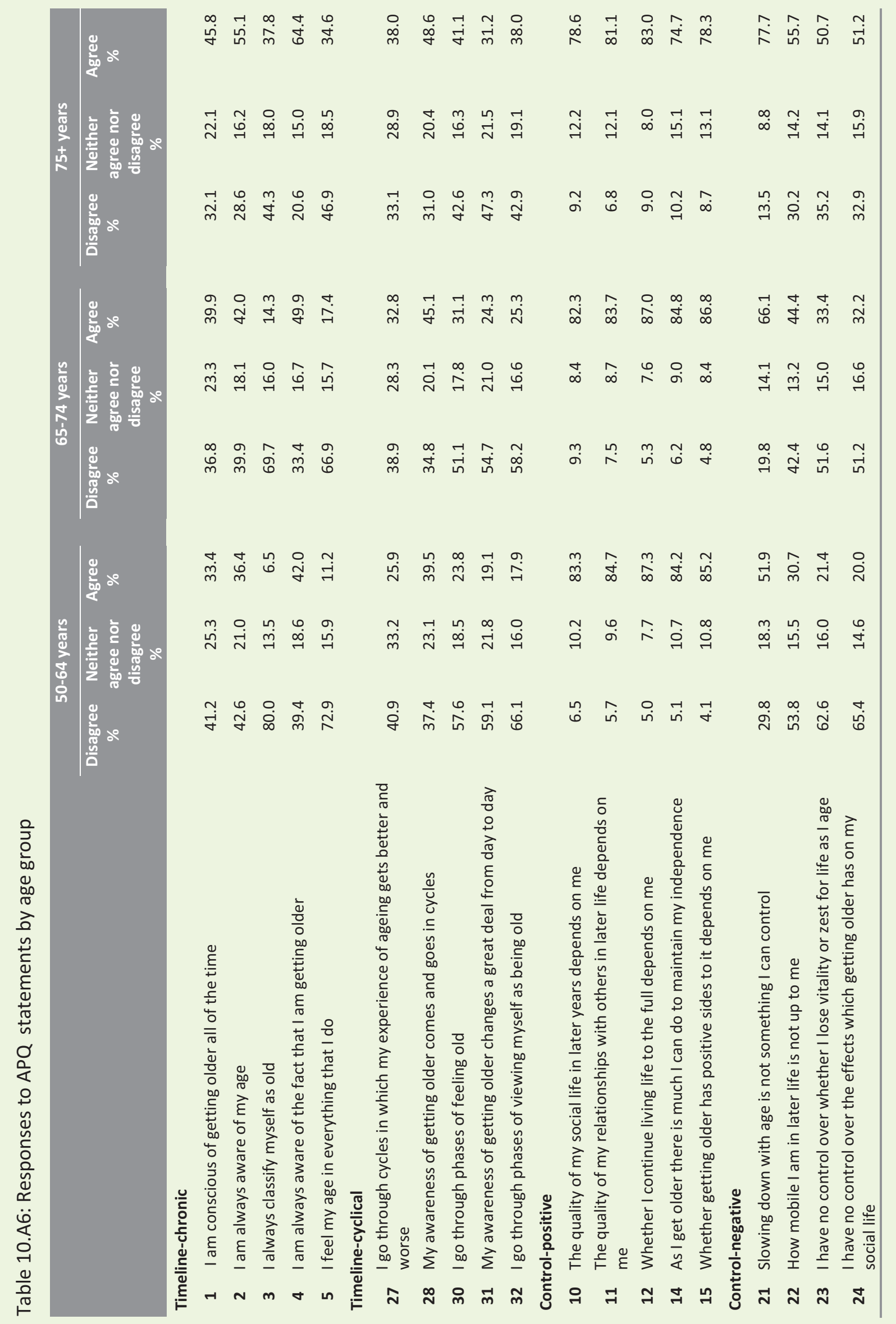




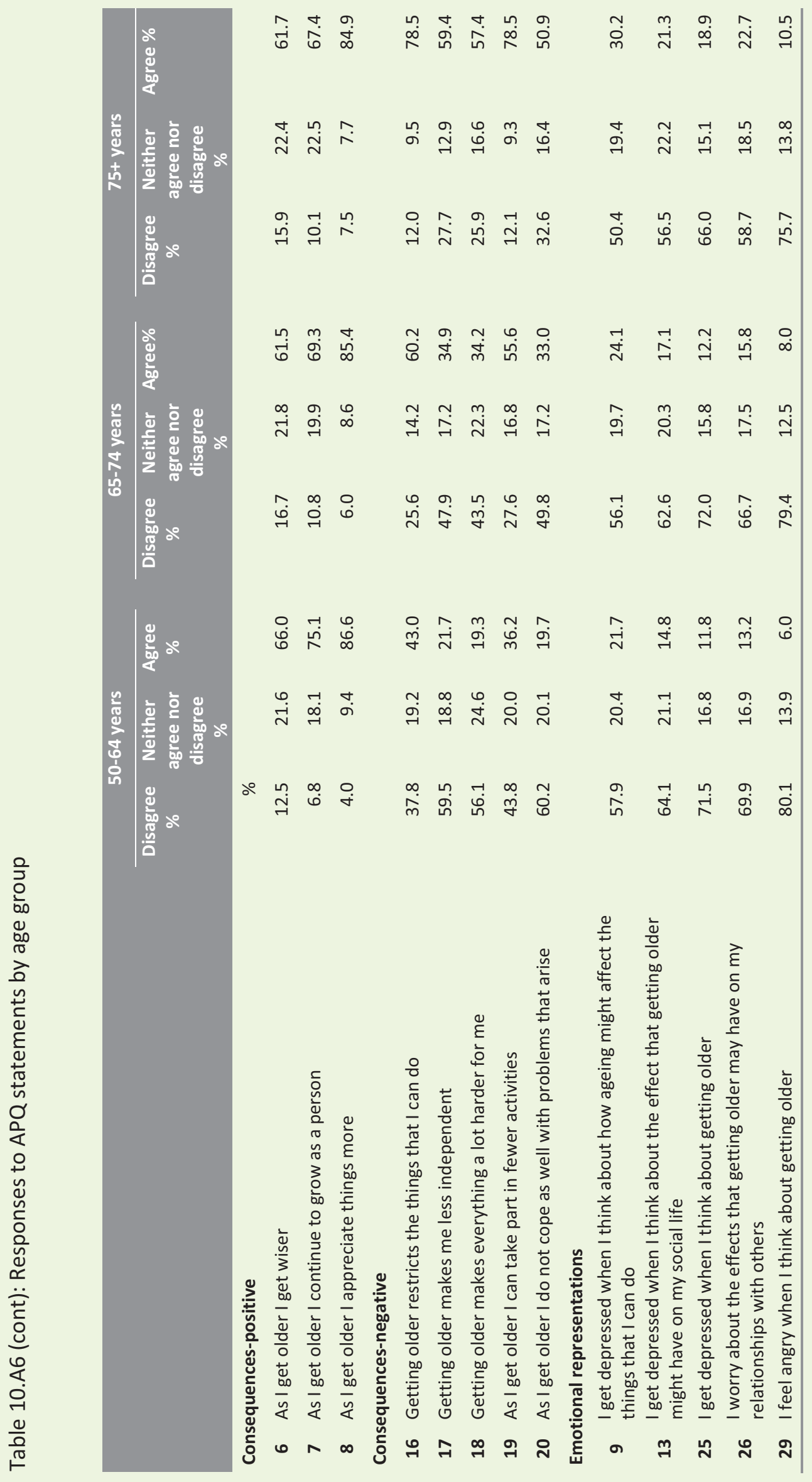




\title{
Methodology
}

\author{
George Savva
}

\section{Contents}

11.1 Target population and design of TILDA _...............................294

11.1.1 Fieldwork report and response rate.......................295

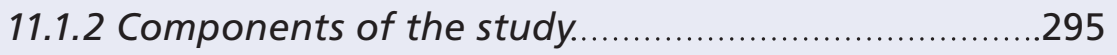

11.1.3 Classification of the population ...............................296

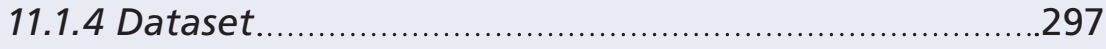

11.2 Analytical methods employed in

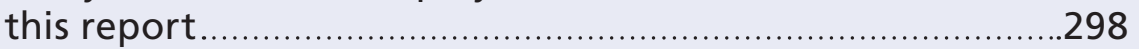

11.2.1 Confidence intervals and

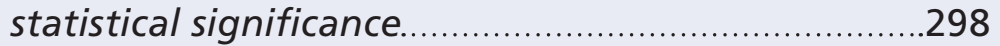

11.2.2 Stratified clustered analysis...................................299

11.2.3 Differential non-response

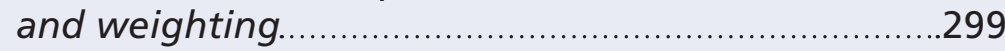

11.2.4 Estimating CAPI weights ......................................299

11.2.5 Estimating health assessment

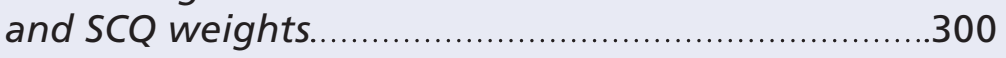

11.2.6 Item non-response ..............................................301

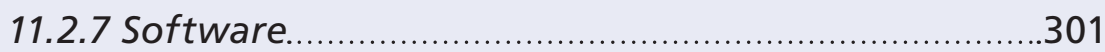

11.3 Limitations of this report and future analyses. 


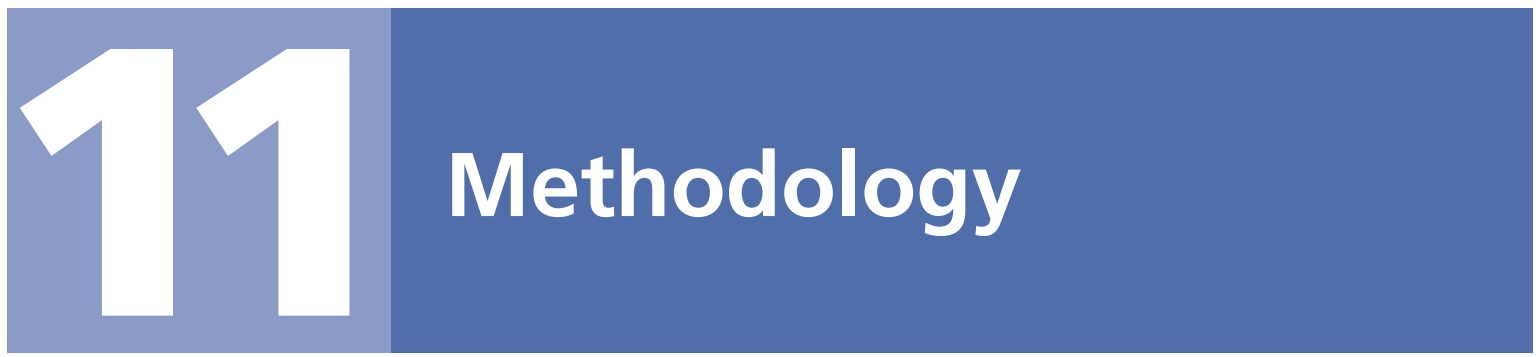

\section{Summary}

- TILDA recruited a stratified clustered sample of 8178 individuals representative of the community living Irish population aged 50 years and over. Younger spouses and partners were also invited to participate, primarily to provide information regarding family and financial circumstances.

- Each participant underwent an extensive face-to-face interview, was left a questionnaire to complete and return and was invited to a health assessment either at a dedicated centre or in the home.

- The overall response rate to the study was $62.0 \%$. The subsequent participation in the health assessment and the proportion returning the self-completion questionnaire is high, and collection of both is ongoing.

This chapter describes the sample selection and analytical methods that were chosen to ensure an efficient design and that valid population based inferences were made based upon the TILDA sample. The sample is described with respect to its representativeness of the target population of all community living adults aged 50 years and over in Ireland.

\subsection{Target population and design of TILDA}

The sampling framework and design of each component of TILDA is described in detail in the TILDA Design Report (1), and is briefly summarised below. The target population, that is the population on which inferences presented in this report can be applied, includes all members of the population of Ireland who are 50 years old or over, and who live in the community (that is do not live in a long-term care institution). While only around $1 \%$ those between the ages of 65 and 74 currently live in long-term care, this figure rises to around $6 \%$ of those aged between 75 and 84 and $21 \%$ of those aged 85 and over (2).

To generate the TILDA sample, all postal addresses in Ireland were assigned to one of 3155 geographic clusters, and a sample of 640 of these clusters was selected, stratified by socio-economic group and geography to maintain a population representative sample. Clusters were selected with a probability proportional to the number of individuals aged 50 and over in each cluster. Forty households were selected from each cluster (it was estimated that 25600 addresses in total would be 
required to achieve the required sample size of 8000). Each of the selected addresses was visited by an interviewer, who attempted to ascertain the eligibility of the address, to contact a household member and determine whether any individuals aged 50 or over lived at that address. All individuals aged 50 or over in each selected household and their partners (even if aged less than 50 themselves) were invited to be included in the study.

\subsubsection{Fieldwork report and response rate}

A total of 8178 interviews were conducted with respondents aged 50 and over belonging to 6282 households. An additional 329 interviews were conducted with younger partners of eligible individuals. The first interview took place on 18 October 2009 , with a steady accrual until the last interview was conducted on 22 February 2011.

The response rate is the proportion of selected households including an eligible participant from which an interview was successfully obtained. Interviewers were sent to all of the initially allocated 25600 addresses. Of these, 22321 were occupied residential addresses. At 11819 addresses contact was made and it was determined than no person aged 50 or over was at that address. In 9818 it was determined that there was a person aged 50 or over. At 684 addresses either no contact was made or contact was made but it was impossible to determine whether there was anybody over 50 living at that address. Based on those households in which eligibility was determined, it is estimated that $9818 /(9818+11819) \times 684=310.4$ of those households were eligible.

The estimated number of selected eligible households is therefore $9818+310.4$ $=10128.4$. Successful interviews were obtained in 6282 households, leading to a response rate of $62.0 \%$.

\subsubsection{Components of the study}

The initial respondent (first eligible household member interviewed) in each household provided details of all of household members. Any household members eligible for the study were subsequently invited to take part in the study.

Each individual agreeing to participate in the study underwent a structured 'CAPI' interview in their own home with a trained interviewer, which included questions on many domains of health, well-being, family and financial circumstances.

Where two respondents were married or were living together as if married, a 'financial respondent' and a 'family respondent' were identified, providing the detailed responses on family and financial circumstances respectively. The financial and family respondents were not necessarily different individuals. 
Each participant was invited to undergo a health assessment, either a full health assessment at a centre in Dublin or Cork or a partial assessment in their own home where travel to either centre was not practicable.

Each participant was also left a 'self-completion questionnaire' (SCQ) including potentially sensitive questions for them to fill in and return to TILDA by mail. This included a range of questions on quality of relationships, quality of life, perceptions of ageing, emotional well-being and health behaviours. There was also a single blank page for each respondent to make any further comment they chose.

The detailed design of each component of the study, including the rationale for the design and the comparability with other European and international studies is described in the TILDA design report (1).

\subsubsection{Classification of the population}

Throughout this report subgroups of the population are defined by socio-economic and health related factors including age, sex, living arrangement, disability level etc. These factors and the their levels were chosen to reflect the diversity in circumstances among the older Irish population while ensuring that each groups was sufficiently well represented within the study sample. Classifications are described in relevant chapters of this report but in brief, those commonly used include:

Age and sex: Age groups are determined as appropriate throughout this report, but in the majority of cases the population is divided into three groups, those aged 5064, those aged 65-74 and those aged 75 and over. Other age groups are employed where needed to reflect for example changes in entitlement to a medical card.

Education: Education is an indicator of socio-economic status as well as directly influencing health behaviours, lifetime environmental exposures and mental activity. The educational attainment of each TILDA respondent is measured in one of seven categories, and these are assigned to one of three groups. Those who did not complete primary education and those with only primary education are classified as 'primary'. Those who completed a junior certificate, or leaving certificate or equivalent are classified as 'secondary', and those who completed a diploma, first degree or higher degree are classified as 'tertiary or higher'.

Location: The population is divided by location of their residence as living in 'Dublin City or County', 'Another town or city in the Republic of Ireland' or 'Another rural area in the Republic of Ireland'. 
Labour market status: Labour market status classifications are described in Chapter 8 , but in brief each participant is classified by their own description of their status as being either 'employed' (including self-employed), 'retired', or 'other', where other includes all those describing themselves as primarily looking after a home or family, out of work through illness or unemployed.

Gross asset wealth: TILDA financial respondents are asked to describe their household's financial and non-financial assets. This total value is assigned to each member of the household and quartiles based on this measure are used to classify the sample into four groups (see chapter 9 for details).

Disability: Respondents are asked whether they have a health-related impairment in carrying out certain activities. Based on this, the sample is divided into those who have 'no impairment' an 'impairment in instrumental activities of daily living (IADL)', 'impairment in activities of daily living (ADL)', or 'impairment in both ADL and IADL.' (see Chapter 7 for details).

Self-rated health: Respondents are asked to rate their physical health as 'excellent', 'very good', 'good', 'fair', or 'poor' (Chapter 5). These are collapsed into two or three groups as appropriate throughout the report.

Depression: Depressive symptomatology is measured using the Centre for Epidemiological Studies Depression (CES-D) scale (see Chapter 6). Based on this individuals are classified as being 'not depressed' (score of 0-7), having 'sub-threshold depression' (score of 8-15) or 'clinically relevant depressive symptoms' (score of 16 or higher).

\subsubsection{Dataset}

All of the results in this report are based on the TILDA dataset version 1.0.1. This dataset includes CAPI data from all 8507 TILDA respondents (from 6282 households), of whom 8178 were aged 50 and over. This 8178 forms the sample for this report. Data from the 329 younger respondents are incorporated where measures are taken at the level of the household or the couple.

At the time of writing TILDA health assessments are ongoing, with an anticipated completion date of June 2011. Up until 27 Feb 2011, 3907 health centre assessments of those aged 50 and over had been completed and data from these are included in this report. Home assessments are also ongoing, and this report incorporates the 477 home assessments conducted to date. By 16 Feb 2011 a total of 6262 SCQs had been returned to TILDA by respondents aged 50 and over and these are included in the current dataset. Table 11.1 shows a breakdown of the response to date to the components of the study. 
Table 11.1: Number of respondents aged 50 and over whose self-completion questionnaires and health assessments have been included in this report

\begin{tabular}{|c|c|c|c|c|}
\hline \multirow[b]{2}{*}{$\begin{array}{l}\text { SCQ received } \\
\text { to date }\end{array}$} & \multicolumn{4}{|c|}{ Health assessment to date } \\
\hline & None to date & $\begin{array}{l}\text { Health centre } \\
\text { assessment }\end{array}$ & $\begin{array}{c}\text { Home } \\
\text { assessment }\end{array}$ & Total (\%) \\
\hline No & 1419 & 404 & 93 & $1916(23.4)$ \\
\hline Yes & 2375 & 3503 & 384 & $6262(76.6)$ \\
\hline Total (\%) & $3794(46.4)$ & $3907(47.8)$ & $477(5.8)$ & 8178 \\
\hline
\end{tabular}

\subsection{Analytical methods employed in this report}

For estimates to be unbiased and for their uncertainty to be correctly determined, analyses used to generate the findings in this report incorporate the design of the study and the pattern of non-response (missing data). Statistical methods used to calculate the estimates presented in this report are described below.

\subsubsection{Confidence intervals and statistical significance}

The majority of the estimates presented in this report are the percentages of older people falling into various groups or averages of quantities. Mean or median averages are used as appropriate for each quantity of interest.

Each estimate based on the TILDA sample corresponds to a true value in the population. TILDA represents a random sample of the population, and so some uncertainty or imprecision arises due to fluctuations associated with the sampling process. Many of the estimates are provided with a $95 \%$ confidence interval reflecting this uncertainty which should be interpreted as the plausible range for the true value in the target population. More precise estimates have smaller confidence intervals.

The formal interpretation of the $95 \%$ confidence interval is that there is a $95 \%$ chance of the sampled confidence interval encompassing the true population parameter. In other words, $95 \%$ of confidence intervals include the true population value.

Unless otherwise stated, the results we present in this report are 'statistically significant' at the $5 \%$ level, that is for each of the differences or trends we report there is a smaller than $5 \%$ chance that the difference is not present in the population. In most cases the chance of such a false positive results is much smaller than this. 


\subsubsection{Stratified clustered analysis}

Stratified sampling was used to select the clusters used for TILDA. Stratification ensures an efficient and population representative sample. A further benefit of stratification occurs when strata indicators are incorporated into estimation procedures, by explaining variability among individuals and improving the precision of estimators.

Geographic clustering increases the efficiency of the data collection process, resulting in a lower fieldwork cost per interview. However, clustering also reduces the effective contribution of each individual taking part, since there is likely to be some correlation in the responses of individuals from the same cluster. The effect of this is to reduce the precision of estimates, reflected by wider confidence intervals. The confidence intervals included in this report incorporate the effects of stratification and clustering on precision.

\subsubsection{Differential non-response and weighting}

As described above, the response rate to the study was $62.0 \%$. Differential nonresponse, where response rates vary among subgroups of the population, may lead to biased estimates. To eliminate this source of bias, weights were applied in calculations with the weight corresponding to the number of members of the population that was represented by each participant. Those respondents arising from subgroups of the population less likely to respond were assigned higher weights than those coming from subgroups more likely to respond.

Formally, the weight applied to each participant was the reciprocal of the probability of that participant's inclusion in the final study sample, given their characteristics and that they were a member of the target population.

Non-response varied by study component, and so different weights were applied in each analysis depending on the component of the study being used. The calculation of each set of weights is described below.

\subsubsection{Estimating CAPI weights}

Before an interview is conducted it is not possible to know the characteristics of respondents and non-responders, making direct calculation of the probability of participation impossible. Weights applied to the main (CAPI) sample were estimated by comparing the numbers of individuals in the sample with a given combination of characteristics with the same number in the population, estimated using the Quarterly National Household Survey (QNHS 2010). The characteristics compared were age, sex and educational attainment. Table 11.2 illustrates the calculation of weights assigned to each sub-group of the population when estimates are based 
on the whole CAPI sample. The key determinant of the participation of the study is education. Each participant with third level education represents around 70100 members of the population depending on their age and sex, while those with primary education represent around 150-250 individuals.

Table 11.2: The distribution of age, sex and educational attainment in the population compared to the sample, and the consequent weight applied to each participant in estimation

\begin{tabular}{|c|c|c|c|c|c|c|c|}
\hline \multirow{3}{*}{$\begin{array}{l}\text { Age at } \\
\text { interview }\end{array}$} & & \multicolumn{6}{|c|}{ Educational attainment and sex } \\
\hline & & \multicolumn{2}{|c|}{ Primary } & \multicolumn{2}{|c|}{ Secondary } & \multicolumn{2}{|c|}{ Third level } \\
\hline & & Male & Female & Male & Female & Male & Female \\
\hline \multirow[t]{3}{*}{$50-64$} & N (sample) & 471 & 486 & 967 & 1152 & 643 & 949 \\
\hline & $N(p o p ’ n)$ & 95600 & 80800 & 176300 & 187000 & 79100 & 82000 \\
\hline & Weight & 203.0 & 166.3 & 182.3 & 162.3 & 123.0 & 86.4 \\
\hline \multirow[t]{3}{*}{$65-74$} & N (sample) & 457 & 408 & 337 & 391 & 275 & 294 \\
\hline & $N(p o p ' n)$ & 72800 & 65900 & 44400 & 56600 & 20000 & 21200 \\
\hline & Weight & 159.3 & 161.5 & 131.8 & 144.8 & 72.7 & 72.1 \\
\hline \multirow[t]{3}{*}{$>=75$} & N (sample) & 323 & 361 & 151 & 266 & 124 & 119 \\
\hline & $N(p o p ' n)$ & 57300 & 86800 & 20600 & 33800 & 9600 & 10600 \\
\hline & Weight & 177.4 & 240.4 & 136.4 & 127.1 & 77.4 & 89.1 \\
\hline
\end{tabular}

\subsubsection{Estimating health assessment and SCQ weights}

Table 11.3 shows the probability of attending a health centre or completing a home assessment in subgroups of the sample. Those with more education, people in better health and those in the youngest age groups were more likely to complete health assessment.

Most objective measures of health included in this report were taken during both the health centre assessment and the home assessment. A 'health assessment' weight was created so that results based on these measures can be applied to the population.

The health assessment weight for each respondent is calculated by dividing the CAPI weight shown above by the respondents' subsequent probability of having completed a health assessment. This probability is estimated using multivariate logistic regression and is based on the characteristics shown to significantly affect participation in the health assessment. 
Only one measure reported here (osteoporosis as measured by heel ultrasound) is recorded in the health centre but not the home assessment. In this case a separate health centre assessment weight was applied using the same principle as the health assessment weight. Age, disability and location were the main determinants of choosing a home assessment over a health centre assessment, although the health centre assessment was well attended by all subgroups of respondents.

Table 11.3 also includes the proportion of those respondents who had returned a self-completion questionnaire. Older people, those with less education, less wealthy, more depressed respondents and those who reported their own health as poorer were less likely to return questionnaires. A new weight was therefore applied to each participant when estimates were based on the self-completion questionnaire subgroup.

\subsubsection{Item non-response}

As well as refusal at the individual level, respondents may have refused to answer or been unable to answer certain questions or perform certain tests. This 'item-level' non-response has the potential to bias individual estimates if certain groups of the population are less likely to respond than others.

In the majority of cases the number of individuals not responding to specific items is very small. Where this is the case the missing data is considered to be missing at random, and a complete-case analysis is conducted. We have conducted several analyses to test the sensitivity of our findings to this assumption, with no substantive difference in results.

Approximately half of the sample did not respond fully to questions concerning their financial assets, and these respondents are not included when the population is classified by asset wealth. In order to adjust for any potential bias caused by this non-response, the populations who did and did report their asset wealth were compared. Table 11.3 shows that the oldest old, women and those living outside Dublin were less likely to fully report their asset wealth. Based on these differences, a weight was constructed so that population based inference regarding asset wealth and association with health and social circumstances can be made.

\subsubsection{Software}

All analysis was conducted using Stata 10.0. 
Table 11.3: Classification of respondents by socio-economic and health status and their subsequent participation in the health assessment, whether an SCQ was received and whether sufficient information was obtained during the CAPI to calculate asset wealth

\begin{tabular}{|c|c|c|c|c|c|}
\hline & \multirow[b]{2}{*}{$\begin{array}{l}\text { Number in } \\
\text { sample }\end{array}$} & \multicolumn{2}{|c|}{$\begin{array}{l}\text { Health assessment } \\
\text { (up to } 27 \text { Feb 2011) }\end{array}$} & \multirow{2}{*}{$\begin{array}{c}\text { SCQ returned } \\
\text { (up to } 16 \text { Feb } \\
\text { 2011) }\end{array}$} & \multirow{2}{*}{$\begin{array}{c}\text { Complete } \\
\text { asset wealth } \\
\text { data }\end{array}$} \\
\hline & & $\begin{array}{l}\text { Health } \\
\text { centre }\end{array}$ & $\begin{array}{c}\text { Home } \\
\text { assessment }\end{array}$ & & \\
\hline \multicolumn{6}{|l|}{ Age } \\
\hline $50-64$ & 4,668 & $2491(53 \%)$ & $135(3 \%)$ & $3593(77 \%)$ & $2377(51 \%)$ \\
\hline $65-74$ & 2,163 & $1061(49 \%)$ & $131(6 \%)$ & $1694(78 \%)$ & $1031(48 \%)$ \\
\hline$>=75$ & 1,347 & $355(26 \%)$ & $211(16 \%)$ & $975(72 \%)$ & $541(40 \%)$ \\
\hline \multicolumn{6}{|l|}{ Sex } \\
\hline Male & 3,749 & $1803(48 \%)$ & $239(6 \%)$ & $2858(76 \%)$ & $1940(52 \%)$ \\
\hline Female & 4,429 & $2104(48 \%)$ & $238(5 \%)$ & $3404(77 \%)$ & $2009(45 \%)$ \\
\hline \multicolumn{6}{|l|}{ Education } \\
\hline Primary/none & 2,506 & $860(34 \%)$ & $251(10 \%)$ & $1723(69 \%)$ & $1181(47 \%)$ \\
\hline Secondary & 3,264 & $1630(50 \%)$ & $173(5 \%)$ & $2568(79 \%)$ & $1550(47 \%)$ \\
\hline Tertiary or higher & 2,404 & $1416(59 \%)$ & $53(2 \%)$ & $1969(82 \%)$ & $1216(51 \%)$ \\
\hline \multicolumn{6}{|l|}{ Location } \\
\hline Dublin & 1,936 & $1113(57 \%)$ & $45(2 \%)$ & $1489(77 \%)$ & $1175(61 \%)$ \\
\hline Other town or city & 2,312 & $1103(48 \%)$ & $144(6 \%)$ & $1780(77 \%)$ & $1101(48 \%)$ \\
\hline Rural area & 3,918 & $1686(43 \%)$ & $288(7 \%)$ & $2984(76 \%)$ & $1667(43 \%)$ \\
\hline \multicolumn{6}{|l|}{ Labour Market Status } \\
\hline Employed & 2,934 & $1612(55 \%)$ & $74(3 \%)$ & $2276(78 \%)$ & $1400(48 \%)$ \\
\hline Retired & 3,048 & $1390(46 \%)$ & $268(9 \%)$ & $2386(78 \%)$ & $1434(47 \%)$ \\
\hline Other & 2,196 & $905(41 \%)$ & $135(6 \%)$ & $1600(73 \%)$ & $1115(51 \%)$ \\
\hline \multicolumn{6}{|l|}{ Asset wealth } \\
\hline Lowest & 988 & $337(34 \%)$ & $77(8 \%)$ & $707(72 \%)$ & - \\
\hline 2nd & 999 & $461(46 \%)$ & $75(8 \%)$ & $786(79 \%)$ & - \\
\hline 3rd & 975 & $573(59 \%)$ & $41(4 \%)$ & $824(85 \%)$ & - \\
\hline Highest & 987 & $634(64 \%)$ & $14(1 \%)$ & $829(84 \%)$ & - \\
\hline \multicolumn{6}{|l|}{ Disability } \\
\hline Not disabled & 7,192 & $3551(49 \%)$ & $333(5 \%)$ & $5535(77 \%)$ & $3457(48 \%)$ \\
\hline IADL limitation only & 287 & $90(31 \%)$ & $38(13 \%)$ & $205(71 \%)$ & $141(49 \%)$ \\
\hline ADL limitation only & 387 & $174(45 \%)$ & $40(10 \%)$ & $308(80 \%)$ & $198(51 \%)$ \\
\hline Both IADL and ADL & 312 & $92(29 \%)$ & $66(21 \%)$ & $214(69 \%)$ & $153(49 \%)$ \\
\hline \multicolumn{6}{|l|}{ Self-rated health } \\
\hline Excellent & 1,715 & $1007(59 \%)$ & $60(3 \%)$ & $1398(82 \%)$ & $840(49 \%)$ \\
\hline Very good & 2,745 & $1319(48 \%)$ & $113(4 \%)$ & $2129(78 \%)$ & $1378(50 \%)$ \\
\hline Good & 2,442 & $1136(47 \%)$ & $149(6 \%)$ & $1836(75 \%)$ & $1088(45 \%)$ \\
\hline Fair & 994 & $355(36 \%)$ & $114(11 \%)$ & $707(71 \%)$ & $499(50 \%)$ \\
\hline Poor & 268 & $86(32 \%)$ & $38(14 \%)$ & $183(68 \%)$ & $141(53 \%)$ \\
\hline \multicolumn{6}{|l|}{ Depression } \\
\hline Not depressed & 5,853 & $2880(49 \%)$ & $312(5 \%)$ & $4559(78 \%)$ & $2772(47 \%)$ \\
\hline Sub-threshold & 1,417 & $660(47 \%)$ & $86(6 \%)$ & $1071(76 \%)$ & $713(50 \%)$ \\
\hline Depressed & 777 & $319(41 \%)$ & $69(9 \%)$ & $541(70 \%)$ & $418(54 \%)$ \\
\hline
\end{tabular}




\subsection{Limitations of this report and future analyses}

While this report provides an overview of the circumstances of older people and identifies many factors that are associated with successful ageing in Ireland, future analyses will provide in depth explorations that are outside the scope of the current report. Although future waves will capture the transition to long-term care, the current baseline sample only includes those living in the community.

A further limitation of the current analyses is that so far only the first wave of data collection has been undertaken. This means that while we are able to describe the current circumstances of the older population of Ireland and report many differences across sub-groups of the population we are unable to directly explore the causal relationships between factors. For example, while differences between age groups with respect to church attendance is reported in Chapter 4 - it is not possible to say whether older people attend church more frequently as they age (an age effect) or whether that cohort of people, who are in the oldest age group now, have always attended church more regularly than those who were born later and so are younger now (a cohort effect). Similarly, we cannot say whether people have better social networks because they are in better health, or vice versa.

The longitudinal aspect of TILDA is crucial to address these questions. TILDA will return to the field later this year and by 2013 will be able to provide the first direct analysis of the trajectories of ageing within the Irish population and, therefore, an analysis of the determinants as opposed to the correlates of successful ageing. As subsequent waves of data collection are undertaken, a complete picture of the factors that shape the ageing process in Ireland will emerge.

\section{References}

1 The Irish Longitudinal Study on Ageing. The design of the Irish Longitudinal Study on Ageing (TILDA). 2010.

2 Wren, M-A; Long-term health and social care. In Layte, R, editor. Projecting the impact of demographic change on the demand for and delivery of health care in Ireland. The Economic and Social Research Institute, Dublin; 2009. 
